\title{
DETERMINACIÓN AUTOMÁTICA DE LAS CARGAS TRANSPORTADAS POR LOS VEHÍCULOS PESADOS MEDIANTE PESAJE DINÁMICO
}

Tesis Doctoral

PROGRAMA DE DOCTORADO: Sistemas de Ingeniería Civil

Director de la Tesis: Jose Mạ Pardillo Mayora

Autor: Jesús Ma Leal Bermejo

Junio de 2018 


\section{Índice}

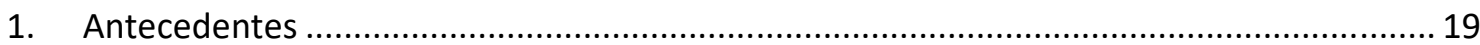

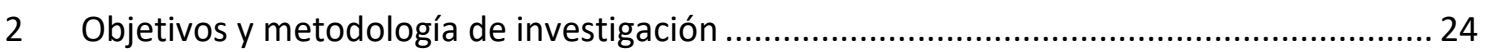

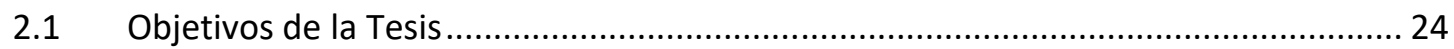

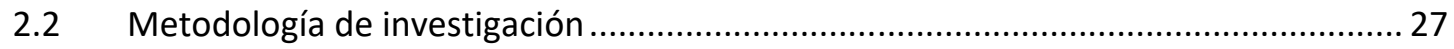

3 Definiciones sobre el tráfico pesado, su composición y sobre las características de los

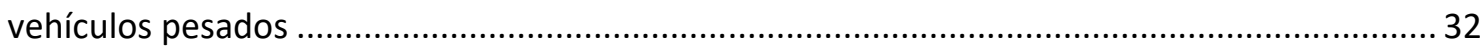

3.1 Definiciones en relación con los ejes de los vehículos pesados..................................32

3.2 Definiciones en relación con los vehículos.................................................................. 34

3.3 Limitaciones legales de los pesos totales, pesos por eje y dimensiones de los

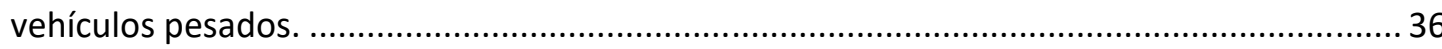

4 Situación de la técnica en el campo de la toma de datos del tráfico, la clasificación de vehículos y la estimación de las cargas transportadas

4.1 Técnicas de recogida de datos del tráfico y de las características de los vehículos ... 41

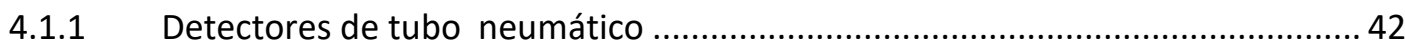

4.1.2 Detectores de lazo de inducción .......................................................................... 43

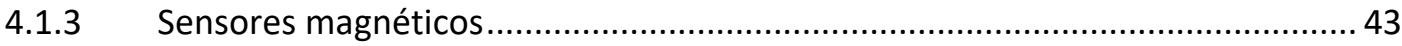

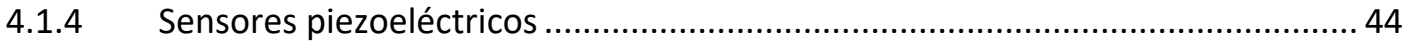

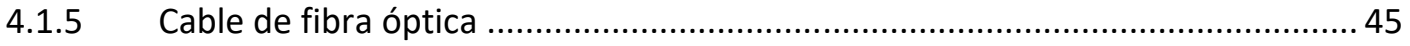

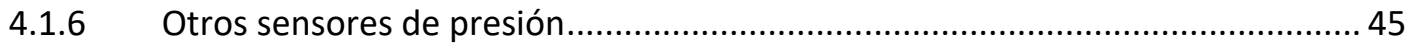

4.1.7 Sistemas de procesamiento de imágenes de vídeo ............................................. 46

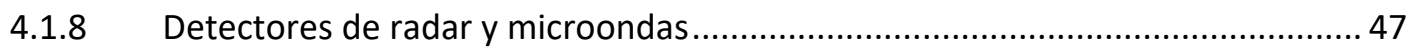

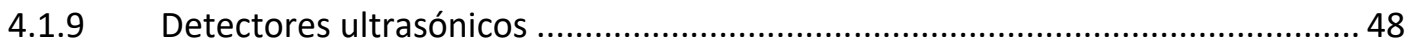

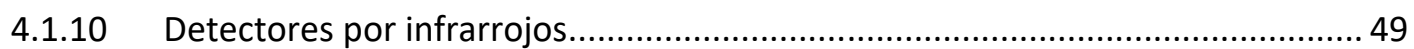

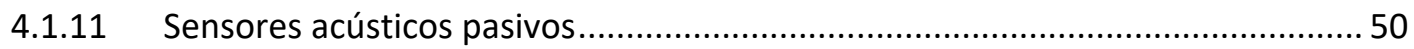

4.1.12 Sistemas de pesaje en movimiento................................................................. 51

4.1.13 Ventajas e inconvenientes y aplicabilidad de cada tecnología para su empleo en la clasificación de vehículos y en la medida de pesos y cargas ........................................52

4.2 El pesaje de vehículos en movimiento o pesaje dinámico .........................................57

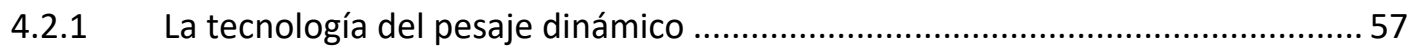

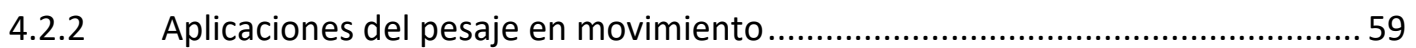

4.2.3 Datos que proporciona un sistema de pesaje dinámico ......................................61

4.3 Revisión de procedimientos de clasificación automática de vehículos .......................65 
4.3.1 Cuestiones generales

4.3.2 Esquemas de clasificación de la Administración de las Carreteras Federales

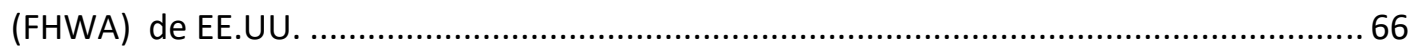

4.3.3 Esquema europeo de clasificación EURO 13 .................................................... 70

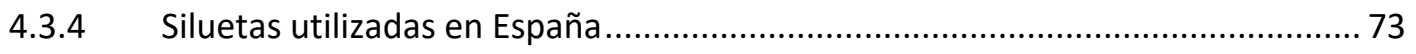

4.3.5 Metodología para realizar una clasificación automática .................................... 79

4.3.6 Recientes desarrollos para la mejora y optimización de los procedimientos de

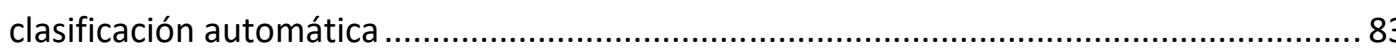

4.4 Revisión de trabajos e investigaciones dirigidos a estimar las cargas transportadas

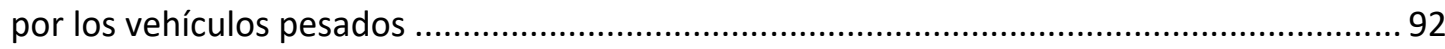

5 Desarrollo de los procedimientos de estimación automática .......................................... 103

5.1 Desarrollo de un procedimiento automático de clasificación de vehículos mediante

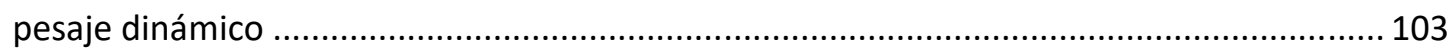

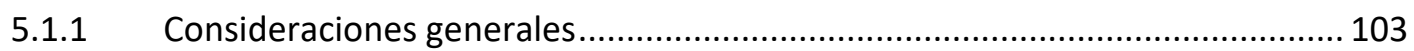

5.1.2 Procedimiento experimental específico utilizado para obtener la silueta del tráfico 104

5.1.3. Metodología seguida para obtener la silueta del tráfico .................................. 104

5.1.4 Esquema de clasificación automática propuesto............................................. 108

5.1.5 Explicación de las condiciones de clasificación que se han desarrollado ..........118

5.1.6 Análisis detallado de los resultados para los casos de solapamiento entre las

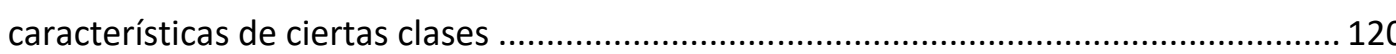

5.2 Presentación y descripción del método de determinación automática del peso de las cargas transportadas por los vehículos............................................................................. 134

5.2.1 Planteamiento general del método ................................................................ 134

5.2.2 Exposición detallada del método de determinación automática de la carga

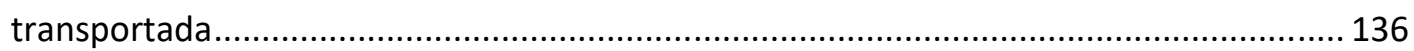

5.2.3 Bases de datos de las taras de los vehículos ................................................... 139

6 Resultados de los ensayos para la comprobación de los métodos de estimación

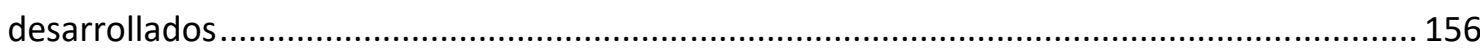

6.1 Comprobación de la exactitud de la silueta obtenida automáticamente.................. 156

6.1.1 Ensayos y descripción del procedimiento seguido para efectuar la comprobación 156

6.1.2 Resultados de precisión de la clasificación obtenidos en El Molar (A-1, pk. 41) 158

6.1.3 Resultados de precisión de la clasificación obtenidos en Trijueque (A-2, pk. 82) 159 
6.2 Comprobación del método de determinación automática de las cargas transportadas por los vehículos pesados mediante pesaje dinámico

6.2.1 Ensayo de comprobación del método

6.2.2 Cálculo de la exactitud y precisión del sistema de pesaje dinámico utilizado.. 162

6.2.3 Planteamiento general de la comprobación del método de estimación de la carga transportada

6.2.4 Estudio de comprobación del método realizado con la muestra reducida ..... 166

6.2.4.1 Datos y cálculos previos realizados para la comprobación. 166

6.2.5 Estudio de comprobación del método realizado con la muestra amplia, de más de 600 vehículos pesados fotografiados

6.2.6 Comparación de los resultados obtenidos con ambas muestras.

6.2.7 Análisis de sensibilidad del método de estimación del peso de las cargas transportadas

6.2.8 Mejora potencial del método de estimación de la carga transportada a través de utilizar unas taras medias obtenidas directamente de los pesajes en la carretera..... 195

6.2.9 Adaptación del procedimiento desarrollado al cálculo de los efectos de las cargas sobre los firmes

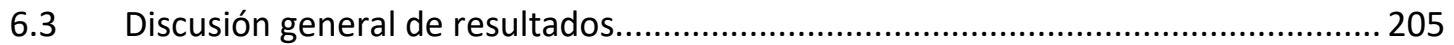

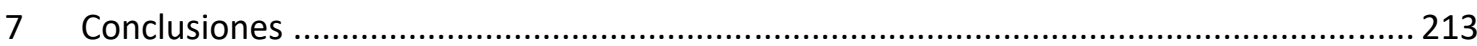

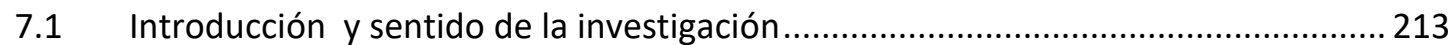

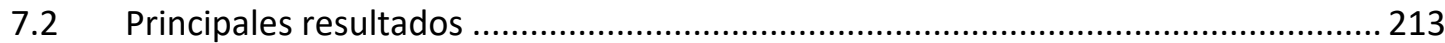

7.2.1 Tecnología de toma de datos del tráfico que se debe utilizar ...........................213

7.2.2 Procedimiento de clasificación de los vehículos pesados ................................... 214

7.2.3 Procedimiento de estimación de la carga transportada .................................... 218

7.2.4 Comprobación de la exactitud del método..................................................... 219

7.3 Principales aportaciones del estudio ………........................................................ 222

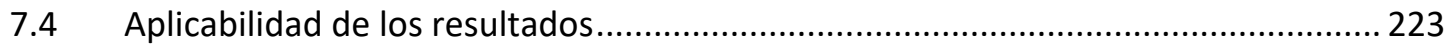

7.5 Futuros desarrollos y líneas de investigación .......................................................... 224

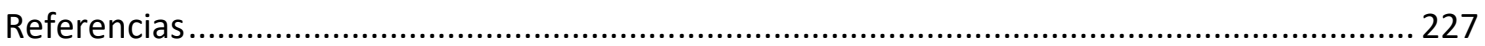

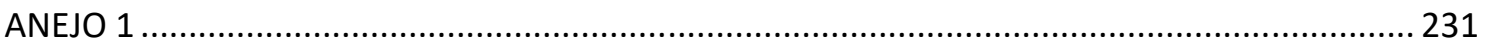

DATOS REGISTRADOS DE LA MUESTRA AMPLIA DE VEHÍCULOS ............................................. 231

1. Datos registrados automáticamente por el sistema de pesaje dinámico.......................233

2. Datos tomados visualmente por operarios o recibidos de la Dirección General de Tráfico 
Tabla 1 (I). Sensores invasivos: ventajas e inconvenientes de cada tecnología. . .54

Tabla 1 (II). Sensores invasivos: ventajas e inconvenientes de cada tecnología..................55

Tabla 2. (I). Sensores no invasivos: Ventajas e inconvenientes.............................................56

Tabla 2 (II). Sensores no invasivos: Ventajas e inconvenientes............................................ 57

Tabla 3. Salida de datos del sistema de pesaje dinámico utilizado por el CEDEX............64

Tabla 4 Detalles del esquema " $A$ " de clasificación de vehículos de la FHWA................ 66

Tabla 5 Esquema "F" de clasificación de vehículos de FHWA ….......................................68

Tabla 6 Esquema de clasificación de vehículos de FHWA modificado en California.....69

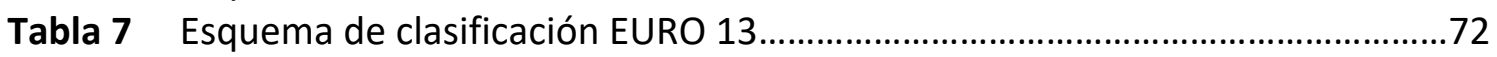

Tabla 8 Clases de vehículos obtenidas visualmente...................................................76

Tabla 9 Diferentes tipos de vehículos considerados visualmente, incluyendo su configuración de ejes...................................................................................78

Tabla 10 Principales resultados, incluyendo la carga media transportada por cada clase de vehículo, obtenidos con el procedimiento semiautomático establecido en 2000-2003 por el CEDEX.

Tabla 11 Valores de los diferentes parámetros medidos en El Molar para cada tipo de vehículos.

Tabla 12 Condiciones de clasificación de los vehículos ligeros......................................110

Tabla 13 (I) Condiciones de clasificación de los vehículos pesados............................111

Tabla 13 (II) Condiciones de clasificación de los vehículos pesados.............................112

Tabla 13 (III) Condiciones de clasificación de los vehículos pesados...........................113

Tabla 13 (IV) Condiciones de clasificación de los vehículos pesados.............................114

Tabla 13 (V) Condiciones de clasificación de los vehículos pesados............................115

Tabla 13 (VI) Condiciones de clasificación de los vehículos pesados...........................116

Tabla 14 Resumen de condiciones de clasificación para los diferentes tipos de vehículos pesados, expresadas en formato lógico.

Tabla 15 Valores promedio de las taras de los distintos tipos de camiones registrados en la muestra visual de la campaña de pesaje dinámico 2000-2003 realizada por el CEDEX

Tabla 16 Taras medias de cada tipo de vehículo obtenidas en la Encuesta Permanente del Transporte de Mercancías por Carretera de

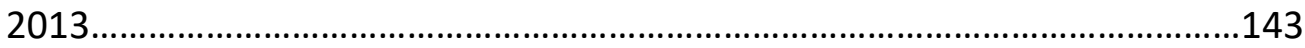

Tabla 17 Datos que aparecen en el Registro General de Vehículos de la Dirección General de Tráfico sobre cada vehículo. 144

Tabla 18.Correspondencia entre las diferentes clases de vehículos definidas en el Registro General de Vehículos por su masa máxima admitida (MMA) con las clases definidas por su número de unidades (vehículos) independientes (rígido, tractor+semirremolque, rígido+remolque), y número de ejes.......146

Tabla 19 Taras medias de cada tipo de vehículo definido según su masa máxima admitida (Registro General de Vehículos) y según el esquema de clasificación típico propuesto

Tabla 20 Valores de las taras y otras características de los camiones nuevos en España. 
Tabla 21. Diferentes tipos de carrocerías para semirremolques y remolques, y rangos de taras de cada una de ellas.

Tabla 22. Antigüedad de los vehículos en la campaña de pesaje del CEDEX realizada entre 2000 y 2003 .152

Tabla 23. Taras medias y dispersiones de las taras para los distintos tipos de vehículos según la campaña de pesaje dinámico del CEDEX 2000-2003, la Encuesta Permanente del Transporte de Mercancías por Carretera (EPTMC) del 2013 y el Registro General de Vehículos de 2017.

Tabla 24. Resultados de comparación de la clasificación visual con la automática en la estación de El Molar (A-1, pk 41).

Tabla 25. Resultados de comparación de la clasificación visual con la obtenida automáticamente en ensayo realizado en Trijueque (A-2, pk 82)...

Tabla 26 Errores relativos del sistema de pesaje dinámico obtenidos en el experimento. .164

Tabla 27. Tabla de datos iniciales del ensayo de Trijueque: pesos estático, dinámico y tara registrada de cada uno de los vehículos de la muestra. 167

Tabla 28. Valores obtenidos del "Peso real de la carga transportada" y del "Peso dinámico real de la carga transportada", en el ensayo realizado en Trijueque .170

Tabla 29. Cálculo de la "Carga transportada estimada" para cada vehículo utilizando las taras medias obtenidas en la campaña de pesaje dinámico 2000-2003 del CEDEX y determinación del error de esta estimación. 171

Tabla 30. Cálculo de la "Carga transportada estimada" para cada vehículo utilizando las taras medias de la Encuesta Permanente del Transporte de Mercancías por Carretera de 2013 y determinación del error de esta estimación.

Tabla 31. Cálculo de la "Carga transportada estimada" para cada vehículo utilizando las taras medias del Registro General de Vehículos de 2017.

Tabla 32 .Ordenación de los vehículos según el valor del error relativo en la estimación del peso de la carga transportada y causas de los errores grandes. 176

Tabla 33. Resultados de clasificación automatizada de los vehículos de la muestra reducida que fueron pesados en una báscula estática 180

Tabla 34. Determinación del error en la determinación de la carga total transportada debido a la clasificación errónea de algunos vehículos

Tabla 35. Resultados obtenidos en la clasificación visual y automática de la muestra amplia de vehículos fotografiados. 185

Tabla 36. Cargas totales transportadas por todos los vehículos de la muestra amplia que han sido estimadas utilizando el procedimiento desarrollado. 186

Tabla 37. Comparación de la exactitud en la determinación de las cargas transportadas en ambas muestras. 189

Tabla 38. Cálculo del error en la estimación de la carga total transportada con una calibración correcta (error relativo medio de los pesos nulo) 192

Tabla 39. Comparación de los valores de varios percentiles de los pesos registrados en báscula con las taras medias reales y las taras medias provenientes de tres fuentes de datos diferentes (Campaña CEDEX, EPTMC y Registro General de Vehículos) 198 
Tabla 40. Factores de equivalencia calculados en el ensayo con los datos de los pesajes estáticos

Tabla 41. Factores de equivalencia calculados en el ensayo con los datos de los pesajes dinámicos. 203

Tabla 42. Resumen de las taras medias de cada tipo de vehículos según la Campaña de pesaje dinámico del CEDEX en la RCE entre 2000 y 2003, la Encuesta Permanente del Transporte de Mercancías por Carretera del año 2013 y el Registro General de Vehículos de 2017. 206

Tabla 43. Resumen de las estimaciones de las cargas transportadas por los vehículos de la muestra reducida en Trijueque, según las tres bases de datos de taras y error cometido en cada una de ellas 208

Tabla 44. Comparación de los valores de las taras estimados con el peso medio de los vehículos por debajo del percentil 5 de los pesos registrados para cada tipo de vehículos, con los valores reales y con los valores medios del Registro General de Vehículos.

Tabla 45. Comparación de los factores de equivalencia obtenidos con pesajes dinámicos y estáticos 212 
Figura 1. Tipos de ejes múltiple de los vehículos pesados..............................................33

Figura 2. Tipos de eje en cuanto al número de ruedas en sus extremos. .33

Figura 3. Envolventes de las líneas de influencia de las cargas de dos ejes individuales en función de la separación entre ambos.

Figura 4. Configuración típica de un camión rígido de 2 ejes............................................35

Figura 5. Configuración típica de un vehículo articulado de 5 ejes.....................................36

Figura 6. Configuración de un tren de carretera de 4 ejes.................................................36

Figura 7. Componentes del sistema de pesaje dinámico utilizado en los ensayos realizados en El Molar y en Trijueque.

Figura 8. Aspecto del sistema de pesaje dinámico utilizado, con su configuración normal en la carretera y camión utilizado en la calibración del sistema.......

Figura 9. Esquema F de clasificación de la FHWA (EE.UU.). .68

Figura 10. Aspecto de la huella inductiva de lazo de un vehículo articulado de 5 ejes de caja cerrada, obtenida con los lazos de inducción de un sistema de pesaje dinámico

Figura 11. Distribución de frecuencias de los pesos de los vehículos articulados de 5 ejes (tipo 3S2) en las carreteras interestatales de Estados Unidos.

Figura 12. Distribución de frecuencias de los pesos de los ejes tándem de los vehículos articulados en las carreteras nacionales de Sudáfrica. 94

Figura 13. Imagen esquemática de las distribuciones de peso de los vehículos que circulan cargados y de los vehículos que van vacíos. .95

Figura 14. Comparación de las distribuciones de frecuencia de las longitudes de los camiones de 2 ejes y de los autobuses de 2 ejes.

Figura 15. Comparación de las distribuciones de frecuencia de las separaciones entre los dos ejes de los camiones de 2 ejes y de los autobuses de 2 ejes.

Figura 16. Comparación de las distribuciones de frecuencia de las separaciones entre el primer y el segundo ejes de los camiones de 3 ejes y de los autobuses de 3 ejes.

Figura 17. Comparación entre las distribuciones de las distancias entre el primer y el segundo eje de los articulados de 4 ejes y de los trenes de 4 ejes con tandem trasero. 
Figura 18. Comparación entre las distribuciones de las longitudes de los articulados de 4 ejes y de los trenes de 4 ejes con tandem trasero.

Figura 19. Comparación entre las distribuciones de la distancia entre los ejes 20 y 30 en los articulados de 4 ejes y en los articulados de 5 ejes.

Figura 20. Comparación de las distribuciones de peso de los articulados de 4 ejes con la de los articulados de 5 ejes que circulan con el tercer eje elevado. .129

Figura 21. Comparación de las distribuciones de longitud de los camiones rígidos de 2 ejes y de los rígidos de 3 ejes. 130

Figura 22. Comparación de las distribuciones de distancia entre los dos ejes apoyados en el pavimento de los camiones de 2 ejes y de los de 3 ejes con el tercer eje levantado. 131

Figura 23 Comparación de las distribuciones del peso total del vehículo para camiones de 2 ejes y camiones de 3 ejes con un eje levantado

Figura 24 Variación de las cargas de un vehículo a diferentes velocidades. 135

Figura 25 Frecuencias absolutas de los distintos intervalos de errores relativos en la determinación del peso de la carga transportada por todos los vehículos de la muestra. 


\section{Resumen de la Tesis}

\section{DETERMINACIÓN AUTOMÁTICA DE LAS CARGAS TRANSPORTADAS POR LOS VEHÍCULOS PESADOS MEDIANTE PESAJE DINÁMICO}

El objetivo de la Tesis es elaborar un procedimiento para determinar de forma totalmente automatizada el peso de la carga transportada por los vehículos pesados mientras circulan por la carretera a su velocidad normal de recorrido, sin necesidad de que intervenga ningún operador. Para conseguir esto, se justifica en el texto que, de todas las técnicas existentes de recogida de datos del tráfico, la única que puede proporcionar los datos adecuados es el pesaje dinámico o pesaje en movimiento de vehículos (más conocido por su siglas en inglés WIM -Weigh-in-Motion-).

El procedimiento desarrollado para la determinación automática de la carga transportada consiste en restar del peso total del vehículo, que es proporcionado automáticamente por un sistema de pesaje dinámico instalado en la carretera, un peso en vacío o tara del vehículo, cuyo valor es, en principio, desconocido, pero que se puede aproximar asignando a cada vehículo la tara media del tipo de vehículo en que puede ser clasificado automáticamente por el sistema de pesaje dinámico. Con este objetivo, para determinar automáticamente el tipo de vehículo que pasa sobre el sistema de pesaje dinámico, ha sido preciso elaborar un procedimiento de clasificación basado principalmente en la longitud del vehículo, en el número de ejes de éste, en las distancias entre cada dos ejes y, aunque en casos especiales de difícil diferenciación entre tipos de vehículos muy semejantes se ha debido acudir a otros parámetros adicionales, como el peso total del vehículo.

Una vez que el vehículo ha sido pesado dinámicamente y clasificado, se le asigna la tara media del tipo de vehículo de que se trate. Para ello, se han estudiado las taras medias proporcionadas por tres bases de datos de características de los vehículos: la de la campaña de pesaje dinámico en la Red de Carreteras del Estado realizada por el CEDEX, la de la Encuesta Permanente de Transporte de Mercancías por Carretera y la del Registro General de Vehículos de la Dirección General de Tráfico. Además se han estudiado las taras de los vehículos nuevos proporcionadas por los fabricantes de vehículos, remolques y semirremolques, que sirven para establecer tendencias futuras. 
Después de elaborar el procedimiento de determinación de las cargas transportadas, se ha realizado un ensayo en la carretera para determinar su exactitud al aplicarlo a una muestra real del tráfico pesado y así comprobar su validez. Para ello, se ha pesado estáticamente una muestra de 30 camiones y se han obtenido las taras reales de los vehículos de esta muestra y de otra mucho más amplia, de más de 600 vehículos. Estas taras reales se han utilizado para calcular las cargas reales transportadas, que se comparan con las cargas estimadas utilizando las taras medias asignadas.

Los resultados de comparación de las cargas transportadas proporcionadas por el procedimiento elaborado en esta Tesis con las cargas reales transportadas por los vehículos muestran que muchas veces se cometen errores bastante grandes al estimar la carga de cada vehículo individual, por lo que no podría aplicarse el método desarrollado para determinar la carga de cada vehículo, pero en cambio, los errores son bastante reducidos cuando se trata de determinar la carga transportada por un conjunto más o menos grande de vehículos, como el que podría ser el del tráfico pesado total que circula por una carretera, obteniéndose unos errores totales de entre el $12 \%$ y el $15 \%$ según la base de datos de taras elegida. Además, si descuenta en estos errores la parte debida al sesgo del sistema de pesaje dinámico (aspecto que se podría corregir con una calibración adecuada), resulta que la componente del error debida a las simplificaciones del método está entre el $4 \%$ y el $6 \%$, lo que demuestra su validez.

Este método aproximado de determinación del peso de la carga transportada por un conjunto de vehículos permitiría obtener una estimación bastante precisa de un dato fundamental en economía del transporte, las t-km transportadas, que constituyen un indicativo fundamental de la actividad económica de un país. 


\section{Summary}

\section{AUTOMATIC DETERMINATION OF THE WEIGHT OF THE LOAD CARRIED BY HEAVY VEHICLES USING WIM TECHNIQUES}

The purpose of this Doctoral Thesis is to develop a procedure for a totally automated process of estimating the weights of the loads transported by heavy vehicles as they travel on the road at their usual speed without the participation of any operator. To achieve this goal, it is proved that, among all the traffic data acquisition techniques, weigh-in motion (WIM) of road vehicles is the only one that can provide the necessary data.

According to the procedure for estimating the transported load that has been developed, the weight of the transported load by a heavy vehicle can be calculated as the difference between the vehicle's total gross weight, provided by the WIM system installed on the road, and its tare weight (i.e. its vehicle curb weight), whose value is, in principle unknown, but that can be approximated by assigning the average curb weight of the vehicle type to which each specific truck is automatically classified by the WIM system.

With this objective, a procedure for the automatic classification of vehicles has been elaborated, in order to determine the type of vehicle that has passed over the WIM system. This procedure is based on the number of axles of each vehicle, the separation between axles and vehicle length, although in special cases in which it is difficult to distinguish between two specific vehicle types, other additional parameters have been considered, such as the vehicle gross weight.

Once the vehicle gross weight has been measured by the WIM system, the average curb weight of the vehicle type to which each specific truck is automatically classified by the WIM system is assigned to that specific truck. Three different sources of vehicle tares have been studied: the last Weighing Campaign in the National Road Network conducted between 2000 and 2003 by CEDEX, the Road Transport Permanent Survey conducted by the Road and Railway Transport Directorate and the Vehicle General Registry of the Traffic Directorate. In addition to those sources, characteristics of the 
new heavy vehicles have been studied, which have been provided by truck and trailer manufacturers. These data are used to establish future vehicle tare trends.

Once the procedure for the automatic determination of transported loads has been prepared, a test on the road has been conducted in order to check the accuracy of the procedure for estimating the transported load, when it is applied to a real heavy traffic sample, so that it can be validated.

In this trial, a sample which consists of 30 trucks has been statically weighed and their curb weights (tares) have been collected as well as those of a larger sample of more than 600 heavy vehicles.

The estimates of the transported loads by the vehicles of these two samples have been determined using the procedure developed in this Thesis, and they have been compared with the real loads transported by the same trucks. The comparison of both values (the estimated load and the real one) for each truck gives the error of the procedure. The results obtained show that in many cases large errors have been obtained, which means that the procedure cannot be applied to obtain the transported load of each specific vehicle. However, the errors of the estimates of the load carried by a group of heavy vehicles (such as, all the vehicles that make up the traffic of a certain road) have also been calculated using this simplified procedure and the total error values obtained range from $12 \%$ to $15 \%$, depending on the curb weight database used, which can be considered rather moderate. Moreover, if error component due to the bias of the WIM system is removed (which could be corrected with an appropriated calibration), the results show that the error component due to the simplified assumptions of the procedure ranges between $4 \%$ and $6 \%$, which proves the procedure validation.

This approximated procedure for determining the weight of the transported loads by a group of vehicles enables an accurate estimate of an important transport economy data, such as the amount of t-km transported, to be obtained, which are a fundamental indicator of the economic activity of a country. 


\section{Antecedentes}

El conocimiento del tráfico y del transporte por carretera es básico para el planeamiento, proyecto y explotación de las redes viarias, así como un indicador de la actividad económica general de un país. Para determinar y comprender las características del tráfico y el transporte es necesario realizar medidas y estudios en las carreteras, habiéndose desarrollado un amplio abanico de técnicas de medición y metodologías de análisis, que tienen por objetivo obtener unos datos suficientemente seguros a un coste razonable.

Las principales características del tráfico que suele ser necesario estudiar son las intensidades de circulación y las velocidades, a las que hay que añadir la composición del tráfico por tipos de vehículo, el tiempo de recorrido de los vehículos y el origen y destino de los viajes. En cuanto al transporte por carretera, también son importantes todas las que se acaban de enumerar para el tráfico en general, pero dirigidas específicamente a captar la información de los vehículos comerciales en particular, así como otras más específicas de esta actividad, como pueden ser el tipo y magnitud de la carga transportada por los vehículos y las clases de vehículos (silueta) con las que se realiza el transporte. El conocimiento de estas características se encuentra muy ligado a su metodología de medición y estimación o análisis, teniendo en cuenta en cada caso los medios de los que se dispone y la precisión y el coste del estudio.

Para la medición de las distintas variables del tráfico se han aplicado y desarrollado diferentes tecnologías. Así, para conocer las intensidades de circulación es necesario contar o aforar los vehículos que pasan, lo que se puede realizar de forma manual (visual) mediante operarios, lo que proporciona resultados de gran fiabilidad pero que solo es aplicable para cortos lapsos, o también mediante la utilización de sistemas automáticos, cuya fiabilidad es variable, pero que permiten realizar las mediciones de forma continua durante periodos largos a un coste razonable. Entre los métodos automáticos para aforar vehículos se pueden citar los detectores de tubo neumático, que son apropiados para estudios de corta duración (aunque mayor en todo caso que las de los operadores manuales), los lazos de inducción magnética, los detectores magnéticos, los piezoeléctricos y otros sensores de presión, los procedimientos de análisis de imágenes de video, el radar de microondas, los sensores por infrarrojos, los detectores por ultrasonidos y los sensores acústicos pasivos.

Casi todas las tecnologías mencionadas, cuyos fundamentos se describirán posteriormente en este documento, sirven también para medir la velocidad de los vehículos y algunas de ellas también su longitud, lo que sirve para obtener una clasificación de estos, dividiéndolos, al menos, entre ligeros y pesados. Esto permite su utilización tanto para planificar una carretera como para la gestión de la circulación en ella, para lo que es necesario conocer al menos las intensidades medias diarias equivalentes de vehículos ligeros, que se determinan a partir de la composición del tráfico, distinguiendo al menos entre vehículos ligeros y pesados. Si se requiere 
obtener una composición más detallada del tráfico, en la que se pueda diferenciar, como mínimo, entre las diferentes clases principales de vehículos de transporte (rígidos, articulados y trenes de carretera), todavía se puede lograr una clasificación en tres o cuatro tipos de estos, basada en la medida de la longitud a través de los lazos de inducción magnética.

Por su parte, los sistemas de pesaje dinámico, permiten conocer además de estas dos variables, otras adicionales, como son los pesos de cada eje de un vehículo y su peso total, así como las distancias entre ejes, lo que se ha venido utilizando desde hace décadas para el proyecto, gestión y conservación de los firmes. Esto requiere, por un lado, una clasificación de vehículos más afinada, en la que se puedan distinguir los diferentes tipos de vehículos pesados según su número de ejes, ya que estos son los que definen las acciones sobre el firme de la carretera y, por otro lado, se necesita conocer la magnitud de la carga impuesta por cada uno de estos ejes.

Un aspecto relacionado con lo anterior es la gestión viaria a través del cobro de peajes, que puede optimizarse si se hace en función del peso de los vehículos, lo cual tiene su razón de ser en que el deterioro de los firmes es debido casi totalmente a la acción de los vehículos pesados, y proporcional (con una relación exponencial) a su peso, por lo que sería natural cobrar más a los vehículos más pesados por el uso de la vía. Para ello se pueden utilizar sistemas de pesaje en movimiento normales (o de baja velocidad si se requiriera mucha precisión) situados en las áreas de peaje de las autopistas o, también, más modernamente, para sistemas de peaje en sombra o de peaje electrónico sin necesidad de que se detengan los vehículos, utilizando sistemas de pesaje dinámico de alta velocidad que funcionen conjuntamente con cámaras dotadas de sistemas de reconocimiento de matrículas.

Existe hoy en día una preocupación creciente en determinar las emisiones de los vehículos, que en los camiones dependen entre otros factores de las cargas, para lo cual también se precisa medirlas en la carretera. Estos estudios, aún no muy desarrollados, son útiles también para el dimensionamiento de la ventilación en los túneles.

Entrando de lleno en el campo del transporte por carretera, de gran importancia por su incidencia no solo viaria, sino sobre la actividad económica general, la información que suele interesar obtener es, tal como se ha comentado, el origen y destino de los viajes con vistas a la planificación tanto de las vías de enlace entre nodos como de los terminales y las instalaciones de carga y descarga, además de la tipología de vehículos utilizados y la determinación del peso y naturaleza de la carga transportada. Para determinar al origen y destino de los vehículos de transporte se ha recurrido tradicionalmente a las encuestas, ya sea en la misma carretera o centro logístico, o las enviadas al domicilio de los transportistas, con las cuales se puede obtener información sobre muchas otras cuestiones aparte del origen y destino: frecuencia de los viajes, rutas seguidas, aspectos empresariales tales como quién es el propietario del vehículo, tipo de mercancía transportada, etc.

Hoy en día para conocer algunos de estos datos se utilizan los dispositivos GPS de posicionamiento global, las tarjetas RFID (Radio Frequency Identification) de identificación por radiofrecuencia y los lectores de matrículas, que pueden 
proporcionar el rastreo del origen y destino de los vehículos y estadísticas de funcionamiento para subgrupos de la población de camiones, pero no dar información sobre su estado de carga (vacío, a media carga, lleno) ni el peso ni el tipo de la carga transportada. Por otro lado, existen preocupaciones significativas de privacidad y de coste que limitan su disponibilidad.

Un ejemplo destacable de las encuestas domiciliarias es la Encuesta Permanente del Transporte de Mercancías por Carretera (EPTMC), que es un estudio llevado a cabo por la Subdirección General de Estudios Económicos y Estadística del Ministerio de Fomento, basado en las respuestas que proporcionan por correo los propios transportistas e incluye datos muy detallados sobre el tipo de los camiones, su peso medio, los kilómetros anuales recorridos por el camión, y el tipo y peso de la mercancía transportada. No obstante, debido a que son los propios transportistas los que proporcionan los datos, los resultados pueden estar sesgados en algunos aspectos, como es el peso de la mercancía transportada, pues a ninguno de ellos le interesa declarar que circulan sobrecargados o que transportan cantidades grandes de mercancía, por la influencia que ellos piensan que podría tener, por ejemplo, en el pago de impuestos.

Por las razones que se acaban de exponer, se ha considerado que en este campo existen lagunas de información y conocimiento que podrían ser abordadas con una investigación práctica basada en la utilización de sistemas y procedimientos que sean capaces de aportar datos suficientemente precisos y no sesgados sobre las proporciones de los distintos tipos de vehículos y los pesos de estos, que permitirán conducir a la estimación del peso de la carga transportada por los vehículos comerciales.

En lo relativo a la información sobre la carga transportada por los vehículos, existen dos aspectos netamente diferenciados:

- Estimar el estado de carga de cada vehículo individual y el peso de la carga transportada por éste, a efectos de transacciones comerciales, especialmente en los entornos de puertos, aeropuertos y centros logísticos y de carga.

- Obtener información estadística del transporte, para el conocimiento específico de sus principales características, como son determinar las toneladas transportadas en una cierta carretera, corredor o en los principales centros generadores de mercancías (centros logísticos), comprender mejor la actividad de los vehículos comerciales, conocer el origen y destino de las mercancías, etc.

Para satisfacer estas necesidades de datos, no solo es necesario conocer el número de vehículos pesados, lo que puede ser proporcionado fácilmente por cualquier sistema de aforo basado en lazos de inducción, sino que se precisa determinar de una forma bastante precisa y detallada los siguientes aspectos de los vehículos de transporte:

- el tipo de vehículos que realiza cada actividad de transporte específica

- el peso de los vehículos y sus cargas por eje

- el peso en vacío (o tara), con objeto de calcular el peso de la carga transportada. 
La única tecnología que puede proporcionar estos datos sobre grandes muestras de vehículos y de forma continua es el pesaje dinámico o en movimiento. Hay que decir que en la última campaña de pesaje dinámico efectuada por el CEDEX, que fue llevada a cabo entre 2000 y 2003 a petición de la Subdirección General de Planificación de la Dirección General de Carreteras, ya hubo un intento de estimar la carga transportada por los vehículos pesados mediante pesaje dinámico, pero el procedimiento que se utilizó requería la participación de observadores, principalmente para determinar la tara de los vehículos, por lo que no podía aplicarse para obtener información de forma continua sobre la carga. No obstante, este estudio podría considerarse un antecedente de la investigación desarrollada en el presente documento.

Dada la incapacidad del procedimiento mencionado para determinar las cargas transportadas de forma continua durante largos periodos de tiempo, se comenzó a pensar en aquella época que era interesante estudiar la posibilidad de desarrollar un nuevo método totalmente automatizado de estimación del peso de la carga transportada por los vehículos pesados, sin requerir la participación de personal alguno, utilizando sistemas de pesaje dinámico. Esto es a lo que se ha tratado de dar respuesta en esta Tesis. Este método totalmente automatizado se debería basar en determinar el peso de la carga transportada partiendo del peso del vehículo suministrado por el sistema de pesaje dinámico. Sin embargo, en este caso, a diferencia del estudio realizado en las campañas de pesaje, a este peso se le restará una tara asignada automáticamente por el sistema en función del tipo de vehículo de que se trate, según una clasificación automática de los vehículos proporcionada también por el sistema de pesaje.

El desarrollo y características de este método es lo que se va a exponer detalladamente en este documento. Así, tras esta introducción, se van a presentar los objetivos de la Tesis y se describirá la metodología de investigación que se ha seguido para su realización.

Después se ha valorado la situación actual de la técnica en cuanto a los sistemas automáticos de toma de datos del tráfico, entre los cuales se van a utilizar específicamente los sistemas de pesaje dinámico de vehículos. Seguidamente se trata el estado del arte tanto de los métodos de clasificación automática de vehículos como de los procedimientos que se han acometido en el mundo para estimar de forma automatizada las cargas de los vehículos.

A continuación se exponen las características principales de los procedimientos automatizados que se han desarrollado tanto para clasificar a los vehículos (lo que se conoce como determinación de la silueta del tráfico) como para estimar las cargas transportadas.

En el capítulo 6 se presentan los resultados de la exactitud de ambos procedimientos, que se han obtenido en un ensayo realizado en la carretera (concretamente en la autovía A-2, pk 82, a la altura del municipio de Trijueque), tanto en lo relativo a la determinación automatizada de la clasificación de los vehículos como en la estimación de las cargas transportadas. 
Después de considerar los resultados obtenidos en el ensayo de comprobación, se han redactado una serie de conclusiones sobre los estudios realizados, con vistas a la aplicación generalizada del procedimiento de determinación automatizada de las cargas transportadas, incluyendo las principales limitaciones de este procedimiento, y proporcionando una lista de aspectos sobre los que sería de utilidad realizar investigaciones adicionales.

Por último, se incluyen en un Anejo los datos que se han registrado de todos los vehículos de la muestra amplia (más de 600) que se tomó en la carretera en el ensayo realizado en Trijueque. Estos datos se muestran en dos bloques: por un lado, se incluye toda la información registrada automáticamente por el sistema de pesaje dinámico y, por otro, se proporcionan todos los datos tomados visualmente de los mismos vehículos. 


\section{Objetivos y metodología de investigación}

\section{$2.1 \quad$ Objetivos de la Tesis}

En esta Tesis se pretende elaborar un método para determinar de forma totalmente automática las cargas transportadas por los vehículos pesados mediante pesajes dinámicos y sin necesidad de tomas de datos visuales.

Las ventajas de disponer de un método automático para determinar las cargas transportadas, tanto si se trata de obtener estas cargas para cada vehículo individual como para conocer la carga total transportada por un conjunto de vehículos, pueden resumirse en las siguientes:

1. La determinación automática de las cargas transportadas por cada vehículo individual permitiría mejorar la eficiencia de las transacciones comerciales, especialmente en terminales de carga y descarga (puertos, mercados centrales, centros logísticos, etc), que posibilitaría que no se formaran colas de vehículos cuando deben ser pesados a la entrada y a la salida de estas instalaciones. Además favorecería una mejor estiba de la carga, especialmente cuando se trata de transportar contenedores por barco, repartiendo adecuadamente el peso de la carga total en los buques.

2. El estimar la carga total transportada por un conjunto de vehículos, cuando circulan por una carretera a su velocidad normal de recorrido y sin interferir el tráfico, posibilitaría mejorar el conocimiento de los flujos de mercancías transportados por una carretera, corredor o red viaria completa, así como determinar el nivel de actividad del transporte por carretera sobre grandes muestras de vehículos $\mathrm{y}$, por su fuerte correlación con la actividad económica general, permitiría realizar estimaciones más ajustadas de los grandes datos estadísticos sobre este particular.

Para lograr este objetivo final de determinar la carga transportada, se ha emprendido el estudio que se describe en esta Tesis, en el que se deben alcanzar una serie de objetivos parciales que se describen a continuación.

Los objetivos parciales que se deben conseguir para estimar la carga transportada por los vehículos pesados son los siguientes:

1. Desarrollar un sistema de clasificación automática de los vehículos, que sea bastante detallado como para describir de forma unívoca el tráfico pesado de vehículos.

El desarrollo de un sistema de clasificación automática del tráfico pesado constituiría por sí solo un objetivo final, pues además de ser un medio necesario para poder determinar la carga transportada por los vehículos pesados, tiene aplicaciones propias de gran utilidad para la gestión del tráfico y transporte. 
La composición detallada o silueta del tráfico es uno de los datos más importantes que pueden ser obtenidos en cualquier estudio de la circulación. Generalmente, las administraciones de carreteras utilizan los datos de clasificación de vehículos para el planeamiento, proyecto, conservación y explotación viaria, tal como se describe a continuación:

- En la fase de planeamiento, los datos de clasificación se emplean para determinar los parámetros de entrada relativos a la capacidad de las carreteras, así como para predecir los flujos de movimientos de mercancías, además de para realizar estudios de impacto ambiental.

- Al proyectar el firme de una carretera, los datos de clasificación aplicados en conjunción con unos datos de agresividad media por tipo de vehículo, sirven para definir los espesores de las distintas capas del firme.

- En la fase de explotación de una carretera, los datos de clasificación se usan para determinar las estrategias de control de tráfico, sin olvidar estudios relativos a la seguridad viaria, pues las diferentes clases de vehículos tienen un comportamiento diferente de funcionamiento, así como en la elaboración de estrategias de control de pesos y cargas de los vehículos.

- En cuanto al mantenimiento y conservación viarios, se emplean los datos de clasificación de vehículos de forma parecida a como se hace en el proyecto de firmes, para programar las actividades de refuerzo y rehabilitación de pavimentos en función de los vehículos pesados que hayan circulado sobre una sección concreta durante un tiempo determinado o, si la clasificación es más afinada, según los camiones de cada tipo, en conjunción con su factor de equivalencia medio, que hayan pasado sobre tal sección.

Normalmente, cada país recoge y analiza los datos de clasificación de vehículos basándose en unas pautas propias, pues las características de los vehículos pueden diferir de un país a otro, debido a que los tipos y modelos de camiones utilizados se ven muy influidos tanto por las actividades económicas (algunos tipos de camiones están diseñados para transportar cargas que son muy específicas de cada país) como por las limitaciones de pesos y dimensiones que imponen los diferentes Estados.

2. Elaborar un procedimiento de asignación automática de la tara de los vehículos en función del tipo de vehículo de que se trate, obtenido éste mediante la clasificación automática mencionada.

Uno de los aspectos más complicados para elaborar un procedimiento de estimación de la carga transportada por los vehículos pesados es establecer la tara de cada vehículo que circule sobre el sistema de pesaje en movimiento, pues éste es un dato, en principio, desconocido y que depende de múltiples factores, como son la clase y tipo de vehículo (que depende a su vez del número de unidades motoras o remolcadas que lo componen y de su número de ejes) y, además, del tipo de carrocería del 
vehículo (volquete, plataforma, portacontenedor, frigorífico, etc.) según la naturaleza de la carga que transporta.

Como sería imposible determinar automáticamente y de forma unívoca la tara de cada vehículo, se tratará de estimarla de forma aproximada en función de la clase y tipo de vehículo de que se trate en cada caso, de acuerdo con el procedimiento de clasificación automática aludido en el objetivo 1. Para ello, es preciso además poseer una base de datos de las taras de los distintos tipos de vehículos, existiendo diferentes fuentes de datos de las taras de los camiones, que se estudian en el apartado correspondiente de este documento.

3. Elaborar el procedimiento de determinación de la carga transportada por cada vehículo individual, y determinar el error que se puede cometer al estimar la carga transportada utilizando este procedimiento.

Una vez conocidos el peso total en carga (partiendo del peso suministrado por el equipo de pesaje dinámico) y el tipo de vehículo de que se trata (y de éste, su tara estimada según el punto anterior), la elaboración del procedimiento de determinación de la carga transportada es bastante inmediata. Además, otro de los aspectos fundamentales es estimar el error que se comete al determinar la carga con este método automático, debido a las simplificaciones que se deben llevar a cabo para que sea practicable.

Por ello, el estudio del error que se comete al calcular la carga de esta forma frente a su valor real, y establecer si este error es asumible y en qué condiciones, es uno de los aspectos fundamentales de este punto.

4. Ampliación del procedimiento anterior de determinación de la carga de cada vehículo individual para determinar la carga total transportada por el conjunto de vehículos que constituyen el tráfico de una carretera, y determinar el error en que se incide al estimar la carga con este procedimiento.

Aunque la determinación de la carga transportada por un conjunto de vehículos no se diferencia demasiado de la estimación de la carga de cada vehículo individual, sus implicaciones exceden en mucho a aquélla. Por otro lado, es en relación a la estimación de la carga transportada por un cierto número de vehículos, donde se puede estudiar en profundidad no solo el error total cometido, sino descender adecuadamente hasta las distintas componentes de este error, que son fundamentalmente dos: la componente debida al error del aparato de medición (el sistema de pesaje dinámico) y la parte del error debida a las simplificaciones del método (la asignación de una tara distinta de la real y la posible clasificación errónea del vehículo dentro de un tipo diferente al que le corresponde realmente). El análisis de estas fuentes de error, permitirá adoptar medidas para minimizar el error total cometido. 
5. Estimar la influencia que pueden tener ciertas circunstancias variables o condiciones, que es muy difícil determinar con seguridad, en el error que se puede cometer al calcular la carga transportada empleando el método automático simplificado propuesto, y de aquí estimar su validez para una aplicación generalizada.

En este documento se muestran las cifras obtenidas en el ensayo realizado para la comprobación del método de estimación de la carga transportada, pero a efectos de evaluar la posible aplicación generalizada del método, es interesante estudiar cuál habría sido el error obtenido si hubieran variado ciertos parámetros, como es la precisión del sistema de pesaje dinámico utilizado, u otras condiciones muy difíciles de controlar o de estimar con seguridad, como es la adecuación del valor de las taras medias de cada tipo de vehículo, una incorrecta calibración del equipo de pesaje utilizado o una clasificación inexacta de los vehículos. Para ello se realizará un análisis de la sensibilidad del método ante la variabilidad o la incertidumbre de los anteriores parámetros.

\subsection{Metodología de investigación}

La metodología de investigación inicialmente prevista para llevar a cabo los trabajos de esta Tesis consistía en aprovechar primeramente, como base, el conocimiento del tráfico pesado y la experiencia previa de toma y tratamiento de datos de clasificación y pesaje dinámico de vehículos llevada a cabo en la última campaña de pesaje dinámico de vehículos efectuada entre 2000 y 2003, junto con la consideración de los aspectos novedosos obtenidos de una revisión del estado actual de la técnica en estas cuestiones. Seguidamente, teniendo en cuenta el conocimiento actualizado obtenido de la revisión del estado del arte en este dominio técnico, se iban a desarrollar unos procedimientos totalmente automatizados de clasificación de los vehículos y, aprovechando esta clasificación automatizada, un método de estimación de las cargas transportadas por los vehículos pesados.

Una vez elaborada una versión inicial de los anteriores métodos de estimación automatizada, se iba a proceder a realizar una primera toma de datos en la carretera (que tuvo lugar en noviembre de 2014 en la autovía A-1, pk. 41, a la altura del municipio de El Molar) para tener en cuenta las características de los vehículos pesados que circulan actualmente por la red de carreteras $y$, por otro lado, para depurar los procedimientos desarrollados. Finalmente, se iba a proceder a realizar una segunda toma de datos en la carretera (que tuvo lugar en junio de 2015 en la autovía A-2, pk 82 en Trijuque (Guadalajara)), que serviría para realizar una comprobación de la exactitud y ajuste de los métodos desarrollados y verificar su adecuación a los objetivos previamente definidos.

Sin embargo, fue preciso modificar ligeramente esta metodología prevista, debido a que en la realización de la toma de datos en la A-1, surgieron los siguientes problemas: 
- El procedimiento previsto para comprobar la adecuación de las taras de los vehículos a las taras reales era tomar visualmente estas últimas de la chapa lateral de los camiones (en la que se incluye su tara y su masa máxima autorizada), tal como se había hecho en las tomas de datos visuales llevadas a cabo en la última campaña de pesaje y en otras campañas anteriores. Sin embargo, habiendo transcurrido más de 10 años de la realización de aquellas campañas, se comprobó que, desafortunadamente, la mayor parte de los camiones (especialmente de los vehículos articulados) ya no tenía la chapa lateral en la que figuraba el dato de la tara, con lo cual no podían obtenerse los datos de referencia de éstas mediante las tomas de datos visuales para comprobar la bondad de la estimación.

- Como se preveía que podían surgir problemas de este tipo, debido al largo periodo de tiempo en que no se había realizado tomas de datos alternativas, se tomó la matrícula de los camiones que iban a servir de comparación, con objeto de solicitar a la Dirección General de Tráfico las taras reales de estos vehículos. Sin embargo, mediante este procedimiento sólo se pudo conseguir la tara de los vehículos rígidos, pues con la matrícula de la cabeza tractora solamente no se podía conocer la tara de los remolques y semirremolques de los vehículos articulados y trenes de carretera, que poseen su propia matrícula. Uno de las razones por las que no se tomaba esta matrícula (cuyo fondo es de color rojo, en vez de blanco como la matrícula de los vehículos rígidos y las cabezas tractoras) era la dificultad de identificarla visualmente según pasaba el camión a velocidades de entre 80 y $90 \mathrm{~km} / \mathrm{h}$, pues los números negros de la matrícula destacan poco frente a su fondo rojo.

- Por último, debido a las adversas condiciones meteorológicas durante la semana de toma de datos (finales de noviembre), se produjo la rotura de los dispositivos de sujeción de alguno de los sensores de peso (esteras capacitivas) al firme de la calzada, por lo que se perdieron parte de los datos de algunos días en dos de los carriles.

Debido a todos estos problemas, sólo pudo utilizarse la toma de datos de El Molar para depurar el procedimiento de clasificación desarrollado, pero no para verificar la precisión en la estimación de las cargas transportadas. Sin embargo, se aprovechó la experiencia fallida en la toma de datos de las taras para corregir el plan de experimentación que se iba a llevar a cabo en la segunda de las tomas de datos, realizada en la A-2 en Trijueque (Guadalajara).

Así, en primer lugar, como se vio que era imprescindible tomar las matrículas rojas de los remolques y semirremolques, se decidió fotografiar la matrícula de todos los camiones que pasaban sobre el sistema de pesaje durante la toma visual de datos con observadores, de forma que con ello, además de obtener con total fiabilidad las matrículas roja y blanca, se disponía de la configuración exacta del vehículo (incluido otro dato muy importante: si el camión llevaba algún eje levantado sobre el pavimento o no), información de gran utilidad a efectos de comprobación en los listados de las salidas del equipo de pesaje dinámico. De esta forma, los datos de las matrículas de 
más de 600 camiones fueron enviados a la Dirección General de Tráfico para que proporcionaran la tara y masa máxima autorizada de los vehículos correspondientes, datos que fueron remitidos por la DGT a finales de marzo de 2016.

Por otro lado, con objeto de tener una seguridad total de que se iban a tener de forma rápida los datos de las taras y el peso estático (real) de al menos una pequeña muestra de vehículos, se decidió realizar las gestiones oportunas para implicar a la Agrupación de Tráfico de la Guardia Civil en la toma de datos, previa petición a la Subdirección de Inspección del Transporte de la Dirección General del Transporte Terrestre del Ministerio de Fomento, pues sus agentes son los únicos que pueden ordenar a los camioneros que se desvíen para su pesaje estático.

Este pesaje se efectuó en una báscula fija situada unos $500 \mathrm{~m}$ corriente abajo del tráfico, en el pk 81 de la A-2, en las cercanías de Trijueque. Con ello, se dispuso casi instantáneamente de los datos necesarios (pesos estáticos, taras reales, etc) para la comprobación del procedimiento de estimación de las cargas transportadas mediante una pequeña muestra de unos 30 camiones.

Teniendo en cuenta lo que se ha explicado y después de las vicisitudes descritas, la metodología de investigación llevada finalmente a cabo para elaborar el procedimiento totalmente automatizado de determinación de las cargas transportadas por los vehículos pesados, objeto de esta Tesis, se puede resumir en los siguientes pasos:

1) Consideración de los trabajos realizados en la campaña de pesaje dinámico 2000-2003 para determinar la carga transportada por los vehículos pesados de forma parcialmente automatizada, pues se basaba todavía en la toma de datos visuales por parte de operarios situados en los márgenes de la carretera.

2) Realización de una revisión bibliográfica sobre los avances surgido en los últimos años tanto en el ámbito de la clasificación automática de vehículos como en la estimación automática de las cargas transportadas por los vehículos pesado mediante sistemas de pesaje dinámico.

3) Elaboración de un primer procedimiento de clasificación automática (conjunto de reglas de diferenciación de los diferentes tipos de camiones) de los vehículos pesados basándose en las características de los vehículos obtenidas de la muestra de la campaña 2000-2003.

4) Adaptación de ese primer procedimiento de clasificación automática a las características del tráfico pesado actual. Para ello se ha realizado una toma de datos de pesaje y medida de las dimensiones de los vehículos en una estación representativa del tráfico pesado nacional e internacional, que se ha llevado a cabo en noviembre de 2014 en la A-1, pk 41, a la altura del municipio de El Molar (Madrid).

5) Análisis de los datos recogidos en El Molar con el objetivo de adaptar los límites y umbrales de diferenciación entre los distintos tipos de vehículos a 
los datos de los vehículos actuales, así como para evaluar la posibilidad de modificar o crear algunas reglas nuevas.

6) Recogida de información sobre las distintas fuentes de datos de taras de los vehículos. Elaboración de un procedimiento de asignación de las taras a los vehículos según el tipo a qué pertenezcan, de acuerdo con el procedimiento de clasificación automática propuesto.

7) Desarrollo del método de estimación de las cargas transportadas a partir de los datos de los pesajes dinámicos y de las taras asignadas a cada uno de los vehículos pesados según el tipo en el que sean clasificados automáticamente con el procedimiento anterior.

8) Realización de una toma de datos de pesajes en una autovía de la Red de Carreteras del Estado, cuyo tráfico sea representativo del tráfico pesado nacional e internacional, con objeto de evaluar la precisión del procedimiento de clasificación automática de los vehículos desarrollado y, asimismo, evaluar el error que se comete al estimar las cargas transportadas por los vehículos pesados mediante la utilización del procedimiento de estimación de las cargas desarrollado. Esta toma de datos de comprobación se ha realizado en la A-2, pk 82, a la altura del municipio de Trijueque (Guadalajara) en junio de 2015.

9) Realización de un análisis de sensibilidad del procedimiento desarrollado para la estimación de las cargas transportadas, respecto de algunos parámetros sobre los cuales existe alguna incertidumbre 0 su determinación es muy imprecisa.

10) Extracción de las conclusiones pertinentes sobre la aplicabilidad del método para determinar cargas transportadas mediante el empleo de sistemas de pesaje dinámico instalados en la carretera.

Con respecto al proceso de comprobación mediante ensayos (uno realizado en la A-1, pk 41, en el Molar y otro en la A-2, pk 82, en Trijueque) tanto de los métodos de clasificación automática como de estimación de la carga transportada desarrollados, es necesario explicar que estos ensayos consisten en aplicar los procedimientos automatizados elaborados sobre condiciones reales del tráfico en una carretera que se considere representativa del tráfico pesado nacional $\mathrm{y}$, al mismo tiempo, se deben obtener unos datos de contraste, es decir, datos de vehículos que hayan pasado sobre el sistema de pesaje, de los cuales se conozca con total seguridad el tipo al que pertenecen y el peso real de la carga que transportan, todo ello con objeto de comparar los resultados obtenidos de la aplicación de los procedimientos desarrollados con estos datos de contraste. A este efecto, se han obtenido visualmente unos datos de contraste durante unas pocas horas, mediante un proceso que se ha denominado "muestreo visual de vehículos".

El muestreo visual de vehículos en la carretera se ha realizado mediante unos operarios que, durante casi 11 horas en cada uno de los dos emplazamientos, han 
apuntado las características de cada uno de los vehículos muestreados (o más bien, para aumentar su capacidad de registro, las han grabado utilizando la voz, y luego, en gabinete, se ha pasado toda esa cantidad de datos al papel) y han realizado fotografías sobre cada uno de los vehículos muestreados en el momento de pesar sobre el equipo de pesaje. Posteriormente en la oficina, tomando como referencia la hora de paso de cada vehículo muestreado sobre el sensor, se ha identificado al vehículo en cuestión sobre el listado registrado automáticamente por el equipo de pesaje. En concreto, las fechas y horas de toma de datos fueron las siguientes:

\section{El Molar (A-1, pk. 41,6)}

- Desde las 10:08 horas hasta las 14:00 horas del 26 de noviembre de 2014

- Desde las 15:43 horas hasta las 17:29 horas del 26 de noviembre de 2014

- Desde las 10:06 horas hasta las 14:00 horas del 27 de noviembre de 2014

- Desde las 15:54 horas hasta las 17:20 horas del 27 de noviembre de 2014

Trijueque (A-2, pk. 82)

- Desde las 16:53 horas hasta las 17:16 horas del 15 de junio de 2015

- Desde las 10:07 horas hasta las 13:50 horas del 16 de junio de 2015

- Desde las 10:06 horas hasta las 13:53 horas del 17 de junio de 2015

- Desde las 10:24 horas hasta las 13:18 horas del 18 de junio de 2015

Una vez localizado cada vehículo sobre el listado del ordenador, se añaden varias columnas más a ese listado automático para introducir manualmente las diferentes características tomadas visualmente (una columna por cada característica tomada por los operarios), obteniéndose un listado completo de la población total de vehículos registrados automáticamente. Cada vehículo con todos sus datos aparece en una línea, algunos de los cuales aparecen con datos (columnas) adicionales, que han sido recogidos visualmente y consignados manualmente (entre los cuales se encuentra su clasificación visual, el peso en báscula estática, la tara real, etc.), que podrían considerarse como verdaderos. Entonces, comparando el tipo del vehículo o la carga transportada que aparece en la columna tomada visualmente (datos "reales" o "verdaderos") con los que se muestran en la columna de la clasificación o del peso de la carga transportada obtenidos automáticamente, se puede determinar la tasa de acierto de la clasificación automática respecto a la real (visual) o el error en la estimación de la carga transportada. 


\section{Definiciones sobre el tráfico pesado, su composición y sobre las características de los vehículos pesados}

Para la correcta interpretación de este documento se hace imprescindible dar una serie de definiciones que aclaren determinados conceptos o términos que van a ser empleados en él. Las utilizadas para el desarrollo de los trabajos se han tomado de la de la colección Textos Legales no 14, vigésimo primera edición (2002), editada por el Ministerio del Interior y el Boletín Oficial del Estado en materia de Tráfico, Circulación y Seguridad Vial [1], principalmente del Reglamento General de Vehículos (aprobado por R.D. 2822/1998 de 23 de diciembre) en su Anexo IX "Masas y dimensiones"; de los artículos 55, 56, 57 y 58 del Código de la Circulación de 25 de septiembre de 1934 [2], vigentes hasta la entrada en vigor del Reglamento General de Vehículos; y de las disposiciones de la Unión Europea, entre las que se puede destacar la Directiva Comunitaria 96/53/CE [3].

Otras definiciones, no contenidas en dichos textos legales, se han tomado de la Norma española 6.1-IC [4] y de la monografía C15 del CEDEX titulada "Caracterización del tráfico pesado en el dimensionamiento de firmes. El espectro de vehículos pesados en España" [5].

\section{Definición general:}

Tráfico pesado. Es el tráfico formado por los vehículos pesados que circulan sobre una carretera, incluyéndose en esta denominación todos los que, de acuerdo con el Reglamento General de Conductores (R.D. 772/1997 de 30 de mayo), tienen una masa máxima admitida (MMA) que excede de $3.500 \mathrm{~kg}$ y para conducirlos precisan de un permiso de conducción de la Clase C o D (+E).

\subsection{Definiciones en relación con los ejes de los vehículos pesados}

Los agrupaciones de ejes individuales, también conocidas como ejes múltiples de los vehículos pesados, pueden ser simples, dobles (tándem) y triples (trídem):

Eje simple. Es aquél que dista del eje más próximo una distancia igual o superior a $1,80 \mathrm{~m}$.

Eje doble o tándem. Es aquel que dista del eje más próximo una distancia inferior a $1,80 \mathrm{~m}$.

Eje triple o trídem. Es un conjunto de tres ejes consecutivos cuyas distancias entre centros de ejes contiguos no supera 1,40 m.

Esta clasificación se basa en la consideración de los efectos de las cargas de los ejes sobre la estructura del firme de la carretera. Así, se supone que un eje es aislado o simple cuando la deformación reversible producida en el pavimento por el paso de ese eje ha desaparecido antes de que en la sección considerada incida un nuevo eje, no existiendo por tanto efectos de superposición de cargas. 
Se ha denominado eje elemental o individual a cada uno de los ejes que posee el vehículo y cuya masa es el dato primario que se obtiene con el sistema de pesaje dinámico, y se ha llamado grupo de ejes o eje múltiple (simple, tándem o trídem) al conjunto de ejes elementales que resulta tras la aplicación de las anteriores relaciones de distancia entre estos. Como se puede comprender, los conceptos de eje elemental y eje múltiple sólo coinciden en el caso de que este último sea simple. Gráficamente se puede visualizar según se muestra en la Figura 1.
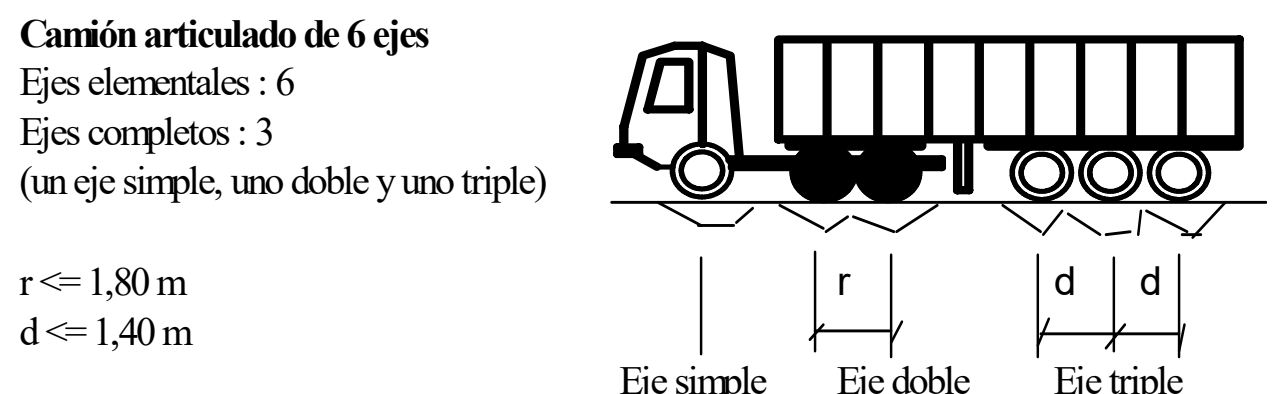

Figura 1 - Tipos de ejes múltiples de los vehículos pesados

Teniendo en cuenta el número de ruedas por eje, se considera eje de ruedas sencillas al que tiene una sola rueda en cada uno de sus extremos, y eje de rueda gemela al que posee dos ruedas en cada uno de sus extremos (véase la Figura 2).

Los neumáticos, en cuanto a su anchura, pueden ser normales o anchos de baja presión, aunque en la realización del estudio no se ha considerado esta característica, por dificultades de obtención de una información fiable al respecto a través de la observación visual en la carretera y por la imposibilidad de obtenerla automáticamente por el sistema.

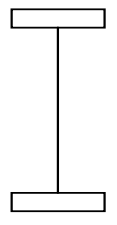

Eje de ruedas sencillas

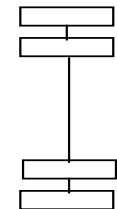

Eje de ruedas gemelas
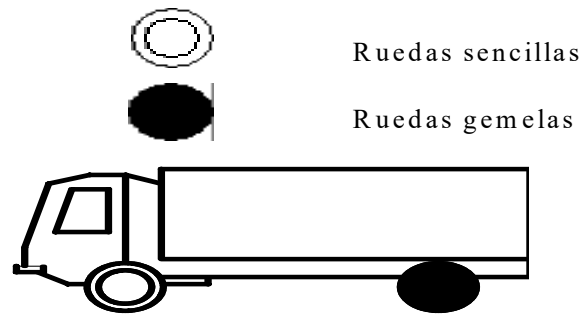

Configuración típica de un camión de dos ejes

Figura 2 - Tipos de eje en cuanto al número de ruedas en sus extremos 
Se aprecia que la carga máxima legal de un eje doble es menor que el doble de la permitida para un eje simple, y análogamente ocurre con los ejes triples. La razón de esta reducción se basa en el hecho de que en los ejes dobles y triples existe un efecto de superposición de las cargas de los ejes elementales que los forman, lo que hace que resulten más perjudiciales para el firme que si actuaran por separado.

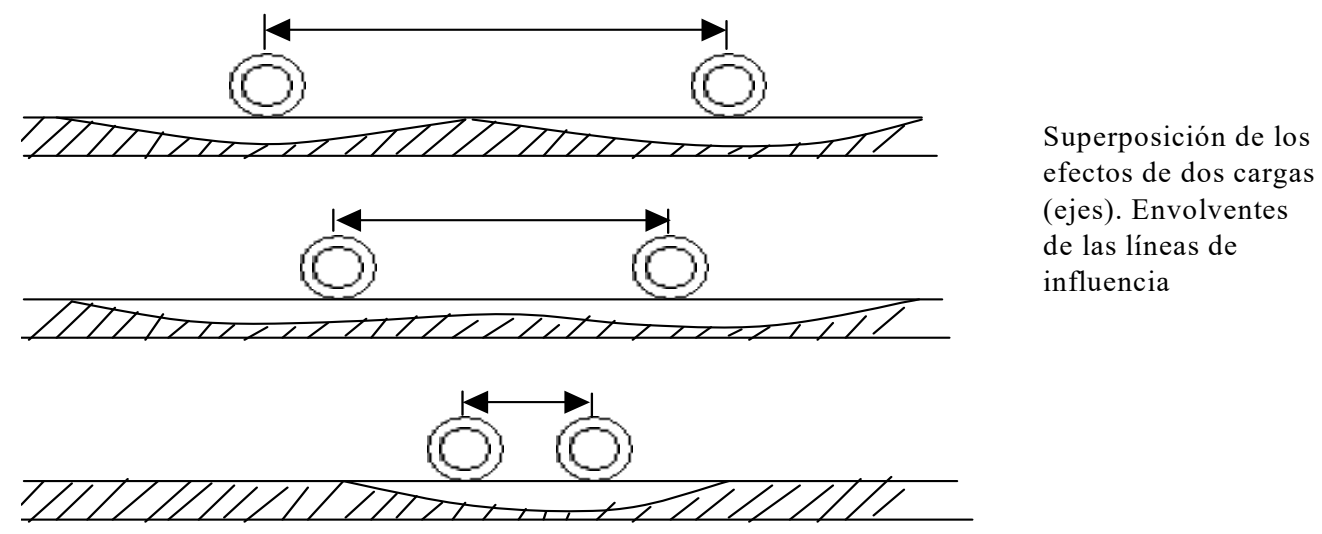

Figura 3 - Envolventes de las líneas de influencia de las cargas de dos ejes individuales en función de la separación entre ambos

\subsection{Definiciones en relación con los vehículos}

El transporte de mercancías puede realizarse en distintos tipos de vehículos, dependiendo del tipo de mercancía, de la distancia, etc. Por ello, en el Anexo II "Definiciones y categorías de los vehículos", del Reglamento General de Vehículos [1] se clasifican los vehículos según dos criterios: construcción y utilización. Para los trabajos del estudio se ha seguido la clasificación del criterio de construcción, exponiendo a continuación las clases de vehículos considerados durante la realización de los trabajos.

Derivado de turismo. Vehículo automóvil destinado a servicios o a transporte exclusivo de mercancías, derivado de un turismo del cual conserva la carrocería y dispone únicamente de una fila de asientos.

Furgón / furgoneta. Automóvil destinado al transporte de mercancías cuya cabina está integrada en el resto de la carrocería y cuya Masa Máxima Autorizada puede ser menor, igual o mayor de $3.500 \mathrm{~kg}$.

Camión. Automóvil de cuatro ruedas o más, concebido y construido para el transporte de mercancías, cuya cabina no está integrada en el resto de la carrocería y con un 
máximo de nueve plazas, incluido el conductor, y cuya Masa Máxima Autorizada puede ser menor, igual o mayor de $3.500 \mathrm{~kg}$.

Vehículo articulado. Automóvil constituido por un vehículo de motor (tractocamión) acoplado a un semirremolque

Semirremolque. Vehículo no autopropulsado diseñado y concebido para ser acoplado a un automóvil, sobre el que reposará una parte del mismo, transfiriéndole una proporción sustancial de su masa.

Tren de carretera. Automóvil constituido por un vehículo de motor enganchado a un remolque.

Remolque. Vehículo no autopropulsado diseñado y concebido para ser remolcado por un vehículo de motor.

Por su parte, los camiones estudiados en esta Tesis están divididos en tres clases: rígidos, articulados y trenes de carretera.

Camiones rígidos: Tienen al menos dos ejes múltiples, uno delantero de dirección y otro trasero motor o de carga, y cada uno de estos puede estar constituido por uno o dos ejes elementales, que a su vez pueden ser de ruedas sencillas o gemelas en el eje motor. La MMA de esta clase varía en función del número de ejes elementales y del tipo de suspensión, y oscila entre 18 t para un camión de dos ejes hasta 32 t para uno de cuatro ejes.

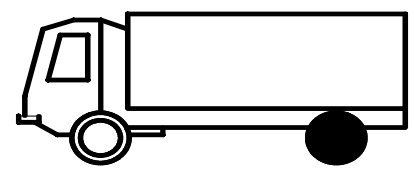

Figura 4. Configuración típica de un camión rígido de 2 ejes, con un eje delantero (direccional) simple de rueda sencilla y un eje trasero (motriz) simple de rueda gemela

Vehículos articulados. Están compuestos por un elemento tractor y un semirremolque. Tienen tres ejes múltiples, de los cuales el de dirección siempre es un eje elemental de ruedas sencillas, el eje motor, donde descansa la parte delantera del semirremolque, puede ser un eje simple o doble, pero siempre de ruedas gemelas y, por último, el eje de carga del semirremolque puede adoptar diferentes combinaciones de uno a tres ejes sencillos, con ruedas sencillas, gemelas o ambas.

La masa máxima autorizada varía en esta clase desde 36 t a 44 t en función de las configuraciones de ejes. 


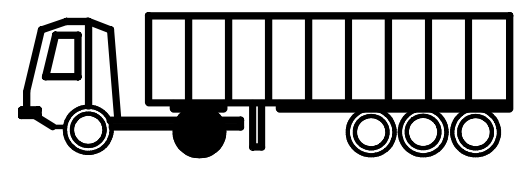

Figura 5. Configuración típica de un vehículo articulado de 5 ejes, con 2 ejes en la cabeza tractora, el delantero (direccional) simple de rueda sencilla y el eje trasero (motriz) simple de rueda gemela, y tres ejes individuales de rueda sencilla, que forman un eje trídem, en la parte trasera del semirremolque.

Trenes de carretera. Los trenes de carretera (o conjunto de vehículos) pueden estar formados por cualquier tipo de vehículo tractor y uno o varios remolques pero a menudo suelen estar formados por un camión rígido y un remolque. Tienen como mínimo tres ejes completos, de los cuales el de dirección siempre es un eje elemental o sencillo de ruedas sencillas y los demás pueden tener cualquier configuración. La MMA varía, en función del número de ejes elementales, de 36 t a $44 \mathrm{t}$.

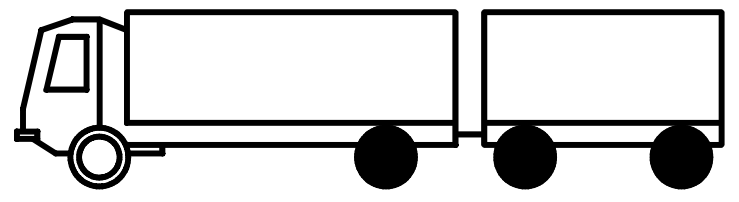

Figura 6. Configuración de un tren de carretera de 4 ejes, siendo el vehículo tractor un camión rígido de 2 ejes, el delantero (direccional) simple de rueda sencilla y el eje trasero (motriz) simple de rueda gemela, y con un remolque de 2 dos ejes, ambos simples de rueda gemela.

En la actualidad coexisten en circulación unos pocos vehículos pesados que se atienen a la reglamentación antigua (la del Código de Circulación de 1934) en materia de pesos máximos y otros a la nueva (la del Reglamento General de Vehículos de 1998). Los valores que se acaban de dar corresponden a la nueva. No obstante, a continuación se enumeran los límites de ambas reglamentaciones.

\subsection{Limitaciones legales de los pesos totales, pesos por eje y dimensiones de los vehículos pesados.}

Actualmente existen dos normativas legales diferentes a las que pueden acogerse los vehículos pesados según su fecha de matriculación, en relación con los límites de peso y dimensiones que pueden tener:

1. La de los artículos 55, 56 y 57 del Código de la Circulación de 1934.

2. La del vigente Reglamento General de Vehículos, aprobado por Real Decreto 2822/1998 de 23 de diciembre.

Esta duplicidad de normativa viene ya de la Ley 339/1990 sobre Tráfico, circulación de vehículos a motor y seguridad vial, que fue aprobada el 2 de marzo de 1990. Para su 
aplicación y desarrollo se aprobó mediante Real Decreto el 17 de enero de 1992 el "Reglamento General de Circulación", que entró en vigor el 15 de junio de 1992. Este Reglamento derogaba ya algunos artículos del anterior Código de la Circulación, entre ellos el 55, 56 y 57, a propuesta del Ministerio de Obras Públicas y Transportes, para adaptarse en materia de pesos de ejes y vehículos y de longitudes a las Directivas de la Unión Europea y, en particular a la Directiva 91/60. Estos artículos fueron derogados mediante Real Decreto el 2 de agosto de 1991, es decir una vez aprobada la Ley pero no el Reglamento.

Las limitaciones que se establecen en los documentos mencionados son las siguientes:

\section{Limitaciones de los Artículos 55, 56 y 57 del Código de la Circulación de 1934}

\section{$\underline{\text { Pesos de ejes }}$}

* Eje simple

* Eje doble

Conjunto de 2 ejes cuya distancia entre centros es inferior a 1,50 m. Si la distancia d entre centros de ejes es de $0,90 \mathrm{~m}$, el peso sobre el eje más cargado no debe ser superior a 7,35 $\mathrm{t}$ (en total 14,7 t). Se podrán aumentar $700 \mathrm{~kg}$ de peso por cada 0,05 m de distancia superior a 0,9 $\mathrm{m}$, sin que en ningún caso pueda superar las $21 \mathrm{t}$ para una distancia de $1,35 \mathrm{~m}$ a $1,50 \mathrm{~m}$.

* Eje triple: no contemplado.

Pesos de vehículos

* Vehículo rígido de 2 ejes ............................................................................ $20 \mathrm{t}$

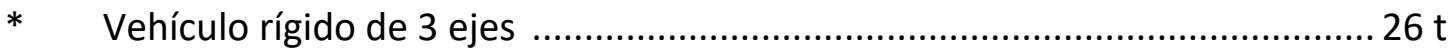

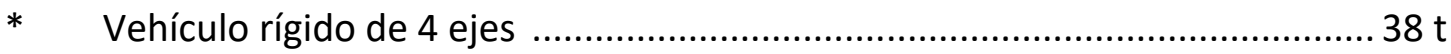

* Vehículo articulado y conjunto de vehículos ................................................ $38 \mathrm{t}$

Longitud de los vehículos

* Vehículo rígido (cualquier número de ejes) ............................................... $12 \mathrm{~m}$

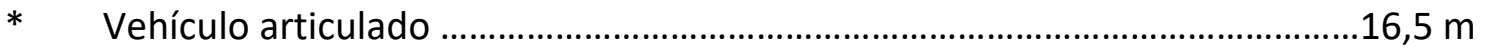

* $\quad$ Autobús articulado y conjunto de vehículos ................................................ $18 \mathrm{~m}$

Limitaciones incluidas en el "Reglamento General de Vehículos", actualmente vigente 
Estas limitaciones aparecen en su Anexo IX "Masas y dimensiones", en relación a los pesos y longitudes de los ejes y vehículos, y son las siguientes:

\section{$\underline{\text { Pesos de ejes }}$}

* Eje simple motor $11,5 \mathrm{t}$

* Eje simple no motor $10 \mathrm{t}$

* Eje doble o tandem: conjunto de 2 ejes cuya distancia entre centros es inferior a $1,80 \mathrm{~m}$.

* Eje doble o tandem con separación $\mathrm{d}<1,00 \mathrm{~m}$ $11,5 \mathrm{t}$

* Eje doble o tandem con separación : 1,00 m $\leq \mathrm{d}<1,30 \mathrm{~m}$ $16 \mathrm{t}$

* Eje doble o tandem con separación : 1,30 m $\leq \mathrm{d}<1,80 \mathrm{~m}$ $18 \mathrm{t}$

* Eje doble o tandem de los remolques y semirremolques con $\mathrm{d}<1,00 \mathrm{~m}$ $11 \mathrm{t}$

* Eje triple o tridem: conjunto de 3 ejes en el que ninguna de las distancias entre centros de ejes contiguos es superior a $1,40 \mathrm{~m}$.

* Eje triple o tridem de remolque o semirremolque :

- Si $d<1,30 \mathrm{~m}$ $21 \mathrm{t}$

- Si : 1,30 m $\leq \mathrm{d}<1,4 \mathrm{~m}$ $24 \mathrm{t}$

Pesos de vehículos

* $\quad$ Rígido de 2 ejes $18 \mathrm{t}$

* $\quad$ Rígido de 3 ejes $25 \mathrm{t}$

* Rígido de 3 ejes (con suspensión neumática y eje motor tándem de neumáticos dobles) $26 \mathrm{t}$

* $\quad$ Rígido de 4 ejes $31 \mathrm{t}$

* Rígido de 4 ejes (con dos ejes direccionales, suspensión neumática y ruedas gemelas en el eje motor)

* Articulado de 4 ejes

(vehículo tractor de 2 ejes, siendo el eje motor de ruedas gemelas con suspensión neumática y el semirremolque con $\mathrm{d}>1,80 \mathrm{~m}$ (es decir, el semirremolque no tiene un tándem gemelo, sino 2 ejes). (Nota: este vehículo no existe en España)

* Articulado de 4 ejes (tractor de 2 ejes y semirremolque de 2 ejes) 
* Articulado de 5 o más ejes $40 \mathrm{t}$

* Vehículo motor de 3 ejes con semirremolque de 2 ó 3 ejes .......................... $44 \mathrm{t}$

* Tren de carretera de 4 ejes ( 2 en vehículo motor y 2 en remolque) ............... $36 \mathrm{t}$

* Tren de carretera de 5 ó más ejes ................................................................ $40 \mathrm{t}$

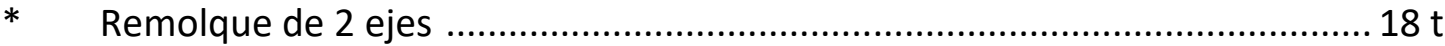

* $\quad$ Remolque de 3 ejes ............................................................................... $24 \mathrm{t}$

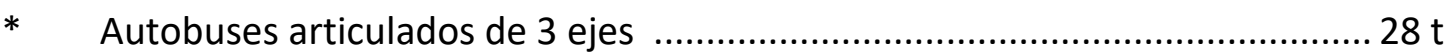

$\underline{\text { Longitud de los vehículos }}$

* Vehículo rígido [cualquier número de ejes (camión o autobús)] ....................12 m

* Vehículo articulado (excepto autobuses) ......................................................16,5 m

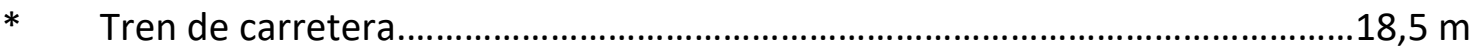

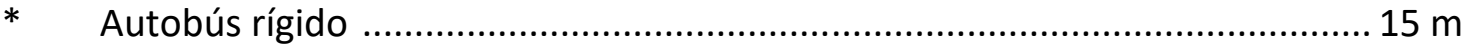

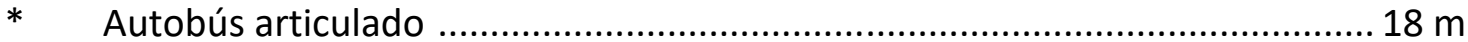

* Remolque (exclusivamente el remolque) ..................................................... $12 \mathrm{~m}$

\section{Transición de la normativa antigua a la actual}

La puesta en práctica de los límites citados requería un periodo de adaptación, durante el cual el tráfico pesado en la carretera estaría compuesto de vehículos pesados a los que les afectaban las normas anteriores y otros vehículos a los que les afectaban las actuales.

La transición a la nueva "Ley de Tráfico, Circulación de vehículos a motor y Seguridad Vial" en materia de pesos y longitudes quedó establecida de la siguiente forma:

a) Vehículos pesados extranjeros (matriculados fuera de España)

Han de atenerse a las disposiciones de la Directiva comunitaria 91/60 contemplada en el actual "Reglamento General de Circulación", que recoge el Real Decreto aprobado el 2 de agosto de 1991. Por la misma razón, los vehículos pesados españoles que circulen por el resto de la Unión Europea deben atenerse a la misma Directiva, aunque por su fecha de matriculación puedan acogerse a la legislación anterior dentro del territorio nacional.

b) Vehículos pesados nacionales

b.1 Matriculados antes del 2 de agosto de 1991: 
Se acogen a la legislación anterior. Pueden circular por todo el territorio nacional hasta dar de baja el vehículo. Tienen limitado el movimiento a itinerarios establecidos.

b.2 Matriculados entre el 2 de agosto de 1991 y el 1 de enero de 1995:

Se acogen a la legislación anterior y tienen limitación de circulación (durante 10 años) y de movimiento (tienen itinerarios establecidos).

b.3 Matriculados entre el 2 de agosto de 1991 y el 1 de enero de 1993:

Este apartado se refiere exclusivamente a los remolques de 3 ejes y a los autocares articulados de 3 ejes. Es decir, se admite la matriculación de estos dos tipos según la reglamentación anterior, hasta la fecha de 1 de enero de 1995, a partir de la cual se les aplica, a estos dos tipos de vehículos, el apartado anterior,

b.4 Matriculados después del 1 de enero de 1995:

Se rigen por el actual "Reglamento General de Circulación". 


\section{$4 \quad$ Situación de la técnica en el campo de la toma de datos del tráfico, la clasificación de vehículos y la estimación de las cargas transportadas}

\subsection{Técnicas de recogida de datos del tráfico y de las características de los vehículos}

Los procedimientos de toma de datos automática del tráfico consisten en utilizar unos aparatos capaces de detectar el paso de los vehículos, registrarlos y contarlos. Así, los sistemas automáticos de aforo, en general tienen los siguientes componentes:

1. Uno o varios sensores que proporcionan al sistema las señales de la presencia o paso de un vehículo.

2. Un detector que recibe las señales de los sensores y las amplifica y/o las interpreta, y que las pasa al registrador.

3. Un registrador que realiza los cálculos básicos de los parámetros medidos del vehículo.

4. Un procesador que trata los datos básicos para presentarlos en el formato requerido.

Generalmente, los tres últimos componentes no vienen separados, sino que están incluidos en una unidad electrónica, situada en los márgenes de la carretera.

A continuación se van describir los principales tipos de detectores automáticos de aforo que se utilizan actualmente, así como de sus características más sobresalientes.

Una clasificación muy utilizada de los tipos de sensores es la que los divide en dos amplias categorías: la de los sensores que se deben introducir o colocar en el pavimento (que, por esta razón se denominan como "invasivos") y la de los que no ("no invasivos").

Las tipos o tecnologías de sensores que se introducen en el pavimento o se colocan sobre él son las siguientes.

- Detectores de tubo neumático

- Lazos de inducción magnética

- Sensores magnéticos

- Sensores piezoeléctricos

- Sensores de fibra óptica

- Oros sensores de presión

Por su parte, las tecnologías de señores que no se introducen en el pavimento que se utilizan actualmente incluyen las que se citan a continuación:

- Sistemas de procesamiento de imágenes de vídeo 
- Radar de microondas

- Sensores infrarrojos

- Sensores ultrasónicos

- Sensores acústicos pasivos

Los sensores que se introducen en los pavimentos se instalan, bien directamente sobre la superficie del firme (anclándoles directamente a la superficie, como es el caso de los detectores de tubos neumáticos o de lazos de inducción portátiles), bien practicando rozas o agujeros en la superficie del pavimento, o realizando una especie de pequeños túneles en el firme. El funcionamiento de estos sensores es muy conocido, pues representan la aplicación de tecnologías ya maduras a la vigilancia y gestión del tráfico. Los inconvenientes de su utilización incluyen las molestias ocasionadas al tráfico en su instalación y reparación, y las averías debidas, bien a su colocación en superficies del firme en mal estado, bien a la utilización de procedimientos de instalación que no cumplen las recomendaciones mínimas.

La búsqueda de una alternativa fiable y rentable de sistemas de detección y seguimiento de vehículos, que puedan instalarse y conservarse con seguridad y mínimas molestias a la circulación y que al mismo tiempo puedan proporcionar datos del tráfico al menos tan exactos como los de un lazo de inducción, ha estado en proceso durante bastante tiempo. Las evaluaciones más recientes han mostrado que los modernos sensores situados por encima de la superficie del pavimento suministran datos que cumplen las exigencias de muchas aplicaciones viarias. Los sensores por encima del nivel del terreno o sobreelevados pueden montarse por encima del carril viario cuyo tráfico están monitorizando o en los márgenes de la vía desde donde pueden tomar datos de varios carriles a la vez en ángulos perpendiculares $u$ oblicuos a la dirección de la corriente del tráfico.

Las tecnologías utilizadas actualmente de sensores situados por encima de la superficie del pavimento son las que se han citado arriba. Además de éstas, se emplean habitualmente ciertas combinaciones de tecnologías de sensores, tales como:

- los infrarrojos pasivos y el radar de microondas

- los infrarrojos pasivos y los ultrasónicos.

Al igual que los sensores empotrados en la superficie del pavimento, los sensores situados por encima de ella pueden contar vehículos, detectar su presencia y su paso, pero, además, la mayor parte de ellos puede proporcionar la velocidad de los vehículos, su clasificación y una cobertura de detección de varios carriles y zonas de ellos.

\subsubsection{Detectores de tubo neumático}

Este detector consiste en un tubo neumático de goma cerrado en un extremo y colocado transversalmente sobre la calzada. Cuando pasan sobre este tubo las ruedas de los vehículos, aumenta la presión de aire en su interior, lo que hace que se cierre un contacto eléctrico, que acciona el dispositivo contador.

Este tipo de detector tiene como ventajas su bajo coste y su fácil y rápida instalación. Sin embargo, tiene el inconveniente de que sufre el impacto directo de las ruedas de 
los vehículos y puede llegar a desprenderse del pavimento al cabo de pocos días de toma de datos, e incluso romperse el tubo debido a frenazos de los vehículos cuando pasan por encima. Por ello, es apropiado para instalaciones provisionales, cuando se hacen aforos de corta duración (unos días o una semana).

Por otro lado, el empleo de los tubos neumáticos tradicionales estaba limitado a los carriles exteriores, debido a que colocar un tubo único a lo ancho de más de un carril genera señales de cada carril. Algunos fabricantes han resuelto el problema haciendo tubos que tengan solo un tramo limitado que sea capaz de producir los impulsos de aire [6]. Por tanto, estos tubos son sensibles a los impulsos de cada carril y pueden utilizarse en vías de varios carriles.

\subsubsection{Detectores de lazo de inducción}

Desde su introducción en Estados Unidos en la década de los 60, el detector de lazo de inducción magnética se ha convertido en el procedimiento de detección más utilizado.

Los componentes principales de un sistema de detección por lazos de inducción magnética incluyen un cable eléctrico con aislamiento, al que se le dan normalmente tres o cuatro vueltas, que se coloca en una ranura o roza de poca profundidad (unos 5 $\mathrm{cm}$ ) practicada con sierra de diamante en el pavimento y un cable de conexión que va hasta la caja o armario donde se sitúa el aparato electrónico de control.

El aparato electrónico de detección contiene un circuito oscilador de frecuencia fija que transmite la energía eléctrica propia a través del lazo. Por su parte, el sistema del lazo forma un circuito eléctrico sintonizado con un oscilador de frecuencia variable, en el cual el cable del lazo es el elemento inductivo. Inicialmente, el lazo se emplea para sintonizar el oscilador a la misma frecuencia que el oscilador del detector, de frecuencia fija. Cuando un vehículo pasa sobre el lazo o se para dentro de él, la inductancia del lazo se reduce, desequilibrando el circuito sintonizado. Esta reducción de la inductancia ocasiona un incremento en la frecuencia de oscilación del oscilador variable, lo que es reconocido por el circuito detector y se emplea para accionar un relé salida, que envía un impulso a la unidad de control, señalando que ha detectado el paso o la presencia de un vehículo [7].

Los datos proporcionados por los detectores de lazo inductivo convencionales son el paso de vehículos, la presencia, el contaje y la ocupación. Aunque los lazos no pueden medir directamente la velocidad, puede determinarse esta magnitud utilizando una instalación de 2 lazos por carril.

\subsubsection{Sensores magnéticos}

Este detector fue introducido en la década de los 60 como una alternativa a los detectores de lazo para situaciones particulares. Su funcionamiento se basa en la medición de la variación del campo magnético de la Tierra (conocida como anomalía magnética) que se produce cuando un cuerpo de metal ferromagnético (como es un vehículo) está cerca de su sensor.

Así, un vehículo de acero distorsiona las líneas de flujo debido a que el material ferromagnético es más permeable a las líneas de flujo que el aire. Es decir, se produce 
un efecto de concentración del campo magnético terrestre, pues las líneas de flujo prefieren pasar a través del vehículo férromagnético. Según se mueve el vehículo, está siempre acompañado por una concentración de las líneas de flujo, fenómeno conocido como su "huella magnética" [8]. Una sonda magnetométrica instalada dentro del firme detecta el incremento de flujo que tiene lugar debajo del vehículo, pudiendo detectar vehículos que circulan entre 0 y $160 \mathrm{~km} / \mathrm{h}$. Esta sonda se conecta a una electrónica de amplificación.

El sensor magnético transforma los cambios en la intensidad del campo magnético terrestre (anomalía magnética) en variaciones de inductancia generadas en una bobina que rodea un núcleo de material magnético blando de alta permeabilidad. El cambio en la inductancia es detectado por una unidad electrónica de detección similar a la de un lazo convencional.

No obstante, la mayoría de los detectores magnéticos no pueden detectar vehículos parados, pues requieren que el vehículo esté moviéndose o cambiando las características de su huella con respecto al tiempo.

Los magnetómetros consisten en unos pequeños sensores empotrados en el firme, a una profundidad de entre 30 y $50 \mathrm{~cm}$, con el tamaño y forma de una lata de bebida (un diámetro de $2,5 \mathrm{~cm}$ y una altura de $9 \mathrm{~cm}$ ), un cable de conexión y un amplificador.

A diferencia del detector de lazo, el magnetómetro funciona en tableros de puente en los que existe acero y donde no se permita cortar el pavimento para la instalación de los lazos. Algunos magnetómetros pueden colocarse directamente sobre el pavimento mientras que otros se insertan dentro de conductos practicados bajo el pavimento. Este último puede realizarse perforando el pavimento desde el arcén, sin necesidad de cortar la circulación del carril.

\subsubsection{Sensores piezoeléctricos}

Un piezoeléctrico es un material procesado especialmente que tiene la capacidad de convertir la energía cinética en energía eléctrica. Algunos materiales poliméricos, otros de tipo cerámico e incluso el cristal de cuarzo tienen estas propiedades en un grado muy elevado y se utilizan en la construcción de sensores piezoeléctricos.

Los materiales piezoeléctricos generan un voltaje cuando son sometidos a un impacto mecánico o una vibración. El voltaje medido es proporcional a la fuerza o peso del vehículo. Como el efecto piezeléctrico es dinámico, es decir, que sólo se genera carga cuando las fuerzas están cambiando, la carga eléctrica inicial decae si la fuerza permanece constante.

Los cables piezocerámicos pueden ser suministrados fijados con resina epoxi dentro de una acanaladura de aluminio, para asegurar que se instala sin pliegues ni curvatura. En el caso de sensores piezopolímeros, el sensor consiste en un pequeño tubo metálico hueco que incluye una lámina del polímero.

Se emplean distintos materiales para encajar y sujetar el sensor en el firme en una roza practicada en el pavimento de dimensiones iguales o menores de unos $50 \times 50 \mathrm{~mm}$, 
con el propósito de reducir las tensiones laterales y de sellar el sensor, de forma que se adapte a las propiedades del firme en el que van insertados.

Los sensores piezoeléctricos pueden proporcionar datos de contaje de vehículos, medición de la velocidad, clasificación de vehículos a través del contaje de ejes y de su separación, y de pesaje en movimiento. Además, tienen la ventaja de que pueden detectar el paso del neumático sobre el sensor, creando una señal analógica que es proporcional a la presión ejercida sobre el sensor. Esta capacidad permite diferenciar los vehículos individuales con una gran precisión, siendo su coste sólo ligeramente más caro que un lazo de inducción.

El inconveniente más importante proviene del hecho de que deben instalarse en firmes en buen estado y sin roderas, pudiendo producirse averías en superficies viarias defectuosas. Asimismo, es ampliamente conocido que los sensores piezoeléctricos son sensibles a la temperatura del firme y a la velocidad de los vehículos (no miden a velocidades menores de unos $30 \mathrm{~km} / \mathrm{h}$ ).

\subsubsection{Cable de fibra óptica}

El empleo de la tecnología de los sensores de fibra óptica para la detección de ejes es bastante nueva y relativamente poco común en comparación con otras tecnologías invasivas.

Los sensores de fibra óptica detectan la presencia de una carga a través de medir la reducción en la transmisión óptica ocasionada por la compresión de las fibras cuando un neumático pasa sobre los sensores. Los sistemas de sensores de fibra óptica constan de un transmisor luminoso (generalmente un LED), un detector fotométrico y un equipo electrónico con su software especializado para analizar la señal, además del sensor de fibra óptica [6].

Este tipo de sensores se utilizan de forma parecida a los sensores piezoeléctricos. La longitud del sensor mismo suele ser la anchura de un carril.

Los sensores de fibra óptica son más sensibles que los tubos neumáticos, lo que les hace más exactos tanto en condiciones de velocidades muy bajas como de intensidades de tráfico muy altas. La ventaja de los sensores de fibra óptica sobre los sensores piezoeléctricos es que los primeros no son sensibles a la temperatura y que los sensores en sí mismos no conducen la electricidad, lo que hace que los aparatos que utilizan estos sensores sean menos susceptibles a los rayos y, además no tengan problemas de compatibilidad electromagnética con otros aparatos instalados en la carretera.

\subsubsection{Otros sensores de presión}

Además de los tubos neumáticos, los sensores piezoeléctricos y los de fibra óptica, existe una amplia gama de otros sensores de presión disponibles para su uso en instalaciones permanentes de aforo y clasificación de vehículos. Las antiguas tecnologías de interruptores (conmutadores) de presión pertenecen a esta categoría, siendo las más utilizadas los interruptores de cinta (tape switch). Todos ellos 
comparten la funcionalidad básica de producir una señal eléctrica cuando la presión ocasionada al pasar un eje cierra un circuito.

Existen sensores de presión de instalación portátil, que se colocan sobre la capa superior de rodadura del firme de un carril y se sujetan mediante una cinta bituminosa. En cuanto a los sensores de presión de instalación fija o permanente en el firme, al igual que los sensores piezoeléctricos, se colocan en pequeñas rozas o ranuras cortadas en el pavimento y se fijan en el emplazamiento mediante algún tipo de resina epoxi u otro agente ligante. No obstante, a diferencia de los sensores piezoeléctricos, la mayoría de estos sensores de presión no son lo bastante sensibles como para funcionar correctamente debajo de una capa bituminosa de rodadura.

Estos sensores de presión son generalmente menos caros que los sensores piezoeléctricos, aunque su tiempo y trabajo de instalación tiende a ser muy similar.

\subsubsection{Sistemas de procesamiento de imágenes de vídeo}

Las cámaras de vídeo fueron introducidas en la gestión de tráfico para la vigilancia de la circulación, gracias a su capacidad para transmitir imágenes de circuito cerrado de televisión (CCTV) a un operador humano para su interpretación. De ahí surgió en la década de los 70 la necesidad de una técnica alternativa para interpretar las imágenes de video a través del procesamiento de imágenes o "visión máquina".

Un sistema de procesamiento de imágenes de vídeo consta normalmente de una o más cámaras, un ordenador con microprocesadores para digitalizar y procesar las imágenes y unos programas para interpretar estas imágenes y convertirlas en datos de flujo del tráfico.

Los sistemas de procesamiento de imágenes de vídeo detectan los vehículos analizando las imágenes de una escena de tráfico para determinar cambios entre fotogramas sucesivos de la película. Los algoritmos de procesamiento de imágenes que analizan las imágenes en blanco y negro examinan la variación de los niveles de grises en grupos de píxeles contenidos en los fotogramas de vídeo. Los algoritmos están diseñados para eliminar las variaciones de nivel de gris en el fondo de las imágenes causadas por las condiciones atmosféricas, sombras y dispositivos de luz diurna y nocturna, y retienen los objetos identificados como automóviles, camiones, motocicletas y bicicletas. Se calculan los parámetros analizando fotogramas sucesivos.

Se utiliza la segmentación de imágenes para dividir el área de la imagen en zonas más pequeñas, donde puedan reconocerse mejor los rasgos distintivos. Estos rasgos se analizan para generar datos de presencia de vehículos, velocidad y clasificación. Los sistemas de procesamiento de imágenes de vídeo con capacidades de rastreo utilizan técnicas de filtro de Kalman para actualizar las estimaciones de la posición de los vehículos y la velocidad [9].

Las cámaras de vídeo se instalan en lugares seleccionados de la autopista y en intersecciones semaforizadas para recoger datos del tráfico en tiempo real. Estas cámaras instaladas transmiten las imágenes a un equipo de procesamiento alojado en la caseta de control (o en una caseta separada) instalada en la intersección. 
El sistema puede detectar el tráfico en un cierto número de lugares (puntos múltiples) dentro del campo de visión de la cámara. Estos lugares son especificados por el usuario con gráficos interactivos y pueden cambiarse todas las veces que se requiera. Para lograr este emplazamiento flexible de los puntos de detección, se insertan en la pantalla las líneas de detección a lo largo o transversalmente a los carriles de la calzada por medio de un ratón o teclado. Cada vez que un vehículo cruza una línea de detección, se genera una señal de detección.

El sistema de procesamiento de imágenes de vídeo proporciona señales comparables a los detectores de lazo, es decir, la presencia y el paso de un vehículo, así como la velocidad. De estas mediciones, pueden extraerse otros parámetros del tráfico, incluyendo la ocupación, volúmenes, longitudes de cola, etc.

La principal ventaja está en que un sistema de procesamiento de imágenes de vídeo puede sustituir varios lazos de inducción en el pavimento, proporcionar la detección de vehículos en varios carriles y unos menores costes de conservación.

\subsubsection{Detectores de radar y microondas}

La palabra radar proviene de las funciones que realiza: Radio Detection And Ranging ("Detección y Medición de Distancias por Radio" o también "Detección y Localización por Radio"). El término microondas se refiere a la longitud de onda de la energía transmitida, generalmente entre 1 y $30 \mathrm{~cm}$. Esto corresponde a una gama de frecuencias de $1 \mathrm{GHz}$ a $30 \mathrm{GHz}$. Los radares que funcionan a frecuencias superiores a $30 \mathrm{GHz}$ funcionan en el espectro de ondas milimétricas y permiten iluminar zonas del terreno más pequeñas con una antena de un tamaño dado y así obtener datos de mayor resolución.

La energía de las microondas es focalizada hacia un área de la carretera desde una antena montada en una posición elevada (en un pórtico o una banderola) o en una posición lateral sobre un poste. Cuando un vehículo atraviesa el haz, la energía es reflejada de vuelta a una unidad sensora (antena) con una frecuencia diferente. El detector capta esta variación de la frecuencia, que denota el paso de un vehículo.

La anchura del haz o área en la cual se transmite la energía del radar (el tamaño y la distribución de energía) se controla a través de la antena. Cuando pasa un vehículo a través del haz de la antena, una parte de la energía transmitida es reflejada de vuelta hacia la antena. Esta energía entra entonces en un receptor donde se realiza la detección y se calculan los datos del vehículo, como son el volumen, la velocidad, la ocupación y la longitud.

Existen dos tipos de sensores de radar de microondas para aplicaciones viales: el radar Doppler de onda continua (CW) y el radar de onda continua modulada (FMCW) [9]. Los datos del tráfico que reciben dependen de la forma de la onda transmitida.

El sensor Doppler de onda continua (CW) transmite una señal cuya frecuencia es constante en el tiempo. De acuerdo con el principio del efecto Doppler, el movimiento de un vehículo en la zona de detección provoca un cambio en la frecuencia de la señal reflejada, lo que puede utilizarse para detectar vehículos en movimiento (deben circular por lo menos a $5 \mathrm{~km} / \mathrm{h}$ ) y determinar su velocidad. Este tipo de radares se 
utilizan para medir el volumen y la velocidad de los vehículos en las vías arteriales y autopistas urbanas.

El sensor de radar de microondas de onda continua modulada (FMCW) transmite una frecuencia que va cambiando continuamente con el tiempo, lo que permite a este tipo de radar funcionar como detector de presencia y puede detectar vehículos parados. Por ello, pueden monitorizar colas de vehículos y se utilizan para controlar semáforos de giro a la izquierda, proporcionan datos en tiempo real del volumen y la ocupación para sistemas adaptativos de control de semáforos.

\subsubsection{Detectores ultrasónicos}

Los detectores ultrasónicos se desarrollaron a mediados de la década de los 50. Actualmente existen dos tipos de sensores ultrasónicos: los basados en el principio de detección electrostática y los basados en el efecto Doppler.

Los dispositivos ultrasónicos de detección electrostática emiten impulsos de energía sonora ultrasónica y miden el tiempo transcurrido (o la distancia) hasta que la señal retorna al aparato. Cuando la energía sonora regresa más rápidamente que el tiempo de retorno normal de energía desde la superficie de la carretera o cuando se mide una distancia diferente de la distancia de la superficie de la calzada, el sensor interpreta esa medida como la presencia de un vehículo [9]. Luego, se convierte la energía ultrasónica recibida en energía eléctrica, que es analizada por un aparato electrónico de procesamiento de señales, que se coloca en el transductor o en un controlador de la señal situado en el margen de la vía.

Si se transmiten los impulsos de energía en dos ángulos incidentes cercanos, a una distancia conocida, se puede calcular la velocidad registrando el tiempo en el que cada vehículo cruza cada haz y, en consecuencia, la longitud del vehículo.

También se fabrican sensores ultrasónicos de frecuencia constante que miden la velocidad utilizando el principio del efecto Doppler. No obstante, estos son más caros que los modelos de impulsos de ondas. Estos detectores funcionan con el mismo principio de los detectores de radar, es decir, transmiten un haz de energía sobre un área y reciben un rayo reflejado desde el vehículo. El paso de un vehículo provoca que estos haces se reflejen de vuelta hacia el transductor a una frecuencia diferente. El transductor capta esta variación y la convierte en energía eléctrica. Entonces se envía un impulso al controlador para señalar el paso de un vehículo.

Los sensores ultrasónicos han sido empleados en el control del tráfico en túneles, donde otros sistemas de aforo como las células fotoeléctricas no eran fiables, debido a la suciedad y el hollín existente en los túneles por causa del tráfico, y los lazos de inducción tienen el inconveniente de que para su instalación, conservación o reparación es preciso cerrar carriles al tráfico. En estos casos, se disponen los sensores ultrasónicos en pares a intervalos regulares, que proporcionan información sobre el volumen de vehículos, la velocidad, la ocupación, la longitud y su clasificación. 
El país donde se han utilizado de una forma más general los sensores ultrasónicos ha sido Japón, debido a que en este país no se permite efectuar cortes en el firme.

Los dispositivos detección por impulsos ultrasónicos permiten obtener un aforo de vehículos de gran exactitud cuando están montados de forma óptima (en posición superior encima de la calzada). No obstante, los ensayos indican que las grandes variaciones de temperatura y las fuertes turbulencias de aire pueden reducir la precisión de los dispositivos ultrasónicos. De hecho, algunos modelos incluyen un dispositivo de compensación de la temperatura.

\subsubsection{Detectores por infrarrojos}

Existen dos tipos claramente diferenciados de sensores infrarrojos para aplicaciones de tráfico: los sistemas activos y los pasivos. La principal diferencia entre ambos estriba en que en los sistemas activos se utiliza un rayo láser de baja potencia que parte del dispositivo de medición hacia la superficie de la vía, midiéndose el tiempo que transcurre hasta que la señal retorna al aparato, con el fin de determinar la presencia de un vehículo, mientras que en los sistemas pasivos se detecta la presencia de los vehículos a través de la comparación de la energía infrarroja que emana de forma natural de la superficie de la carretera con la energía causada por la presencia de un vehículo [9].

\section{Sistemas activos}

En estos sistemas se iluminan las zonas de detección con una luz infrarroja de baja potencia suministrada por diodos láser. La luz infrarroja reflejada por los vehículos que circulan a través de la zona de detección es enfocada por un sistema óptico sobre una matriz sensora (material sensible a los rayos infrarrojos) montada en el plano focal del sistema óptico.

Utilizando una técnica de procesamiento de las señales en tiempo real, se analiza la señal recibida y se determina la presencia de un vehículo. La división del haz laser de un sensor simple en dos señales separadas, sirve para medir la velocidad de los vehículos y su longitud total, a través de registrar los tiempos en los cuales el vehículo entra en la zona de detección de cada haz.

Los sensores infrarrojos activos facilitan información de la presencia de vehículos en los semáforos, volumen, velocidad, longitud, medición de colas y clasificación. Además los sistemas más modernos pueden medir la altura de los vehículos y, a partir de ésta magnitud, crear imágenes bidimensionales y tridimensionales de los vehículos en circulación, lo que permite una clasificación detallada de los vehículos.

\section{$\underline{\text { Sistemas pasivos }}$}

Los sensores pasivos no transmiten ninguna energía propia, sino que detectan la energía que es emitida proveniente de los vehículos, de las superficies de la calzada, de otros objetos en su campo de visión y desde la atmósfera. Esta energía detectada por los sensores pasivos es la llamada "emisión gris", debida a la temperatura distinta de cero de los objetos emisivos. La emisión gris se produce a todas las frecuencias por los 
objetos que no están al cero absoluto $(-273,15$ ㅇ) . Si la emisividad del objeto es perfecta (esto es, emisividad = 1), el objeto es designado como un cuerpo negro. La mayoría de los objetos tienen emisividades menores de 1 , de ahí que sean llamados cuerpos grises [9].

Cuando un vehículo entra en el campo de visión de un detector, se utiliza el cambio en la energía emitida para detectar el vehículo. El sistema pasivo de infrarrojos mide solamente el paso (movimiento) de un vehículo.

Estos sensores proporcionan los mismos datos de salida que los lazos convencionales: volúmenes de vehículos y presencia. La monitorización de estos parámetros en dos localizaciones consecutivas del sensor permite calcular la velocidad y, en consecuencia, la longitud total del vehículo. Los sensores pasivos infrarrojos multi-carril y multi-zona miden, además del volumen de tráfico y la ocupación del carril, también la velocidad y la longitud del vehículo.

Un inconveniente de los sensores infrarrojos es que experimentan una degradación de la señal bajo condiciones atmosféricas que reduzcan la visibilidad. Así, los destellos de la luz solar pueden causar señales confusas e indeseadas. Las partículas atmosféricas y las inclemencias atmosféricas pueden dispersar o absorber la energía que en otro caso alcanzaría el plano focal.

\subsubsection{Sensores acústicos pasivos}

Los sensores acústicos detectan la energía acústica o los sonidos audibles producidos por el tráfico desde el abanico de fuentes sonoras existentes dentro de cada vehículo y de la interacción de los neumáticos con la calzada. El término pasivo aplicado a estos aparatos proviene del hecho de que captan la energía sonora de los vehículos que pasan.

Los detectores acústicos miden físicamente las variaciones en la energía sonora que irradia de la calzada. Los incrementos en energía indican la llegada de un vehículo, y los descensos de energía indican su partida. A partir de estos datos, es posible determinar la ocupación de un carril. Utilizando zonas de detección múltiples, se puede estimar la velocidad del vehículo y su longitud, permitiendo así clasificar a los vehículos por su longitud [9].

Existen dos tipos de sensores acústicos en el mercado. Ambos utilizan una serie bidimensional de micrófonos para detectar el sonido producido por los vehículos que se aproximan.

Uno de los modelos, que consiste en una matriz cuadrada de sensores acústicos, detecta los vehículos a través de la medición del retraso en el tiempo de llegada del sonido entre los micrófonos situados en la posición superior y los situados en una posición inferior.

El otro modelo de dispositivos acústicos pasivos consiste en una hilera de micrófonos dirigidos hacia la corriente del tráfico, montados en una disposición de banda lateral, apuntando a la zona de rodadura de cada carril de circulación. Este modelo utiliza un sistema adaptativo de procesamiento espacial para formar múltiples zonas que 
reciben la energía acústica desde hasta 6 ó 7 carriles. Durante la configuración inicial del sistema, se disponen las zonas de detección en posiciones que se corresponden con los carriles monitorizados y que son equivalentes a las de un lazo de inducción.

Este tipo de sensores se suelen utilizar para la recogida de datos en puentes y otras vías en que se requieran sensores no invasivos y en las que, además, no exista un tráfico de vehículos moviéndose lentamente o en condiciones de parada y arranque, pues experimentan una pérdida de exactitud en estas condiciones.

Los sensores acústicos tienen como ventaja el que son insensibles a las precipitaciones, aunque se ha informado de que las temperaturas frías afectan a la exactitud de los datos proporcionados por los sensores acústicos, pudiendo producirse infracontaje en bajas temperaturas.

\subsubsection{Sistemas de pesaje en movimiento}

Los sistemas de pesaje de vehículos en movimiento son equipos que permiten estimar, de cada uno de los vehículos que circulan por una carretera a su velocidad normal de recorrido, los pesos de cada uno de los ejes del vehículo y su peso total, además de otros parámetros típicos como su longitud, velocidad, distancia entre cada dos ejes, etc.

Aunque en la actualidad existe sistemas con configuraciones muy diferentes, en general un equipo de pesaje dinámico consta de las siguientes partes componentes:

1. Sensor de peso. Es el elemento específico de los sistemas de pesaje en movimiento y es el que define su estructura y tipología. Su función es transformar una variable de tipo físico-mecánico relacionada con el peso del vehículo (presión ejercida por las ruedas sobre el pavimento, deformación producidad en un aparato o en las capas del firme, etc.) en una señal generalmente eléctrica, que es proporcional a la magnitud de la variable de entrada, y que es fácil de medir y cuantificar. Cada sistema específico puede constar de uno o varios sensores de peso instalados en uno o varios de los carriles de una vía.

2. Detectores de presencia. Normalmente son lazos de inducción, aunque a veces también pueden ser utilizados tubos de tipo neumático. Su función puede ser la de detectar simplemente la presencia de un vehículo acercándose al sistema de pesaje con el fin de activar su funcionamiento, o en los sistemas con sensores lineales, medir la velocidad de este vehículo como ayuda para el cálculo de su masa, en conjunción con la señal emitida por el sensor de peso. En general, también suelen ser utilizados para hallar la distancia entre ejes del vehículo, su longitud total, para su clasificación, etc.

3. La electrónica del sistema. Es la encargada de realizar las siguientes operaciones:

a) Supervisión del funcionamiento del sistema (de los niveles eléctricos de referencia, funciones de calibración, inicialización de su funcionamiento).

b) El registro de las señales emitidas por el sensor de peso y los detectores al paso de las ruedas de los vehículos. 
c) Del tratamiento de estas señales para la realización de los cálculos necesarios para la obtención de las magnitudes primarias (las cargas de los ejes elementales, las distancias entre ejes contiguos, velocidad del vehículo).

d) La transferencia de estos datos a las memorias de almacenamiento temporal o permanente (RAM, ROM, discos duros) o a los módems de transmisión hacia una red o un centro especializado.

e) El procesamiento de los datos brutos para la obtención de las magnitudes que requiera el usuario (peso bruto de los vehículos, peso de los ejes completos, histogramas de carga por eje, porcentajes de sobrecargados, etc).

\subsubsection{Ventajas e inconvenientes y aplicabilidad de cada tecnología para su empleo en la clasificación de vehículos y en la medida de pesos y cargas}

Un resumen de las ventajas y los inconvenientes de las tecnologías de toma de datos del tráfico aparecen en la Tabla 1 para los sensores invasivos (que se introducen en el pavimento) y en la Tabla 2 para los sensores no invasivos, que se colocan más arriba de la superficie de la calzada.

Es obvio que, de todas las tecnologías de toma de datos del tráfico que se han descrito, la única que puede proporcionar el peso de los vehículos y sus ejes (y de aquí, potencialmente, facilitar información sobre la carga transportada), sobre una muestra muy grande de vehículos o sobre la población entera que constituye el tráfico de la carretera, es el pesaje dinámico o de vehículos en movimiento.

Sin embargo, esto no implica que se deban dejar de lado todas las demás tecnologías descritas, pues la mayor parte de ellas pueden funcionar de forma coordinada con los sensores y sistemas de pesaje en movimiento (de hecho, algunas como los lazos de inducción suelen formar parte de los sistemas de pesaje dinámico) y, en teoría, podrían ser capaces de llevar a cabo de forma más ventajosa algunas de las funciones auxiliares de la toma de datos de pesaje, como es la medida de la longitud de los vehículos y su clasificación, que luego se pueden utilizar para la determinación de la carga transportada.

Así, por ejemplo, los sistemas de procesamiento de imágenes de vídeo, los detectores ultrasónicos y los de rayos infrarrojos pueden captar la longitud y los volúmenes que constituyen los vehículos, con la ventaja adicional no requerir efectuar cortes en el pavimento ni el cierre de los carriles al tráfico para su instalación. Sin embargo, la mayoría de estas tecnologías tienen como principal inconveniente que su funcionamiento y prestaciones se ven muy influenciados por la variabilidad de las condiciones atmosféricas (lluvia, niebla, nieve, etc) y/o de luminosidad ambiente (día, noche, sol rasante de frente o de espaldas), con una disminución de su fiabilidad, lo que se ha traducido en que su empleo para captar y medir algunos parámetros de los vehículos y para clasificarlos no ha alcanzado el uso generalizado que se preveía, excepto en algunos ambientes cerrados donde no existen los anteriores inconvenientes, como son los túneles. 
Al contrario, otras tecnologías que en principio ofrecen menores prestaciones, pero que no se ven influidas por las condiciones exteriores y de las cuales existe una gran experiencia acumulada de uso en la carretera, como son los lazos de inducción magnética, siguen siendo las más utilizadas para la medida de muchas variables del tráfico y para la clasificación de vehículos. 
Tabla 1. Sensores invasivos: ventajas e inconvenientes de cada tecnología (I)

\begin{tabular}{|c|c|c|}
\hline Tipo de sensor & Ventajas & Inconvenientes \\
\hline $\begin{array}{l}\text { Sensores invasivos } \\
\text { (comentarios } \\
\text { generales) }\end{array}$ & $\begin{array}{l}\text { La mayoría pertenecen a } \\
\text { tecnologías muy conocidas y } \\
\text { experimentadas } \\
\text { Cuando se instalan de forma } \\
\text { permanente, al mismo nivel del } \\
\text { pavimento circundante, } \\
\text { proporcionan medidas de gran } \\
\text { exactitud }\end{array}$ & $\begin{array}{l}\text { Difíciles de instalar en condiciones de mucho } \\
\text { tráfico } \\
\text { Los sensores instalados en el firme tienden a } \\
\text { estar afectados de forma adversa por las } \\
\text { condiciones del pavimento } \\
\text { Si hay cambios de carril frecuentes, su } \\
\text { exactitud es limitada }\end{array}$ \\
\hline Tubos neumáticos & $\begin{array}{l}\text { Baratos } \\
\text { Muy utilizados en instalaciones } \\
\text { temporales } \\
\text { Fáciles de usar }\end{array}$ & $\begin{array}{l}\text { Inexactos con mucho volumen de tráfico } \\
\text { Difíciles de instalar en vías de varios carriles } \\
\text { Los tubos convencionales sólo pueden } \\
\text { proporcionar clasificación de vehículos en } \\
\text { carriles situados al lado del arcén o de la } \\
\text { mediana. La tecnología de los tubos multi- } \\
\text { carril es relativamente nueva en el mercado }\end{array}$ \\
\hline Lazos de inducción & $\begin{array}{l}\text { Baratos } \\
\text { Tecnología muy conocida y } \\
\text { experimentada } \\
\text { Tecnología bastante robusta frente } \\
\text { a las variaciones e inclemencias } \\
\text { atmosféricas } \\
\text { Pueden proporcionar la velocidad y } \\
\text { la longitud de los vehículos }\end{array}$ & $\begin{array}{l}\text { Más difíciles de instalar que los tubos } \\
\text { neumáticos } \\
\text { La exactitud disminuye en zonas con } \\
\text { vehículos muy poco espaciados (intervalos } \\
\text { vehiculares cortos) }\end{array}$ \\
\hline Magnetómetro & $\begin{array}{l}\text { Instalación fácil y simple } \\
\text { Pueden utilizarse en tableros de } \\
\text { puentes, donde no pueden usarse } \\
\text { lazos de inducción } \\
\text { Sufren menos el impacto de los } \\
\text { vehículos que los lazos }\end{array}$ & $\begin{array}{l}\text { Poca información publicada sobre su } \\
\text { fiabilidad } \\
\text { No pueden detectar vehículos parados. } \\
\text { La exactitud disminuye con intervalos } \\
\text { vehiculares cortos } \\
\text { En algunos modelos las zonas de detección } \\
\text { son pequeñas, por lo que deben instalarse } \\
\text { varios sensores por carril. }\end{array}$ \\
\hline
\end{tabular}


Tabla 1. Sensores invasivos: ventajas e inconvenientes de cada tecnología (II)

\begin{tabular}{|c|c|c|}
\hline Tipo de sensor & Ventajas & Inconvenientes \\
\hline $\begin{array}{l}\text { Cables } \\
\text { Piezoeléctricos } \\
\text { (cerámicos, } \\
\text { polímeros, de } \\
\text { cuarzo) }\end{array}$ & $\begin{array}{l}\text { Ampliamente utilizados y } \\
\text { conocidos } \\
\text { Fácil de desplegar } \\
\text { Pueden trabajar en áreas de altos } \\
\text { volúmenes de tráfico si las } \\
\text { velocidades son estables }\end{array}$ & $\begin{array}{l}\text { Requieren un mantenimiento periódico, por } \\
\text { lo que son difíciles de mantener en áreas de } \\
\text { altos volúmenes de tráfico } \\
\text { Deben instalarse en firmes en muy buen } \\
\text { estado y sin roderas } \\
\text { No miden a velocidades menores de } 30 \mathrm{~km} / \mathrm{h}\end{array}$ \\
\hline Fibra óptica & $\begin{array}{l}\text { Tecnología nueva y prometedora. } \\
\text { Gran sensibilidad. } \\
\text { Inmune a los rayos } \\
\text { Barata si es amortizada durante un } \\
\text { periodo de tiempo mediano }\end{array}$ & Pocos datos sobre su precisión y fiabilidad \\
\hline $\begin{array}{l}\text { Otros sensores de } \\
\text { presión }\end{array}$ & $\begin{array}{l}\text { Generalmente inmunes a los rayos } \\
\text { Tecnología bastante conocida } \\
\text { Utilizados frecuentemente en } \\
\text { instalaciones peaje junto con lazos, } \\
\text { lo que permite una exactitud en } \\
\text { condiciones de baja velocidad y de } \\
\text { flujo inestable (paradas-arranques) }\end{array}$ & $\begin{array}{l}\text { No están desplegados ampliamente } \\
\text { Requieren nuevas interfaces de varios } \\
\text { fabricantes }\end{array}$ \\
\hline Pesaje dinámico & $\begin{array}{l}\text { Permite conocer con gran } \\
\text { exactitud, además del peso de los } \\
\text { vehículos, las intensidades de } \\
\text { circulación, la velocidad de los } \\
\text { vehículos y su longitud. } \\
\text { Posibilita obtener una clasificación } \\
\text { muy detallada de los vehículos }\end{array}$ & $\begin{array}{l}\text { Tecnología más cara } \\
\text { Instalación en la carretera más laboriosa y } \\
\text { especializada } \\
\text { Requiere un mantenimiento especializado }\end{array}$ \\
\hline
\end{tabular}


Tabla 2. Sensores no invasivos: ventajas e inconvenientes de cada tecnología (I)

\begin{tabular}{|c|c|c|}
\hline Tipo de Sensor & Ventajas & Inconvenientes \\
\hline $\begin{array}{l}\text { Sensores no } \\
\text { invasivos } \\
\text { (Comentarios } \\
\text { generales) }\end{array}$ & $\begin{array}{l}\text { La exactitud no se ve afectada por } \\
\text { unas malas condiciones del firme } \\
\text { Fácilmente ajustables a una nueva } \\
\text { canalización del tráfico }\end{array}$ & $\begin{array}{l}\text { Requieren una estructura de montaje } \\
\text { (pórtico, poste) } \\
\text { La exactitud tiende a estar afectada por la } \\
\text { altura de montaje y el ángulo de visión } \\
\text { La estabilidad de la plataforma de montaje } \\
\text { afecta a su precisión }\end{array}$ \\
\hline $\begin{array}{l}\text { Tratamiento de } \\
\text { imágenes de vídeo }\end{array}$ & $\begin{array}{l}\text { Permite recoger datos de varios } \\
\text { carriles con una sola cámara } \\
\text { Fácil de instalar } \\
\text { Tecnología ampliamente aceptada } \\
\text { y bien conocida }\end{array}$ & $\begin{array}{l}\text { Afectado por los problemas de visibilidad } \\
\text { (nieve, niebla, lluvia) } \\
\text { Las lentes de la cámara deben estar } \\
\text { protegidas de los elementos } \\
\text { Menos exacto en una instalación multi-carril } \\
\text { Clasificación de vehículos: solamente realiza } \\
\text { de forma precisa la basada en la longitud }\end{array}$ \\
\hline $\begin{array}{l}\text { Radar de } \\
\text { microondas }\end{array}$ & $\begin{array}{l}\text { La exactitud no está afectada por } \\
\text { el tiempo atmosférico o por el mal } \\
\text { estado del pavimento } \\
\text { Permite recoger datos de varios } \\
\text { carriles con un solo aparato } \\
\text { Fácil de instalar. Posibilidad de } \\
\text { usarlo en instalación portátil } \\
\text { Tecnología ampliamente aceptada } \\
\text { y muy conocida }\end{array}$ & $\begin{array}{l}\text { Bajo buenas condiciones, para aplicaciones } \\
\text { multicarril, es generalmente menos exacto } \\
\text { que los sensores tradicionales } \\
\text { Solamente realiza una clasificación basada } \\
\text { en la longitud }\end{array}$ \\
\hline Infrarrojos & $\begin{array}{l}\text { Nueva tecnología que parece } \\
\text { prometedora } \\
\text { Permite recoger datos de varios } \\
\text { carriles con un solo aparato }\end{array}$ & $\begin{array}{l}\text { Afectado por los problemas de visibilidad } \\
\text { (nieve, niebla, lluvia) } \\
\text { Requiere un mantenimiento periódico } \\
\text { No tan preciso en una instalación multi-carril } \\
\text { Se dispone de pocos datos sobre fiabilidad }\end{array}$ \\
\hline
\end{tabular}


Tabla 2. Sensores no invasivos: Ventajas e inconvenientes de cada tecnología (II)

\begin{tabular}{|l|l|l|}
\hline Tipo de Sensor & Ventajas & Inconvenientes \\
\hline Ultrasonidos & $\begin{array}{l}\text { Nueva tecnología que parece } \\
\text { prometedora }\end{array}$ & $\begin{array}{l}\text { Se dispone de pocos datos sobre fiabilidad } \\
\text { Requiere una instalación de varios sensores } \\
\text { Su exactitud disminuye según aumentan los } \\
\text { volúmenes de circulación } \\
\text { Algunas condiciones ambientales } \\
\text { (turbulencias de aire) puede reducir la } \\
\text { exactitud del sistema }\end{array}$ \\
\hline Acústico & $\begin{array}{l}\text { Nueva tecnología } \\
\text { Son insensibles a las }\end{array}$ & $\begin{array}{l}\text { Se dispone de pocos datos sobre fiabilidad. } \\
\text { Las temperaturas frías afectan a su exactitud } \\
\text { Su exactitud disminuye al aumentar la } \\
\text { variabilidad de las velocidades de circulación }\end{array}$ \\
\hline
\end{tabular}

\subsection{El pesaje de vehículos en movimiento o pesaje dinámico}

\subsubsection{La tecnología del pesaje dinámico}

El pesaje de vehículos en movimiento o pesaje dinámico, normalmente conocido por sus siglas en inglés WIM (Weigh-In-Motion), abarca una serie de tecnologías y procedimientos dirigidos a evaluar las masas o pesos de los vehículos en la carretera, realizadas en condiciones normales de circulación y sin perturbar el tráfico rodado.

Los sistemas de pesaje dinámico proporcionan de forma automática y continua datos sobre el peso total de cada vehículo que pasa sobre el sistema y de cada uno de sus ejes, además de otros parámetros de los vehículos, como la longitud, la distancia entre ejes y su velocidad. Todo ello, sin necesidad de la intervención humana y durante largos periodos de tiempo, durante las 24 horas del día, lo que constituye una poderosa herramienta para la obtención de datos, tanto individualizados como estadísticos, que son de gran ayuda para los organismos gestores de la carretera o del transporte.

El pesaje dinámico o de vehículos en movimiento surgió a en la década de los años 60 y 70, pero no fue hasta finales de la década de los 80 cuando las administraciones de carreteras comenzaron a utilizarlo de una forma más o menos generalizada. Tras diferentes proyectos europeos de investigación en décadas pasadas, como el COST 323 "Weigh-in-motion of road vehicles" (1993-1998) [10], el proyecto WAVE ("Weighing-in-Motion of Axles and Vehicles in Europe") (1996-1999), el Proyecto Top Trial (2000-2002) y el Proyecto REMOVE (2004-2006), esta técnica ha alcanzado 
actualmente su madurez, que se ha traducido en la existencia de normativas en diferentes áreas geográficas del mundo que regulan los procedimientos de pesaje, las condiciones que deben cumplir los emplazamientos de los equipos, y los métodos de calibración y de evaluación de la precisión de estos, entre las que se pueden citar la norma estadounidense ASTM E-1318 [11] y las Especificaciones Europeas del Pesaje en Movimiento [12] elaboradas en el marco del COST 323 y la Especificación R 134-1 de la OIML (Organización Internacional de Metrología Legal) sobre "Instrumentos automáticos de medición del peso de los vehículos en movimiento y de sus cargas por eje" [13] .

Sin embargo, la precisión en las medidas de los pesos que puede ofrecer el pesaje dinámico es menor que la de una báscula de pesaje estático, debido a que lo que realmente miden los sistemas de pesaje en movimiento es la fuerza dinámica que ejercen las ruedas del vehículo al circular a su velocidad de recorrido sobre el sensor de pesaje y esta fuerza dinámica está influenciada por la oscilación de la suspensión del vehículo debida a las irregularidades del pavimento. Por tanto, la precisión de los sistemas de pesaje en movimiento depende, además de la calidad intrínseca del sistema, de las irregularidades del pavimento sobre el que está instalado el sensor y, además, algunas tecnologías de pesaje se ven influenciadas por otras variables como la temperatura, humedad, etc.

Existen diferentes tecnologías de pesaje en movimiento, entre las que se pueden citar las siguientes como las más comunes:

- Los sensores piezoeléctricos, basados en la generación de una corriente eléctrica al ser presionados por las ruedas de los vehículos, entre los cuales existen las tecnologías de los sensores piezocerámicos, los piezopolímeros y los de cristal de cuarzo.

- Las placas en flexión, que son placas metálicas instrumentadas en su parte inferior con bandas extensométricas.

- Las esteras capacitivas, muy utilizadas en instalaciones temporales de pesaje, en las que el sensor es un condensador eléctrico con sus placas metálica separadas por un dieléctrico, que disminuye su espesor al pasar las reudas de los vehículos.

- Los puentes de pesaje en movimiento (en inglés, "Bridge-WIM") que consisten en puentes de carretera cuyo tablero ha sido instrumentado en su parte inferior con bandas extensométricas, para medir su deformación al paso de los vehículos.

Se han realizado numerosos ensayos para verificar la precisión de cada una de las tecnología mencionadas, pudiéndose decir que las placas en flexión alcanzan una precisión de $\pm 10 \%$ para el $95 \%$ de los vehículos, los sensores piezoeléctricos tienen una precisión que puede variar en función de las distintas tecnologías y métodos de autocalibración, pudiendo alcanzar los piezocerámicos hasta un $\pm 10 \%$ para el $95 \%$ de los vehículos (Stanczyk y Jacob,1998 [14]; Leal, 2012) [15], que representa una clase $\mathrm{B}(10)$ de las especificaciones europeas WIM del COST 323, y los cristales de cuarzo valores aún mejores (clase $\mathrm{B}(7)$ ). Por su parte, las esteras capacitivas en instalación 
portátil llegan a un $\pm 25 \%$ para el $95 \%$ de los vehículos (Blab, Jacob and Schahubber, 1998) [16], mientras que alcanzan aproximadamente un $\pm 10 \%$ en instalación fija para el $95 \%$ de los vehículos. Para acabar, los sistemas de puentes de pesaje en movimiento (Bridge-WIM) pueden alcanzar precisiones de aproximadamente hasta un $\pm 10 \%$ para el $95 \%$ de los vehículos, lo que es aproximadamente la clase $B(10)$ de las especificaciones europeas WIM del COST 323 en puentes losa de hormigón (Lavric, Znidaric y Kalin,2008) [17], pero su precisión es algo menor (Clase $C(15)$ de las Especificaciones Europeas WIM) cuando se instrumentan puentes metálicos (F Schmidt y B. Jacob, 2012) [18].

\subsubsection{Aplicaciones del pesaje en movimiento}

Una de las principales ventajas del pesaje en movimiento radica en la capacidad de estos equipos de funcionar automáticamente 24 horas al día durante largos períodos de tiempo, lo que tiene una doble gama de aplicaciones:

- La obtención de estadísticas acumuladas del trafico pesado, principalmente de los pesos medios de ejes y vehículos, para su uso en la optimización del diseño y mantenimiento de firmes y puentes viarios o en estudios económicos y de planeamiento del transporte por carretera.

La disposición de datos detallados, vehículo a vehículo, de sus pesos brutos y cargas por eje, para su utilización en la preselección y control legal de los mismos, la restricción de paso de vehículos pesados por algunos lugares (zonas urbanas, puentes antiguos, etc) o para el cobro de peajes en función del peso del vehículo.

La mayoría de las anteriores aplicaciones son actualmente una realidad, debiéndose esperar al resultado de investigaciones actualmente en curso o futuras, para que los sistemas de pesaje en movimiento puedan llevar a cabo adecuadamente algunas otras, entre las que se puede destacar el control legal de los pesos y cargas de los camiones. De hecho, ya existe algún país europeo, como la República Checa, donde se ha certificado algún sistema para realizar el control legal directo de pesos (Doupal, 2012).

En las siete Conferencias Internacionales sobre el pesaje en movimiento celebradas (Zurich, 1995; Lisboa, 1998; Orlando, 2002; Taipei, 2005; París, 2008; Dallas, 2012 y Foz do Iguaçu, 2016) han existido sesiones específicas sobre las diferentes aplicaciones de los sistemas de pesaje en movimiento, pudiéndose destacar entre las dos últimas conferencias WIM celebradas, las siguientes ponencias así como otros artículos de revistas técnicas:

- Aplicaciones de los sistemas WIM a los pavimentos: Los sistemas de pesaje dinámico se han utilizado para la optimización del diseño, mantenimiento y conservación de firmes viarios gracias a que pueden proporcionar datos de pesos y cargas por eje de todos los vehículos que circulan por una carretera, frente a las básculas de tipo estático, que solo pueden suministrar 
información sobre un pequeño número de vehículos (unas pocas decenas) cada día. Esta ha sido la aplicación más común de los sistemas WIM, que se expone de forma general en la ponencia de L. Poulikakos "Application of Weigh-In-Motion in Paviment Engineering" [19], en la Conferencia de Dallas (2012) y se puede destacar, entre otras, también los artículos de A. Abbas et al. "Effect of Traffic Load Input Level on Mechanistic-Empirical Pavment Design" [20] y las ponencias de S. Yousif et al., titulada "Evaluating the role of WIM in Mechanistic Pavement Analysis" [21], también en Dallas (2012) y la de David Timm et al. "Effects of axle load spectra shifts on highway infrastructure damage and cost".

Precisamente, dentro de los trabajos de esta Tesis se ha elaborado un artículo relacionado con esta aplicación, cuyo título es "Aplicación del pesaje de vehículos en movimiento al dimensionamiento de firmes. Influencia de la precisión de los pesajes", que ha sido publicado en la Revista "Informes de la Construcción, no 545 [22].

- Aplicaciones de los sistemas WIM a los puentes: Los sistemas de pesaje dinámico pueden server para optimizar el diseño, mantenimiento y conservación de los puentes viarios, especialmente de los de grandes luces, gracias a una determinación más ajustada a las condiciones reales de cada emplazamiento de las cargas que deben soportar. Se han publicado numerosas investigaciones a este respecto, entre los que destacaron en la Conferencia de Paris (2008) los trabajos de A. Znidaric "Measurement of bridge dynamics with a bridge WIM system" [23], la de A. O'Connor "Application of WIM in probability based safety assessment of bridges", y en la Conferencia de Dallas (2012) los documentos presentados por A. Nowak y P. Pakoczy de título "WIM-Based Simulation Model of Site Specific Live Load Effect on the Bridges" [24], el artículo escrito por A. O'Connor y E. $O$ 'Brien "Traffic Load Modelling and factors influencing the accuracy of predicted extremes" [25].

- Aplicación del pesaje en movimiento a los estudios de tráfico y clasificación de vehículos. Los sistemas WIM son aparatos de aforo y clasificación de vehículos con algunas capacidades específicas adicionales (la medida del peso), por lo cual, su aplicación a cualquier estudio de tráfico es inmediata, sobre todo en aspectos ligados a la determinación con gran fiabilidad o detalle de la composición (silueta) del tráfico, existiendo numerosos trabajos al respecto, entre los que se pueden citar la ponencia de P. Burnos "Automatic Vehicle Classification for WIM Systems" [26], presentada en la Conferencia de Dallas en 2012, el informe V. Kwigizile de título "Conectionist approach to Developing Highway vehicles Classification Table for use in Florida" [27] (2004) o el artículo de A. Nichols y D. Bullock titulado "Automatic speed calibration methodology for traffic monitoring sites".

- Aplicación a la preselección de vehículos sobrecargados y al control legal 
directo: La diferencia entre ambas aplicaciones consiste en que en la preselección de vehículos sobrecargados se utiliza el sistema de pesaje WIM para detectar todos los vehículos que sobrepasan un cierto peso umbral, los cuales son desviados para su pesaje estático en un área adyacente a la carretera (es decir, que el sistema WIM es solo un medio para mejorar la productividad de una báscula estática) mientras que en el control directo lo que se persigue es que el sistema WIM sea capaz de medir los pesos con una precisión suficiente como para poder imponer las multas directamente (utilizando un sistema AVI de reconocimiento de matrículas) a los vehículos sobrecargados. Destacan en estos ámbitos los trabajos de E.Doupal y R. Calderara de título "Combined LS (Low Speed) and HS (High Speed) WIM systems for law enforcement and toll road applications" [28] en París (2008) y E. Doupal et al. "One year WIM Direct Enforcement Experiences in Czech Republic" [29] en Dallas (2012). A este respecto, hay que decir que la República Checa ha sido el primer país en Europa (y probablemente en el mundo) en el cual se utilizan los sistemas WIM para el control legal directo con imposición de las correspondientes multas a los vehículos sobrecargados. Podría decirse que una gran parte de la investigación en el campo del pesaje en movimiento actualmente está dirigida a posibilitar el empleo de esta técnica para el control legal directo de los pesos de los vehículos, debido a las grandes ventajas económicas, tanto por el pago de las multas como por la reducción de los costes de conservación de los firmes viarios, que ello reportaría.

Aparte de las mencionadas, existen algunas otras aplicaciones adicionales, como la del pago de peajes en función del peso del vehículo, que se lleva años utilizando en algunos países del sureste asiático, el control de la restricción de paso de vehículos que superan un cierto peso a puentes antiguos o a centros urbanos o el control del peso de los vehículos que salen o acceden a centros de carga, como son los puertos, centros logísticos, aeropuertos, mercados centrales, etc. Sin embargo, hasta la fecha no se ha intentado determinar el peso de la carga que transportan los vehículos pesados a partir de los datos de pesajes dinámicos, ni individualmente (vehículo a vehículo), ni como dato estadístico de la carga acumulada transportada por el conjunto de vehículos que circulan por una carretera, a pesar de las ventajas que ello reportaría por su aplicación a estudios económicos y de planificación del transporte. En vista de esta situación, se decidió emprender la investigación que se expone en el presente documento.

\subsubsection{Datos que proporciona un sistema de pesaje dinámico}

Los sistemas de pesaje dinámico son fundamentalmente equipos aforadores de tráfico muy evolucionados, que además de los datos típicos que proporciona un equipo aforador-clasificador de tráfico (el número de vehículos, y su velocidad y longitud) suministran otros parámetros adicionales, algunos relacionados con el peso (el peso total de un vehículo y de cada uno de sus ejes) y otros de diferente tipo, como son la distancia entre ejes consecutivos, la batalla (distancia entre el primer y último ejes de 
un vehículo), que considerados conjuntamente permiten realizar una clasificación bastante detallada del tráfico, en especial del pesado.

En la Tabla 3 puede verse una salida de resultados del sistema de pesaje dinámico utilizado por el CEDEX, así como la descripción de los datos que se obtienen. En las Figuras 7 y 8 se muestran unas imágenes de este sistema de pesaje dinámico.

Un sólo equipo de registro es capaz de almacenar los datos correspondientes a cuatro carriles, en cada uno de los cuales hay un sensor de peso y dos lazos de inducción. El equipo, una vez puesto en estación y programado y calibrado con los parámetros correspondientes, registra todos los vehículos, tanto ligeros como pesados, uno a uno, clasificando y pesando todos y cada uno de sus ejes.

En el caso de turismos que sean muy pequeños, es posible que el sistema no detecte el peso de alguno de los ejes o incluso de los dos ejes, sin embargo, el vehículo sí que es aforado, es decir, en el listado aparece un vehículo en el que no figuran datos en las columnas de peso de ejes y peso total. No obstante, en las demás columnas aparecen los datos correspondientes (número de orden, fecha, velocidad, clasificación, etc.).

Como se puede ver en la Tabla 3, el equipo el proporciona en cada fila los datos relativos a un vehículo determinado, entre los cuales se encuentra el número de secuencia, la fecha y hora de paso, el carril de circulación, los pesos de cada eje (AW), el peso total del vehículo (GVM), las distancias entre ejes consecutivos (AD), la velocidad (SPD), la longitud del vehículo (LENG), así como algunos códigos de violación (hasta la columna designada como BL).

Además de las anteriores, se ha añadido una serie de columnas a la derecha para introducir manualmente los datos adicionales que pueden tomarse, por ejemplo, en muestreos visuales, y que pueden servir para realizar pruebas de comparación de los resultados tomados por el equipo con los datos reales. Los datos de estas columnas adicionales se refieren a la clasificación visual de los vehículos (categoría, clase y tipo), si el vehículo lleva algún eje elevado, las taras y PMA de cada una de las unidades (tractor y semirremolque o remolque) de las que consta el vehículo en cuestión, su matrícula y su marca. En definitiva, son datos que no pueden ser captados por el equipo o que se introducen para realizar verificaciones de los datos que suministra automáticamente el equipo. 


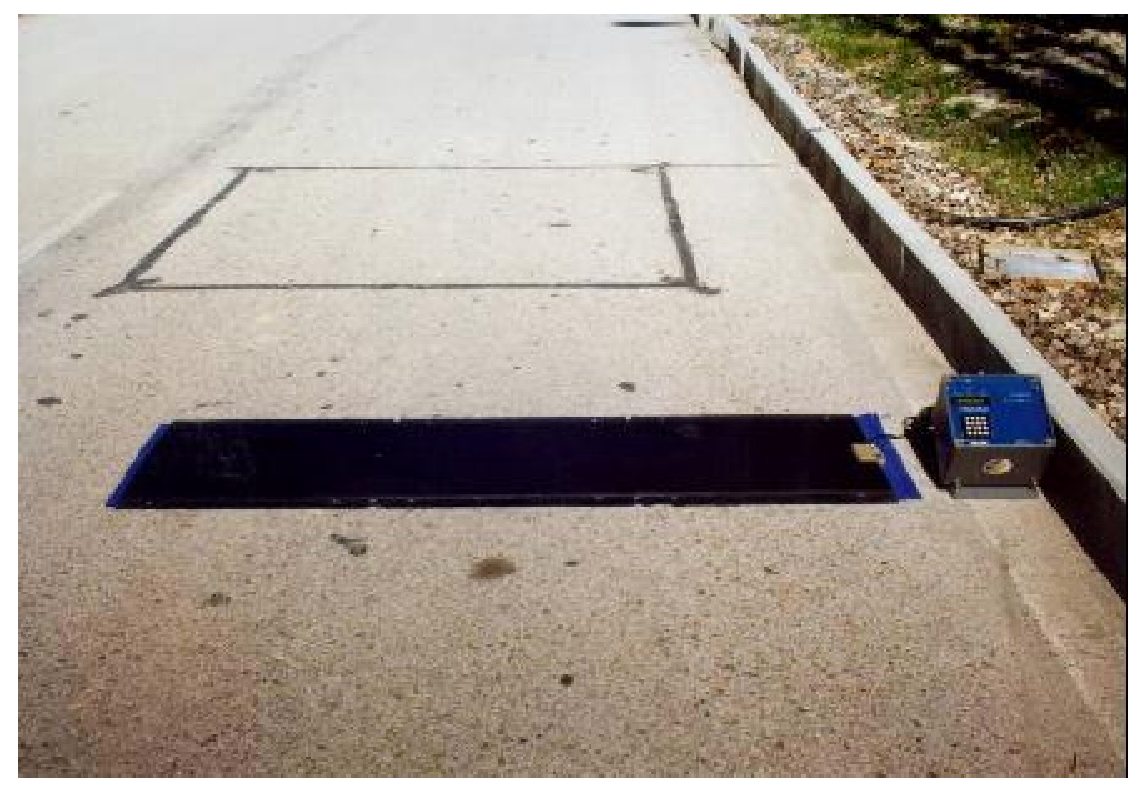

Figura 7. Componentes del sistema de pesaje dinámico utilizado en los ensayos realizados en El Molar y en Trijueque

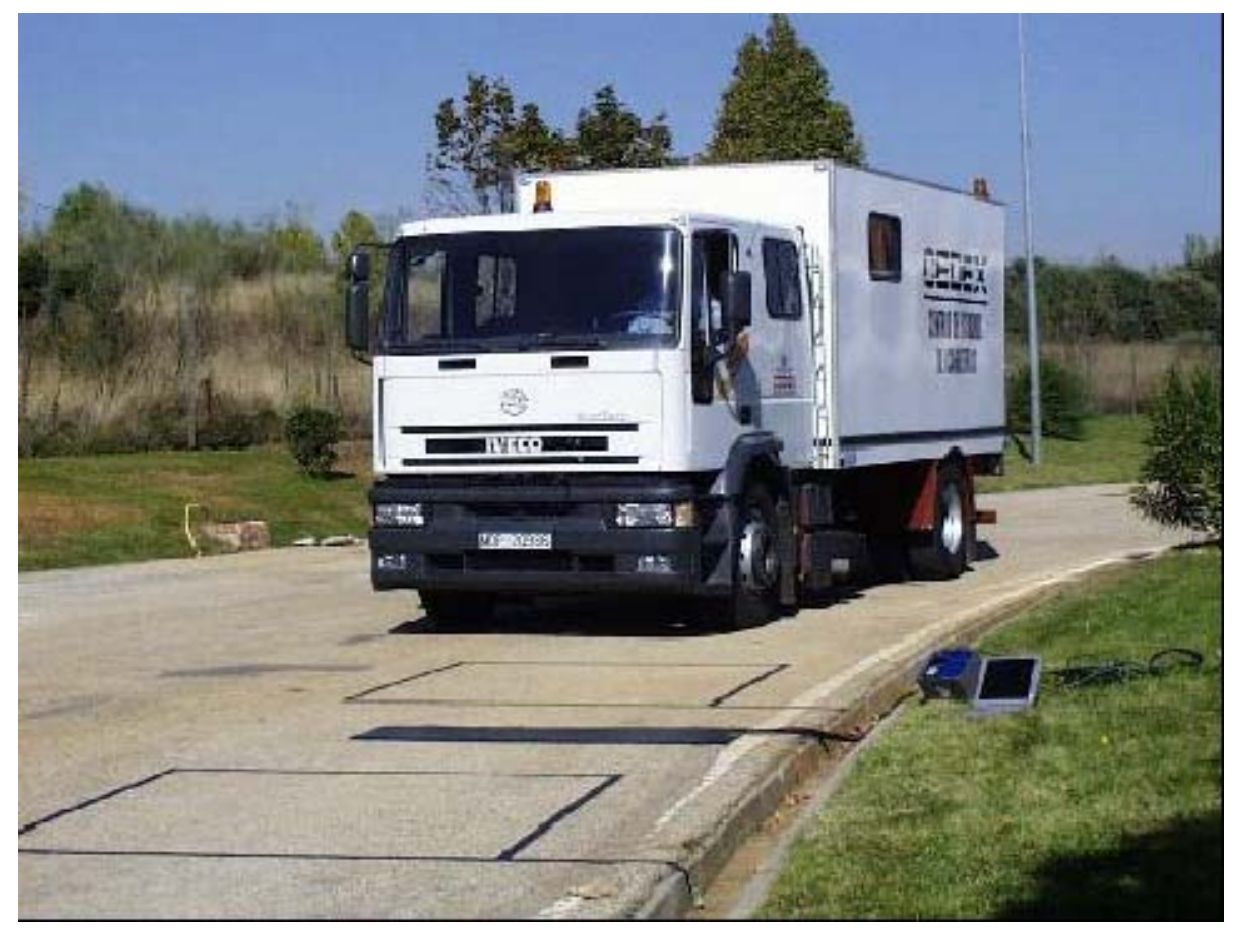

Figura 8. Aspecto del sistema de pesaje dinámico utilizado, con su configuración normal en la carretera y camión utilizado en la calibración del sistema 
Tabla 3. Salida de datos del sistema de pesaje dinámico utilizado por el CEDEX

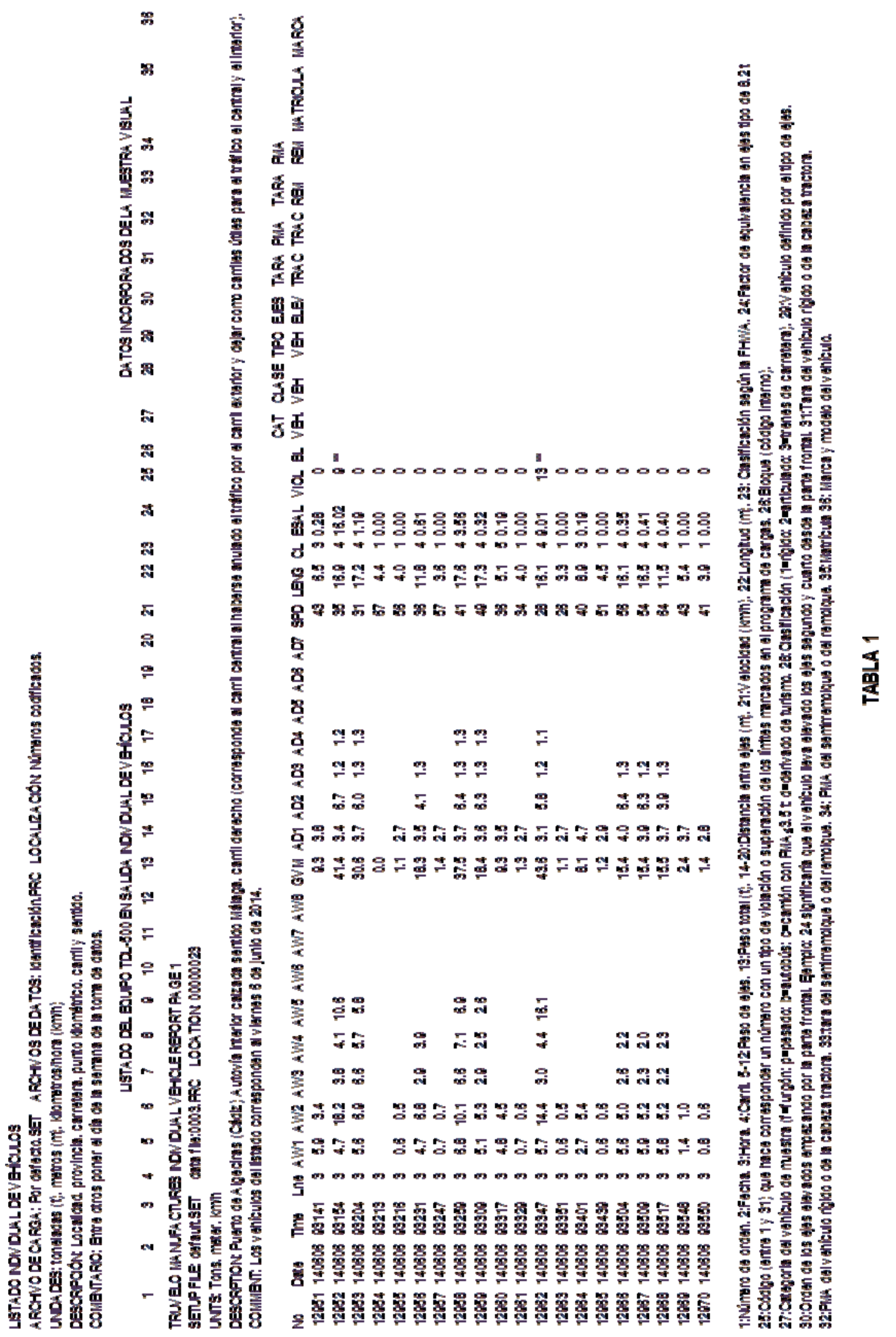




\subsection{Revisión de procedimientos de clasificación automática de vehículos}

\subsubsection{Cuestiones generales}

Existen muchos esquemas o siluetas diferentes de clasificación de los vehículos, que en general dependen del equipamiento necesario para recoger los datos de clasificación de los vehículos en la carretera. La mayor parte de estos aparatos recogen datos sobre los siguientes parámetros de los vehículos:

- la longitud,

- el número de ejes,

- la separación entre ejes

- el peso de los vehículos.

Los dos tipos principales de sensores utilizados por estos sistemas de clasificación son los sensores de ejes, que captan el golpe del eje de un vehículo al pasar; y los sensores de presencia, que captan la presencia de un vehículo mediante la detección de sus partes metálicas. En muchos de los equipos se utiliza una combinación de estos dos tipos de sensores, como suele ocurrir en los sistemas de pesaje dinámico de vehículos.

La clasificación de los vehículos se realiza utilizando la información proporcionada por los sensores para encajar a los distintos vehículos en ciertas "plantillas" o "esquemas" de clasificación. El sistema de clasificación más simple que puede tener una administración de carreteras es el que emplea solamente dos clases: los coches y los camiones; y el criterio de diferenciación suele ser la longitud del vehículo, pues se puede medir esta magnitud utilizando solamente lazos de inducción. Una mejora sobre éste es el que divide a su vez a los camiones en dos clases: los vehículos rígidos (single unit trucks) y los articulados (combination trucks). Esta diferenciación también puede realizarse por medio de la longitud de los vehículos, pues la mayor parte de los articulados superán el límite de longitud máxima admitida para los vehículos rígidos.

A partir de estos esquemas simples se ha ido desarrollando una expansión de estas clases de vehículos en unas más detalladas, incluyendo gran número de (sub)tipos, creciendo al mismo tiempo la dificultad de diferenciación entre los (sub)tipos. Por otro lado, según aumenta el número de tipos, es necesario disponer de un sistema de recogida de datos del tráfico más sofisticado y de un esquema de decisión con un mayor número de criterios relacionados con las características de los vehículos.

Aunque cada país ha tratado de desarrollar su propio esquema de clasificación adaptado a los tipos de vehículos (y a las características de estos) presentes en sus carreteras, se ha creído conveniente describir a continuación los esquemas de clasificación más utilizados internacionalmente, que son el esquema F de la FHWA de Estados unidos y el esquema EURO-13, utilizado en Europa. Por último, también se describirán los esquemas de clasificación utilizados en España. 


\subsubsection{Esquemas de clasificación de la Administración de las Carreteras Federales (FHWA) de EE.UU.}

A comienzos de la década de los 80 se acometieron en Estados Unidos varios trabajos interesantes para separar a los vehículos en diferentes categorías. Entre ellos cabe destacar el realizado por Mactavish y Neumann en 1982 en su Estudio de Clasificación de los Vehículos [30] llevado a cabo para el Highway Performance Monitoring System (HPMS), en el que se dividió a los vehículos en 13 categorías.

Desde septiembre de 1980 a julio de 1982, la División de Materiales e Investigación del Laboratorio del Departamento de Transporte del Estado de Maine llevó a cabo un estudio para la FHWA de evaluación del equipamiento de clasificación de vehículos (Lyles y Wyman, 1982) [31]. En este estudio se desarrollaron secuencialmente varios esquemas de clasificación de vehículos, que iban desde el esquema $A$ al Esquema $F$. A continuación se dan unas breves notas de los más importantes de estos esquemas.

Con respecto al esquema de clasificación "A", se separó a los vehículos en las 7 clases que se muestran en la Tabla 4. La evaluación de campo reveló varios problemas asociados con el empleo de este Esquema. El inconveniente más importante estaba en diferenciar entre los vehículos estándar/compactos y los vehículos sub-compactos debido a la evolución de la industria del automóvil en Estados Unidos hacia coches más pequeños.

Tabla 4. Detalles del esquema " $A$ " de clasificación de vehículos de la FHWA

\begin{tabular}{|c|c|c|}
\hline $\begin{array}{l}\text { Categoría } \\
\text { de } \\
\text { vehículo }\end{array}$ & Descripción & Regla de decisión \\
\hline$A-1$ & $\begin{array}{l}\text { Vehículos de pasajeros estándar y compactos } \\
\text { (incluyendo pick-ups, furgonetas y otros } \\
\text { vehículos de } 2 \text { ejes y } 4 \text { neumáticos) }\end{array}$ & $\begin{array}{l}2,54 \mathrm{~m}\left(100^{\prime \prime}\right) \leq \text { batalla } \leq \\
3,66 \mathrm{~m}\left(144^{\prime \prime}\right) \text { y longitud } \\
\geq 4,57 \mathrm{~m}\left(180^{\prime \prime}\right)\end{array}$ \\
\hline A-2 & $\begin{array}{l}\text { Vehículos sub-compactos (incluyendo pick-ups } \\
\text { ligeros) }\end{array}$ & 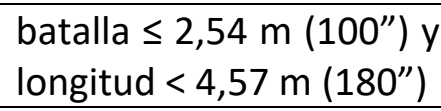 \\
\hline A-3 & Motocicletas & Sin comentarios \\
\hline A-4 & $\begin{array}{l}\text { Camiones simples (rígidos) de } 2 \text { ejes y } 6 \\
\text { neumáticos }\end{array}$ & $\begin{array}{l}2 \text { ejes y batalla }>3,66 \mathrm{~m} \\
(12 \text { pies) }\end{array}$ \\
\hline A-5 & Camiones simples (rígidos) de 3 ó más ejes & $\begin{array}{l}3 \text { ejes o } 4 \text { ejes y batalla } \\
\leq 7,93 \mathrm{~m} \text { ( } 26 \text { pies) }\end{array}$ \\
\hline A-6 & Combinaciones de 3 o 4 ejes & $\begin{array}{l}3 \text { ejes o } 4 \text { ejes y batalla } \geq \\
7,93 \mathrm{~m} \text { ( } 26 \text { pies) }\end{array}$ \\
\hline A-7 & Combinaciones de 5 o más ejes & 5 o más ejes \\
\hline
\end{tabular}

Además, todas las furgonetas y camiones de reparto fueron agrupados en una categoría. Esto resultó en unos errores de clasificación que eran independientes del equipamiento utilizado. Otro problema fue la diferenciación entre los 2 ejes y 4 neumáticos (en la primera categoría) y los 2 ejes y 6 neumáticos (en la cuarta 
categoría), debido al solape de las distribuciones de distancias entre los dos ejes, que tiene una gran importancia, pues normalmente supone distinguir entre los furgones (que la mayor parte de las veces son vehículos ligeros) y los camiones de dos ejes en que el trasero tiene rueda gemela, pues son vehículos pesados.

En el mismo estudio se desarrollaron otros sistemas de clasificación, del esquema "B" al esquema " $F$ ", cada uno de ellos tratando de mejorar el sistema precedente, en el sentido de que pudiera obtenerse de forma automática con el menor error posible. El esquema " $B$ " constaba de 13 categorías de vehículos, el esquema " $C$ " de 19 categorías, el esquema " $D$ " de 32 categorías de vehículos, el esquema " $E$ " con 13 categorías de vehículos nuevamente y por último el esquema " $F$ ", también con 13 categorías de vehículos.

La práctica actual en Estados Unidos en cuanto a la clasificación de vehículos es utilizar el Esquema de Clasificación $\mathrm{F}$ de la FHWA. Este esquema de clasificación se basa en la configuración de los ejes y utiliza un método de árbol de decisión que emplea las distancias de separación entre ejes como características de entrada para identificar 13 clases diferentes de vehículos, de las cuales 11 son distintos tipos de vehículos comerciales, según se muestra en la Tabla 5 y Figura 9. 
Tabla 5. Esquema " $F$ " de clasificación de vehículos de FHWA

\begin{tabular}{|l|l|}
\hline Clase & \multicolumn{1}{|c|}{ Descripción } \\
\hline 1 & Motocicletas \\
\hline 2 & Coches \\
\hline 3 & Otros vehículos simples de 2 ejes y 4 neumáticos \\
\hline 4 & Autobuses \\
\hline 5 & Camiones simples (rígidos) de 2 ejes y 6 neumáticos \\
\hline 6 & Camiones simples (rígidos) de 3 ejes \\
\hline 7 & Camiones simples (rígidos) de 4 ó más ejes \\
\hline 8 & Camiones de 4 ó menos ejes, con remolque simple (articulados o trenes) \\
\hline 9 & Camiones de 5 ejes, con remolque simple (articulados o trenes) \\
\hline 10 & Camiones de 6 ó más ejes, con remolque simple (articulados o trenes) \\
\hline 11 & Camiones de 5 ó menos ejes con varios remolques (o semirremolques) \\
\hline 12 & Camiones de 6 ejes, con varios remolques (o semirremolques), \\
\hline 13 & Camiones de 7 ó más ejes, con varios remolques (o semirremolques) \\
\hline
\end{tabular}

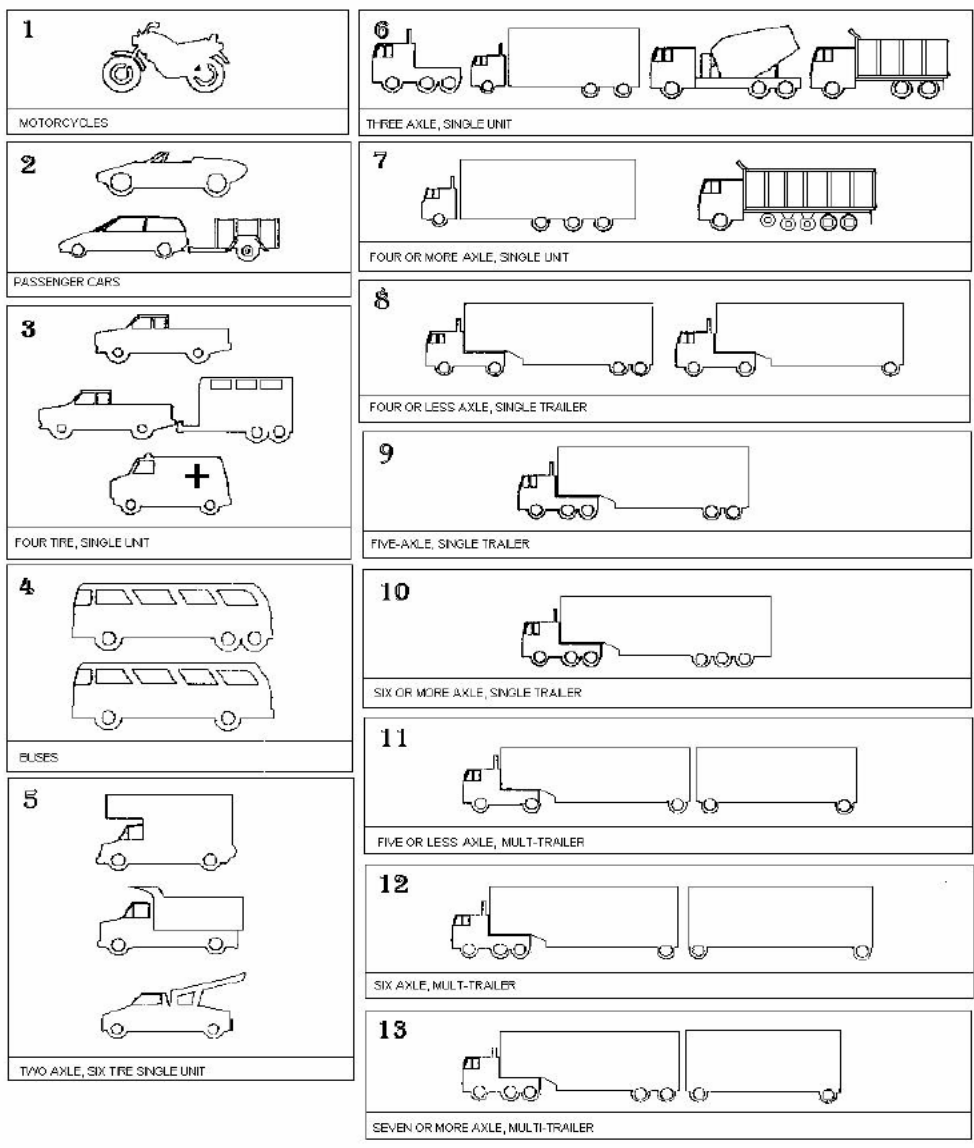

Figura 9. Esquema " $F$ " de clasificación de la FHWA (EE.UU.) 
Existen algunos estados, como el de California, que adoptan un esquema ligeramente modificado respecto al Esquema $\mathrm{F}$ de la FHWA según se muestra en la Tabla 6, pues incluye una clase adicional para diferenciar los camiones de 3 ejes que tiran de remolques (o semirremolques de 2 ejes), de las cabezas tractoras de 3 ejes que remolcan semirremolques de 2 ejes -ambos tipos son clasificados dentro de la clase 9 (Camiones de 5 ejes incluyendo un remolque o semirremolque simple)- dentro del Esquema " $F$ " de clasificación de la FHWA, mientras que en la del Estado de California corresponden respectivamente a las clases 9 y 14 . Asimismo, se incluye una clase decimoquinta para los vehículos que no pertenecen a ninguna de las catorce primeras categorías.

Tabla 6. Esquema de clasificación de vehículos de FHWA modificado en California

\begin{tabular}{|l|l|}
\hline Clase & \multicolumn{1}{|c|}{ Descripción } \\
\hline 1 & Motocicletas \\
\hline 2 & Coches \\
\hline 3 & Otros vehículos simples de 2 ejes y 4 neumáticos \\
\hline 4 & Autobuses \\
\hline 5 & Camiones simples (rígidos) de 2 ejes y 6 neumáticos \\
\hline 6 & Camiones simples (rígidos) de 3 ejes \\
\hline 7 & Camiones simples (rígidos) de 4 ó más ejes \\
\hline 8 & Camiones de 4 ó menos ejes, con remolque simple (articulados o trenes) \\
\hline 9 & Camiones de 5 ejes, con remolque simple (articulados o trenes) \\
\hline 10 & Camiones de 6 ó más ejes, con remolque simple (articulados o trenes) \\
\hline 11 & Camiones de 5 ó menos ejes con varios remolques (o semirremolques) \\
\hline 12 & Camiones de 6 ejes, con varios remolques (o semirremolques), \\
\hline 13 & Camiones de 7 ó más ejes, con varios remolques (o semirremolques) \\
\hline 14 & $\begin{array}{l}\text { Vehículos de } 5 \text { ejes, con una cabeza tractora de } 3 \text { ejes y un remolque de } 2 \\
\text { ejes }\end{array}$ \\
\hline 15 & Vehículos sin clasificar \\
\hline
\end{tabular}

Las configuraciones de los ejes de los vehículos para ambos esquemas de clasificación de obtienen mediante Clasificadores Automáticos de Vehículos (Automatic Vehicle Classifiers (AVCs)), que consisten, a grandes rasgos, en sensores piezoeléctricos colocados entre sensores de lazos de inducción situados delante y detrás de ellos. Los lazos de inducción indican la presencia de un vehículo según pasa sobre los sensores, mientras que los sensores piezoeléctricos determinan la configuración de ejes del vehículo detectado.

El esquema $\mathrm{F}$ de clasificación de la FHWA es el utilizado no sólo en Estados Unidos, sino en otros muchos países de distintos continentes, pues es el que suele venir incorporado, ya sea por defecto o de forma opcional, en la mayor parte de los equipos de pesaje dinámico utilizados en el mundo, aunque en cada país deben ser adaptados los umbrales de diferenciación de las distintas clases de vehículos a las características de los vehículos típicos de cada país. 


\subsubsection{Esquema europeo de clasificación EURO 13}

Una de las regiones del mundo donde es más problemática la adaptación del Esquema $F$ de la Federal Highway Administration (FHWA) es en Europa, pues los tipos de camiones más utilizados son bastante diferentes de los que se usaron para desarrollar el esquema $\mathrm{F}$ en Estados Unidos y la adaptación no constituye solamente un problema de ajustar las dimensiones o valores umbrales de diferenciación entre las distintas clases, sino que algunas clases de vehículos utilizados en Europa son en sí mismas muy diferentes.

Por ello, en Europa es de uso común el esquema de clasificación denominado EUR13, de 13 clases, con algunas variantes entre los diferentes países, y cuyas características se muestran en la Tabla 7.

Tal como se puede ver en la Tabla 7, el esquema europeo de clasificación EURO 13, incluye las trece clases siguientes:

- Una primera clase que engloba a todos diversos tipos de vehículos ligeros:

coches,

vehículos ligeros de transporte (furgones, camiones ligeros)

coches con caravana o remolque ligero de 1 eje

coches con caravana o remolque ligero de 2 ejes

- Las clases 2, 3 y 4 son para los camiones pesados de 2, 3 y 4 ejes respectivamente (aunque dentro de cada una de estas clases, pueden coexistir vehículos que aunque tengan el mismo número de ejes, la ordenación de estos puede ser diferente)

- La clase 5 es para los trenes de carretera formados por un camión rígido de 2 ejes y un remolque de 1,2 ó 3 ejes.

- La clase 6 engloba a los trenes de carretera formados por un camión rígido de 3 ejes más un remolque de 2 ó 3 ejes.

- Las clases 6, 7 y 8 incluyen a los vehículos articulados de 3, 4 y 5 ejes respectivamente, en los que la cabeza tractora tiene solamente 2 ejes.

- La clase 10 abarca para los articulados de 4 ó 5 ejes en los que la cabeza tractora tiene 3 ejes

- La clase 11 es para los articulados de 6 ejes en los que la cabeza tractora tiene 3 ejes.

- La clase 12 engloba a los autobuses de 2 y de 3 ejes 
- La última clase incluye a todos los vehículos y combinaciones de estos con 7 ejes o más

Como se puede ver en la Tabla 7, este esquema de clasificación está más adaptado a los vehículos más frecuentes en el tráfico de España y los países europeos, dejando una única clase para las combinaciones de vehículos del tipo (tractor + semirremolque + remolque), que son muy raras en nuestro continente (en comparación con Estados Unidos y Australia), excepto en algunos países nórdicos para camiones utilizados para el transporte de troncos de árboles (y que actualmente se acaba de autorizar su circulación en España, el conocido como megacamión de hasta 60 t de peso)

Este esquema de clasificación se ha adoptado en algunos países europeos, con ciertas variaciones para acomodarse mejor a las características particulares del tráfico en cada país. 
Tabla 7. Esquema de clasificación EURO-13

\begin{tabular}{|c|c|c|c|}
\hline \multicolumn{2}{|r|}{$\begin{array}{c}\text { Class } \\
\text { No }\end{array}$} & \multicolumn{2}{|c|}{$\begin{array}{c}\text { Class: } \\
\text { No }^{\circ}\end{array}$} \\
\hline 1 & car, lightvan, taxi की & 5 & $\begin{array}{l}\text { rigid } 2 \text { axle HGy }+ \\
2 \text { axle (close.. } \\
\text { coupled) traller. }\end{array}$ \\
\hline 1 & $\begin{array}{l}\text { líght goods vehicle } \\
\text { (LGV) }\end{array}$ & 6 & $\begin{array}{l}\text { rigid } 3 \text { axle HGV. } \\
\text { 2.axle drawbar } \\
\text { trailer }\end{array}$ \\
\hline$i$. & $\begin{array}{l}\text { car or LGV + } 1 \text { axle } \\
\text { caravan or trailer }\end{array}$ & 6 & $\begin{array}{l}\text { rigid } 3 \text { axle HGV }+ \text { if } \\
3 \text { axle drawbar } \\
\text { trailer }\end{array}$ \\
\hline$i$. & $\begin{array}{l}\text { car or LGV + } 2 \text { axle. } \\
\text { caravan or trailer. }\end{array}$ & 7. & $\begin{array}{l}\text { artic, } 2 \text { axle tractor }+ \\
1 \text { axle semi-trailer. }\end{array}$ \\
\hline 2 & rigid 2 axle HGV & 8 & $\begin{array}{l}\text { artic, } 2 \text { axle tracior }+ \\
2 \text { axle semi-trailer }\end{array}$ \\
\hline 3 & rigid 3 áxle $\mathrm{HGV}$ & 9 & $\begin{array}{l}\text { artic, } 2 \text { axle tractor }+ \\
3 \text { axle semi-trailer }\end{array}$ \\
\hline 3 & rigid 3 axle HGV & 10 & $\begin{array}{l}\text { artic, } 3 \text { axle Iractor }+ \\
.1 \text { axle semi-trailer }\end{array}$ \\
\hline 4 & rigid 4 axle HGV & 10 & $\begin{array}{l}\text { artic, } 3 \text { aste tractor }+ \\
2 \text { axle semi-trailer }\end{array}$ \\
\hline 4 & rigid a axle HGV & 11 & $\begin{array}{l}\text { artic, } 3 \text { axle tracion } \\
+3 \text { axle } \\
\text { semitrailer. }\end{array}$ \\
\hline 5 & $\begin{array}{l}\text { rigid } 2 \text { axle HGV }+2 \text {. } \\
\text { axle uraw bar trailer }\end{array}$ & 12 & bus or conch, 2 ary \\
\hline 5 & $\begin{array}{l}\text { rigid 2 axle HGV }+ \\
3 \text { axle draw var } \\
\text { liailer }\end{array}$ & 12 & bus or coach, 3 oxle \\
\hline 5 & $\begin{array}{l}\text { rigid } 2 \text { axle HGV }+1 \\
\text { axle caravan or } \\
\text { lrailer. }\end{array}$ & 13. & $\begin{array}{l}\text { vehicle with } 7 \text {, } \\
\text { or more axles. }\end{array}$ \\
\hline
\end{tabular}




\subsubsection{Siluetas utilizadas en España}

\subsubsection{Siluetas que obtiene la Dirección General de Carreteras del Ministerio de Fomento}

La Dirección General de Carreteras del Ministerio de Fomento obtiene a través del Plan Nacional de Aforos, desarrollado a principios de la década de los 80, dos clasificaciones diferentes de los vehículos que circulan por la red de carreteras del Estado: una obtenida automáticamente, por medio de los equipos de aforo funcionando con lazos de inducción magnética, y otra más detallada, pero que no se obtiene de forma automática, sino mediante observación visual directa de unos operarios.

A. Silueta utilizada en los aforos automáticos (realizados con un par de lazos de inducción por carril conectados a un equipo electrónico de registro), clasificando los vehículos por longitud:

- Vehículos ligeros: Longitud de hasta 6 m

- Vehículos pesados: Longitud de más de $6 \mathrm{~m}$

B. Silueta utilizada en los aforos manuales, obtenida visualmente por los operarios:

1. Motos

2. Coches

3. Coches con caravana

4. Camionetas

5. Tractores agrícolas

6. Camiones sin remolque

7. Camiones articulados

8. Trenes de carretera

9. Vehículos especiales

10. Autobuses.

Hay que señalar que esta última silueta más detallada, que requiere observadores manuales, y por tanto no se obtiene de forma continua, ni siquiera se recoge todos los años a través de aforos visuales de corta duración, sino que cada cierto número de años, a veces 10 , se contrata la recogida de datos por este procedimiento. 
4.3.4.2 Siluetas obtenidas por el CET (CEDEX) en las campañas de aforo y pesaje realizadas entre 1987 y 2003

El Centro de Estudios del Transporte (CET) del CEDEX durante la realización de las campañas de pesaje dinámico en la Red de Carreteras del Estado, llevadas a cabo entre 1987 y 2003, recogía también cuatro siluetas diferentes sobre distintas muestras de vehículos: dos de tipo automático, y otras dos, más detalladas, de tipo manual:

Silueta A: Se obtenía en el aforo automático realizado por el equipo de pesaje dinámico, pero sin utilizar los datos proporcionados por el sensor de peso, por lo que solamente se tenían en cuenta los datos de longitud de los vehículos proporcionados por los lazos de inducción del equipo de pesaje, obteniendo la siguiente composición:

- Vehículos ligeros: longitud menor de $6 \mathrm{~m}$

- Vehículos pesados: longitud igual o mayor de $6 \mathrm{~m}$

El propósito de obtener esta composición tan simple del tráfico, pudiendo obtener otras más detalladas con los equipos de pesaje dinámico, era comparar la exactitud en el número de vehículos pesados obtenidos en los aforos automáticos recogidos en la Red de Aforos de la Dirección General de Carreteras (y que sirven para determinar la categoría de tráfico pesado a introducir en el dimensionamiento de firmes) con los valores más cercanos a la realidad proporcionados por la medición del peso del vehículo mediante el sistema de pesaje dinámico.

Silueta B: Esta silueta se recogía en el aforo manual de 6 horas que se realizaba simultáneamente a la toma de datos del equipo de pesaje dinámico. En este aforo manual se clasificaban los vehículos visualmente por los operarios en:

- Turismos

- Derivados de turismo

- Furgón de 2 ejes sencillos

- Furgón de eje sencillo y eje gemelo y $\mathrm{PMA} \leq 3,5 \mathrm{t}$

- Furgón de eje sencillo y eje gemelo y PMA >3,5 t

- Camiones nacionales rígidos con PMA $\leq 3,5 \mathrm{t}$

- Camiones nacionales rígidos con PMA $>3,5 \mathrm{t}$

- Camiones nacionales articulados

- Camiones extranjeros rígidos

- Camiones extranjeros articulados

- Autocares nacionales

- Autocares extranjeros 
Silueta C: Se obtenía de la población de vehículos, a partir de los datos tomados automáticamente por el sistema de pesaje dinámico, según el peso y longitud de cada vehículo.

- Se obtiene separando automáticamente los vehículos de la población cuyo peso en báscula es mayor o igual a 3,5 t, según su número de ejes elementales.

- Además, con los vehículos pesados obtenidos con la condición anterior, se clasificaba a estos vehículos por su longitud, en:

- $\quad$ Vehículos rígidos $(6 \mathrm{~m}<$ Longitud $<12 \mathrm{~m}$ ) y

- Vehículos articulados+trenes de carretera (Longitud >12 m).

Silueta D: Esta silueta se obtenía visualmente mediante operarios situados en los márgenes de la carretera sobre una muestra visual tomada durante las 6 horas de aforo manual, al realizar la toma de datos de las estaciones de pesaje dinámico. Se la designaba como Silueta BDP de vehículos pesados, tomados visualmente por los operarios durante las 6 horas de aforo manual, y filtrados por las condiciones restrictivas del programa del aforo automático de 24 horas. En esta silueta se diferenciaba entre los siguientes tipos de vehículos:

- Camiones rígidos: 6 tipos

- Semirremolques: 9 tipos

- Trenes de carretera: 27 tipos

Aunque en cada una de estas clases pudiera existir algún tipo de vehículo adicional, sobre todo en los trenes de carretera, se tomaron los tipos mencionados por ser los más comunes a lo largo de las sucesivas campañas.

Por ser la silueta más completa que se puede obtener, se utilizará como referencia varias veces a lo largo de este documento para designar a los tipos, por lo cual se va a explicar a continuación su sistema de designación de los diferentes tipos de vehículos.

Clasificación y designación de los vehículos según la muestra visual de las campañas de pesaje dinámico realizadas por el CEDEX.

De acuerdo con el sistema de clasificación utilizado en la muestra visual de las campañas de pesaje dinámico, se designaba a cada vehículo pesado según su clase y su tipo (configuración) de ejes. En la Tabla 8 pueden observarse las cuatro grandes clases de vehículos que se consideran en este esquema:

o Camión rígido Clase $1(\mathrm{R})$

- Camión articulado Clase 2 (S)

o Tren de carretera (camión + remolque) Clase $3(\mathrm{~T})$

o Tren de carretera (articulado + remolque) Clase $4(\mathrm{~S}+\mathrm{T})$ 


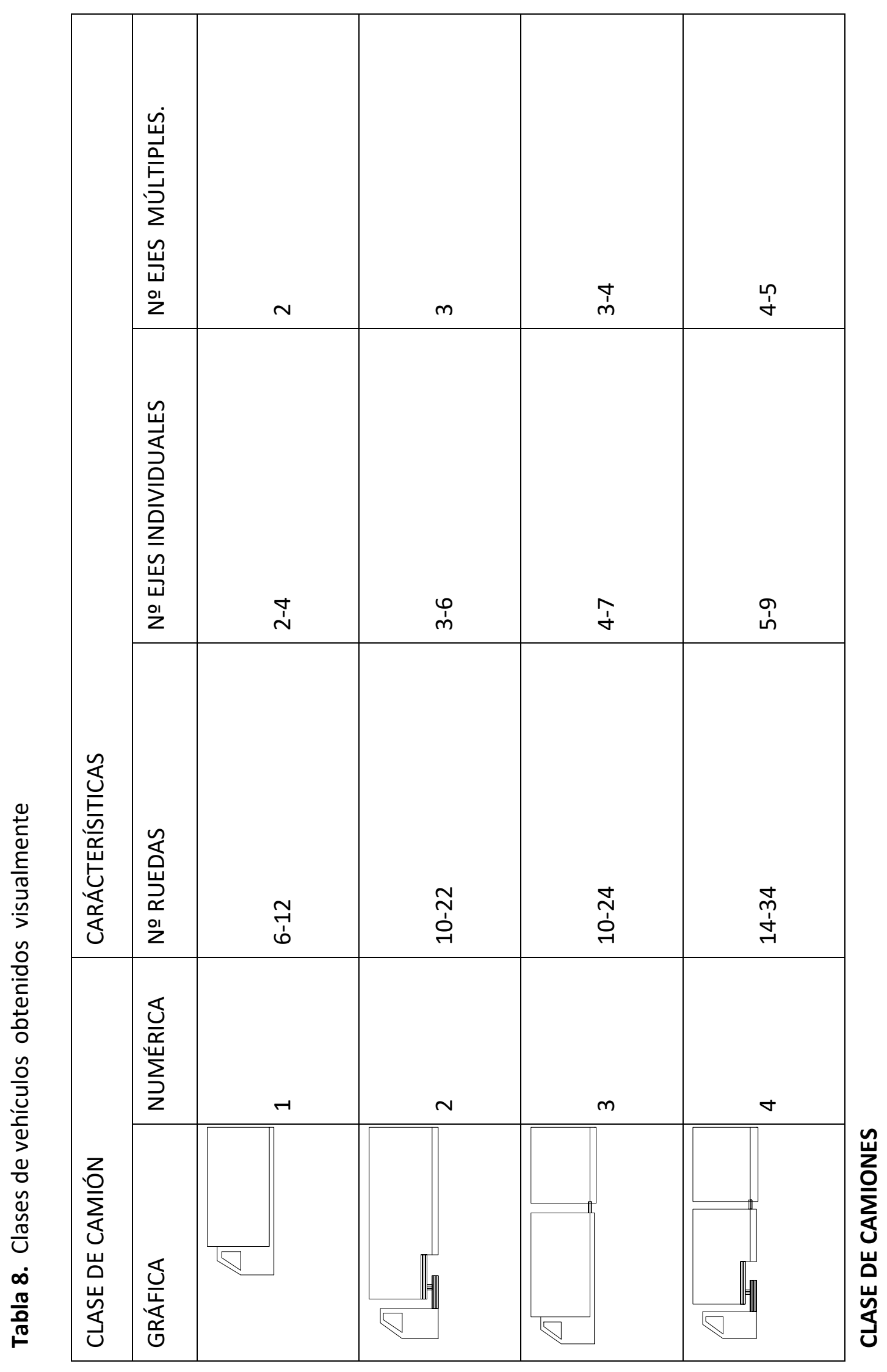


Antiguamente se utilizaba la designación numérica (1, 2, 3 ó 4), por considerarla más práctica con vistas a su codificación, pero modernamente se prefiere hacerlo por la letra inicial $(R, S, T$ ó $S+T)$, por ser más descriptiva.

El número completo de clasificación de un vehículo contiene los siguientes dígitos, tal como se muestra en la Tabla 9:

$$
\begin{aligned}
& 1 \text { o dígito .................................. Clase a la que pertenece. } \\
& 2 \text { o dígito ....................................... Número de ejes elementales. } \\
& \text { Resto de dígitos ….......................... Configuración de ejes múltiples (o completos) } \\
& \text { del vehículo. }
\end{aligned}
$$

Lo que define más plenamente a un vehículo pesado es el número y tipología de sus ejes, que viene descrita por el resto de los dígitos. En cuanto a la tipología de los ejes, los denominados "ejes múltiples" se pueden clasificar, atendiendo a la distancia entre los ejes individuales que los forman, en simples, tándem (dobles) y trídem (triples), mientras que si se considera también al número de ruedas existentes en cada uno de los extremos de cada eje que lo forman, pueden clasificarse en ejes de ruedas sencillas (con una sola rueda en cada extremo del eje), ejes de ruedas gemelas (con dos ruedas en cada extremo del eje) y ejes asimétricos (cuando en un eje múltiple existen unos ejes individuales de ruedas sencillas y otros ejes individuales de ruedas gemelas).

De esta forma, teniendo en cuenta los anteriores criterios, pueden definirse 8 clases principales de ejes, asignándole un número a cada una de ellas:

1. Eje simple de ruedas sencillas

2. Eje simple de ruedas gemelas

3. Eje tándem de ruedas sencillas

4. Eje tandem de ruedas gemelas

5. Eje trídem de ruedas sencillas

6. Eje trídem de ruedas gemelas

7. Eje tándem asimétrico

8. Eje trídem asimétrico.

Así, por ejemplo, los dos tipos de camiones más comunes son:

- El R12, que es el vehículo rígido (R) con un eje simple delantero de ruedas sencillas (1), que es el eje direccional, y el eje trasero es un eje simple de ruedas gemelas (2), que es el eje motriz.

- El S125, que es un vehículo articulado compuesto de cabeza tractora más un semirremolque (S), con un eje simple delantero direccional de ruedas sencillas (1) en la cabeza tractora, un eje simple de ruedas gemelas (2) en la parte trasera de la cabeza tractora, que es el eje tractor, y en el semirremolque hay un eje trídem de ruedas sencillas (5).

De acuerdo con lo que se acaba de explicar, se obtenía el esquema completo de clasificación que se puede ver en la Tabla 9: 
Tabla 9. Diferentes tipos de vehículos considerados visualmente, incluyendo su configuración de ejes (Por ejemplo: la configuración 12 significa que el primer eje múltiple es simple de ruedas sencillas (1) y el segundo eje es simple de ruedas gemelas (2). La configuración 14 indica que el primer eje es simple de ruedas sencillas (1) y el segundo eje múltiple es tándem de ruedas gemelas (4).

\begin{tabular}{|c|c|c|c|c|}
\hline \multicolumn{5}{|c|}{ CONFIGURACIONES DE VEHÍCULOS PESADOS } \\
\hline $\begin{array}{l}\text { CLASE } \\
\text { DE } \\
\text { VEHÍC. }\end{array}$ & $\begin{array}{l}\text { TIPO } \\
\text { DE } \\
\text { VEHÍCULO } \\
\end{array}$ & CLAVE & $\begin{array}{l}\text { NÚMERO } \\
\text { DE EJES } \\
\text { INDIVIDUALES }\end{array}$ & $\begin{array}{l}\text { CONFIGURACIÓN } \\
\text { DE } \\
\text { EJES }\end{array}$ \\
\hline \multirow{6}{*}{1} & 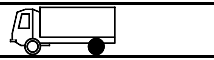 & 1212000 & 2 & 12 \\
\hline & 可 & 1314000 & 3 & 14 \\
\hline & $\frac{100}{0=10}$ & 1317000 & 3 & 17 \\
\hline & 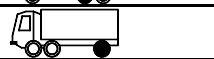 & 1332000 & 3 & 32 \\
\hline & $\sqrt{4-\infty}$ & 1434000 & 4 & 34 \\
\hline & $\sqrt{400}-0$ & 1437000 & 4 & 37 \\
\hline \multirow{9}{*}{2} & 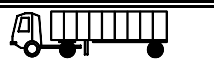 & 2312200 & 3 & 122 \\
\hline & 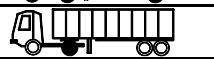 & 2412300 & 4 & 123 \\
\hline & 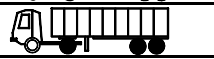 & 2412400 & 4 & 124 \\
\hline & 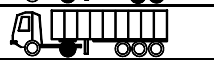 & 2512500 & 5 & 125 \\
\hline & 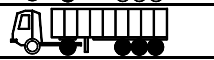 & 2512600 & 5 & 126 \\
\hline & 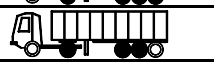 & 2512800 & 5 & 128 \\
\hline & 国 & 2514400 & 5 & 144 \\
\hline & \multirow{2}{*}{ 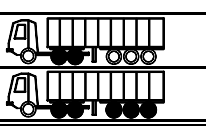 } & 2614500 & 6 & 145 \\
\hline & & 2614600 & 6 & 146 \\
\hline & {$\left[\begin{array}{lll}\pi & 0 & 0\end{array}\right.$} & 3412110 & 4 & 1211 \\
\hline & 喓 $=0$ & 3412220 & 4 & 1222 \\
\hline & 哥 & 3412300 & 4 & 123 \\
\hline & $a_{0}=0$ & 3412400 & 4 & 124 \\
\hline & 000 & 3512130 & 5 & 1213 \\
\hline & $=0$ & 3512240 & 5 & 1224 \\
\hline & In & 3512500 & 5 & 125 \\
\hline & 砶 & 3512600 & 5 & 126 \\
\hline & If $=0$ & 3514220 & 5 & 1411 \\
\hline & 可 & 3517220 & 5 & 1422 \\
\hline$\nabla$ & (nd $)$ & 3514400 & 5 & 144 \\
\hline \multirow[t]{4}{*}{3} & 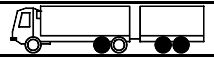 & 3517400 & 5 & 174 \\
\hline & {$\left[\begin{array}{ll}4 & -6\end{array}\right.$} & 3532220 & 5 & 3222 \\
\hline & 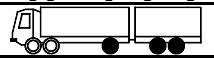 & 3532400 & 5 & 324 \\
\hline & $-10-000$ & 3632240 & 6 & 3224 \\
\hline
\end{tabular}




\subsubsection{Metodología para realizar una clasificación automática}

\subsubsection{Consideraciones generales}

La metodología para establecer un esquema de clasificación automática se debe basar en la consideración de dos aspectos principales:

1- Por un lado, por las necesidades o exigencias de datos del organismo que recoge los datos, de acuerdo con la aplicación que vaya a dar a esos datos. En efecto, muchas veces sólo se requiere determinar la composición del tráfico en un número muy reducido de clases de vehículos (por ejemplo, para ciertos estudios de capacidad de tráfico, basta con conocer la composición en ligeros y pesados), mientras que en otros casos (como los estudios detallados de transporte), es preciso "afinar" más en la distinción de un mayor número de clases diferentes de vehículos.

2- Por otro lado, por la capacidad de los medios o de los equipos de recogida automática de datos de que se disponga para diferenciar un número mayor o menor de clases. Así, si sólo se dispone de equipos aforadores de tráfico que utilizan lazos de inducción, únicamente se podrán obtener unas pocas clases de vehículos, mientras que si se dispone de equipos de pesaje dinámico se podrá conseguir diferenciar en un mayor número de clases. De igual manera, cuando sólo sea necesario recoger datos de clasificación durante unas pocas horas, y se requiera una gran precisión y fiabilidad en la recogida de datos de un cierto número de clases de vehículos, puede ser más conveniente utilizar personal para realizar una toma de datos visual, especialmente si se trata de hacerlo en entornos complicados, como pueden ser las intersecciones o los enlaces.

La metodología utilizada para la clasificación automática de vehículos consiste en establecer unas reglas de decisión ("árbol de decisión") basadas en los valores que toman ciertos parámetros del vehículo que pueden ser determinados automáticamente (longitud, no de ejes, distancia entre ejes, peso total del vehículo, peso de cada eje). Así, si los anteriores parámetros de un vehículo determinado, encajan dentro de los valores umbrales y/o límite de una clase determinada, el vehículo quedará encuadrado en la clase en cuestión.

Cuando el equipo de medida es solamente un aforador de vehículos con lazos de inducción que permiten determinar la longitud del vehículo, la regla de decisión para determinar si un vehículo pertenece a una clase u otra se basa en si su longitud es mayor o menor que un cierto umbral de longitud predefinido. Así, por ejemplo, si se trata de implementar una clasificación en vehículos ligeros o pesados, el vehículo quedará clasificado normalmente como ligero si su longitud es menor de la longitud establecida como umbral y como pesado si es mayor. De esta forma, en la red de carreteras del Estado de España se suele tomar como longitud umbral para diferenciar los vehículos ligeros de los vehículos pesados los $6 \mathrm{~m}$. 
En general, con los típicos sistemas de aforo de tráfico basados en lazos de inducción, se puede obtener una clasificación de los vehículos en unos pocos tipos (normalmente solo 2, ligeros y pesados, aunque se puede llegar a distinguir hasta 5 tipos diferentes aproximadamente) basada en su longitud. Mediante los sistemas de pesaje dinámico se puede clasificar de una manera muy detallada a los distintos tipos de vehículos gracias a la capacidad de estos sistemas de medir, además de la longitud, varios parámetros más, como son el número de ejes, la distancia entre ejes, y el peso del vehículo y el de cada uno de sus ejes, lo que permite diferenciar muchos tipos de vehículos de características bastante parecidas.

Actualmente, los equipos de pesaje dinámico suelen llevar incorporado un programa para obtener una composición detallada del tráfico basada en los parámetros anteriormente mencionados. Sin embargo, frecuentemente debe llevarse a cabo un cierto trabajo de adaptación o puesta a punto de su capacidad o funcionalidad de clasificación de los vehículos, por las siguientes razones:

1. Los parámetros que definen a las diferentes clases de vehículos que vienen programadas en los sitemas de pesaje dinámico suelen ser los del tráfico dominante en el país o área geográfica de la empresa fabricante, que normalmente difieren en mayor o menor medida de los del país en el que se está instalando el sistema.

2. Aun en el caso de que los parámetros de los distintos tipos de vehículos coincidan con los fijados (programados) por defecto en el equipo, por coincidir con los del país del fabricante, una vez en la carretera, su valor registrado puede diferir de sus valores reales por la manera en que son captados estos parámetros por los equipos. Esto se debe a que los vehículos pueden circular en diferentes posiciones a lo ancho del carril, que provocan que no siempre pisen los lazos de inducción o los sensores de peso de una forma adecuada, lo que se traduce en imprecisiones en la determinación de los parámetros de los vehículos utilizados para su clasificación.

3. Por otro lado, muchas veces los parámetros que definen los diferentes tipos de vehículos pueden variar algo, aunque sea ligeramente, con respecto a los umbrales máximos o mínimos definidos en la normativa vigente en el país de que se trate; por ejemplo, éste es el caso de la longitud máxima de los vehículos articulados, que frecuentemente sobrepasa a la máxima definida en el Reglamento General de Vehículos, pues al efectuarse el acople del semirremolque a la cabeza tractora mediante enganche en la llamada " 5 a rueda", se puede hacer variar en varios decímetros la posición exacta de ésta.

4. En muchas ocasiones, existe un cierto solape entre las características de los vehículos de varias clases, lo que exige el definir un umbral de separación entre esas clases diferentes que minimice el error en la determinación de la clase a la que pertenece cada vehículo individual. 
Una vez expuestas las anteriores consideraciones, a continuación se va a describir el procedimiento que se siguió para desarrollar los esquemas de clasificación de la FHWA, pues fueron unos de los primeros en ser elaborados y, además, el método utilizado para hacerlo es bastante representativo del que se debe llevar a cabo para establecer un sistema de clasificación.

\subsubsection{Procedimiento seguido para desarrollar los esquemas de clasificación de la FHWA}

Como ejemplo de la metodología que se debe seguir para desarrollar un esquema de clasificación automática de vehículos, se detalla a continuación el procedimiento utilizado para elaborar los sistemas de clasificación de la FHWA, pues aparte de ser el primer intento de gran envergadura acometido en este campo, resulta bastante representativo del compromiso al que se debe llegar entre las capacidades de los equipos de aforo para realizar tal clasificación y el número óptimo de clases de vehículos de interés. Este trabajo parte del estudio realizado en septiembre de 1982 por Lyles y Wyman [31], [32] en el que se probaron cinco esquemas diferentes de clasificación, que incluían de 7 a 32 categorías de vehículos. Finalmente se seleccionó el llamado Esquema "E", que incluía 14 categorías de vehículos, pues se consideró que era el que proporcionaba un número adecuado de clases de vehículos para las capacidades que tenían entonces los equipos de recogida de datos.

Al cabo de un par de años, la Oficina de Planeamiento de Carreteras de la FHWA y varias agencias de diferentes Estados propusieron algunas modificaciones para algunas de las clases de vehículos seleccionadas en el Esquema "E". En consecuencia, se le encargó a una agencia de un Estado (la División de Materiales e Investigación del Departamento de Transportes de Maine) revisar los posibles cambios y también llevar a cabo un estudio sobre la precisión y calidad del equipamiento disponible en aquel momento para recoger esos datos en la carretera.

Así, el objetivo concreto del estudio fue evaluar la capacidad de 5 aparatos de clasificación de vehículos disponibles en esa época en el mercado, para identificar de forma precisa los tipos de vehículos incluidos en el esquema de clasificación de la FHWA, así como examinar las posibles modificaciones propuestas por la FHWA al esquema "E" de clasificación. Asimismo, tras la revisión del esquema de clasificación, se incluía el desarrollo de las reglas de decisión necesarias para posibilitar la elaboración de los programas de ordenador para clasificar los vehículos de acuerdo con el esquema final.

Primeramente se evaluó la precisión de los equipos de clasificación probados, así como su capacidad de funcionamiento en la carretera sin averías ni problemas durante un periodo típico de recogida de datos, de 1 ó 2 semanas. Los ensayos se llevaron a cabo en una carretera rural de 2 carriles y en una autopista interestatal.

- De los 5 equipos de clasificación probados, dos de ellos contaban con 2 lazos de inducción y un sensor de peso utilizado principalmente como contador de ejes, uno de tipo magnético (de la empresa IRD) y otro de tipo estera (de la empresa Golden River) aunque no se utilizó en el ensayo su capacidad de medir el peso, otros dos sistemas (pertenecientes a las casas 
Streeter-Amet y GK Instruments) contaban con tubos neumáticos sobre un solo carril y luego otro utilizaba dos lazos de inducción. Por tanto, cuatro de los clasificadores efectuaban la clasificación a través de medir las velocidades de los vehículos y las distancias entre ejes y el último a través de medir las longitudes solamente.

- Como resultado del estudio, se modificó el esquema original de clasificación "E" y se desarrolló el llamado esquema " $F$ ", que incluía la corrección de ciertos errores lógicos en el esquema " $E$ " y que permitía añadir unas clases para las motocicletas y los autobuses.

La evaluación se desarrolló en tres fases:

1.- Revisión inicial de los sistemas

2.- Evaluación de la capacidad de los sistemas para clasificar correctamente a los vehículos. Fue realizada en una carretera del Estado utilizando un remolque para llevar un equipo de grabación de imágenes y fotografía, con el fin de poder registrar y analizar las clases de unos 500 vehículos que pasaron sobre los sistemas.

3.-Evaluación del contaje (aforo) de vehículos a través de la medición del volumen de tráfico en varios periodos de 24 horas, que se llevó a cabo en una vía interestatal en algunos de los sistemas y en la carretera anterior para otros.

Los resultados de los ensayos mostraron que los 4 equipos que agrupaban a los vehículos por ejes pudieron obtener unos porcentajes de clasificación correcta de entre el $91 \%$ y el $96 \%$ para agrupar a los vehículos según el esquema "F", Ilegando al 98\% de corrección para el sistema que sólo utilizaba la longitud como parámetro de diferenciación, pero únicamente sobre un esquema con 7 clases.

Además, pudo concluirse que el esquema de clasificación " $F$ " constituía un sistema de clasificación aceptable y factible, para el que podían desarrollarse programas lógicos de ordenador para la obtención automática de esta clasificación.

Los sistemas no tuvieron ninguna avería durante el periodo de evaluación. No obstante se detectaron problemas de vehículos perdidos en el contaje cuando circulaban a bajas velocidades (por debajo de unos $30 \mathrm{~km} / \mathrm{h}$ ) o cuando formaban colas. También se incidió en los problemas con los sensores, algunos relacionados con su alto coste (los sistemas magnéticos o las esteras) o la corta vida útiles de los tubos neumáticos, por lo que se concluyó la necesidad de desarrollar contadores de ejes baratos y preferiblemente permanentes 0 , al menos, resistentes a todo tipo de condiciones atmosféricas.

Uno de los aspectos más sobresalientes y útiles del informe son los diagramas de flujo proporcionados para programar la clasificación de los vehículos según el esquema " $F$ " de la FHWA, que consta de 14 clases diferentes.

Uno de los errores más usuales de mala clasificación experimentado por los esquemas de basados en el contaje y medida de la separación entre ejes es el causado por el solape del número de ejes y las configuraciones de separación entre estos de las 
diferentes categorías de vehículos (Lyles y Wyman, 1982). Por ejemplo, el caso más patente es que muchos turismos comparten una configuración de ejes común con los vehículos comerciales ligeros (normalmente furgones), lo que hace que contribuyan a incrementar unos errores significativos de clasificación errónea.

Un estudio llevado a cabo por Kwigizile et al. [27] en 2005 informó de un error de clasificación global del 9,5 \% utilizando un método basado en un árbol de decisión para el Esquema de clasificación F de la FHWA mostrado en la Tabla 5. No obstante, hubo una tasa significativa de clasificación errónea entre las clases de vehículos 3 ("otros vehículos de 2 ejes y 4 neumáticos") y 5 ("camiones simples de 2 ejes y 6 neumáticos"), que como se ha explicado anteriormente, es la que plantea más problemas de diferenciación.

\subsubsection{Recientes desarrollos para la mejora y optimización de los procedimientos de clasificación automática}

En los últimos años se han ido realizando una serie de estudios para la mejora y la optimización de los procedimientos de clasificación automática de vehículos, que se han desarrollado en dos direcciones distintas:

1. Los procedimientos basados en nuevas tecnologías de sensores de captación de datos.

Los trabajos más prometedores en este sentido han sido los estudios sobre la aplicación de la llamada huella inductiva de lazo a la mejora de la clasificación de vehículos, llevados a cabo por un equipo de la Universidad de Irvine (California, EE.UU.).

2. Las metodologías basadas en la aplicación de procedimientos matemáticos de clasificación.

A continuación se explican más pormenorizadamente estas dos líneas de investigación en el campo de la clasificación automática de vehículos.

4.3.6.1 Aplicación de la tecnología de la huella inductiva de lazo a la clasificación de vehículos

Una reciente mejora significativa en los procedimientos de clasificación de vehículos ha sido el llevado a cabo por Hernandez, S., Tok, A, y Ritchie, S [33], un equipo de la Universidad de Irvine, California (EE.UU.) en el que se han utilizado los datos proporcionados por sistemas de pesaje en movimiento instalados en el Estado mencionado, pero no limitándose a los datos normalmente proporcionados por este tipo de sistemas (pesos de los ejes, distancias entre ejes, pesos totales del vehículo, longitud), sino que han utilizado también un nuevo sistema de procesamiento de las señales de los lazos de los equipos de pesaje dinámico, con objeto de obtener lo que se denomina como firma o huella inductiva de lazo (inductive loop signature). 
En los estudios realizados por los autores mencionados se presenta este nuevo enfoque de integrar datos del pesaje en movimiento (WIM) y los de la huella de lazo inductivo, pues son bastante complementarios.

El objetivo de este estudio era proporcionar una clasificación basada no sólo en los tipos determinados por la configuración de ejes del esquema $F$ de la FHWA, sino en obtener también la configuración del chasis (o caja) del vehículo (es decir, si se trata de una cisterna, una plataforma, un portacontendores, una caja cerrada, etc), pues se ha comprobado que este dato está más relacionado con el tipo de carga transportada, lo que tiene una utilidad adicional.

Los datos de los sistemas de pesaje dinámico proporcionan información sobre la configuración de ejes del camión y de sus pesos; no obstante, la información basada en los ejes no puede asociarse directamente su configuración de chasis ni desde luego con la función del camión, por lo que se recurre a determinar la huella inductiva de lazo para tratar de obtener estos parámetros.

Por otro lado, los detectores usuales de lazo inductivo miden señales bivalentes de los lazos empotrados en el pavimento y son capaces de medir Intensidades (volúmenes) agregadas y ocupaciones. A diferencia de otros muchos otros sistemas de detección, tales como los sensores de imágenes o acústicos, los detectores de lazo son inherentemente exactos, logrando exactitudes en el aforo de vehículos típicamente entre el $98 \%$ y el $99 \%$ incluso en aplicaciones de sistemas de señales convencionales bivalentes, lo que proporciona una buena plataforma tecnológica para desarrollar el sistema propuesto. Además, como la inductancia magnética es invariable a los cambios de la temperatura, iluminación, visibilidad y humedad, los sistemas de detección basados en lazos de inducción son robustos.

Los detectores avanzados de lazo inductivo miden la variación de la inductancia en un sensor de lazo a tasas de hasta 1.200 lecturas por segundo, produciendo unas señales de salida con forma de onda analógica para cada vehículo (véase la Figura 10), que se designan como firmas o huellas inductivas o de lazo. Una ventaja significativa de los detectores avanzados de lazo inductivo es su compatibilidad con los existentes detectores de lazo bivalentes, con lo cual no exige mejoras en la infraestructura. Esto permite que los detectores convencionales de lazo ya existentes puedan sustituirse por los detectores de lazo avanzados sin sufrir ninguna pérdida en la funcionalidad del sistema. 

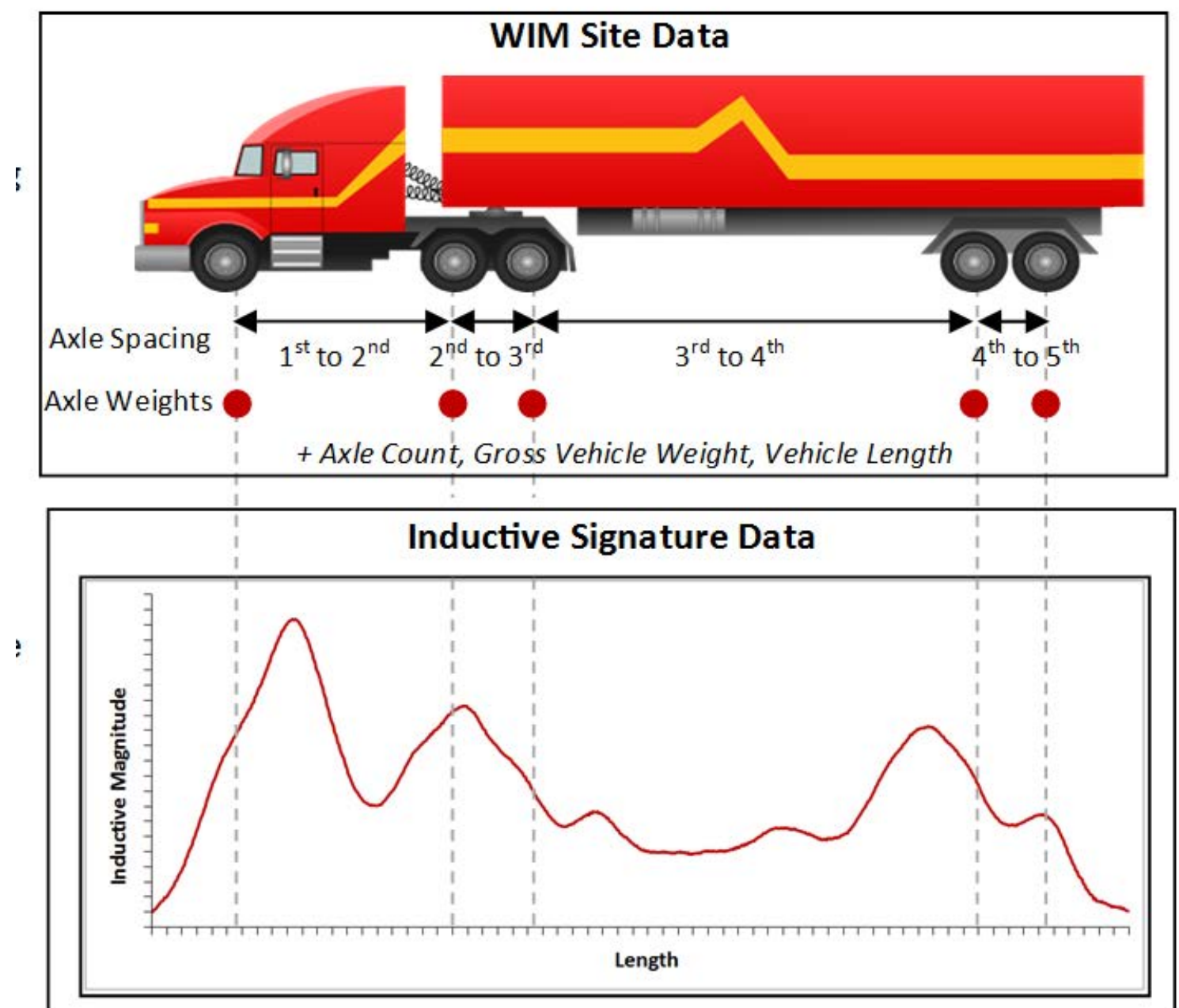

Figura 10. Aspecto de la huella inductiva de lazo de un vehículo articulado de 5 ejes de caja cerrada, obtenida con los lazos de inducción de un sistema de pesaje dinámico. Fuente: [33]

La serie de datos de la huella inductiva de lazo incluye magnitudes interpoladas y diferencias de magnitudes interpoladas. Las huellas se procesan de la siguiente manera: primeramente, se limpia la huella inductiva bruta de un vehículo aplicando un criterio de magnitud de recorte para reducir el ruido de medición en las colas de la huella. Después, se normaliza la huella en el eje vertical según su magnitud pico y en el eje horizontal según la longitud total del vehículo. En tercer lugar, se interpolan de 20 a 30 magnitudes de igual separación. Se computa una segunda serie de características como la diferencia entre puntos consecutivos de magnitud interpolada.

Para los vehículos articulados de 5 ejes de tipo cabeza tractora+semirremolque se utilizan las mediciones de las separaciones entre ejes para analizar las huellas inductivas parciales de la cabeza tractora y del semirremolque. La sección analizada de la huella que representa el semirremolque se procesa de acuerdo al mismo procedimiento de extracción de las características, excepto que se normaliza la huella según el pico de solamente la parte del semirremolque. Esto mejora la exactitud de clasificación, debido a que el modelo no está influido por las características de la cabeza tractora para predecir la clase de chasis del semirremolque. 
$\underline{\text { Integración de ambas fuentes de datos }}$

Dada la complementariedad de los datos del pesaje en movimiento y de los obtenidos de las huellas inductivas de lazo, junto con la configuración física de estos sistemas en que los lazos de inducción están insertados dentro de un sistema WIM, ambos pueden adaptarse con vistas a su integración para aprovechar las sinergias de ambos en una única fuente de datos.

El procedimiento de integración de los datos consta de dos partes: la integración del hardware y el tratamiento de los datos. La integración del hardware implica reemplazar el módulo existente de lazos inductivos bivalentes de la unidad de control del equipo WIM por tarjetas detectoras avanzadas de la huella de lazo inductivo. EI manejo de los datos incluye un procesamiento previo de las huellas inductivas y de los registros WIM en una de base de datos estructurada, a la que se puede acceder a través de una interfaz de usuario adaptada al cliente.

Resultados preliminares obtenidos del modelo de clasificación del chasis

En un primer caso práctico de clasificación del tipo de chasis del camión, utilizando datos recogidos en California, se trató de demostrar el potencial de la fuente de datos integrados propuesta.

Para evaluar el modelo de clasificación se utilizó como criterio de desempeño la "tasa de clasificación correcta" por clase de vehículo, así como la tasa de clasificación correcta media para el modelo. Se define la tasa de clasificación correcta como el número de vehículos correctamente emparejados divididos por el número total de vehículos. La tasa global obtenida para el modelo de clasificación del chasis del semirremolque de la Clase 9 fue del 75\%. Los diversos tipos de chasis dentro de la clase 9 obtuvieron también diferentes tasas de clasificación correcta: las cisternas tuvieron una tasa baja de acierto (70\%) y muchas veces fueron clasificadas erróneamente como plataformas básicas. Los contenedores tuvieron también una tasa muy baja de clasificación correcta (36\%) y fueron incluidos de forma equivocada como semirremolques de cajas cerradas. Por otro lado, varias clases tuvieron unas altas tasas de acierto en la clasificación como fueron las plataformas básicas, las cajas cerradas, las cajas abiertas, los contenedores de 40 pies, los semirremolques de transporte de vehículos, los de transporte de ganado.

Posteriormente, Hernández, Tok y Ritchie introdujeron mejoras en el procedimiento de clasificación que se acaba de explicar utilizando sistemas de clasificadores matemáticos (de los cuales se hablará en el siguiente apartado) múltiples, según se expone en la ponencia "Multiple-Classifier Systems for Truck Body Classification at WIM Sites with Inductive Signature Data" [34], presentada en 2015 en el 94 Congreso Anual del TRB, con el fin de aumentar la exactitud de clasificación, especialmente para las clases de chasis menos frecuentes, y para asegurar la transferibilidad espacial y temporal del modelo. 
Los resultados obtenidos utilizando los sistemas clasificadores múltiples, expresados en términos de tasa de clasificación correcta, fueron para los camiones rígidos del 98,4\% para la clase 4 de la FHWA, 80,3\% para la clase 5 pero sin remolque, 80,0\% para la clase 6 y un 100\% para la clase 7. Con respecto a los camiones de varias unidades, la clase 8 de la FHWA tuvo una tasa de acierto del 98,4\%, la clase 9 del 81,8 \% y la clase 10 del $100 \%$. Para las clases 11 y 12 de la FHWA (unidades multi-remolque) la tasa de clasificación correcta fue del $92 \%$.

4.3.6.2 Técnicas de reconocimiento de patrones para la mejora de la clasificación de vehículos

El problema de clasificar vehículos pude ser considerado como una cuestión de lo que se conoce como "reconocimiento de patrones". Así, las clases de vehículos manifiestan un cierto patrón, que puede ser procesado para identificarlas.

El reconocimiento de patrones abarca disciplinas tales como el análisis discriminante, el reconocimiento de características, la estimación de errores, el análisis de conglomerados (todas juntas llamadas a veces como reconocimiento estadístico de patrones), la inferencia gramatical y "parsing" (a veces llamada reconocimiento sintáctico de patrones).

Las áreas relacionadas con el reconocimiento de patrones incluyen redes neuronales, inteligencia artificial, visión cognitiva y percepción biológica, estadística matemática y optimización no-lineal.

Se ha investigado sobre la aplicación un cierto número de técnicas de reconocimiento de patrones para determinar su adecuación para su empleo en la clasificación de vehículos, entre las cuales están las siguientes:

a) las redes probabilísiticas neuronales (PNN -probabilistic neural networks-),

b) la lógica difusa

c) la regla del vecino más próximo, estimación de los $\mathrm{k}$ vecinos más próximos

d) las máquinas de soporte de vectores (SVM -support vector machines-)

\section{a) Redes probabilísticas neuronales}

Una red probabilística neuronal es una técnica de clasificación de patrones que se considera que proporciona un método general para estos problemas de clasificación, combinando algunos de los mejores atributos del reconocimiento estadístico de patrones, que son las redes neuronales de alimentación hacia delante (feed-forward neural networks).

Tras la programación de una red neuronal probabilística, su aplicación conlleva ejecutar las siguientes fases:

- entrenamiento (training), 
- ensayo (testing) y

- clasificación.

Precisamente, una de las mayores ventajas de la red neuronal probabilística es su capacidad para realizar una clasificación basada en datos de entrenamiento de vehículos reales obtenidos de la carretera (que, por ejemplo, pueden incluir el número de ejes por vehículo, la separación entre ejes o el peso total del vehículo), pues así se consigue una rápida velocidad de entrenamiento, que el entrenamiento sea incremental para conseguir un funcionamiento rápido y robusto contra los ejemplos que se salen de lo usual y una convergencia garantizada a un clasificador Bayesiano.

La selección puede mejorarse incrementando el número de parámetros, por ejemplo, en el caso de una división de acuerdo con el número de ejes, puede lograrse una mejor selección midiendo un segundo parámetro, como la separación entre ejes.

Existen dos maneras principales de "entrenar" una red neuronal: de forma supervisada y de forma no supervisada. En el procedimiento supervisado, las categorías de entrada son conocidas de antemano, así como las salidas; así, las salidas reales se comparan con las salidas deseadas asociadas con una serie de patrones de entrenamiento. En el procedimiento no supervisado, normalmente conocido como "clustering (agrupación), los patrones de entrenamiento se usan solamente como entradas, y se le pide al sistema que agrupe las entradas sin indicación de cuál es la respuesta correcta o equivocada. Básicamente, el aprendizaje no supervisado persigue encontrar una cierta clase de regularidad en los datos representados por los patrones de entrenamiento.

Aplicándolo a la clasificación de vehículos, como las clases de salida son conocidas (es decir, se pide clasificar a los vehículos, por ejemplo, según el "Esquema F" de categorías mostrado en la Tabla 5), se "entrena" a la red neuronal probabilística de forma supervisada.

Para ello, se debe escoger como serie de datos de entrenamiento una que contenga como datos de entrada los de los vehículos representativos de cada clase.

Kwigizile et al. [27] propusieron en 2005 un método que utiliza Redes Neuronales Probabilísticas para obtener los umbrales de separación óptimos entre ejes para las diferentes clases de vehículos del Esquema F de la FHWA.

Como se ha comentado anteriormente, el esquema " $F$ " es el utilizado por la mayor parte de los Estados para clasificar a los vehículos, y se utilizar para obtener el espectro de cargas por ejes pedido. Sin embargo, en la práctica se ha visto que es difícil de automatizar la obtención de este esquema " $F$ " $y$ además es bastante susceptible de que haya errores debidos a la imprecisa determinación de los valores umbrales de las distintas clases.

Por ello, en el trabajo de Kwigizile se consideró al problema de clasificación como un problema de reconocimiento de patrones, en el que se podía utilizar las redes neuronales probabilísticas - RNP - (Probabilistic Neural networks -PNN-) como técnica de reconocimiento para asignar a los vehículos a sus clases correctas y, de aquí, establecer los umbrales óptimos de separación de ejes. 
Para ello, se desarrolló, entrenó y aplicó una red neuronal probabilística a varios grupos de datos de campo que constaban de separación entre ejes de vehículos individuales, número de ejes por vehículos y peso total del vehículo.

Se escogieron dos series de patrones de entrenamiento:

e) uno con la separación entre ejes y el número variable de ejes y

f) otra serie que incluía, además de las anteriores, también el peso total del vehículo.

La selección de los patrones de entrenamiento fue realizada cuidadosamente para coger los vehículos representativos que reflejaran todas las características exigidas a los vehículos de cada clase.

Se evaluó la red neuronal en dos etapas:

1. Actuando la red neuronal probabilística sobre una serie de datos que incluía solamente dos variables: el número de ejes y la separación entre estos, que son las mismas variables que las utilizadas Departamento de Transportes de Florida por el para la clasificación.

2. En la segunda etapa, la RNP actuó sobre otra serie de datos que incluía el peso total del vehículo además de las 2 variables anteriores. El propósito de emplear el peso total del vehículo fue ayudar a mejorar la demarcación de los umbrales entre las clases. Obviamente, esto solo se puede realizar cuando se dispone de equipos de pesaje dinámico.

La aplicación del sistema clasificación basado en la red neuronal redujo la tasa de error del algoritmo de clasificación existente utilizado por el Departamento de Transportes del Estado de Florida (FDOT) del 9,7\% al 6,1\% cuando se utilizaban como datos de entrada para la clasificación el número de ejes de los vehículos y la distancia entre ejes. Los errores restantes se debían aún al solapamiento de la configuración de ejes entre clases, lo que indica que la clasificación de vehículos no es un problema separable utilizando la configuración de ejes del vehículo como único criterio de discernimiento.

Cuando se incluyó también el peso total del vehículo como variable adicional de clasificación se redujo el error del 6,1\% al 2,9\%.

Como se ha comentado, esto sólo es aplicable en emplazamientos que dispongan de equipos de pesaje dinámico que puedan recoger el dato del peso total del vehículo, lo que permite incrementar la separabilidad de los vehículos en el análisis de la RNP, para que se puedan ser definir mejor los umbrales de espaciamiento entre los ejes. No obstante, una vez que se han calculado los nuevos umbrales siguiendo esta técnica, no sería necesario usar el peso como variable en el algoritmo de clasificación, por lo que bastaría con realizar un pesaje de corta duración con un sistema de pesaje dinámico portátil.

Estos resultados fueron utilizados para establecer nuevos umbrales que redujeran la tasa de error de clasificación. La tabla propuesta de umbrales de clasificación de los 
vehículos fue validada utilizando datos de campo adicionales, obteniéndose una mejora significativa en la precisión de la tabla de clasificación de vehículos en comparación con el procedimiento llevado a cabo hasta entonces por el Departamento de Transportes de Florida. Por otro lado, se concluyó que la tabla desarrollada de valores umbrales permitiría obtener de forma coherente unos datos más precisos de clasificación de vehículos utilizando un equipo de cualquier marca.

Uno de los inconvenientes de utilizar un modelo de clasificación como el descrito puede ser el menor rendimiento (precisión) que se obtiene bajo condiciones diferentes del tráfico o en lugares donde las distribuciones de los tipos de vehículos son significativamente distintas.

\section{b) Lógica difusa}

La utilización de la lógica difusa a la clasificación de vehículos trata de resolver el problema que se presenta normalmente de que el conjunto de parámetros característicos de un vehículo suele poder asignarse a más de una de las categorías de clasificación establecidas, con lo cual el problema de clasificación no es unívoco, sino multiunívoco, impreciso y, en definitiva, difuso.

En los procedimientos normales de clasificación, la decisión sobre en qué categoría o tipo se debe encuadrar un vehículo determinado se toma basándose en la lógica clásica ("verdadero" o "falso"), lo que muchas veces puede ser la causa de la baja efectividad de tales algoritmos de decisión.

Para resolver esto, en el planteamiento de la lógica difusa se establece una función de pertenencia (membership) que asigna a cualquier elemento del espacio de una serie de valores un grado de pertenencia a la serie difusa dada: desde la no pertenencia (valor 0 ), pasando por una pertenencia parcial (valor entre 0 y 1 ) a la pertenencia completa (valor 1).

Un ejemplo de procedimiento de clasificación de vehículos utilizando la lógica difusa fue el desarrollado por Piotr Burnos [26], ya comentado en el apartado sobre las aplicaciones del pesaje dinámico a los estudios de tráfico y clasificación de vehículos, cuyos resultados fueron presentados en la Conferencia sobre el Pesaje en Movimiento celebrada en 2008 en París.

Los procedimientos normalmente utilizados para la clasificación de vehículos se basan en la medición de unos parámetros característicos del vehículo, tales como el número de ejes, su separación o el perfil o huella magnética, los cuales conforman el llamado "vector de parámetros característicos". La decisión de si un vehículo entra dentro de una categoría dada se toma comparando el vector característico con el vector modelo de esa categoría.

El caso más simple de lo anterior es una división simple en vehículos grandes y pequeños basada en la medida de un solo parámetro, normalmente la longitud. La selección puede mejorarse incrementando el número de parámetros, por ejemplo, en 
el caso de una división de acuerdo con el número de ejes, puede lograrse una mejor selección midiendo un segundo parámetro, como es la separación entre los ejes.

El proceso de clasificación es, por tanto, multifásico y jerarquizado y la decisión se toma basándose en la lógica clásica ("verdadero" o "falso"), lo que de acuerdo con P. Burnos es la causa de la baja efectividad de tales algoritmos de decisión, que no sobrepasa el 60-70\%.

Sin embargo, dado que la asignación única de un elemento a una serie de datos no es aplicable a este problema, P. Burnos propone emplear la lógica difusa como una medida de la difusión, los valores múltiples y los conceptos imprecisos.

Así, de acuerdo con el planteamiento de la lógica difusa, se establece una función de pertenencia (membership) que asigna a cualquier elemento del espacio de una serie de valores un grado de pertenencia a la serie difusa dada: desde la no pertenencia (valor 0 ), pasando por una pertenencia parcial (valor entre 0 y 1 ) a la pertenencia completa (valor 1$)$.

En la teoría de las series difusas, la transición desde la no pertenencia a la pertenencia es gradual en vez de abrupta, como ocurre en las series no-difusas. La forma de la función de pertenencia depende del problema considerado y puede tomar una forma que varía desde una función analítica simple a relaciones complejas que son combinaciones de muchas funciones simples. Al mismo tiempo, no hay reglas exactas para elegir la forma exacta de la función de pertenencia; el procedimiento es altamente subjetivo y no formalizado, lo que constituye el principal inconveniente de este método.

Para los propósitos del algoritmo de clasificación automática de vehículos, P. Burnos seleccionó una forma triangular y trapezoidal para la función de pertenencia. Aplicando la lógica difusa con esta función de pertenencia al problema de la clasificación de los vehículos del tráfico pesado de las autopistas polacas, llegó a una tasa de acierto casi del $95 \%$.

\section{c) Regla del vecino más próximo}

En la regla del vecino más próximo, la decisión para clasificar una entrada $x$ en la clase $c_{i}$ depende solamente de una recogida de datos de entrenamiento correctamente clasificados y etiquetados.

Si se supone que $S_{m}=\left(x_{1}, x_{2}, \ldots ., x_{n}\right)$ es una serie de muestras de entrenamiento y que $x^{\prime} € S_{m}$ es la muestra de entrenamiento más próxima a una entrada $x$, entonces, la entrada $x$ es clasificada asignándole una etiqueta similar a $x^{\prime}$. No obstante, la regla del vecino más cercano es un procedimiento sub-óptimo, porque su empleo conduce a un error más grande que el mínimo posible, que es, el índice de Bayes.

La regla de los $\mathrm{k}$ vecinos más cercanos es una extensión de la regla del vecino más cercano. En este planteamiento, una entrada $x$ es clasificada asignándola la etiqueta más frecuentemente representada entre los $\mathrm{k}$ ejemplos más próximos. Esta técnica 
implica encontrar una hiperesfera alrededor del punto $x$ que contenga $k$ puntos $y$ entonces asignar $\mathrm{x}$ a la clase que tenga el mayor número de representantes dentro de la hiperesfera. La desventaja de la regla de los $\mathrm{k}$ vecinos más cercanos es que la estimación resultante no es una verdadera densidad de probabilidad. Para obtener una densidad de probabilidad verdadera, se requiere una probabilidad previa.

\section{d) Máquinas de soporte de vectores}

Las Máquinas de Soporte de Vectores (Support Vector Machines -SVM-) trazan el mapa de la entrada $x$ en un espacio de características de muchas dimensiones a través de un cálculo no lineal escogido a priori. En este espacio, se construye un hiperplano de separación óptima. Si los datos de entrenamiento son separables linealmente, un hiperplano óptimo separa los datos sin error y la distancia entre el hiperplano y el punto de entrenamiento más cercano es máxima.

La mayor limitación de la máquina de soporte de vectores están en la elección del núcleo para el entrenamiento del algoritmo. Dado que el núcleo es la gran alfombra bajo la cual se arrastran los parámetros, se requiere un conocimiento previo para escoger la mejor función para un problema dado.

La velocidad, el tamaño y el diseño estructural general para las máquinas de soporte de vectores multi-clases también plantean limitaciones adicionales que desaniman el empleo de SVMs incluso con problemas moderados de clasificación.

\subsection{Revisión de trabajos e investigaciones dirigidos a estimar las cargas transportadas por los vehículos pesados}

Hasta fechas muy recientes no se han publicado trabajos dirigidos a estimar, de forma más o menos automatizada, las cargas transportadas por los vehículos pesados, probablemente porque se pensaba que era un objetivo muy difícil de lograr con una cierta precisión, ya que requiere una clasificación detallada de los vehículos, que debe de realizarse también automáticamente, y una determinación bastante exacta de los pesos de los vehículos, lo cual no se ha logrado hasta el perfeccionamiento y sistematización de la técnica del pesaje dinámico. Por otro lado, la primera aplicación de los sistemas de pesaje dinámico ha sido obtener las cargas que soportan los firmes de las carreteras, para lo que solamente es necesario conocer el peso bruto total de los vehículos y los pesos de cada uno de sus ejes, mientras que la determinación del peso de la carga transportada exige un estudio y una elaboración adicionales.

Una primera aproximación al estudio de las cargas transportadas por los vehículos a partir de los datos proporcionados por los sistemas de pesaje dinámico hay que buscarla en los gráficos de las distribuciones de frecuencias (normalmente representados en forma de histogramas) de los distintos intervalos de peso de los vehículos y de los ejes. Es importante señalar que estos estudios no tenían como 
objetivo principal el estudiar las cargas transportadas, sino que iban dirigidos a tratar de encontrar posibles regularidades o periodicidades en las distribuciones de los pesos de vehículos y ejes, como medio para poder detectar cualquier error o deriva de los datos suministrados por los sistemas de pesaje dinámico instalados y funcionando durante largos periodos en la carretera, donde pueden surgir numerosos problemas de descalibración de los equipos. Es decir, el objetivo de estos estudios era garantizar la calidad de los datos recogidos por los sistemas de pesaje dinámico.

Así, al observar la forma de estas distribuciones de frecuencias de pesos de cada clase de vehículos, se pudo observar que existen dos máximos (modas) de frecuencias [35] [36]: uno situado cerca de los pesos en vacío de cada tipo de vehículo y el otro localizado en las inmediaciones del peso máximo admitido para cada clase de vehículo. Este tipo de distribución bimodal también se puede ver en las distribuciones de frecuencias de los pesos de cada tipo de eje (simples, tándem, tridem). Todo lo anterior parecía indicar que la distribución de las frecuencias de los pesos de cada tipo de vehículo (o de cada eje) se podía dividir en una distribución correspondiente a los vehículos que circulaban en vacío y otra distribución correspondiente a los vehículos que circulaban cargados.

Este tipo de distribuciones de frecuencia de los pesos de los vehículos se han tratado de ajustar a diferentes distribuciones estadísticas (distribuciones beta, normal y lognormal [36]) con objeto de aprovecharse de las propiedades de estas distribuciones y poder efectuar correcciones (o más bien recalibraciones) de los datos a partir de unos pocos resultados fiables obtenidos con ensayos con vehículos de peso conocido.

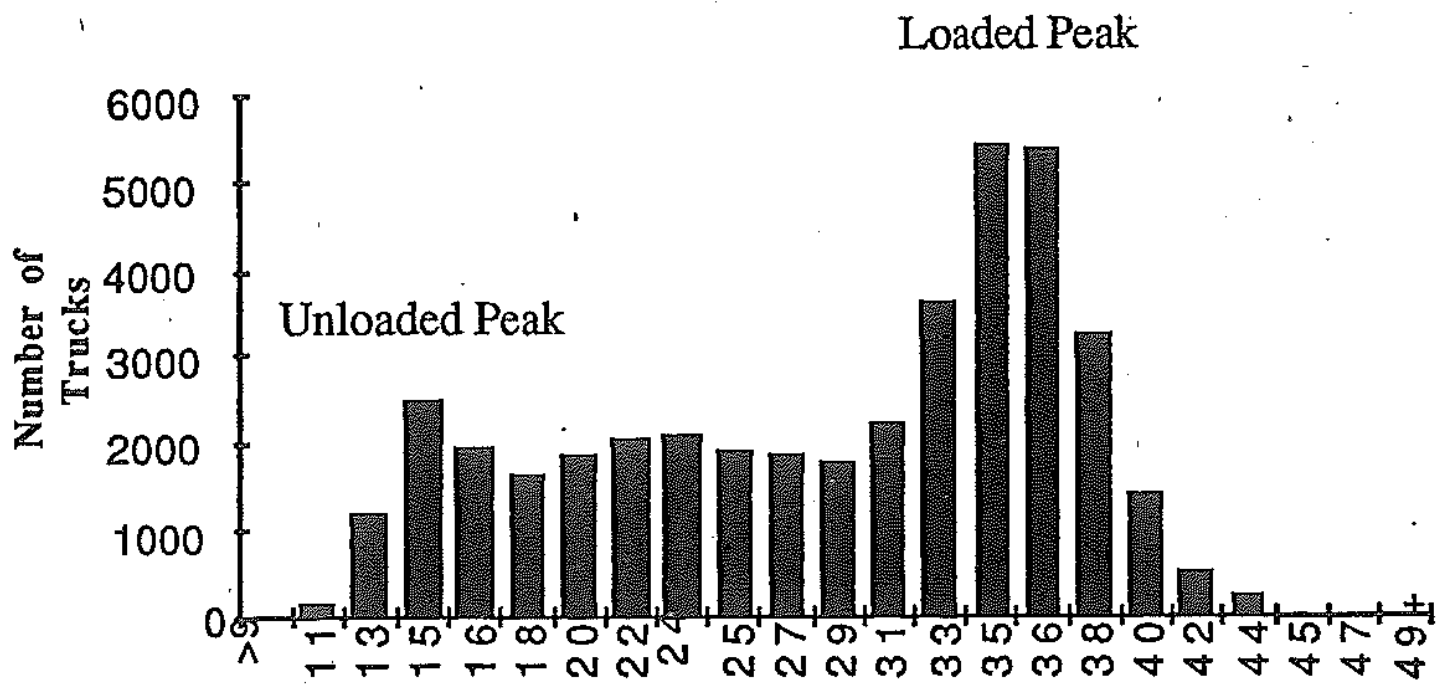

Gross Vehicle Weight (Metric Tons - Converted from

Figura 11. Distribución de frecuencias de los pesos de los vehículos articulados de 5 ejes (tipo 3S2) en las carreteras interestatales de Estados Unidos. Fuente: [35]

En Estados Unidos, las distribuciones de frecuencia de pesos de los vehículos de la clase 9 de la FHWA (tipo 3S2 -articulado de 5 ejes con cabeza tractora de 3 ejes y 
semirremolque con dos ejes, que forman un tándem-) muestran (véase la Figura 11) que el pico correspondiente a los vehículos vacíos tiene lugar entre las 12,7 y las $14,5 \mathrm{t}$, mientras que el pico de frecuencia correspondiente a los vehículos cargados tiene lugar un poco por debajo del límite legal de peso para esa clase de vehículos, que son 36,4 t (80.000 libras). La posición de estos valores máximos es muy fija (tanto, que se puede utilizar para determinar si el sistema de pesaje está funcionando adecuadamente o está bien calibrado), pues muy pocos camiones van a circular con cargas muy pequeñas, porque es antieconómico. Normalmente, se mantiene también la carga media transportada por tipo de vehículo, aunque el mismo autor cita unos ejemplos de casos en que puede variar esta carga media [37], como son un cambio en el tipo de mercancías transportadas (lo que suele ocurrir en zonas agrícolas en las épocas de recolección) o una reducción temporal en el límite de peso legal debido a la presencia de obras o a los periodos de hielo/deshielo en las carreteras de ese país.

Por otro lado, en el estudio llevado a cabo en Estados Unidos era menos importante la altura de estos máximos (es decir, la frecuencia relativa correspondiente) a efectos de calibración de los equipos (pero no a efectos de conocer la carga transportada, que es el caso de esta Tesis), debido a su variabilidad, ya que esta frecuencia puede cambiar notablemente con las condiciones del ciclo económico del país, que afectan al índice de camiones cargados en relación con los descargados.

Hay que señalar que estas distribuciones bimodales son más patentes en unas clases de vehículos y de ejes que en otras. Así, se puede ver muy claramente en la distribución de los pesos de los vehículos articulados de 5 ejes, los más utilizados en Europa y en España para el transporte de largo recorrido, así como en la distribución de los pesos de los ejes tándem (véase la Figura 12) y trídem, que casi siempre están situados en la parte trasera de los semirremolques a los cuales les afecta en mucha mayor medida el peso de la carga del vehículo.

\section{Lang Vehicles - Tandem Axles}

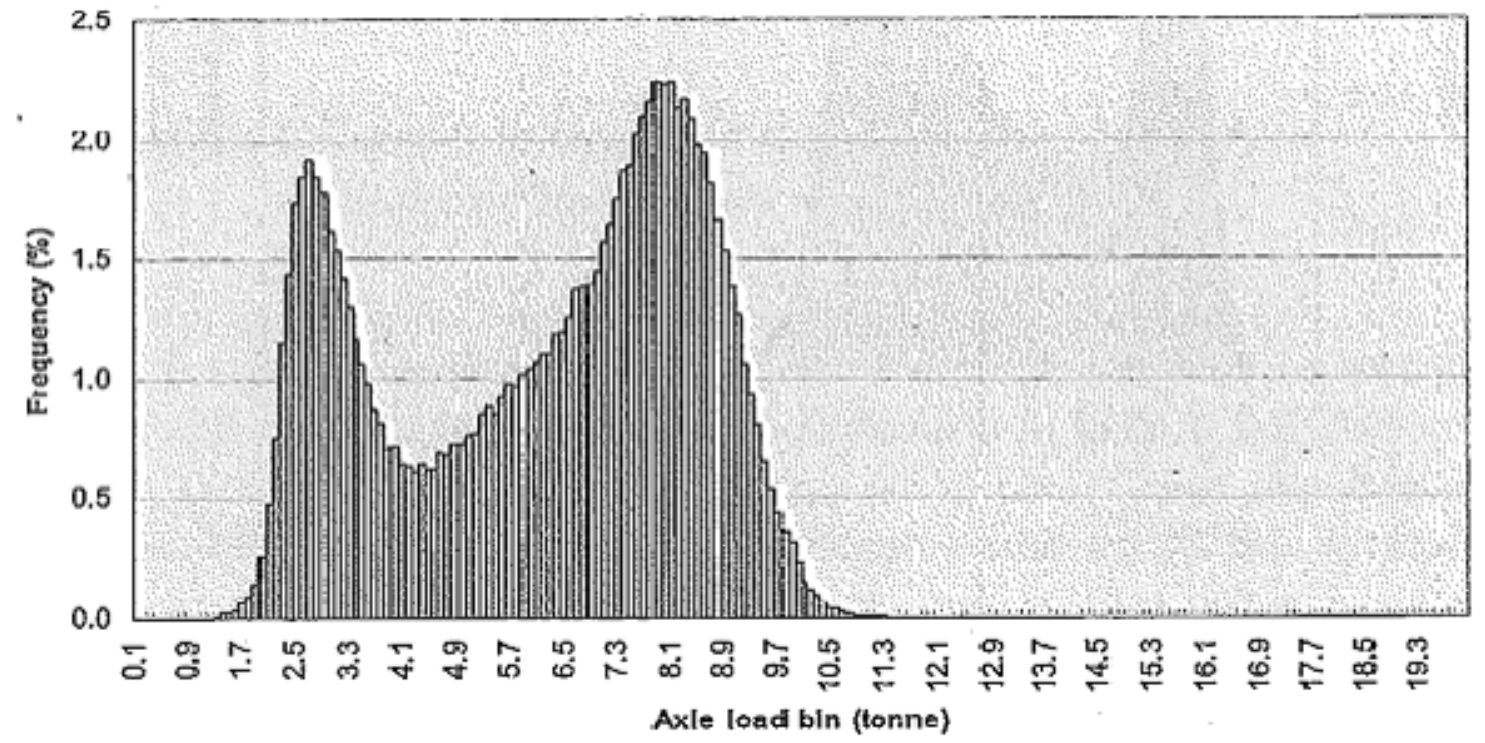

Figura 12. Distribución de frecuencias de los pesos de los ejes tándem de los vehículos articulados en las carreteras nacionales de Sudáfrica. Fuente: [36] 
Sin embargo, es más difícil de apreciar la bimodalidad de la distribución de pesos en los vehículos rígidos de 2 ejes, debido en primer lugar a que dentro de esta categoría de vehículos, existen camiones de tamaño muy diferente con un amplio rango de taras, mezclándose en la distribución los pesos en vacío de los camiones de dos ejes más grandes con los pesos a plena carga de los camiones de dos ejes más pequeños. También es más difícil de observar esta bimodalidad en la distribución de los pesos de los ejes simples, pues muchos de estos ejes corresponden a los ejes delanteros direccionales de los vehículos, a los cuales les afecta menos el peso de la carga, por lo cual el máximo correspondiente al peso en vacío de este tipo de ejes es muy acusado $y$, como el peso de la carga transportada que se apoya en estos ejes es menor, el máximo de frecuencia de los ejes simples cargados está muy cerca del máximo correspondiente al peso en vacío.

Por tanto, las distribuciones reales de frecuencias de los pesos de cada clase de vehículos y tipo de ejes son una composición de las distribuciones de los vehículos que circulan vacíos o casi vacíos con la de los vehículos que circulan cargados. No obstante, esto no debe entenderse como que los vehículos circulan totalmente vacíos o totalmente cargados [38], sino que se dan también las situaciones intermedias de vehículos circulando a media carga (por ejemplo, a veces esta media carga puede ser en peso, pero el vehículo puede ir completamente lleno de carga en volumen), aunque como se puede observar al ver las distribuciones de frecuencia de pesos, la probabilidad de encontrar a un vehículo medio cargado es menor que la de que vaya vacío o a plena carga.

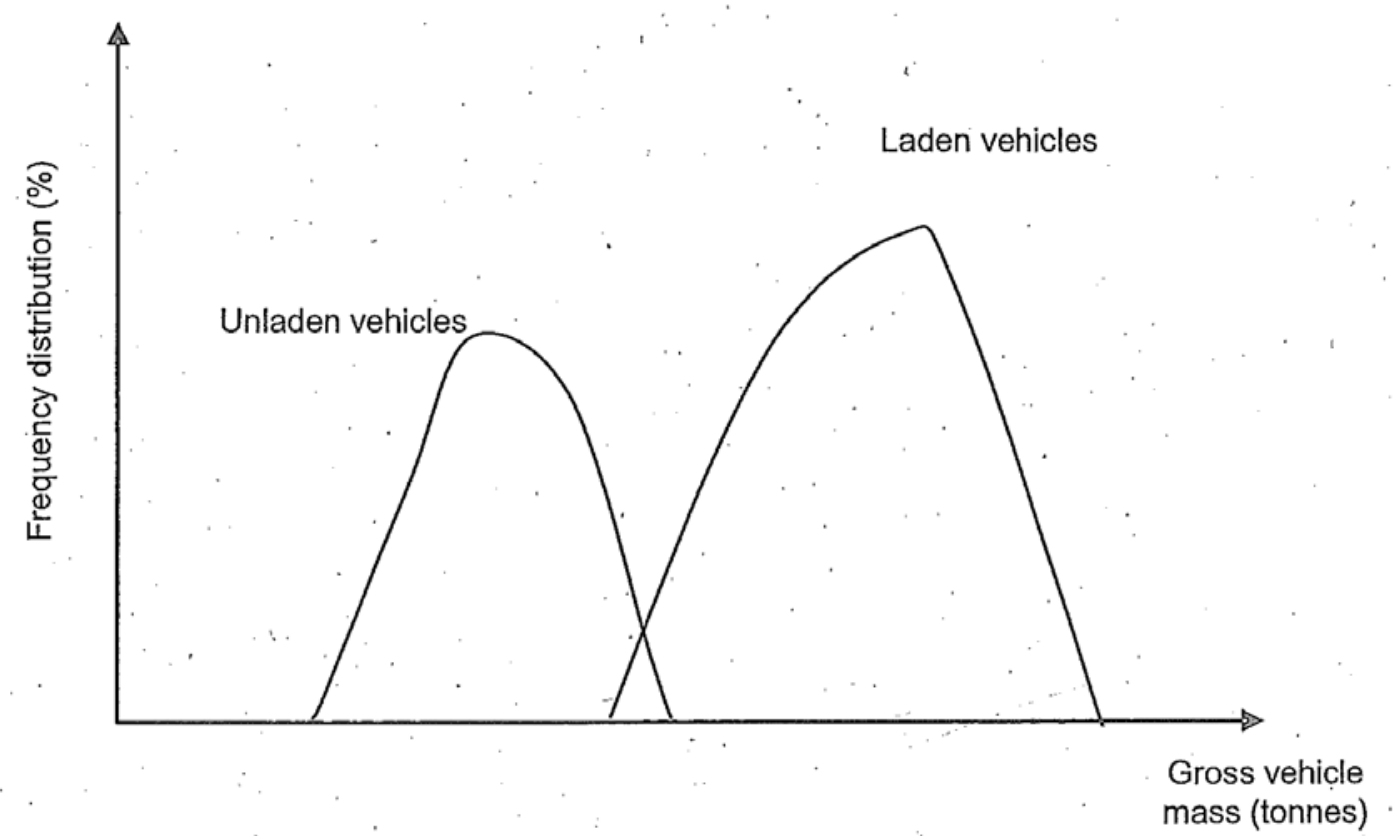

Figura 13. Imagen esquemática de las distribuciones de peso de los vehículos que circulan cargados y de los vehículos que van vacíos. Fuente: [38]

Debido a esta circunstancia, muchas veces es difícil distinguir cuándo van los vehículos "algo cargados" o "más bien vacíos" en los análisis de las distribuciones de frecuencias 
de los pesos, por lo que las administraciones de carreteras o de transportes decidieron establecer un valor umbral o límite [38] (por ejemplo, en Estados Unidos es conocido como "break point" o punto de rotura o de inflexión), por debajo del cual los vehículos de una clase determinada son tratados como "descargados" o "vacíos", mientras que los vehículos cuyo peso supera este valor umbral son tratados como "cargados". Así, algunas administraciones establecieron el término "nivel de descarga" como el porcentaje de vehículos que serían tratados como descargados, por tener un peso por debajo de un cierto umbral de carga. Este porcentaje es también al área por debajo de un cierto umbral en la distribución de frecuencias de los pesos brutos de una cierta clase de vehículos. Este umbral no es algo fijo, sino que se establece más o menos arbitrariamente, dependiendo del estudio y su aplicación.

Un siguiente paso ya dirigido específicamente a estimar las cargas transportadas por los vehículos según circulaban en la carretera fue el ya mencionado intento realizado por el CEDEX con ocasión de la última campaña de pesaje dinámico realizada en la red de carreteras del Estado, por encargo de la Subdirección General de Planificación de la Dirección General de Carreteras del Ministerio de Fomento. En este trabajo, el CEDEX desarrolló un procedimiento semiautomático para calcular la carga transportada por los camiones en la muestra visual que se tomaba durante 6 horas en cada emplazamiento de instalación de los equipos de pesaje en movimiento, según fue explicado en una ponencia [39] presentada en la Conferencia sobre el Pesaje en Movimiento celebrada en París en mayo de 2008.

Este procedimiento consistía primeramente en tomar visualmente, mediante observadores entrenados, la tara y la masa máxima admitida (MMA) de muchos de los camiones (leyendo la información que figuraba al respecto en una chapa colocada en el lateral en la cabina) que pasaban sobre el sistema de pesaje dinámico, anotando al mismo tiempo la hora exacta (incluyendo minutos y segundos) de paso de cada camión muestreado, con objeto de poder identificarlo en el listado de salida del equipo y así poder obtener su peso bruto total. Luego, se obtenía en gabinete la carga transportada por cada vehículo restando la tara del peso total del vehículo. Además, también se obtenía la capacidad total de carga de cada camión restando la MMA menos la tara. EI objeto era comparar la carga transportada estimada con la capacidad total de carga, para determinar el estado de carga (mediante el cociente de la carga transportada entre la capacidad total de carga) con la que circulaba cada vehículo.

Los principales datos obtenidos sobre una muestra de más de 27.000 camiones se muestran en la Tabla 10. El resultado obtenido más importante fue que la carga media transportada por los vehículos articulados (formados por cabeza tractora + semirremolque) era mayor que la carga media transportada por los trenes de carretera (formados por un camión rígido + remolque) a pesar de la mayor capacidad de carga de estos últimos, lo que indica que estos vehículos tienden a transportar cargas de mayor volumen pero de menos peso. 
Tabla 10. Principales resultados, incluyendo la carga media transportada por cada clase de vehículo, obtenidos con el procedimiento semiautomático establecido en 2000-2003 por el CEDEX

\begin{tabular}{|l|c|c|c|c|c|}
\hline Tipo de Vehículo & $\begin{array}{l}\text { No de } \\
\text { vehículos } \\
\text { (muestra } \\
\text { visual) }\end{array}$ & $\begin{array}{c}\text { Peso } \\
\text { bruto } \\
\text { medio } \\
\text { (t) }\end{array}$ & $\begin{array}{c}\text { Desviación } \\
\text { típica (\%) }\end{array}$ & $\begin{array}{c}\text { Carga media } \\
\text { transportada } \\
\text { (t) }\end{array}$ & $\begin{array}{l}\text { Desviación } \\
\text { típica (\%) }\end{array}$ \\
\hline Vehículos rígidos & 8.400 & 14,6 & 8,66 & 6,5 & 6,54 \\
\hline $\begin{array}{l}\text { Vehículos } \\
\text { articulados }\end{array}$ & 17.785 & 31,6 & 10,63 & 16,9 & 10,73 \\
\hline $\begin{array}{l}\text { Trenes de } \\
\text { carretera }\end{array}$ & 832 & 28,9 & 9,01 & 14,9 & 10,02 \\
\hline
\end{tabular}

Naturalmente, el principal inconveniente del método descrito de estimación de cargas llevado a cabo por el CEDEX en la campaña de pesaje 2000-2003 estribaba en que requería la utilización de personal para la observación y toma visual de los datos de tara y MMA de la chapa lateral de cada camión, por lo que su aplicación no podía ser continua ni generalizada a toda la red.

Pasando ahora a describir los pocos estudios que incluyen investigaciones para estimar las cargas transportadas, el primero de ellos es el elaborado F. Schmidt, B. Jacob y F. Domprobst [40], y presentado al 60 Congreso europeo TRA (Transport Research Arena), celebrado en abril de 2016 en Varsovia, en el que se mostraron los resultados de una investigación financiada por el fabricante francés de neumáticos Michelin, cuyo objetivo principal era conocer el reparto real de las cargas entre los distintos ejes y ruedas de los camiones en condiciones normales de uso (es decir, tanto cuando circulan en vacío, como a media carga y a plena carga), con objeto de optimizar el desgaste de los neumáticos. Este estudio ha sido realizado en Francia, basándose en los datos sobre más de 3 millones de vehículos pesados, suministrados por varias estaciones fijas de pesaje dinámico.

Para conseguir determinar los repartos reales de las cargas entre los distintos ejes en primer lugar se realizó una clasificación muy detallada de los camiones de acuerdo con su silueta, número de ejes y configuración de los ejes (simples, tándem y trídem) y de las ruedas en cada eje (sencillas normales, sencillas anchas o rudas gemelas), tratando de diferenciar entre los ejes direccionales, los ejes tractores y los demás ejes de un vehículo. Combinando los anteriores criterios, se consiguió clasificar a los vehículos en 19 categorías, tratando en el estudio de determinar las proporciones de cada tipo o categoría de vehículo en el tráfico de los distintos tipos de carreteras (autopistas, carreteras convencionales de 2 carriles) y de itinerarios (de tráfico nacional o internacional).

El siguiente paso fue determinar la distribución real de la carga transportada por los vehículos registrados por los equipos de pesaje dinámico de las estaciones escogidas en el estudio y localizar su centro de gravedad, con objeto de que el fabricante de neumáticos pudiera mejorar su conocimiento de las condiciones de carga de los 
camiones. Para ello, se siguió el siguiente procedimiento experimental:

1. Se identificó la población de camiones que circulaban vacíos, con objeto de determinar la tara de cada tipo de vehículos. Para ello, se consideró que circulaban vacíos el percentil del $5 \%$ del peso bruto registrado por el sistema de pesaje dinámico para los vehículos de cada categoría.

2. Se determinó la distribución por ejes del peso del camión para los que circulaban vacíos, calculándose el peso medio de cada eje según su orden de colocación en el camión (así, el eje más delantero es el primer eje, el siguiente será el segundo eje y así sucesivamente hasta el orden del eje situado más atrás)

3. Determinación de la distribución de la carga transportada en cada eje: para cada categoría de vehículo, se restaron las cargas por eje calculadas en el punto 2 (es decir, las cargas por eje en vacío) de las cargas por eje medidas de los camiones cargados.

4. Separación entre ejes: se calculó la distancia entre cada dos ejes según su orden de colocación en el vehículo para cada categoría de camión.

5. Localización del centro de gravedad de la carga transportada: con los resultados de las fases 3 y 4 , se calculó el centroide de la carga transportada repartida por ejes, añadiéndose la distancia (abscisa) del paragolpes delantero al primer eje para obtener la abscisa del centro de gravedad de la carga transportada.

Una vez calculados los datos anteriores, se obtuvieron los histogramas de frecuencias de las cargas transportadas por intervalos de carga para cada categoría de camión. Así, tal como se ha comentado antes, se encontró que la distribución de frecuencias de la carga transportada para los camiones rígidos de 2 ejes era prácticamente monomodal (o con 2 modas muy cercanas entre las $2 t$ y las $5 \mathrm{t}$ ), con una cola larga hacia las cargas mayores, mientras que en los vehículos articulados de 5 ejes (la categoría de camiones más común en Europa para el transporte de largo recorrido) la distribución de frecuencias de las cargas era claramente bimodal, tal como se ha dicho antes, con uno de los picos (modas) correspondiente a los vehículos que circulan vacíos, mientras que el otro pico de las cargas transportadas aparece sobre las $26 \mathrm{t}$ (para los vehículos a plena carga), a la que si se añaden las 14 t de peso en vacío (tara) de este tipo de vehículo, dan un peso bruto total muy cercano al límite legal (40 t). Estos resultados confirman los obtenidos en estudios realizados al respecto en los diferentes países (incluido España).

Una de las cuestiones que se trataba de averiguar era si los camiones circulan llenos por el volumen de carga o por el peso bruto máximo. De las distribuciones anteriores se pudo deducir que los camiones rígidos de 2 ejes circulaban prácticamente llenos en volumen antes de alcanzar su peso máximo admitido (las modas de la carga transportada eran 2 t y $5 \mathrm{t}$ ), mientras que los articulados de 5 ejes circulaban a plena carga por su peso máximo. Se confirmó asimismo que alrededor del $20 \%$ de los vehículos medidos circulaban a plena carga. 
El otro trabajo importante a este respecto ha sido el publicado recientemente por S. Hernandez [41] de la Universidad de Arkansas, y presentado en enero de 2017 en la Reunión Anual del TRB, en el cual se trata de desarrollar un método para obtener las cargas transportadas, que no dependa, al menos de forma directa, de encuestas a los camioneros, pues según se comenta en el estudio, cuesta mantenerlas actualizadas y además se considera que son poco representativas. El objetivo de obtener estas cargas transportadas por los camiones es mejorar los factores de conversión de los cifras de camiones a las de toneladas, que son unos datos de entrada críticos para los modelos de previsión de transporte de los distintos tipos de mercancías.

Así, en la citada investigación se comenta que los modelos de previsión de transporte de mercancías que vienen definidos en el sistema de análisis del transporte de mercancías (FAF -Freight Analysis Framework-) de Estados Unidos se basan fundamentalmente en una encuesta realizada a nivel nacional sobre los tipos de vehículos de transporte existentes y su utilización, conocida como "Vehicle Inventory and Use Survey (VIUS)", similar a la Encuesta Permanente del Transporte de Mercancías por Carretera en España. En la encuesta VIUS se definen unas cargas medias específicas para cada mercancía, y constituye la única combinación existente de fuentes de datos sobre el peso de los camiones, su configuración, los vehículos-km recorridos y los datos de mercancías. En consecuencia, los grados de utilización de cada vehículo se basan únicamente en unos factores de conversión de vehículos (camiones) a toneladas transportadas, que son específicos para cada mercancía, configuración del vehículo (en cuanto a número de ejes y separación entre estos) y tipo de chasis del vehículo.

Para superar, la dependencia de los datos de esta encuesta, se postula en la citada ponencia que los medios tecnológicos y metodológicos que se han ido desarrollando en los últimos años permiten medir las configuraciones de los camiones, los tipos de mercancía y los pesos, lo que permite ser una alternativa viable a las encuestas. Los nuevos métodos varían desde la implantación de tecnologías de sensores avanzados en los emplazamientos de pesaje dinámico a nuevos procedimientos matemáticos basados en los datos usuales de los pesajes dinámicos.

El método que se propone en este documento consiste en obtener las cargas transportadas por cada tipo de camión y de chasis (caja cerrada, frigorífico, plataforma, cisterna, etc) restando un peso en vacío estimado de un peso total medio también estimado. Tanto el peso en vacío como el peso cargado se obtienen a partir de un modelo de ajuste de tipo gaussiano que se ajusta a la distribución de frecuencias de pesos de cada tipo de camión, que como se ha comentado, para cada tipo de camión es de tipo bimodal (con un pico de frecuencias correspondiendo a los camiones que circulan vacíos y el otro es cercano al peso máximo admitido para ese tipo de vehículo, y corresponde a los camiones que circulan cargados).

En el artículo se expone en detalle el análisis para los camiones pertenecientes al tipo más típico utilizado en Estados Unidos, que es el articulado de 5 ejes con cabeza tractora de tres ejes y semirremolque de dos ejes (también conocido como 3-S2), formando un tándem en la parte trasera y que corresponde a la Clase 9 del esquema "F" de la FHWA. Este camión es algo diferente al más típico utilizado en España y 
Europa en general, que es también el articulado de 5 ejes, pero en el caso europeo éste dispone de una cabeza tractora de 2 ejes solamente y un eje trídem en la parte trasera del semirremolque. En el estudio se incluye el reparto entre los distintos tipos de configuración de chasis (caja) del vehículo (que definen el tipo de mercancía transportada), los pesos en vacío y a plena carga, así como los pesos resultantes de las cargas transportadas.

Para realizar esta estimación de carga transportada por cada tipo de vehículo y configuración de chasis, previamente se debe obtener una clasificación muy detallada de los camiones según estos dos parámetros. Aunque esta clasificación de los vehículos se obtiene a partir de los pesajes dinámicos, no proviene exclusivamente de los datos típicos suministrados por este tipo de sistemas (los pesos y las distancias entre ejes, ambos obtenidos por los sensores de peso), sino que además se utiliza la función avanzada de los sistemas de lazos de inducción presentes en los equipos de pesaje dinámico que se ha explicado en el Apartado 4.3.6.1, que permite obtener lo que se llama "huella" o "firma" (signature) de lazo correspondiente a cada tipo de vehículo, que puede correlacionarse con el tipo de chasis del vehículo, posibilitando una clasificación mejorada y algo más precisa.

Por otro lado, en este estudio para calcular las cargas transportadas a partir de los datos de pesos medidos, debe restarse el peso del camión descargado del peso del camión cargado. Mientras que el peso cargado (normalmente el peso bruto del vehículo) puede obtenerse de las básculas dinámicas, se comenta que es más difícil determinar el peso descargado. En teoría esto podría determinarse si se conociera la marca, modelo y año de fabricación de cada camión que pasa sobre el emplazamiento de pesaje, pero esto no es practicable. En lugar de esto, se comenta que podrían utilizarse existen unos llamados "break-points" estáticos o puntos umbral o de inflexión utilizados en la encuesta del Sistema de Información de los Viajes de los Vehículos ( TRIS -Vehicle Travel Information System-) de la FHWA, para determinar si un camión está vacío o cargado, aunque existe el inconveniente de que estos puntos de inflexión estáticos no tienen en cuenta la variación geográfica de las configuraciones de los camiones o de las mercancías transportadas.

En vista de esta situación, se menciona que, como solución alternativa, los métodos han desarrollado una representación de las distribuciones de frecuencias de los pesos brutos de los vehículos como mezcla de dos o tres distribuciones normales de frecuencias, en las que cada distribución representa una clase de carga específica: la distribución inferior representa los camiones vacíos, la distribución media representa los camiones parcialmente cargados y la distribución superior representa los camiones cargados.

En resumen, en el artículo se presentan dos mejoras a la estimación de los factores de conversión de camión a toneladas (TEFs), ambos basados en la inclusión de los datos de los pesos medidos en el procedimiento de estimación. Primeramente, las proporciones de cada tipo de chasis de vehículo medidos dentro de cada grupo (tipo) de vehículo, estimadas según el procedimiento de medir la huella inductiva de lazo. En segundo lugar, un procedimiento para extraer las cargas transportadas de las distribuciones de los pesos brutos medidos por cada tipo de chasis, aunque en la 
ponencia solo se desarrolla esto para los vehículos articulados de 5 ejes. Con respecto a la carga transportada, ésta fue calculada restando el peso en vacío de cada tipo de vehículo (desglosado cada tipo en subtipos según el tipo de chasis, es decir, no se utiliza únicamente el peso global del tipo) del peso en carga estimado.

Como resultado de todo el procedimiento, se ha obtenido primeramente que las cargas transportadas registradas con los pesajes dinámicos son algo menores que las obtenidas en las encuesta del VIUS. Con respecto a este resultado, es necesario señalar que va en sentido contrario al que se obtuvo en España, en la Red de Carreteras del Estado, al llevar a cabo el método semi-automático de estimación de las cargas transportadas en la última campaña de pesaje dinámico realizada por el CEDEX, en la que se obtuvo que las cargas transportadas obtenidas de los pesaje eran apreciablemente más altas que las declaradas por los camioneros en la Encuesta Permanente del Transporte de Mercancías por Carretera.

Así, en primer lugar, se ha visto en Estados Unidos que los pesos de los vehículos cargados en las encuestas VIUS (con respuestas corregidas de alguna forma) indicaban que el peso medio cargado era de 80.000 libras (36.240 kg), el límite de carga para esa clase de vehículos, lo que se daba en un $34 \%$ de las muestras, mientras que los pesos medidos con el sistema WIM se ajustaban a una distribución normal centrada cerca de las 70.400 libras (31.900 kg) con un pequeño pico cerca en las 80.000 libras. Además, se comprobó que había una alta variabilidad de los pesos según el tipo de mercancía al que estaba dedicado el vehículo (por ejemplo, los camiones de transporte de vehículos tuvieron unas distribuciones de pesos diferentes, de tipo trimodal), lo que indica que si se hace el cálculo para un tipo de vehículo sin tener en cuenta las diferencias en la mercancía puede resultar en unas estimaciones algo sesgadas de la carga transportada.

En segundo lugar, en este método resultó más problemática la determinación de los pesos en vacío. Para calcular estos pesos en vacío, se les hizo corresponder con el valor medio de la distribución normal de la cola más baja de la distribución de frecuencias de los pesos brutos de la clase de vehículo. Con la excepción de los camiones dedicados al transporte de troncos, los pesos en vacío medidos resultaron sistemáticamente mayores que los que muestra la encuesta VIUS. Sin embargo, para todas las series de datos, los pesos medios en vacío cayeron por debajo del punto umbral (o de rotura) en la encuesta VTRIS (Vehicle Travel Information System) definido en las 37.500 libras (unos $17.000 \mathrm{~kg}$ aproximadamente) para los camiones de 5 ejes vacíos.

Tras determinar la carga transportada restando del peso suministrado para cada vehículo su correspondiente peso en vacío según el subtipo de vehículo y chasis que corresponda, se calcularon los errores en el valor de esta carga transportada, como la suma de las varianzas de las distribuciones normales representando los camiones vacíos y cargados. Las cargas transportadas que fueron estimadas de los datos de pesos medidos por el sistema WIM fueron sistemáticamente menores que las obtenidas de la encuesta VIUS, con la excepción de los camiones de transporte de troncos. Este resultado se debe a que los pesos de los camiones cargados obtenidos de los pesajes fueron generalmente menores que los de la encuesta VIUS, mientras que 
las estimaciones de los pesos en vacío fueron más altas que los de la encuesta VIUS, con lo cual la diferencia entre ambos términos fue menor. 


\section{Desarrollo de los procedimientos de estimación automática}

\subsection{Desarrollo de un procedimiento automático de clasificación de vehículos mediante pesaje dinámico}

\subsubsection{Consideraciones generales}

La clasificación detallada o silueta del tráfico es uno de los datos más importantes que pueden ser obtenidos en cualquier estudio de la circulación, que se puede utilizar para el planeamiento, proyecto, conservación y explotación viaria.

Normalmente cada país recoge y analiza los datos de clasificación de vehículos basándose en unas pautas propias, pues las características de los vehículos pueden diferir de un país a otro, ya que los tipos y modelos de camiones utilizados se ven muy influidos tanto por las actividades económicas (algunos tipos de camiones están diseñados para transportar cargas que son muy específicas para cada país) como por las limitaciones de pesos y dimensiones que imponen los diferentes Estados.

Para obtener la composición detallada del tráfico (silueta), se ha contado con un equipo de pesaje dinámico de tipo capacitivo, que ha sido descrito en el apartado 4.2.4, y que es el mismo con el que se realizó la campaña de pesajes dinámicos en la Red de Carreteras del Estado entre 2000 y 2003. Al igual que otros equipos de pesaje dinámico, éste lleva incorporado un programa para obtener una composición detallada del tráfico, que es la del esquema " $F$ " de la FHWA. No obstante, como los tipos de vehículos existentes en España difieren apreciablemente de los del esquema " $\mathrm{F}$ " de la FHWA, en ningún momento de su vida operativa se planteó el realizar la adaptación de los parámetros de clasificación a los de los vehículos pesados presentes en las carreteras españolas.

Por tanto, como el objetivo de este trabajo es implantar un procedimiento de clasificación adaptado a las condiciones de los vehículos de nuestro país (y de Europa, en general), y por otro lado, como se pretende desarrollar es una clasificación que no esté basada en el número de ejes apoyados en el pavimento como principal parámetro de diferenciación, sino que con vistas a la determinación de la carga transportada interesa conocer cuál es el verdadero tipo de vehículo más probable en cada caso (aunque circule con ejes elevados del pavimento), se ha optado por desarrollar un procedimiento totalmente nuevo de clasificación en lugar de adaptar uno existente.

A continuación, se va a entrar en el procedimiento experimental que se ha seguido para establecer un nuevo sistema de clasificación detallada de vehículos aplicado a las carreteras españolas. Para ello, se empieza explicando la metodología específica de toma de datos y análisis de estos que se ha llevado a cabo. Seguidamente se muestra el esquema de clasificación que se pretende desarrollar, exponiendo el procedimiento para realizar la clasificación de los vehículos según este esquema y se muestra en detalle las reglas, condiciones y umbrales de diferenciación/clasificación de los vehículos a los que se ha llegado. 
Por último, se analizará en detalle el procedimiento que se ha seguido para tratar de distinguir entre los vehículos de algunas de las clases cuya diferenciación plantea más problemas, debido a la similitud en ambas clases de los valores de los parámetros utilizados en la clasificación, como ocurre, por ejemplo, en la diferenciación entre los camiones de 2 ejes y los autobuses del mismo número de ejes.

\subsubsection{Procedimiento experimental específico utilizado para obtener la silueta del tráfico}

Teniendo en cuenta, por un lado, las anteriores premisas y, por otro, el procedimiento general utilizado en otros países para obtener una silueta del tráfico que se ha comentado, se ha seguido el siguiente proceso experimental para obtener la silueta del tráfico vehicular de las carreteras españolas:

1. Considerar como datos de partida los de los pesajes obtenidos en la campaña 2000-2003, que como se ha dicho incluyen, además de los pesos, el número de ejes, las distancias entre ejes y la longitud de cada vehículo registrado en la campaña. Hay que señalar que es necesario considerar esta muestra de datos, a pesar de su antigüedad, porque para obtener información sobre las características de los vehículos menos frecuentes que permitan realizar la clasificación se requiere una muestra de un tamaño muy grande, en la cual exista un número apreciable de vehículos de cada clase, incluidas las menos frecuentes, lo que no es posible lograr con un par de tomas de datos reales en la carretera, como las efectuadas para realizar esta Tesis.

2. Realizar una primera toma de datos actuales, para adaptar los límites de diferenciación entre las distintas clases a las condiciones de los vehículos actuales que componen el tráfico. Esta toma de datos se realizó en noviembre de 2014, durante 3 días, en la A-1, pk 41 a la altura de El Molar (Madrid).

3. Analizar los datos obtenidos en El Molar para fijar las condiciones de separación entre clases del sistema de clasificación propuesto. Una vez analizadas estas condiciones, se incorporan al esquema de clasificación y se comprueba el error que se cometería con este esquema actualizado en la clasificación de los vehículos del tráfico de esta misma estación.

4. Realizar una nueva toma y análisis de datos para comprobar en otro emplazamiento la exactitud del sistema de clasificación que se ha actualizado con las condiciones de El Molar. Esta nueva toma de datos se llevó a cabo en junio de 2015 en la A-2, pk 82, en Trijueque (Guadalajara).

\subsubsection{Metodología seguida para obtener la silueta del tráfico}

Tal como se ha comentado, al comienzo de la realización de este estudio se partía de los datos recogidos, tanto visualmente mediante operarios como automáticamente 
por el equipo de pesaje en movimiento en las 70 estaciones de la campaña de pesaje dinámico en la Red de Carreteras del Estado llevada a cabo entre 2000 y 2003.

Los datos tomados en la citada campaña incluían, por un lado, todas las típicas características recogidas automáticamente por el equipo de pesaje (longitud, número de ejes, distancia entre ejes, peso de cada uno de los ejes y peso total del vehículo). Pero lo importante de dicha campaña es que, simultáneamente a la toma de datos del equipo, se realizaba una toma de datos visual que permitía obtener otros datos (entre ellos la clasificación correcta de cada vehículo), que no podían ser captados de forma automática, pero que servían para afinar y/o comprobar la clasificación automática. Entre estos datos se encontraban los siguientes:

- la presencia de ejes levantados en un vehículo,

- el tipo y clase verdadero de cada vehículo,

- si los ejes llevaban ruedas sencillas o gemelas,

- la matrícula.

Teniendo en cuenta todos los datos tomados tanto automática como visualmente y considerando como parámetros de clasificación primarios el número de ejes del vehículo, su longitud, y la distancia entre cada dos ejes; y como parámetros de clasificación secundarios, su peso total y el peso de cada eje, se desarrolló un primer sistema de clasificación que, al estar basado en los datos tomados entre 2000 y 2003 , se refería naturalmente al tráfico de esa época.

En este primer procedimiento, para realizar la clasificación se atendió, por el orden que figura a continuación, a los siguientes parámetros:

1. Para diferenciar entre vehículos ligeros y pesados, se escogió como principal parámetro de diferenciación, la longitud de los vehículos, a pesar de que hacerlo basándose en el peso de los vehículos hubiera sido más exacto, para obtener una clasificación similar a la del Plan de Aforos de la Dirección General de carreteras del Ministerio de Fomento.

2. Para diferenciar entre las clases de vehículos pesados (rígidos, articulados o trenes de carretera), se utilizó preferentemente la longitud total de los vehículos.

3. Dentro de cada una de estas tres grandes clases, para distinguir entre unos tipos y otros se consideró:

Primeramente, el número de ejes registrados por el sistema de pesaje de cada vehículo.

- $\quad$ En segundo lugar, las distancias entre ejes individuales, para determinar su configuración en ejes múltiples o grupos de ejes (simples, tándem, trídem). 
Estos fueron los parámetros de clasificación utilizados para diferenciar a los vehículos en una "primera vuelta" o "ronda". Como tras realizar esta primera ronda, todavía existían problemas de diferenciación entre algunos tipos determinados, para realizar la clasificación total se realizó una segunda ronda atendiendo a los siguientes parámetros adicionales:

4. Las distancias entre ejes que no formaban parte del mismo eje múltiple (es decir, por ejemplo, la distancia entre el primer eje (el direccional), que suele ser simple, y el eje motriz, que puede ser simple o tándem), el peso total del vehículo y, por último, el peso de alguno de los ejes.

En el apartado 5.1 .6 se explican más detenidamente los valores concretos que se fijaron en los parámetros para diferenciar entre las clases de vehículos.

Para realizar la adaptación/actualización de la anterior clasificación así formada a las condiciones del tráfico actual, se decidió realizar una toma de datos en una estación con gran tráfico pesado, como es la situada en la A-1, pk 41 en El Molar. Una vez ejecutada la toma de datos a finales de noviembre de 2014, se analizó en gabinete la información obtenida, con vistas a actualizar los parámetros y umbrales de diferenciación de las distintas clases y tipos de vehículos.

Así, con los datos recogidos en El Molar se obtuvieron para cada una de los diferentes tipos de vehículos, unos valores máximos, mínimos y medios de los diferentes parámetros de clasificación (longitud, peso y separación entre ejes contiguos). Estos valores obtenidos aparecen reflejados en la Tabla 11.

Teniendo en cuenta los valores máximos y mínimos de los parámetros obtenidos para cada tipo de vehículo en El Molar, se modificó de acuerdo con ellos el esquema de clasificación antiguo desarrollado con los datos de la campaña 2000-2003, obteniéndose un nuevo esquema de clasificación, que puede considerarse definitivo y cuyas condiciones generales se expresan en las Tablas 13 (I, II, II, IV, V y VI) del apartado 5.1.4.

Como entre ciertas clases de vehículos muy parecidas entre sí existían algunos solapes en los parámetros de clasificación, que dificultaban la distinción entre los vehículos de una u otra clase, fue preciso llevar a cabo un estudio más detallado, que se muestra al final de este capítulo en el apartado 5.1.6. 
Tabla 11. Valores de los diferentes parámetros medidos en El Molar para cada tipo de vehículos

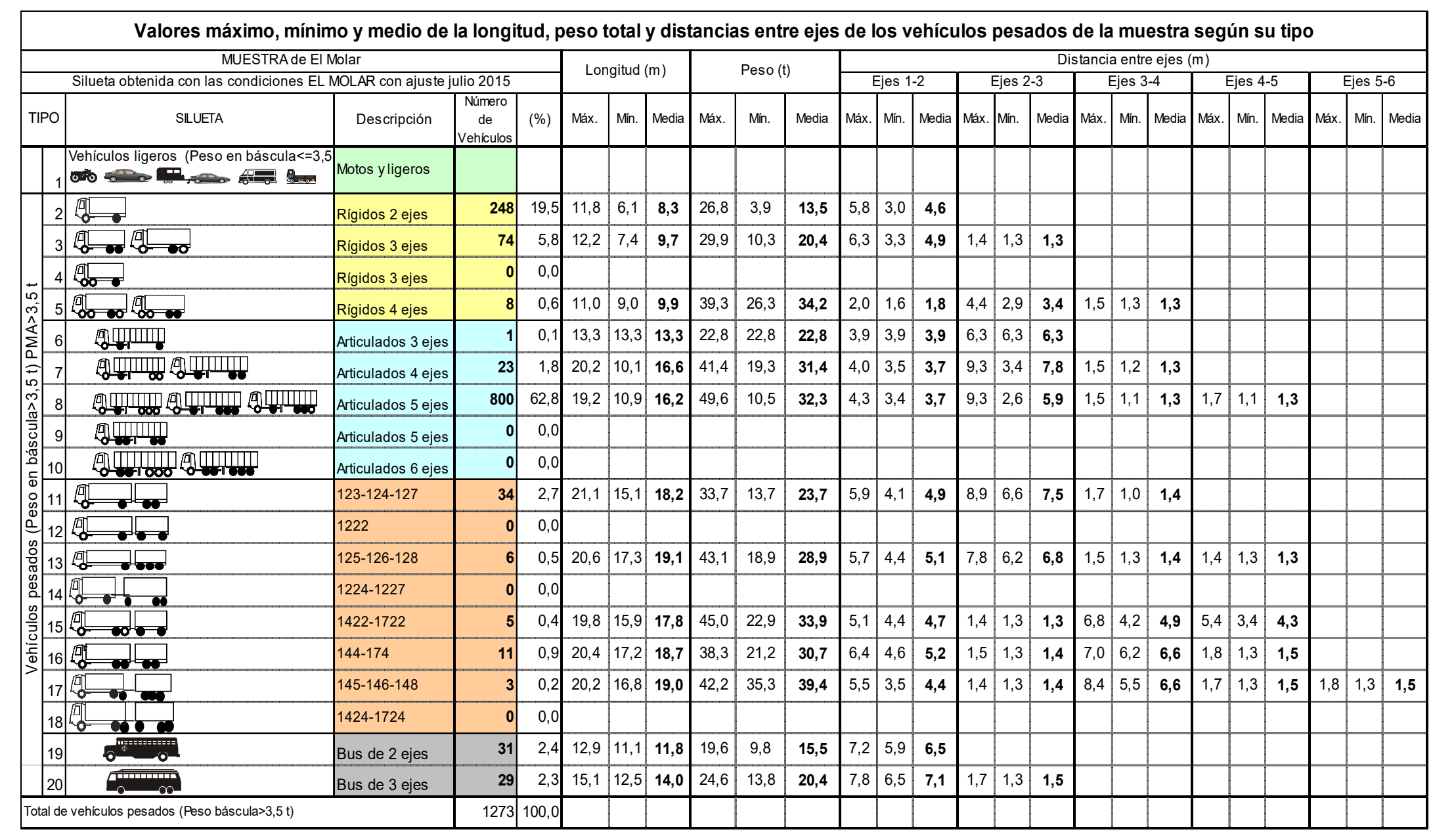




\subsubsection{Esquema de clasificación automática propuesto}

Teniendo en cuenta, por un lado, los esquemas de clasificación más utilizados en el ámbito internacional, así como los esquemas utilizados en los últimos años en España $y$, por otro lado, los datos que es posible obtener con los sistemas de pesaje en movimiento respecto de cada vehículo, se va proponer el sistema de clasificación automática que se especifica a continuación.

Como se ha comentado anteriormente, cuando se realiza una toma de datos de pesaje en un punto determinado de una carretera, de una duración dada, se obtiene un listado en ASCll con los datos registrados por el equipo, que se puede transformar en un archivo Excel, lo que permite su tratamiento. El paso siguiente consiste en programar en Excel las reglas que se deducen de las condiciones para cada clase de vehículos (en cuanto a longitud, número de ejes, distancias entre estos, peso total, etc), que aplicadas al listado de datos de los vehículos recogidos por el equipo, permitirán obtener la clase o tipo en el que queda encuadrado cada uno de ellos.

Llevando a cabo el procedimiento anteriormente expuesto, se ha intentado implantar y programar un esquema de clasificación de los vehículos del tráfico que contiene los siguientes tipos:

Vehículos ligeros:

- Turismos

- Derivados de turismo

- Coches con caravana

- Furgones ligeros

Vehículos pesados

1- Camiones rígidos de 2 ejes ( $R$ 12)

2- Camiones rígidos de tres ejes (con un eje tándem motriz trasero) ( $R 14$ y $R$ 17)

3- Camiones rígidos de tres ejes (con un eje tándem direccional delantero) ( $R$ 32)

4- Camiones rígidos de 4 ejes (R 34)

5- Vehículo articulado de 3 ejes (con 2 ejes en la cabeza tractora y 1 eje en el semirremolque) (S 122)

6- Vehículo articulado de 4 ejes (con 2 ejes en la cabeza tractora y 2 ejes en el semirremolque) (S 123 y S 124)

7- Vehículo articulado de 5 ejes (con 2 ejes en la cabeza tractora y 3 ejes en el semirremolque) (S 125, S 126 y S 128)

8- Vehículo articulado de 5 ejes (con 3 ejes en la cabeza tractora y 2 ejes en el semirremolque) (S 144)

9- Vehículo articulado de 6 ejes (con 3 ejes en la cabeza tractora y 3 ejes en el semirremolque) (S 145 y S 146) 
10-Tren de carretera de 4 ejes (con 2 ejes en el camión tractor y 2 ejes, que forman un eje tándem, en el remolque) ( $T$ 124)

11-Tren de carretera de 4 ejes (con 2 ejes en el camión tractor y 2 ejes simples en el remolque) ( $T$ 1222)

12-Tren de carretera de 5 ejes (con 2 ejes en el camión tractor y 3 ejes, que forman un eje trídem, en el remolque)(T 125 y T 126)

13-Tren de carretera de 5 ejes (con 2 ejes en el camión tractor y 3 ejes, uno simple y los otros dos formando un eje tándem, en el remolque) (T 1224)

14-Tren de carretera de 5 ejes (con 3 ejes en el camión tractor y 2 ejes simples en el remolque) (T 11422)

15-Tren de carretera de 5 ejes (con 3 ejes en el camión tractor y 2 ejes, que forman un eje tándem, en el remolque) (T 144)

16-Tren de carretera de 6 ejes (con 3 ejes en el camión tractor y 3 ejes, que forman un eje trídem, en el remolque) (T 145)

17-Tren de carretera de 6 ejes (con 3 ejes en el camión tractor y 3 ejes, uno de ellos simple y los otros dos formando un eje tándem, en el remolque) (T 1424)

\section{8-Autobuses de 2 ejes ( $A$ 12)}

19-Autobuses de 3 ejes (A 17).

Hay que señalar que, en el momento de emprenderse el estudio, se pretendía dividir los vehículos ligeros enumerados por tipos (ligeros, derivados de turismo, coches con caravana, furgones ligeros), pero tras examinar las características de estos vehículos se vio que iba a ser prácticamente imposible diferenciarlos entre sí, pues existe un solapamiento casi total entre las características de los turismos con las de los derivados de turismo, así como entre algunos turismos grandes con los furgones ligeros, por lo que se desechó la idea de realizar esta diferenciación.

Por otro lado, el objetivo de esta clasificación es obtener la composición del tráfico pesado para estimar las cargas transportadas, por lo que tiene más importancia centrarse en diferenciar los distintos tipos de vehículos pesados que transportan cargas de una cierta magnitud, siendo menos prioritario distinguir los diferentes tipos de vehículos que constituyen el tráfico ligero. No obstante, antes de la tabla de clasificación de vehículos pesados, se va a proporcionar una tabla de diferenciación de vehículos ligeros, pero se resalta que la exactitud de clasificación conseguida es mucho menor que la obtenida con los vehículos pesados.

En sentido contrario a lo que se acaba de decir para los vehículos ligeros, es importante poner de manifiesto que en cuanto a los trenes de carretera, podrían haberse programado fácilmente las condiciones para un mayor número de tipos, pero se ha escogido programar solamente los de los tipos que aparecen con una cierta frecuencia.

A continuación, en la Tabla 12 se expresan las condiciones de clasificación a las que se ha llegado para los vehículos ligeros y en las Tablas 13 (I, II, III, IV, V, VI) figuran las condiciones de clasificación para los vehículos pesados, que debido a que la influencia de este tráfico sobre la vida útil de los firmes viarios es más grande y a su relación 
directa con las actividades económicas de transporte, será la que se explique más en detalle.

Tabla 12 - Condiciones de clasificación de los vehículos ligeros

\begin{tabular}{|c|c|c|}
\hline Tipo & Denominación & Condiciones de clasificación \\
\hline 1 & Vehículo ligero & Longitud $\leq 6 \mathrm{~m}$ \\
\hline 2 & Vehículo pesado & Longitud $>6 \mathrm{~m}$ \\
\hline 3 & Derivado de turismo & $\begin{array}{l}\text { Peso primer eje } \leq 1,2 \mathrm{t} \\
\text { Peso segundo eje } \leq 1,2 \mathrm{t} \\
\text { Peso total vehículo } \leq 2,1 \mathrm{t} \\
\text { Distancia entre ejes } \leq 3 \mathrm{~m} \\
\text { Longitud } \leq 5 \mathrm{~m}\end{array}$ \\
\hline 4 & $\begin{array}{lll}\text { Caravanas } & \text { (coche } & + \\
\text { caravana) } & & \end{array}$ & $\begin{array}{l}\text { Peso total } \leq 3,5 \mathrm{t} \\
\text { Longitud }>6 \mathrm{~m} \\
\text { Distancia entre } 2 \text { ㅇ y } 3 \circ \text { eje }>0 \mathrm{~m} \text { (o sea, existe } \\
\text { un } 30 \text { eje) } \\
\text { Distancia } 4 \text { y } 5 \text { o eje } \leq 0 \mathrm{~m} \text { (o sea, no existe 5o } \\
\text { eje) }\end{array}$ \\
\hline 5 & Furgones ligeros & $\begin{array}{l}3,5 \mathrm{~m}<\text { Longitud }<7 \mathrm{~m} \\
\text { Distancia entre } 10 \text { y } 20 \text { ejes }>2,5 \mathrm{~m} \\
\text { Distancia entre } 2 \text { y } 30 \text { eje } \leq 0 \mathrm{~m} \text { (o sea, no existe } \\
\text { un } 30 \text { eje) } \\
\text { Peso total } \leq 3,5 \mathrm{t}\end{array}$ \\
\hline 6 & Furgones pesados & $\begin{array}{l}\text { Longitud }>6 \mathrm{~m} \\
\text { Peso total }>3,5 \mathrm{t} \\
\text { Distancia } 20 \text { y } 3 \circ \text { eje } \leq 0 \mathrm{~m} \text { (o sea, no existe un } \\
\text { 3o eje) }\end{array}$ \\
\hline
\end{tabular}

Como se puede ver en la Tabla 12, tal como se ha dicho, se ha considerado primeramente la división tradicional entre vehículos ligeros y pesados, clasificados solamente por la longitud, para poder comparar los resultados con los de la Dirección General de Carreteras en su Plan de Aforos.

A continuación, se han añadido otras cuatro clases: los vehículos derivados de turismo, que suelen estar dedicados al transporte, los turismos con caravana (de 1 ó 2 ejes) y los furgones ligeros (MMA $\leq 3,5 \mathrm{t}$ ) y pesados (MMA $>3,5 \mathrm{t}$ ). No obstante, dada la dificultad de poder diferenciar adecuadamente este tipo de vehículos, pues sus características son muy similares a la de muchos camiones pesados de 2 ejes, se decidió no tenerlos en cuenta separadamente, en el esquema global de clasificación que se ha desarrollado. 
Tabla 13 (I)- Condiciones de clasificación de los vehículos pesados

\begin{tabular}{|c|c|c|}
\hline Tipo & Denominación & Condiciones de clasificación \\
\hline 1 & Vehículo ligero & Condición: Longitud $\leq 6 \mathrm{~m}$ \\
\hline \multirow[t]{4}{*}{2} & \multirow[t]{4}{*}{$\begin{array}{l}\text { Camión rígido de } 2 \text { ejes (tipo } \mathbf{R} \\
\text { 12) }\end{array}$} & $\begin{array}{l}\text { Condiciones generales } \\
5,8 \mathrm{~m}<\text { Longitud } \leq 12 \mathrm{~m} \\
3,5 \mathrm{t}<\text { Peso total } \leq 10 \mathrm{t} \\
\text { Distancia entre } 10 \text { y } 20 \text { ejes } \leq 5,8 \mathrm{~m} \\
\text { Distancia entre 2ㅇ y } 30 \text { eje }=0 \mathrm{~m} \text { (o sea, no existe un 3ㅇe eje) }\end{array}$ \\
\hline & & 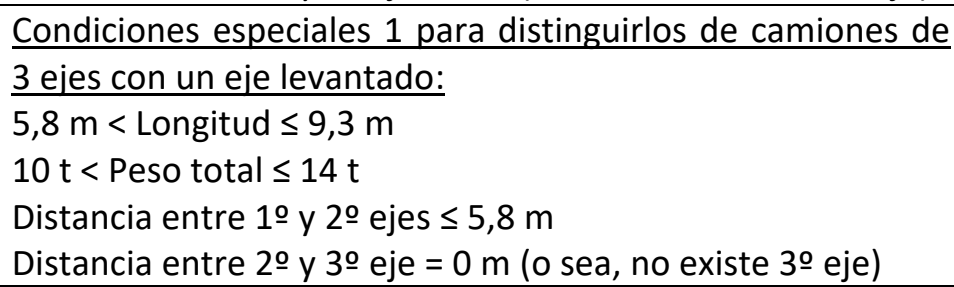 \\
\hline & & $\begin{array}{l}\text { Condiciones especiales } 2 \text { para distinguirlos de camiones de } \\
3 \text { ejes con un eje levantado: } \\
5,8 \mathrm{~m}<\text { Longitud } \leq 12 \mathrm{~m} \\
\text { Peso total }>14 \mathrm{t} \\
\text { Distancia entre } 1 \text { 으 y } 2 \text { o ejes } \leq 5,8 \mathrm{~m} \\
\text { Distancia entre } 2 \text { 으 } 3 \text { eje }=0 \mathrm{~m} \text { (o sea, no existe } 3 \text { o eje) }\end{array}$ \\
\hline & & $\begin{array}{l}\text { Condiciones especiales para vehículos de } 2 \text { ejes que no } \\
\text { cumplen alguna condición de los grupos anteriores } \\
\text { Longitud }>6 \mathrm{~m} \\
\text { Peso total }>3,5 \mathrm{t} \\
\text { Peso } 20 \text { eje }>0 \text { (o sea, existe un } 2 \text { o eje) } \\
\text { Peso } 30 \text { eje }=0 \text { (o sea, no existe un tercer eje) }\end{array}$ \\
\hline \multirow[t]{3}{*}{3} & \multirow[t]{3}{*}{$\begin{array}{l}\text { Camión rígido de } 3 \text { ejes (con } \\
\text { tándem trasero) (Tipos R14 y } \\
\text { R17) }\end{array}$} & $\begin{array}{l}\text { Condiciones generales } \\
6 \mathrm{~m}<\text { Longitud }<12,4 \mathrm{~m} \\
\text { Peso total }>3,5 \mathrm{t} \\
\text { Distancia entre } 10 \text { y } 20 \text { ejes } \leq 6,8 \mathrm{~m} \\
\text { Distancia entre } 20 \text { y } 30 \text { eje } \leq 1,8 \mathrm{~m} \text { (o sea, forman tándem) } \\
\text { Distancia entre } 30 \text { y } 40 \text { eje }=0 \mathrm{~m} \text { (o sea, no existe } 40 \text { eje) }\end{array}$ \\
\hline & & $\begin{array}{l}\text { Condiciones especiales de los camiones de } 3 \text { ejes con un eje } \\
\text { levantado para distinguirlos de los camiones de } 2 \text { ejes } \\
9,3 \mathrm{~m}<\text { Longitud } \leq 12 \mathrm{~m} \\
10 \mathrm{t}<\text { Peso total } \leq 14 \mathrm{t} \\
\text { Distancia entre } 10 \text { y } 20 \text { ejes } \leq 5,8 \mathrm{~m} \\
\text { Distancia entre } 20 \text { y } 30 \text { eje }=0 \mathrm{~m} \text { (o sea, no existe } 30 \text { eje) }\end{array}$ \\
\hline & & $\begin{array}{l}\text { Condiciones especiales para vehículos de } 3 \text { ejes que no } \\
\text { cumplen alguna condición de los grupos anteriores } \\
\text { Longitud }>6 \mathrm{~m} \\
\text { Peso total }>3,5 \mathrm{t} \\
\text { Peso 3o eje }>0 \text { (o sea, existe un } 3 \text { o eje) } \\
\text { Peso } 4 \text { ㅇ eje }=0 \text { (o sea, no existe un cuarto eje) }\end{array}$ \\
\hline
\end{tabular}


Tabla 13 (II) - Condiciones de clasificación de los vehículos pesados

\begin{tabular}{|c|c|c|}
\hline Tipo & Denominación & Condiciones de clasificación \\
\hline \multirow[t]{2}{*}{4} & \multirow[t]{2}{*}{$\begin{array}{l}\text { Camión rígido de } 4 \text { ejes (R34 - } \\
\text { R37) }\end{array}$} & 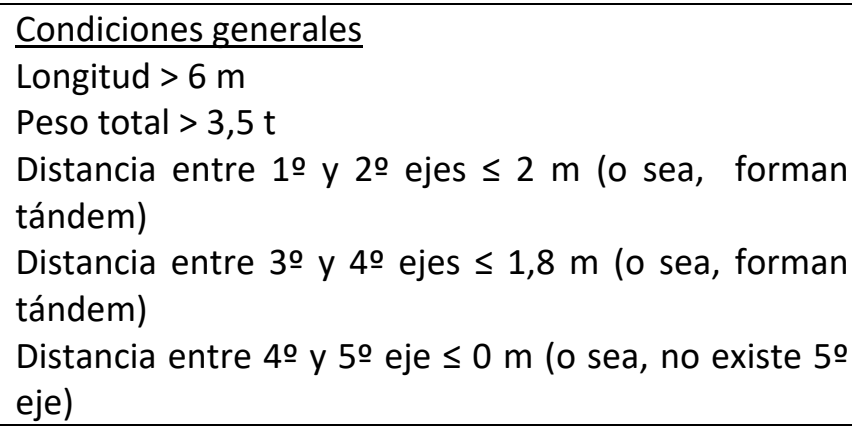 \\
\hline & & 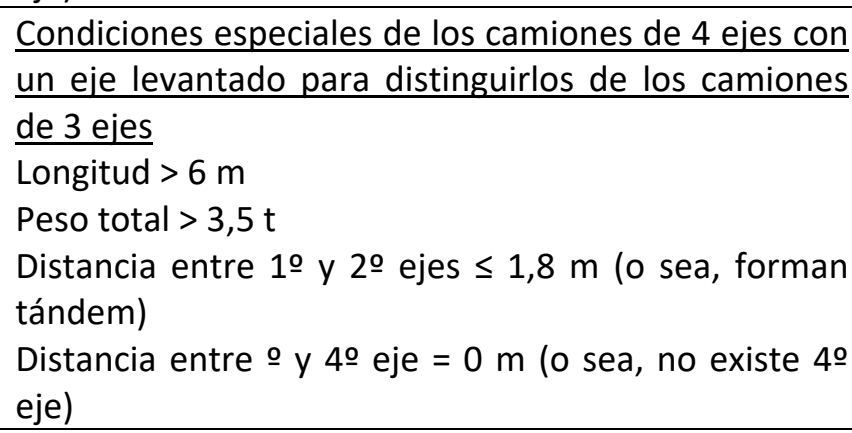 \\
\hline 4 & $\begin{array}{l}\text { Vehículo articulado, tipo tractor } \\
\text { + semirremolque, de } 3 \text { ejes (S } \\
\text { 122) }\end{array}$ & 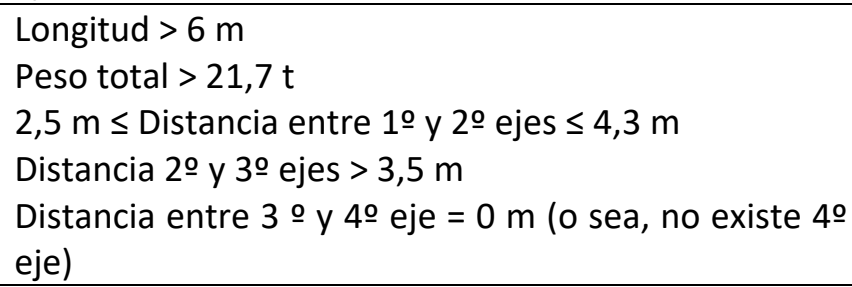 \\
\hline \multirow[t]{2}{*}{5} & \multirow[t]{2}{*}{$\begin{array}{l}\text { Vehículo articulado, tipo tractor } \\
\text { + semirremolque, de } 4 \text { ejes } \\
\text { (S } 123 \text {-S 124) }\end{array}$} & 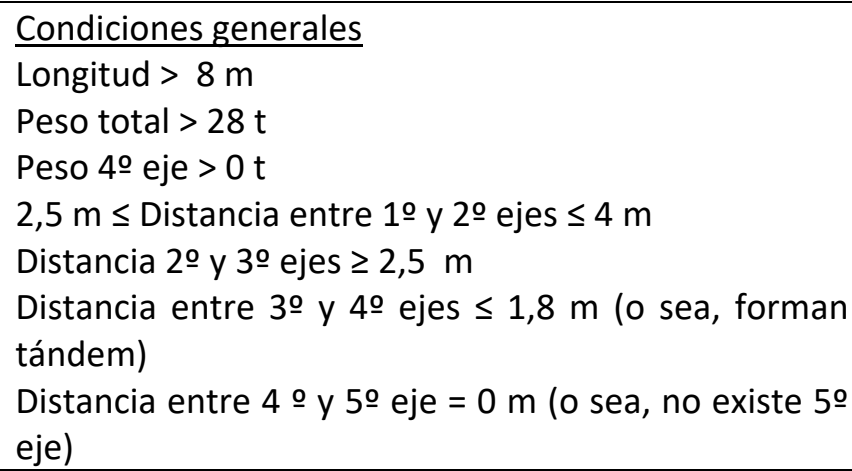 \\
\hline & & 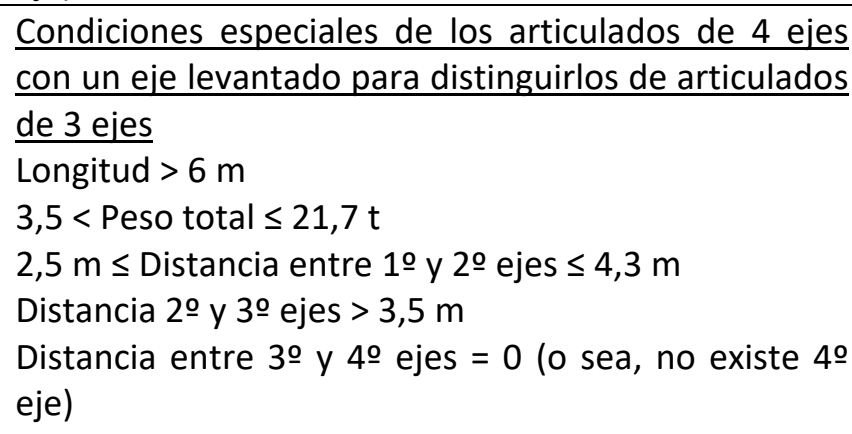 \\
\hline
\end{tabular}


Tabla 13 (III) - Condiciones de clasificación de los vehículos pesados

\begin{tabular}{|c|c|c|}
\hline Tipo & Denminación & Condiciones de clasificación \\
\hline \multirow[t]{3}{*}{6} & \multirow[t]{3}{*}{$\begin{array}{l}\text { Vehículo articulado, tipo tractor } \\
\text { + semirremolque, de } 5 \text { ejes } \\
\text { (S } 125 \text {-S 126-S 128) }\end{array}$} & $\begin{array}{l}\text { Condiciones generales } \\
\text { Longitud }>6 \mathrm{~m} \\
\text { Peso total }>3,5 \mathrm{t} \\
2,5 \mathrm{~m} \leq \text { Distancia entre } 10 \text { y } 20 \text { ejes } \leq 4,3 \mathrm{~m} \\
\text { Distancia } 2 \circ \text { y } 30 \text { ejes } \leq 9 \mathrm{~m} \\
\text { Distancia entre } 3 \circ \text { y } 4 \text { 을 ej } \leq 1,8 \mathrm{~m} \text { y distancia entre } \\
40 \text { y } 5 \circ \text { ejes } \leq 1,8 \mathrm{~m} \text { (es decir, que forman un eje } \\
\text { trídem) }\end{array}$ \\
\hline & & 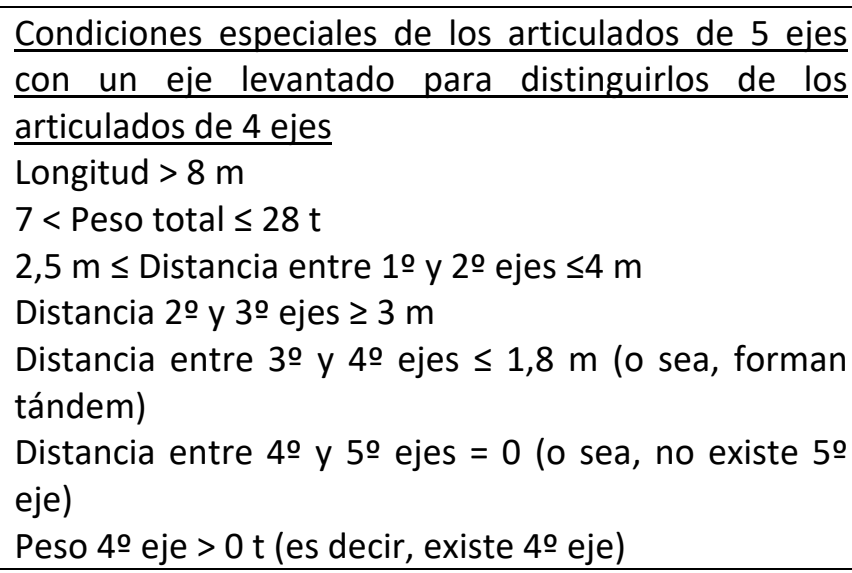 \\
\hline & & $\begin{array}{l}\text { Condiciones especiales para vehículos de } 5 \text { ejes que } \\
\text { no cumplen alguna condición de los grupos } \\
\text { anteriores } \\
\text { Longitud }>6 \mathrm{~m} \\
\text { Peso total }>3,5 \mathrm{t} \\
\text { Peso } 50 \text { eje }>0 \text { (es decir, que existe un } 5 \text { o eje) } \\
\text { Peso } 60 \text { eje }=0 \text { (o sea, que no existe un sexto eje) }\end{array}$ \\
\hline 7 & $\begin{array}{l}\text { Vehículo articulado, tipo tractor } \\
+ \text { semirremolque, de } 5 \text { ejes, } \\
\text { siendo el tractor de } 3 \text { ejes (S } \\
\text { 144) }\end{array}$ & 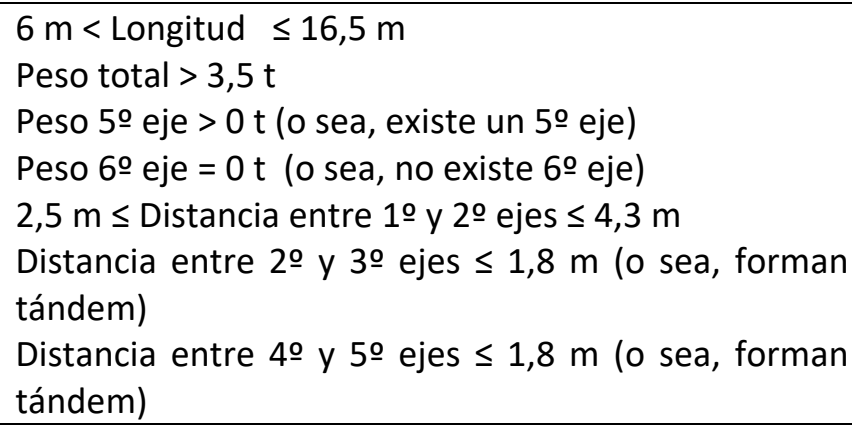 \\
\hline 8 & $\begin{array}{l}\text { Vehículo articulado, tipo tractor } \\
\text { + semirremolque, de } 6 \text { ejes } \\
\text { (S } 145 \text { - S 146) }\end{array}$ & 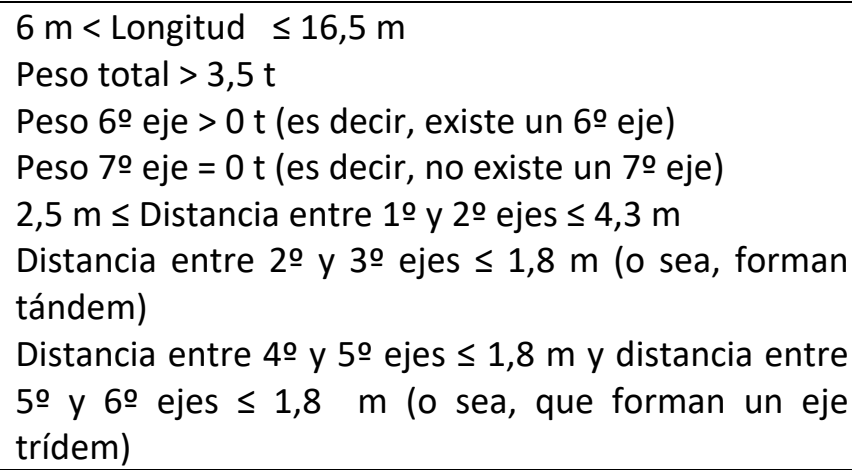 \\
\hline
\end{tabular}


Tabla 12 (IV) - Condiciones de clasificación de los vehículos pesados

\begin{tabular}{|c|c|c|}
\hline Tipo & Denominación & Condiciones de clasificación \\
\hline \multirow[t]{2}{*}{9} & \multirow[t]{2}{*}{$\begin{array}{l}\text { Tren de carretera de } 4 \text { ejes (con } \\
\text { tándem en el remolque) } \\
\text { (T 124) }\end{array}$} & $\begin{array}{l}\text { Longitud total }>15 \mathrm{~m} \\
\text { Peso total }>3,5 \mathrm{t} \\
\text { Peso } 40 \text { eje }=0 \mathrm{t} \text { (o sea, existe un } 4 \text { o eje) } \\
\text { Peso } 50 \text { eje }=0 \mathrm{t} \text { (o sea, no existe un } 5 \circ \text { eje) } \\
4 \mathrm{~m} \leq \text { Distancia entre } 10 \text { y } 2 \circ \text { ejes } \leq 6,2 \mathrm{~m} \\
\text { Distancia entre } 30 \text { y } 4 \text { o ejes } \leq 1,8 \mathrm{~m} \text { (o sea, forman } \\
\text { tándem) }\end{array}$ \\
\hline & & $\begin{array}{l}\text { Condiciones especiales para vehículos de } 4 \text { ejes tipo } \\
\text { C2+R2 que no cumplen alguna condición de los } \\
\text { grupos anteriores } \\
\text { Longitud }>6 \mathrm{~m} \\
\text { Peso total }>3,5 \mathrm{t} \\
\text { Peso } 40 \text { eje }>0 \text { (es decir, que existe un 4ㅇ eje) } \\
\text { Peso } 50 \text { eje }=0 \text { (o sea, que no existe un quinto eje) }\end{array}$ \\
\hline 10 & $\begin{array}{l}\text { Tren de carretera de } 4 \text { ejes (con } \\
2 \text { ejes simples en el remolque), } \\
\text { (T 1222) }\end{array}$ & 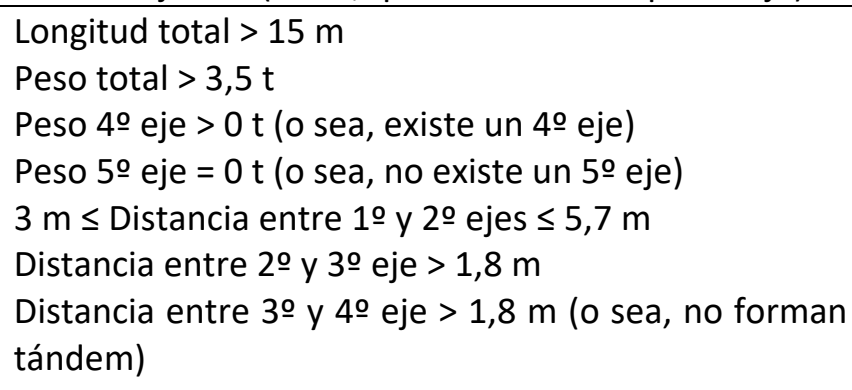 \\
\hline 11 & $\begin{array}{l}\text { Tren de carretera de } 5 \text { ejes (con } \\
\text { trídem en el remolque) } \\
\text { (T } 125 \text { ó T 126) }\end{array}$ & 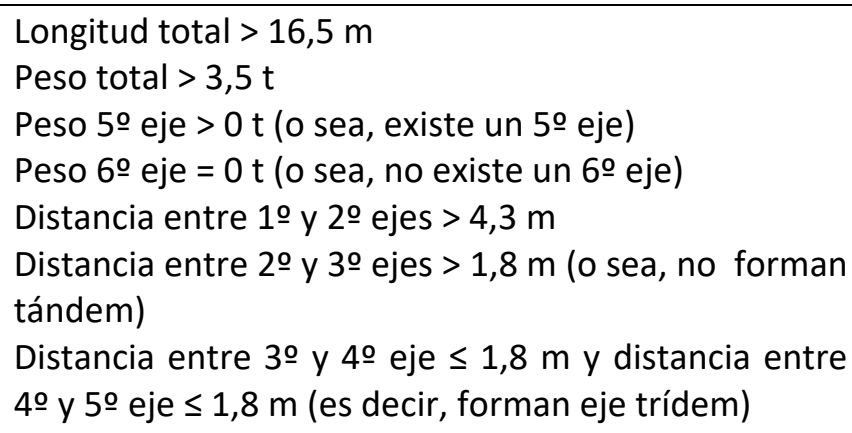 \\
\hline 12 & $\begin{array}{l}\text { Tren de carretera de } 5 \text { ejes (con } \\
\text { tándem en el remolque) } \\
\text { (T 1224) }\left(^{*}\right)\end{array}$ & 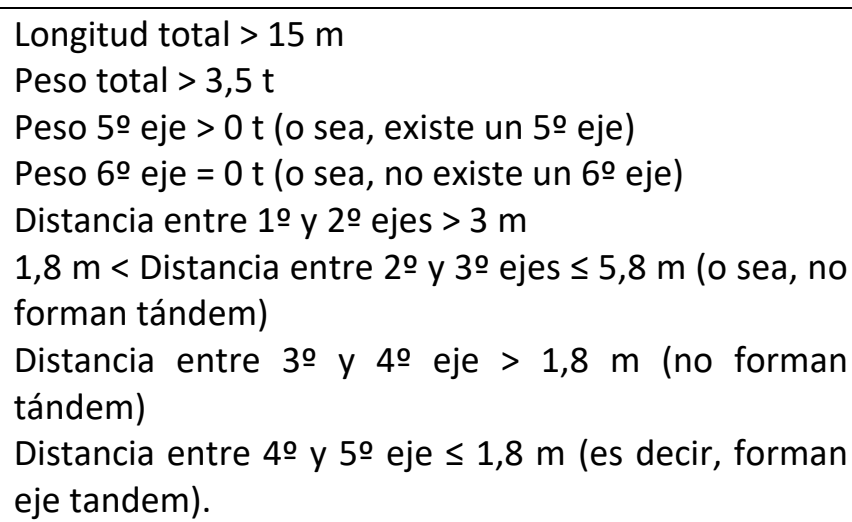 \\
\hline
\end{tabular}


Tabla 12 (V) - Condiciones de clasificación de los vehículos pesados

\begin{tabular}{|c|c|c|}
\hline Tipo & Denominación & Condiciones de clasificación \\
\hline \multirow[t]{2}{*}{13} & \multirow[t]{2}{*}{$\begin{array}{l}\text { Tren de carretera de } 5 \text { ejes (con } \\
\text { tándem en el camión tractor) } \\
\text { (T 1422) }\end{array}$} & $\begin{array}{l}\text { Condiciones generales } 1 \\
\text { Longitud total }>15 \mathrm{~m} \\
\text { Peso total }>3,5 \mathrm{t} \\
\text { Peso 60 eje }=0 \mathrm{t} \text { ( o sea, no existe un 6ㅇ eje) } \\
\text { Distancia entre } 19 \text { y } 20 \text { ejes }>3 \mathrm{~m} \\
\text { Distancia entre } 20 \text { y } 30 \text { ejes } \leq 1,8 \mathrm{~m} \text { (forman tándem) } \\
\text { Distancia entre } 40 \text { y } 50 \text { eje }>1,8 \mathrm{~m} \text { (es decir, que no } \\
\text { forman eje tándem). }\end{array}$ \\
\hline & & 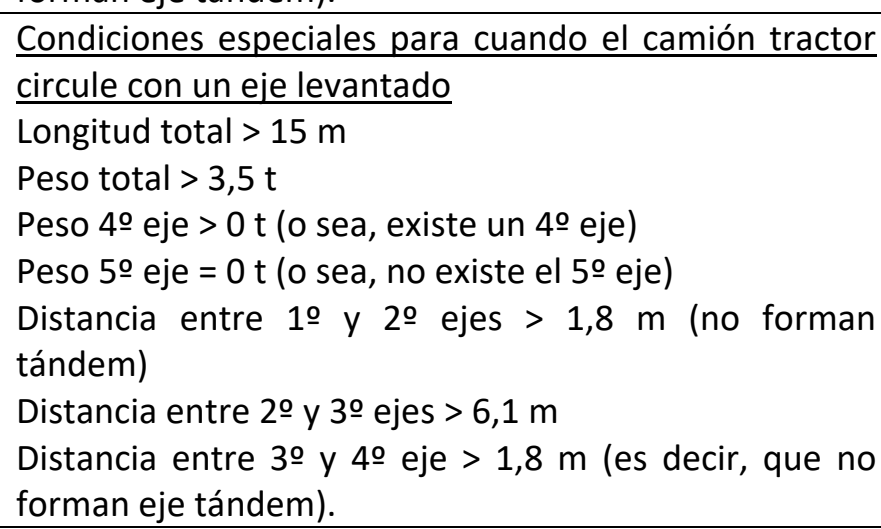 \\
\hline \multirow[t]{2}{*}{14} & \multirow[t]{2}{*}{$\begin{array}{l}\text { Tren de carretera de } 5 \text { ejes (con } \\
\text { tándem en el tractor y tándem } \\
\text { en el remolque) } \\
\text { (T 144) }\end{array}$} & $\begin{array}{l}\text { Condiciones generales } 1 \\
\text { Longitud total }>15 \mathrm{~m} \\
\text { Peso total }>3,5 \mathrm{t} \\
\text { Peso en el } 40 \text { eje }>0 \text { (o sea, existe un 40 eje) } \\
\text { Peso en el } 50 \text { eje }>0 \text { (o sea, existe un } 50 \text { eje) } \\
\text { Peso 60 eje }=0 \mathrm{t} \text { (o sea, no existe un 6ㅇ eje) } \\
\text { Distancia entre } 10 \text { y } 20 \text { eje }>4,3 \mathrm{~m} \\
\text { Distancia entre } 20 \text { y } 30 \text { eje } \leq 1,8 \mathrm{~m} \text { (forman eje tándem) } \\
\text { Distancia entre } 40 \text { y } 50 \text { eje } \leq 1,8 \mathrm{~m} \text { (forman eje } \\
\text { tándem). }\end{array}$ \\
\hline & & 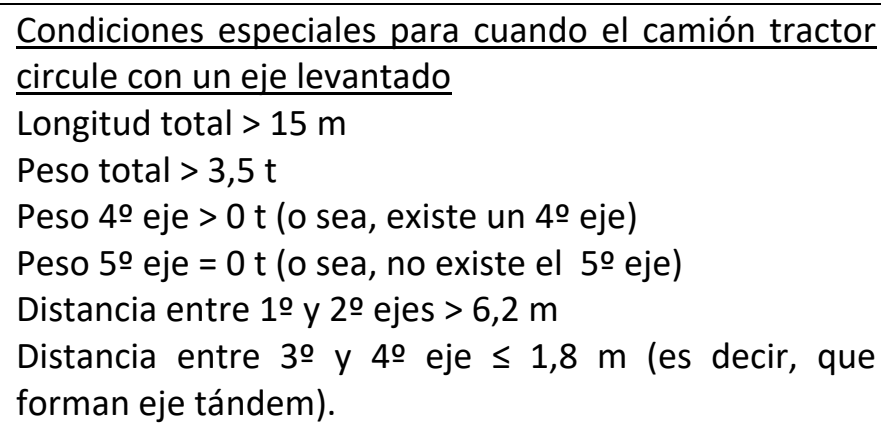 \\
\hline 15 & $\begin{array}{l}\text { Tren de carretera de } 6 \text { ejes (con } \\
\text { tándem en el tractor y un eje } \\
\text { trídem en el remolque) } \\
\text { (T 145) }\end{array}$ & $\begin{array}{l}\text { Longitud total }>16,5 \mathrm{~m} \\
\text { Peso total }>3,5 \mathrm{t} \\
\text { Peso en el } 60 \text { eje }>0 \text { (o sea, existe un } 60 \text { eje) } \\
\text { Peso en el } 70 \text { eje }=0 \text { (o sea, no existe un } 70 \text { eje) } \\
\text { Distancia entre } 10 \text { y } 20 \text { eje }>3 \mathrm{~m} \\
\text { Distancia entre } 20 \text { y } 30 \text { eje } \leq 1,8 \mathrm{~m} \text { (forman eje tándem) } \\
\text { Distancia entre } 4 \text { \% y } 50 \text { eje } \leq 1,8 \mathrm{~m} \text { y distancia entre } 5 \text { o } \\
\text { y } 60 \text { ejes } \leq 1,8 \mathrm{~m} \text { (forman eje trídem). }\end{array}$ \\
\hline
\end{tabular}


Tabla 12 (VI) - Condiciones de clasificación de los vehículos pesados

\begin{tabular}{|c|c|c|}
\hline Tipo & Denominación & Condiciones de clasificación \\
\hline \multirow[t]{2}{*}{16} & \multirow[t]{2}{*}{$\begin{array}{l}\text { Tren de carretera de } 6 \text { ejes (con } \\
\text { tándem en el tractor y tres ejes } \\
\text { en el remolque, con los dos } \\
\text { últimos formando un eje } \\
\text { tándem) } \\
\text { (T 1424) }\end{array}$} & $\begin{array}{l}\text { Condiciones generales } 1 \\
\text { Longitud total }>15 \mathrm{~m} \\
\text { Peso total }>3,5 \mathrm{t} \\
\text { Peso en el } 60 \text { eje }>0 \text { (o sea, existe un } 60 \text { eje) } \\
\text { Peso en el } 70 \text { eje }=0 \mathrm{t} \text { (o sea, no existe un 70 eje) } \\
\text { Distancia entre } 10 \text { y } 20 \text { eje }>3 \mathrm{~m} \\
\text { Distancia entre } 20 \text { y } 30 \text { eje } \leq 1,8 \mathrm{~m} \text { (forman eje } \\
\text { tándem) } \\
\text { Distancia entre 4 y } 50 \text { eje }>1,8 \mathrm{~m} \text { (no forman } \\
\text { tándem). } \\
\text { Distancia entre 5o y } 60 \text { eje } \leq 1,8 \mathrm{~m} \text { (forman eje } \\
\text { tándem) }\end{array}$ \\
\hline & & 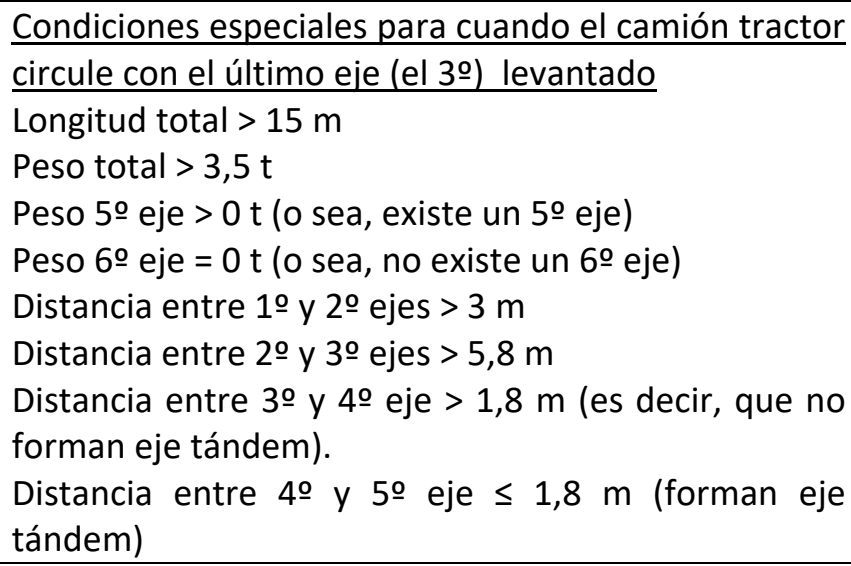 \\
\hline 17 & Autobús de 2 ejes (A 12) & $\begin{array}{l}11 \mathrm{~m} \leq \text { Longitud total } \leq 13 \mathrm{~m} \\
\text { Peso total }>8 \mathrm{t} \\
\text { Peso en el } 10 \text { eje }>3 \mathrm{t} \\
\text { Peso en el } 20 \text { eje } \geq 6 \mathrm{t} \\
\text { Distancia entre } 10 \text { y } 20 \text { eje }>5,8 \mathrm{~m} \\
\text { Distancia entre } 2 \circ \text { y } 30=0 \mathrm{~m} \text { (o sea, no existe el } 3 \text { o } \\
\text { eje) }\end{array}$ \\
\hline 18 & Autobús de 3 ejes (A 17) & $\begin{array}{l}\text { Longitud total } \geq 12,4 \mathrm{~m} \\
\text { Peso total }>3,5 \mathrm{t} \\
\text { Distancia entre } 20 \text { y } 3 \text { ㅇ eje } \leq 1,8 \mathrm{~m} \text { (forman eje } \\
\text { tándem) } \\
\text { Distancia entre } 3 \text { ㅇ y } 4 \text { 으 eje = } 0 \text { (o sea, no existe el 3ㅇ } \\
\text { eje) }\end{array}$ \\
\hline
\end{tabular}

Las condiciones del procedimiento de clasificación que se acaban de mostrar en las distintas partes de la Tabla 13 se expresan de manera resumida (para los vehículos pesados solamente), en formato lógico, en la Tabla 14 que se muestra a continuación. 
Tabla 14. Resumen de las condiciones de clasificación para los diferentes tipos de vehículos expresadas en formato lógico

\begin{tabular}{|c|c|c|c|c|c|c|c|c|c|c|c|c|c|c|c|c|c|c|c|c|c|c|c|}
\hline \multicolumn{24}{|c|}{ CRITERIOS EL MOLAR DE CLASIFICACIÓN DE VEHÍCULOS PARA LA POBLACIÓN (Usando la muestra de EL MOLAR 2014) } \\
\hline & & \multicolumn{22}{|c|}{ Columna de Excel } \\
\hline & & A & B & C & D & $\mathrm{E}$ & $\mathrm{F}$ & G & $\mathrm{H}$ & $\mathrm{I}$ & $\mathrm{J}$ & $\mathrm{K}$ & $\mathrm{L}$ & $\mathrm{M}$ & $\mathrm{N}$ & $\mathrm{O}$ & $\mathrm{P}$ & $\mathrm{Q}$ & $\mathrm{R}$ & $\mathrm{S}$ & $\mathrm{T}$ & $\mathrm{u}$ & $\mathrm{V}$ \\
\hline \multicolumn{2}{|c|}{ Vehículos } & & & & & \multicolumn{8}{|c|}{ Peso del eje } & Peso Total & \multicolumn{7}{|c|}{ Distancia entre ejes } & Velod & Longitud \\
\hline Clase & Tipo & $\mathrm{No}$ & pate & imet & Lne & AW1 & $\mathrm{AW} 2$ & AW3 & AW4 & AW5 & AW6 & AW7 & AW8 & GVM & AD1 & $\mathrm{AD2}$ & AD3 & AD4 & AD5 & AD6 & AD7 & SPD & LENG \\
\hline \multirow{10}{*}{$\frac{\tilde{8}}{\frac{0}{x}}$} & \multirow{4}{*}{ R 12} & & & & & & $>0$ & & & & & & & $3,5<\mathbf{P}<=10$ & $0<\mathbf{D}<=5,8$ & $=0$ & & & & & & & $5,8<L<=12$ \\
\hline & & & & & & & $>0$ & & & & & & & $>14$ & $0<\mathbf{D}<=5,8$ & $=0$ & & & & & & & $5,8<\mathbf{L}<=12$ \\
\hline & & & & & & & $>0$ & & & & & & & $10<P<=14$ & $0<\mathbf{D}<=5,8$ & $=0$ & & & & & & & $5,8<\mathbf{L}<=9,3$ \\
\hline & & & & & & & $>0$ & $=0$ & & & & & & $>3,5$ & & & & & & & & & $>6$ \\
\hline & \multirow{3}{*}{ R 14-17 } & & & & & & & & & & & & & $>3,5$ & $0<\mathrm{D}<=6,8$ & $0<\mathrm{D}<=1,8$ & $=0$ & & & & & & $6<L<12,4$ \\
\hline & & & & & & & & & & & & & & $10<P<=14$ & $0<\mathbf{D}<=5,8$ & $=0$ & & & & & & & $9,3<\mathbf{L}<=12$ \\
\hline & & & & & & & & $>0$ & $=0$ & & & & & $>3,5$ & & & & & & & & & $>6$ \\
\hline & R 32 & & & & & & & & & & & & & & Sin fórmula & & & & & & & & \\
\hline & & & & & & & & & & & & & & $>3,5$ & $0<\mathrm{D}<=2$ & & $0<\mathrm{D}<=1,8$ & $=0$ & & & & & $>6$ \\
\hline & $R$ 34-37 & & & & & & & & & & & & & $>3,5$ & $0<\mathbf{D}<=1,8$ & & $=0$ & & & & & & $>6$ \\
\hline \multirow{8}{*}{ 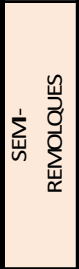 } & $\mathrm{S} 122$ & & & & & & & & & & & & & $>21,7$ & $2,5<=D<4,3$ & $>3,5$ & $=0$ & & & & & & $>6$ \\
\hline & \multirow{2}{*}{ S $123-124$} & & & & & & & & $>0$ & & & & & $>28$ & $2,5<=D<=4$ & $>=2,5$ & $0<\mathrm{D}<=1,8$ & $=0$ & & & & & $>8$ \\
\hline & & & & & & & & & & & & & & $3,5<\mathbf{P}<=21,7$ & $2,5<=D<=4,3$ & $>3,5$ & $=0$ & & & & & & $>6$ \\
\hline & \multirow{3}{*}{ s 125-126-128 } & & & & & & & & & & & & & $>3,5$ & $2,5<=D<=4,3$ & $<=9$ & $0<\mathbf{D}<=1,8$ & $0<\mathrm{D}<=1,8$ & & & & & $>6$ \\
\hline & & & & & & & & & $>0$ & & & & & $7<P<=28$ & $2,5<=D<=4$ & $>=3$ & $0<\mathrm{D}<=1,8$ & $=0$ & & & & & $>8$ \\
\hline & & & & & & & & & & $>0$ & $=0$ & & & $>3,5$ & & & & & & & & & $>6$ \\
\hline & S 144 & & & & & & & & & $>0$ & $=0$ & & & $>3,5$ & $2,5<=\mathrm{D}<=4,3$ & $0<\mathrm{D}<=1,8$ & & $0<\mathrm{D}<=1,8$ & & & & & $6<L<=16,5$ \\
\hline & \begin{tabular}{|l} 
S 145-146 \\
\end{tabular} & & & & & & & & & & $>0$ & $=0$ & & $>3,5$ & $2,5<=\mathrm{D}<=4,3$ & $0<\mathrm{D}<=1,8$ & & & & & & & $6<\mathrm{L}<=16,5$ \\
\hline \multirow{12}{*}{$\sum_{\underset{F}{\tilde{F}}}^{\stackrel{u}{~}}$} & \multirow{2}{*}{ Т 124} & & & & & & & & $>0$ & $=0$ & & & & $>3,5$ & $4<D<=6,2$ & & $0<D<=1,8$ & & & & & & $>15$ \\
\hline & & & & & & & & & $>0$ & $=0$ & & & & $>3,5$ & & & & & & & & & $>6$ \\
\hline & T 1222 & & & & & & & & $>0$ & $=0$ & & & & $>3,5$ & $3<\mathbf{D}<=5,7$ & $1,8<D<=6,1$ & $>1,8$ & & & & & & $>15$ \\
\hline & \begin{tabular}{|l|} 
T 125-126 \\
\end{tabular} & & & & & & & & & $>0$ & $=0$ & & & $>3,5$ & $>4,3$ & $>1,8$ & $0<\mathrm{D}<=1,8$ & $0<\mathrm{D}<=1,8$ & & & & & $>16,5$ \\
\hline & T 1224 & & & & & & & & & $>0$ & $=0$ & & & $>3,5$ & $>3$ & $1,8<\mathrm{D}<=5,8$ & $>1,8$ & $0<\mathbf{D}<=1,8$ & & & & & $>15$ \\
\hline & \multirow{2}{*}{ T 1422} & & & & & & & & & & $=0$ & & & $>3,5$ & $>3$ & $0<\mathbf{D}<=1,8$ & & $>1,8$ & & & & & $>15$ \\
\hline & & & & & & & & & $>0$ & $=0$ & & & & $>3,5$ & $>1,8$ & $>6,1$ & $>1,8$ & & & & & & $>15$ \\
\hline & \multirow{2}{*}{ T 144} & & & & & & & & $>0$ & $>0$ & $=0$ & & & $>3,5$ & $>4,3$ & $0<\mathrm{D}<=1,8$ & & $0<\mathrm{D}<=1,8$ & & & & & $>15$ \\
\hline & & & & & & & & & $>0$ & $=0$ & & & & $>3,5$ & $>6,2$ & & $0<\mathrm{D}<=1,8$ & & & & & & $>15$ \\
\hline & T 145 & & & & & & & & & & $>0$ & $=0$ & & $>3,5$ & $>3$ & $0<\mathrm{D}<=1,8$ & & $0<\mathrm{D}<=1,8$ & $0<\mathrm{D}<=1,8$ & & & & $>16,5$ \\
\hline & \multirow{2}{*}{ T 1424} & & & & & & & & & & $>0$ & $=0$ & & $>3,5$ & $>3$ & $0<\mathrm{D}<=1,8$ & & $>1,8$ & $0<\mathrm{D}<=1,8$ & & & & $>15$ \\
\hline & & & & & & & & & & $>0$ & $=0$ & & & $>3,5$ & $>3$ & $>5,8$ & $>1,8$ & $0<\mathrm{D}<=1,8$ & & & & & $>15$ \\
\hline प्यू & A 12 & & & & & $>3$ & $>=6$ & & & & & & & $>8$ & $>5,8$ & $=0$ & & & & & & & $11<\mathrm{L}<=13$ \\
\hline בె & A 17 & & & & & & & & & & & & & $>3,5$ & & $0<\mathrm{D}<=1,8$ & $=0$ & & & & & & $>=12,4$ \\
\hline
\end{tabular}

Texto en rojo: Diferencias con los criterios INTERMEDIOS (8 jifes y longi

Fondo en rojo: Criterios empleados para reclasificar, en segunda vuelta, los vehículos NO CLASIFICADOS en la primera 
Se ha elaborado un programa de clasificación en Excel que, tomando como parámetros de entrada directamente las salidas de datos del equipo de pesaje dinámico, proporciona la clasificación de los vehículos en las 18 clases o tipos descritos. En este programa, se parte las distintas características de los vehículos (pesos de cada eje, peso bruto del vehículo, longitud, distancia entre ejes consecutivos), que aparecen cada una de ellas en una columna en la hoja Excel, y se imponen las condiciones entre los distintos parámetros que se muestran en la Tabla anterior.

\subsubsection{Explicación de las condiciones de clasificación que se han desarrollado}

En este apartado se va a tratar de explicar las razones por las que se han escogido las condiciones y umbrales de clasificación que se han mostrado detalladamente en las Tablas 12, 13 (I, II, III, IV, V y VI) y 14.

En primer lugar, hay que decir que para distinguir los vehículos pesados de los vehículos ligeros se suelen imponer dos condiciones: que su longitud sea mayor de unos $6 \mathrm{~m}$ y que su peso dado por la báscula dinámica sea mayor de $3,5 \mathrm{t}$.

Para distinguir dentro de estas dos grandes clases a cada tipo específico de vehículo se recurre primeramente a imponer ciertas condiciones sobre el número de ejes. Así, las caravanas (ligeras) son vehículos ligeros con más de 2 ejes ( $3 \circ 4$ ), mientras que los distintos tipos de camiones, sean rígidos, articulados o trenes, tienen también un número específico de ejes, imponiéndose esa condición de la siguiente forma: si un tipo específico de vehículo tiene $n$ ejes, entonces se impone como condición que el peso del eje $n+1$ debe ser 0 , o alternativamente que la distancia entre el eje $n$ y el eje $\mathrm{n}+1$ debe ser igualmente 0 .

La distinción entre vehículos rígidos, articulados (semirremolques) y trenes de carretera se basa fundamentalmente (aunque no solo) en la longitud de los vehículos, imponiéndose, de acuerdo con el Reglamento General de Vehículos, la condición de que esta longitud sea menor o igual de $12 \mathrm{~m}$ para los vehículos rígidos, entre $12 \mathrm{~m}$ y $16,5 \mathrm{~m}$ para los vehículos articulados (conjunto de cabeza tractora + semirremolque) y mayor de 16,5 $\mathrm{m}$ para los trenes de carretera. No obstante, en algunos tipos de vehículo determinados se han modificado ligeramente esos umbrales de distinción para tener en cuenta posibles imprecisiones del sistema de pesaje.

Como puede existir un cierto solape en la longitud y número de ejes entre ciertos tipos de vehículos articulados (cabeza tractora + semirremolque) y de trenes de carretera (camión rígido + remolque), para distinguir ambos tipos de vehículos se suele imponer como condición adicional que en los articulados la distancia entre el primer y el segundo eje es menor de unos $4 \mathrm{~m}$, mientras que en los trenes de carretera esta distancia es algo mayor, debido a que las cabezas tractoras de los vehículos articulados son bastante más cortas que los camiones de dos ejes que tiran de un remolque.

En cuanto a la tipología de los ejes, se ha impuesto como condición de que dos ejes consecutivos forman un eje tándem si su distancia es menor o igual de 1,8 $\mathrm{m}$, mientras que para que tres ejes consecutivos formen un eje trídem, se impone la condición de 
que tanto la distancia entre el primero con el segundo como la distancia entre el segundo con el tercero deben ser menores o iguales a $1,8 \mathrm{~m}$.

Para tratar de clasificar adecuadamente los vehículos que llevan algún eje levantado (esto es, según su número verdadero de ejes, no según el número de ellos que llevan apoyados sobre el pavimento), se ha recurrido al artificio de considerar (en algunos casos) que un cierto vehículo captado por el sistema como de $\mathrm{n}$ ejes puede ser clasificado como un vehículo de $n+1$ ejes si su peso es menor de un cierto umbral (es decir, si va descargado). Así, por ejemplo el vehículo más común, que es el articulado de 5 ejes con un eje trídem en el semirremolque, puede llevar un eje del semirremolque levantado y es captado por el sistema de pesaje como un vehículo de 4 ejes solamente. Sin embargo, este vehículo será clasificado como vehículo de 5 ejes (aunque el sistema sólo registre 4) si su peso total es menor de $28 \mathrm{t}$. Está claro que con ello se puede cometer el error de clasificar como vehículo articulado de 5 ejes a un vehículo articulado de 4 ejes que circule descargado, pero se optado por hacerlo de esta manera debido a que actualmente existen muy pocos vehículos de 4 ejes, y el error que se cometería en estos casos es muy pequeño.

Se hace notar que, además de las mencionadas, existen otras condiciones más específicas adaptadas a cada tipo de vehículo, que sería muy prolijo enumerar, por lo que se ha creído conveniente sólo explicar las condiciones que aparecen más frecuentemente.

Por último, cabe preguntarse cuál serían las condiciones de clasificación del nuevo tipo de vehículo aprobado por la Orden PRE/2788/2015, de 18 de diciembre, por el que se modificaba el anexo IX del Reglamento General de Vehículos, en el sentido de incorporar el llamado coloquialmente "megatruck", que se designa en el apartado 1 de dicha Orden como:

"1.23 Configuración euro-modular: Conjunto de vehículos con más de 6 líneas de ejes, cuyos módulos separadamente no superan los límites máximos de masas y dimensiones establecidos para el tipo de vehículo que corresponda"

Se incorpora además el apartado 6 "Masa máxima autorizada de los conjuntos de vehículos en configuración euro-modular",

"Se podrá autorizar por el órgano competente en materia de tráfico, previo informe vinculante del titular de la vía, la circulación de conjuntos de vehículos en configuración euro-modular, con una masa máxima de hasta 60 toneladas y una longitud máxima de hasta 25,25 metros por un plazo determinado, en las condiciones que se fijen en la autorización. La carga no podrá sobresalir de la proyección en planta del vehículo. Siempre que sea posible, los itinerarios de estos transportes deberán transcurrir por autopistas y autovías.

No se podrá conceder la autorización a la que se refiere el párrafo anterior cuando se pretenda realizar transporte de mercancías peligrosas por carretera"

Pues bien, a la vista de las disposiciones sobre masas y dimensiones de los vehículos en configuración euro-modular, cabría decir que las condiciones de clasificación automática de esos vehículos podrían ser las siguientes: 
5. Longitud total $>20,25 \mathrm{~m}$ (es decir, una longitud mayor del tren de carretera constituido por un camión rígido+remolque que sea más largo, que es el destinado al transporte de vehículos)

6. Peso total $>3,5 \mathrm{t}$

7. Peso en el 70 eje $>0$ (es decir, que existe un 70 eje)

Posiblemente, con estas tres condiciones bastaría para distinguir de forma automática a este tipo de vehículos. No obstante, como posiblemente podrán existir algunos vehículos de configuración euro-modular cortos (longitud $<20,25 \mathrm{~m}$ ) para transportar cargas pesadas, podrían producirse solapes entre con algunos trenes de carretera largos (como los destinados al transporte de vehículos), por lo que es posible que en esos casos se requiriera alguna condición adicional para clasificarlos adecuadamente, como podría ser el imponer una distancia máxima entre primer y segundo ejes (menor de unos $4 \mathrm{~m}$ ), para indicar que se trata de un vehículo con cabeza tractora, y no un tren de carretera tirado por un camión de dos ejes.

No obstante, según vayan apareciendo los distintos tipos de vehículos de configuración euro-modular, se podrá comprobar si se necesita alguna condición adicional para clasificar adecuadamente estos vehículos, con objeto de diferenciarlos de otros tipos que puedan ser bastante similares.

\subsubsection{Análisis detallado de los resultados para los casos de solapamiento entre las características de ciertas clases}

A continuación se va a explicar más detalladamente cómo se ha llegado a establecer los umbrales de separación entre algunas clases en las cuales existe cierto solapamiento de las principales condiciones de clasificación, esto es, que para una o varias de las variables que se utilizan para separar las clases en cuestión, existen valores respecto de esa(s) característica(s), que pueden tomar los vehículos de dos o más clases, con lo cual, se debe realizar un estudio más detallado para poder discernir cuál es el tipo de vehículo de que se trata. A este respecto, puede decirse que los principales caso de solapamiento de condiciones ( $y$, por tanto, de mayor dificultad de clasificación) se dan entre los siguientes tipos:

1. Camiones de 2 ejes y autobuses de 2 ejes

2. Camiones de 3 ejes y autobuses de 3 ejes

3. Articulados de 4 con un eje tándem en el semirremolque y trenes de 4 ejes con un eje tándem en el semirremolque

4. Articulados de 4 ejes con un eje tándem en el semirremolque y articulados de 5 ejes con un eje tridem en el semirremolque que circulan con un eje levantado

5. Camiones de 2 ejes y camiones de 3 ejes que circulan con un eje levantado.

Para tratar este problema se ha escogido un planteamiento similar al realizado por Kwigizile, 2004 [27], que consiste en comparar las distribuciones (histogramas) de frecuencias de los valores que toman los vehículos de dos o más clases, respecto de las variables de clasificación entre las que existe solapamiento. 
5.1.6.1 Diferenciación entre camiones de 2 ejes y autobuses de 2 ejes

Tanto los camiones de dos ejes como los autobuses de dos ejes son vehículos que no se pueden diferenciar entre sí por su número de ejes ni su peso total, por lo que se debe acudir a otros parámetros en los cuales se puedan observar ciertas diferencias.

En la Figura 14, se representan las frecuencias relativas de los distintos intervalos de longitud tanto de los camiones de 2 ejes como de los autobuses de 2 ejes. Como se puede comprobar, el máximo de la distribución de longitudes de los camiones de 2 ejes está entre 7 y $8 \mathrm{~m}$, existiendo un porcentaje apreciable de ellos que está entre 8 y $10 \mathrm{~m}$, mientras que solo un $15 \%$ aproximadamente supera los $10 \mathrm{~m}$ de longitud y solo un $4 \%$ supera los $11 \mathrm{~m}$, siendo su límite legal de longitud los $12 \mathrm{~m}$. En comparación, la frecuencia máxima de longitud de los autocares tiene lugar entre los $10,5 \mathrm{~m}$ y los 11,5 m y aproximadamente un $21 \%$ supera los $11,5 \mathrm{~m}$, siendo su límite legal de longitud los $15 \mathrm{~m}$. Como se puede ver, aunque las distribuciones de longitud sean bastante diferentes, existe un cierto solape entre ambos tipos de vehículo entre los 10 y los 11 m.

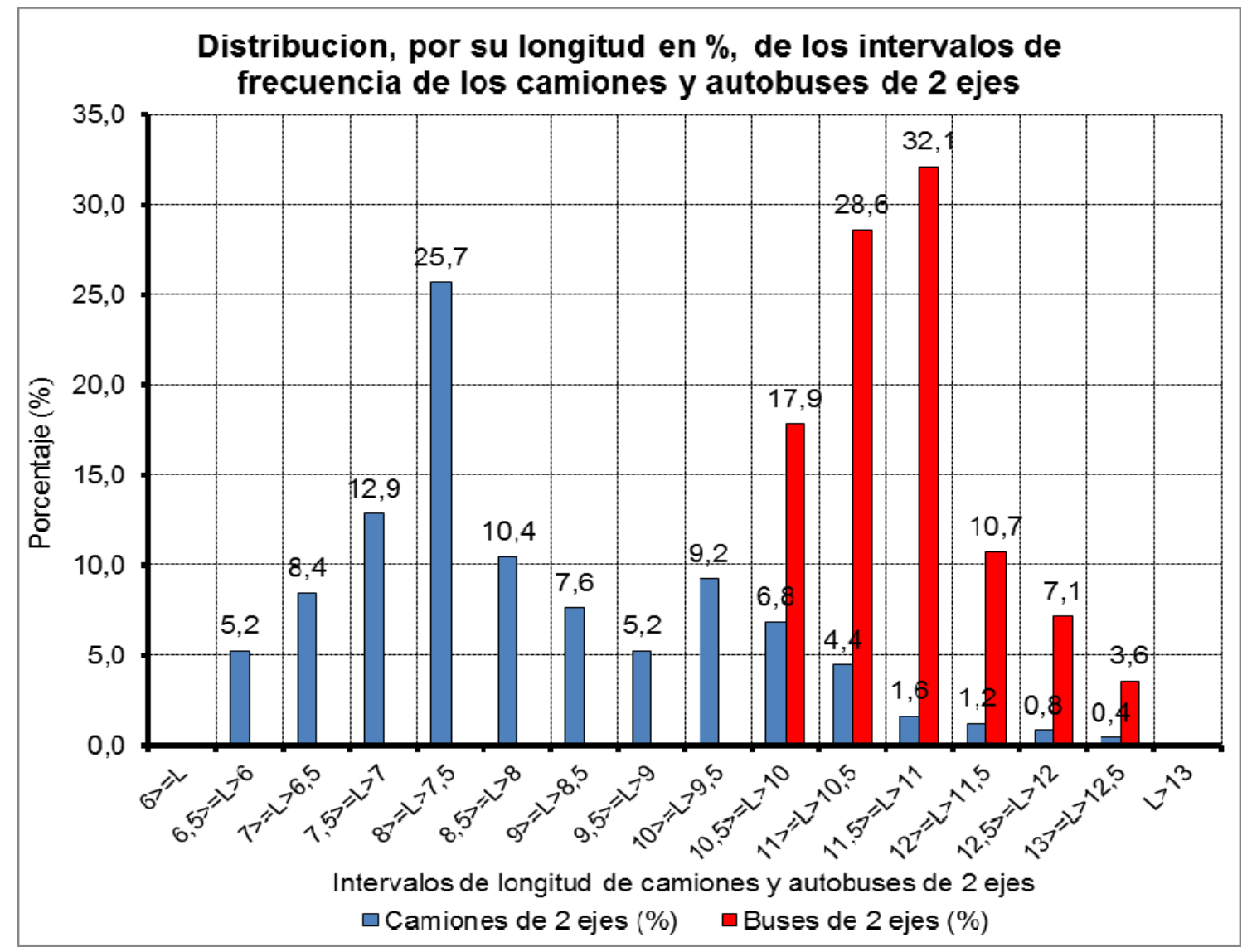

Figura 14. Comparación de las distribuciones de frecuencia de las longitudes de los camiones de 2 ejes y de los autobuses de 2 ejes

Si se observa la Figura 15 que representa la distribución de frecuencias de las distancias entre los ejes de los camiones de 2 ejes y de los autobuses de 2 ejes, se puede comprobar que los máximos de la distribución de los camiones tienen lugar 
entre los 4 y los $5 \mathrm{~m}$, mientras que las de los autobuses de dos ejes se produce entre los $5,5 \mathrm{~m}$ y los $7 \mathrm{~m}$, existiendo un cierto solape en el intervalo de separación entre ejes de 5,5 y $6 \mathrm{~m}$.

Pues bien, teniendo en cuenta todo lo anterior, se decidió imponer como condiciones de separación (distinción) entre ambos tipos de vehículos un valor de la longitud de 11 $m$ y de la separación entre ejes de 5,8 m, de manera que si un vehículo pesado (peso total $>3,5 \mathrm{t}$ ) de 2 ejes supera ambos valores, tanto de longitud como de distancia entre ejes, se le considerará como autobús y en caso de no superar alguno ( o ninguno de ellos), se le considerará camión rígido de 2 ejes.

Es obvio que al existir un cierto solape entre ambos tipos de vehículos en las dos variables (longitud y separación entre ejes), se dará lugar a un cierto porcentaje de error en la clasificación, pero procediendo de esta forma este error se reducirá al mínimo.

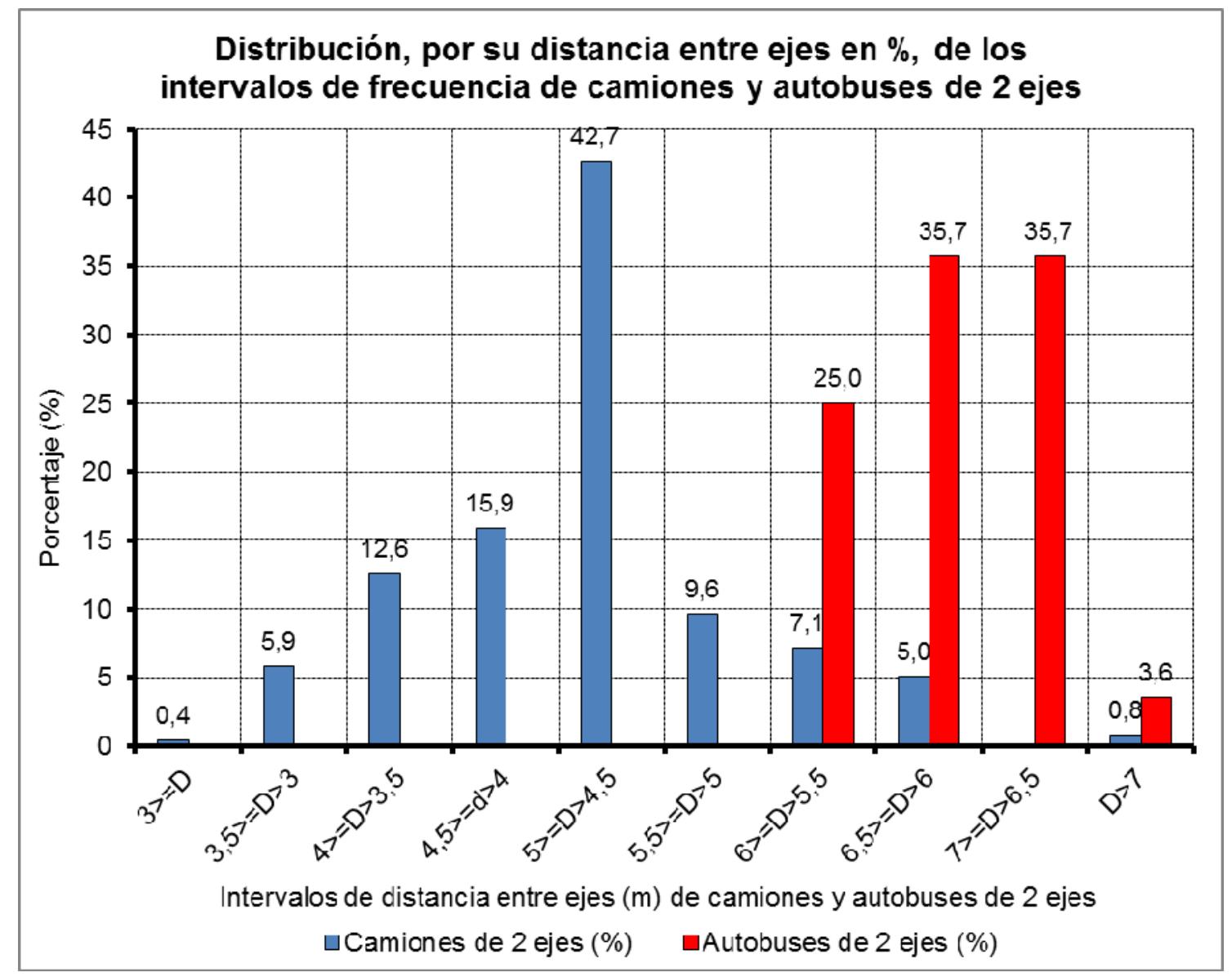

Figura 15. Comparación de las distribuciones de frecuencia de las separaciones entre los dos ejes de los camiones de 2 ejes y de los autobuses de 2 ejes 


\subsubsection{Diferenciación entre camiones de 3 ejes y autobuses de 3 ejes}

Al igual que ocurre en el caso anteriormente expuesto, tanto los camiones de tres ejes como los autobuses de tres ejes son vehículos que no se pueden diferenciar entre sí por su número de ejes ni su peso total, ni siquiera por su tipo de ejes (pues ambos tienen un eje simple delantero y un eje tándem trasero), por lo que para distinguir unos de otros se debe recurrir a otros parámetros en los cuales se puedan observar ciertas diferencias.

Si se representan las frecuencias relativas de los distintos intervalos de longitud tanto de los camiones de 3 ejes como de los autobuses de 3 ejes,se puede comprobar, el máximo de la distribución de longitudes de los camiones de 3 ejes está entre 9 y $11 \mathrm{~m}$, existiendo un porcentaje apreciable de ellos que está entre 11 y $12 \mathrm{~m}$, mientras que solo un 5\% aproximadamente supera los $12 \mathrm{~m}$ de longitud, que es su límite legal de longitud los $12 \mathrm{~m}$ (esto se debe en parte también al error de medición de la longitud por parte del equipo). En comparación, la frecuencia máxima de longitud de los autocares tiene lugar entre los $13 \mathrm{~m}$ y los $15 \mathrm{~m}$, que es su límite legal de longitud máxima. Además, en este caso existe un pequeño solape entre ambos tipos de vehículo entre los 12 y los $13 \mathrm{~m}$, intervalo en el que coinciden aproximadamente un $5 \%$ de los vehículos de ambos tipos.

Si se observa la Figura 16 que representa la distribución de frecuencias de las distancias entre el primer y segundo ejes de los camiones de 3 ejes y de los autobuses de 3 ejes, se puede comprobar que los máximos de la distribución de los camiones tienen lugar entre los 4 y los $6 \mathrm{~m}$, mientras que las de los autobuses de tres ejes se produce entre los 6 y los $8 \mathrm{~m}$, existiendo un pequeño solape en el intervalo de separación entre ejes de 6 y $7 \mathrm{~m}$. 


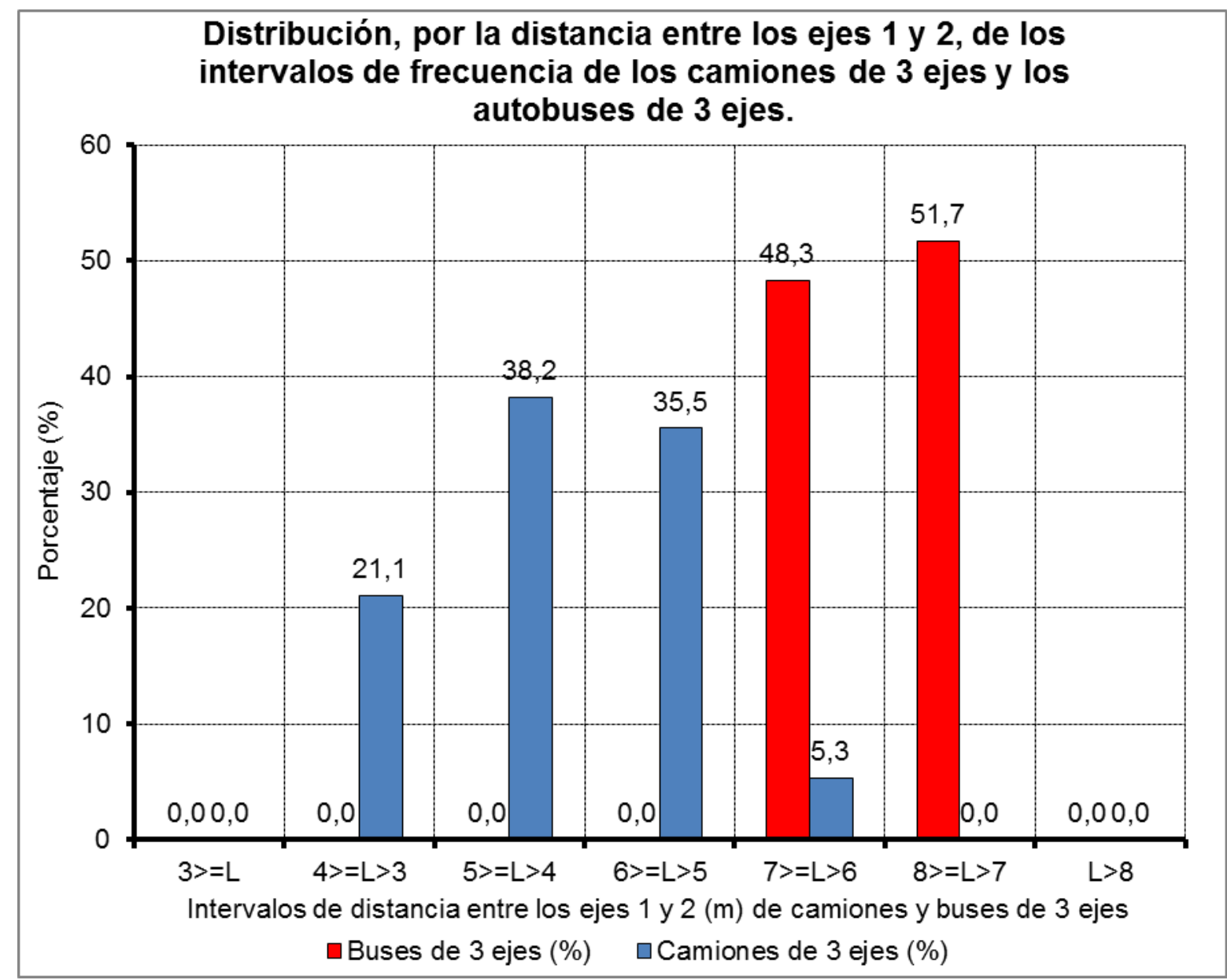

Figura 16. Comparación de las distribuciones de frecuencia de las separaciones entre el primer y el segundo ejes de los camiones de 3 ejes y de los autobuses de 3 ejes

Pues bien, considerando todo lo anterior, se decidió que bastaba imponer como condiciones de separación entre ambos tipos de vehículos un valor de la longitud de 12,4 m (si se supera este umbral, un vehículo pesado de tres ejes será considerado autobús de tres ejes), teniendo en cuenta que en este caso la separación entre ambas distribuciones de longitud es más clara y que prácticamente ningún camión de 3 ejes supera esta longitud.

\subsubsection{Diferenciación entre los articulados de 4 ejes y los trenes de} carretera de 4 ejes, cuando ambos tienen un eje tándem trasero

En relación con estos dos tipos de vehículos de 4 ejes, compuestos en ambos casos por una unidad tractora de 2 ejes simples y un semirremolque o remolque de 2 ejes que forman un eje tándem, podrían existir dos parámetros de diferenciación: la distancia entre los ejes 1 y 2 de las unidades tractoras, pues las cabezas tractoras que tiran de los semirremolque suelen ser más cortas que las de los camiones de dos ejes que arrastran un remolque, y la longitud total del vehículo, pues el límite de longitud de los articulados es de 16,5 m, mientras que el de los trenes de carretera es de 18,75 m. 
A continuación se ha examinado más detenidamente las distribuciones de estos dos parámetros, con objeto de tratar de encontrar diferencias en las que se pueda basar la clasificación de estos dos tipos.

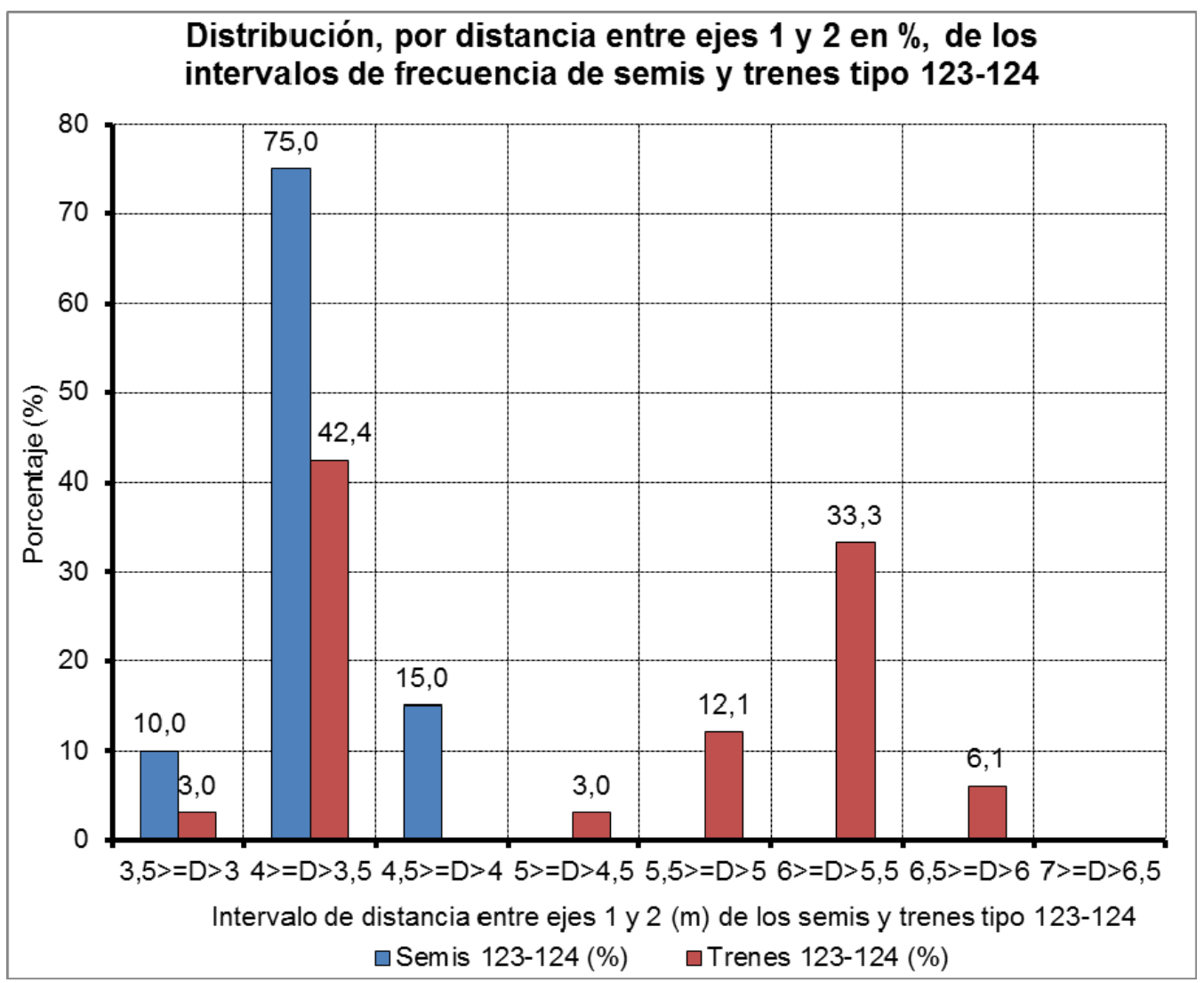

Figura 17. Comparación entre las disitribuciones de las distancias entre el primer y el segundo eje de los articulados de 4 ejes y de los trenes de 4 ejes con tandem trasero.

Como se puede ver en el histograma de frecuencias relativas de las distancias de separación entre ejes de las cabezas tractoras de los articulados y de los camiones de dos ejes (véase la Figura 17), el intervalo de separación entre el primer y segundo eje con frecuencia máxima para las cabezas tractoras está entre los 3,5 y los $4 \mathrm{~m}$, existiendo muy pocas cabezas tractoras que superen los $4,5 \mathrm{~m}$ de distancia entre ejes, pero desafortunadamente el intervalo de frecuencia máxima de la separación entre ejes de los camiones de 2 ejes está también entre los 3,5 y los $4 \mathrm{~m}$, aunque su distribución es mucho más tendida, existiendo un porcentaje grande (aproximadamente un 40\%) de camiones con una separación entre ejes mayor de 5,5 m.

Por otro lado, se tiene el histograma de la Figura 18, que muestra la distribución de frecuencias de los distintos intervalos de longitud de los articulados de 4 ejes y de los trenes de 4 ejes también, ambos tipos con un eje tándem en su parte trasera. El límite legal de longitud de los articulados es de $16,5 \mathrm{~m}$, mientras que el de los trenes de carretera es de 18,75 m, existiendo entre ellos algunos tipos de vehículos a los que se les permite llagar a los 20,25 m (los destinados al transporte de coches). Como se puede ver en dicho histograma, las frecuencias máximas de longitud de los semirremolques aparecen entre los 15 y los $17 \mathrm{~m}$, cercanos a su límite legal o incluso 
sobrepasándolo ligeramente, pues en la práctica existe una cierta holgura en el punto de conexión de la llamada 5a rueda para ensamblar el semirremolque a la cabeza tractora, y muchos camioneros sobrepasan ligeramente ese límite, mientras que los intervalos de frecuencia máxima de longitud entre los trenes están entre los 18 y los 20 metros, pues también existe cierta holgura para realizar el enlace. Sin embargo, existen unos intervalos donde se dan unas pequeñas proporciones de solape de longitud entre los articulados y los trenes, pues hay un $10 \%$ de articulados en que se han medido longitudes de entre 18 y $20 \mathrm{~m}$, mientras que por el otro lado existe una pequeña proporción de trenes (un $6,1 \%$ ) con una longitud entre 16 y 17 metros.

Como se puede comprobar, parece mucho más clara la diferenciación atendiendo al parámetro de la longitud total de los vehículos que si se tiene en cuenta la distancia entre el primer y segundo ejes, aunque en el procedimiento de clasificación desarrollado se prefirió escoger este último parámetro para diferenciar ambos tipos de vehículo, debido a que la precisión del sistema de pesaje dinámico al determinar las distancias entre ejes es mayor que al determinar longitudes de vehículos.

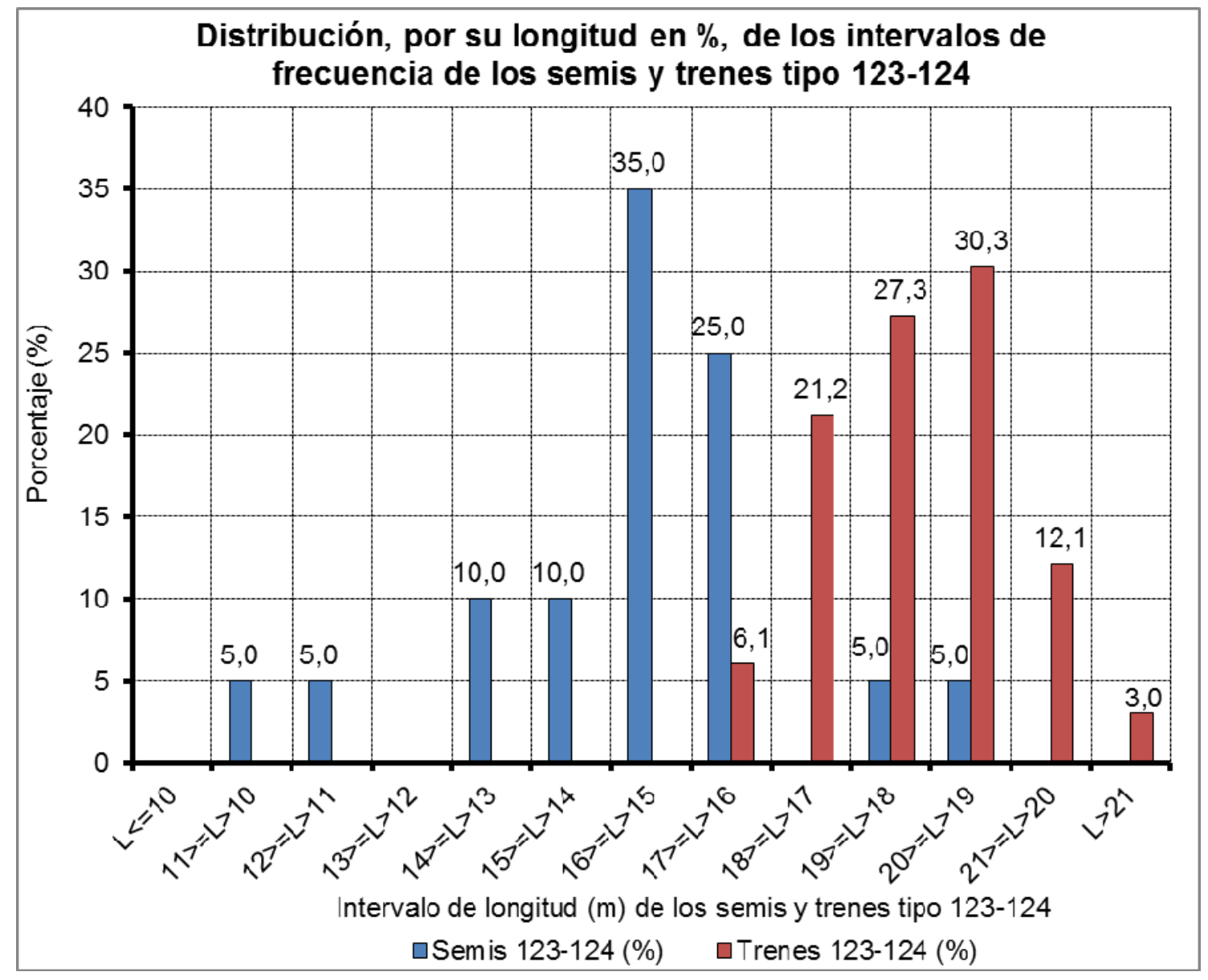

Figura 18. Comparación entre las distribuciones de las longitudes de los articulados de 4 ejes y de los trenes de 4 ejes con tandem trasero. 
5.1.6.1 Diferenciación entre los articulados de 4 ejes con un eje tándem trasero y los articulados de 5 ejes (con eje trídem trasero), cuando llevan el $3^{\circ}$ eje levantado

Estos dos tipos de vehículos articulados (los de 4 ejes y los de 5 ejes) tienen unas características muy similares, tanto en peso total como en longitud, siendo el número de ejes el parámetro más usual de diferenciación entre ambos tipos. Naturalmente, esta fácil posibilidad de diferenciación desaparece en el momento en que un articulado de 5 ejes lleva un eje del semirremolque levantado, por circular descargado, pues en ambos casos el sistema de pesaje dinámico sólo va a detectar 4 ejes. Por tanto, en estos casos, se deberá acudir a otros posibles parámetros de diferenciación, que son los siguientes:

La distancia entre los ejes 2 (el trasero de la unidad tractora) y 3 (el primero del semirremolque), pues al ser la longitud total del vehículo similar en ambos tipos y también la posición del segundo eje de la cabeza tractora, por utilizar ambos tipos cabezas tractoras similares, deberá ser mayor la distancia entre el segundo y el tercer eje detectado en los articulados de 4 ejes que en los de 5 ejes, si llevan el tercer eje elevado, pues la posición del eje trídem es algo más centrada en el semirremolque que la del eje tándem.

El peso total del vehículo, pues en los articulados de 5 ejes que circulan con un eje levantado, normalmente van descargados, con lo cual su peso será menor que el de los articulados de 4 ejes que circulan cargados. En este caso, existirá un cierto solape en el peso total de los articulados de 5 ejes descargados con los articulados de 4 ejes descargados, pero este solape será pequeño (en frecuencia) si uno de los dos tipos es mucho menos numeroso que el otro, lo que ocurre en la composición actual del tráfico pesado con los articulados de 4 ejes.

Igualmente, se ha examinado más detenidamente las distribuciones de estos dos parámetros, con objeto de tratar de encontrar diferencias en las que se pueda basar la clasificación de estos dos tipos.

Como se puede ver en el histograma de frecuencias relativas de las distancias de separación entre el segundo y el tercer eje (véase la Figura 19), el intervalo de frecuencia máxima para los articulados de 4 ejes está entre los 8,5 y los $9 \mathrm{~m}$, aunque existen bastantes entre 6,5 y 7,5 m, que es el intervalo de separación más frecuente entre los ejes 20 y 3 으 de los articulados de 5 ejes que circulan con un eje levantado, por lo que existe bastante solape en este parámetro. 


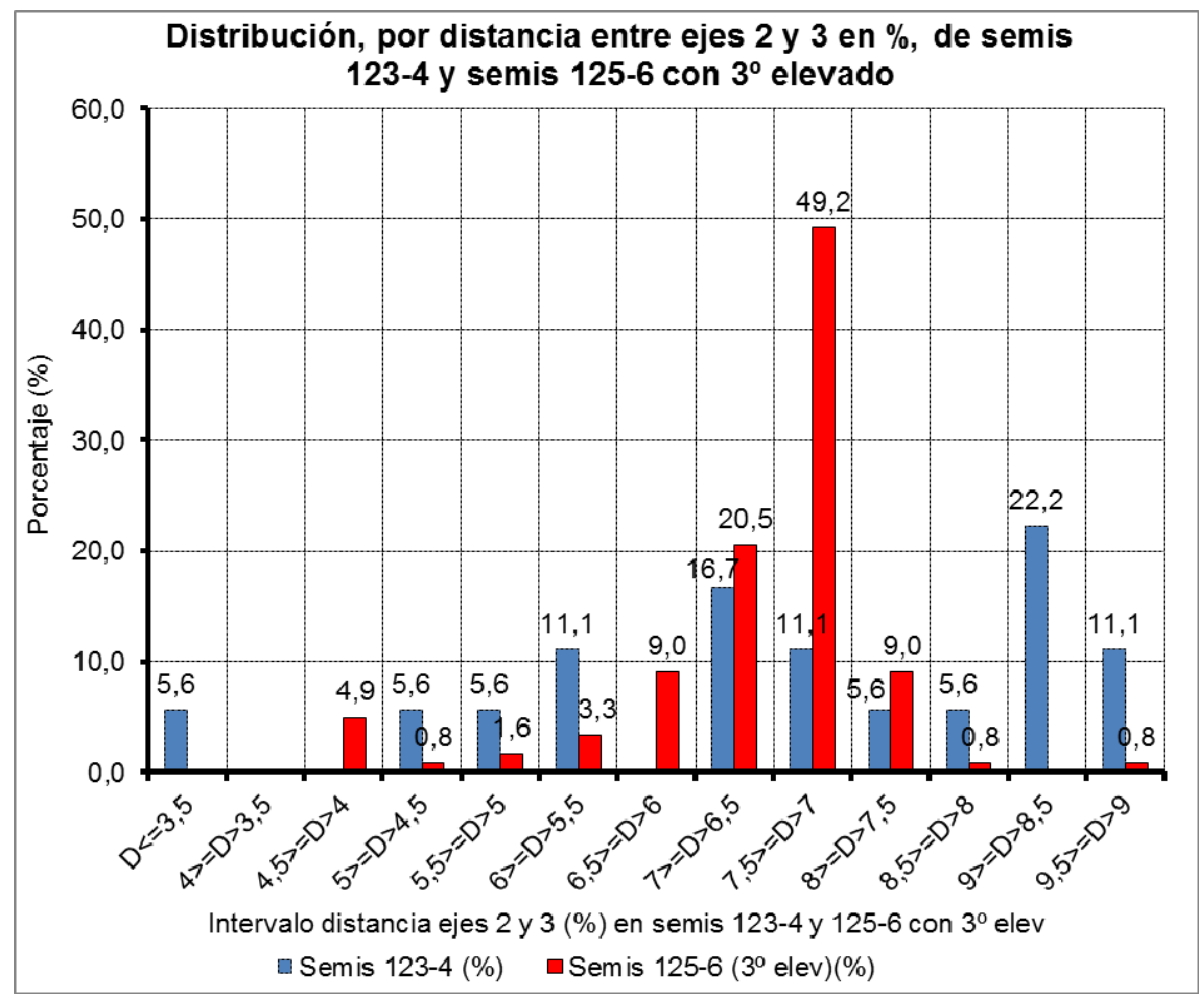

Figura 19. Comparación entre las distribuciones de la distancia entre los ejes 2 y 30 en los articulados de 4 ejes y en los articulados de 5 ejes.

En cuanto a la distribución de frecuencias por peso total en ambos tipos de vehículos, que se muestra en la Figura 20, se comprueba que los intervalos de peso de mayor frecuencia entre los articulados de 4 ejes están bastante repartidos entre las 18 toneladas y las 32 toneladas, mientras que para los articulados de 5 ejes que llevan el 30 eje elevado las frecuencias máximas se dan de forma más marcada entre las 16 t y las 24 toneladas. Parece claro también, tal como se ha comentado, que entre las $18 \mathrm{y}$ las 24 toneladas existe un claro solape de pesos totales entre ambos tipos de vehículos, pero hay que tener en cuenta que estás distribuciones son porcentuales, por lo que que al existir muchos menos vehículos articulados de 4 ejes, en la práctica, el número total de vehículos de uno y otro tipo que se solapan será pequeña.

Teniendo en cuenta lo anterior, en el procedimiento desarrollado se ha escogido únicamente el peso total como parámetro de diferenciación entre los articulados de 4 ejes y los de 5 ejes que circulan con el 3o ejes levantado, estableciéndose un umbral de 28 toneladas, por debajo del cual un vehículo será considerado como articulado de 5 ejes con uno levantado por circular descargado, y por encima de ese umbral será considerado como articulado de 4 ejes. 


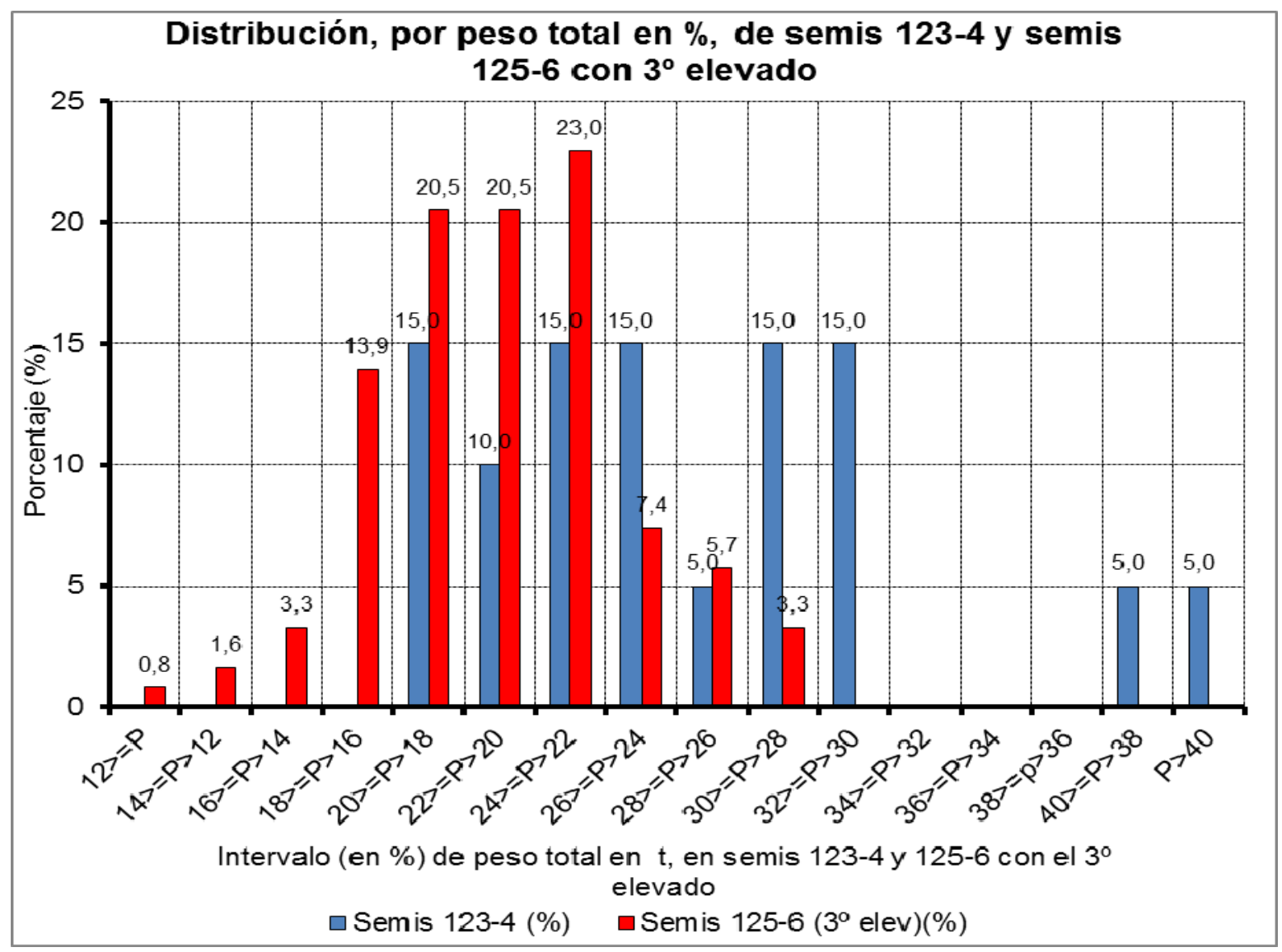

Figura 20 Comparación de las distribuciones de peso de los articulados de 4 ejes con la de los articulados de 5 ejes que circulan con el tercer eje elevado

\subsubsection{Diferenciación entre los camiones rígidos de 2 ejes y los} camiones rígidos de 3 ejes que llevan un eje levantado

El principal parámetro de diferenciación entre los camiones rígidos de dos ejes y los camiones rígidos de tres ejes es el número de ejes detectados por el sistema de pesaje dinámico. Sin embargo, esta diferencia desaparece cuando el de tres ejes lleva un eje elevado sobre el pavimento, pues el sistema de pesaje dinámico sólo será capaz de detectar dos ejes.

Por tanto, para diferenciar estos dos tipos de vehículos cuando el rígido de tres ejes lleva un eje elevado sobre el pavimento se debe atender a otros parámetros, entre los cuales se ha escogido estudiar, como más susceptibles de ayudar a distinguir a los dos tipos de vehículos, los siguientes:

1. La longitud de ambos tipos de vehículos

2. La distancia entre los dos ejes apoyados en el pavimento de los camiones de 2 ejes y de los de 3 ejes que llevan un eje levantado

3. El peso de los camiones de 2 ejes y de los de 3 ejes que llevan un eje levantado.

Para visualizar las distribuciones de estos tres parámetros, se han elaborado los histogramas de frecuencia de las Figuras 21, 22 y 23. 


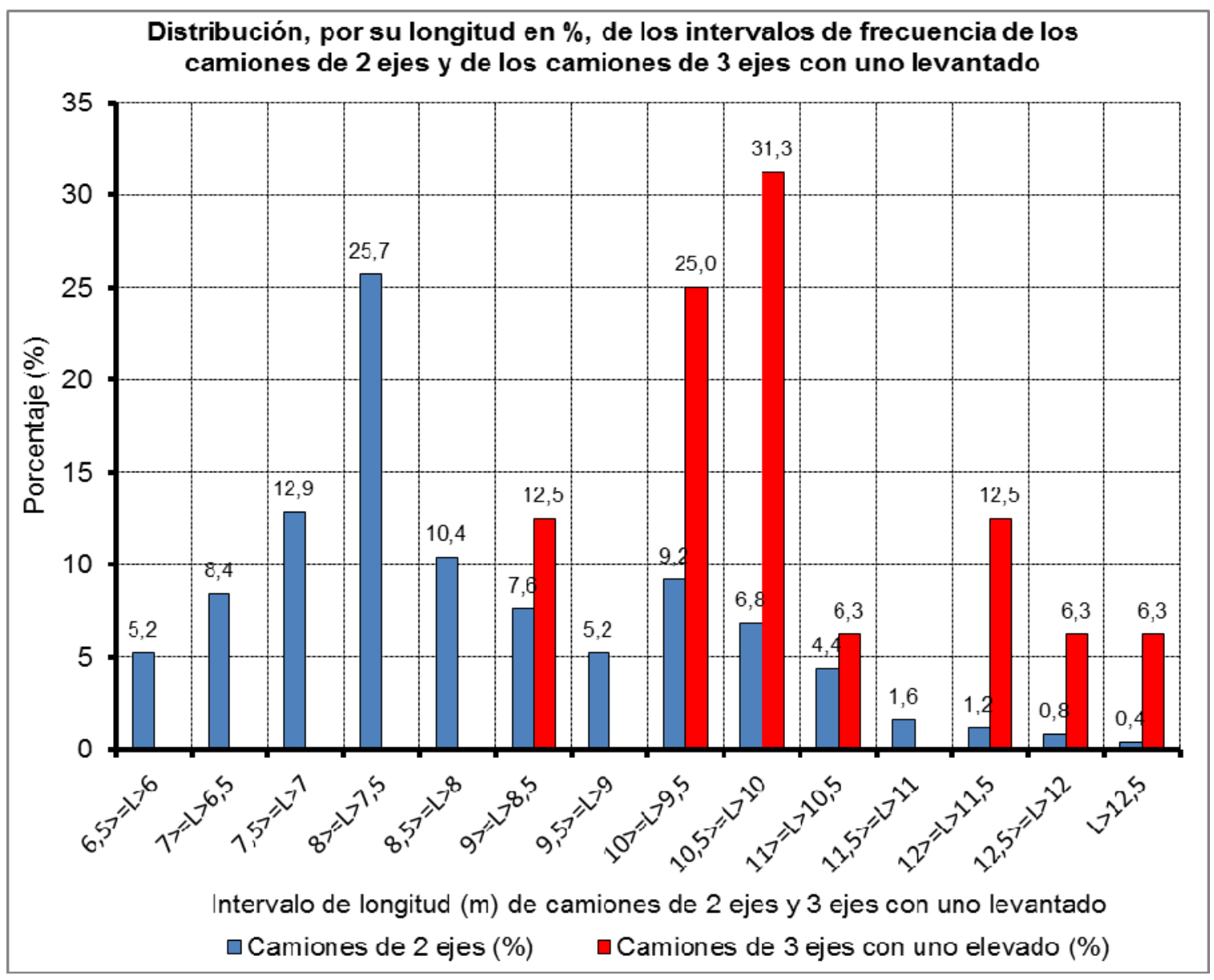

Figura 21. Comparación de las distribuciones de longitud de los camiones rígidos de 2 ejes y de los rígidos de 3 ejes

Como se puede ver en la Figura 21, la distribución de longitud de los camiones de dos ejes es apreciablemente diferente de la de los camiones de tres ejes (Ileven un eje levantado o no), pues aunque tienen el mismo límite legal de longitud (12 m), el valor más frecuente de la longitud de los camiones de dos ejes es entre $7 \mathrm{~m} \mathrm{y} \mathrm{8,5} \mathrm{m}$, mientras que entre los camiones de tres ejes el valor más frecuente es entre $9,5 \mathrm{~m}$ y $10,5 \mathrm{~m}$. No obstante existe un cierto solape entre ambas distribuciones, pues aunque apenas existen camiones de 3 ejes de menos de $8,5 \mathrm{~m}$, en cambio sí que existe un número apreciable de camiones de dos ejes de longitud entre 9,5 y 10,5 m, por lo que se deberá acudir a otros parámetros de diferenciación para mejorar la separabilidad de ambos tipos de vehículos. 


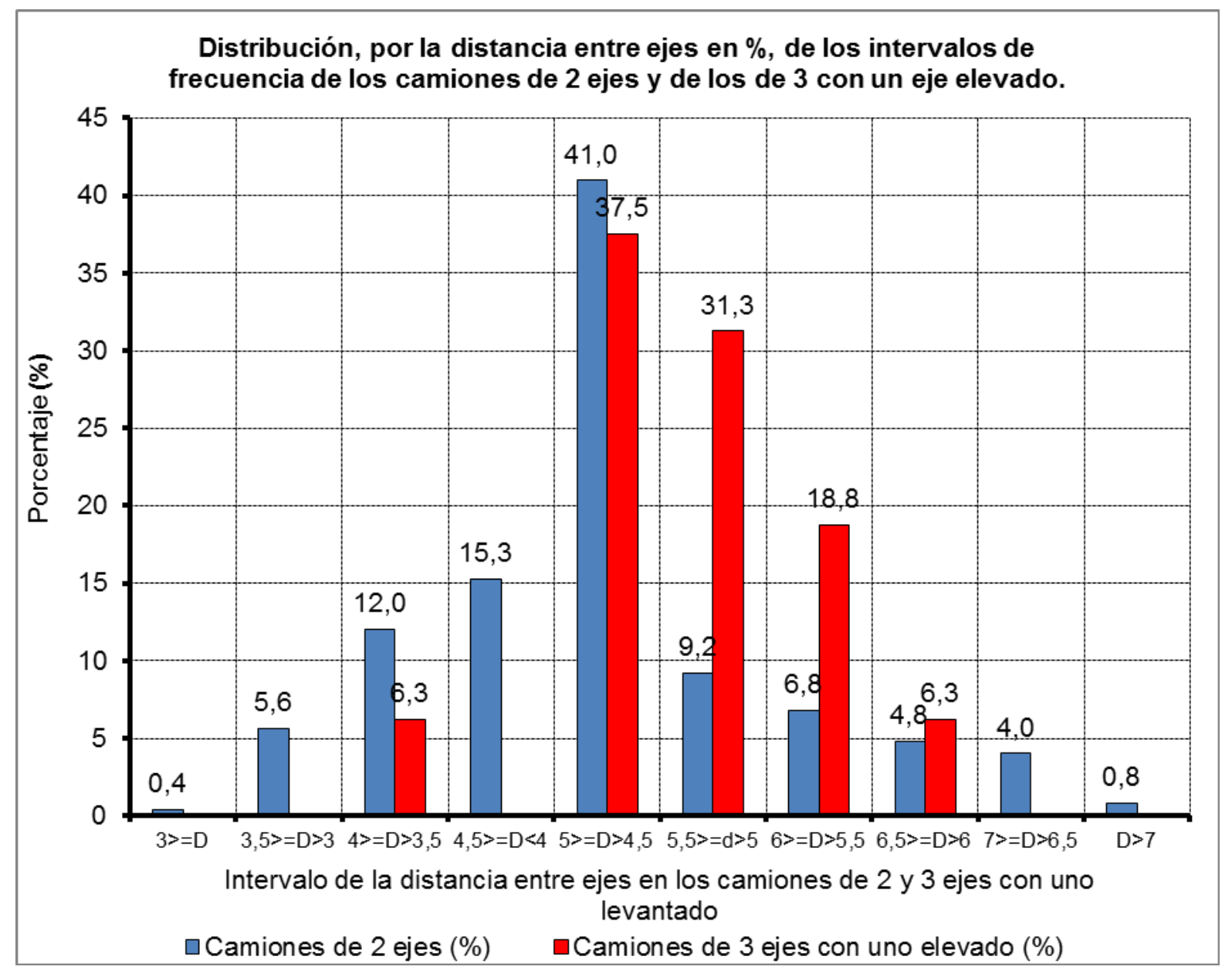

Figura 22. Comparación de las distribuciones de distancia entre los dos ejes apoyados en el pavimento de los camiones de 2 ejes y de los de 3 ejes con el tercer eje levantado.

Teniendo en cuenta lo anterior, se ha buscado otro parámetro cuyos valores pudieran ser diferentes entre los camiones de 2 y de 3 ejes, para que ayudara a distinguir ambos tipos de vehículos. Se ha probado con la distancia entre los dos ejes apoyados en el pavimento de cada tipo de vehículo (véase la Figura 22), pues habiéndose visto que la longitud de los camiones de tres ejes tiende a ser apreciablemente mayor que la de los de dos ejes, sería natural que también lo fuera la distancia entre ejes apoyados.

Sin embargo, a la vista del gráfico de distribuciones de las distancias entre ejes de ambos tipos de vehículo que aparece en la Figura 22, se comprueba que existe bastante solape en esta magnitud en ambos tipos de vehículo, especialmente en el intervalo de separación entre 4,5 m y $5 \mathrm{~m}$, que es el máximo de la dos distribuciones de distancias, por lo cual difícilmente se podrá utilizar este parámetro para distinguir ambos tipos de vehículos. La razón de este fuerte solapamiento entre la separación entre ejes de los dos tipos de vehículo considerados, a pesar de la mayor longitud media del camión de tres ejes, hay que buscarla en que el eje que más frecuentemente aparece levantado es el último eje (el tercero) de los camiones de 3 ejes, estando apoyado en el pavimento el segundo eje (el delantero del tándem trasero), que está 
situado en una posición más adelantada respecto a la cola del vehículo, coincidiendo la separación del eje delantero del tándem con la de la separación entre ambos ejes existente en los camiones de 2 ejes.

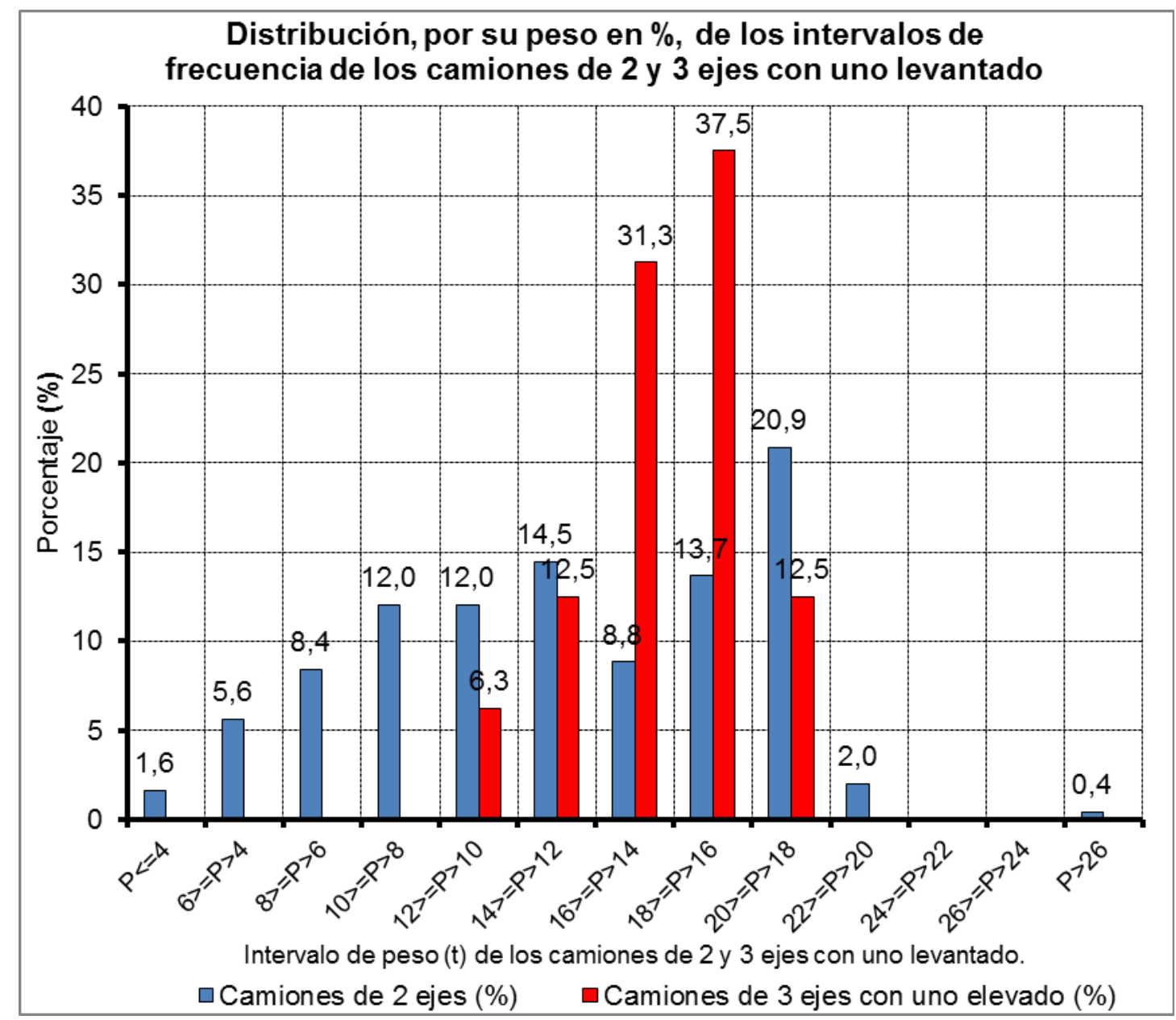

Figura 23. Comparación de las distribuciones del peso total del vehículo para camiones de 2 ejes y camiones de 3 ejes con un eje levantado.

Por tanto, se ha acudido a otro parámetro de posible diferenciación, como es el peso de ambos tipos de vehículo (véase la Figura 23), pues se supone que si el camión de tres ejes lleva un eje levantado es porque circula vacío o casi vacío, con lo cual la distribución de sus pesos se aproximaría a la de las taras de este tipo de vehículo.

No obstante como se puede ver en la Figura 23, existe también un amplio solape entre las distribuciones de peso de los camiones de 2 ejes y la de los camiones de 3 ejes con un eje levantado, en los intervalos de peso de $10 \mathrm{t}$ a $18 \mathrm{t}$. En efecto, en estos intervalos coinciden las distribuciones de peso de los camiones de 2 ejes que circulan cargados con la de los camiones de 3 ejes (que se supone que van vacíos o casi vacíos), no existiendo solape en los intervalos de peso por debajo de las $10 \mathrm{t}$, pues ahí solo existen camiones de 2 ejes, ya que el peso en vacío (tara) de los camiones de 3 ejes suele ser de 10 a $12 \mathrm{t}$.

Por tanto, no se ha podido encontrar un parámetro que haga que ambos tipos de vehículos sean separables con un alto grado de fiabilidad. En consecuencia, para 
considerar a un vehículo como camión de 3 ejes con un eje levantado, se ha puesto como condiciones adicionales que:

1. su longitud sea mayor de 9,5 m (hasta $12 \mathrm{~m}$, el límite legal), aunque se sabe que con esta condición todavía pueden entrar aproximadamente el $20 \%$ de los camiones de 2 ejes,

2. tener un peso total de entre $10 \mathrm{t}$ y $14 \mathrm{t}$, para tener en cuenta que el camión va a circular probablemente vacío (aun a sabiendas de que muchos vehículos de 3 ejes con un eje levantado van a circular con más peso), y

3. tener una distancia entre $1^{\circ}$ y $2^{\circ}$ ejes menor o igual a $5,8 \mathrm{~m}$.

Tal como se ha mencionado, va a existir un cierto número de vehículos de 3 ejes con un eje levantado que no cumplan alguna estas condiciones ( $y$ viceversa, va a existir un número apreciable de camiones de 2 ejes que cumplan alguna de ellas), pero el imponer que se cumplan simultáneamente las tres condiciones va a maximizar la probabilidad de que el vehículo que las cumpla sea un camión de tres ejes con un eje levantado, aunque la probabilidad de acierto no va a ser un $100 \%$. 


\subsection{Presentación y descripción del método de determinación automática del peso de las cargas transportadas por los vehículos}

El pesaje dinámico de vehículos proporciona de forma automática y continua el peso total de cada vehículo que pasa sobre el sistema y de cada uno de sus ejes, además de otros parámetros de los vehículos, como la longitud, la distancia entre ejes y su velocidad.

Tal como se ha comentado en el apartado 4.2.3, las principales aplicaciones del pesaje de vehículos en movimiento han sido hasta ahora la optimización del diseño, mantenimiento y conservación de pavimentos y de puentes, los estudios de tráfico y clasificación de vehículos, y la preselección de vehículos sobrecargados (para detectar todos los vehículos que sobrepasan un cierto peso umbral, y desviarlos a una báscula en un área adyacente a la carretera para su pesaje estático). Además, existe el objetivo a corto-medio plazo de conseguir que los sistemas de pesaje dinámico sean capaces de medir los pesos con una precisión suficiente como para poder efectuar su control legal directo.

Sin embargo, hasta ahora no ha sido posible obtener de forma automática mediante el pesaje dinámico un dato de gran utilidad tanto en cuestiones comerciales como en economía del transporte: el peso de la carga transportada por los vehículos.

\subsubsection{Planteamiento general del método}

El peso de la carga que transporta un vehículo, en principio, puede calcularse como la diferencia entre su peso total y la tara del vehículo. Si se pretende obtener este peso de la carga transportada, aunque sea de forma aproximada, sobre grandes muestras de vehículos (o incluso sobre la población total), deberá idearse un procedimiento que se base en la recogida automática de datos, que como se ha explicado en el apartado 4.1.13 "Ventajas e inconvenientes y aplicabilidad de cada tecnología (de toma de datos del tráfico) para su empleo en la clasificación de vehículos y en la medida de pesos y cargas" solo puede realizarse con sistemas de pesaje dinámico de vehículos.

En efecto, utilizando este tipo de equipos de pesaje se puede obtener automáticamente y de forma continua tanto el peso de los vehículos como su clasificación, que puede servir para estimar su tara de forma aproximada. Sin embargo, el problema para realizar la anterior operación estriba en que tanto el peso del vehículo proporcionado por el equipo de pesaje dinámico como la tara obtenida a partir de su clasificación son magnitudes sobre las que existe un alto grado de incertidumbre

Comenzando por la tara de los vehículos basada en su clasificación automatizada, es necesario recalcar en primer lugar que esta clasificación siempre está sujeta a errores, especialmente para algunos tipos de vehículo. Pero, además, incluso aunque la clasificación sea correcta, dentro de cada tipo de vehículos existe una amplia 
variabilidad de taras, pues los camiones de cada tipo pueden estar dedicados al transporte de diferentes tipos de carga (bañeras de obra, cisternas, frigoríficos, portacontenedores, etc) que hacen que exista una cierta dispersión de taras dentro del mismo tipo de vehículos, como se verá posteriormente en el apartado 5.2.3 "Bases de datos de las taras de los vehículos".

Entrando en profundidad en el otro término de la operación, el peso total del vehículo proporcionado por el sistema de pesaje dinámico, podría parecer en un principio que es una cantidad bastante estable en relación con el peso real del vehículo, del que al menos se podría determinar la magnitud de su desviación con respecto a éste. Sin embargo, esto no es tan directo, pues tal como se explica detenidamente en el artículo [22] realizado por el autor de esta Tesis, la fuente de más importante de errores en los sistemas de pesaje en movimiento tiene su causa en que lo que realmente miden estos sistemas son las fuerzas que ejercen los neumáticos de los vehículos sobre el pavimento, que tienen una componente de tipo dinámico debida a la vibración del vehículo al ser excitado por la superficie del firme. Debido a este efecto puede variar apreciablemente el peso obtenido por un sistema de pesaje dinámico del peso medido en una báscula estática, que puede considerarse como el real.
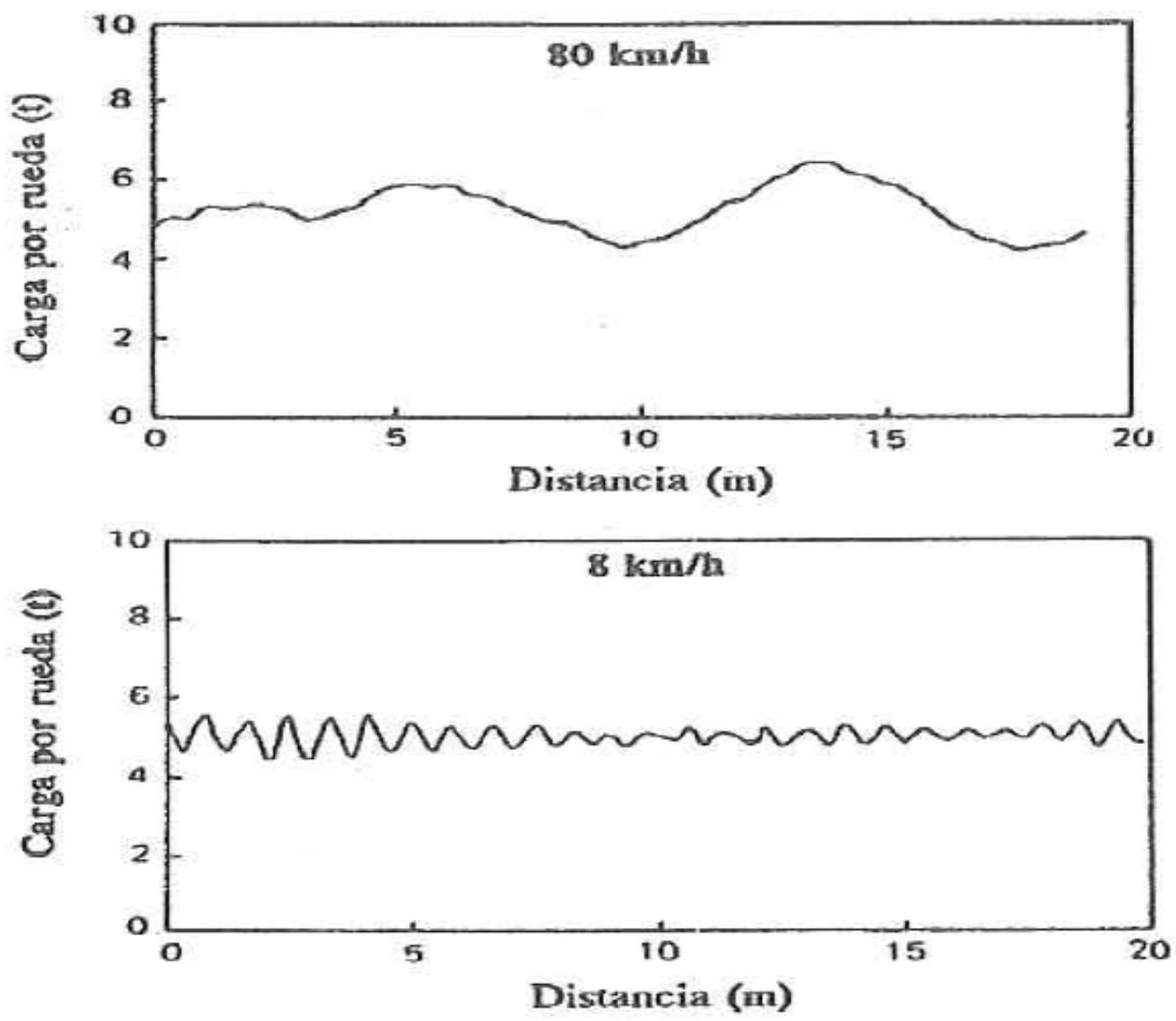

Figura 24. Variación de las cargas de un vehículo a diferentes velocidades [42].

En algunos estudios se ha tratado de evaluar el valor de la amplitud de estas oscilaciones, como el llevado a cabo por S. Ma y M. Caprez [43], que determinó que la 
amplitud de oscilación puede llegar a un $40 \%$ o un $50 \%$ de la carga estática en pavimentos en estado deficiente con $\mathrm{PSI}=2$, debiendo de tener el pavimento como mínimo un PSI $=3,5$ para que estas cargas dinámicas no superen el $15 \%$ para una velocidad del vehículo de $80 \mathrm{~km} / \mathrm{h}$.

El problema que plantea esta circunstancia proviene de que el sensor de peso queda instalado en un punto determinado de la carretera, y solamente podrá medir la carga aplicada por el vehículo en ese lugar, que constituye un punto de la función de variación en el espacio de su carga dinámica, pudiendo apartarse bastante de su peso estático (alrededor de un $\pm 20 \%$ de su valor en firmes en buen estado), que es normalmente la magnitud que se pretende medir.

Como consecuencia, aunque los anteriores efectos se pueden corregir en gran medida con una adecuada calibración, será de gran importancia instalar los sensores en un pavimento cuyas características superficiales sean suficientemente buenas como para acotar los efectos dinámicos de las cargas y de esta forma mejorar la exactitud de sus medidas.

Por tanto, teniendo en cuenta las anteriores incertidumbres, se va a establecer un procedimiento totalmente automático para la determinación de las cargas transportadas por los vehículos pesados mientras circulan por la carretera, mediante la utilización de sistemas de pesaje dinámico, en el cual se va a estudiar en profundidad el error (tanto de cada vehículo individual como del conjunto de vehículos que constituye el tráfico de una carretera) que se comete al seguir este método aproximado frente a los valores reales de estas cargas transportadas, con objeto de tratar de limitar su magnitud y permitir su aplicabilidad en condiciones reales en la carretera.

\subsubsection{Exposición detallada del método de determinación automática de la carga transportada}

Para comenzar, es claro que el peso total de cada vehículo se corresponde con la suma de la tara del vehículo más el peso de la carga que transporta, es decir:

Peso total del vehículo $=$ Tara del vehículo + Peso de la carga transportada

Por tanto, si se desea obtener el peso de la carga que transporta un vehículo, éste podría obtenerse realizando la operación:

Carga transportada $=$ Peso Total vehículo (medido con WIM) - Tara (desconocida)

El problema para realizar la anterior operación estriba, como se ha dicho, en que no se puede conocer directamente la tara de cualquier vehículo pesado que pase sobre el equipo de pesaje, por lo que la cuestión que se deberá resolver para calcular la carga transportada, estará en realizar, de forma automática, una estimación de la tara de cada vehículo, que sea suficientemente precisa. 
La forma más fácil y directa de llevar esto a cabo sería asignar a todos los vehículos pesados de transporte la tara media de todo el parque de vehículos pesados, pero es obvio que, dada la diversidad de vehículos pesados de transporte existentes, este procedimiento no produciría resultados medianamente ajustados, por lo que se debería afinar más en dicha estimación. Parece claro que si se pudiera distinguir de forma automática, al menos, entre las tres grandes clases de vehículos pesados existentes (camiones rígidos, articulados y trenes de carretera), la precisión en la estimación de la tara para cada una de estas tres clases de vehículos de trasporte mejoraría.

Si se pudiera desglosar a su vez estas tres grandes clases mencionadas de vehículos pesados en tipos más homogéneos, se podría minimizar el error que se comete al asignar a cada vehículo la tara media correspondiente al tipo específico al que pertenece. Obviamente, este paso debería apoyarse en una determinación automática bastante detallada y fiable de la silueta (composición) del tráfico, operación que se podría apoyar en el sistema de clasificación desarrollado en el Apartado 5.1.

Por otro lado, para poder asignar como tara de cada vehículo de un tipo determinado a la tara media del tipo de que se trate se deberá disponer de los datos de las taras medias de cada tipo de vehículo. De las diferentes bases de datos que existen sobre las características de los vehículos, algunas se refieren al parque de general de vehículos (como es el Registro General de Vehículos, de la Dirección General de Tráfico), otras a los vehículos nuevos que se venden cada año (datos de los fabricantes o de los carroceros) y otras a los vehículos que circulan por la carretera (provenientes de datos de campañas de pesaje o de encuestas a los transportistas). Posteriormente se explicará cada una de ellas.

En resumen, el procedimiento de determinación automática del peso de las cargas transportadas que se desarrolla en este artículo se basará en llevar a cabo los siguientes pasos:

1- Determinación automática del peso total de cada vehículo, que será directamente el peso medido en la carretera proporcionado por el sistema de pesaje dinámico.

Con ello se obtendría lo que se denominará el peso dinámico total del vehículo, de forma abreviada, Pdin, que normalmente se diferenciará en alguna medida del peso real del vehículo, que a efectos prácticos puede considerarse como el que es obtenido en una báscula de pesaje estático homologada, que se designará como Pest, y que puede considerarse como el peso verdadero.

2- Clasificación de forma también automática de cada vehículo según un esquema de silueta (composición) del tráfico lo más detallada posible, acción que realizará también el sistema de pesaje dinámico (o un ordenador auxiliar que contenga el programa de clasificación). 
De esta forma, se obtendrá el tipo estimado de vehículo, que la mayor parte de las veces coincidirá con el tipo real, si el procedimiento de clasificación ha sido suficientemente exacto, aunque podrá diferir en algunos casos.

3- Asignación a cada vehículo de una tara, cuyo valor se corresponderá con el del estimador más fácil de obtener, que es la tara media del tipo en que ha sido clasificado por el sistema de pesaje dinámico.

Es decir, que en el proceso de cálculo se sustituirá el valor de la tara real de cada vehículo (normalmente desconocida) por una tara estimada, que por principio se ha establecido que tendrá como valor el de la tara media del tipo de vehículos al que pertenece el vehículo en cuestión.

4- Cálculo de la carga transportada por cada vehículo, restando del peso del vehículo proporcionado por el sistema de pesaje dinámico la tara asignada al vehículo en cuestión (la media del tipo en el que ha sido clasificado).

Por tanto, la carga transportada estimada (designada como carga estimada) equivaldrá al peso dinámico (Pdin) del vehículo menos su tara estimada.

Carga estimada $=$ Pdin - Tara estimada

Esta carga estimada que transporta el vehículo, en principio, diferirá de la carga real del vehículo, que será igual al peso real (estático) del vehículo, Pest, menos la tara real del vehículo.

$$
\text { Carga real }=\text { Pest }- \text { Tara real }
$$

Es decir, que el método producirá una estimación de la carga transportada, que se denominará carga estimada, que tendrá un cierto error en relación con la carga real, cuyo valor vendrá dado por la expresión:

$$
\text { Error absoluto }=\text { Carga estimada }- \text { Carga real }
$$

Y el error relativo vendrá dado por la expresión:

$$
\text { Error relativo }(\%)=(\text { Error absoluto } / \text { Carga real }) \cdot 100
$$

De todos los pasos del anterior proceso, el que entraña una mayor dificultad es la asignación a cada vehículo de una tara media correspondiente al tipo al que pertenece, pues requiere un estudio cuidadoso, basado en el análisis de la variabilidad de la tara media de los vehículos de cada tipo, todo ello con objeto de maximizar la precisión en la estimación de la carga transportada. Uno de los estudios que se lleva a cabo en este documento consiste en determinar el error que se comete al sustituir la carga real transportada (en principio, desconocida, salvo que se realice un ensayo en que se pese estáticamente al vehículo y, además se conozca su tara real) por la carga 
estimada, que se puede determinar automáticamente según el procedimiento que se acaba de explicar.

\subsubsection{Bases de datos de las taras de los vehículos}

Como se ha expuesto en el apartado anterior, en el que se ha presentado el método de estimación de la carga transportada, para llegar a determinar este resultado se deberá restar del peso proporcionado para cada vehículo por el sistema de pesaje dinámico, un peso en vacío o tara, que sea lo más ajustado posible a la tara real de éste. Para ello, se deberá disponer de los datos de las taras medias de cada tipo de vehículo, con el fin de asignar a cada vehículo la tara media del tipo al que supuestamente pertenezca, que será el tipo en el que sea clasificado automáticamente por el sistema de pesaje dinámico.

En consecuencia, para conseguir este objetivo, el procedimiento debe apoyarse en:

- Lograr una clasificación muy detallada, en tipos de vehículos que sean lo más homogéneos posible.

- Poseer una base de datos de las taras de los vehículos existentes o que circulan por la carretera, que permita estimar la tara media de cada tipo de vehículo con suficiente exactitud respecto a la del tráfico de la carretera.

De las diferentes bases de datos que existen sobre las características de los vehículos, éstas se pueden clasificar en dos grandes grupos:

- Las que se refieren al parque de vehículos existente. Entre éstas bases de datos se puede citar la del Registro General de Vehículos, de la Dirección General de Tráfico, que incluye los datos del parque total de vehículos en España, y las bases de datos de los fabricantes y carroceros sobre las características de los vehículos nuevos que se venden cada año.

- Las que se refieren al parque de vehículos circulante, que es el que se mueve en cada momento por una red de carreteras (por ejemplo, la red total de carreteras interurbanas de España, la Red de Carreteras del Estado, la Red de cada una de las Comunidades Autónomas o de las Diputaciones) o por alguna carretera en particular. Entre estas bases de datos se pueden citar la de las campañas de pesaje dinámico realizadas por el CEDEX en la Red de Carreteras del Estado y la base de datos de la Encuesta Permanente del Transporte de Mercancías por Carretera, que se correspondería con el parque circulante en la red total de carreteras interurbanas de nuestro país.

A continuación, se exponen las características principales de cada una de las cuatro bases de datos de características de los vehículos que se acaban de citar.

El orden en el que se van describir estas bases de datos no será el que parece más natural, que es el que se acaba de mencionar, es decir, comenzar por las bases de datos del parque de vehículos existente y pasar después a las bases de datos del parque circulante, sino que se explicarán partiendo del orden en el que han sido 
recibidos los datos de cada una de ellas. Por eso, como las bases de datos del parque circulante fueron obtenidas antes, comenzando por la base de datos de la campaña de pesaje dinámico realizada por el CEDEX entre 2000 y 2003, en la cual participó el autor de esta Tesis, se describirá ésta en primer lugar. Además, como se conocen en profundidad los supuestos en que se basó la recogida y el tratamiento de la información contenida en la base de datos de la campaña de pesaje 2000-2003 del CEDEX, así como su fiabilidad, será ésta base la que sirva de referencia en los cálculos que se van a exponer en apartados posteriores.

Después de la base de datos de la campaña de pesaje del CEDEX, se continuará con la de la Encuesta Permanente del Transporte de Mercancías por Carretera (EPTMC) y luego se pasarán a describir las bases de datos relativas al parque de vehículos, que son la del Registro General de Vehículos de la DGT y, por último, la de los fabricantes y carroceros de camiones, remolques y semirremolques.

\subsubsection{Base de datos de las campaña de pesaje dinámico realizada por} el CEDEX en la RCE

Esta base se refiere a los datos de una muestra de 35.538 vehículos pesados cuyos datos fueron recogidos en la última campaña de pesaje dinámico realizada por el CEDEX en la Red de Carreteras del Estado (RCE), que se llevó a cabo entre los años 2000 y 2003. Esta muestra se recogía durante 6 horas simultáneamente a la realización de los pesajes en cada una de las 70 estaciones de la campaña.

Por tanto, de todos los datos obtenidos en esta muestra de cada uno de los vehículos, algunos fueron recogidos automáticamente por los sistemas de pesaje dinámico utilizados en la campaña (como pueden ser la longitud de los vehículos, el número de ejes (apoyados sobre el pavimento) de cada vehículo, o la separación entre cada uno de estos dos ejes); mientras que otros datos de los mismos vehículos fueron tomados visualmente en la carretera por unos operarios al mismo tiempo que se realizaban los pesajes, recogiéndose de esta forma una información que no podía ser captada por el equipo de pesaje dinámico, como son las taras y los PMA de los vehículos, si los ejes eran de rueda sencilla o gemela, si el vehículo llevaba ejes levantados sobre el pavimento, la matrícula, etc.

Estos datos tomados visualmente son de gran valor, pues por un lado sirven de comprobación de algunas de las características de los vehículos obtenidas automáticamente (por ejemplo, el número de ejes de cada vehículo) y, por otro, proporcionan información sobre algunos parámetros importantes, como es la tara o la antigüedad de los vehículos.

Uno de los resultados de más interés práctico de esta muestra fue la realización de unas Tablas en las que se exponían los valores obtenidos sobre ciertos parámetros de los vehículos (tara, longitud, distancia entre cada dos ejes), incluyendo su valor medio y su desviación típica, desglosados en más de 30 tipos de vehículos, pues al tratarse de una muestra tomada visualmente por operarios muy entrenados, se pudo diferenciar entre los distintos tipos de vehículos no sólo en cuanto a su número de ejes y la 
configuración de estos, sino atendiendo también a otros parámetros, como eran la existencia de ejes de rueda sencilla o gemela, o el tipo de vehículo (furgón, camión) y de carga (cisterna, bañera de obra, plataforma, volquete, portacontenedores, frigorífico, etc).

En la Tabla 15 se muestra el valor promedio de las taras obtenidas en la base en la campaña de pesaje dinámico 2000-2003 para cada uno de los tipos agrupados de vehículos que se pueden obtener para su clasificación automática, así como los valores de dispersión de las taras de cada tipo respecto a sus valores medios. Las casillas que figuran en blanco se refieren a tipos de los cuales no se registraron vehículos en la campaña 2000-2003.

Tabla 15. Valores promedio de las taras de los distintos tipos de camiones registrados en la muestra visual de la campaña de pesaje dinámico 2000-2003 realizada por el CEDEX, así como desviación típica absoluta y porcentual de las taras de cada tipo respecto a su valor medio.

\begin{tabular}{|l|r|r|r|}
\hline \multicolumn{4}{|c|}{ Campaña de pesaje CEDEX 2000-2003 } \\
\hline Tipo de vehículo & Tara media tipo (kg) & Desv. típica (kg) & Coef. Varia (\%) \\
\hline Camión 2 ejes & 6372 & 2005 & 31,5 \\
Camión 3 ejes & 11386 & 985 & 8,7 \\
Camión 4 ejes & 13917 & 546 & 3,9 \\
Camión de más de 4 ejes & & & 7,0 \\
\hline Tractor 2 ejes + semirremolque 1 eje & 13638 & 948 & 7,5 \\
Tractor 2 ejes + semirremolque 2 ejes & 14085 & 1055 & 7,3 \\
Tractor 2 ejes + semirremolque 3 ejes & 14669 & 1065 & 1,5 \\
Tractor 3 ejes + semirremolque 2 ejes & 17250 & 250 & \\
Tractor 3 ejes + semirremolque 3 ejes & & & 10,0 \\
Tractor + semirremolque: otras comb. & & & 10,3 \\
\hline Tren: Camión 2 ejes-Remolque 1 eje & 12917 & 1294 & 8,2 \\
Tren: Camión 2 ejes-Remolque 2 ejes & 13187 & 1352 & 7,7 \\
Tren: Camión 2 ejes-Remolque 3 ejes & 15874 & 1301 & \\
Tren: Camión 3 ejes-Remolque 2 ejes & 16213 & 1246 & \\
Tren: Camión 3 ejes-Remolque 3 eje & & & \\
Tren. Camión y remolque: otras comb. & & & \\
\hline
\end{tabular}

\subsubsection{Base de datos de la Encuesta Permanente de Transporte de} Mercancías por Carretera (EPTMC)

La Encuesta Permanente del Transporte de Mercancías por Carretera se trata de una encuesta realizada a los transportistas mediante el envío postal de un cuestionario de actividad semanal de una muestra suficiente de vehículos, repitiéndose este proceso durante las 52 semanas del año; de ahí la denominación de "encuesta permanente" [44]. 
El tamaño de la muestra es de 41.600 vehículos entrevistados al año. El ámbito de estudio o población de referencia son los vehículos autorizados para el transporte pesado de mercancías por carretera, es decir, los vehículos en disposición de la tarjeta que bien el Ministerio, bien la Comunidad Autónoma correspondiente, otorga para la habilitación de la actividad del transporte de mercancías.

El transporte cubierto por la Encuesta es el denominado transporte pesado, que de acuerdo con el Reglamento de la Ley de Ordenación del Transporte Terrestre (LOTT), son los vehículos con más de 6 toneladas de peso y más de 3,5 toneladas de capacidad de carga.

Los vehículos incluidos son los vehículos de tracción, es decir, tanto los vehículos rígidos como las cabezas tractoras, que cumplen las condiciones de vehículos pesados.

Lo que se investiga en esta encuesta son tanto las operaciones interurbanas de transporte como los viajes realizados por los vehículos. En la Encuesta se recogen únicamente los desplazamientos que supongan la salida de un mismo término municipal, es decir, quedan excluidos los desplazamientos dentro de un mismo municipio.

Las variables recogidas en la EPTMC son:

Relativas a los vehículos:

- Tipo de servicio

- Ámbito de autorización

- Antigüedad

- Capacidad de carga

- PMA

- № de ejes

Del vehículo remolcado:

- Capacidad de carga

- PMA

- № de ejes

Relativas a las operaciones de transporte:

- Día de la semana de comienzo

- Origen (municipio)

- Destino (municipio

- Distancia recorrida

- Carga transportada

- Tipo de mercancías (NSTR)

- Tipo de operación

- toneladas-km

- la pertenencia de la mercancía a alguna clase ADR de mercancía peligrosa

- El precio del servicio (en esta variable la falta de respuesta es del 20 al 40\%) 
El procedimiento utilizado para realizar la Encuesta consiste en las siguientes fases:

- Primeramente, en realizar una estratificación de la población de vehículos autorizados.

- Selección aleatoria de la muestra, realizada por la Dirección General del Transporte Terrestre, a partir de las instrucciones de la Subdirección General de Estadística del Ministerio de Fomento. La muestra anual se fija en 41.600 vehículos, que repartida entre las 52 semanas del año, lo que supone que semanalmente se investiga la actividad de 800 vehículos.

- Trabajos de campo, enviándose los 800 cuestionarios semanales además de otros 200 de muestra suplente.

- Validación de la información

- Explotación de los resultados, calculando los estimadores correspondientes

- Publicación y difusión de los resultados.

Para el estudio realizado en este documento, se ha dispuesto de los datos de una de las Encuestas más recientes, la del año 2013. En la Tabla 16 se muestran los valores promedio de las taras de cada tipo de vehículo de la Encuesta Permanente del Transporte de Mercancías del citado año 2013, así como los valores de dispersión correspondientes.

Tabla 16. Taras medias de cada tipo de vehículo obtenidas en la Encuesta Permanente del Transporte de Mercancías por Carretera (EPTMC) de 2013, así como desviación típica absoluta y porcentual de las taras de cada tipo.

\section{Encuesta Permanente del Transporte de Mercancías por Carretera (EPTMC) 2013}

\begin{tabular}{|l|r|r|r|}
\hline Descripción & Tara media tipo $(\mathrm{kg})$ & Desv. típica (kg) & Coef. Varia (\%) \\
\hline Camión 2 ejes & 7905 & 2570,8 & 32,5 \\
Camión 3 ejes & 12250 & 2111,8 & 17,2 \\
Camión 4 ejes & 14396 & 2423,1 & 16,8 \\
Camión más de 4 ejes & 11053 & 1303,2 & 11,8 \\
\hline Tractor 2 ejes + semirremolque 1 eje & & & \\
Tractor 2 ejes + semirremolque 2 ejes & 13084 & 3574,2 & 27,3 \\
Tractor 2 ejes + semirremolque 3 ejes & 14524 & 2275,0 & 15,7 \\
Tractor 3 ejes + semirremolque 2 ejes & 9273 & 4178,7 & 45,1 \\
Tractor 3 ejes + semirremolque 3 ejes & 14116 & 3204,0 & 22,7 \\
Tractor + semirremolque: otras comb. & 15128 & 6122,9 & 40,5 \\
\hline Tren: Camión 2 ejes-Remolque 1 eje & 8000 & 0,0 & 0,0 \\
Tren: Camión 2 ejes-Remolque 2 ejes & 17316 & 3724,6 & 21,5 \\
Tren: Camión 2 ejes-Remolque 3 ejes & 17709 & 3998,5 & 22,6 \\
Tren: Camión 3 ejes-Remolque 2 ejes & 17751 & 3711,4 & 20,9 \\
Tren: Camión 3 ejes-Remolque 3 eje & 18448 & 4161,9 & 22,6 \\
Tren. Camión y remolque: otras comb. & 16754 & 4069,6 & 24,3 \\
\hline
\end{tabular}




\subsubsection{Registro General de Vehículos de la Dirección General de Tráfico}

El artículo 5 de la Ley sobre Tráfico, aprobada por Real Decreto Legislativo 339/1990, atribuye al Ministerio del Interior la competencia sobre el Registro de Vehículos. Las características de este Registro se desarrollan en el Reglamento General de Vehículos, aprobado por Real Decreto 2822/1998, que, en su artículo 2, encomienda a la Jefatura Central de Tráfico la responsabilidad de llevar un registro de todos los vehículos matriculados, que adoptará para su funcionamiento medios informáticos y en el que figurarán, al menos, los datos que deben ser consignados obligatoriamente en el permiso o licencia de circulación.

Los objetivos preferentes del Registro son la identificación del titular del vehículo, el conocimiento de las características técnicas del mismo y de su aptitud para circular, la comprobación de las inspecciones realizadas, la concertación del seguro obligatorio de automóviles y del cumplimiento de otras obligaciones legales, y finalmente la constatación del Parque de Vehículos y su distribución, con fines estadísticos.

Por ello, el Registro General de Vehículos de la Dirección General de Tráfico incluye los datos que vienen reflejados en la Ficha Técnica de todos los vehículos (ligeros y pesados) que conforman el parque de vehículos existente en España. En la Tabla 17 figuran los datos que posee la Dirección General de Tráfico sobre cada vehículo, aunque no de todos se puede realizar un tratamiento u ordenación.

Tabla 17. Datos que aparecen en el Registro General de Vehículos de la Dirección General de Tráfico sobre cada vehículo

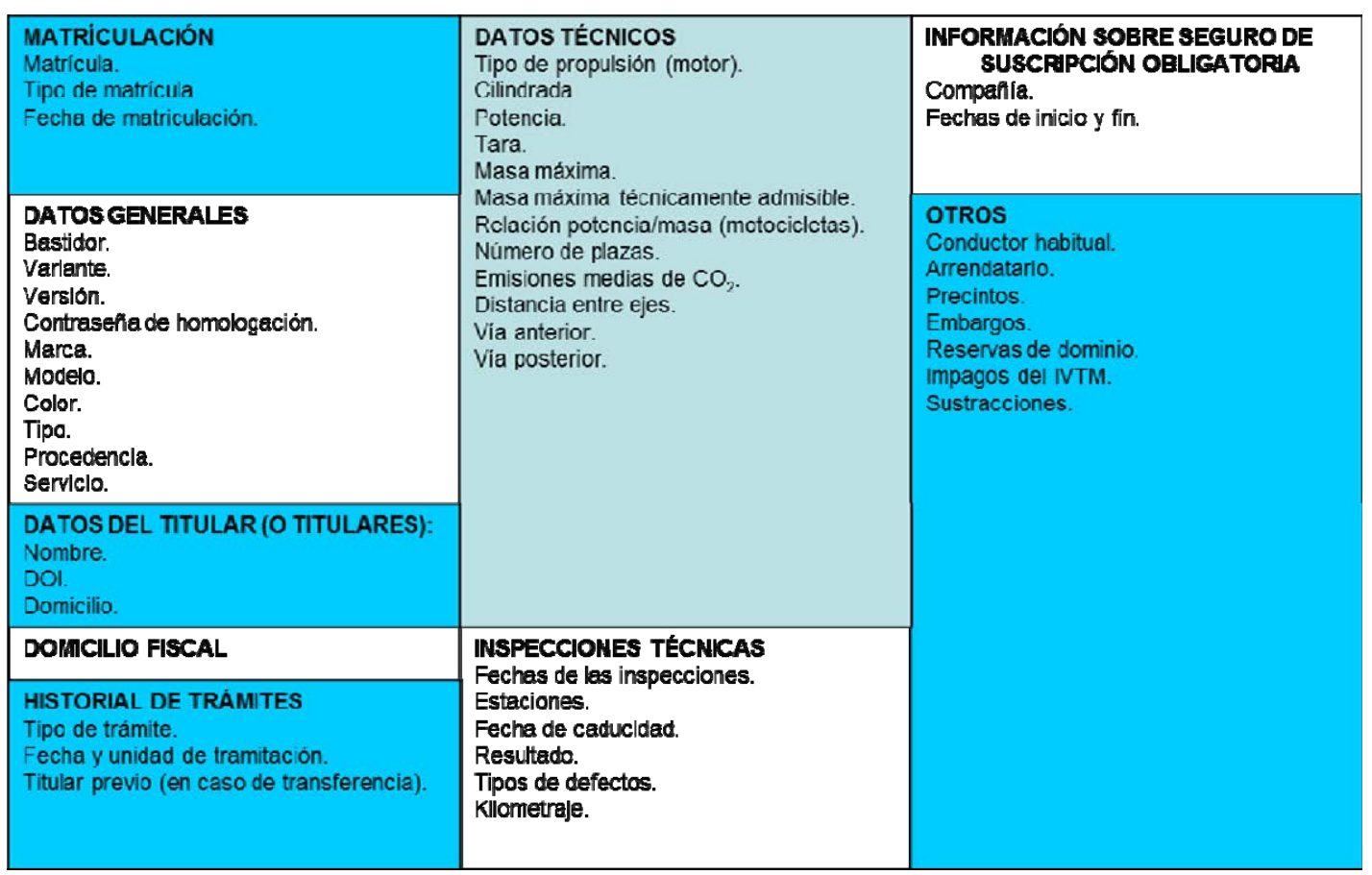

Hay que señalar que la base de datos del Registro General de Vehículos no contiene como datos ni la clase del vehículo (rígido, articulado, tren de carretera) ni, dentro de 
estas tres grandes clases, el tipo concreto, basado en el número de ejes y la ordenación de estos. Por otro lado, aunque contiene el número de ejes de cada vehículo y la distancia entre cada dos ejes, no permite realizar la ordenación de los vehículos de acuerdo con estos parámetros, por lo cual, en primera instancia, no se puede obtener la clasificación de los vehículos pesados según uno de los esquemas típicos utilizados por las administraciones de carreteras de los distintos países.

Además, en el Registro General de Vehículos no aparecen los vehículos articulados ni los trenes de carretera como vehículos unitarios, sino que se encuentran por un lado las cabezas tractoras y, por otro, los remolques y los semirremolques, lo que aumenta la dificultad para obtener una clasificación similar a la de los esquemas de clasificación normalmente utilizados.

Por tanto, ha sido preciso realizar un estudio ad hoc para poder establecer una correspondencia aproximada entre los tipos definidos por el Registro General de Vehículos con los de los esquemas de clasificación en que se muestran los resultados de la Campaña de Pesaje del CEDEX y de la Encuesta Permanente del Transporte de Mercancías por Carretera, que son susceptibles de ser programados en el sistema de pesaje para su obtención automatizada.

Afortunadamente, la base de datos del Registro General de Vehículos sí que contiene un dato que puede hacerse corresponder aproximadamente con las clases y tipos de vehículos de los típicos esquemas de clasificación utilizados por las administraciones de carreteras, que es el peso (masa) máximo admitido (PMA o MMA).

La correspondencia es bastante buena debido a que en el Anexo IX "Masas y dimensiones" del Reglamento General de Vehículos (véase el Apartado 3.3) vienen especificados los pesos máximos en función de unos tipos y clases de vehículos, que están definidos en función del número de ejes (dos, tres, cuatro o más ejes) y de la clase de vehículos (rígidos, articulados, trenes de carretera), es decir, que se basan en unos parámetros similares a los utilizados por los esquemas de clasificación de las administraciones de carreteras

No obstante, aun así existe la dificultad de que las masas máximas admitidas para cada vehículo que aparecen en el Registro General de Vehículos para las cabezas tractoras, semirremolques y remolques no especifican muchas veces el valor máximo permitido para estos elementos de los vehículos, sino que frecuentemente informan del peso (masa) máximo admitido para el conjunto de vehículos completo (cabeza tractora + semirremolque o camión rígido + remolque). Por último, hay que señalar que el Registro General de Vehículos contiene los datos de todos los vehículos, remolques y semirremolques matriculados en España, tanto ligeros como pesados, pero como el presente estudio se refiere solamente a los vehículos pesados, se han considerado sólo los datos de los vehículos cuya MMA es de más $3.500 \mathrm{~kg}$.

Por consiguiente, sobre la base de las masas máximas admitidas especificadas para cada unidad vehicular, se ha realizado la correspondencia que se muestra en la Tabla 18. 
Tabla 18. Correspondencia entre las diferentes clases de vehículos definidas en el Registro General de Vehículos por su masa máxima admitida (MMA) con las clases definidas por su número de unidades (vehículos) independientes (rígido, tractor+semirremolque, rígido+remolque), y número de ejes.

\begin{tabular}{|c|c|c|c|}
\hline $\begin{array}{l}\text { MMA según Registro } \\
\text { General de Vehículos }\end{array}$ & $\begin{array}{l}\text { № de } \\
\text { vehículos }\end{array}$ & $\begin{array}{l}\text { Se corresponde } \\
\text { con... }\end{array}$ & $\begin{array}{l}\text { Tipo real de vehículo } \\
\text { asimilable }\end{array}$ \\
\hline \multicolumn{4}{|l|}{ Vehículos rígidos } \\
\hline - de $3.501 \mathrm{~kg}$ a $18.000 \mathrm{~kg}$ & 223.159 & $\rightarrow$ & Rígido de 2 ejes \\
\hline - de $18.001 \mathrm{~kg}$ a $20.000 \mathrm{~kg}$ & 18.966 & $\rightarrow$ & Rígido de 2 ejes \\
\hline - de $20.001 \mathrm{~kg}$ a $26.000 \mathrm{~kg}$ & 59.841 & $\rightarrow$ & Rígido de 3 ejes \\
\hline - de $26.001 \mathrm{~kg}$ a $38.000 \mathrm{~kg}$ & 12.181 & $\rightarrow$ & Rígido de 4 ó más ejes \\
\hline \multicolumn{4}{|l|}{ Cabezas tractoras } \\
\hline - de $3.501 \mathrm{~kg}$ a $40.000 \mathrm{~kg}$ & 205.141 & $\rightarrow$ & Cabeza tractora de 2 ejes \\
\hline - de 40,001 kg a $44.000 \mathrm{~kg}$ & 83 & $\rightarrow$ & Cabeza tractora de 3 ejes \\
\hline \multicolumn{4}{|l|}{ Semirremolques } \\
\hline - de $3.501 \mathrm{~kg}$ a $40.000 \mathrm{~kg}$ & 250.594 & $\rightarrow$ & Semirremolque de 1,2 ó 3 ejes \\
\hline - de $40,001 \mathrm{~kg}$ a $44.000 \mathrm{~kg}$ & 2.250 & $\rightarrow$ & Semirremolque de 2 ó 3 ejes \\
\hline \multicolumn{4}{|l|}{ Remolques } \\
\hline - de $3.501 \mathrm{~kg}$ a $40.000 \mathrm{~kg}$ & 40.806 & $\rightarrow$ & Remolque de 2,3 ó 4 ejes \\
\hline - de $40,001 \mathrm{~kg}$ a $44.000 \mathrm{~kg}$ & 384 & $\rightarrow$ & Remolque de 2,3 ó 4 ejes \\
\hline
\end{tabular}

Teniendo en cuenta el valor promedio de las taras de todos los vehículos según los tipos definidos por intervalos de MMA en el Registro General de Vehículos, y asimilando estos tipos a los correspondientes en los esquemas de clasificación utilizados por las administraciones de carreteras, se obtienen las taras medias y medidas de dispersión que se muestran en la Tabla 19. 
Tabla 19. Taras medias de cada tipo de vehículos definidos según su masa máxima admitida (Registro General de Vehículos) y según el esquema de clasificación típico propuesto (basado en el número de ejes y unidades de vehículo).

\begin{tabular}{|c|c|c|c|c|c|c|}
\hline MMA según RGV & $\begin{array}{l}\text { Tara } \\
\text { media } \\
(\mathrm{kg})\end{array}$ & & $\begin{array}{l}\text { Tipo real de vehículo } \\
\text { asimilable }\end{array}$ & $\begin{array}{l}\text { Tara } \\
\text { media } \\
(\mathrm{kg})\end{array}$ & $\begin{array}{l}\text { Desv. } \\
\text { Típica } \\
\text { (kg) }\end{array}$ & $\begin{array}{l}\text { Coef. } \\
\text { Variac. } \\
(\%)\end{array}$ \\
\hline \multicolumn{7}{|l|}{ Vehículos rígidos } \\
\hline de $3.501 \mathrm{~kg}$ a $18.000 \mathrm{~kg}$ & 6.191 & $\rightarrow$ & \multirow[b]{2}{*}{ Rígido de 2 ejes } & \multirow[b]{2}{*}{6.416} & \multirow[b]{2}{*}{2.706} & \multirow[b]{2}{*}{$42,2 \%$} \\
\hline de $18.001 \mathrm{~kg}$ a $20.000 \mathrm{~kg}$ & 9.063 & $\rightarrow$ & & & & \\
\hline de $20.001 \mathrm{~kg}$ a $26.000 \mathrm{~kg}$ & 12.913 & $\rightarrow$ & Rígido de 3 ejes & 12.913 & 2.701 & $20,9 \%$ \\
\hline de $26.001 \mathrm{~kg}$ a $38.000 \mathrm{~kg}$ & 14.476 & $\rightarrow$ & Rígido de 4 ó más ejes & 14.476 & 4.132 & $28,5 \%$ \\
\hline \multicolumn{7}{|l|}{ Cabezas tractoras } \\
\hline de $3.501 \mathrm{~kg}$ a $40.000 \mathrm{~kg}$ & 7.591 & $\rightarrow$ & Cabeza tractora de 2 ejes & \multirow[b]{2}{*}{7.591} & \multirow[b]{2}{*}{1.321} & \multirow[b]{2}{*}{$17,4 \%$} \\
\hline de $40,001 \mathrm{~kg}$ a $44.000 \mathrm{~kg}$ & 7.591 & $\rightarrow$ & Cabeza tractora de 3 ejes & & & \\
\hline \multicolumn{7}{|l|}{ Semirremolques } \\
\hline de $3.501 \mathrm{~kg}$ a $40.000 \mathrm{~kg}$ & 7.295 & $\rightarrow$ & Semirremolque de 1,2 ó 3 ejes & \multirow[b]{2}{*}{7.295} & \multirow[b]{2}{*}{3.438} & \multirow[b]{2}{*}{$47,1 \%$} \\
\hline de $40,001 \mathrm{~kg}$ a $44.000 \mathrm{~kg}$ & 7.294 & $\rightarrow$ & Semirremolque de 2 ó 3 ejes & & & \\
\hline \multicolumn{7}{|l|}{ Remolques } \\
\hline de $3.501 \mathrm{~kg}$ a $40.000 \mathrm{~kg}$ & 6.538 & $\rightarrow$ & Remolque de 2,3 ó 4 ejes & 6.538 & 2.674 & $40,9 \%$ \\
\hline de $40,001 \mathrm{~kg}$ a $44.000 \mathrm{~kg}$ & 6.550 & $\rightarrow$ & Remolque de 2,3 ó 4 ejes & 6.550 & 2.683 & $41,0 \%$ \\
\hline \multicolumn{7}{|l|}{ Conjuntos de vehículos } \\
\hline \multicolumn{4}{|c|}{ Veh. articulado $=$ Cabeza tractora $(M M A \leq 44 t)+$ Semirremolque $($ MMA $\leq 44 t)$} & 14.886 & 3.683 & $24,7 \%$ \\
\hline \multicolumn{4}{|c|}{ Tren 1: Camión 2 ejes (MMA $\leq 20 \mathrm{t})+$ Remolque (MMA $\leq 40 \mathrm{t}$ ) } & 12.954 & 3.804 & $29,4 \%$ \\
\hline \multicolumn{4}{|c|}{ Tren 2: Camión 3 ejes (MMA $\leq 26 \mathrm{t})+$ Remolque $(\mathrm{MMA} \leq 44 \mathrm{t})$} & 19.462 & 3.806 & $19,6 \%$ \\
\hline
\end{tabular}

Como se puede ver en la Tabla 18, se han asimilado a vehículos rígidos de 2 ejes tanto los camiones pesados con $\mathrm{MMA} \leq 18 \mathrm{t}$, pues éste es su límite en el Reglamento General de Vehículos vigente, como los camiones pesados con $18 \mathrm{t}<\mathrm{MMA} \leq 20 \mathrm{t}$, pues éste era el límite de peso para este tipo de vehículos en el antiguo Código de Circulación y todavía quedan en circulación una cantidad apreciable de estos vehículos. 
Hay que señalar que la mayor parte de los camiones de 2 ejes tienen masas máximas admitidas inferiores a los límites genéricos establecidos para el grupo completo (18 t si se trata de vehículos "nuevos", entendiendo como tales los matriculados después del 1 de enero de 1995, y 20 t para los vehículos "antiguos", matriculados antes de 1.995), pues en la categoría de los camiones de 2 ejes entran vehículos de tipos muy diferentes, desde pequeños camiones de reparto hasta camiones grandes de transporte de áridos, cuyas masas se aproximan a las 18 o $20 \mathrm{t}$.

Con los camiones rígidos de 3 y de 4 ó más ejes no existe ningún problema, pues los límites de peso de estos tipos según su MMA en el Reglamento General de Vehículos coinciden con las clases definidas según el número de ejes. Además, en estas categorías de vehículos una gran parte de ellos tienden a tener una MMA cercana a la máxima admitida para el grupo completo, por lo que la posibilidad de que exista un solape con las taras de los vehículos de categoría inferiores (camiones de 2 ejes) es pequeña, lo que posibilita su diferenciación y clasificación atendiendo a este parámetro.

En lo relativo a las cabezas tractoras se han asimilado todas las cabezas tractoras de cuyo límite de peso son 40 toneladas a cabezas tractoras de 2 ejes, pues más del $99 \%$ de las cabezas tractoras en España tienen este número de ejes y dan lugar al vehículo articulado más común, que es el articulado de 5 ejes (que incluye un eje trídem en el semirremolque), cuya masa máxima admitida son $40 \mathrm{t}$. Por su parte, las cabezas tractoras cuya masa máxima admitida está entre las $40 \mathrm{t}$ y las $44 \mathrm{t}$ se han asimilado a cabezas tractoras de 3 ejes, pues cuando se conectan con un semirremolque en transporte combinado dan lugar a un tipo de vehículo articulado cuya MMA son $44 \mathrm{t}$.

De todas maneras, como se puede ver en la Tabla 16, esta distinción entre las cabezas tractoras tiene pocos efectos prácticos en cuanto a la tara media de todo el conjunto, pues la tara media tanto de las cabezas de MMA $\leq 40 \mathrm{t}$ como de las cabezas de MMA entre 40 t y $44 \mathrm{t}$ es prácticamente la misma: $7.591 \mathrm{~kg}$.

Es necesario señalar también que no se han tenido en cuenta las cabezas tractoras cuya MMA es mayor de 44 toneladas, pues normalmente se trata de elementos de tracción para vehículos especiales.

Al igual que para las cabezas tractoras, se ha realizado una distinción entre dos categorías de semirremolques según su masa máxima admitida: la de los semirremolques cuya MMA está entre 3,5 t y $40 \mathrm{t}$, que es la típica del transporte pesado nacional, y la de los semirremolques cuya MMA está entre $40.001 \mathrm{~kg}$ y 44.000 $\mathrm{kg}$, pues se supone que estos se utilizarán conjuntamente con cabezas tractoras de 3 ejes para transporte combinado. Aun así, la distinción es meramente formal en cuanto a las taras, pues, como se puede ver, en ambos tipos la tara media es prácticamente la misma (unos $7.295 \mathrm{~kg}$ ).

El hecho de que las taras medias sean las mismas tanto para las dos categorías de cabezas tractoras como para las dos categorías de semirremolques, hace posible establecer una única categoría de vehículo articulado para la definición de las taras medias de este tipo de vehículo, que es la suma de la taras medias de cada uno de sus 
componentes: cabezas tractoras $(7.591 \mathrm{~kg})$ y semirremolques $(7.295 \mathrm{~kg})$, dando lugar a una tara media del conjunto general de los vehículos articulados en de $14.886 \mathrm{~kg}$.

En cuanto a los remolques se han establecido también las dos mismas categorías que para las cabezas tractoras y para los semirremolques: los de masa máxima admitida hasta $40 \mathrm{t}$ y los de MMA entre $40 \mathrm{t}$ y $44 \mathrm{t}$. Igualmente, para ambas categorías resultan unas taras medias muy similares (6.538 kg y $6.550 \mathrm{~kg}$ respectivamante), Sin embargo, al considerar el conjunto de vehículos completo (tren de carretera), en este caso se debe realizar una distinción en función del tipo de camión tractor al que se acoplen, pudiendo establecerse dos grupos:

1. Camión de 2 ejes + remolque (MMA $\leq 40 \mathrm{t}$ ), cuya tara media es de: $6.416 \mathrm{~kg}+6.538 \mathrm{~kg}=12.954 \mathrm{~kg}$

2. Camión de 3 ejes + semirremolque ( $M M A \leq 44 \mathrm{t}$ ), con tara media de $12.913 \mathrm{~kg}+6.550 \mathrm{~kg}=19.462 \mathrm{~kg}$.

\subsubsection{Datos de características de los vehículos proporcionados por} los fabricantes o por los carroceros/adaptadores de los vehículos pesados

Esta base se refiere a los datos que proporcionan los fabricantes de vehículos sobre las características de los vehículos fabricados o vendidos cada año en España. Naturalmente, para conocer las características del conjunto total de vehículos se deben realizar hipótesis sobre la tasa de sustitución de los vehículos viejos por otros nuevos en nuestro país, lo cual es un procedimiento bastante laborioso.

En el año 1986 el CEDEX publicó una monografía titulada "Caracterización del tráfico pesado en el dimensionamiento de firmes. El espectro de vehículos pesados en España" [5], escrita por Ramón Crespo, que realizó unas hipótesis de sustitución de los vehículos antiguos por otros nuevos. No obstante, éste es un aspecto bastante complicado, pues no se trata solamente de actualizar las características (taras principalmente) de los distintos tipos de vehículos, sino que en periodos largos también cambia la participación (composición) de los distintos tipos de vehículos e, incluso, pueden aparecer tipos nuevos.

Hay que decir que desde finales de la década de los 80 al año 2000 cambiaron significativamente las características del parque de vehículos pesados en España, pues entonces todavía predominaban los vehículos rígidos (camiones de 2,3 o 4 ejes) incluso para el transporte de largo recorrido, mientras que actualmente predominan para este tipo de transporte los vehículos articulados, habiéndose mantenido en una proporción bastante reducida (del orden del $2 \%$ ) los trenes de carretera. Actualmente, se mantiene a grandes rasgos la tipología de vehículos que existía en el 2000, lo cual facilita la realización de las hipótesis de variación de las características (taras) del parque.

Las empresas fabricantes de camiones pesados y cabezas tractoras, o que las comercializan en España, son las siguientes: BMC, DAF, IVECO, MAN, Mercedes -Benz, Renault Trucks, Scania y Volvo. Además, existen algunas otras más que fabrican o 
venden furgones y camiones de tipo ligero (hasta unas 7,5 t de MMA) como son Isuzu, Peugeot, Opel y Nissan.

En la Tabla 20 figuran los datos de las taras, peso máximo admitido y otras variables adicionales de vehículos nuevos extraídos del Catálogo de 2017 publicado en la Revista "Transporte Profesional" [45].

Tabla 20. Valores de las taras y otras características de los camiones nuevos en España (Fuente: Transporte profesional. Catálogo 2017, no 369, año 2016).

\begin{tabular}{|l|l|rrrrr|}
\hline Tipo de vehículo & & $\begin{array}{r}\text { Cilindrada } \\
(\mathrm{cm})\end{array}$ & $\begin{array}{r}\text { Potencia } \\
(\mathrm{CV})\end{array}$ & $\begin{array}{r}\text { Tara } \\
(\mathrm{kg})\end{array}$ & $\begin{array}{r}\text { Carga Útil } \\
(\mathrm{kg})\end{array}$ & $\begin{array}{r}\text { MMA } \\
(\mathrm{kg})\end{array}$ \\
\hline Rígido de 2 ejes & Media & 7685 & 297 & 5084 & 8757 & 13840 \\
& Desviación típica & 3647 & 125 & 1820 & 3435 & 4992 \\
& Valor máximo & 16400 & 750 & 8255 & 14300 & 18000 \\
& Valor mínimo & 1796 & 87 & 1675 & 1095 & 3500 \\
\hline Rígido de 3 ejes & Media & 11137 & 411 & 8385 & 17527 & 25969 \\
& Desviación típica & 2166 & 87 & 959 & 1096 & 352 \\
& Valor máximo & 16400 & 750 & 10270 & 20650 & 26000 \\
& Valor mínimo & 6700 & 238 & 5350 & 11520 & 22000 \\
\hline Rígido de 4 ejes & Media & 12232 & 455 & 10042 & 22195 & 31990 \\
& Desviación típica & 1511 & 76 & 1306 & 1636 & 110 \\
& Valor máximo & 16100 & 750 & 14990 & 28000 & 32000 \\
& Valor mínimo & 8709 & 286 & 6537 & 17010 & 30750 \\
\hline Cabezas tractoras & Media & 12118 & 454 & 7755 & 32216 & 39955 \\
& Desviación típica & 2132 & 86 & 1191 & 1303 & 673 \\
& Valor máximo & 16400 & 750 & 10957 & 33776 & 40000 \\
& Valor mínimo & 7700 & 238 & 6110 & 23890 & 30000 \\
\hline
\end{tabular}

Para obtener la tara total de los vehículos articulados y trenes de carretera, además de la información proveniente de los fabricantes de vehículos, es necesario obtener datos por parte de las empresas fabricantes de los semirremolques y remolques, de las cuales existe un gran número que opera en España y que además de fabricar el chasis de la unidad remolcada, se ocupan de carrozar el camión según el tipo de transporte específico a que se vaya a dedicar el vehículo (camiones frigoríficos, portacontenedores, plataformas, volquetes y bañeras de obra, cajas cerradas, lonas, etc).

Entre las empresas más importantes que fabrican semirremolques y remolques se pueden citar las siguientes: CMC Cerezuela, Farcinox, Feldbinder, Granalu, Grupo Guillén, Krone, Kogel, Lamberet, Leciñena, Parcisa; Lecitrailer, Schmitz Cargobull, etc.

Algunas fabrican todo tipo de semirremolques, como Leciñena, Lecitrailer o Schmitz Cargobull, mientras que otras están especializadas en algunos tipos específicos, como por ejemplo Lamberet, que fabrica sobre todo vehículos frigoríficos o cisternas, o 
incluso hay otras especializadas en transportes especiales y grúas de gran tamaño, como la compañía Semirremolques Rojo.

El estudio que se ha realizado sobre los pesos de los semirremolques exige un análisis en profundidad, pues los fabricantes de semirremolques solamente suelen dar el dato de la tara del chasis del semirremolque limpio, debiendo añadirse luego el peso de la carrocería específica que se ponga en cada caso. Por otro lado, por ejemplo en las plataformas portacontenedores, la tara no incluye nunca el peso del contenedor.

A continuación se muestra la Tabla 21 con los principales tipos de usos o aplicaciones de los semirremolques y remolques, el rango de taras de los vehículos de cada uso y el nombre de las empresas fabricantes de las que se ha podido obtener datos.

Tabla 21. Diferentes tipos de carrocerías para semirremolques y remolques, y rangos de taras de cada una de ellas

\begin{tabular}{|c|c|c|c|}
\hline Tipo de uso & $\begin{array}{c}\text { № de } \\
\text { modelos } \\
\text { con datos }\end{array}$ & Taras (kg) & Empresas fabricantes \\
\hline Bañera de obra & 6 & de 6.700 a 15.300 & Lecitrailer, Meiller \\
\hline $\begin{array}{l}\text { Volquete } \\
\text { basculante }\end{array}$ & 6 & $\begin{array}{c}\text { de } 3.950 \text { a } 8.300 \text { (la mayoría está } \\
\text { entre } 5.000 \text { y } 6.000 \mathrm{~kg} \text { ) }\end{array}$ & $\begin{array}{l}\text { Leciñena, Danima, } \\
\text { Galtrailer }\end{array}$ \\
\hline Cisterna & 45 & $\begin{array}{c}\text { de } 3.900 \text { a } 9.600 \text { (la mayoría está } \\
\text { en torno a } 6.000 \text { ) }\end{array}$ & $\begin{array}{l}\text { Feldbinder ; Leciñena, } \\
\text { Indox, }\end{array}$ \\
\hline Frigorífico & 11 & $\begin{array}{l}\text { de } 4.100 \text { a } 9.750 \text { (la mayoría está } \\
\text { en el intervalo de } 7.000 \text { a } 7.500 \text { ) }\end{array}$ & $\begin{array}{l}\text { Lamberet, Leciñena, } \\
\text { Lecitrailer, Guillén, } \\
\text { Schmitz }\end{array}$ \\
\hline Furgón & 4 & 7.130 & Lecitrailer, Guillén \\
\hline Lonas & 13 & $\begin{array}{c}\text { de } 5.300 \text { a } 7.129 \text { (la mayoría en el } \\
\text { entorno de los } 6.500 \mathrm{~kg}\end{array}$ & $\begin{array}{l}\text { Lecitrailer, Schmitz; } \\
\text { Leciñena, Guillén }\end{array}$ \\
\hline Plataforma & 5 & $\begin{array}{c}\text { de } 4.420 \text { a } 8.300 \text { (la mayoría está } \\
\text { entre } 4.500 \text { y } 5.000 \text { ) }\end{array}$ & Leciñena \\
\hline Portacontenedor & 17 & $\begin{array}{c}\text { de } 3.080 \text { a } 8.480 \text { (sin incluir el peso } \\
\text { del contenedor). La mayoría está } \\
\text { entre } 4.500 \text { y } 5.000\end{array}$ & $\begin{array}{l}\text { Leciñena, Schmitz, } \\
\text { Tomcisa, Feldbinder; } \\
\text { Galtrailer, Trainar }\end{array}$ \\
\hline Remolque & 6 & $\begin{array}{c}\text { de } 3.070 \text { a } 5.400 \text { (la mayoría en } \\
\text { torno a } 4.000 \text { ) }\end{array}$ & Leciñena, Schmitz \\
\hline
\end{tabular}


Como se puede ver en la Tabla 21, el peso de los semirremolques (incluyendo la carrocería) varía según los tipos de carga a los que vayan a ser destinados y existe un amplio abanico de taras, incluso dentro de un mismo tipo de carrocería o uso. Uno de los tipos en que existe más disparidad es el que figura primero en la Tabla 21, que son las bañeras de obra, donde existe una distribución bimodal, pues están por un lado las bañeras de acero cuya tara oscila entre $12.000 \mathrm{~kg}$ y $15.000 \mathrm{~kg}$ y, por otro, las bañeras de aluminio y de chapa de acero cuya tara está en el entorno de los $7.000 \mathrm{~kg}$. Otro de los tipos de carrocería que arroja un peso total mayor son los semirremolques frigoríficos, que incluyendo el equipo de frío tienen normalmente una tara de entre $7.000 \mathrm{~kg}$ y unos $7.500 \mathrm{~kg}$, aunque puede superarse esta cifra.

La combinación de las taras de los camiones rígidos y cabezas tractoras, dadas por los fabricantes de los vehículos, con las taras de los semirremolques y remolques, según sus diferentes usos o utilizaciones, nos darán los intervalos de taras de los distintos tipos de vehículos nuevos.

Evidentemente, las cifras obtenidas por este procedimiento no se referirán al parque de vehículos actual, sino al parque de vehículos futuro. Teniendo en cuenta los datos proporcionados en las Tablas 20 y 21, para obtener las taras medias de cada tipo de vehículos que compondrán el parque dentro de unos 10 años, se deben hacer las siguientes suposiciones:

- Establecer una hipótesis de tasa de sustitución anual del parque de vehículos. Para ello se pueden tener en cuenta las cifras de antigüedad media de los vehículos que circulaban por la red de carreteras del Estado (RCE) en el momento de la realización de la campaña de pesaje dinámico 2000-2003, que eran las que se muestran en la Tabla 22, desglosadas según el tipo de vehículo pesado.

Tabla 22. Antigüedad de los vehículos en la campaña de pesaje del CEDEX realizada entre 2000 y 2003

\begin{tabular}{|l|c|c|}
\hline Tipo de vehículo & Antigüedad media (años) & Desviación típica (años) \\
\hline Camión rígido & 8,4 & 5,7 \\
\hline Articulado & 6,1 & 4,8 \\
\hline Tren de carretera & 6,2 & 5,2 \\
\hline
\end{tabular}

Como se puede ver en la Tabla 22, la antigüedad media de los vehículos de transporte del largo recorrido (articulados y trenes) es menor que la de los de corto recorrido (rígidos). Habría que tener en cuenta que los vehículos que circulan por la RCE son algo más nuevos que los que circulan por redes más locales o por vías urbanas. Aun así, considerando los valores medios de antigüedad y su dispersión (medidas por la desviación típica), se podría suponer 
que en unos 20 años la mayor parte del parque (al menos un 90\%) ya ha sido sustituido.

- No obstante lo anterior, se podría suponer que en los últimos 10 años las características de los vehículos nuevos ya han estado siendo bastante similares a las que proporcionan los fabricantes actuales, por lo que en un periodo de otros 10 años, la mayor parte del parque ya habrá adoptado las características de los vehículos nuevos que se están vendiendo actualmente.

- Por otro lado, se necesitaría conocer las proporciones de los distintos tipos de usos o carrocerías específicas en cada tipo de vehículo. Esto se podría obtener de las ventas de los fabricantes o de la Encuesta Permanente del Transporte de Mercancías por Carretera.

Teniendo en cuenta las anteriores hipótesis, así como los valores medios de las taras y sus dispersiones según los usos o carrocerías, que se muestran en las Tablas 20 y 21 , se podría determinar la tara previsible de los distintos tipos de vehículos en un futuro próximo, que se concretarán en unos 10 años.

No obstante, como conclusión general, de la comparación de las taras de los vehículos nuevos dadas por los fabricantes con las del parque de vehículos existente (provenientes del Registro General de Vehículos), parece que puede deducirse que existe una tendencia a disminuir las taras medias de los vehículos pesados.

\subsubsection{Comparación de las taras obtenidas en las diferentes bases de datos}

Como resumen de lo que se acaba de exponer sobre las bases de datos de las taras de los vehículos y para que sirva de comparación de las cifras obtenidas en ellas, se ha elaborado la Tabla 23, en la que se muestran los valores medios de las taras (expresados en $\mathrm{kN}$ ) de los distintos tipos de vehículos pesados, así como la dispersión de las taras en relación con los valores medios en cada caso.

No se ha considerado útil incluir en la tabla las taras de los fabricantes y carroceros de vehículos y elementos remolcados, debido a los amplios intervalos de variación de los valores medios y a que estos datos pueden considerarse sólo como una tendencia a lo que será el parque en años venideros.

A la vista de los datos de la Tabla 23 se pueden hacer los siguientes comentarios:

- $\quad$ No existe una coincidencia perfecta en cuanto a los tipos de vehículos sobre los que se proporcionan las taras medias en las distintas bases de datos. La principal diferencia está en que en el Registro General de Vehículos, por la forma en que se han suministrado los datos (tal como se ha comentado, clasificados en función de la MMA del vehículo o conjunto de vehículos), no ha sido posible dividir la clase de los vehículos articulados (cabeza tractora + semirremolque) en tipos más homogéneos según su número de ejes, mientras que para la clase de los trenes de carretera sólo 
ha podido efectuarse una división en dos tipos diferentes de vehículos: la de los camiones rígidos de 2 ejes + remolque ( 2 o 3 ejes) y la de los camiones rígidos de 3 ejes + remolque ( 2 o 3 ejes). Afortunadamente, en estas clases de vehículos no existe una gran diferencia de taras entre los distintos tipos que las forman, por lo que la aproximación sigue siendo aceptable. Por otro lado, también faltan en la base de datos de la campaña de pesaje dinámico del CEDEX algunas clases de vehículos (por ejemplo, los camiones rígidos de más de 4 ejes), pero los tipos de los que no hay datos son muy poco frecuentes, por lo que esta ausencia tiene una importancia muy pequeña.

- Para casi todos los tipos de vehículos, los valores de la taras medias dados por la EPTMC de 2013 y del Registro General de Vehículos son algo mayores que los de la campaña de pesaje dinámico 2000-2003 del CEDEX, excepto para los vehículos articulados, en que los valores de las taras medias dados por las tres bases de datos casi coinciden. Como estos vehículos son los más comunes, la diferencia total ponderada (por la proporción de cada tipo de vehículos en el tráfico o en el parque total) entre las tres bases de datos es pequeña.

Tabla 23. Taras medias y dispersiones de las taras para los distintos tipos de vehículos según la campaña de pesaje dinámico del CEDEX 2000-2003, la Encuesta Permanente del Transporte de Mercancías por Carretera (EPTMC) del año 2013 y el Registro General de Vehículos de 2017

\begin{tabular}{|l|r|r|r|r|r|r|}
\hline & \multicolumn{2}{|c|}{$\begin{array}{c}\text { Campaña CEDEX } \\
\mathbf{2 0 0 0 - 2 0 0 3}\end{array}$} & \multicolumn{2}{c|}{$\begin{array}{c}\text { Encuesta PTMC } \\
\text { 2013 }\end{array}$} & \multicolumn{2}{c|}{$\begin{array}{c}\text { Registro General } \\
\text { Vehículos 2017 }\end{array}$} \\
\hline \multicolumn{1}{|c|}{ Tipos de vehículos } & $\begin{array}{c}\text { Tara } \\
\text { media } \\
(\mathrm{kN})\end{array}$ & $\begin{array}{c}\text { Coef. } \\
\text { Var } \\
(\%)\end{array}$ & $\begin{array}{c}\text { Tara } \\
\text { media } \\
(\mathrm{kN})\end{array}$ & $\begin{array}{c}\text { Coef. } \\
\text { Var } \\
(\%)\end{array}$ & $\begin{array}{c}\text { Tara } \\
\text { media } \\
(\mathrm{kN})\end{array}$ & $\begin{array}{c}\text { Coef. } \\
\text { Var } \\
(\%)\end{array}$ \\
\hline Camión 2 ejes & 62,51 & 31,5 & 77,55 & 32,5 & 62,91 & 42,2 \\
Camión 3 ejes & 111,70 & 8,7 & 120,17 & 17,2 & 126,67 & 20,9 \\
Camión 4 ejes & 136,53 & 3,9 & 141,22 & 16,8 & 142,01 & 28,5 \\
Camión más de 4 ejes & & & 108,43 & 11,8 & & \\
\hline Tractor 2 ejes + semirremolque 1 eje & 133,79 & 7,0 & & & & \\
Tractor 2 ejes + semirremolque 2 ejes & 138,17 & 7,5 & 128,35 & 27,3 & & \\
Tractor 2 ejes + semirremolque 3 ejes & 143,90 & 7,3 & 142,48 & 15,7 & 146,03 & 24,7 \\
Tractor 3 ejes + semirremolque 2 ejes & 169,22 & 1,5 & 90,97 & 45,1 & & \\
Tractor 3 ejes + semirremolque 3 ejes & & & 138,48 & 22,7 & & \\
Tractor + semirremolque: otras comb. & & & 148,41 & 40,5 & & \\
\hline Tren: Camión 2 ejes-Remolque 1 eje & & & 78,48 & 0,0 & & \\
Tren: Camión 2 ejes-Remolque 2 ejes & 126,72 & 10,0 & 169,87 & 21,5 & 127,08 & 29,4 \\
Tren: Camión 2 ejes-Remolque 3 ejes & 129,36 & 10,3 & 173,73 & 22,6 & & \\
Tren: Camión 3 ejes-Remolque 2 ejes & 155,72 & 8,2 & 174,14 & 20,9 & 190,92 & 19,6 \\
Tren: Camión 3 ejes-Remolque 3 eje & 159,05 & 7,7 & 180,97 & 22,6 & & \\
Tren. Camión y remolque: otras comb. & & & 164,36 & 24,3 & & \\
\hline
\end{tabular}


La Encuesta Permanente del Transporte de Mercancías por Carretera (EPTMC) da una tara media apreciablemente mayor para los camiones rígidos de 2 ejes, debido a que la EPTMC sólo incluye los camiones con capacidad de carga mayor de 3,5 t (34,3 kN) y una Masa Máxima Admitida (MMA) superior a $6 \mathrm{t}$, mientras que la campaña del CEDEX y el Registro General de Vehículos incluyen todos los vehículos de MMA mayor de 3,5 $\mathrm{t}$, acorde con la definición de vehículo pesado en el Reglamento General de Vehículos.

- En lo relativo a las dispersiones de las taras respecto al valor medio, medidas a través del coeficiente de variación, se puede ver que los valores mínimos de dispersión, para todos los tipos de vehículos, son los de la campaña de pesaje del CEDEX, lo que puede ser debido a que los datos de esta campaña fueron tomados todos en la Red Estatal de Carreteras, con lo cual las características del tráfico y de los vehículos son más homogéneas que en la otras dos bases de datos. Así, la EPTMC incluye datos del transporte interurbano en cualquier red de carreteras, mientras que el Registro General de Vehículos incluye en cada categoría todos los vehículos del parque, por lo que abarca tanto los vehículos destinados al transporte urbano como al interurbano o incluso, vehículos pesados no destinados al transporte, como pueden ser camiones grúa, por lo que la variabilidad de las taras es mayor.

- Las mayores dispersiones de la taras, para los tipos de vehículos más comunes se dan en los camiones rígidos de 2 ejes, pues en esta categoría se incluyen vehículos muy diferentes, desde pequeños camiones de reparto hasta camiones bastante grandes.

- Para los vehículos más abundantes en carretera, los articulados tipo T2S3, es decir, los formados por una cabeza tractora de 2 ejes y un semirremolque de 3 ejes, las taras medias son muy parecidas en las tres fuentes de datos y también es más reducida su dispersión con respecto a las de los demás tipos de vehículo. 
Resultados de los ensayos para la comprobación de los métodos de estimación desarrollados

\subsection{Comprobación de la exactitud de la silueta obtenida automáticamente}

\subsubsection{Ensayos y descripción del procedimiento seguido para efectuar la comprobación}

Una vez obtenida la silueta, el siguiente paso es comprobar la precisión del esquema de clasificación desarrollado. Para ello, no queda más remedio que obtener unos datos de contraste, es decir, de vehículos que hayan pasado sobre el sistema de pesaje, y de los cuales se conozca con total seguridad el tipo al que pertenecen. A este efecto, se han obtenido visualmente unos datos de contraste durante unas pocas horas mediante un proceso que se ha denominado "muestreo visual de vehículos".

Con objeto de verificar la precisión de la muestra obtenida visualmente, se han realizado tomas de datos en dos emplazamientos diferentes de la red de carreteras del Estado: el primero, en la A-1, pk 41, a la altura de El Molar, y el segundo, en la A-2, pk 81, a la altura de Trijueque (Guadalajara). Hay que decir que la toma de datos en El Molar se utilizó no solo para comprobar la precisión del programa de clasificación, sino también para actualizar algunos parámetros utilizados en el programa, y que se habían fijado sobre la base de los datos obtenidos en la última campaña de pesaje dinámico realizada entre 2000 y 2003.

El muestreo visual de vehículos en la carretera se ha realizado mediante unos operarios que, durante un cierto periodo de tiempo, apuntan las características de cada uno de los vehículos muestreados (o más bien, para aumentar su capacidad de registro, las graban utilizando la voz, y luego, en gabinete, se pasa toda esa cantidad de datos al papel). Posteriormente, en la oficina, tomando como referencia la hora de paso de cada vehículo muestreado sobre el sensor, se identifica al vehículo en cuestión sobre el listado registrado automáticamente por el equipo de pesaje. Una vez localizado cada vehículo sobre el listado del ordenador, se añaden varias columnas más a ese listado automático para introducir manualmente las diferentes características tomadas visualmente (una columna por cada característica tomada visualmente). De esta forma, se obtiene un listado completo de la población total de vehículos registrados automáticamente (cada vehículo con todos sus datos aparece en una línea), algunos de los cuales aparecen con datos (columnas) adicionales, que han sido consignados manualmente y recogidos visualmente, entre las cuales se encuentra su clasificación visual, que podría considerarse como verdadera. Entonces, comparando la clase o el tipo del vehículo que aparece en la columna tomada visualmente (clasificación "verdadera") con la que se muestra en la columna de clasificación obtenida automáticamente, se puede obtener la tasa de aciertos de la clasificación automática respecto a la real (visual). 
Naturalmente, este proceso de comparación puede realizarse solamente con los vehículos en los cuales la casilla correspondiente a la columna de la clasificación en la muestra visual no está vacía, es decir, con los vehículos que han sido muestreados visualmente. Esta muestra que incluye todos los vehículos cuyas características han sido tomadas visualmente, se le denomina "Muestra visual". La comparación de la clase tomada visualmente con la suministrada automáticamente por el equipo conjuntamente con el programa de clasificación desarrollado al efecto dará una tasa de coincidencia o tasa de acierto del citado programa de clasificación automático.

No obstante, aunque la tasa de acierto de la clasificación obtenida automáticamente con respecto a la recogida en la muestra visual total es el índice más directo de estimar la exactitud del procedimiento de clasificación desarrollado, existe otro índice intermedio que también pueden dar una idea de la precisión del programa de clasificación automática. El objeto de este índice es soslayar el problema (o más bien el "desafío") de la clasificación incorrecta de los vehículos que circulan con algún eje levantado cuando van de vacío, circunstancia que los sistemas de pesaje dinámico no pueden detectar.

Durante la realización de las campañas de pesaje dinámico en la Red de Carreteras del Estado se comprobó que el número de vehículos pesados que circula con algún eje levantado no podía considerarse despreciable, pues mediante un estudio visual realizado al efecto se obtuvo que, en autovías, de todos de los vehículos que tenían la capacidad de llevar un eje elevado (por tanto, no se contaban, por ejemplo, los vehículos de 2 ejes), hasta un 15\% los llevaban realmente levantados.

Teniendo en cuenta la anterior circunstancia, se podría comprobar el grado de precisión del programa de clasificación expuesto, eliminando de la comparación a todos los vehículos que circulan con los ejes levantados, pues su número de ejes nunca va poder ser detectado correctamente, con lo que se obtendría su "precisión primaria", que será siempre igual o superior a su "precisión total". Para poder calcular esta "precisión primaria" se elaboró una segunda muestra de comparación de la silueta, en la que se eliminaron todos los vehículos que circulaban con algún eje levantado, denominándola "muestra depurada".

En consecuencia, la tasa de acierto del programa de clasificación automática sobre esta muestra depurada se podría tomar en principio como tasa de precisión primaria del programa de clasificación, mientras que la tasa o porcentaje de acierto del programa de clasificación sobre la muestra visual total será la precisión real o verdadera de clasificación.

No obstante, aunque podría haberse empleado la tasa de acierto primaria del programa de clasificación, se ha preferido determinar la precisión sobre la muestra visual total, es decir, la que incluye todos los vehículos aunque lleven algún eje levantado, pues es ésta la que da una idea de la verdadera tasa de acierto del programa de clasificación con vistas a la estimación de las cargas transportadas por los vehículos, objetivo final para el que fue realizado el programa. Por el contrario, si se hubiera realizado el programa para estimar las cargas del tráfico sobre el pavimento, podría haberse eliminado de la comparación a los vehículos que circulaban con ejes levantados, pues estos ejes no suponen una carga para el firme. 


\subsubsection{Resultados de precisión de la clasificación obtenidos en El Molar}

(A-1, pk. 41)

En la Tabla 24 que se muestra a continuación se pueden ver los resultados de la comparación realizada entre la clasificación realizada por el equipo de pesaje junto con el programa de clasificación desarrollado en Excel (columna "Aforo") y la clasificación tomada visualmente (columna "Muestra real visual") por operarios del CEDEX, que puede considerarse como la clasificación real, en una toma de datos de tres días de duración realizada en la autopista A-1, pk 41, a la altura de el Molar (Madrid).

Tabla 24. Resultados de comparación de la clasificación visual con la automática en el ensayo de El Molar

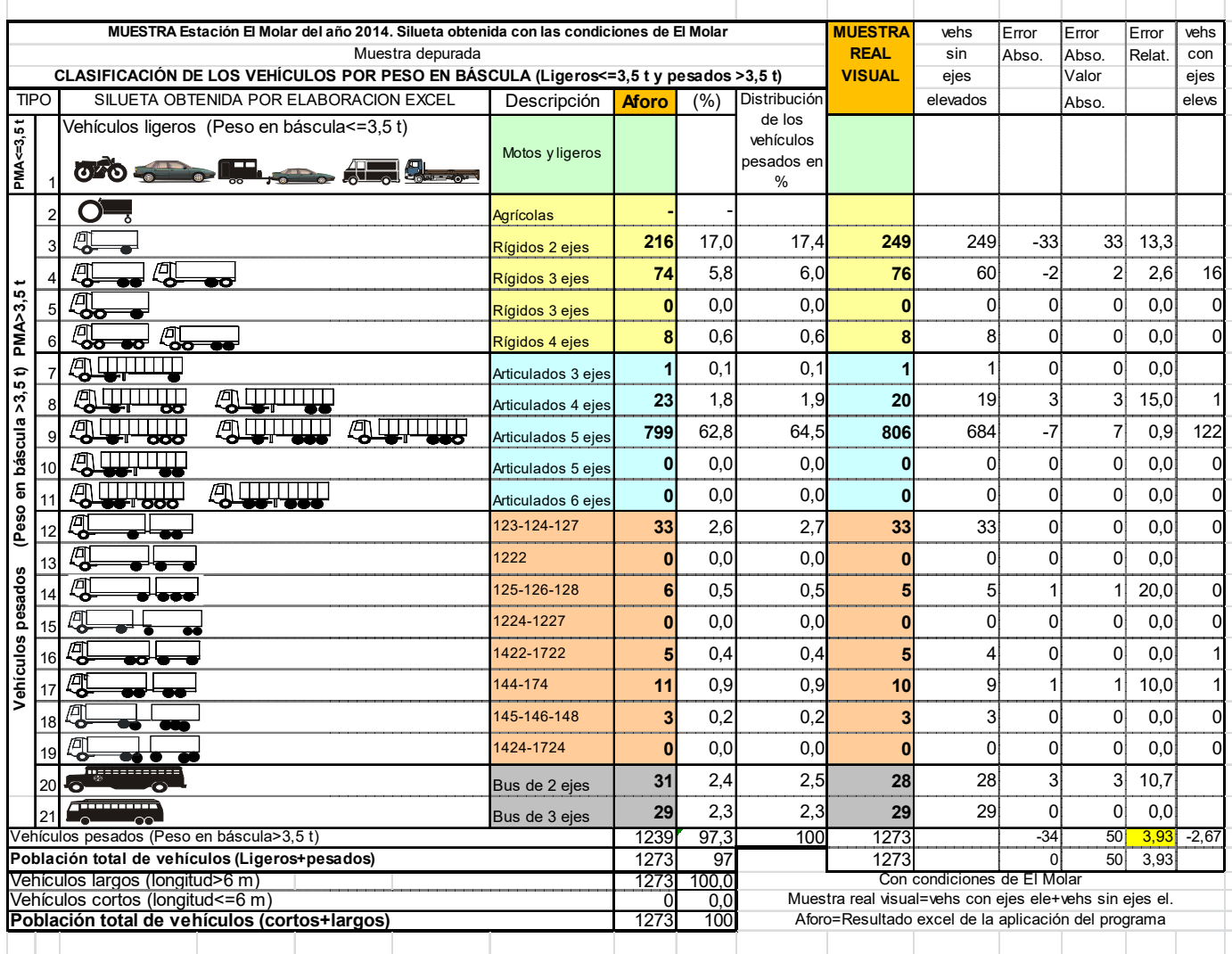

Como se puede ver en la Tabla 24, la comparación efectuada arroja unos resultados bastante satisfactorios en cuanto a la precisión del procedimiento automático de clasificación desarrollado, pues de los 1.273 vehículos que circularon sobre el sistema de pesaje, solamente 50 vehículos fueron clasificados erróneamente, resultando un error relativo total es del 3,9\%.

Hay que señalar que en la práctica el error total de clasificación fue algo menor, pues los vehículos clasificados erróneamente en unos tipos se compensaban parcialmente con los mal clasificados en otros tipos. Esto ocurre, por ejemplo, si un camión de 2 ejes es clasificado erróneamente como autobús de 2 ejes, y luego otro autobús de 2 ejes es clasificado equivocadamente como camión de 2 ejes, pues ambos errores se compensan, resultando un error "ficticio" de clasificación nulo, cuando en realidad ha 
habido dos vehículos clasificados en un tipo incorrecto. Así, en toma de datos de El Molar resultó un error total de sólo 34 vehículos mal clasificados, aunque se ha preferido utilizar la cifra de 50 , pues es más estable, por no depender de la "suerte" en las posibles compensaciones de errores.

No obstante, se puede comprobar que el porcentaje de error no ha sido similar en todos los tipos de vehículos. Así, por ejemplo, en los camiones rígidos de 2 ejes, la proporción de error ha sido de un 13\%, lo que podría arrojar unos resultados globales diferentes en otras estaciones donde predomine este tipo de vehículos.

El examen detallado de los errores de clasificación en el Molar permitió afinar algunos de los umbrales fijados para las condiciones de clasificación de algunos tipos de vehículos, constituyendo lo que se denominaron las "Condiciones de clasificación de El Molar", que fueron las que se utilizaron en el ensayo realizado en la A-2 a la altura de Trijueque.

\subsubsection{Resultados de precisión de la clasificación obtenidos en Trijueque (A-2, pk. 82)}

Se realizó una segunda comprobación del procedimiento de clasificación desarrollado mediante la toma de datos de clasificación (así como de pesos) realizada en la estación de Trijueque, junto a la báscula estática de pesaje del Ministerio de Fomento, situada en la autopista A-2, pk. 82.

La toma de datos visual fue de una fiabilidad total, pues se tomaron fotografías de todos y cada uno de los más de 600 vehículos pesados muestreados.

Primeramente se van a mostrar unas cifras descriptivas de la composición de la muestra amplia de más de 600 vehículos pesados a través de la Tabla 25 obtenida de la clasificación de los vehículos de ésta. En una de las columnas ("Vehículos muestreados clasificados visualmente") aparecen los datos de la composición real, obtenida mediante la observación por operarios de los vehículos de la muestra en la carretera y de las fotos tomadas de cada uno de ellos, mientras que en otra columna aparece la clasificación obtenida automáticamente por el sistema de pesaje dinámico, mediante un programa de clasificación ("Vehículos clasificados con Excel"). La comparación de los datos de ambas columnas, proporciona una idea de la precisión de la clasificación automática. 
Tabla 25. Resultados de comparación de la clasificación visual con la automática en la estación de Trijueque (A-2, pk 82)

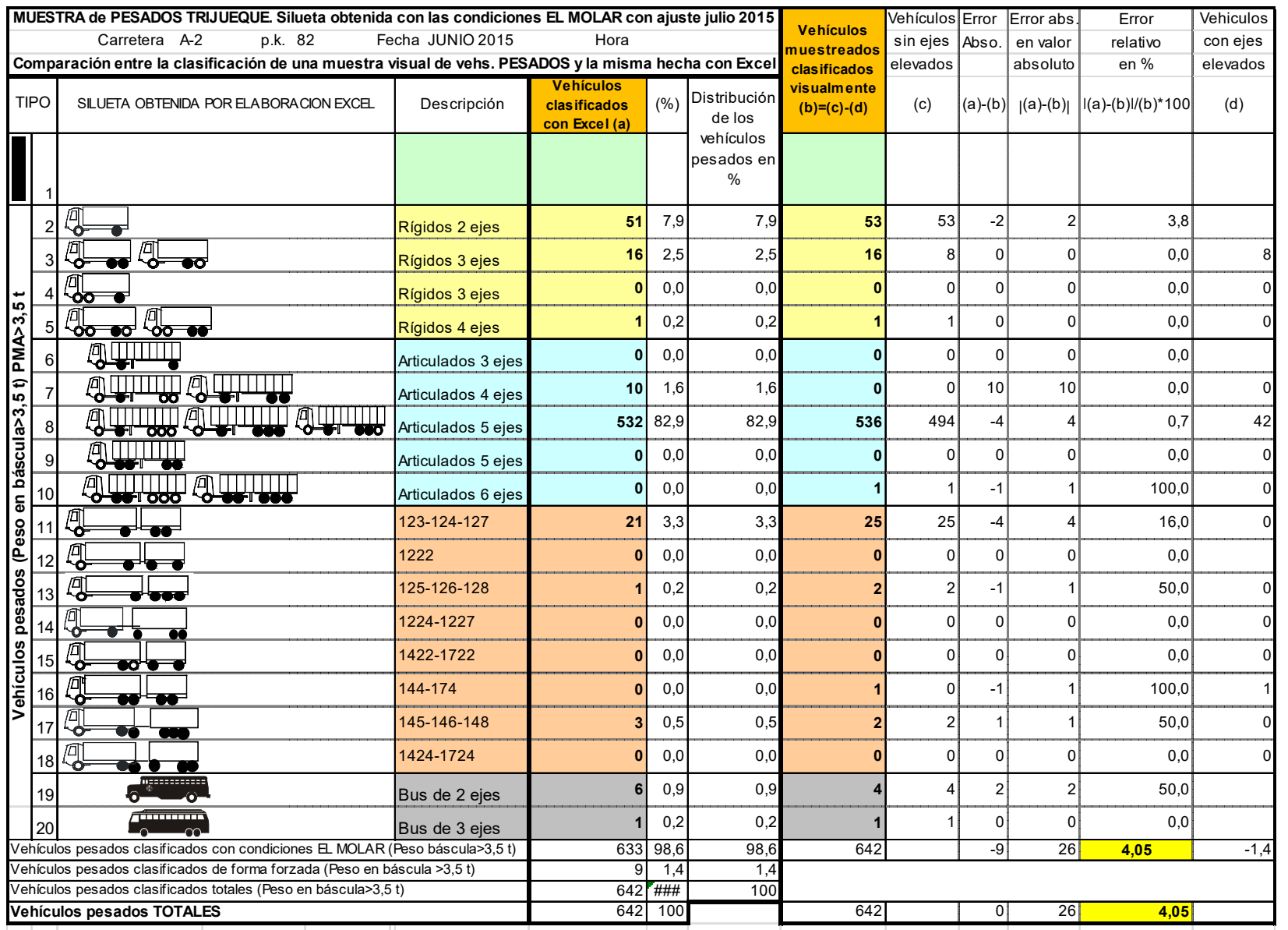

RUTA: Compartida/Plantillas/Plantillas con ajuste julio 2015 (condiciones El Molar)/Plantilla silueta Muestra condiciones EL MOLAR con ajustes julio 2015 (para 5000 veh)juanjo.xls

Como se puede ver en la Tabla 25, la muestra estaba formada por 642 vehículos pesados, de los cuales la mayor parte (más del 80\%) fueron vehículos articulados de 5 ejes (cabeza tractora de 2 ejes + semirremolque de eje trídem).

En total resultaron clasificados erróneamente 26 vehículos de los 642 registrados, aunque debido a compensaciones parciales de los errores en los distintos tipos de vehículos, se puede decir que el error total en toda la muestra fue sólo de 9 vehículos. No obstante, al igual que en El Molar, se ha tomado la cifra de 26 vehículos como la indicativa del error absoluto de clasificación, que se traduce en un error relativo de clasificación automática de un 4,05\%, que como puede comprobarse, es muy cercano al obtenido en El Molar, lo que probaría la estabilidad del método de clasificación automática desarrollado, además de su alta exactitud. 


\subsection{Comprobación del método de determinación automática de las cargas transportadas por los vehículos pesados mediante pesaje dinámico}

\subsubsection{Ensayo de comprobación del método}

Para comprobar la exactitud y precisión del método de cálculo automático del peso de las cargas transportadas cuyos fundamentos se han explicado en el Capítulo 5, se ha llevado a cabo el ensayo en la autopista A-2 que une Madrid y Barcelona, a la altura del municipio de Trijueque (Guadalajara), que se ha comentado anteriormente en la comprobación de la clasificación automática de vehículos. En lo relativo a la comprobación de las cargas transportadas, la principal novedad de este ensayo ha consistido en desviar una serie de vehículos pesados, que previamente habían circulado sobre el sistema de pesaje dinámico a su velocidad de recorrido, hacia una báscula de pesaje estático, con objeto de contrastar los pesos suministrados por el sistema de pesaje dinámico con los pesos dados por la báscula estática, que se pueden considerar como reales, y donde asimismo se anotó la tara y MMA (masa máxima admitida) de cada uno de los vehículos desviados.

Así, en la semana del 15 al 19 de junio de 2015 se instaló un sistema de pesaje dinámico de tipo capacitivo portátil en el carril derecho de la calzada sentido Madrid, $\mathrm{km} 82$, de la autovía A-2, aproximadamente unos $500 \mathrm{~m}$ antes de donde se encuentra una báscula de pesaje estático del Ministerio de Fomento, en un área situada junto a la autovía, que es utilizada frecuentemente por la Agrupación de Tráfico de la Guardia Civil para efectuar controles de pesaje dirigidos a vigilar el cumplimiento de las normas en esta materia.

La calibración del sistema de pesaje dinámico se realizó simultáneamente a la toma de datos, pasando un cierto número de veces un camión de 2 ejes de peso conocido (181,09 kN) sobre el sensor de peso del sistema WIM, a una velocidad próxima a la media de los vehículos pesados en la autopista (entre 80 y $90 \mathrm{~km} / \mathrm{h}$ ).

Posteriormente, con el objetivo de obtener datos de referencia para comprobar los pesos de las cargas transportadas, se tomaron dos muestras de vehículos:

1. Una pequeña muestra de unos 30 vehículos pesados (que se designará como "muestra reducida"). Para tomar esta muestra, se trabajó conjuntamente con la Agrupación de Tráfico de la Guardia Civil para seleccionar a los vehículos que, tras pasar sobre el sistema de pesaje dinámico a su velocidad usual de circulación (anotándose su hora de paso y el peso bruto dado por el sistema de pesaje dinámico), después se les desvió para su pesaje estático en la báscula situada unos $500 \mathrm{~m}$ más allá, donde asimismo se anotaron los datos de su matrícula y de su tara y masa máxima admitida, con objeto proceder a su comparación con los suministrados automáticamente por el sistema de pesaje dinámico y el método aproximado propuesto.

2. Una muestra más grande de más de 600 vehículos (que se designará como "muestra amplia") de camiones que pasaron sobre el sistema de pesaje 
dinámico, anotando la hora de paso de cada uno de ellos, con objeto de identificar sus pesos en el listado del equipo, al mismo tiempo que se tomaban fotografías de estos vehículos con objeto de identificar su matrícula (a efectos de poder determinar su tara a través del registro de vehículos de la Dirección General de Tráfico) y el tipo de vehículo de que se trataba. Asimismo, se realizó simultáneamente, durante 4 cuatro horas, un aforo manual, con el propósito de verificar el ajuste del programa de clasificación automática de vehículos desarrollado igualmente por el Área de Tráfico y Seguridad Vial del CEDEX.

\subsubsection{Cálculo de la exactitud y precisión del sistema de pesaje dinámico utilizado}

Respecto de los vehículos de la "muestra reducida", que fueron desviados para su pesaje estático por los agentes de la Agrupación de Tráfico de la Guardia Civil, se obtuvieron los siguientes datos y cálculos inmediatos, que sirven de base primeramente para la evaluación de la precisión del sistema de pesaje dinámico en el emplazamiento:

1- Peso estático real (Pest) proporcionado por la báscula de pesaje estático para cada uno de los vehículos de la muestra.

2- Peso dinámico calibrado (Pdin) suministrado por el equipo de pesaje dinámico para cada uno de los vehículos.

Una vez obtenidos o determinados los anteriores datos de los vehículos pesados, se han realizado los siguientes cálculos para determinar el sesgo y la dispersión de las medidas de los pesos proporcionadas por el sistema de pesaje dinámico:

1. Cálculo del error relativo (positivo o negativo), en porcentaje, para cada vehículo en la determinación de su peso bruto total, a través de dividir el error absoluto por el peso estático de cada vehículo. En la columna de más a la derecha de la Tabla 26 se muestran los valores del error relativo incurrido en el pesaje dinámico de cada vehículo.

$$
\begin{aligned}
& \text { Error absoluto }(\mathrm{kN})=\text { Pdin }- \text { Pest } \\
& \text { Error relativo }(\%)=[(\text { Pdin }- \text { Pest }) / \text { Pest }] \cdot 100
\end{aligned}
$$

2. Determinación del valor medio de todos los errores relativos obtenidos para cada vehículo individual, obteniéndose el llamado error relativo medio del pesaje dinámico para el conjunto de vehículos de la muestra, que representa el sesgo medio (\%) del sistema de pesaje dinámico.

Teóricamente, este sesgo medio debería poder eliminarse mediante una adecuada calibración del equipo de pesaje dinámico, pero en la práctica es bastante difícil eliminarlo completamente. Así, en este ensayo, el valor 
promedio de todos los errores relativos ha resultado ser del 6,35\%, valor que puede ser considerado como bastante mediocre.

Este alto sesgo puede ser debido a que la calibración se ha realizado utilizando un solo vehículo (en este caso un camión rígido tarado de 2 ejes), como suele normal en los equipos portátiles de pesaje, utilizados para tomas de datos de corta duración, mientras que los vehículos pesados predominantes en el emplazamiento son de tipo articulado, cuyas características dinámicas y de suspensión son bastante diferentes.

3. Determinación de la desviación típica de los errores relativos obtenidos para cada vehículo, que representa la precisión teórica del sistema de pesaje, valor que normalmente es inherente al equipo, aunque en un emplazamiento determinado depende también de las características superficiales y estructurales del firme en el que esté instalado el equipo.

El valor obtenido para la desviación típica porcentual ha sido del 8,41\%, que, al contrario que el valor obtenido para el sesgo medio, puede considerarse bastante bueno, pues es algo inferior al obtenido en el ensayo de referencia de sistemas portátiles de pesaje en movimiento realizado en Trappes (Francia) en 1996 (Blab et al., 1998) [16], lo que puede ser debido a que las condiciones del pavimento en el emplazamiento del ensayo eran muy buenas.

Esta cifra de desviación típica porcentual indica que si el sistema estuviera correctamente calibrado (sesgo próximo a cero) el equipo podría clasificarse dentro de la clase D (20) de precisión, de acuerdo con las Especificaciones Europeas del Pesaje en Movimiento del COST 323 [12] . 
Tabla 26. Errores relativos del sistema de pesaje dinámico obtenidos en el experimento

\begin{tabular}{|c|c|c|c|c|c|}
\hline Veh $n^{\circ}$ & Matrícula & Tipo de vehíc & Peso estático $(\mathrm{kN})$ & Peso dinámico $(\mathrm{kN})$ & Error relativo (\%) \\
\hline 1 & $68 X X \mathrm{HGP}$ & T2S3 & 378,37 & 362,97 & $-4,07$ \\
\hline 2 & 28XX HMP & T2S3 & 415,01 & 411,04 & $-0,96$ \\
\hline 3 & 53-BH-XX & T2S3 & 281,55 & 301,17 & 6,97 \\
\hline 4 & 99XX HZJ & T2S3 & 237,16 & 255,06 & 7,55 \\
\hline 5 & $84 X X \mathrm{JBV}$ & T2S3 & 341,83 & 337,46 & $-1,28$ \\
\hline 6 & $43 X \times H H D$ & T2S3 & 326,72 & 337,46 & 3,29 \\
\hline 7 & $66 X \times C S G$ & $\mathrm{C} 2$ & 113,35 & 135,38 & 19,43 \\
\hline 8 & M-01XX-TK & $\mathrm{C} 2$ & 48,46 & 51,99 & 7,29 \\
\hline 9 & 06XXCJL & T2S3 & 320,79 & 305,09 & $-4,89$ \\
\hline 10 & $34 X X H L P$ & T2S3 & 219,20 & 244,27 & 11,43 \\
\hline 11 & $68 X \times B W J$ & $\mathrm{C} 2$ & 110,56 & 129,49 & 17,13 \\
\hline 12 & $90 X \times \mathrm{HBC}$ & T2S3 & 192,82 & 230,54 & 19,56 \\
\hline 13 & $11 \mathrm{X} \times \mathrm{CDH}$ & T2S3 & 394,56 & 412,02 & 4,43 \\
\hline 14 & $54 X X F C S$ & T2S3 & 418,64 & 376,70 & $-10,02$ \\
\hline 15 & 70XXFFY & C2R2 & 305,68 & 309,02 & 1,09 \\
\hline 16 & $36 X X \mathrm{HNY}$ & T2S3 & 388,82 & 383,57 & $-1,35$ \\
\hline 17 & 04XX HZF & T2S3 & 292,83 & 330,60 & 12,90 \\
\hline 18 & CO-55XX-AS & T2S3 & 414,42 & 393,38 & $-5,08$ \\
\hline 19 & 31XXFJM & T2S3 & 239,81 & 254,08 & 5,95 \\
\hline 20 & $81 X X D D G$ & $\mathrm{C} 2$ & 122,33 & 142,25 & 16,28 \\
\hline 21 & 89XXDYV & $\mathrm{C} 3$ & 256,29 & 266,83 & 4,11 \\
\hline 22 & 90XXGRD & T2S3 & 314,07 & 318,83 & 1,51 \\
\hline 23 & 08XXHXK & T2S3 & 307,84 & 317,84 & 3,25 \\
\hline 24 & 16XXFYK & $\mathrm{C} 2$ & 143,81 & 164,81 & 14,60 \\
\hline 25 & $20 X X Z J J$ & T2S3 & 394,75 & 412,02 & 4,37 \\
\hline 26 & 02XXFFG & T2S3 & 403,58 & 411,04 & 1,85 \\
\hline 27 & $22 X X H Z T$ & T2S3 & 408,05 & 426,74 & 4,58 \\
\hline 28 & 93XXFSJ & T2S3 & 250,30 & 312,94 & 25,02 \\
\hline 29 & 23XXFVV & T2S3 & 403,83 & 464,01 & 14,90 \\
\hline \multirow[t]{7}{*}{30} & $82 X X \mathrm{HBK}$ & T2S3 & 229,85 & 254,08 & 10,54 \\
\hline & & & & & Error rel. medio \\
\hline & & & & & $\begin{array}{r}6,35 \\
\end{array}$ \\
\hline & & & & & \\
\hline & & & & & \\
\hline & & & & & Desv. Típica \\
\hline & & & & & 8,41 \\
\hline
\end{tabular}

\subsubsection{Planteamiento general de la comprobación del método de estimación de la carga transportada}

Tal como se ha descrito en el apartado 6.2.1, dedicado al desarrollo del ensayo realizado en la A-2 en Trijueque, la comprobación del método de determinación automática de las cargas transportadas se ha basado en la toma de datos de dos muestras diferentes de vehículos:

1- Una pequeña muestra de unos $\mathbf{3 0}$ vehículos pesados ("muestra reducida"), pesados estáticamente en un puente-báscula situado junto a la autopista. 
2- Una muestra más amplia de más de 600 vehículos pesados (“Muestra amplia"), que fueron fotografiados para identificar su número de matrícula.

Con respecto a la muestra reducida, en la que 30 vehículos fueron pesados estáticamente, se podido determinar su peso dinámico suministrado por el sistema, así como su peso estático proporcionado por el puente-báscula y, además, fue anotada su tara (en los vehículos articulados, tanto la tara de su cabeza tractora como del remolque o semirremolque) por los miembros de la Guardia Civil que manejaban la báscula estática a través de los datos que figuraban en la Ficha Técnica del vehículo.

De esta manera, respecto de los vehículos de esta primera muestra, se han podido obtener los siguientes resultados:

- la "carga real transportada" por ellos, restando el peso estático total menos la tara real, obtenida de la Ficha Técnica,

- la "carga dinámica real transportada", restando el peso dinámico obtenido por el sistema de pesaje en movimiento menos la tara real extraída de la Ficha Técnica,

- la "carga dinámica estimada transportada", restando el peso dinámico total suministrado por el sistema de pesaje dinámico menos la tara estimada según el tipo de vehículo en el que pudiera ser clasificado.

Por tanto, gracias a que se han podido conocer los anteriores resultados, con respecto a la muestra reducida se podrá obtener tanto el error total del procedimiento de determinación de la carga transportada, a través de la comparación entre la "carga dinámica estimada transportada" con la "carga real transportada", como el error debido solamente a las simplificaciones del método, es decir, descontando la componente del error debido a la exactitud del sistema de pesaje dinámico

Sin embargo, sobre la muestra amplia de vehículos fotografiados, no es posible conocer el peso estático total de cada vehículo, por no haber sido pesados estáticamente, pero a través de las matrículas fotografiadas sí que se ha podido determinar las taras. La razón de que se tomaran fotografías para identificar las matrículas en vez de anotarlas visualmente según pasaban los camiones está en que en los vehículos articulados y trenes de carretera se debe anotar tanto la matrícula del vehículo tractor como la del semirremolque o remolque: Esta última matrícula tiene los números en color negro sobre fondo de color rojo, lo que hace que sea muy difícil distinguir los números visualmente cuando pasa el vehículo a la velocidad normal de recorrido. Ambas matrículas de cada vehículo fueron enviadas a la Dirección General de Tráfico, con objeto de que localizar los datos de las taras en el Registro General de Vehículos.

En consecuencia, de los vehículos de esta segunda muestra no se ha podido conocer el peso de la "carga real transportada", al faltar el dato del peso bruto real (estático) del vehículo, pero sí que se han podido determinar las otras dos cargas:

- la "carga dinámica real transportada", a través de restar el peso dinámico obtenido por el sistema de pesaje en movimiento menos la tara, también real, obtenida del Registro General de Vehículos, y 
- la "carga dinámica estimada transportada", restando el peso dinámico total proporcionado por el sistema de pesaje menos la tara estimada según el tipo de vehículo en el que pudiera ser clasificado, ya sea de manera visual o automática (mediante el sistema de pesaje dinámico) .

Por tanto, respecto de la muestra amplia, no podrá obtenerse el error total del procedimiento, al faltar el dato del peso real (estático) de cada vehículo y no poder calcularse la "carga real transportada", pero en cambio sí que podrá obtenerse la componente del error debida a las simplificaciones del método, y eso sí, con una fiabilidad mayor, al estar basada en los datos de una muestra de más de 600 vehículos.

\subsubsection{Estudio de comprobación del método realizado con la muestra reducida}

\subsubsection{Datos y cálculos previos realizados para la comprobación}

Además de los datos descritos en el apartado 6.2.2, para la comprobación de la exactitud y precisión del sistema de pesaje dinámico, se obtuvieron también otros datos de los vehículos de la muestra reducida que fueron desviados para su pesaje estático por la Guardia Civil, que sirven de base para la comprobación del método aproximado propuesto para la determinación automática del peso de la carga transportada. Estos datos son:

1- Anotación por parte del personal del CEDEX de la clasificación real (tipo de vehículo) de cada uno de los camiones que pasaba por encima del sensor de pesaje dinámico y luego era desviado para su peso estático.

2- Anotación por parte de la guardia Civil de la tara y masa máxima admitida (MMA) de cada uno de los vehículos que fueron pesados estáticamente.

3- Anotación por parte del personal del CEDEX del tipo de vehículo (real) en que podía ser clasificado cada uno de los camiones de la muestra que pasaron primeramente sobre el sistema de pesaje dinámico.

En la Tabla 27 se muestran todos los datos iniciales, incluyendo el número de secuencia de peso de cada vehículo de la muestra, su matrícula (con los dos últimos dígitos numéricos codificados), la hora de paso sobre el sistema de pesaje dinámico, el tipo de vehículo tomado visualmente, el peso estático proporcionado por la báscula fija, el peso dinámico (ya corregido con el factor de calibración) suministrado por el equipo de pesaje dinámico y la tara real anotada por la Guardia Civil al realizar los pesajes estáticos.

Posteriormente, con objeto de realizar la comprobación del método, entre otros datos, se comparará este tipo de vehículo tomado visualmente con el tipo de vehículo clasificado automáticamente por el sistema de pesaje dinámico y la tara real anotada con la tara asignada según el tipo de vehículo registrado por el sistema. 
Tabla 27. Tabla de datos iniciales del ensayo de Trijueque: tipo real de vehículo, pesos estático, dinámico y tara registrada visualmente de cada uno de los vehículos de la muestra reducida.

\begin{tabular}{|c|c|c|c|c|c|c|}
\hline Veh $n^{\circ}$ & Matrícula & Hora & Tipo de vehículo & Peso estático $(\mathrm{kN})$ & Peso dinámico $(\mathrm{kN})$ & Tara real anotada $(\mathrm{kN})$ \\
\hline 1 & $68 X X \mathrm{HGP}$ & $10: 06: 18$ & $\mathrm{~T} 2 \mathrm{~S} 3$ & 378,37 & 362,97 & 155,98 \\
\hline 2 & $28 X \times \mathrm{HMP}$ & $10: 24: 11$ & T2S3 & 415,01 & 411,04 & 165,67 \\
\hline 3 & $53-\mathrm{BH}-\mathrm{XX}$ & $10: 25: 30$ & T2S3 & 281,55 & 301,17 & 121,64 \\
\hline 4 & 99XX HZJ & $10: 54: 08$ & T2S3 & 237,16 & 255,06 & 162,86 \\
\hline 5 & $84 X X \mathrm{JBV}$ & $10: 57: 32$ & T2S3 & 341,83 & 337,46 & 168,05 \\
\hline 6 & $43 X \times H H D$ & $11: 25: 42$ & T2S3 & 326,72 & 337,46 & 160,88 \\
\hline 7 & $66 X \times C S G$ & $11: 35: 16$ & $\mathrm{C} 2$ & 113,35 & 135,38 & 96,48 \\
\hline 8 & M-01XX-TK & $11: 53: 12$ & $\mathrm{C} 2$ & 48,46 & 51,99 & 42,48 \\
\hline 9 & 06XX CJL & $12: 08: 59$ & T2S3 & 320,79 & 305,09 & 152,64 \\
\hline 10 & $34 X X H L P$ & $12: 15: 55$ & T2S3 & 219,20 & 244,27 & 169,80 \\
\hline 11 & $68 X \times B W J$ & $12: 26: 01$ & $\mathrm{C} 2$ & 110,56 & 129,49 & 93,20 \\
\hline 12 & $90 \times \times H B C$ & $12: 41: 11$ & T2S3 & 192,82 & 230,54 & 154,31 \\
\hline 13 & $11 \mathrm{XXCDH}$ & $12: 49: 54$ & T2S3 & 394,56 & 412,02 & 125,67 \\
\hline 14 & $54 X \times F C S$ & $10: 24: 30$ & T2S3 & 418,64 & 376,70 & 165,79 \\
\hline 15 & 70XXFFY & $10: 38: 00$ & C2R2 & 305,68 & 309,02 & 183,84 \\
\hline 16 & $36 X X H N Y$ & $10: 51: 19$ & T2S3 & 388,82 & 383,57 & 157,30 \\
\hline 17 & 04XX HZF & $10: 54: 49$ & T2S3 & 292,83 & 330,60 & 135,32 \\
\hline 18 & CO-55XX-AS & $11: 00: 21$ & T2S3 & 414,42 & 393,38 & 142,24 \\
\hline 19 & 31XXFJM & $11: 13: 59$ & T2S3 & 239,81 & 254,08 & 160,32 \\
\hline 20 & 81XXDDG & $11: 14: 58$ & $\mathrm{C} 2$ & 122,33 & 142,25 & 109,77 \\
\hline 21 & 89XXDYV & $11: 24: 05$ & C3 & 256,29 & 266,83 & 104,57 \\
\hline 22 & 90XXGRD & $11: 38: 15$ & T2S3 & 314,07 & 318,83 & 137,14 \\
\hline 23 & 08XXHXK & $11: 43: 38$ & T2S3 & 307,84 & 317,84 & 160,15 \\
\hline 24 & 16XXFYK & $11: 53: 14$ & $\mathrm{C} 2$ & 143,81 & 164,81 & 82,89 \\
\hline 25 & $20 X X Z J O$ & $12: 03: 36$ & T2S3 & 394,75 & 412,02 & 142,88 \\
\hline 26 & 02XXFFG & $12: 19: 03$ & T2S3 & 403,58 & 411,04 & 121,74 \\
\hline 27 & $22 X X H Z T$ & $12: 35: 12$ & T2S3 & 408,05 & 426,74 & 165,19 \\
\hline 28 & $93 X X F S J$ & $12: 38: 01$ & T2S3 & 250,30 & 312,94 & 141,07 \\
\hline 29 & 23XXFVV & $13: 01: 53$ & T2S3 & 403,83 & 464,01 & 134,40 \\
\hline 30 & $82 X \times H B K$ & $13: 17: 58$ & T2S3 & 229,85 & 254,08 & 135,03 \\
\hline
\end{tabular}

\begin{tabular}{|l|l|||l|l|}
\hline Leyenda. & \\
\hline C2 & Camión rígido de 2 ejes & \\
\hline C3 & Camión rígido de 3 ejes \\
\hline T2S2 & Tractor de 2 ejes + semirremolque de 2 ejes & \\
\hline T2S3 & Tractor de 2 ejes + semirremolque de 3 ejes & \\
\hline C2R2 & Camión rígido de 2 ejes + remolque de 2 ejes \\
\hline
\end{tabular}

\subsubsection{Cálculos realizados con la muestra reducida para la estimación de las cargas transportadas}

De acuerdo con el método desarrollado, la estimación de las cargas transportadas por los vehículos pesados se basa en restar del peso dinámico proporcionado por el sistema WIM para un cierto vehículo una tara correspondiente a la tara media del tipo en que puede ser clasificado el vehículo.

Por ello, el primer paso de este cálculo consistirá en presentar los valores para las taras medias de cada tipo vehículo pesado, de acuerdo con diferentes fuentes de datos.

\subsection{Propuesta de taras medias para cada tipo de vehículo pesado}

Para asignar una tara a cada vehículo pesado registrado por el sistema de pesaje, se ha acudido a cada una de las fuentes o bases de datos de las características de los 
vehículos pesados que se han descrito en el apartado 5.2.3, y que se citan a continuación:

- Taras recogidas visualmente en la campaña de pesaje dinámico realizada por el CEDEX en la RCE entre los años 2000 y 2003.

- Taras obtenidas de la Encuesta Permanente del Transporte de Mercancías por Carretera (EPTMC). Se dispone de los datos de la Encuesta más reciente (2013) en el momento de llevar a cabo el ensayo de Trijueque (2015).

- Las taras de cada vehículo en el Registro General de Vehículos de la Dirección General de Tráfico, del año 2017.

Los datos de las taras medias de cada tipo de vehículo pesado que se han introducido en los cálculos, así como de su dispersión respecto a los valores promedio, se han proporcionado en la Tabla 23 del apartado 5.2.3.5.

Tal como se ha comentado en el apartado 5.2.3, a la hora de realizar los cálculos se optó por considerar en primer lugar las taras de la campaña de pesaje dinámico 20002003 del CEDEX, pues era la única de la que se disponía en el momento realizar el ensayo y, además, porque se consideraba que sus datos eran los más fiables, pues se participó en su elaboración al realizar la campaña de pesaje. Poco tiempo después se recibieron los datos de la EPTMC del año 2013, por lo que fue la segunda en ser considerada.

Por otro lado, se pensaba en un primer momento que era más conveniente emplear estas dos bases de datos de taras fundamentalmente porque reflejan más fielmente la composición real del tráfico pesado en la carretera, ya que la base de datos del Registro General de Vehículos se refiere al parque total de vehículos existentes, pero no a su participación porcentual en el tráfico de la carretera. De hecho, muchos de los vehículos presentes en el Registro General de Vehículos apenas circulan por carretera, por ser muy antiguos o por estar dedicados al transporte urbano.

Por otro lado, los datos del Registro General de Vehículos no han sido recibidos en su totalidad hasta enero de 2018, por lo que han sido los últimos en ser considerados para los cálculos.

Por la influencia de los valores proporcionados en la Tabla 23 en la precisión de los cálculos del procedimiento de estimación del peso de la carga transportada por los vehículos pesados, conviene hacer unos breves comentarios, algunos de las cuales son repetición de los ya expresados en el apartado 5.2.3.5, que clarifiquen la situación:

- $\quad$ El valor de la tara media para los camiones rígidos de 2 ejes dado en la EPTMC 2013 es bastante mayor que el dado en las otras dos bases de datos, lo que se debe a que la EPTMC sólo incluye los camiones con capacidad de carga mayor de 3,5 t (34,3 kN) y una Masa Máxima Admitida superior a $6 \mathrm{t}$, mientras que la campaña del CEDEX y el Registro General de Vehículos incluyen todos los vehículos de MMA mayor de 3,5 t, acorde con la definición implícita de vehículo pesado en el Reglamento General de Conductores. 
- Las mayores dispersiones de la taras, para los tipos de vehículos más comunes se dan en los camiones rígidos de 2 ejes, pues en esta categoría se incluyen vehículos muy diferentes, desde pequeños camiones de reparto hasta camiones bastante grandes, como camiones grúa. Esta mayor dispersión de las taras en este tipo de vehículo implica que la tara asignada a cada vehículo rígido de 2 ejes es más incierta, por lo que el error que se comete al determinar la carga transportada puede ser mayor.

- Para los vehículos más abundantes en carretera, los articulados tipo T2S3, es decir, los formados por una cabeza tractora de 2 ejes y un semirremolque de 3 ejes, las taras medias son muy parecidas en las tres fuentes y también bastante reducida su dispersión, lo que asegura que la exactitud en la determinación de las cargas transportadas por este tipo de vehículos será mayor.

6.2.4.2.2 Cálculos para la determinación de la carga transportada por cada vehículo

Una vez escogidas las bases de datos de taras medias, se deben realizar una serie de cálculos para determinar el peso de la carga transportada, con vistas a su comparación con los valores reales:

1 Determinación del peso real de la carga tansportada por los vehículos de la muestra. Este peso se determina efectuando la resta de la tara real ("Tara") del vehículo respecto del peso estático ("Pest") de éste.

Peso real de la carga $(k N)=$ Pest - Tara

Este valor es el que servirá de referencia para calcular el ajuste y precisión del método que se pretende desarrollar.

2 Determinación del peso dinámico real de la carga transportada por los vehículos muestreados. La sustracción de la tara real del vehículo respecto del peso dinámico ("Pdin") de éste suministrado por el sistema de pesaje dinámico nos dará el valor de lo que se designará como "peso dinámico real de la carga transportada" por los vehículos pesados.

\section{Peso dinámico real de la carga $(k N)=$ Pdin - Tara}

En las dos columnas de más a la derecha de la Tabla 28 se muestran los valores obtenidos para las anteriores variables para cada uno de los vehículos de los vehículos pesados estáticamente. 
Tabla 28. Valores del "Peso real de la carga transportada" (Carga real = Peso estático - Tara) y del "Peso dinámico real de la carga transportada" (Peso dinámico -Tara).

\begin{tabular}{|c|c|c|c|c|c|c|}
\hline Veh $n^{\circ}$ & Tipo de vehículo & Peso estático $(\mathrm{kN})$ & Peso dinámico $(\mathrm{kN})$ & Tara real anotada $(\mathrm{kN})$ & Pdin - Tara (kN) & $\begin{array}{l}\text { Carga real }= \\
\text { Pest-Tara }(\mathrm{kN})\end{array}$ \\
\hline 1 & T2S3 & 378,37 & 362,97 & 155,98 & 206,99 & 222,39 \\
\hline 2 & T2S3 & 415,01 & 411,04 & 165,67 & 245,37 & 249,34 \\
\hline 3 & T2S3 & 281,55 & 301,17 & 121,64 & 179,52 & 159,90 \\
\hline 4 & T2S3 & 237,16 & 255,06 & 162,86 & 92,20 & 74,30 \\
\hline 5 & T2S3 & 341,83 & 337,46 & 168,05 & 169,42 & 173,78 \\
\hline 6 & T2S3 & 326,72 & 337,46 & 160,88 & 176,58 & 165,84 \\
\hline 7 & $\mathrm{C} 2$ & 113,35 & 135,38 & 96,48 & 38,90 & 16,87 \\
\hline 8 & C2 & 48,46 & 51,99 & 42,48 & 9,52 & 5,98 \\
\hline 9 & T2S3 & 320,79 & 305,09 & 152,64 & 152,45 & 168,14 \\
\hline 10 & T2S3 & 219,20 & 244,27 & 169,80 & 74,47 & 49,40 \\
\hline 11 & C2 & 110,56 & 129,49 & 93,20 & 36,30 & 17,36 \\
\hline 12 & T2S3 & 192,82 & 230,54 & 154,31 & 76,22 & 38,50 \\
\hline 13 & T2S3 & 394,56 & 412,02 & 125,67 & 286,35 & 268,89 \\
\hline 14 & T2S3 & 418,64 & 376,70 & 165,79 & 210,92 & 252,85 \\
\hline 15 & C2R2 & 305,68 & 309,02 & 183,84 & 125,18 & 121,84 \\
\hline 16 & T2S3 & 388,82 & 383,57 & 157,30 & 226,27 & 231,52 \\
\hline 17 & T2S3 & 292,83 & 330,60 & 135,32 & 195,28 & 157,51 \\
\hline 18 & T2S3 & 414,42 & 393,38 & 142,24 & 251,15 & 272,19 \\
\hline 19 & T2S3 & 239,81 & 254,08 & 160,32 & 93,76 & 79,49 \\
\hline 20 & C2 & 122,33 & 142,25 & 109,77 & 32,47 & 12,56 \\
\hline 21 & C3 & 256,29 & 266,83 & 104,57 & 162,26 & 151,71 \\
\hline 22 & T2S3 & 314,07 & 318,83 & 137,14 & 181,68 & 176,92 \\
\hline 23 & T2S3 & 307,84 & 317,84 & 160,15 & 157,70 & 147,69 \\
\hline 24 & C2 & 143,81 & 164,81 & 82,89 & 81,91 & 60,92 \\
\hline 25 & T2S3 & 394,75 & 412,02 & 142,88 & 269,14 & 251,87 \\
\hline 26 & T2S3 & 403,58 & 411,04 & 121,74 & 289,30 & 281,84 \\
\hline 27 & T2S3 & 408,05 & 426,74 & 165,19 & 261,54 & 242,86 \\
\hline 28 & T2S3 & 250,30 & 312,94 & 141,07 & 171,87 & 109,23 \\
\hline 29 & T2S3 & 403,83 & 464,01 & 134,40 & 329,62 & 269,43 \\
\hline \multirow[t]{3}{*}{30} & T2S3 & 229,85 & 254,08 & 135,03 & 119,04 & 94,81 \\
\hline & & & & Carga total transportada & 4903,36 & 4525,97 \\
\hline & & & & Error debido al aparato (\%) & & 8,34 \\
\hline
\end{tabular}

3 Determinación del peso dinámico estimado de la carga transportada por los vehículos muestreados. Este valor se obtiene restando del peso dinámico del vehículo (suministrado por el sistema WIM) una "tara estimada" en función del tipo de vehículo en el que pueda ser clasificado.

\section{Peso dinámico estimado de la carga $(\mathrm{kg})=$ Pdin - Tara estimada}

Por tanto, se tendrá para cada una de estas tres bases de datos de taras utilizadas (Campaña de pesaje del CEDEX, EPTMC 2013 y RGV 2017) un peso dinámico estimado de la carga, que se calculará respectivamente con las operaciones:

a) Peso dinámico estimado de la carga según la campaña de pesaje realizada por el CEDEX = Pdin - Tara estimada en campaña CEDEX.

b) Peso dinámico estimado de la carga según la EPTMC = Pdin - Tara estimada en la encuesta EPTMC. 
c) Peso dinámico estimado de la carga transportada según el Registro General de Vehículos (RGV) de 2017 = Pdin - Tara estimada según el RGV 2017.

Tabla 29. Calculo de la "carga transportada estimada" para cada vehículos utilizando las taras medias de los tipos de vehículos obtenidas en la campaña de pesaje dinámico 2000-2003 del CEDEX y determinación del error de esta estimación.

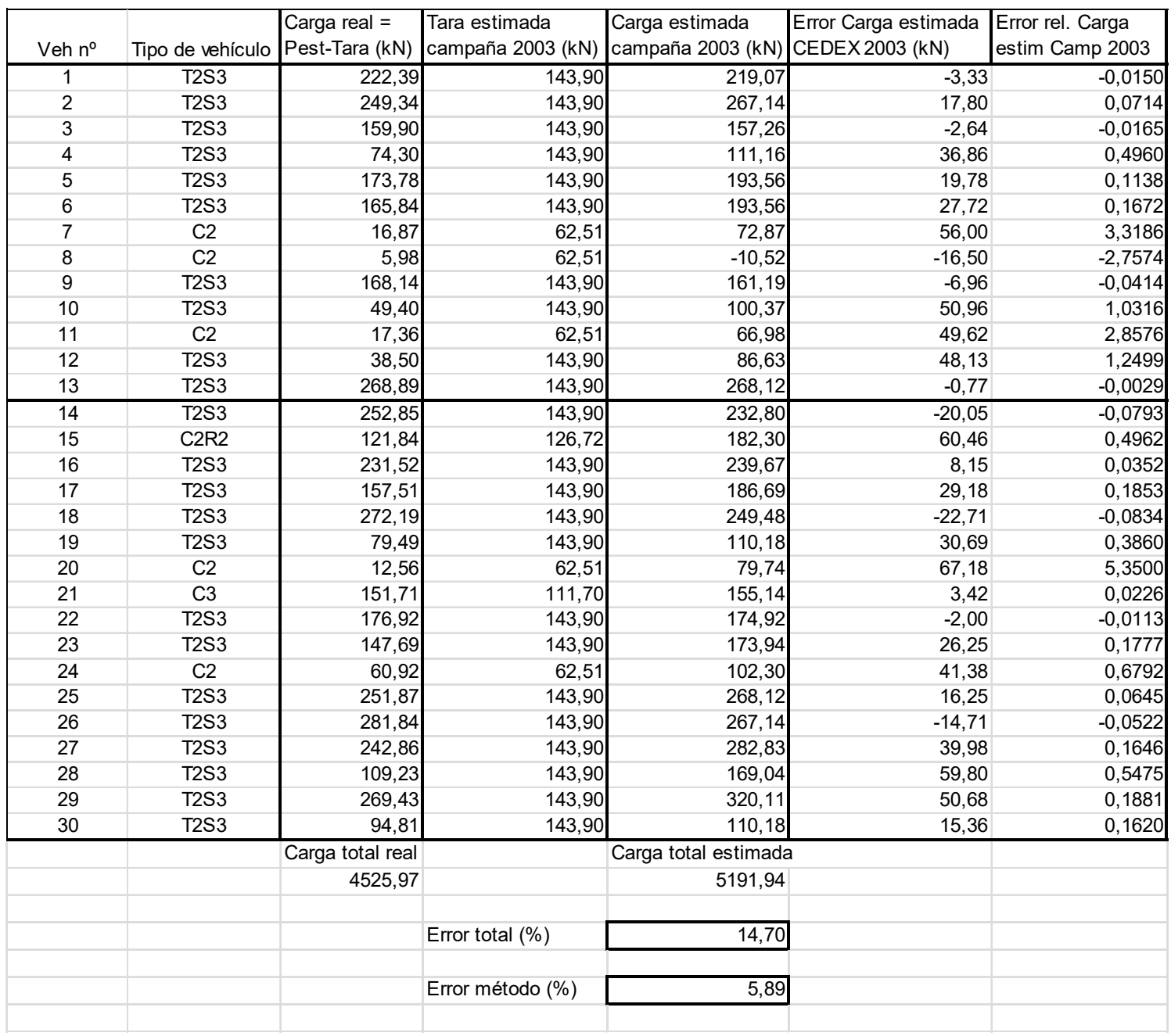

En las Tablas 29, 30 y 31 se muestran los cálculos realizados para determinar los pesos dinámicos estimados, para cada uno de los vehículos, utilizando los valores de las taras estimadas a través de los datos obtenidos en:

a) la campaña de pesaje dinámico realizada entre 2000 y 2003 por el CEDEX (Tabla 29)

b) la Encuesta Permanente del Transporte de Mercancías por Carretera (EPTMC) del año 2013 (Tabla 30).

c) El Registro General de Vehículos de 2017 (Tabla 31). 
Tabla 30. Cálculo de la "carga transportada estimada" para cada vehículo utilizando las taras medias de la Encuesta Permanente del Transporte de Mercancías por Carretera de 2013 y determinación del error de esta estimación

\begin{tabular}{|c|c|c|c|c|c|c|}
\hline Veh $n^{\circ}$ & Tipo de vehículo & $\begin{array}{l}\text { Carga real = } \\
\text { Pest-Tara }(k N)\end{array}$ & $\begin{array}{l}\text { Tara estimada } \\
\text { EPTMC }(\mathrm{kN})\end{array}$ & \begin{tabular}{|l|} 
Carga estimada \\
EPTMC $(k N)$
\end{tabular} & \begin{tabular}{|l|} 
Error Carga estim \\
EPTMC $(\mathrm{kN})$
\end{tabular} & \begin{tabular}{|l|} 
Error rel. Carga \\
estim EPTMC
\end{tabular} \\
\hline 1 & $\mathrm{~T} 2 \mathrm{~S} 3$ & 222,39 & 142,48 & 220,49 & $-1,90$ & $-0,0086$ \\
\hline 2 & T2S3 & 249,34 & 142,48 & 268,56 & 19,22 & 0,0771 \\
\hline 3 & T2S3 & 159,90 & 142,48 & 158,69 & $-1,22$ & $-0,0076$ \\
\hline 4 & T2S3 & 74,30 & 142,48 & 112,58 & 38,28 & 0,5152 \\
\hline 5 & T2S3 & 173,78 & 142,48 & 194,98 & 21,20 & 0,1220 \\
\hline 6 & T2S3 & 165,84 & 142,48 & 194,98 & 29,15 & 0,1757 \\
\hline 7 & $\mathrm{C} 2$ & 16,87 & 77,55 & 57,83 & 40,95 & 2,4272 \\
\hline 8 & $\mathrm{C} 2$ & 5,98 & 77,55 & $-25,56$ & $-31,54$ & $-5,2710$ \\
\hline 9 & T2S3 & 168,14 & 142,48 & 162,61 & $-5,53$ & $-0,0329$ \\
\hline 10 & T2S3 & 49,40 & 142,48 & 101,79 & 52,39 & 1,0604 \\
\hline 11 & $\mathrm{C} 2$ & 17,36 & 77,55 & 51,94 & 34,58 & 1,9914 \\
\hline 12 & T2S3 & 38,50 & 142,48 & 88,05 & 49,55 & 1,2869 \\
\hline 13 & T2S3 & 268,89 & 142,48 & 269,54 & 0,65 & 0,0024 \\
\hline 14 & T2S3 & 252,85 & 142,48 & 234,22 & $-18,63$ & $-0,0737$ \\
\hline 15 & $\mathrm{C} 2 \mathrm{R} 2$ & 121,84 & 169,87 & 139,15 & 17,31 & 0,1420 \\
\hline 16 & T2S3 & 231,52 & 142,48 & 241,09 & 9,57 & 0,0414 \\
\hline 17 & T2S3 & 157,51 & 142,48 & 188,12 & 30,61 & 0,1943 \\
\hline 18 & T2S3 & 272,19 & 142,48 & 250,90 & $-21,29$ & $-0,0782$ \\
\hline 19 & T2S3 & 79,49 & 142,48 & 111,60 & 32,11 & 0,4039 \\
\hline 20 & $\mathrm{C} 2$ & 12,56 & 77,55 & 64,69 & 52,14 & 4,1521 \\
\hline 21 & C3 & 151,71 & 120,17 & 146,66 & $-5,05$ & $-0,0333$ \\
\hline 22 & T2S3 & 176,92 & 142,48 & 176,34 & $-0,58$ & $-0,0033$ \\
\hline 23 & T2S3 & 147,69 & 142,48 & 175,36 & 27,67 & 0,1874 \\
\hline 24 & $\mathrm{C} 2$ & 60,92 & 77,55 & 87,26 & 26,34 & 0,4323 \\
\hline 25 & T2S3 & 251,87 & 142,48 & 269,54 & 17,67 & 0,0701 \\
\hline 26 & T2S3 & 281,84 & 142,48 & 268,56 & $-13,28$ & $-0,0471$ \\
\hline 27 & T2S3 & 242,86 & 142,48 & 284,25 & 41,40 & 0,1705 \\
\hline 28 & T2S3 & 109,23 & 142,48 & 170,46 & 61,22 & 0,5605 \\
\hline 29 & T2S3 & 269,43 & 142,48 & 321,53 & 52,10 & 0,1934 \\
\hline 30 & T2S3 & 94,81 & 142,48 & 111,60 & 16,79 & 0,1770 \\
\hline & Carga real total & 4525,97 & \multirow{2}{*}{$\begin{array}{l}\text { Carga estimada total } \\
\text { Error total }(\%)\end{array}$} & 5097,83 & & \\
\hline & & & & 12,64 & & \\
\hline & & & & & & \\
\hline & & & Error método (\%) & 3,97 & & \\
\hline
\end{tabular}

Así, en las tres tablas se incluye una columna en la que, a modo de referencia, se muestra la carga real transportada por todos y cada uno de los vehículos desviados y pesados estáticamente por la Guardia Civil. A continuación, en la columna siguiente, se proporcionan los datos de la tara estimada de cada uno de los vehículos pesados muestreados, en función del tipo en que pueden ser clasificados, de acuerdo con la base de datos elegida, que en la Tabla 29 es la de la campaña de pesaje dinámico realizada por el CEDEX, en la Tabla 30 es la EPTMC del año 2013 y en la Tabla 31 es el Registro General de Vehículos de 2017. Seguidamente, en la columna contigua, se muestran los valores del peso dinámico estimado de la carga transportada por cada vehículo, calculado según el método aproximado propuesto. 
Tabla 31. Cálculo de la "Carga transportada estimada" para cada vehículo utilizando las taras medias de los tipos de vehículos del Registro General de Vehículos de 2017

\begin{tabular}{|c|c|c|c|c|c|c|}
\hline Veh $n^{\circ}$ & Tipo de vehículo & $\begin{array}{l}\text { Carga real = } \\
\text { Pest-Tara }(k N)\end{array}$ & $\begin{array}{l}\text { Tara estimada RGV- } \\
\text { DGT }(\mathrm{kN})\end{array}$ & \begin{tabular}{|l|} 
Carga estimada \\
RGV-DGT $(\mathrm{kN})$
\end{tabular} & \begin{tabular}{|l|} 
Error Carga estim \\
RGV-DGT (kN)
\end{tabular} & \begin{tabular}{|l|} 
Error rel. Carga \\
estim RGV-DGT
\end{tabular} \\
\hline 1 & $\mathrm{~T} 2 \mathrm{~S} 3$ & 222,39 & 146,03 & 216,94 & $-5,45$ & $-0,0245$ \\
\hline 2 & T2S3 & 249,34 & 146,03 & 265,01 & 15,67 & 0,0628 \\
\hline 3 & T2S3 & 159,90 & 146,03 & 155,14 & $-4,77$ & $-0,0298$ \\
\hline 4 & T2S3 & 74,30 & 146,03 & 109,03 & 34,73 & 0,4674 \\
\hline 5 & T2S3 & 173,78 & 146,03 & 191,43 & 17,65 & 0,1016 \\
\hline 6 & T2S3 & 165,84 & 146,03 & 191,43 & 25,60 & 0,1543 \\
\hline 7 & $\mathrm{C} 2$ & 16,87 & 62,94 & 72,44 & 55,56 & 3,2931 \\
\hline 8 & C2 & 5,98 & 62,94 & $-10,95$ & $-16,93$ & $-2,8293$ \\
\hline 9 & T2S3 & 168,14 & 146,03 & 159,06 & $-9,08$ & $-0,0540$ \\
\hline 10 & T2S3 & 49,40 & 146,03 & 98,24 & 48,84 & 0,9885 \\
\hline 11 & $\mathrm{C} 2$ & 17,36 & 62,94 & 66,55 & 49,19 & 2,8328 \\
\hline 12 & T2S3 & 38,50 & 146,03 & 84,51 & 46,00 & 1,1947 \\
\hline 13 & T2S3 & 268,89 & 146,03 & 265,99 & $-2,90$ & $-0,0108$ \\
\hline 14 & T2S3 & 252,85 & 146,03 & 230,67 & $-22,18$ & $-0,0877$ \\
\hline 15 & C2R2 & 121,84 & 127,08 & 181,94 & 60,09 & 0,4932 \\
\hline 16 & $\mathrm{~T} 2 \mathrm{~S} 3$ & 231,52 & 146,03 & 237,54 & 6,02 & 0,0260 \\
\hline 17 & T2S3 & 157,51 & 146,03 & 184,57 & 27,06 & 0,1718 \\
\hline 18 & T2S3 & 272,19 & 146,03 & 247,35 & $-24,84$ & $-0,0913$ \\
\hline 19 & T2S3 & 79,49 & 146,03 & 108,05 & 28,56 & 0,3593 \\
\hline 20 & $\mathrm{C} 2$ & 12,56 & 62,94 & 79,31 & 66,75 & 5,3157 \\
\hline 21 & C3 & 151,71 & 126,67 & 140,16 & $-11,55$ & $-0,0761$ \\
\hline 22 & $\mathrm{~T} 2 \mathrm{~S} 3$ & 176,92 & 146,03 & 172,80 & $-4,13$ & $-0,0233$ \\
\hline 23 & T2S3 & 147,69 & 146,03 & 171,81 & 24,12 & 0,1633 \\
\hline 24 & $\mathrm{C} 2$ & 60,92 & 62,94 & 101,87 & 40,95 & 0,6722 \\
\hline 25 & T2S3 & 251,87 & 146,03 & 265,99 & 14,12 & 0,0561 \\
\hline 26 & T2S3 & 281,84 & 146,03 & 265,01 & $-16,83$ & $-0,0597$ \\
\hline 27 & T2S3 & 242,86 & 146,03 & 280,71 & 37,85 & 0,1558 \\
\hline 28 & T2S3 & 109,23 & 146,03 & 166,91 & 57,67 & 0,5280 \\
\hline 29 & T2S3 & 269,43 & 146,03 & 317,98 & 48,55 & 0,1802 \\
\hline 30 & T2S3 & 94,81 & $\begin{array}{r}146,03 \\
\end{array}$ & 108,05 & 13,24 & 0,1396 \\
\hline & Carga real total & 4525,97 & \multirow{2}{*}{$\begin{array}{l}\text { Carga estimada total } \\
\text { Error total }(\%)\end{array}$} & 5125,53 & & \\
\hline & & & & 13,25 & & \\
\hline & & & Error método (\%) & 4,53 & & \\
\hline
\end{tabular}

Como se puede comprobar a la vista de estas tablas, el error total obtenido en la determinación del peso de la carga total transportada utilizando las taras de la campaña de pesaje del CEDEX ha sido del $14,7 \%$, cuando se han utilizado las taras de la Encuesta Permanente del Transporte de Mercancías por Carretera ha alcanzado un $12,64 \%$ y si se utilizan las taras del Registro General de Vehículos el error total es el $13,25 \%$. Por otro lado, el error en la determinación del peso de la carga transportada debido solamente a las simplificaciones del método de estimación desarrollado (es decir, excluyendo el error del aparato de medida) ha sido del 5,89\% utilizando las taras de la campaña del CEDEX, del 3,97 \% con las taras de la EPTMC 2013 y del 4,53 \% con los datos del Registro General de Vehículos de 2017. 
6.2.4.3 Determinación de los errores cometidos en el cálculo de la carga transportada por cada vehículo

Una vez estimado el peso de la carga para cada vehículo según ambas bases de datos, se debe realizar la comprobación de la exactitud y precisión del método.

Para ello, se ha determinado para cada vehículo el error absoluto incurrido al estimar el peso de la carga transportada, que será igual al peso dinámico estimado de esta carga (columna central de las Tablas 28, 29 y 30) menos la carga realmente transportada (la siguiente columna situada más a la derecha en esas mismas tablas):

Error absoluto de peso de la carga = Peso estimado de la carga - peso real de la carga $=($ Pdin - Tara estimada $)-($ Peso estático - Tara real $)$

Dividiendo el error absoluto en el peso de la carga transportada entre el peso real de esta carga se obtiene el error relativo cometido al estimar el peso de la carga transportada por cada vehículo por el método descrito:

Error relativo del peso carga $(\%)=($ Error absoluto peso carga $/$ Peso real carga $) * 100$

Los valores del error absoluto y el error relativo obtenidos para cada vehículo en la estimación del peso de la carga transportada para ambas bases de datos de taras, se muestran en las dos columnas de más a la derecha de las Tablas 29, 30 y 31.

La causa inmediata de los altos valores de los errores hay que buscarla en lo que se conoce como el efecto de "propagación de los errores". Así, en los experimentos (procedimientos) que requieren varias medidas para llegar al resultado final por aplicación de una fórmula, como es el caso que nos ocupa, es importante considerar las reglas de lo que se conoce como "propagación de errores" [46], que permiten asignar una incertidumbre al resultado final.

Dado que el método de determinación del peso de la carga transportada se basa en la resta de dos cantidades, la incertidumbre total del método estará asociada con la operación de restar dos cantidades: el peso en báscula y la tara asignada.

Según la teoría de análisis y propagación de errores, es bien conocido que:

- Si una magnitud es suma de otras dos, el error de la magnitud suma será, en el caso más desfavorable, la suma de los errores de los sumandos. Es decir, si $z=x+y$, el error de $z$ será, $\delta z=\delta x+\delta y$.

- Si una magnitud es resta de otras dos $\left(z^{\prime}=x-y\right)$, el error de la magnitud diferencia, en el caso más desfavorable, también es la suma de los errores de los sumandos (y no su resta): $\delta z^{\prime}=\delta x+\delta y$.

Por eso, restar dos números inciertos (en el caso que nos ocupa, serían el peso suministrado por el sistema WIM y la tara asignada) suele plantear problemas porque, 
al final, nos quedamos con un número menor que los originales y con un error mayor; con lo cual el error relativo aumenta irremediablemente [47]. Si además los dos números que se restan fueran de una magnitud muy parecida (por ejemplo, cuando el vehículo circula descargado), puede ocurrir que la diferencia sea menor que su incertidumbre (error mayor del $100 \%$ ), con lo cual tal diferencia no significaría nada; es decir, no sabremos si los verdaderos valores de las magnitudes especificadas por los números inciertos son realmente diferentes o no.

No obstante, se ha realizado un estudio más detallado para explorar la posibilidad de que en algunos casos sí que se puedan utilizar esos datos.

\subsection{Estudio en detalle de los errores individuales en la estimación de la carga transportada}

Como resumen de la magnitud de los errores relativos obtenidos en la estimación del peso de la carga transportada por cada uno de los vehículos pesados de la muestra, se proporciona la Figura 25, en el que aparece un histograma de las frecuencias de los distintos intervalos de errores relativos para el caso de estimación del peso de la carga transportada partiendo de los datos de taras de la campaña CEDEX 2000-2002.

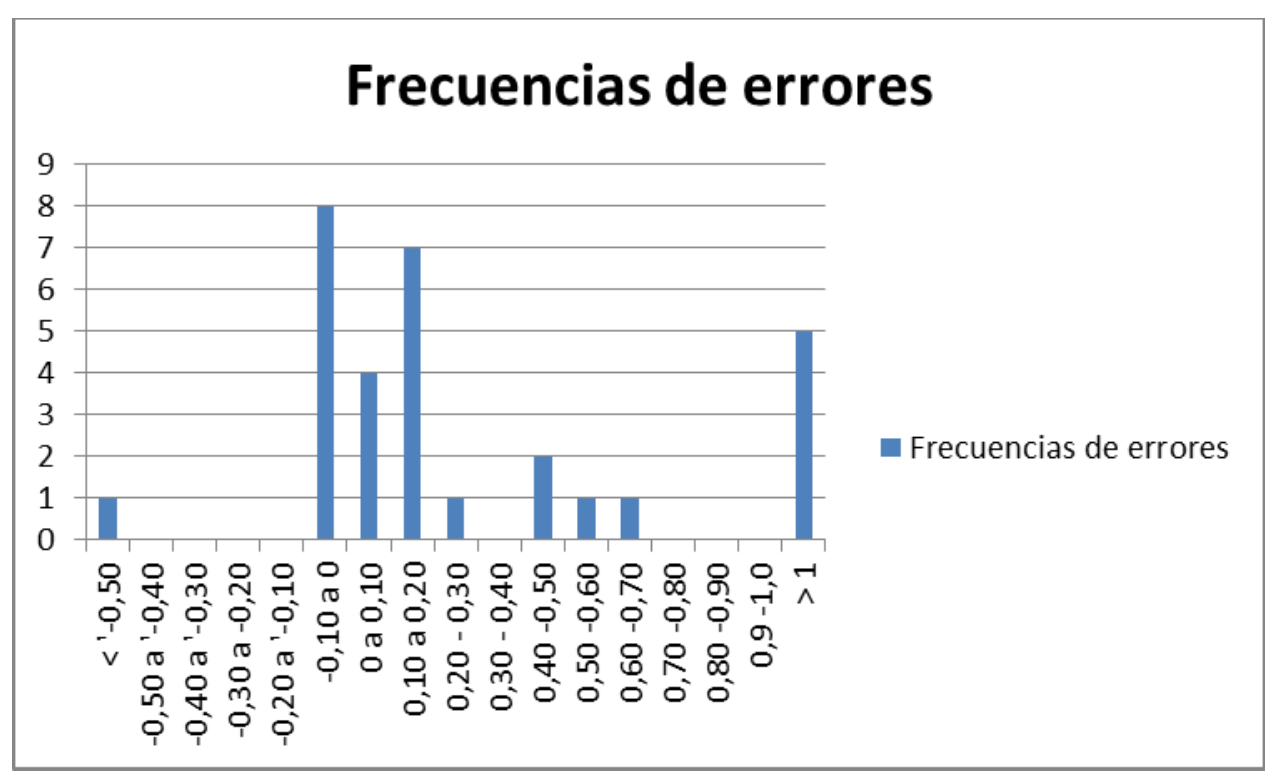

Figura 25. Frecuencias absolutas de los distintos intervalos de errores relativos en la determinación del peso de la carga transportada por todos los vehículos de la muestra

Como se puede ver en la Figura 25, para 12 vehículos (un 40\%) de los 30 que componen la muestra, el error en la determinación del peso de la carga se ha mantenido en un nivel bastante bajo del $\pm 10 \%$, mientras que para 19 vehículos (un $63 \%)$ el error ha estado dentro del intervalo $(-10 \%,+20 \%)$, que no es simétrico respecto al valor 0 debido al sesgo remanente de las mediciones del sistema de pesaje 
dinámico, pero que quiere decir que en casi $2 / 3$ de los vehículos el error del peso de la carga se ha mantenido dentro de niveles tolerables.

Tabla 32. Ordenación de los vehículos según el valor del error relativo en la estimación del peso de la carga transportada y causas de los errores grandes.

\begin{tabular}{|c|c|c|c|c|}
\hline Veh $n^{\circ}$ & Tipo de vehícı ${ }^{*}$ & $\begin{array}{l}\text { Error Carga } \\
\text { estimada Camp } \\
\text { CEDEX } 2003(\mathrm{k}=\end{array}$ & \begin{tabular}{|l|} 
Error rel. \\
Carga estim \\
Camp 2003
\end{tabular} & Causas de error alto \\
\hline 20 & $\mathrm{C} 2$ & 67,18 & 5,3500 & Alto error en tara \\
\hline 7 & $\mathrm{C} 2$ & 56,00 & 3,3186 & Alto error en tara \\
\hline 11 & $\mathrm{C} 2$ & 49,62 & 2,8576 & Alto error en tara + alto error en peso total \\
\hline 12 & T2S3 & 48,13 & 1,2499 & Alto error en peso total \\
\hline 10 & T2S3 & 50,96 & 1,0316 & Alto error en tara + alto error en peso total \\
\hline 24 & $\mathrm{C} 2$ & 41,38 & 0,6792 & Alto error en tara + alto error en peso total \\
\hline 28 & T2S3 & 59,80 & 0,5475 & Alto error en peso total \\
\hline 15 & $\mathrm{C} 2 \mathrm{R} 2$ & 60,46 & 0,4962 & Alto error en tara \\
\hline 4 & T2S3 & 36,86 & 0,4960 & Poca carga + error medio en tara \\
\hline 19 & T2S3 & 30,69 & 0,3860 & Poca carga + error medio en tara \\
\hline 29 & T2S3 & 50,68 & 0,1881 & \\
\hline 17 & T2S3 & 29,18 & 0,1853 & \\
\hline 23 & T2S3 & 26,25 & 0,1777 & \\
\hline 6 & T2S3 & 27,72 & 0,1672 & \\
\hline 27 & T2S3 & 39,98 & 0,1646 & \\
\hline 30 & T2S3 & 15,36 & 0,1620 & \\
\hline 5 & T2S3 & 19,78 & 0,1138 & \\
\hline 2 & T2S3 & 17,80 & 0,0714 & \\
\hline 25 & T2S3 & 16,25 & 0,0645 & \\
\hline 16 & T2S3 & 8,15 & 0,0352 & \\
\hline 21 & $\mathrm{C} 3$ & 3,42 & 0,0226 & \\
\hline 13 & T2S3 & $-0,77$ & $-0,0029$ & \\
\hline 22 & T2S3 & $-2,00$ & $-0,0113$ & \\
\hline 1 & T2S3 & $-3,33$ & $-0,0150$ & \\
\hline 3 & T2S3 & $-2,64$ & $-0,0165$ & \\
\hline 9 & T2S3 & $-6,96$ & $-0,0414$ & \\
\hline 26 & T2S3 & $-14,71$ & $-0,0522$ & \\
\hline 14 & T2S3 & $-20,05$ & $-0,0793$ & \\
\hline 18 & T2S3 & $-22,71$ & $-0,0834$ & \\
\hline 8 & $\mathrm{C} 2$ & $-16,50$ & $-2,7574$ & Casi sin carga + alto error en tara \\
\hline
\end{tabular}

Sin embargo, este error ha resultado ser muy alto (> del 100\%) para 6 vehículos de los 30 que forman la muestra. Para estudiar más detenidamente los posibles motivos de que se produzcan unos errores tan grandes, en la Tabla 32 se ha realizado una ordenación de los errores relativos de mayor a menor, habiéndose examinado la causa de los errores anormalmente altos (véase en la columna de más a la derecha), considerando como tales a todos los que superan el $\pm 20 \%$ del peso de la carga real.

En primer lugar, se observa que los errores más altos, tanto por defecto como por exceso, se han producido en los camiones rígidos de 2 ejes (tipo C2), lo que se debe a que en este tipo de vehículo, se engloban camiones de tamaños y tipología muy diferentes entre sí, por lo que la dispersión de la tara es muy grande (desviación típica 
mayor del $30 \%$ ), con lo cual el valor de la tara es muy incierto, pudiendo existir errores grandes al asignar una tara media a los vehículos.

No obstante, como se puede ver en la Tabla 32, los errores relativos altos no se circunscriben solamente a los camiones rígidos de 2 ejes, sino que también se pueden dar en otros tipos de vehículos, lo que se ha debido a errores altos en el peso del camión suministrado por el sistema WIM o a que el vehículo circula casi descargado y un pequeño error absoluto en la determinación del peso de la carga representa un porcentaje grande de error al dividirlo por una carga muy pequeña.

\subsubsection{Estimación de la carga total transportada por el conjunto de vehículos de la muestra reducida}

Una vez determinados los pesos de las cargas transportadas por cada vehículo según el método aproximado, el paso siguiente que se debe realizar es:

1- Calcular el valor del peso total de la carga transportada por el conjunto de vehículos de la muestra reducida, pues tiene una aplicación práctica en economía para determinar las toneladas-km transportadas por todos los vehículos que circulan por una carretera.

Este peso total de la carga transportada se ha calculado directamente como suma de los pesos de las cargas de cada vehículo individual (véanse las tablas 29,30 y 31 ).

2- Comprobar el error que se comete al estimar este peso de la carga total transportada por el conjunto de vehículos de la muestra.

Esta comprobación del error que en la estimación del peso de la carga total transportada por el conjunto de vehículos es inmediata, pues lo único que hace falta es sumar el peso de las cargas estimadas de todos los vehículos de la muestra y compararlo con la suma de los pesos de las cargas reales de los mismos vehículos.

En un recuadro en la parte de debajo de las Tablas 29, 30 y 31 se ha calculado el valor de este error relativo en la estimación del peso de la carga total transportada, que ha resultado ser de un 14,7\% por exceso para el caso de utilizar las taras medias de la campaña de pesaje dinámico realizada por el CEDEX, de un 12,6 \% también por exceso para el caso de utilizar en la estimación las taras medias de la Encuesta EPTMC y de un $13,3 \%$ por exceso igualmente si se utiliza la estimación de las taras del Registro General de Vehículos.

Como se puede ver, el valor del error en el peso de la carga total transportada por el conjunto de vehículos de la muestra es bastante reducido, por un lado, a pesar del elevado sesgo (6,35\%) de los pesos proporcionados por el equipo de pesaje dinámico $y$, por otro, de los altos valores del error en las cargas de muchos de los vehículos individuales, que superó el $\pm 20 \%$ en más de $1 / 3$ de los 30 vehículos, llegando a un valor superior al $100 \%$ en 5 de ellos. 
La causa de que este error relativo en la carga total transportada por el conjunto de vehículos sea reducido está en que algunos de los errores que se cometen por exceso para algunos vehículos se compensan con los errores que se cometen por defecto para otros (es decir, que existe una compensación de errores de signo negativo con los positivos), resultando un error en la carga total transportada por todos los vehículos de la muestra bastante tolerable, que permitiría la aplicación efectiva de este método de estimación para el cálculo de la carga total transportada por todos los vehículos que circulan por una carretera o por toda la red.

Por otro lado, de acuerdo con las cifras mostradas en la Tabla 28, si se compara la carga real transportada por el conjunto de vehículos de la muestra (calculada como la suma de los valores de la columna de Pest -Tara real) con la carga dinámica real transportada que ha sido medida por el sistema WIM (la suma de los valores de la columna Pdin - Tara real), se obtiene el error debido únicamente a las imprecisiones (sesgo + dispersión) del sistema de pesaje dinámico, resultando un valor de aproximadamente el 8\%, por exceso; por tanto cabría atribuir el error restante (entre un $4 \%$ y un $6 \%$ ) hasta completar el $15 \%$ para la utilización de las taras del CEDEX, el $12,64 \%$ si se utilizan las taras de la EPTMC o el $13.25 \%$ si se utilizan las taras medias del Registro General de Vehículos, a las simplificaciones del método aproximado propuesto.

\subsubsection{Consideración del error en la clasificación automática de los vehículos}

Aunque la determinación automatizada de la clasificación por tipos (silueta) de los vehículos que forman el tráfico de una carretera es el primer paso que se debe realizar para aplicar el método de estimación del peso de las cargas transportadas que se explica en este documento, se ha escogido deliberadamente tratarlo al final, pues constituye por sí mismo un procedimiento completamente diferenciado.

Así, partiendo de los datos sobre los vehículos aportados por el sistema de pesaje dinámico (como son su longitud, peso, número de ejes y distancia entre ejes consecutivos y peso de cada uno de los ejes) y su tratamiento, se ha elaborado un programa que se basa en el establecimiento de relaciones y límites entre los anteriores parámetros, para obtener una silueta detallada (en 15 tipos diferentes de vehículos) del tráfico que circula por el emplazamiento del sistema WIM.

No se van a explicar en detalle las condiciones que se imponen para diferenciar unos tipos de vehículos de otros, pues ya se han explicado en el Apartado 5.1. Solamente se desea reseñar que, entre las principales novedades de este programa en relación con otros existentes en el mercado está el que no se basa únicamente en el número de ejes como parámetro principal para diferenciar unas clases de vehículos de otras, pues se ha tratado de que para determinar el tipo en el que puede ser clasificado un vehículo tenga en cuenta si éste lleva algún eje elevado o no, pues la mayor parte de los sistemas de clasificación por ejemplo consideran, por ejemplo, que si un vehículo de 5 ejes lleva un eje levantado es como si se tratara de un vehículos de 4 ejes, lo cual, además de facilitar enormemente la clasificación, puede tener su utilidad en cuanto a 
la determinación de los efectos del paso del vehículo sobre los firmes de las carreteras, pues estos solo perciben las cargas de los ejes apoyados sobre el pavimento.

Sin embargo, el anterior planteamiento (esto es, clasificar a los vehículos según el número de ajes apoyados en el pavimento) introduciría un cierto error para determinar la tara de los vehículos que llevan un eje levantado, pues como se ha mencionado, el método de determinación automática de la carga transportada por los vehículos asignaría a estos vehículos la tara media de un tipo de vehículo que tendría un eje menos del tipo al que pertenece realmente, por lo que se optó por elaborar un programa que tratara de determinar, en lo posible, el tipo verdadero de vehículo de que se trata en cada caso, aunque pudiera llevar algún eje elevado.

La exactitud del programa de clasificación elaborado para realizar la diferenciación de los vehículos según el tipo al que pertenecen se evaluó para dos muestras diferentes de vehículos pesados:

- La muestra reducida de 30 vehículos pesados que fueron desviados para su pesaje estático.

- La muestra amplia tomada visualmente (y mediante fotografía) durante varias horas de los 4 días en que estuvo funcionando el equipo, compuesta de 653 vehículos

Con respecto a la muestra reducida de los 30 vehículos que, tras pasar por el sistema de pesaje dinámico, luego fueron pesados estáticamente en la báscula fija existente en el km 82 de la A-2 a la altura de Trijueque, los resultados de la clasificación se muestran en la Tabla 33.

Aunque los resultados no se pueden considerar muy representativos por el reducido tamaño de la muestra, se puede ver en la Tabla 33 que, de los 31 vehículos que pasaron (de los cuales 30 eran vehículos pesados) sólo hubo un vehículo clasificado erróneamente en un tipo equivocado, con lo cual, como al sumar los vehículos clasificados erróneamente en cada una de las clases, este vehículo cuenta como dos (uno, la del tipo en que fue encasillado equivocadamente, y el otro, en la del tipo real al que pertenece, en el que no fue asignado). 
Tabla 33 Resultados de clasificación automatizada de los vehículos de la muestra reducida que fueron pesados en una báscula estática

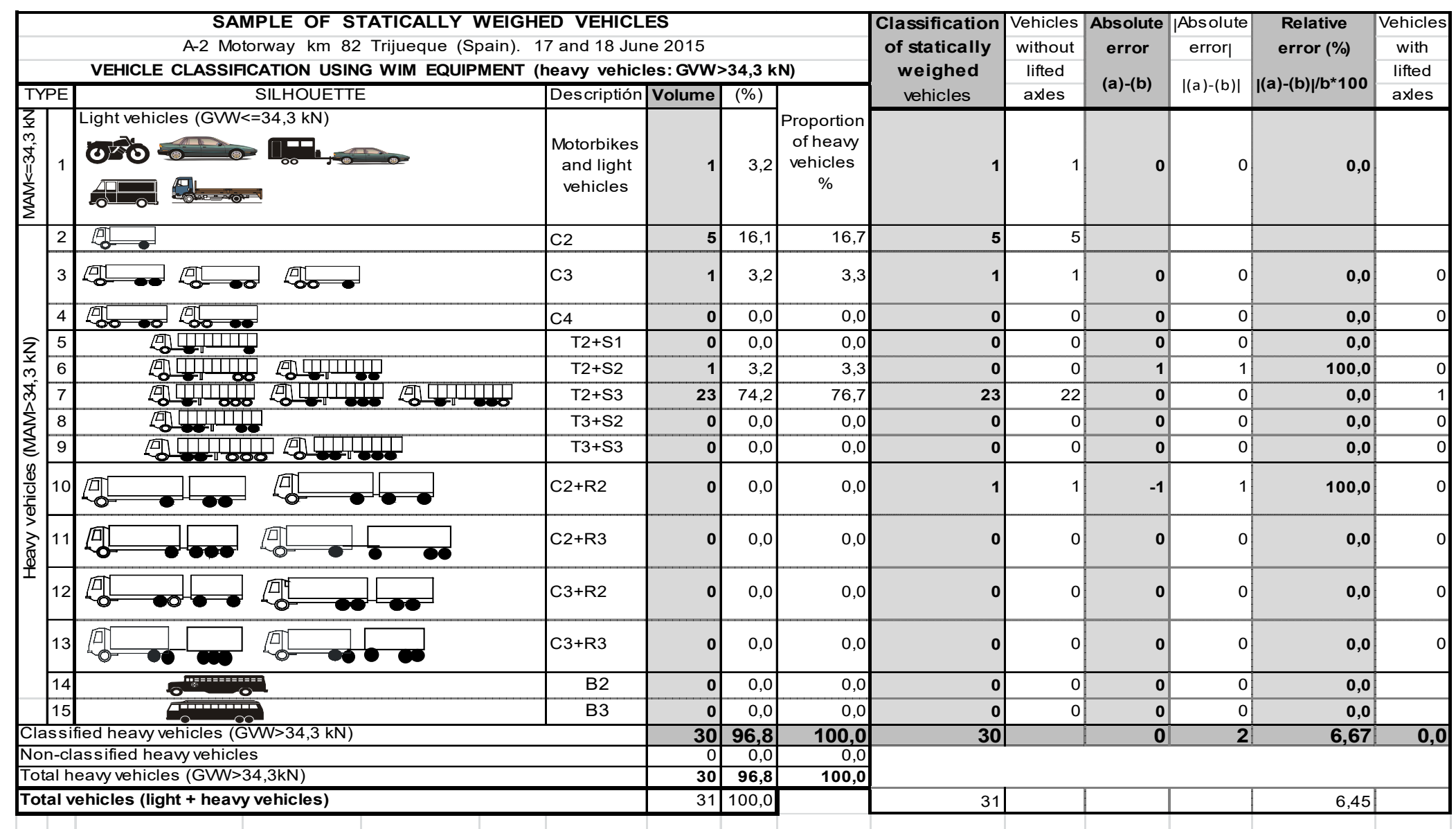

\section{NOTE:}

C: Rigid lorry $\quad \mathrm{T}$ : Tractor $\quad \mathrm{S}$ : Semi - trailer

R: Trailer

B: Bus 
El vehículo clasificado en un tipo erróneo fue un tren de carretera de 4 ejes tipo C2+R2, utilizado para el transporte de coches, formado por un camión rígido de 2 ejes y un remolque de otros dos ejes que forman un eje tándem. Este camión fue clasificado como vehículo articulado tipo T2S2, formado por una cabeza tractora de 2 ejes y un semirremolque de otros 2 ejes que forman tándem entre sí.

En definitiva, se puede decir que la tasa de clasificación errónea fue de 2 vehículos sobre 30 vehículos pesados, que es un $6,7 \%$, que no puede considerarse muy buena, aunque tampoco es demasiado mala.

Por último, como comparación cabe decir que, al realizar la clasificación de los vehículos de la muestra amplia, fueron clasificados erróneamente 25 vehículos, que frente a los 653 de la muestra representa un porcentaje de error del 3,83\%. Una parte importante de los fallos se produjeron al clasificar a vehículos articulados de 5 ejes (T2S3) con algún eje levantado como articulados de 4 ejes (T2S2), con 9 vehículos erróneamente clasificados, que puede parecer bastante alto, pero no lo es tanto si se tiene en cuenta que hubo 42 vehículos del tipo T2S3 que viajaban con un eje levantado.

\subsection{Influencia de la exactitud en la clasificación de los vehículos para el} cálculo aproximado de las cargas transportadas

La influencia de estos errores de clasificación automática de los vehículos en la determinación del peso de la carga transportada se calculó tal como se muestra en la Tabla 34, que es similar a las Tablas 29 y 30, pero en la que se ha sustituido la tara correspondiente al tipo real al que pertenece el vehículo erróneamente clasificado por la tara estimada del tipo al que fue asignado por el sistema (véase el vehículo marcado en color amarillo en la Tabla 34).

Como se puede ver en la Tabla 34, la pequeña incorrección que ha cometido el programa de clasificación de los vehículos para obtener la composición correcta del tráfico pesado no se han traducido en un gran aumento del error total en el peso de la carga transportada por el conjunto de vehículos de la muestra, pues la variación ha sido aproximadamente de un 1\% para ambas bases de datos de taras (Campaña de pesaje del CEDEX y EPTMC 2013), e incluso se ha reducido (del $14,7 \%$ al $14,5 \%$ ) al utilizar las taras estimadas de la campaña del CEDEX.

La generalización de la posible influencia de los errores de determinación de la silueta en los errores del peso total de la carga transportada por el conjunto de vehículos se tratará a continuación al exponer el análisis de sensibilidad del método propuesto. 
Tabla 34. Determinación del error en la determinación de la carga total transportada debido a la clasificación errónea de algunos vehículos

\begin{tabular}{|c|c|c|c|c|c|c|c|c|c|c|}
\hline Veh $n^{\circ}$ & \begin{tabular}{|l|} 
Tipo de \\
vehículo real
\end{tabular} & \begin{tabular}{|l|} 
Tipo vehículo \\
según \\
sistema \\
WIM
\end{tabular} & $\begin{array}{l}\text { Peso estático } \\
(\mathrm{kN})\end{array}$ & $\begin{array}{l}\text { Peso dinámico } \\
(\mathrm{kN})\end{array}$ & $\begin{array}{l}\text { Tara real } \\
(\mathrm{kN})\end{array}$ & $\begin{array}{l}\text { Carga real = } \\
\text { Pest -Tara } \\
(\mathrm{kN})\end{array}$ & \begin{tabular}{|l|} 
Tara \\
estimada \\
campaña \\
$\operatorname{CEDEX~}(\mathrm{kN})$ \\
\end{tabular} & \begin{tabular}{|l} 
Tara \\
estimada \\
EPTMC (kN)
\end{tabular} & \begin{tabular}{|l|} 
Carga \\
estimada \\
campaña \\
$\operatorname{CEDEX~}(\mathrm{kN})$ \\
\end{tabular} & $\begin{array}{l}\text { Carga } \\
\text { estimada } \\
\text { EPTMC }(\mathrm{kN})\end{array}$ \\
\hline 1 & $\mathrm{~T} 2 \mathrm{~S} 3$ & $\mathrm{~T} 2 \mathrm{~S} 3$ & 378,37 & 362,97 & 155,98 & 222,39 & 143,90 & 142,48 & 219,07 & 220,49 \\
\hline 2 & T2S3 & T2S3 & 415,01 & 411,04 & 165,67 & 249,34 & 143,90 & 142,48 & 267,14 & 268,56 \\
\hline 3 & T2S3 & T2S3 & 281,55 & 301,17 & 121,64 & 159,90 & 143,90 & 142,48 & 157,26 & 158,69 \\
\hline 4 & T2S3 & T2S3 & 237,16 & 255,06 & 162,86 & 74,30 & 143,90 & 142,48 & 111,16 & 112,58 \\
\hline 5 & T2S3 & T2S3 & 341,83 & 337,46 & 168,05 & 173,78 & 143,90 & 142,48 & 193,56 & 194,98 \\
\hline 6 & T2S3 & T2S3 & 326,72 & 337,46 & 160,88 & 165,84 & 143,90 & 142,48 & 193,56 & 194,98 \\
\hline 7 & C2 & C2 & 113,35 & 135,38 & 96,48 & 16,87 & 62,51 & 77,55 & 72,87 & 57,83 \\
\hline 8 & $\mathrm{C} 2$ & $\mathrm{C} 2$ & 48,46 & 51,99 & 42,48 & 5,98 & 62,51 & 77,55 & $-10,52$ & $-25,56$ \\
\hline 9 & T2S3 & T2S3 & 320,79 & 305,09 & 152,64 & 168,14 & 143,90 & 142,48 & 161,19 & 162,61 \\
\hline 10 & T2S3 & T2S3 & 219,20 & 244,27 & 169,80 & 49,40 & 143,90 & 142,48 & 100,37 & 101,79 \\
\hline 11 & C2 & $\mathrm{C} 2$ & 110,56 & 129,49 & 93,20 & 17,36 & 62,51 & 77,55 & 66,98 & 51,94 \\
\hline 12 & T2S3 & T2S3 & 192,82 & 230,54 & 154,31 & 38,50 & 143,90 & 142,48 & 86,63 & 88,05 \\
\hline 13 & T2S3 & T2S3 & 394,56 & 412,02 & 125,67 & 268,89 & 143,90 & 142,48 & 268,12 & 269,54 \\
\hline 14 & T2S3 & T2S3 & 418,64 & 376,70 & 165,79 & 252,85 & 143,90 & 142,48 & 232,80 & 234,22 \\
\hline 15 & C2R2 & T2S2 & 305,68 & 309,02 & 183,84 & 121,84 & 138,17 & 128,35 & 170,85 & 180,67 \\
\hline 16 & T2S3 & T2S3 & 388,82 & 383,57 & 157,30 & 231,52 & 143,90 & 142,48 & 239,67 & 241,09 \\
\hline 17 & T2S3 & T2S3 & 292,83 & 330,60 & 135,32 & 157,51 & 143,90 & 142,48 & 186,69 & 188,12 \\
\hline 18 & T2S3 & T2S3 & 414,42 & 393,38 & 142,24 & 272,19 & 143,90 & 142,48 & 249,48 & 250,90 \\
\hline 19 & T2S3 & T2S3 & 239,81 & 254,08 & 160,32 & 79,49 & 143,90 & 142,48 & 110,18 & 111,60 \\
\hline 20 & C2 & C2 & 122,33 & 142,25 & 109,77 & 12,56 & 62,51 & 77,55 & 79,74 & 64,69 \\
\hline 21 & $\mathrm{C} 3$ & C3 & 256,29 & 266,83 & 104,57 & 151,71 & 111,70 & 120,17 & 155,14 & 146,66 \\
\hline 22 & T2S3 & T2S3 & 314,07 & 318,83 & 137,14 & 176,92 & 143,90 & 142,48 & 174,92 & 176,34 \\
\hline 23 & T2S3 & T2S3 & 307,84 & 317,84 & 160,15 & 147,69 & 143,90 & 142,48 & 173,94 & 175,36 \\
\hline 24 & $\mathrm{C} 2$ & $\mathrm{C} 2$ & 143,81 & 164,81 & 82,89 & 60,92 & 62,51 & 77,55 & 102,30 & 87,26 \\
\hline 25 & T2S3 & T2S3 & 394,75 & 412,02 & 142,88 & 251,87 & 143,90 & 142,48 & 268,12 & 269,54 \\
\hline 26 & T2S3 & T2S3 & 403,58 & 411,04 & 121,74 & 281,84 & 143,90 & 142,48 & 267,14 & 268,56 \\
\hline 27 & T2S3 & T2S3 & 408,05 & 426,74 & 165,19 & 242,86 & 143,90 & 142,48 & 282,83 & 284,25 \\
\hline 28 & T2S3 & T2S3 & 250,30 & 312,94 & 141,07 & 109,23 & 143,90 & 142,48 & 169,04 & 170,46 \\
\hline 29 & T2S3 & T2S3 & 403,83 & 464,01 & 134,40 & 269,43 & 143,90 & 142,48 & 320,11 & 321,53 \\
\hline \multirow[t]{4}{*}{30} & T2S3 & T2S3 & 229,85 & 254,08 & 135,03 & 94,81 & 143,90 & 142,48 & 110,18 & 111,60 \\
\hline & & & & & Suma & 4525,97 & & Suma & 5180,49 & 5139,35 \\
\hline & & & & & & & & & & \\
\hline & & & & & & & & Error total $(\%)$ & 14,5 & 13,6 \\
\hline
\end{tabular}

\subsubsection{Estudio de comprobación del método realizado con la muestra amplia, de más de 600 vehículos pesados fotografiados}

A continuación se va a exponer el estudio llevado a cabo para determinar los errores que se cometen al determinar la carga transportada utilizando el método de estimación desarrollado sobre la muestra amplia de vehículos, que incluye más de 600 vehículos fotografiados en el momento de pasar sobre el sistema de pesaje dinámico, con objeto de obtener, además de los datos proporcionados automáticamente por el sistema de pesaje, sus taras y MMA.

\subsubsection{Datos obtenidos y cálculos realizados con la muestra amplia de vehículos}

En esta muestra amplia se recogieron datos de 653 vehículos fotografiados y registrados por el equipo de pesaje. Sus números de matriculación fueron enviados a la Dirección General de Tráfico que remitió en abril de 2016 las taras y MMA de cada uno de ellos. Una vez obtenidos todos los datos de estos vehículos, se cotejaron con ciertas condiciones preestablecidas para comprobar su corrección: que estuvieran correctamente registrados por el equipo de pesaje (con todos sus ejes), que se tratara 
de vehículos pesados (peso $>3.500 \mathrm{~kg}$ ), una tara de los vehículos acorde con su tipo, etc. Después de realizar este filtrado, se eliminaron 11 vehículos, con lo cual el número final de vehículos de la muestra amplia cuyos datos han sido analizados en este apartado ha sido de 642 .

Al igual que se realizó con la muestra reducida de 30 vehículos pesados estáticamente, siguiendo los pasos del procedimiento determinación de la carga transportada desarrollado, se anotaron los siguientes datos de cada uno de los vehículos de la muestra amplia:

1. el peso dinámico total del vehículo, que fue obtenido por el sistema de pesaje en movimiento,

2. la tara real de cada vehículo, proporcionada por la Dirección General de Tráfico.

3. la tara estimada del vehículo en función del tipo real (tomado visualmente) de vehículo de que se trate y utilizando una base de datos de taras, que en el caso que se muestra a continuación la utilizada fue la de la campaña de pesaje 2000-2003 (aunque también se puede realizar el cálculo usando la base de datos de la Encuesta Permanente del Transporte de Mercancías por Carretera de 2013).

Todo lo anterior se refiere a la clasificación de los vehículos realizada visualmente por medio de observadores humanos. Sin embargo, como el objetivo es automatizar completamente el proceso a través de los datos suministrados por el sistema de pesaje dinámico, se debe conseguir asignar una tara a cada vehículo en función del tipo en el que es clasificado automáticamente por el sistema de pesaje. Por ello, también se anotaron los siguientes datos:

4. el tipo en el que fue clasificado cada vehículo por el sistema de pesaje dinámico

5. la tara estimada del vehículo en función del tipo en el que fue clasificado automáticamente por el sistema de pesaje.

Tras realizar todas estas operaciones, se han obtenido como resultados:

6. una carga transportada estimada visualmente para cada vehículo, que vendrá dada por la resta del peso dinámico total del vehículo (1) menos la tara estimada a partir de la clasificación visual del vehículo (3),

7. una carga transportada estimada automáticamente para cada vehículo que resultará de la resta del peso dinámico total del vehículo (1) menos la tara estimada (5) a partir de la clasificación automática del vehículo por parte del sistema de pesaje dinámico. 
6.2.5.2 Resultados obtenidos con la muestra amplia de más de 600 vehículos pesados

La composición de la muestra amplia de 642 vehículos pesados se ha mostrado en la Tabla 25 del apartado 6.1.3, al hablar de la precisión de la clasificación automática de los vehículos (que fue un 4,05\%, valor bastante reducido).

En la columna de "Vehículos muestreados clasificados visualmente" de la Tabla 24 aparecen los datos de la composición real de la muestra, obtenida mediante la observación por operarios de los vehículos en la carretera, y de las fotos tomadas de cada uno de ellos, mientras que en otra columna aparece la clasificación obtenida automáticamente por el sistema de pesaje dinámico, mediante el programa de clasificación elaborado ("Vehículos clasificados con Excel”).

Tomando como ciertos los datos de la clasificación real, se puede ver que la muestra está formada por 642 vehículos pesados, de los cuales, 536 (más del 80\%) son vehículos articulados de 5 ejes (cabeza tractora de 2 ejes + semirremolque de eje trídem), existiendo también una cantidad apreciable de vehículos rígidos de 2 ejes (51 vehículos) y de 3 ejes (16 camiones), así como de trenes de carretera de 4 ejes (camión rígido tractor de 2 ejes + remolque de 2 ejes), con 25 vehículos. Existen además pequeñas proporciones de camiones de otros tipos, así como 5 autobuses.

Pasando a la determinación de la carga total transportada por el conjunto de los vehículos la muestra amplia de vehículos fotografiados, los resultados de peso total obtenido se muestran en las Tablas 35 y 36.

Concretamente, en la Tabla 35 aparece el peso total de la carga transportada por los 637 camiones de la muestra amplia (642 vehículos pesados -5 autobuses $=637$ camiones), que se ha calculado utilizando, por un lado, las taras reales de cada vehículo y, por otro, las taras asignadas para cada tipo de vehículo según las tres bases de datos de taras consideradas: la Campaña de pesaje dinámico 2000-2003 del CEDEX, la Encuesta Permanente del Transporte de Mercancías por Carretera (EPTMC) de 2013 y el Registro General de Vehículos de 2017. También se ha calculado el error relativo cometido al utilizar las taras asignadas según el tipo de vehículo frente al empleo de las taras reales, obteniéndose lo que sería el error debido a las simplificaciones del método. Por último, se muestra el peso de la carga media por camión obtenido con cada base de datos de taras utilizada.

De forma más detallada, estos valores del peso de la carga total transportada que aparecen en la Tabla 34 se han calculado utilizando:

1. Las taras reales de cada vehículo (columna de "Taras reales DGT"), proporcionadas por la Dirección General de Tráfico. Es decir, se ha calculado la carga de cada vehículo restando el peso dinámico proporcionado por el sistema de pesaje menos su tara real, obteniéndose lo que anteriormente se ha designado como "carga dinámica real transportada".

2. Las taras estimadas en función del tipo y la clasificación visual (en las tres columnas de más a la derecha), es decir, a cada vehículo se le ha asignado una tara según el tipo en el que ha sido clasificado visualmente, para cada 
una de las tres bases de datos de taras antes enumeradas, calculándose la carga como diferencia entre el peso del vehículo suministrado por el sistema de pesaje dinámico y la tara asignada según su tipo real, con el fin de obtener la llamada "carga dinámica estimada transportada", en función de su tipo real (visual).

Tabla 35. Resultados de la carga total transportada por el conjunto de 637 camiones de la muestra amplia, obtenidos con distintas bases de datos de taras

\begin{tabular}{|l|c|c|c|c|}
\hline \multirow{2}{*}{} & \multicolumn{4}{|c|}{ Base de datos de taras utilizada } \\
\cline { 2 - 5 } & $\begin{array}{c}\text { Taras reales } \\
\text { DGT }\end{array}$ & $\begin{array}{c}\text { Campaña } \\
\text { pesaje } \\
\text { CEDEX } \\
\mathbf{2 0 0 0 - 2 0 0 3}\end{array}$ & $\begin{array}{c}\text { Encuesta } \\
\text { Permanente } \\
\text { Transporte } \\
\text { Mercancías } \\
\mathbf{2 0 1 3}\end{array}$ & $\begin{array}{c}\text { Registro } \\
\text { General } \\
\text { de } \\
\text { Vehículos } \\
\mathbf{2 0 1 7}\end{array}$ \\
\hline $\begin{array}{l}\text { Carga total } \\
\text { transportada (t) }\end{array}$ & $10.147,2$ & $10.572,3$ & $10.422,1$ & $10.407,4$ \\
\hline Error (\%) & - & 4,19 & 2,71 & 2,56 \\
\hline $\begin{array}{l}\text { Carga media } \\
\text { transportada por } \\
\text { vehículo (t) }\end{array}$ & 15,9 & 16,6 & 16,4 & 16,3 \\
\hline
\end{tabular}

La Tabla 36 muestra de forma desglosada las cargas totales transportadas por los vehículos de cada tipo, que se han calculado utilizando tanto las taras reales como las taras asignadas en función del tipo, empleando en este caso solamente las obtenidas de la base de datos de la campaña de pesaje dinámico del CEDEX.

Además, en las dos columnas de más a la derecha de la Tabla 36, en que se muestran los valores de las cargas transportadas estimadas en función del tipo de vehículo, se ha comparado la carga calculada utilizando las taras estimadas, en un caso obteniendo el tipo de vehículo mediante clasificación visual (recogida por operarios) de los vehículos $y$, en el otro caso, obteniendo el tipo de vehículo mediante clasificación automática. Por tanto, en este último caso se ha llevado a cabo el procedimiento de forma totalmente automatizada, es decir, tal como se haría una vez que el procedimiento desarrollado estuviera totalmente implantado, pues a cada vehículo se le ha asignado una tara según el tipo en el que ha sido clasificado automáticamente por el sistema de pesaje dinámico, calculándose la carga como diferencia entre el peso del vehículo suministrado por el sistema de pesaje dinámico y la tara asignada según su tipo clasificado automáticamente, con el fin de obtener la llamada "carga dinámica estimada transportada". 
Tabla 36. Cargas totales transportadas por todos los vehículos de la muestra amplia que han sido estimadas utilizando el procedimiento desarrollado

\begin{tabular}{|c|c|c|c|c|c|}
\hline \multirow[b]{2}{*}{ Tipo de vehículo } & \multicolumn{2}{|c|}{ Número de vehículos } & \multicolumn{3}{|c|}{ Cargas de los vehículos ( $t$ ) } \\
\hline & Visual & $\begin{array}{l}\text { Sistema } \\
\text { de pesaje } \\
\text { dinámico }\end{array}$ & $\begin{array}{l}\text { Con taras reales } \\
\text { (DGT) }\end{array}$ & $\begin{array}{l}\text { Con taras } \\
\text { estimadas y } \\
\text { clasificación } \\
\text { visual (1) }\end{array}$ & \begin{tabular}{|lr} 
Con & taras \\
estimadas y \\
clasificación \\
automática (2)
\end{tabular} \\
\hline Rígidos de 2 ejes & 53 & 51 & 210,8 & 313,3 & $\begin{array}{r}308,5 \\
\end{array}$ \\
\hline Rígidos de 3 ejes & 16 & 16 & 103,2 & 115,9 & 95,7 \\
\hline Rígidos de 4 ejes & 1 & 1 & 18,2 & 13,9 & 17,1 \\
\hline $\begin{array}{l}\begin{array}{l}\text { Articulados de } 4 \\
\text { ejes }(2+2)\end{array} \\
\end{array}$ & 0 & 10 & 0 & 0 & 183,2 \\
\hline $\begin{array}{l}\text { Articulados de } 5 \\
\text { ejes }(2+3)\end{array}$ & 536 & 532 & $9.455,2$ & $9.650,3$ & $9.611,1$ \\
\hline $\begin{array}{l}\text { Articulados de } 6 \\
\text { ejes }(3+3)\end{array}$ & 1 & 0 & 11,7 & 16,0 & 0 \\
\hline Trenes $(2+2)$ & 25 & 21 & 296,4 & 393,1 & 269,8 \\
\hline Trenes $(2+3)$ & 2 & 1 & 20,6 & 29,6 & 15,3 \\
\hline Trenes $(3+2)$ & 1 & 0 & 4,9 & 6,8 & 0 \\
\hline Trenes $(3+3)$ & 2 & 3 & 26,3 & 33,4 & 45,0 \\
\hline Bus de 2 ejes & 4 & 6 & 5,28 & 29,3 & 0 \\
\hline Bus de 3 ejes & 1 & 1 & 3,7 & 8,3 & 0 \\
\hline $\begin{array}{l}\text { TOTAL } \\
\text { autobuses) }\end{array}$ & 637 & 635 & $10.147,2$ & $10.572,3$ & $10.545,7$ \\
\hline
\end{tabular}

Como se puede ver en la Tabla 36, las cifras que aparecen en relación con la estimación de las cargas totales transportadas son las siguientes:

1. Carga total transportada utilizando el peso dinámico y las taras reales (“Carga dinámica real”): 10.147,2 t.

2. Carga total transportada estimada utilizando el peso dinámico y las taras (de la base de datos de la campaña de pesaje del CEDEX) estimadas en función del tipo real de vehículo ("Carga dinámica estimada (1)"), clasificado visualmente: $10.572,3 \mathrm{t}$.

3. Carga real transportada estimada utilizando el peso dinámico y las taras (de la base de datos de la campaña de pesaje del CEDEX) estimadas ("Carga dinámica estimada (2)") en función del tipo de vehículo determinado automáticamente por el sistema de pesaje dinámico: 10.545,7 t.

En consecuencia, el error que se comete al calcular las cargas transportadas utilizando las taras estimadas en función del tipo real de vehículo, será igual a:

$$
E_{1}=(10.572,3-10.147,2) / 10.147,2=4,2 \% .
$$

Este error del 4,2\% puede considerarse como el error debido a las simplificaciones del método de estimación de las cargas transportadas. 
Por otro lado, el error que se comete al determinar la carga total transportada utilizando tanto las taras estimadas en función del tipo de vehículo, siendo este tipo a su vez estimado utilizando la clasificación automática del sistema de pesaje dinámico, vendrá dado por la operación:

$$
E_{2}=(10.545,7-10.147,2) / 10.147,2=3,9 \%
$$

Este error del 3,9 \% es el error que se comete al estimar tanto las taras de cada vehículo como el tipo al que pertenece $y$, como se puede ver, es de menor valor que el error incurrido al estimar solamente las cargas transportadas pero utilizando la clasificación real de los vehículos, lo que quiere decir que, al menos en este caso, ambas componentes del error (la debida a las simplificaciones del método al sustituir la tara real por la tara media del tipo, y la debida a la clasificación automática de vehículos) se compensan parcialmente entre sí. Por otro lado, puede considerarse que este error debido a las simplificaciones conjuntas de ambos procedimientos es de un valor bastante reducido.

Si se atiende a las cargas transportadas por cada tipo de vehículo, considerando solamente los tipos en los cuales existe un número apreciable de vehículos $(>10)$, (frecuencia absoluta que sólo alcanzan los rígidos de 2 y de 3 ejes, los articulados de 5 ejes y los trenes de carretera formados por un camión rígido de 2 ejes y un remolque también de 2 ejes), se observa que el error mayor en la determinación de la carga al utilizar las taras estimadas en vez de las reales corresponde a los rígidos de 2 ejes, lo que se debe a que en este tipo existen vehículos de tipologías, tamaños $y$, en consecuencia. taras muy diferentes. Así, un examen más detallado indica que la tara real media de los camiones de 2 ejes en la muestra ha sido 8,1 t, mientras que la tara media asignada (la de la campaña del CEDEX) sólo fue 6,4 t, por lo cual la estimación de la carga transportada no puede ser buena. Esta diferencia se debe a que en esta muestra faltan entre los camiones de 2 ejes los camiones de reparto, que suelen ser pequeños.

Sin embargo, la estimación de la carga transportada es muy precisa en los vehículos articulados de 5 ejes, que constituyen más del $80 \%$ del total de vehículos de la muestra (que por otro lado es bastante representativa del tráfico pesado en vías de transporte de largo recorrido), debido a la poca variabilidad de la tara de estos vehículos, lo que trae como resultado que el error en la estimación del total de la carga transportada sea también bastante pequeño.

\subsubsection{Comparación de los resultados obtenidos con ambas muestras}

En la Tabla 37 se ha realizado una comparación de los resultados obtenidos tanto en la muestra reducida de 30 vehículos pesados estáticamente como de la muestra amplia de 637 vehículos, cuyas taras fueron proporcionadas por la DGT a partir de los datos de la matrícula, en cuanto a la determinación del peso total de la carga transportada y al error incurrido al realizar esta estimación en relación con la carga realmente transportada. 
A la vista de los datos y resultados de la Tabla 37, se pueden hacer las siguientes precisiones:

1 Respecto de la muestra pequeña de 30 vehículos pesados estáticamente, al conocerse tanto el peso estático de los vehículos como las taras reales de todos ellos, se puede obtener el valor real (a) de la carga transportada, así como los valores de la carga dinámica real (b), la carga dinámica estimada al asignar las taras del tipo de vehículo obtenido visualmente (c) y de la carga dinámica estimada al asignar las taras del tipo de vehículo obtenido en la clasificación realizada automáticamente (f). Al poderse obtener todos estos valores de la carga transportada, se pueden determinar los errores tanto con respecto a la carga real (estática) transportada por los vehículos, como respecto a la carga dinámica real, obtenida a partir del peso suministrado por el sistema de pesaje dinámico y las taras reales.

2 En cuanto a los resultados obtenidos respecto a esta muestra de 30 vehículos, se puede ver que la relación entre la carga dinámica real y la carga estática real es de 1,083, que representaría el error debido al equipo de pesaje (es decir, un 8,3\%). A continuación, las relaciones entre cualquiera de las dos cargas dinámicas estimadas utilizando las taras de la campaña de pesaje del CEDEX de 2003 (ya sea mediante la clasificación visual (real) o mediante la clasificación automática) con la carga real, nos dan el error total conjunto en que se ha incurrido, debido tanto a la imprecisión de la báscula de pesaje como al procedimiento aproximado de determinar la tara, y se puede ver que este error es de aproximadamente un $14,5 \%$ para ambas estimaciones de las taras. Por otro lado, si se calculan las relaciones (e) y (h) de las dos cargas dinámicas estimadas con las taras de la campaña de pesaje del CEDEX de 2003 (ya sea con el tipo real de vehículo o con el tipo obtenido con la clasificación automática) frente a la carga dinámica real (peso dinámico - tara real), se obtiene el error debido al procedimiento de asignación de la tara, que ha resultado ser muy parecido para ambas estimaciones de las taras, que resulta ser de un 5,7 \% aproximadamente. 
Tabla 37 Comparación de la exactitud en la determinación de las cargas transportadas en ambas muestras

\begin{tabular}{|c|c|c|c|c|c|c|c|c|c|}
\hline Muestra & $\begin{array}{c}\text { Carga real } \\
\text { total = } \Sigma \text { (Peso } \\
\text { estático-Tara } \\
\text { real) }(t)\end{array}$ & $\begin{array}{l}\text { Carga dinámica } \\
\text { real = } \\
\sum \text { (Peso dinámico } \\
\text {-Tara real) }(t)\end{array}$ & $\begin{array}{c}\text { Carga } \\
\text { dinámica } \\
\text { real / } \\
\text { Carga real } \\
\text { (estática) }\end{array}$ & $\begin{array}{c}\text { Carga } \\
\text { dinámica } \\
\text { estimada } \\
\text { con taras } \\
\text { campaña } \\
\text { CEDEX } 2003 \\
=\sum \text { (Peso } \\
\text { dinámico- } \\
\text { Tara } \\
\text { estimada) } \\
\text { (t) }\end{array}$ & $\begin{array}{c}\text { Carga } \\
\text { dinámica } \\
\text { estimada } \\
\text { / Carga } \\
\text { real }\end{array}$ & $\begin{array}{c}\text { Carga } \\
\text { dinámica } \\
\text { estimada } \\
\text { / Carga } \\
\text { dinámica } \\
\text { real }\end{array}$ & $\begin{array}{l}\text { Carga dinámica } \\
\text { estimada con taras } \\
\text { campaña CEDEX } \\
2003 \text { según } \\
\text { clasificación } \\
\text { automática = } \Sigma \\
\text { (Peso dinámico - } \\
\text { Tara estimada } \\
\text { automáticamente) } \\
\text { (t) }\end{array}$ & $\begin{array}{c}\text { Carga } \\
\text { dinámica } \\
\text { estimada } \\
\text { automát./ } \\
\text { Carga real }\end{array}$ & $\begin{array}{c}\text { Carga dinámica } \\
\text { estimada } \\
\text { automáticamente / } \\
\text { Carga dinámica } \\
\text { real }\end{array}$ \\
\hline & (a) & (b) & (b)/(a) & (c) & $\begin{array}{l}(d)= \\
(c) /(a)\end{array}$ & $\begin{array}{l}\text { (e) }= \\
(c) /(b)\end{array}$ & (f) & $(g)=(f) /(a)$ & $(h)=(f) /(b)$ \\
\hline $\begin{array}{l}30 \text { vehículos } \\
\text { pesados } \\
\text { estáticamente }\end{array}$ & 461,4 & 499,83 & 1,083 & 529,25 & 1,147 & 1,059 & 528,08 & 1,145 & 1,057 \\
\hline $\begin{array}{l}637 \text { vehículos } \\
\text { fotografiados }\end{array}$ & - & $10.147,2$ & & $10.572,3$ & - & 1,042 & $10.545,7$ & - & 1,039 \\
\hline
\end{tabular}


3. Respecto de la muestra amplia de 637 vehículos fotografiados, al no conocerse los pesos estáticos de estos, sólo se puede obtener como valor de referencia el peso dinámico real (b) de la carga transportada, resultante de restar para cada vehículo el peso dinámico menos la tara real. Por tanto, los otros valores estimados que pueden obtenerse, que son la carga dinámica estimada al asignar las taras del tipo de vehículo obtenido visualmente (c) y de la carga dinámica estimada al asignar las taras del tipo de vehículo obtenido en la clasificación realizada automáticamente (f), se deberán comparar con el peso dinámico real de la carga transportada (b).

4. En cuanto a los resultados obtenidos respecto a esta muestra de 637 camiones, tal como se ha comentado, no puede determinarse el error debido al equipo de pesaje, ya que no se ha podido pesar estáticamente a todos estos vehículos. No obstante, se puede decir sin temor a equivocarse demasiado, que al ser la composición de ambas muestras parecida, el error sería del mismo orden que el obtenido para la muestra reducida, es decir de entre el $8 \%$ y el $9 \%$.

5. Como no se puede determinar el peso de la carga real total en esta muestra amplia de 637 camiones, el valor de referencia será la carga dinámica real (b) obtenida para el conjunto total de vehículos. La comparación de la carga dinámica estimada con taras de la campaña del CEDEX de 2003 y asignación mediante clasificación visual (c) con la carga dinámica real nos da un error (e) del 4,2 \%, mientras que la comparación de la carga dinámica estimada y asignación de taras mediante clasificación automática (f) con la carga dinámica real nos da un error (h) de un 3,9\%. Estos errores serían los debidos a las simplificaciones del método, y como se puede ver, son apreciablemente inferiores a los obtenidos para la muestra de 30 vehículos (un 5,9\% y un 5,7\%, respectivamente), lo que indica que al aumentar el tamaño de la muestra, el error al estimar las cargas transportadas mediante el método tiende a reducirse, lo que demostraría su validez.

\subsubsection{Análisis de sensibilidad del método de estimación del peso de las cargas transportadas}

Una vez expuestos los fundamentos del método de estimación del peso de la carga transportada por los vehículos y mostrados los principales resultados del ensayo de comprobación, es conveniente realizar un análisis de sensibilidad del método respecto de los parámetros en los cuales está basado y en los que existe mayor incertidumbre.

Estos parámetros cuyo valor puede variar en las diferentes circunstancias, por no ser muy conocidos o por ser muy difícil su ajuste, son los siguientes:

1. Los errores debidos al sistema WIM, que pueden ser a su vez de dos tipos: 
a. Los debidos a una incorrecta calibración del equipo, que introduce un sesgo (error sistemático) en los pesos dinámicos suministrados.

b. Los inherentes a la propia incertidumbre del aparato de medición, que se reflejan a través de la desviación típica de los errores.

2. Los posibles errores debidos a una mala estimación de los pesos medios de las taras de los diferentes vehículos.

3. Los errores debidos a las incorrecciones en la clasificación de los vehículos.

A continuación, se ha realizado un análisis de sensibilidad en el ámbito de la muestra reducida de 30 vehículos pesados estáticamente por la Guardia Civil, consistente en variar los valores de los parámetros que se acaban de mencionar con objeto de estimar el error que se podría cometer en esas circunstancias.

\subsubsection{Influencia de la calibración del equipo}

Como se explicó anteriormente, la calibración del sistema WIM que se consiguió realizar en el ensayo fue bastante pobre, pues el error relativo medio (sesgo) remanente tras la calibración de los pesos dinámicos fue de un 6,35\%. Hay que decir que aunque teóricamente sea posible, en la práctica es muy difícil eliminar completamente el sesgo, pudiendo considerarse buena la aproximación cuando el error sistemático es menor del $2 \%$.

Parece por tanto interesante estudiar qué precisión se habría obtenido al determinar las cargas transportadas mediante el método aproximado si se hubiera conseguido calibrar correctamente el equipo y se hubiera eliminado completamente el sesgo de las cargas dinámicas, es decir, se van a calcular cuáles habrían sido los resultados si el error relativo medio en los pesos dinámicos hubiera sido nulo.

Los resultados de la recalibración (Peso dinámico corregido) que habría que realizar para conseguir un error relativo medio (sesgo) nulo se muestran en la Tabla 38 , en la que aparecen estos pesos dinámicos corregidos en la columna "Peso dinámico corregido". En las siguientes columnas de la misma tabla, se comprueba el error que se obtendría al aplicar el método de estimación de las cargas transportadas con esos pesos recalibrados.

Tal como se observa en la Tabla 38, si el sistema hubiera estado calibrado correctamente, el error relativo que se hubiera obtenido en la estimación de suma total de las cargas transportadas hubiera sido un $2,78 \%$, es decir, que reduciendo el sesgo del pesaje dinámico en un $6,35 \%$, el error total del método para estimar las cargas disminuye aproximadamente un $11 \%$ (desde el $14 \%$ al $2,78 \%$ ), con lo cual se puede concluir que una correcta calibración del pesaje dinámico es muy importante para que el método de estimación de las carga total transportada por un conjunto de vehículos sea suficientemente exacto. 
Tabla 38. Cálculo del error en la estimación de la carga total transportada con una calibración correcta (error relativo medio de los pesos nulo)

\begin{tabular}{|c|c|c|c|c|c|c|c|c|c|c|}
\hline $\begin{array}{c}\text { Veh } \\
\text { no }\end{array}$ & $\begin{array}{l}\text { Tipo de } \\
\text { vehículo }\end{array}$ & $\begin{array}{c}\text { Peso } \\
\text { estático }(k N)\end{array}$ & $\begin{array}{c}\text { Peso } \\
\text { dinámico } \\
\text { corregido } \\
(\mathrm{kN})\end{array}$ & Error relativo & $\begin{array}{c}\text { Tara real } \\
\text { anotada }(\mathrm{kN})\end{array}$ & $\begin{array}{c}\text { Carga real }= \\
\text { Pest -Tara }(\mathrm{kN})\end{array}$ & $\begin{array}{c}\text { Tara estimada } \\
\text { campaña CEDEX } \\
(\mathrm{kN})\end{array}$ & \begin{tabular}{|c|} 
Carga \\
estimada \\
campaña \\
CEDEX $(\mathrm{kN})$
\end{tabular} & \begin{tabular}{|c|} 
Error Carga \\
estimada \\
Camp \\
CEDEX 2003 \\
$(\mathrm{kN})$
\end{tabular} & \begin{tabular}{|l} 
Error rel. \\
Carga estim \\
Camp \\
CEDEX 2003
\end{tabular} \\
\hline 1 & $\mathrm{~T} 2 \mathrm{~S} 3$ & 378,37 & 341,31 & $-0,09795$ & 155,98 & 222,39 & 143,90 & 197,41 & $-24,99$ & $-0,1124$ \\
\hline 2 & $\mathrm{~T} 2 \mathrm{~S} 3$ & 415,01 & 386,51 & $-0,06868$ & 165,67 & 249,34 & 143,90 & 242,61 & $-6,73$ & $-0,0270$ \\
\hline 3 & $\mathrm{~T} 2 \mathrm{~S} 3$ & 281,55 & 283,19 & 0,00585 & 121,64 & 159,90 & 143,90 & 139,29 & $-20,61$ & $-0,1289$ \\
\hline 4 & $\mathrm{~T} 2 \mathrm{~S} 3$ & 237,16 & 239,84 & 0,01131 & 162,86 & 74,30 & 143,90 & 95,94 & 21,63 & 0,2912 \\
\hline 5 & $\mathrm{~T} 2 \mathrm{~S} 3$ & 341,83 & 317,32 & $-0,07169$ & 168,05 & 173,78 & 143,90 & 173,42 & $-0,36$ & $-0,0021$ \\
\hline 6 & $\mathrm{~T} 2 \mathrm{~S} 3$ & 326,72 & 317,32 & $-0,02876$ & 160,88 & 165,84 & 143,90 & 173,42 & 7,58 & 0,0457 \\
\hline 7 & $\mathrm{C} 2$ & 113,35 & 127,30 & 0,12302 & 96,48 & 16,87 & 62,51 & 64,79 & 47,92 & 2,8398 \\
\hline 8 & $\mathrm{C} 2$ & 48,46 & 48,89 & 0,00885 & 42,48 & 5,98 & 62,51 & $-13,62$ & $-19,60$ & $-3,2759$ \\
\hline 9 & $\mathrm{~T} 2 \mathrm{~S} 3$ & 320,79 & 286,88 & $-0,10569$ & 152,64 & 168,14 & 143,90 & 142,98 & $-25,16$ & $-0,1496$ \\
\hline 10 & $\mathrm{~T} 2 \mathrm{~S} 3$ & 219,20 & 229,69 & 0,04784 & 169,80 & 49,40 & 143,90 & 85,79 & 36,39 & 0,7365 \\
\hline 11 & $\mathrm{C} 2$ & 110,56 & 121,76 & 0,10135 & 93,20 & 17,36 & 62,51 & 59,25 & 41,89 & 2,4126 \\
\hline 12 & $\mathrm{~T} 2 \mathrm{~S} 3$ & 192,82 & 216,78 & 0,12427 & 154,31 & 38,50 & 143,90 & 72,87 & 34,37 & 0,8926 \\
\hline 13 & $\mathrm{~T} 2 \mathrm{~S} 3$ & 394,56 & 387,43 & $-0,01806$ & 125,67 & 268,89 & 143,90 & 243,53 & $-25,36$ & $-0,0943$ \\
\hline 14 & $\mathrm{~T} 2 \mathrm{~S} 3$ & 418,64 & 354,22 & $-0,15388$ & 165,79 & 252,85 & 143,90 & 210,32 & $-42,53$ & $-0,1682$ \\
\hline 15 & C2R2 & 305,68 & 290,57 & $-0,04942$ & 183,84 & 121,84 & 126,72 & 163,86 & 42,02 & 0,3449 \\
\hline 16 & $\mathrm{~T} 2 \mathrm{~S} 3$ & 388,82 & 360,68 & $-0,07237$ & 157,30 & 231,52 & 143,90 & 216,78 & $-14,74$ & $-0,0637$ \\
\hline 17 & $\mathrm{~T} 2 \mathrm{~S} 3$ & 292,83 & 310,87 & 0,06160 & 135,32 & 157,51 & 143,90 & 166,96 & 9,46 & 0,0600 \\
\hline 18 & $\mathrm{~T} 2 \mathrm{~S} 3$ & 414,42 & 369,90 & $-0,10742$ & 142,24 & 272,19 & 143,90 & 226,00 & $-46,19$ & $-0,1697$ \\
\hline 19 & $\mathrm{~T} 2 \mathrm{~S} 3$ & 239,81 & 238,92 & $-0,00371$ & 160,32 & 79,49 & 143,90 & 95,01 & 15,52 & 0,1953 \\
\hline 20 & $\mathrm{C} 2$ & 122,33 & 133,76 & 0,09340 & 109,77 & 12,56 & 62,51 & 71,25 & 58,69 & 4,6740 \\
\hline 21 & C3 & 256,29 & 250,91 & $-0,02099$ & 104,57 & 151,71 & 111,70 & 139,21 & $-12,50$ & $-0,0824$ \\
\hline 22 & $\mathrm{~T} 2 \mathrm{~S} 3$ & 314,07 & 299,80 & $-0,04543$ & 137,14 & 176,92 & 143,90 & 155,90 & $-21,03$ & $-0,1189$ \\
\hline 23 & $\mathrm{~T} 2 \mathrm{~S} 3$ & 307,84 & 298,88 & $-0,02911$ & 160,15 & 147,69 & 143,90 & 154,97 & 7,28 & 0,0493 \\
\hline 24 & $\mathrm{C} 2$ & 143,81 & 154,97 & 0,07759 & 82,89 & 60,92 & 62,51 & 92,46 & 31,54 & 0,5178 \\
\hline 25 & $\mathrm{~T} 2 \mathrm{~S} 3$ & 394,75 & 387,43 & $-0,01855$ & 142,88 & 251,87 & 143,90 & 243,53 & $-8,34$ & $-0,0331$ \\
\hline 26 & $\mathrm{~T} 2 \mathrm{~S} 3$ & 403,58 & 386,51 & $-0,04231$ & 121,74 & 281,84 & 143,90 & 242,61 & $-39,24$ & $-0,1392$ \\
\hline 27 & $\mathrm{~T} 2 \mathrm{~S} 3$ & 408,05 & 401,27 & $-0,01661$ & 165,19 & 242,86 & 143,90 & 257,37 & 14,51 & 0,0597 \\
\hline 28 & $\mathrm{~T} 2 \mathrm{~S} 3$ & 250,30 & 294,26 & 0,17563 & 141,07 & 109,23 & 143,90 & 150,36 & 41,13 & 0,3765 \\
\hline 29 & $\mathrm{~T} 2 \mathrm{~S} 3$ & 403,83 & 436,32 & 0,08046 & 134,40 & 269,43 & 143,90 & 292,42 & 22,99 & 0,0853 \\
\hline 30 & $\mathrm{~T} 2 \mathrm{~S} 3$ & 229,85 & 238,92 & 0,03945 & 135,03 & 94,81 & 143,90 & 95,01 & 0,20 & 0,0021 \\
\hline
\end{tabular}

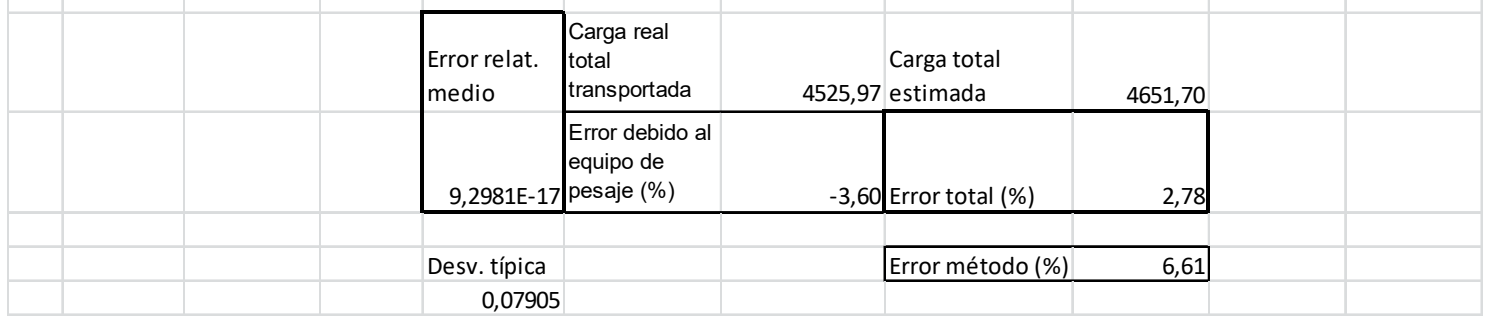

Sin embargo, esa calibración correcta no se hubiera traducido en un aumento apreciable del porcentaje de vehículos individuales cuya carga transportada hubiera sido calculada con una precisión aceptable, considerando como tales a las calculadas con un error $< \pm 20 \%$. Así, para ambas bases de datos de taras (campaña de pesaje del CEDEX y encuesta EPTMC), con la calibración correcta habría 20 vehículos (un $67 \%$ del total) cuya carga sería calculada con un error menor del $20 \%$, es decir solamente un vehículo más que cuando el error sistemático de la calibración era del 6,35\%, mientras que todavía habría 4 vehículos cuya carga habría sido calcula con un error mayor del $100 \%$ (un vehículo menos que cuando el sesgo de los pesajes era el 6,35\%). 


\subsubsection{Influencia de la precisión del equipo de pesaje}

Se ha tratado de estimar la influencia de la precisión del sistema de pesaje dinámico en el error que se cometería al estimar las cargas transportadas por el conjunto de los vehículos de la muestra. La precisión de un equipo de pesaje dinámico viene dada por la repetibilidad de sus medidas, lo que se expresa normalmente en términos de la desviación típica porcentual del error relativo de éstas, de manera que cuanto menor es la desviación típica de los errores, mayor será la precisión del aparato de pesaje.

Para ello, se han realizado los cálculos anteriores, suponiendo que la desviación típica de los errores de las medidas es del 4,2\%, es decir, la mitad del $8,4 \%$ obtenido realmente con el equipo de pesaje, lo que supondría ascender de un sistema de pesaje dinámico de la categoría $D$, según las especificaciones Europeas del Pesaje en Movimiento del COST 323, a un sistema de alta precisión de la categoría B, en el cual aproximadamente un $95 \%$ de las medidas estarían dentro de un intervalo del $\pm 10 \%$ de error.

Realizando unos cálculos similares a los que se exponen en la Tabla 38, se obtiene que, al contrario de lo que podría esperarse, tanto si se realizan los cálculos para el error relativo medio realmente obtenido (un 6,35\%) como para un error relativo medio nulo, al disminuir a la mitad de desviación típica de las medidas aumenta ligeramente el error relativo total en la estimación del peso de la carga transportada, que pasaría del $8 \%$ al $10 \%$ para un error relativo medio del $6,35 \%$, y del $2,78 \%$ al $4,58 \%$ para error relativo medio nulo.

Esta paradoja de que pueda aumentar el error en el cálculo de la carga transportada al aumentar la precisión del sistema de pesaje, se puede deber a que el error total se compone de la suma del error debido al aparato y del error debido a las simplificaciones del método $\mathrm{y}$, en ocasiones las desviaciones de ambos métodos pueden tener un signo contrario que hagan que se reduzca el error total. En cualquier caso, la variación del error de la carga total no parece muy elevada (un $2 \%$ ).

\subsubsection{Influencia de la representatividad de la base de datos utilizada} para estimar las taras medias de los vehículos

Tal como se ha explicado, el método de estimación de las cargas transportadas por los vehículos se basa en asignar como tara de cada vehículo pesado la tara media del tipo al que pertenece. A este respecto pueden darse varias inexactitudes:

1 Que las taras medias del parque de vehículos no hayan sido determinadas con suficiente exactitud

2 Que el tráfico de la carretera donde se instalan los equipos sea algo diferente del tráfico medio de la red o del parque de vehículos a partir del cual se obtuvieron las taras medias. 
Es obvio que casi siempre se va a dar en un cierto grado la segunda fuente de inexactitud, pues es muy difícil que las características de los vehículos que constituyen el tráfico de una carretera particular coincidan en su totalidad con las del conjunto de la red o del país. Así, en el ensayo realizado, la tara real media de los 30 vehículos de la muestra fue de 134, $49 \mathrm{kN}$, mientras que la tara media de esos mismos 30 vehículos obtenida de la base de datos de la campaña de pesaje realizada por el CEDEX entre 2000 y 2003 era de 127,2 kN, es decir, que la tara estimada media era aproximadamente un $5,4 \%$ inferior a la real.

Para tratar de valorar la influencia de la representatividad de la base de datos de taras en la determinación del peso de la carga total transportada, se ha procedido a realizar los cálculos suponiendo que el valor medio de los pesos de las taras asignadas coincidiera con el valor medio de los pesos de las taras reales registradas.

Por ello, se ha multiplicado primeramente los pesos de las taras estimadas por el factor que hace que se iguale su valor medio con el valor medio de la tara real de los vehículos de las muestra. Una vez aplicado el método con estas nuevas taras estimadas a los pesos dinámicos corregidos para que su error relativo medio respecto a los pesos reales sea 0 , se obtiene que, el error relativo total en la determinación de la suma total de las cargas transportadas pasa de un 2,78 \% por exceso a un 3,6\% por defecto, siendo en este caso el error debido al método de un valor nulo (pues lo que se ha hecho realmente es imponer la condición de que el error medio del método sea nulo), con lo cual no existe compensación en este caso entre el error debido al aparato y el error del método, coincidiendo el error total con el error debido al sistema WIM.

Por tanto, la influencia de la representatividad de la base de datos de taras utilizada puede ser muy apreciable (aunque en este caso no lo parezca, por haber cambiado el error de signo), pues ha variado el error total cometido en un 6,4\%. En un caso más extremo en que la diferencia entre las taras medias de la base de datos con las taras medias reales del tráfico en el lugar fuera mayor, por ejemplo un $10 \%$, el sesgo introducido en la carga total transportada aumentaría aproximadamente esta cifra, que además podría sumarse al sesgo introducido por el sistema de pesaje dinámico.

\subsubsection{Influencia del error en la clasificación automática de los vehículos}

Tal como se ha mostrado en la Tabla 24, las pequeñas incorrecciones que ha cometido el programa de clasificación de los vehículos al obtener la composición del tráfico pesado (1 vehículo de los 30 de la muestra reducida fue clasificado erróneamente) no se han traducido en un aumento apreciable del error en el peso de la carga total transportada por el conjunto de vehículos de la muestra, pues la variación obtenida en el peso total de la carga transportada fue aproximadamente del $1 \%$, tanto para la base de datos de la campaña de pesaje 2003 del CEDEX como para la base de la EPTMC de 2013 , en un caso por defecto y en otro por exceso.

Tratando de hacer una generalización de los anteriores resultados a otros posibles errores de clasificación, se podría decir que, normalmente, estos errores de 
clasificación automatizada de vehículos no van a influir demasiado en la estimación del valor total de las cargas transportadas $y$, sobre todo, que no va a incrementarlo apreciablemente, debido a que, normalmente, los errores de clasificación de los vehículos se producen por clasificar un vehículo de un tipo determinado en otro de características muy parecidas, por lo que ambos tipos suelen tener taras bastante similares, con lo cual no se introduce un error adicional apreciable al asignar la tara del tipo equivocado, siempre que éste sea muy próximo.

La fuente más típica de errores de clasificación suele consistir en clasificar a un vehículo articulado de 5 ejes tipo T2S3 (cuya tara media es 143,90 kN, según base de datos de la campaña del CEDEX) que circula con algún eje del semirremolque elevado del pavimento, en un articulado con cabeza tractora de 4 ejes tipo T2S2, cuya tara media $(138,17 \mathrm{kN})$ es sólo un $4 \%$ inferior aproximadamente a la del T2S3, por lo que la carga calculada será algo superior a la real.

Otro caso típico de error en clasificación ha sido el que ha tenido lugar en este ensayo cuando se clasificó un tren de carretera de 4 ejes del tipo C2R2 como si fuera un articulado de 4 ejes del tipo T2S2, cuyas taras difieren en un 9\%. Otro error normal sería clasificar a un autobús de 2 ejes como un camión del mismo número de ejes, cuyas taras tampoco difieren demasiado.

\subsubsection{Mejora potencial del método de estimación de la carga transportada a través de utilizar unas taras medias obtenidas directamente de los pesajes en la carretera}

Mediante el experimento de la toma de datos de pesos dinámicos y estáticos de vehículos realizado en la A-2 en Trijueque se ha demostrado que con el método automático de estimación de las cargas transportadas desarrollado en esta Tesis se puede determinar el peso de la carga total transportada por cualquier número de vehículos (por ejemplo, por el conjunto del tráfico pesado que circula durante un cierto tiempo por una carretera determinada) utilizando un sistema de pesaje dinámico, con una precisión total bastante aceptable, que podría cifrarse aproximadamente en un $5 \%$ por defecto o por exceso, más una cierta componente de error debida tanto al sesgo como a la incertidumbre de las medidas del sistema de pesaje, que puede variar bastante, pero que incluso para aparatos deficientemente calibrados y de una precisión intrínseca media tirando a baja, como el utilizado en este experimento, difícilmente puede llegar a superar un $10 \%$ adicional.

El reducido valor de la componente del error debida a las simplificaciones del método se basa tanto en una correcta clasificación automática de los vehículos como en una adecuada estimación de sus taras. De lo primero se encarga el sistema de clasificación automática desarrollado en la primera parte de esta Tesis, aunque hay que señalar que incluso aunque la clasificación no sea muy afinada, normalmente no se incrementará el error en gran medida, siempre que los fallos de clasificación no sean muy groseros, pues como se ha visto en el experimento realizado en Trijueque, lo más corriente es que estos fallos consistan en clasificar un vehículo de un tipo determinado en otro tipo 
bastante parecido, con una tara similar, lo que no suele significar un aumento de la magnitud total del error.

En cuanto a la adecuada estimación de las taras medias de los vehículos, se ha visto en el experimento que la utilización de distintas bases de datos generales de taras de los vehículos, como pueden ser la del Registro General de Vehículos de la Dirección General de Tráfico o la de la Encuesta Permanente del Transporte de Mercancías por Carretera, conducen a resultados parecidos, normalmente bastante aceptables, para carreteras de tráfico mixto representativas de algunas de las categorías típicas del tráfico de nuestro país.

Sin embargo, el error podría aumentar apreciablemente si las características de los vehículos pesados predominantes en el tráfico de una carretera determinada se apartan de las características típicas de un tráfico mixto representativo de la media nacional, lo que puede ocurrir con cierta frecuencia en vías en las que predomina algún tipo particular de camiones por causa de la naturaleza de las actividades económicas de la zona atravesada por la carretera o de las zonas que constituyen el origen o destino ésta vía. Un caso típico de este tipo de carreteras son las que sirven de acceso o están situadas en zonas de minas o canteras, pues las taras medias de los vehículos utilizados en este tipo de transporte (normalmente grandes camiones rígidos de 2 ó 3 ejes) suelen ser más altas que las taras medias para estos tipos de vehículos en el tráfico general.

Por tanto, en estos casos sería de gran ayuda contar con un método de estimación de las taras basado directamente en los datos suministrados por el sistema de pesaje dinámico instalado en la carretera en cuestión, de forma que a través de los datos suministrados por éste se puedan atisbar ciertas características definitorias de los vehículos de un tipo determinado de transporte. Pues bien, para este propósito fueron desarrollados los procedimientos descritos en un estudio francés, realizado por $F$. Schmidt y B. Jacob [40], y en otro norteamericano llevado a cabo por S. Hernández [41], ambos expuestos en el Apartado 4.4, los cuales abordan la determinación de las taras directamente de los pesos suministrados por el sistema de pesaje dinámico para cada tipo de vehículo.

Comenzando por el estudio realizado por S. Hernández, en éste se trataba de realizar una clasificación extremadamente detallada de los vehículos, que pudiera diferenciar dentro de cada tipo de vehículo (por ejemplo, los articulados de 5 ejes), los dedicados específicamente a diferentes tipo determinados de transporte, para lo que se utilizaba, además de los datos suministrados por un sistema de pesaje dinámico, los proporcionados por la tecnología de los lazos de inducción con una tasa de registro aumentada, que permite determinar la presencia de los diferentes cuerpos o volúmenes (por ejemplo, una cisterna, una plataforma, un contenedor, etc) que componen un vehículo. Posteriormente, con los pesos de los vehículos de cada tipo determinado con las herramientas mencionadas se calculaban las distribuciones de frecuencias de pesos totales del tipo en cuestión, que como se ha comentado, son unas distribuciones bimodales. Estas distribuciones bimodales se aproximaban mediante dos distribuciones normales, una para los vehículos que circulaban en vacío y otra para los que circulaban cargados, escogiéndose como tara media del tipo de 
vehículo en cuestión el valor de peso para el que se produce el máximo de la distribución normal de los vehículos vacíos.

Este método llevado a cabo en el estudio americano precisa utilizar, tal como se ha dicho, una moderna técnica de registro muy detallado de las señales proporcionadas por los lazos de inducción, por lo que no se puede aplicar directamente cuando se utiliza únicamente un sistema de pesaje dinámico para obtener los datos de los vehículos. Sin embargo, el método francés precisa solamente utilizar sistemas de pesaje dinámico para clasificar los vehículos en los tipos corrientemente incluidos en los esquemas de clasificación de las administraciones de carreteras, y consiste en que, una vez obtenidas las distribuciones de frecuencias de los pesos brutos de los vehículos de cada tipo, se considera que la población de vehículos vacíos son todos los que su peso está por debajo del percentil 5 de la distribución del peso bruto registrado por el sistema de pesaje para los vehículos de ese tipo y se asigna como valor de la tara media del tipo en cuestión al valor promedio de los pesos brutos registrados por debajo de ese percentil 5.

Las ventajas de utilizar tal procedimiento para estimar las taras medias de los vehículos de cada tipo son evidentes, pues, además de la simplicidad del método, permitiría ajustar estos valores a los de los pesos de los vehículos específicos que circulan realmente por una determinada carretera, en vez de utilizar unos valores medios nacionales. El principal inconveniente de este procedimiento radica en que, para los tipos de vehículos menos frecuentes, a veces será difícil obtener un registro suficientemente amplio de vehículos de esos tipos como para determinar de forma fiable el valor de las taras medias de los tipos en cuestión, lo que puede ocurrir especialmente en carreteras con un tráfico pesado reducido, que, por otro lado, son las vías en las que puede existir un tráfico pesado de características netamente diferentes del tráfico medio de la red de carreteras y en las que, por tanto, sería más útil aplicar este método.

Pues bien, como las ventajas de utilizar tal método superan en gran medida a los inconvenientes, se ha explorado la posibilidad de utilizarlo. Para ello, partiendo de los datos de los vehículos registrados en la muestra amplia de más de 600 camiones tomada en el ensayo de Trijueque y cuyas taras reales fueron proporcionadas por la Dirección General de Tráfico, se ha procedido a calcular, para los tipos más comunes de camiones, el valor promedio de los pesos por debajo de varios percentiles bajos (percentil 5, 10, 15 y 20) de los pesos de los vehículos de esos tipos registrados por el sistema de pesaje dinámico y se han comparado con los valores medios de las taras reales de los vehículos de cada tipo suministradas por la Dirección General de Tráfico, así como con las taras medias obtenidas de las bases de datos del tráfico pesado utilizadas en los apartados anteriores (campaña del CEDEX, EPTMC y Registro General de Vehículos), resultando los valores que se muestran en la Tabla 39.

Como se puede ver en dicha Tabla, en que aparece sombreado para cada tipo de vehículo el valor medio de los pesos por debajo del percentil que se aproxima más a las taras reales medias suministradas por la DGT, para los camiones rígidos de 2 ejes es el valor medio hasta el percentil 20 de los pesos totales registrados el que se aproxima más a la tara real media del tipo, pero todavía inferior en unos $1.100 \mathrm{~kg}$, para los 
rígidos de 3 ejes es el valor medio de los pesos hasta el percentil 10, mientras que para los articulados de 5 ejes y trenes de 4 ejes es el valor medio de los pesos hasta el percentil 5 de los pesos totales registrados el que se aproxima más a la tara real media del tipo en cuestión, pero superándola ampliamente (en varios miles de kg).

Tabla 39 Comparación de los valores de varios percentiles de los pesos registrados en báscula con las taras medias reales y las taras medias provenientes de tres fuentes de datos diferentes (Campaña CEDEX, EPTMC y Registro General de Veh.)

\begin{tabular}{|c|c|c|c|c|c|c|c|c|c|}
\hline \multirow[b]{2}{*}{$\begin{array}{l}\text { Tipo de } \\
\text { vehículo }\end{array}$} & \multirow[b]{2}{*}{$\begin{array}{l}\text { № } \\
\text { de } \\
\text { veh. }\end{array}$} & \multicolumn{4}{|c|}{$\begin{array}{l}\text { Peso registrado por la báscula dinámica } \\
\qquad(\mathrm{kg})\end{array}$} & \multirow{2}{*}{$\begin{array}{c}\text { Tara } \\
\text { real } \\
\text { media }\end{array}$} & \multicolumn{3}{|c|}{ Taras medias } \\
\hline & & $\begin{array}{c}\text { Valor } \\
\text { medio } \\
\text { hasta } \\
\text { percentil } \\
5\end{array}$ & $\begin{array}{c}\text { Valor } \\
\text { medio } \\
\text { hasta } \\
\text { percentil } \\
10\end{array}$ & $\begin{array}{c}\text { Valor } \\
\text { medio } \\
\text { hasta } \\
\text { percentil } \\
15\end{array}$ & $\begin{array}{c}\text { Valor } \\
\text { medio } \\
\text { hasta } \\
\text { percentil } \\
20\end{array}$ & & $\begin{array}{c}\text { Campaña } \\
\text { CEDEX } \\
\text { (kg) }\end{array}$ & $\begin{array}{c}\text { EPTMC } \\
2103 \\
\text { (kg) }\end{array}$ & $\begin{array}{c}\text { RGV- } \\
\text { DGT } \\
\text { (kg) }\end{array}$ \\
\hline $\begin{array}{l}\text { Rígidos de } \\
2 \text { ejes }\end{array}$ & 57 & 5.200 & 5.783 & 6.456 & 7.042 & 8.148 & 6.372 & 7.905 & 6.416 \\
\hline $\begin{array}{l}\text { Rígidos de } \\
3 \text { ejes }\end{array}$ & 17 & 11.500 & 12.600 & 13.067 & 13.400 & 12.418 & 11.386 & 12.250 & 12.913 \\
\hline $\begin{array}{l}\text { Articulados } \\
\text { de } 5 \text { ejes }\end{array}$ & 537 & 18.037 & 19.392 & 20.444 & 21.337 & 15.067 & 14.669 & 14.524 & 14.886 \\
\hline $\begin{array}{l}\text { Tren de } 4 \\
\text { ejes }\end{array}$ & 25 & 18.000 & 18.950 & $19 . .775$ & 20.080 & 16.747 & 12.917 & 17.316 & 12.954 \\
\hline
\end{tabular}

El estimador del percentil 5 como tara media del tipo es particularmente deficiente en el caso de los vehículos más numerosos, los articulados de 5 ejes, precisamente donde debería haber sido más exacto este estimador, pues la diferencia con las taras reales es de unos $3.000 \mathrm{~kg}$. De hecho, ningún vehículo de los 537 registrados tuvo un peso por debajo de la tara media real. Un primer examen de esto podría atribuir parcialmente tal diferencia a que debido al sesgo positivo de los pesos suministrados por el sistema de pesaje dinámico (un 6\% aproximadamente) estos pesos estuvieran sobreestimados en ese porcentaje por el equipo. Sin embargo, si se corrigen los pesos dinámicos en esa cantidad, sigue resultando una cifra muy superior a la tara media real. Por tanto, la única explicación de este hecho sería que los vehículos articulados de 5 ejes cuando viajan por carreteras con tráfico predominante de largo recorrido (como lo es la A-2 en el pk 82 , donde se tomaron los datos), prácticamente nunca van vacíos y siempre llevan algún tipo de carga.

Esta conclusión queda reforzada cuando se observa que este hecho se da también con el otro vehículo de transporte de largo recorrido, el tren de 4 ejes. Sin embargo, esto invalidaría el poder determinar las taras de los vehículos directamente de los pesajes 
de la carretera, debido a que en algunos tipos de vehículo, al menos en este punto de esta carretera, prácticamente ninguno circula descargado, con lo cual no se podrá determinar la tara del tipo a partir de los datos de los pesos de los vehículos en la carretera.

\subsubsection{Adaptación del procedimiento desarrollado al cálculo de los efectos de las cargas sobre los firmes}

\subsubsection{Consideraciones generales}

La aplicación más conocida del pesaje de vehículos en movimiento es la obtención de las cargas debidas al tráfico para el dimensionamiento de firmes viarios. En este caso no es necesario ni tiene importancia conocer o estimar la tara del vehículo, pues el efecto causado sobre el firme se debe al peso total de éste, es decir, al conjunto de tara+carga transportada. Los sistemas de pesaje dinámico proporcionan de forma directa este dato de todos los vehículos que circulan sobre los sensores del equipo de pesaje, tanto los pesos de cada uno de los ejes como el peso bruto total del vehículo.

No obstante, varias de las cualidades del procedimiento desarrollado en esta Tesis para la estimación de las cargas transportadas por los vehículos pueden ayudar a mejorar también algunos aspectos de la determinación de los efectos o deterioros causados por los ejes de los vehículos sobre los firmes. Así, las ventajas que puede proporcionar la aplicación del método de determinación de las cargas transportadas al dimensionamiento de firmes tienen que ver con los siguientes aspectos:

1. La correcta clasificación de los vehículos que proporciona el método. En el dimensionamiento de firmes lo más importante no son los vehículos propiamente dichos, sino los ejes de estos vehículos, pues son los que ejercen las cargas sobre los firmes. Por tanto, en una primera impresión, si un vehículo de $n$ ejes circula con algún eje levantado, en cuanto a su efecto sobre los firmes, en teoría, sería como si se tratara de un vehículo de n-1 ejes.

Sin embargo, aun siendo cierto lo anterior, muchas veces interesa establecer una equivalencia de los vehículos de cada tipo en ejes patrón, por lo cual es de gran importancia una correcta determinación del tipo real de vehículo de que se trate. Como no se pueden instalar equipos de pesaje dinámico en todos los tramos de una red de carreteras, en muchos lugares sólo será posible conocer una cierta clasificación, más o menos detallada, obtenida a partir de equipos de aforo, por lo que interesa establecer la equivalencia de cada tipo concreto de vehículo en ejes estándar (o el deterioro medio ocasionado por cada uno de los tipos), para determinar el tráfico equivalente: en función de un aforo y de una clasificación de vehículos proporcionada por equipos de aforo usuales o por sistemas de pesaje dinámico poco perfeccionados, basándose en la equivalencia media de los vehículos de cada tipo en ejes estándar o patrón, se puede calcular el 
número de ejes patrón (y, por tanto, el número de vehículos de cada tipo) que debe ser soportado por el firme proyectado.

Este procedimiento se ha seguido en los métodos de dimensionamiento utilizados en Francia y Gran Bretaña en la década de los años 70 y 80 [48].

2. La estimación del error que se comete al determinar los ejes equivalentes (o el deterioro medio ocasionado) mediante pesaje dinámico. Así, aunque los sistemas de pesaje dinámico suministran directamente los pesos de los ejes de los vehículos, debido a la incertidumbre en las medidas proporcionadas por estos equipos de pesaje, se comete siempre un cierto error al determinar estos pesos. Estos errores en el peso dinámico de los ejes pueden incrementar notablemente los errores al obtener los valores de las variables que definen el comportamiento de los firmes y que entran en los métodos de dimensionamiento.

Mediante el ensayo de comprobación realizado en la A-2 en Trijueque, se ha podido conocer el efecto que tiene la precisión de los pesajes dinámicos en la determinación del efecto destructivo de un espectro de cargas de distinta magnitud (determinación de ejes equivalentes) cuando se sigue la fórmula del ensayo AASHO u otra similar. De la misma manera, si se sigue un método de dimensionamiento mecánico-empírico, se podría evaluar la influencia de la precisión de los pesajes dinámicos en la determinación de los deterioros parciales producidos $y$, en definitiva en la estimación de la vida útil del firme.

6.2.9.2 Comprobación de la influencia de la precisión del pesaje en el número de ejes equivalentes en el ensayo realizado en la A-2 en Trijueque

En el ensayo realizado en junio de 2015 en la autopista A-2, pk. 82, en Trijueque (Guadalajara), cuyo objetivo principal era comprobar la precisión del método de estimación de la carga transportada, también se trató de comprobar el efecto de la exactitud y precisión del pesaje dinámico en la estimación del número de ejes equivalentes que debe soportar el firme de una carretera ( $y$, por tanto de su vida útil). Este estudio aparece detallado en el artículo [22], firmado por el autor de esta Tesis, de título "Aplicación del pesaje en movimiento al dimensionamiento de firmes. Influencia de la precisión de los pesajes", publicado en la revista Informes de la construcción, no 545, enero-marzo 2017.

Como se ha explicado en apartados anteriores, la Guardia Civil desvió a una pequeña muestra (representativa del tráfico pesado en la autovía) de 30 vehículos pesados que previamente habían circulado sobre el sistema de pesaje dinámico a su velocidad normal de recorrido, hacia una báscula de pesaje estático perteneciente al Ministerio de Fomento, situada unos 500 m más allá, con objeto de contrastar los pesos suministrados por el sistema de pesaje dinámico con los dados por la báscula estática, que se pueden considerar como reales. 


\subsection{Datos y cálculos previos realizados para la comprobación}

Respecto de los vehículos de la muestra que fueron desviados para su pesaje estático por la Guardia Civil, se obtuvieron los siguientes datos y cálculos inmediatos, que sirven de base para la comprobación:

1. Peso dinámico calibrado (Pdin) suministrado por el equipo de pesaje dinámico para cada uno de los vehículos.

2. Peso estático real (Pest) proporcionado por la báscula de pesaje estático para cada uno de los vehículos de la muestra.

3. Clasificación automática (en tipos) de los vehículos de la muestra a partir de los datos suministrados por el sistema de pesaje dinámico, mediante un programa desarrollado al efecto.

4. Clasificación real (en tipos) de los vehículos de la muestra, obtenida visualmente

En la Tabla 26 (Errores relativos del sistema de pesaje dinámico obtenidos en el experimento) se han mostrado todos estos datos y cálculos de cada vehículo de la muestra, incluyendo el tipo de vehículo, el peso estático proporcionado por la báscula fija, el peso dinámico (ya corregido con el factor de calibración) suministrado por el equipo de pesaje dinámico y el error relativo obtenido en las-medición del peso de cada uno de los vehículos.

\subsection{Calculo de la exactitud y precisión del sistema de pesaje en movimiento}

Una vez obtenidos o determinados los anteriores datos o parámetros de los vehículos pesados, se realizaron los siguientes cálculos para determinar el sesgo y la dispersión de las medidas de los pesos proporcionadas por el sistema WIM, obteniéndose, como ya se ha comentado en el Apartado 6.2.3, un valor promedio de todos los errores relativos en el ensayo del 6,35\%, que representa el sesgo medio (\%) del sistema de pesaje dinámico. También se ha determinado la desviación típica de los errores relativos obtenidos para cada vehículo, que representa la precisión del sistema de pesaje instalado en el firme de este emplazamiento, y que ha sido del $8,41 \%$.

\subsection{Cálculo del factor de equivalencia}

Se han realizado los cálculos del factor de equivalencia, tanto en ejes de 128 kN (antiguo límite legal de peso para los ejes simples en España) como en ejes de 113 kN (actual límite legal en España), de cada vehículo de la muestra utilizando la fórmula del ensayo AASHO, tanto para un exponente 4 (firmes flexibles) como para un exponente 8 (firmes semirrígidos) y se ha hallado el factor de equivalencia medio por vehículo pesado en ambos casos, utilizando las dos series de datos siguientes:

- los pesos obtenidos mediante pesaje estático (Tabla 40), que sirven de referencia. 
- los pesos por eje de cada vehículo y las distancias entre los distintos ejes individuales (con objeto de determinar si forman un eje tándem o trídem) proporcionados por el sistema de pesaje dinámico (Tabla 41).

Para el cálculo se ha utilizado la equivalencia de que cada eje tándem equivale a 1,4 ejes simples de peso $\mathrm{P} / 2$ y cada eje trídem equivale a 2,325 ejes simples de peso $\mathrm{P} / 3$.

En las Tablas 40 y 41 se muestran los resultados de los cálculos del factor de equivalencia obtenidos con ambas series de datos (pesos estáticos y dinámicos), incluyendo las diferencias existentes entre la clasificación real de los vehículos y la proporcionada automáticamente por el equipo de pesaje dinámico, utilizando el procedimiento de clasificación desarrollado.

Tabla 40. Factores de equivalencia calculados en el ensayo con los datos de los pesajes estáticos

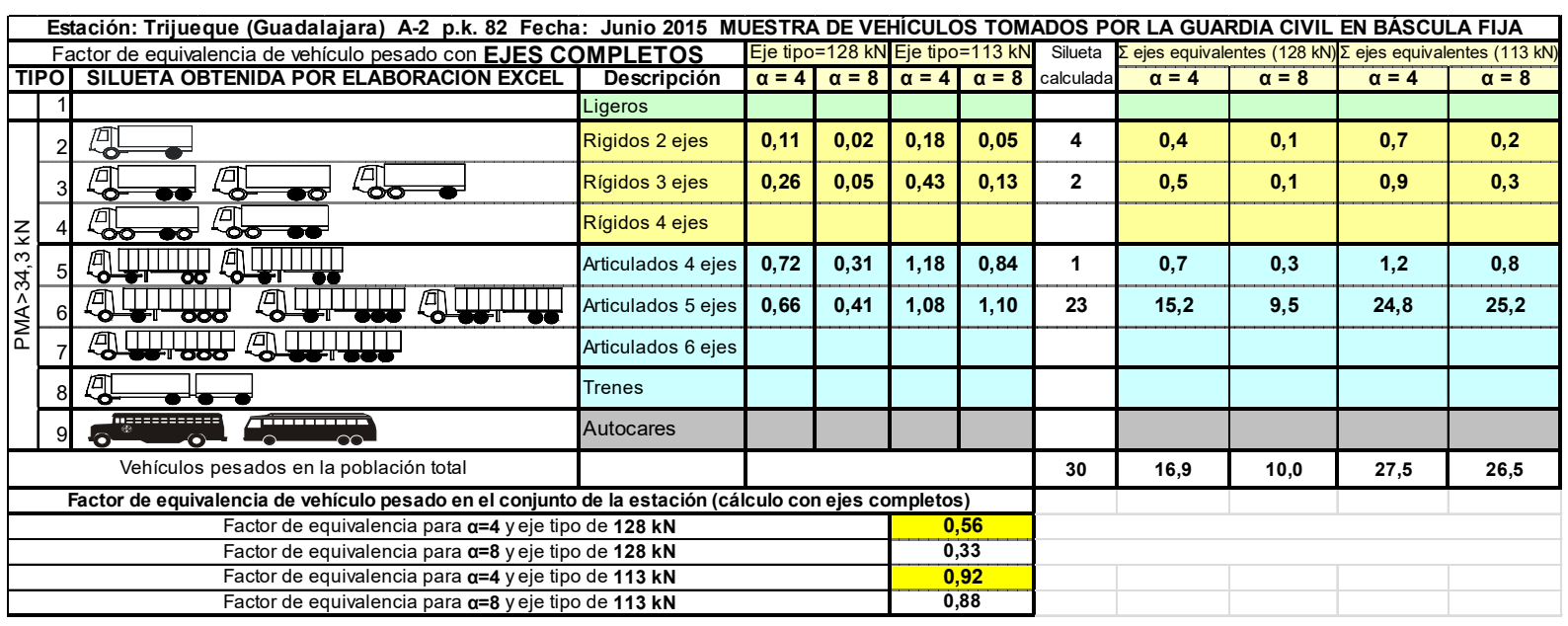

Como se puede ver, las diferencias entre los valores de ejes equivalentes dados por cada una de las tablas, son apreciablemente diferentes, especialmente en los tipos de vehículo donde ha existido un error de clasificación (los rígidos de 2 y de 3 ejes), pues al considerer erróneamente un vehículo de tres ejes (que posiblemente circularía descargado y con un eje levantado) como uno de 2 ejes, se incrementa en gran medida el factor de equivalencia medio de los camiones rígidos de 2 ejes, y también se incrementa el factor de equivalencia de los vehículos de 2 ejes, al ser considerados como tales solamente los que no llevan un eje levantado y, por ello, posiblemente circular cargados. 
Tabla 41. Factores de equivalencia calculados en el ensayo con los datos de los pesajes dinámicos

\begin{tabular}{|c|c|c|c|c|c|c|c|c|c|c|c|}
\hline \multicolumn{12}{|c|}{ Estación: Trijueque (Guadalajara) A-2 p.k. 82 Fecha: Junio 2015 MUESTRA DE VEHICULOS TOMADOS POR LA GUARDIA CIVIL EN BDP } \\
\hline \multicolumn{3}{|c|}{ Factor de equivalencia de vehículo pesado con EJES COMPLETOS } & \multicolumn{2}{|c|}{ Eje tipo=128 kN } & \multicolumn{2}{|c|}{ Eje tipo=113 kN } & \multirow{2}{*}{$\begin{array}{c}\text { Silueta } \\
\text { calculada }\end{array}$} & \multicolumn{2}{|c|}{$\Sigma$ ejes equivalentes $(128 \mathrm{kN}$} & \multicolumn{2}{|c|}{$\Sigma$ ejes equivalentes $(113 \mathrm{kN})$} \\
\hline TIPC & SILUETA OBTENIDA POR ELABORACION EXCEL & Descripción & $\alpha=4$ & $\alpha=8$ & $\alpha=4$ & $\alpha=8$ & & $\alpha=4$ & $\alpha=8$ & $\alpha=4$ & $\alpha=8$ \\
\hline & & Ligeros & & & & & & & & & \\
\hline \multirow{14}{*}{$\mid \begin{array}{l}z \\
z \\
m \\
m \\
\tilde{y} \\
\tilde{n} \\
\hat{n} \\
\vdots \\
0 \\
0\end{array}$} & 5 & Rigidos 2 ejes & 0,20 & 0,05 & 0,33 & 0,13 & 5 & 1,0 & 0,2 & 1,7 & 0,7 \\
\hline & 荷 & Rígidos 3 ejes & 0,57 & 0,16 & 0,93 & 0,43 & 1 & 0,6 & 0,2 & 0,9 & 0,4 \\
\hline & 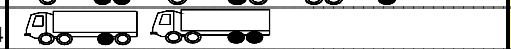 & Rígidos 4 ejes & & & & & & & & & \\
\hline & 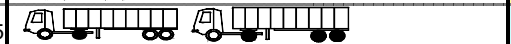 & Articulados 4 ejes & 0,64 & 0,21 & 1,04 & 0,57 & 1 & 0,6 & 0,2 & 1,0 & 0,6 \\
\hline & 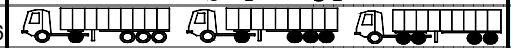 & Articulados 5 ejes & 0,76 & 0,49 & 1,24 & 1,30 & 23 & 17,5 & 11,2 & 28,6 & 29,8 \\
\hline & 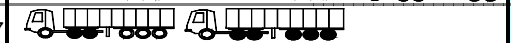 & Articulados 6 ejes & & & & & & & & & \\
\hline & 骂 & Trenes & & & & & & & & & \\
\hline & 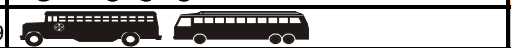 & Autocares & & & & & & & & & \\
\hline & Vehículos pesados en la población total & & & & & & 30 & 19,7 & 11,8 & 32,2 & 31,5 \\
\hline & Factor de equivalencia de vehículo pesado en el conjunt & to de la estación (c & álculo cc & n ejes C & omplet & & & & & & \\
\hline & Factor de equivalencia para $\alpha=4$ y eje tip & o de $128 \mathrm{kN}$ & & & & & & & & & \\
\hline & Factor de equivalencia para $\alpha=8$ y eje tip & o de $128 \mathrm{kN}$ & & & & & & & & & \\
\hline & Factor de equivalencia para $\alpha=4$ y eje tip & o de $113 \mathrm{kN}$ & & & & & & & & & \\
\hline & Factor de equivalencia para $\alpha=8$ y eje tip & 0 de $113 \mathrm{kN}$ & & & & & & & & & \\
\hline
\end{tabular}

\subsubsection{Resultados obtenidos}

A la vista de los resultados, puede comprobarse que el factor de equivalencia por vehículo pesado para un valor del exponente $\alpha=4$, calculado utilizando los pesos obtenidos mediante pesaje dinámico, ha sido de 0,66 ejes equivalentes de $128 \mathrm{kN}$ por vehículo pesado, que ha resultado ser casi un $18 \%$ mayor que el que se ha obtenido utilizando los pesos medidos mediante básculas estáticas $(0,56$ ejes equivalentes de $128 \mathrm{kN}$ ). Para un valor del exponente $\alpha=8$, el factor de equivalencia medio obtenido mediante los pesajes en movimiento ha sido igualmente un $18 \%$ mayor que el que se ha obtenido con los pesajes estáticos $(0,39$ ejes equivalentes frente 0,33 mediante pesajes estáticos).

Por tanto, el error en el que se ha incurrido al determinar los pesos de los vehículos mediante pesaje dinámico, que como se ha visto ha tenido un sesgo de un 6,35 \% por exceso y una dispersión del $8,41 \%$, se ha magnificado al utilizar la expresión potencial obtenida en el ensayo AASHO, resultando un error del $18 \%$ por exceso en la determinación del coeficiente de equivalencia medio de los vehículos y, por tanto, del número total de aplicaciones de la carga tipo de $128 \mathrm{kN}$, lo que viene a significar que con ello se estaría infraestimando la vida útil del firme en ese porcentaje del $18 \%$, dado que ésta se estima en función del número de aplicaciones de la carga tipo que puede resistir el firme.

Sin embargo, el error total obtenido en la determinación de la vida de servicio es apreciablemente menor que el que podría estimarse por las consideraciones estadísticas dadas en [49], relativas al sesgo adicional introducido por el error relativo medio y la dispersión de las medidas del sistema de pesaje dinámico, debido a la incertidumbre de las medidas provocada por las oscilaciones inducidas en la 
suspensión de los vehículos por las irregularidades de los pavimentos, que vendría dado por la fórmula (4):

$$
z=[(1+b) \alpha-1]+\frac{\alpha(\alpha-1)}{2} \cdot(1+b) \alpha-2 \cdot \sigma^{2}
$$

Siendo:

$\varepsilon$ : error relativo medio en la estimación del deterioro total (o en la vida de servicio) del firme

b: error relativo medio de las mediciones del sistema de pesaje

$\sigma:$ desviación típica de las medidas del sistema de pesaje

$\alpha$ : exponente de la ley de fatiga ( $\alpha=4$ para firmes flexibles, $\alpha=8$ para firmes semirrígidos)

Así, si se entra en la fórmula anterior con los valores $b=0,0635$ y $\sigma=0,0841$, se obtendría que, por ejemplo, para firmes flexibles $(\alpha=4)$ el error en la vida de servicio del firme sería del $32,7 \%$, y la diferencia sería aún mayor para firmes semirrígidos.

Con objeto de ver la causa de esta diferencia, se ha realizado un breve análisis de sensibilidad del cálculo de los ejes equivalentes obtenidos en el ensayo, comprobándose que los valores resultantes son muy dependientes del error que se haya cometido al determinar los pesos dinámicos de los vehículos más cargados. Por ello, como los sistemas de pesaje dinámico normalmente determinan con mayor exactitud los pesos de los vehículos más cargados, el error realmente obtenido ha sido menor que el esperado.

\subsubsection{Influencia de la precisión del pesaje en movimiento en el dimensionamiento mecánico-empírico de firmes}

Todo lo tratado en el apartado anterior de refiere a la aplicación del pesaje en movimiento para la determinación de los efectos de las cargas sobre el firme siguiendo el planteamiento basado en la equivalencia desarrollada en el ensayo AASHO. Sin embargo, la tendencia más actual encaminada al empleo de métodos mecánicoempíricos de dimensionamiento de firmes, como es la propuesta en la MechanisticEmpirical Pavement Design Guide (MEPDG) [50] de la AASTHO, sigue un planteamiento basado en describir el tráfico en términos del número de ejes por tipos y las distribuciones de frecuencias de los pesos de cada tipo de eje, calculándose el grado de deterioro específico ocasionado por los ejes de cada peso. Por ello, numerosos autores se han centrado en evaluar la influencia de los errores en la determinación del espectro completo de cargas mediante pesaje en movimiento sobre la estimación de la vida de servicio de los firmes utilizando los principios mecánico-empíricos.

En dos estudios, uno llevado a cabo por SW. Haider et al [51] y otro por R. Tarefder et al. [52], se ha investigado el impacto de los errores de los pesajes dinámicos (y por tanto de los espectros de cargas por eje) sobre el comportamiento de pavimentos 
tanto flexibles como rígidos, mostrando en ambos estudios que la fisuración es el deterioro más afectado por las variaciones en los espectros de cargas, tanto en firmes flexibles como rígidos, mientras que también queda afectada de forma moderada la formación de roderas en pavimentos flexibles y no observándose ningún efecto apreciable sobre la regularidad superficial.

\subsection{Discusión general de resultados}

En este apartado se va a hacer un resumen y discusión de los principales resultados obtenidos, con el objetivo de que sirvan de base para llegar a las conclusiones de la Tesis.

Tal como se ha comentado en apartados anteriores, como medio para desarrollar el método de determinación automática de la carga transportada, se ha elaborado un procedimiento de clasificación enteramente automátizada de los vehículos basado, como la mayor parte de los sistemas existentes, en función del número de ejes, de la separación entre estos y de la longitud del vehículo. No obstante, con objeto de poder registrar en su tipo correcto principalmente a los vehículos que circulan con algún eje levantado (en vez de en el tipo correspondiente al del número de ejes que llevan apoyados en el pavimento), se han incluido otros parámetros de clasificación, principalmente el peso del vehículo.

Tras una primera elaboración en gabinete basándose en datos provenientes de la última campaña de pesaje dinámico del CEDEX, se realizó una primera toma de datos en la carretera, en la A-1, pk 41, a la altura de El Molar, con objeto de adaptar los límites inicialmente establecidos de los parámetros de clasificación a las condiciones del tráfico actual, obteniéndose un error total de clasificación del 3,9\%.

Una vez efectuadas las oportunas correcciones y fijados unos nuevos umbrales o límites para los parámetros de clasificación, se realizó una toma de datos del tráfico en la carretera (en la A-2, pk 81, en Trijueque (Guadalajara)) para contrastar la precisión de la clasificación obtenida con el procedimiento automático finalmente establecido en relación con la clasificación realizada visualmente por varios operarios entrenados, que puede considerarse como la real. El resultado obtenido arroja un porcentaje de vehículos clasificados erróneamente de aproximadamente un $4 \%$, lo que significa una tasa de clasificación correcta (calculada como el número de vehículos clasificados correctamente dentro de cada clase, divididos por el número de vehículos totales de la clase en cuestión) del 96\%, lo que demuestra la exactitud y fiabilidad del procedimiento desarrollado (véase la Tabla 25), aunque en alguna clase con un número reducido de vehículos el error de clasificación pueda ser mayor.

De entre los vehículos más típicos, el que puede registrar un error mayor de clasificación es el camión rígido de 2 ejes, pues en zonas periurbanas, algunos furgones o camiones ligeros muy cargados pueden ser clasificados como camiones rígidos de 2 ejes. 
Tal como se ha comentado, el método de determinación automática del peso de la carga transportada que se ha desarrollado en esta Tesis se basa en restar del peso total registrado por el sistema de pesaje para el vehículo, la tara media del tipo en que ese vehículo puede ser clasificado automáticamente por el sistema de pesaje dinámico.

Para conocer las taras medias de cada tipo de vehículo se ha acudido a varias fuentes o bases de datos de las características de los vehículos pesados: la Campaña de pesaje dinámico del CEDEX realizada en la Red de Carreteras del Estado, la Encuesta Permanente del Transporte de Mercancías por Carretera y el Registro General de Vehículos de la Dirección General de Tráfico.

En la Tabla 42 se muestran las taras medias para cada tipo de vehículos de cada una de las bases de datos anteriores. También se han obtenido datos de los fabricantes de camiones, remolques y semirremolques, pero se ha considerado impracticable para el propósito de esta Tesis obtener las taras medias del parque de vehículos a partir de los datos de los fabricantes, pues para ello habría que disponer de datos de las ventas anuales de cada tipo de vehículo y de las proporciones de las distintas carrocerías (volquetes, portacontenedores, frigoríficos, además de la tasa de renovación del parque).

Tabla 42 Resumen de taras medias de cada tipo de vehículos según la Campaña de pesaje dinámico del CEDEX en la RCE entre 2000 y 2003, la Encuesta Permanente del Transporte de Mercancías por Carretera (EPTMC) del año 2013 y el Registro General de Vehículos de 2017.

\begin{tabular}{|l|r|r|r|}
\hline \multicolumn{1}{|c|}{ Tipos de vehículos } & $\begin{array}{c}\text { Campaña CEDEX } \\
\mathbf{2 0 0 0 - 2 0 0 3}\end{array}$ & $\begin{array}{c}\text { Encuesta PTMC } \\
\mathbf{2 0 1 3}\end{array}$ & $\begin{array}{c}\text { Registro General } \\
\text { Vehículos 2017 }\end{array}$ \\
\hline Camión 2 ejes & $\begin{array}{c}\text { Tara media } \\
(\mathrm{kN})\end{array}$ & $\begin{array}{c}\text { Tara media } \\
(\mathrm{kN})\end{array}$ & $\begin{array}{c}\text { Tara media } \\
(\mathrm{kN})\end{array}$ \\
Camión 3 ejes & 62,51 & 77,55 & 62,91 \\
Camión 4 ejes & 111,70 & 120,17 & 126,67 \\
Camión más de 4 ejes & 136,53 & 141,22 & 142,01 \\
\hline Tractor 2 ejes + semirremolque 1 eje & 133,79 & 108,43 & \\
Tractor 2 ejes + semirremolque 2 ejes & 138,17 & 128,35 & \\
Tractor 2 ejes + semirremolque 3 ejes & 143,90 & 142,48 & 146,03 \\
Tractor 3 ejes + semirremolque 2 ejes & 169,22 & 90,97 & \\
Tractor 3 ejes + semirremolque 3 ejes & & 138,48 & \\
Tractor + semirremolque: otras comb. & & 148,41 & \\
\hline Tren: Camión 2 ejes-Remolque 1 eje & & 78,48 & \\
Tren: Camión 2 ejes-Remolque 2 ejes & 126,72 & 169,87 & 127,08 \\
Tren: Camión 2 ejes-Remolque 3 ejes & 129,36 & 173,73 & \\
Tren: Camión 3 ejes-Remolque 2 ejes & 155,72 & 174,14 & \\
Tren: Camión 3 ejes-Remolque 3 eje & 159,05 & 180,97 & \\
Tren. Camión y remolque: otras comb. & & 164,36 & \\
\hline
\end{tabular}


Como se puede ver en la Tabla 42, los valores medios de las taras proporcionados por la campaña de pesaje del CEDEX entre 2000 y 2003 han sido más bajos para casi todos los tipos de vehículos que los proporcionados por la Encuesta Permanente del Transporte de Mercancías por Carretera (EPTMC) del año 2013 y por el Registro General de Vehículos de 2017. Estos valores de las taras medias para cada tipo de vehículo son los que han sido introducidos en los cálculos de estimación de las cargas transportadas, según el método propuesto en esta Tesis, que se acaba de describir.

Para la comprobación del procedimiento de estimación de las cargas transportadas se utilizó también la toma de datos de campo realizada en la autovía A-2, p.k. 82 en Trijueque, donde se instaló el equipo de pesaje dinámico en el carril derecho en sentido Madrid, de manera que los camiones que circulaban sobre este equipo luego podían ser pesados de forma estática en una báscula fija del Ministerio de Fomento situada unos $500 \mathrm{~m}$ más abajo.

Para la comprobación del procedimiento de estimación de la carga transportada se tomaron datos de dos muestras distintas de camiones:

1. Una muestra reducida de 30 camiones que, tras pasar sobre el equipo de pesaje en movimiento a su velocidad normal de recorrido, luego fueron desviados por la Guardia Civil para ser pesados estáticamente. Además, se les pidió su ficha técnica para conocer su tara y otros datos del vehículo.

2. Una muestra amplia de más de 600 camiones de diverso tipo que fueron fotografiados al pasar sobre el equipo de pesaje, con objeto de registrar sus matrículas, al mismo tiempo que se anotaba su hora de paso sobre el equipo, para su identificación posterior en los listados. Los datos de matrícula fueron enviados a la Dirección General de Tráfico para obtener las taras de cada vehículo.

Los resultados de comprobación de la exactitud y precisión del método de estimación de la carga transportada por cada vehículo individual de la muestra reducida de 30 vehículos de peso estático conocido muestran que, aunque aproximadamente en un $60 \%$ de ellos el peso fue estimado con una precisión aceptable dentro de un intervalo del $\pm 20 \%$, difícilmente podría ser utilizado este procedimiento para estimar la carga de los vehículos individuales, pues se dan casos en los que el error que se puede cometer es muy grande (incluso mayor del 100\%) y difícil de evitar, especialmente para los camiones rígidos de 2 ejes o cuando los vehículos circulan descargados.

La razón de estos altos errores en la determinación de la carga transportada por los vehículos individuales hay que buscarla en los efectos de propagación de errores al realizar la operación aritmética de estimación de la carga, en la que se restan dos cantidades que conllevan una cierta incertidumbre (el peso del vehículo suministrado por el sistema de pesaje dinámico y la tara media del tipo de vehículo en que es clasificado automáticamente el camión). En estos casos, es bien conocido que los errores de los factores que intervienen en la resta se suman, mientras que la cantidad sobre la que intervienen (el resultado de la resta) es menor que las originales, con lo cual el error relativo aumenta. 
Sin embargo, la aplicación del método ha resultado satisfactoria para estimar el peso de la carga total transportada por un conjunto de vehículos (en este caso, el de la muestra de 30 camiones pesados estáticamente por la Guardia Civil), pues a pesar del alto sesgo de las medidas proporcionadas por el sistema WIM utilizado, que superaba el $6 \%$, han resultado unos errores totales en la determinación de la carga total transportada del $12 \%$ al $15 \%$ (véase la Tabla 43), según la base de datos de taras utilizada, que se pueden desglosar en dos componentes:

a) Una componente del error es debida a la imprecisión del sistema de pesaje dinámico, y para el ensayo realizado tiene una magnitud del $8 \%$ al $9 \%$.

b) La otra componente del error es debida a las simplificaciones del método de estimación y tiene una magnitud más pequeña, de entre el $4 \%$ y el $6 \%$, según la base de datos de taras utilizada.

Tabla 43. Resumen de las estimaciones de las cargas transportadas por los vehículos de la muestra reducida en Trijueque, según las tres bases de datos de taras (CEDEX, EPTMC y RGV) y error cometido en cada una de ellas,

\begin{tabular}{|c|c|c|c|c|c|c|c|c|}
\hline Veh $n^{\circ}$ & $\begin{array}{l}\text { Tipo de } \\
\text { vehículo }\end{array}$ & $\begin{array}{l}\text { Carga real = } \\
\text { Pest-Tara }(\mathrm{kN})\end{array}$ & $\begin{array}{l}\text { Tara estimada } \\
\text { campaña } 2003 \\
(\mathrm{kN})\end{array}$ & $\begin{array}{l}\text { Carga estimada } \\
\text { campaña } 2003 \\
(\mathrm{kN})\end{array}$ & $\begin{array}{l}\text { Tara estimada } \\
\text { EPTMC }(k N)\end{array}$ & $\begin{array}{l}\text { Carga estimada } \\
\text { EPTMC }(\mathrm{kN})\end{array}$ & $\begin{array}{l}\text { Tara estimada } \\
\text { RGV-DGT (kN) }\end{array}$ & $\begin{array}{l}\text { Carga } \\
\text { estimada RGV } \\
\text { DGT }(\mathrm{kN})\end{array}$ \\
\hline 1 & T2S3 & 222,39 & 143,90 & 219,07 & 142,48 & 220,49 & 146,03 & 216,94 \\
\hline 2 & T2S3 & 249,34 & 143,90 & 267,14 & 142,48 & 268,56 & 146,03 & 265,01 \\
\hline 3 & T2S3 & 159,90 & 143,90 & 157,26 & 142,48 & 158,69 & 146,03 & 155,14 \\
\hline 4 & T2S3 & 74,30 & 143,90 & 111,16 & 142,48 & 112,58 & 146,03 & 109,03 \\
\hline 5 & T2S3 & 173,78 & 143,90 & 193,56 & 142,48 & 194,98 & 146,03 & 191,43 \\
\hline 6 & T2S3 & 165,84 & 143,90 & 193,56 & 142,48 & 194,98 & 146,03 & 191,43 \\
\hline 7 & C2 & 16,87 & 62,51 & 72,87 & 77,55 & 57,83 & 62,94 & 72,44 \\
\hline 8 & $\mathrm{C} 2$ & 5,98 & 62,51 & $-10,52$ & 77,55 & $-25,56$ & 62,94 & $-10,95$ \\
\hline 9 & T2S3 & 168,14 & 143,90 & 161,19 & 142,48 & 162,61 & 146,03 & 159,06 \\
\hline 10 & T2S3 & 49,40 & 143,90 & 100,37 & 142,48 & 101,79 & 146,03 & 98,24 \\
\hline 11 & C2 & 17,36 & 62,51 & 66,98 & 77,55 & 51,94 & 62,94 & 66,55 \\
\hline 12 & T2S3 & 38,50 & 143,90 & 86,63 & 142,48 & 88,05 & 146,03 & 84,51 \\
\hline 13 & T2S3 & 268,89 & 143,90 & 268,12 & 142,48 & 269,54 & 146,03 & 265,99 \\
\hline$\overline{14}$ & T2S3 & 252,85 & 143,90 & 232,80 & 142,48 & 234,22 & 146,03 & 230,67 \\
\hline 15 & C2R2 & 121,84 & 126,72 & 182,30 & 169,87 & 139,15 & 127,08 & 181,94 \\
\hline 16 & T2S3 & 231,52 & 143,90 & 239,67 & 142,48 & 241,09 & 146,03 & 237,54 \\
\hline 17 & T2S3 & 157,51 & 143,90 & 186,69 & 142,48 & 188,12 & 146,03 & 184,57 \\
\hline 18 & T2S3 & 272,19 & 143,90 & 249,48 & 142,48 & 250,90 & 146,03 & 247,35 \\
\hline 19 & T2S3 & 79,49 & 143,90 & 110,18 & 142,48 & 111,60 & 146,03 & 108,05 \\
\hline 20 & C2 & 12,56 & 62,51 & 79,74 & 77,55 & 64,69 & 62,94 & 79,31 \\
\hline 21 & C3 & 151,71 & 111,70 & 155,14 & 120,17 & 146,66 & 126,67 & 140,16 \\
\hline 22 & T2S3 & 176,92 & 143,90 & 174,92 & 142,48 & 176,34 & 146,03 & 172,80 \\
\hline 23 & T2S3 & 147,69 & 143,90 & 173,94 & 142,48 & 175,36 & 146,03 & 171,81 \\
\hline 24 & C2 & 60,92 & 62,51 & 102,30 & 77,55 & 87,26 & 62,94 & 101,87 \\
\hline 25 & T2S3 & 251,87 & 143,90 & 268,12 & 142,48 & 269,54 & 146,03 & 265,99 \\
\hline 26 & T2S3 & 281,84 & 143,90 & 267,14 & 142,48 & 268,56 & 146,03 & 265,01 \\
\hline 27 & T2S3 & 242,86 & 143,90 & 282,83 & 142,48 & 284,25 & 146,03 & 280,71 \\
\hline 28 & T2S3 & 109,23 & 143,90 & 169,04 & 142,48 & 170,46 & 146,03 & 166,91 \\
\hline 29 & T2S3 & 269,43 & 143,90 & 320,11 & 142,48 & 321,53 & 146,03 & 317,98 \\
\hline \multirow[t]{5}{*}{30} & T2S3 & 94,81 & 143,90 & 110,18 & 142,48 & 111,60 & 146,03 & 108,05 \\
\hline & & Carga real total & & Carga estim tot.. & & Carga estim. tot & & Carga estim to \\
\hline & & 4525,97 & & \begin{tabular}{|r|}
5191,94 \\
\end{tabular} & & 5097,83 & & 5125,53 \\
\hline & & & Error total $(\%)$ & 14,70 & Error total $(\%)$ & 12,64 & Error total $(\%)$ & 13,25 \\
\hline & & & Error método (\%) & 5,89 & Error método (\%) & 3,97 & Error método (\%) & 4,53 \\
\hline
\end{tabular}


Como se puede deducir de los resultados expuestos en la Tabla 43, las estimaciones de la carga transportada calculados con las taras de la Campaña de pesaje del CEDEX 2000-2003 han sido algo peores que las obtenidas con las taras medias de la Encuesta Permanente del Transporte de Mercancías por Carretera (EPTMC) del año 2013 y del Registro General de Vehículos de 2017, y ello a pesar de que la campaña del CEDEX se realizó en las carreteras de la Red del Estado, es decir, en vías en muchos casos similares a la A-2 en donde se realizó el ensayo, por lo que cabe deducir que quizás ha influido el hecho de que esta base de datos sea algo antigua, y puede que en estos 15 años hayan podido variar ligeramente algunas características de los vehículos, como es la tara.

Al evaluar los resultados de la muestra amplia, de más 600 vehículos fotografiados en el momento de pasar sobre el sistema de pesaje, sólo se puede obtener la componente del error debida al método de estimación, pues en esta muestra no se conocen los pesos estáticos (reales) de los vehículos que la integran. De acuerdo con los resultados obtenidos al aplicar el método de estimación de las cargas transportadas sobre esta muestra mucho más amplia de vehículos, queda confirmada la pequeña magnitud del error debido a las simplificaciones del procedimiento desarrollado_(es decir, excluyendo el error del sistema de pesaje en movimiento), pues se obtiene un error en la estimación de la carga total transportada debido al procedimiento del 3,9\%, tal como se puede ver en la Tabla 37.

La razón de los reducidos errores del método propuesto al estimar la carga total transportada por un conjunto de vehículos frente a los errores de gran magnitud que tienen lugar al determinar la carga transportada por cada vehículo individual está en la compensación de los errores accidentales (los de los errores por defecto con los errores por exceso) incurridos en los distintos vehículos individuales, quedando sólo las componentes sistemáticas del error (sesgo medio de los pesajes y de la base de datos de taras utilizada), lo que permite la aplicación de este método para obtener datos estadísticos de las cargas totales transportadas en una carretera por todos los vehículos que circulan por ella.

El único reparo que cabe poner al procedimiento desarrollado es que la exactitud en la determinación de la carga transportada depende del tipo de vehículos pesados para el que se calcule el peso de esta carga. Así, en los resultados de la muestra amplia de más de 600 vehículos, se ha podido comprobar que, para los tipos de vehículos de los cuales existe un número mínimo en la muestra que haga posible realizar esta evaluación con cierta fiabilidad, se ha comprobado que el error debido a las simplificaciones del método en la determinación de la carga transportada por los vehículos articulados de 5 ejes, que es el camión más común en el tráfico pesado en España, fue de sólo un 1,65 \%, pero en los vehículos rígidos de 2 ejes, que es el segundo vehículo más común, ascendió a un $46,3 \%$.

Este alto error al estimar la carga transportada por los camiones rígidos de 2 ejes se debe a que dentro de este tipo de camiones existe una gran variedad de tamaños y, por tanto, de taras (la dispersión de los valores de sus taras supera el $30 \%$ en cualquiera de las 3 bases de datos de taras estudiadas), con lo cual al sustituir la tara 
real por la tara media se comete para este tipo de vehículo una imprecisión importante. Así, en esta autovía, al tratarse de una vía de largo recorrido, es probable que la mayor parte de los camiones fueran del segmento superior del tipo, es decir, que tuvieran un tamaño grande, por lo cual, su tara real sería bastante superior a la tara media nacional del tipo, lo que se tradujo en una notable sobreestimación de la carga transportada por estos vehículos, al calcularse la carga transportada como la diferencia entre el peso dinámico registrado por el equipo y la tara media del tipo. En efecto, al realizar las comprobaciones pertinentes, se ha verificado que la tara real media de los vehículos rígidos de 2 ejes en la muestra amplia del ensayo de Trijueque fue de $8.148 \mathrm{~kg}(79,93 \mathrm{kN})$ mucho más alta que la tara media asignada en esta comprobación (la de la campaña del CEDEX para ese tipo, 62,51 kN). Esta tara media registrada es muy próxima a la tara media del tipo según la EPTMC $(77,55 \mathrm{kN})$, pues en ella solo se incluyen los vehículos de MMA > $6 \mathrm{t}$. De hecho, si se hubiera asignado esta última tara media para determinar la carga transportada por los camiones rígidos de 2 ejes, se habría obtenido solamente un error aproximado del $10 \%$ en la carga total transportada por este tipo de vehículos.

Con objeto de determinar la influencia en la exactitud de la estimación de ciertos parámetros cuyo valor puede variar, por ser muy difícil su determinación exacta o su ajuste, se ha realizado un análisis de sensibilidad del método respecto de algunos de ellos, como son algunas componentes de los errores de medición del equipo, entre las que se encuentran la incorrecta calibración de éste y la propia incertidumbre del sistema de medición, así como otras posibles imprecisiones del método, entre las que se encuentran una mala estimación de las taras de los diferentes tipos de vehículos o los errores del método automático de clasificación desarrollado.

Las conclusiones de este análisis de sensibilidad muestran que el factor más importante para que los resultados del método de estimación de la carga total transportada por un conjunto de vehículos pesados sean suficientemente exactos es que el equipo de pesaje dinámico esté correctamente calibrado, pues si la calibración del equipo de pesaje fuera correcta con un sesgo nulo, el error relativo que se hubiera obtenido en la estimación total de las cargas transportadas hubiera sido un 2,78 \%, es decir, que reduciendo el sesgo del pesaje en un 6,35 \%, el error total del procedimiento desarrollado para estimar las cargas transportadas disminuiría un $11 \%$ (desde el $14 \%$ al 2,76 \%). El segundo factor en orden de importancia sería la representatividad de las taras de la base de datos elegida, pues de no serlo, puede empeorar en gran medida los resultados del peso total de la carga transportada; mientras que otros factores, como la mayor o menor dispersión de las medidas o la adecuación del método de clasificación automatizada de vehículos parecen tener menor influencia, que además en algunos casos puede compensar parcialmente los errores debidos al aparato de pesaje.

En la práctica, es muy difícil conseguir que el sesgo sea nulo, pero es factible dejarlo en el entorno del $2 \%$ al $3 \%$, con lo cual se podría conseguir un error total en la determinación de la carga transportada del $7 \%$ al $8 \%$.

Por último, se ha tratado de comprobar si se podrían obtener las taras directamente de los pesos de los vehículos registrados por la báscula dinámica en la carretera, pues 
ello permitiría reducir el error en la estimación de la carga cuando se trata de obtener este dato en vías en las que los vehículos pesados tienen unas características bastante diferentes de los más representativos del tráfico pesado medio nacional. Para ello, se ha comprobado un procedimiento descrito en un estudio francés [40], que propugna:

1. Considerar como vehículos vacíos a los que su peso registrado por el sistema de pesaje está por debajo del percentil 5 de la distribución de pesos de los vehículos de cada tipo,

2. Asignar como tara media de estos vehículos de cada tipo el valor medio de los pesos registrados para cada tipo por debajo de ese percentil 5 de pesos.

Esta comprobación se ha realizado sobre los pesos registrados en la muestra amplia de más de 600 vehículos, y se ha comparado con los valores de la tara real de esos mismos vehículos proporcionados por la Dirección General de Tráfico. En la Tabla 44 se muestran los valores de pesos determinados por ambos métodos para los tipos de vehículos más comunes $\mathrm{y}$, además, con los valores medios de las taras proporcionados por el Registro General de Vehículos.

Tabla 44. Comparación de los valores de las taras estimados con el peso medio de los vehículos por debajo del percentil 5 de los pesos registrados para cada tipo de vehículos, con los valores reales y con los valores medios del Registro General de Vehículos

\begin{tabular}{|l|r|r|r|}
\hline Tipo de vehículo & $\begin{array}{c}\text { Peso medio de los } \\
\text { vehículos dentro } \\
\text { percentil 5 del peso } \\
\text { registrado (kg) }\end{array}$ & $\begin{array}{c}\text { Tara real media (DGT) } \\
\mathbf{( k g )}\end{array}$ & $\begin{array}{c}\text { Tara media } \\
\text { Registro General de } \\
\text { vehículos } \mathbf{( k g )}\end{array}$ \\
\hline Rígidos de 2 ejes & 5.200 & 8.148 & 6.416 \\
\hline Rígidos de 3 ejes & 11.500 & 12.418 & 12.913 \\
\hline Articulados de 5 ejes & 18.037 & 15.067 & 14.886 \\
\hline Tren de 4 ejes & 18.000 & 16.747 & 12.954 \\
\hline
\end{tabular}

Como se puede ver en la Tabla 44, en los camiones rígidos el peso medio de los vehículos dentro del percentil 5 de pesos registrados para cada tipo es menor que las taras reales de esos mismos vehículos proporcionadas por la DGT así como por las taras medias del conjunto de vehículos del tipo en el parque español, extraídas del Registro General de Vehículos, mientras que para los vehículos articulados el peso medio de los vehículos dentro del percentil 5 es mucho mayor que las taras reales o las tras medias del parque, lo que indica que deben de circular casi todos con algo de carga. Por tanto, cabe concluir que, al menos en primera instancia, no es posible estimar las taras de los vehículos pesados siguiendo las indicaciones del método francés y, peor aún, parece que el percentil de pesos que se corresponde para cada tipo de vehículo con las taras medias, varía según el tipo de que se trate. 
Aparte de todo lo anterior, dado que una de las principales aplicaciones del pesaje de vehículos en movimiento es el dimensionamiento de firmes viarios, se ha tratado de evaluar el efecto que puede tener el error con el que son obtenidos los pesos de ejes y vehículos mediante esta técnica en la predicción de la vida de servicio de los firmes.

Para ello, se ha aplicado el procedimiento de cálculo del número de ejes equivalentes, utilizando la ley de potencias del ensayo AASHO, a los resultados de pesos obtenidos tanto con pesaje dinámico como con pesaje estático, en la muestra reducida de 30 camiones del ensayo de Trijueque. Es decir, se ha calculado el factor de equivalencia de todos los vehículos de la muestra mediante ambos procedimientos de pesaje a efectos de comparación, obteniéndose los resultados que se muestran en la Tabla 45.

Tabla 45 Comparación de los factores de equivalencia obtenidos con pesajes dinámicos y estáticos

\begin{tabular}{|l|l|l|}
\hline & $\begin{array}{l}\text { Pesos } \\
\text { obtenidos con } \\
\text { pesaje dinámico }\end{array}$ & $\begin{array}{l}\text { Pesos obtenidos } \\
\text { con pesaje } \\
\text { estático }\end{array}$ \\
\hline Factor de equivalencia para $\alpha=4$ y eje tipo de $128 \mathrm{kN}$ & 0,66 & 0,56 \\
\hline Factor de equivalencia para $\alpha=8$ y eje tipo de $128 \mathrm{kN}$ & 0,39 & 0,33 \\
\hline Factor de equivalencia para $\alpha=4$ y eje tipo de $113 \mathrm{kN}$ & 1,07 & 0,92 \\
\hline Factor de equivalencia para $\alpha=8$ y eje tipo de $113 \mathrm{kN}$ & 1,05 & 0,88 \\
\hline
\end{tabular}

Como se puede ver en la tabla, los factores de equivalencia medios calculados con los pesos obtenidos dinámicamente son aproximadamente un $18 \%$ superiores a los mismos factores de equivalencia medios obtenidos con los pesos de los vehículos parados, tanto para un exponente $\alpha=4$ como para un exponente $\alpha=8$. Es decir, que las inexactitudes del equipo de pesaje dinámico $(\mathrm{Er}=6,35 \%$; $\mathrm{CoV}=8,4 \%$ ) incrementan su efecto sobre la exactitud en la estimación de la vida de servicio de los firmes, aproximadamente en un $18 \%$, debido a la aplicación de la ley de potencias del ensayo AASHO.

No obstante, este error obtenido en el ensayo al determinar el coeficiente de equivalencia mediante pesajes dinámicos es apreciablemente menor que el que resulta de la aplicación de una ley estadística (relativa al sesgo adicional introducido por el error relativo medio y la dispersión de las medidas), lo que parece deberse a que el error relativo cometido al pesar los vehículos más cargados, que son los que tienen una mayor influencia en el factor de equivalencia obtenido, es más pequeño que el error relativo medio en toda la muestra de vehículos. 


\section{Conclusiones}

\subsection{Introducción y sentido de la investigación}

En esta Tesis se ha tratado de demostrar la viabilidad de un procedimiento totalmente automático para determinar el peso de las cargas transportadas por los vehículos pesados, sin necesidad de detenerlos para realizar su pesaje estático, con objeto de poder conocer este dato fundamental en el transporte por carretera sobre grandes muestras de vehículos o incluso sobre el tráfico pesado completo que circula por una carretera.

Los métodos utilizados hasta el presente para obtener datos de las cargas transportadas por los vehículos se basan en encuestas realizadas a los transportistas (en España, la Encuesta Permanente del Transporte de Mercancías por Carretera (EPTMC)), que tienen diversas limitaciones (posibles problemas derivados de la falta de representatividad) y además, al basarse en las respuestas de los mismos transportistas, pueden proporcionar datos sesgados al respecto.

Para dar respuesta a la necesidad de conocer de forma fiable las cargas transportadas por los camiones, se ha desarrollado en esta Tesis un procedimiento de determinación automática del peso de la carga transportada mediante pesaje dinámico. Este método sirve para obtener, de forma continua y sin necesidad de encuestas o tomas de datos que requieren la utilización de operarios, la carga total transportada por el conjunto de vehículos que constituyen el tráfico de una carretera.

Las aplicaciones principales de conocer la carga total transportada por el conjunto de vehículos que constituyen el tráfico pesado de una carretera son, primeramente, cuantificar el flujo de mercancías entre distintos centros de carga y poblaciones, así como poder determinar, a escala regional o nacional, de forma fiable, representativa y no sesgada, el indicador más importante de la actividad del transporte, que son las toneladas-km transportadas por carretera. Además, dada la fuerte correlación de este indicador con otras magnitudes económicas, se puede utilizar para monitorizar el nivel de actividad económica general de un país.

\subsection{Principales resultados}

\subsubsection{Tecnología de toma de datos del tráfico que se debe utilizar}

Tras exponer las limitaciones legales en cuanto a pesos, totales y por eje, y a las dimensiones de los vehículos pesados, se ha explicado la situación de la técnica en el campo de toma de datos del tráfico (Apartado 4.1), con objeto de determinar cuál es la tecnología más adecuada para llevar a cabo los objetivos de esta Tesis, es decir, para determinar de forma automatizada el peso de la carga transportada por los vehículos pesados. 
Las diferentes tecnologías existentes para la toma de datos del tráfico se pueden clasificar en dos grandes grupos: las técnicas invasivas del pavimento (en las que los sensores quedan fijados al firme o se introducen en él) y las no invasivas (en las que los sensores se instalan a una cierta distancia por encima del pavimento, con la ventaja de que su instalación no requiere cortar el tráfico, aunque su funcionamiento se puede ver alterado por las condiciones de luminosidad y atmosféricas). Entre las primeras cabe citar los lazos de inducción, los magnetómetros, los sensores piezoeléctricos, los de fibra óptica y otros sensores de presión, así como los sistemas de pesaje dinámico. Entre las técnicas no invasivas se encuentran los sistemas de procesamiento de imágenes de vídeo, el radar de microondas, los detectores por infrarrojos, los detectores ultrasónicos y los sensores acústicos pasivos.

Tras realizar un examen detallado de las ventajas e inconvenientes de cada tecnología se ha llegado a la conclusión de que la única que es capaz de suministrar datos del peso de los vehículos al mismo tiempo que realiza una clasificación fiable y detallada de estos, operaciones necesarias para alcanzar los objetivos de esta Tesis, es el pesaje dinámico o pesaje de vehículos en movimiento, técnica conocida frecuentemente por sus siglas en inglés WIM (Weigh-in-Motion).

\subsubsection{Procedimiento de clasificación de los vehículos pesados}

Una vez escogida la tecnología que se iba a utilizar para realizar la toma de datos de esta Tesis, se ha establecido que como medio auxiliar para determinar de forma automatizada la carga transportada por los vehículos, se debía desarrollar primeramente un procedimiento de clasificación detallada de estos, con objeto de poder estimar de una manera suficientemente precisa sus pesos en vacío o taras.

Existen diversos esquemas de clasificación detallada de los vehículos utilizados en los diferentes países y regiones geográficas del mundo (Estados Unidos, Europa, etc), pero para los propósitos de esta Tesis, es indispensable que el esquema de clasificación propuesto esté adaptado a las condiciones y tipos de vehículos que constituyen el tráfico pesado en España.

Por otro lado, cualquier esquema de clasificación de vehículos está completamente relacionado con las capacidades de la tecnología de toma de datos del tráfico utilizada para proporcionar esa clasificación. Por tanto, dado que, como se ha establecido, la clasificación va a ser realizada por un equipo de pesaje dinámico, que suministra datos del peso total del vehículo, los pesos de cada uno de sus ejes, la separación entre cada dos ejes y la longitud total del vehículo, este procedimiento de clasificación se basa en un conjunto de reglas de decisión en relación con los mencionados parámetros.

Mediante el procedimiento de clasificación desarrollado en este documento, se ha podido clasificar a los vehículos, principalmente a los pesados, en una silueta del tráfico muy detallada, con más de 20 tipos diferentes (aunque, como sólo se han considerado entre los trenes de carretera los tipos más frecuentes, se ha limitado la clasificación a 18 tipos). 
En cuanto a la definición de las condiciones de clasificación de los diferentes tipos de vehículos, se ha podido extraer las siguientes conclusiones:

1. La primera distinción que cabe realizar en una sistema de clasificación es la separación entre los vehículos ligeros y los pesados. Aunque en el procedimiento de clasificación desarrollado podría haberse realizado esta distinción exclusivamente en función del peso (considerando como pesados a los vehículos cuyo peso registrado por el sistema de pesaje dinámico sea mayor de 3,5 toneladas), por ser más ajustada, también se ha realizado en función de la longitud del vehículo (de manera que se considera que un vehículo es pesado si su longitud es mayor de $6 \mathrm{~m}$ ), para poder seguir y comparar los resultados con el procedimiento de diferenciación más simple (por estar basado únicamente en los datos proporcionados por lazos de inducción) utilizado por la Dirección General de Carreteras del Ministerio de Fomento.

2. En un primer momento, dentro de los vehículos ligeros se abordó la clasificación de estos en varios tipos diferentes (turismos, derivados de turismo, coches con caravana, furgones ligeros). En la Tabla 12 se muestran las condiciones de diferenciación y clasificación de estos vehículos. No obstante, debido al solape casi total de características entre algunos de los tipos (entre turismos y derivados de turismo, así como entre los turismos grandes y los furgones ligeros), se ha considerado que no es posible realizar esta diferenciación de forma adecuada. Por otro lado, como el objetivo de todo el procedimiento es estimar la carga transportada, a este respecto son mucho más importantes los vehículos pesados, por lo que se decidió no profundizar en la diferenciación de los distintos tipos de vehículos ligeros.

3. Una vez clasificado un vehículo como pesado, la distinción entre las tres grandes clases de camiones (vehículos rígidos, vehículos articulados y trenes de carretera) se realiza primeramente en función de la longitud del vehículo, pues por cuestiones de normativa legal de pesos y dimensiones, los rígidos no pueden medir más de $12 \mathrm{~m}$ ni los articulados más de 16,5 m (aunque deben tenerse en cuenta ciertas tolerancias a los anteriores valores), ocurriendo que la mayor parte de los vehículos de cada una de estas clases (excepto los camiones rígidos de 2 ejes) tienden a tener una longitud próxima al límite superior, con objeto de poseer mayor capacidad de carga. Sin embargo, como dentro de cada una de estas tres clases existen algunos tipos particulares de vehículos que tienen longitudes menores que las típicas de su clase (como las bañeras de obra de tipo articulado, que suelen medir menos de $12 \mathrm{~m}$ ), aparte de la longitud, se debe acudir a algún parámetro adicional para asignarlos a la clase correcta.

4. Dentro de cada clase de vehículo, la forma de distinguir unos tipos de vehículos de otros se apoya fundamentalmente en el número de ejes que poseen y en la configuración de estos (es decir, si se trata de ejes simples, tándem o trídem), imponiéndose unas condiciones de distancia máxima 
para que dos o tres ejes consecutivos constituyan un eje múltiple (normalmente, separación menor de 1,8 m). También se suele incluir, como condición adicional, la separación entre algunos ejes individuales que no forman eje múltiple.

5. No obstante, para diferenciar entre tipos de vehículos parecidos, en ocasiones, se debe acudir a otros parámetros o características de los vehículos, debido a que:

- Existe un solape en los valores que toman los parámetros de clasificación en varios tipos de vehículos, por lo que resulta bastante difícil diferenciarlos. En estos casos, para poder diferenciar adecuadamente estos "casos difíciles", en el apartado 5.1 .6 se ha realizado un estudio pormenorizado de las distribuciones de frecuencias (mediante histogramas) de algunos parámetros de clasificación en los tipos de vehículos susceptibles de ser confundidos entre sí,.

- Un porcentaje apreciable de camiones circula con algún eje levantado sobre el pavimento (normalmente por circular en vacío). La principal novedad de este procedimiento de clasificación respecto de otros existentes es que, aunque los camiones circulen con algún eje elevado, se intenta clasificar a los vehículos dentro de su tipo correcto. Así, por ejemplo, a un camión de 3 ejes que lleve uno de ellos elevado sobre el firme, los procedimientos actuales de clasificación tienden a considerarlo como un camión de 2 ejes solamente, pues el sistema de pesaje dinámico sólo puede detectar los 2 ejes apoyados sobre el pavimento. Sin embargo, el procedimiento de clasificación desarrollado en esta Tesis trata de clasificar este tipo de vehículo como un camión de 3 ejes, su tipo verdadero, basándose en otras características adicionales de las que se tiene conocimiento.

6. Normalmente, uno de los casos más típicos de solape entre tipos de vehículos parecidos y que plantean más problemas para su clasificación son los autobuses de 2 y de 3 ejes, pues resulta muy difícil distinguirlos de los camiones rígidos del mismo número de ejes. Como el límite legal máximo de longitud de los autobuses es de $15 \mathrm{~m}$ (en comparación con los $12 \mathrm{~m}$ de longitud límite para los camiones rígidos), los autobuses suelen ser algo más largos que los camiones rígidos correspondientes, por lo que se impone la condición de que su longitud mínima sea de $11 \mathrm{~m}$ para los de 2 ejes y de $12,4 \mathrm{~m}$ para los de 3 ejes. No obstante, existe una cierta proporción de autobuses pequeños de 2 ejes, cuya identificación es muy difícil.

Otros casos típicos de solape de características se dan entre los vehículos articulados y los trenes de carretera del mismo número de ejes. Para realizar la diferenciación entre esos dos tipos de vehículos se acude a la 
distancia entre el primer eje del vehículo tractor (eje direccional) y el segundo eje (eje motriz), que en las cabezas tractoras de los articulados está entre $2,5 \mathrm{~m}$ y $4,3 \mathrm{~m}$, mientras que los camiones de 2 ejes que tiran de un remolque suelen ser algo más largos, imponiéndose una distancia entre ambos ejes mayor de los 4,3 $\mathrm{m}$.

7. Como ya se ha comentado, el otro grupo de casos de difícil diferenciación es el de los vehículos de $\mathrm{n}$ ejes que llevan un eje levantado sobre el pavimento, pues suelen ser confundidos con el tipo de vehículo parecido de n-1 ejes. Los dos casos más típicos donde se produce esto son :

- El articulado de 5 ejes con eje trídem trasero, cuando lleva el tercer eje levantado, con el articulado de 4 ejes con eje tándem trasero. Se ha escogido como umbral de diferenciación entre ambos tipos el peso total del vehículo, de manera que si el peso es menor de 28 toneladas, se considera que se trata de un articulado de 5 ejes que circula con un eje levantado por circular casi descargado. Aunque esta condición pueda parecer un poco arbitraria, sus resultados son muy buenos, debido a que actualmente existen muy pocos articulados de 4 ejes en las carreteras españolas.

- Los camiones rígidos de 3 ejes que llevan un eje levantado con los camiones rígidos de 2 ejes y los autobuses de 2 ejes. En este caso existe una coincidencia muy grande entre muchas de las características de estos tipos, por lo que se ha establecido el cumplimiento simultáneo de las siguientes condiciones para que un camión con 2 ejes registrados por el sistema de pesaje dinámico sea considerado como un camión de 3 ejes con un eje levantado:

- Que su longitud sea mayor de 9,5 m

- Que su peso total esté entre 10 t y 14 t (es decir, que circula vacío)

- Tener una distancia entre el 10 y $2^{\circ}$ eje menor de $5,8 \mathrm{~m}$.

Las condiciones completas de clasificación que se han impuesto para lograr la clasificación correcta de cada uno de los tipos de vehículos pesados existentes en las carreteras españolas aparecen expuestas de forma pormenorizada dentro del Apartado 5.1.5 del texto, en las Tablas 13 (I, II, III, IV, V y VI) y, de forma resumida y en formato lógico, en la Tabla 14.

Los resultados de la evaluación de la exactitud del procedimiento de clasificación desarrollado, obtenidos en el ensayo de comprobación llevado a cabo en la A-2, pk 81, en Trijueque, han arrojado solamente un $4 \%$ de vehículos clasificados erróneamente, que supone para el conjunto del tráfico pesado una tasa de clasificación correcta del $96 \%$, lo que demuestra la exactitud y fiabilidad del procedimiento desarrollado. 


\subsubsection{Procedimiento de estimación de la carga transportada}

Una vez clasificados los vehículos pesados en una silueta suficientemente detallada, se ha desarrollado el procedimiento para estimar la carga transportada por estos (obteniendo lo que se llama la "carga estimada"), que es el objetivo principal de esta Tesis. Este procedimiento se basa en restar del peso dinámico registrado para cada vehículo por el sistema de pesaje ("peso dinámico"), el peso en vacío del mismo vehículo, que como no se puede conocer su valor exacto, se sustituye por una "tara estimada", que se corresponde con la tara media del tipo de vehículos en el que es clasificado automáticamente por el método descrito anteriormente.

$$
\text { Carga estimada }=\text { Peso dinámico }- \text { Tara estimada }
$$

Por otro lado, si se suman las "cargas estimadas" de todos los vehículos de una muestra, se obtiene la "carga estimada total".

Fuentes de datos sobre taras medias de los diferentes tipos de vehículo

Para determinar los valores promedio de las taras de los distintos tipos de vehículo existentes se ha acudido a las siguientes bases o fuentes de datos de taras de los vehículos:

1. El Registro General de Vehículos (datos de 2017) de la Dirección General de Tráfico.

2. La Encuesta Permanente del Transporte de Mercancías por Carretera (EPTMC) del año 2013.

3. Las taras recogidas en el muestreo visual llevado a cabo simultáneamente a los pesajes dinámicos de la campaña 2000-2003, realizada por el CEDEX en la Red de Carreteras del Estado.

Las primera fuente de datos (Registro General de Vehículos) se refiere al parque de vehículos existente en España, mientras que las otras dos fuentes (Encuesta Permanente del Transporte de Mercancías y la Campaña de pesaje dinámico realizada por el CEDEX) se refieren al tráfico real de vehículos pesados por la carretera.

También se han estudiado los datos de los catálogos de fabricantes de camiones y de remolques y semirremolques (véase el Apartado 5.2.3.4), que constituyen una valiosa fuente de información sobre las características de los vehículos nuevos, aunque no se pueden aplicar directamente para determinar las taras del conjunto del parque ya existente. No obstante, su estudio sirve para conocer las tendencias, entre las cuales parece existir una cierta disminución de la tara de los vehículos.

Entre las tres bases de datos estudiadas se pueden observar las principales diferencias y similitudes que se apuntan a continuación:

1. Afortunadamente, las tres bases de datos dan un valor muy similar para la tara media del vehículo articulado de 5 ejes (entre $14.475 \mathrm{~kg}$ y $14.882 \mathrm{~kg}$ ), que es con mucho el más común en el transporte interurbano, lo que 
asegura unos resultados parecidos en la estimación de las cargas totales transportadas utilizando cualquiera de las tres bases de datos.

2. El tipo de camión en el que se observan las diferencias más altas entre las tres bases de datos es en el rígido de 2 ejes, pues en la EPTMC la tara media de este tipo es claramente mayor $(7.905 \mathrm{~kg}$ ) que en las otras dos fuentes de datos: $6.372 \mathrm{~kg}$ en la base de la campaña del CEDEX y $6.412 \mathrm{~kg}$ en el Registro General de Vehículos. La razón de esta diferencia hay que buscarla en el hecho de que estas dos últimas bases de datos se refieren a todos los vehículos pesados, es decir, a los de $\mathrm{MMA} \geq 3.500 \mathrm{~kg}$, mientras que la EPTMC se refiere solamente a los vehículos de transporte interurbano con más de $6 \mathrm{t}$ de peso y 3,5 t de capacidad de carga. Como prácticamente todos los vehículos de los estratos inferiores de peso son camiones rígidos de 2 ejes, la diferencia en las taras medias afecta fundamentalmente a este tipo de vehículo y no a los demás.

Por otro lado, como en zonas de transporte predominantemente interurbano casi todos los camiones rígidos de 2 ejes pertenecen a los de los estratos superiores del tipo (es decir, los que tienen una MMA cercana a $18 \mathrm{t} \circ 20 \mathrm{t}$ ), cabe concluir que en carreteras de tráfico interurbano convendría utilizar el valor de la tara media dado por la EPTMC para este tipo de camiones. Precisamente, esto es lo que ha ocurrido en el ensayo de comprobación llevado a cabo en la A-2, pk 81 en Trijueque, en que la tara media ha sido $8.148 \mathrm{~kg}$, bastante similar al valor dado por la EPTMC. Al contrario, cuando se utilice el método desarrollado para estimar las cargas de los vehículos en vías periurbanas o con tráfico de corto recorrido, en el que predominen los camiones de reparto, conviene utilizar como tara media de este tipo la dada por la campaña de pesaje dinámico del CEDEX o por el Registro General de Vehículos, unos 6.400 kg.

\subsubsection{Comprobación de la exactitud del método}

Para comprobar la exactitud del método, se han comparado las cargas estimadas mediante el procedimiento desarrollado con unas cargas reales que sirven de referencia. Con objeto de obtener en un mismo emplazamiento ambos tipos de datos, se ha realizado un ensayo en la A-2, pk 81, en Trijueque (Guadalajara), en el que se han tomado una serie de datos del tráfico real en la carretera sobre dos muestras de vehículos:

1. Una muestra reducida de 30 camiones que, después de pasar sobre el sistema de pesaje dinámico, han sido pesados en una báscula estática y, además, se conoce su tara real por medio de la ficha técnica del vehículo.

2. Una muestra amplia de más de 600 vehículos fotografiados al pasar sobre el sistema de pesaje dinámico, de los cuales, por medio de su matrícula, se ha recabado de la Dirección General de Tráfico su tara real. 
De la muestra reducida de vehículos se ha podido determinar el error total del procedimiento desarrollado, pues se conocen tanto las cargas (estáticas) reales (ya que se tiene el dato del peso estático del vehículo) como las dinámicas. Este error total del procedimiento de cálculo incluye una componente debida al error del equipo de pesaje dinámico y otra componente debida a las simplificaciones del método. De la muestra amplia de vehículos sólo puede calcularse la componente del error debida a las simplificaciones del procedimiento desarrollado, pues sólo se conocen las cargas dinámicas. En este caso se han comparado las cargas dinámicas reales, obtenidas restando la tara real de cada vehículo a su peso dinámico proporcionado por el sistema de pesaje, con las cargas dinámicas estimadas, obtenidas restando la tara estimada según el tipo de vehículo al peso dinámico.

De la comparación de las cargas reales con las cargas estimadas de los vehículos de ambas muestras, se pueden extraer las siguientes conclusiones:

1. En cuanto a la la carga transportada por cada vehículo individual, para un 60 $\%$ de los vehículos el error relativo de la estimación está dentro de un $\pm 20 \%$ de la carga real del vehículo, lo que entra dentro límites tolerables, pero existe un número apreciable de casos en que este error es muy grande, superando incluso el $100 \%$ del valor de la carga real. Esto último suele ocurrir cuando el valor de la carga real es muy pequeño, es decir, cuando el vehículo circula descargado, y también frecuentemente para vehículos rígidos de 2 ejes incluso cuando van cargados, lo que se debe a que en este tipo de vehículos la variabilidad de las taras es muy grande (con cualquier base de datos su desviación típica supera el 30\%), debido a que existen camiones de 2 ejes de tamaños muy diferentes.

Además, al realizar el análisis de sensibilidad del método, se ha comprobado que este error es muy difícil de evitar, pues no decrece apreciablemente ni mejorando la calibración del equipo de pesaje ni su calidad, que viene determinada por la dispersión de sus mediciones. Por tanto, esto invalidaría la aplicación del método para obtener la carga de cada vehículo individual.

2. Por otro lado, al estimar la carga total transportada por un cierto número de vehículos, que pueden llegar a ser todos los que constituyen el tráfico de una carretera durante un cierto periodo de tiempo (1 día, 1 semana, 1 mes, etc.), se ha cometido un error total que ha variado, según la base de datos de taras elegida, entre un $12 \%$ y un $15 \%$ en relación al valor de la carga real total transportada, lo que significa que este valor es bastante aceptable y permite su aplicación en la práctica. Esto queda confirmado si se tiene en cuenta que, eliminando la componente del error debida al equipo de pesaje dinámico (que, a pesor de su alto sesgo en el ensayo realizado en Trijueque, se puede cifrar en un 8\%), quedaría una componente del error debida a las simplificaciones o aproximaciones del 
método desarrollado, que podría cifrarse entre el $3 \%$ y el $6 \%$ del peso de la carga real total transportada.

Este resultado, unido a un análisis de sensibilidad realizado variando el valor de algunos parámetros que son muy difíciles de conocer con exactitud, permite asegurar que la estimación proporcionada por el método desarrollado mejoraría apreciablemente, acercándose el error total a estas cifras, si mejorara la calibración del sistema de pesaje.

Esta precisión del método podrá mantenerse siempre que el tráfico de vehículos pesados de la carretera tenga una composición mixta, típica de cualquier vía interurbana española. No obstante, si la carretera en cuestión está situada en una vía urbana o periurbana, este error podrá aumentar en cierta medida, al existir una mayor proporción de camiones de 2 ejes en el tráfico, pues en estos vehículos la precisión del método es menor. Este problema podría presentarse también en carreteras con un tráfico pesado muy diferente del tráfico promedio, como pueden ser las carreteras que son el origen o destino de canteras, obras o actividades mineras, y su resolución requeriría un estudio más pormenorizado de las taras de los vehículos presentes en la vía en cuestión.

Por eso, se ha estudiado la posibilidad de estimar las taras de los vehículos directamente de los resultados de los pesajes en la carretera, pues ello proporcionaría una estimación más exacta de la carga transportada total cuando los vehículos predominantes en una carretera tienen características diferentes de los de la media de la red. Para ello se ha seguido la metodología de un estudio al respecto realizado en Francia, que propone adoptar como valor medio de la tara de cada tipo de vehículos el peso medio de los vehículos cuyo peso registrado por el equipo de pesaje está por debajo del percentil 5 de la distribución de los pesos de todos los vehículos del tipo. Sin embargo, los resultados obtenidos en la comprobación con los datos de la muestra amplia tomada en Trijueque no han sido buenos, pues:

1. El percentil de pesos que habría que tomar para definir las taras de cada tipo de vehículo varía según el tipo particular de que se trate.

2. Para el tipo de vehículo más común, el articulado de 5 ejes, el peso medio de los vehículos por debajo del percentil 5 de los pesos registrados es muy superior a la tara media real del tipo, y lo que es peor, prácticamente ningún vehículo de ese tipo circulaba de vacío en ese punto de la A-2, lo que indicaría que no es posible estimar las taras de ese tipo de vehículo mediante los pesajes en la carretera.

Por último, en cuanto a la aplicación del pesaje dinámico a la determinación del efecto de las cargas sobre los firmes viarios, se ha realizado el cálculo del factor de equivalencia medio de los 30 vehículos de la muestra reducida del ensayo de Trijueque, utilizando, por un lado, los datos de los pesajes dinámicos y, por otro, los pesos obtenidos en los pesajes estáticos (es decir, los pesos reales), habiéndose obtenido con los pesajes dinámicos una sobreestimación del factor de equivalencia 
medio de un $18 \%$, tanto para un exponente $\alpha=4$ como para $\alpha=8$. Sin embargo, esta sobreestimación ha sido apreciablemente menor que la que predecía una fórmula teórica basada en los valores del sesgo y la dispersión de las medidas, lo que se ha debido a que la precisión conseguida en los pesajes de los vehículos más cargados, que son los que influyen en mayor medida en el valor concreto del coeficiente de equivalencia, ha sido mayor que en los vehículos descargados, aspecto que se suele cumplir siempre en los pesajes dinámicos.

\subsection{Principales aportaciones del estudio}

Las principales aportaciones de esta investigación para obtener un procedimiento enteramente automático para determinar la carga transportada por los vehículos pesados son las que se describen a continuación:

1. En cuanto al procedimiento de clasificación automatizada de los vehículos pesados, se ha realizado un estudio para ir más allá de las típicas clasificaciones automáticas, que se basan solamente en el número de ejes de cada vehículo y las distancias de separación entre cada dos ejes, con lo cual dan resultados erróneos cuando tratan de clasificar camiones que circulan con algún eje levantado del suelo. Para tratar de superar este obstáculo se ha introducido como parámetro adicional de clasificación el peso total del vehículo, que junto con un estudio más detallado de las distribuciones de los parámetros usuales (longitud del vehículo, separación entre cada dos ejes) y un conocimiento actualizado de cómo suelen circular los vehículos de transporte tanto cuando van cargados como cuando lo hacen de vacío, permiten mejorar la tasa de acierto de la clasificación automática de los camiones que llevan un eje levantado, asignándoles el tipo correcto en vez del tipo que señala el número de ejes apoyados en el pavimento.

2. En lo relativo al procedimiento mismo de determinación de la carga transportada, esta investigación ha permitido disponer de un método para estimar un dato fundamental para conocer el grado de aprovechamiento de los vehículos comerciales, que además sirve de indicativo de la actividad del transporte, cuya determinación automatizada sólo se había empezado a acometer en un par de estudios muy recientes (que datan de hace uno o dos años todo lo más), tal como se ha demostrado en la revisión bibliográfica.

Pero además, ha sido interesante la comparación de las fuentes o bases de datos de las taras de los vehículos, pues en ella se ha puesto de manifiesto las diferencias y peculiaridades cada una, que dependen a su vez de la forma de recoger la información de los vehículos. Así, en el Registro General de Vehículos de la Dirección General de Tráfico, se incluyen las taras de 
todos los vehículos del parque nacional, mientras que las taras proporcionadas por la Encuesta Permanente del Transporte de Mercancías por Carretera se refieren a los vehículos que realizan transporte interurbano y con una capacidad de carga a partir de $3.500 \mathrm{~kg}$ y con un peso bruto a partir de 6 toneladas, con lo cual se deja fuera los típicos vehículos de transporte urbano, como los utilizados en el reparto, para centrarse en los modelos de mayor tamaño presentes en el transporte interurbano.

3. En la aplicación del sistema de pesaje dinámico a la determinación de los efectos de las cargas sobre los firmes, se ha proporcionado un indicador del error que se comete al estimar el coeficiente de equivalencia de cada vehículo pesado en ejes tipo. Así, el error del sistema de pesaje en la determinación de los pesos por eje se magnifica al calcular los ejes equivalentes, debido a que estos dependen de una función exponencial de las cargas. Por otro lado, el error del sistema de pesaje en la determinación de las cargas se debe no sólo a una deficiente calibración de equipo de pesaje, que conlleva un sesgo en los datos proporcionados, sino también a la incertidumbre de las medidas, que tiene su causa en las cargas dinámicas provocadas por la excitación que ocasionan las irregularidades del pavimento en la suspensión del vehículo y que, por tanto, no se puede eliminar con una correcta calibración del equipo. Afortunadamente, según se ha obtenido en el ensayo de toma de datos en Trijueque, el error al determinar los ejes equivalentes parece ser algo menor que el que predicen las fórmulas teóricas, debido a que la precisión de los equipos de pesaje es mejor al medir el peso de los vehículos que circulan bastante cargados, que son los que influyen en mayor medida en los ejes equivalentes, debido a la ley exponencial de fatiga.

\subsection{Aplicabilidad de los resultados}

Las principales aplicaciones de los resultados de esta investigación tienen que ver con la ingeniería de tráfico, el transporte por carretera y el dimensionamiento de firmes viarios, y se explican de forma detallada a continuación:

1. Obtención de la clasificación automática de los vehículos que constituyen el tráfico pesado, que se puede utilizar no sólo para determinar la carga transportada, sino en otras muchas aplicaciones de todo el proceso de concepción (planificación y proyecto) y explotación de una carretera. Así, gracias a una determinación más exacta del número y tipos de los vehículos pesados que circulan por una carretera, se puede optimizar el número necesario de carriles en una vía, para que sea capaz de dar cabida al tráfico con el mejor nivel de servicio posible. Por otro lado, el conocimiento detallado de los tipos de vehículos más frecuentes sirve para un correcto dimensionamiento de algunos elementos viarios (incorporaciones, ramales de enlace, rotondas, giros, etc), mientras que la disposición en tiempo real de esta composición del tráfico posibilita una gestión optimizada de la 
circulación, pues se pueden tener en cuenta las prestaciones de cada tipo de vehículo para determinar su efecto en el flujo del tráfico. Por otro lado, el estudio de la participación de cada tipo de vehículo de transporte en el tráfico es un dato de gran importancia en estudios de economía de transporte, pues sirve para estimar de una manera más exacta los valores medios nacionales del coste de operación del transporte por carretera y permite estimar las proporciones de las diferentes categorías de transporte

2. La determinación del peso de la carga transportada por todos los vehículos que circulan por una carretera o que salen o entran a un puerto, aeropuerto, centro logístico, mercado central, etc., lo que permite conocer algunos indicativos fundamentales de la actividad económica y del transporte. Así, cuando se trata de una instalación terminal de mercancías, uno de los indicativos más utilizados es el total de toneladas que entran o salen de ese terminal (por ejemplo, uno de los indicadores de la importancia de un puerto es el total de toneladas transportadas a las que sirve de origen o destino). Cuando se trata de una autopista o carretera, el indicador son las toneladas transportadas multiplicadas por la distancia, es decir, las toneladas-km, que son uno de los datos utilizados para medir la actividad del sector del transporte por carretera.

3. La determinación del coeficiente de equivalencia medio de cada vehículo pesado en ejes tipo (de $13 \mathrm{t}$ o, de acuerdo con el límite de peso actual, de $11,5 \mathrm{t}$ ) sobre todos los vehículos pesados que circulan por la carretera durante las 24 horas del día, evitando el sesgo en los resultados debido a la evasión de vehículos sobrecargados por otras rutas cuando se realizan pesajes estáticos. Esto permite un dimensionamiento más ajustado de los firmes viarios que con los valores que resultarían de utilizar unos factores de equivalencia medios nacionales.

\subsection{Futuros desarrollos y líneas de investigación}

Una vez demostrada la aplicabilidad de este método para estimar las cargas transportadas por el conjunto de vehículos que circulan por una carretera, cabe exponer algunas sugerencias respecto a futuros trabajos que se podrían realizar con vistas a la confirmación y generalización de los resultados de esta Tesis:

1. Tal como se ha comentado, los datos obtenidos en la carretera con el sistema de pesaje dinámico utilizado han mostrado un sesgo muy alto (superior al 6\%), lo que unido a la poca precisión intrínseca del sistema de pesaje dinámico portátil, han empeorado los resultados obtenidos en la aplicación del procedimiento de estimación de las cargas transportadas. Es por ello por lo que convendría profundizar en esta investigación utilizando uno o varios sistemas de pesaje dinámico de instalación fija, que tienen una mayor precisión, en primer lugar porque el sensor no supone un resalto en 
el pavimento sino que está empotrado en él, y que, sobre todo, bien emplean sensores de tecnologías muy estables ante los cambios de temperatura, como los sensores de cuarzo, bien disponen de algoritmos de autocalibración (en función de ciertas características del tráfico pesado que permanecen estables), que permiten eliminar en gran medida el sesgo de los resultados de los pesajes. Todo ello, conduciría a un mejor ajuste del procedimiento.

2. Por otro lado, se están desarrollando nuevas técnicas de toma de datos que, funcionando conjuntamente con los sistemas de pesaje dinámico, no sólo permiten mejorar la clasificación de los vehículos, sino también identificar el tipo de chasis y de caja de los camiones, como podrían ser los sensores basados en lazos de inducción con una más alta frecuencia de registro, que permiten hallar la "huella inductiva" del vehículo, o ciertos sistemas de procesamiento de imágenes o de sensores por infrarrojos, que permiten captar los volúmenes y formas concretas de los vehículos. Esto posibilitaría utilizar el procedimiento para determinar no sólo el peso, sino para inferir el tipo de mercancía transportada (líquidos, graneles, troncos, vehículos, etc), lo que aumentaría el campo de aplicaciones del método.

3. Una mejora del propio método de estimación consistiría en incorporar la capacidad de obtener las taras medias de los vehículos directamente de los datos de los pesos suministrados por el equipo de pesaje dinámico en la carretera, pues esto permitiría obtener una estimación más exacta de las cargas transportadas en los casos en que el tipo de tráfico pesado de una carretera determinada se desviara apreciablemente de las características medias del tráfico en el conjunto de la red de carreteras de todo el país, como ocurre por ejemplo en las carreteras que son el origen o destino de ciertas actividades mineras. Como se ha comentado anteriormente, se han acometido algunos estudios para tratar de resolver esta cuestión (ambos descritos en el Apartado 4.4), pero los resultados de la comprobación que se ha realizado siguiendo el método propuesto en uno de ellos utilizando los datos obtenidos en el ensayo de Trijueque, han sido bastante malos. Por ello, se requeriría profundizar en estos estudios, de forma que pudieran adaptarse a los diversos tipos de pesado que circula por las carreteras españolas, pues ello permitiría una aplicación generalizada del procedimiento de estimación de las cargas transportadas desarrollado en esta Tesis a todo tipo de carreteras.

4. En especial, sería interesante profundizar en el conocimiento de las diversas categorías del tráfico de vehículos rígidos de 2 ejes, y en la forma de obtener una posible diferenciación entre los vehículos de los diferentes estratos que lo componen, es decir, de poder distinguir automáticamente entre los camiones y furgones pequeños de 2 ejes, dedicados al reparto, de los furgones pesados y otros camiones de 2 ejes que se sitúan en la banda superior del tipo, cuya MMA está cerca del límite superior de 18 t. En este sentido, en los últimos años han surgido sistemas de pesaje dinámico que 
disponen de sensores de peso situados en posición diagonal al sentido de marcha, lo que les hace capaces de distinguir entre los ejes de rueda gemela y los de rueda sencilla, que servirían para diferenciar los furgones y camiones ligeros de los pesados. Todo ello permitiría una mejora de la clasificación automatizada de los vehículos y una generalización del método de estimación de las cargas transportadas a entornos urbanos y periurbanos manteniendo el nivel de exactitud de las estimaciones de carga transportada. 


\section{Referencias}

1. Dirección General de Tráfico (2002). Tráfico, Circulación y Seguridad Vial, Vigésima primera edición. Madrid. Boletín Oficial del Estado, Textos Legales, 14, 2002. ISBN: 84-340-1343-6.

2. Dirección General de Tráfico (1986). Código de la Circulación, Decimoquinta edición. Madrid. Boletín Oficial del Estado, Colección Textos Legales, 14, 1986. ISBN: 84-340-0277-9.

3. Directiva 96/53/CE del Consejo, de 25 de julio de 1996, sobre las dimensiones máximas autorizadas en el tráfico nacional e internacional y los pesos máximos autorizados en el tráfico internacional. Diario Oficial de las Comunidades Europeas no L 235/59, del 17 de septiembre de 1996.

4. Dirección General de Carreteras (2003). Norma 6.1-IC Secciones de firme. (Orden FOM 3460/2003). Ministerio de Fomento.

5. Crespo, R. (1986). Caracterización del tráfico pesado en el dimensionamiento de firmes. El espectro de vehículos pesados en España, Cuadernos de Investigación, C15, CEDEX.

6. Hallenbeck, M. y Weinblatt, H. (2004). Equipment for collecting Traffic Load Data, NCHRP Report 509, Transportation Research Board, Washington D.C.

7. Huppert, W.(1965, agosto). Aplicación e instalación de los detectores de lazo. En: Traffic Engineering \& Control, Agosto de 1965 (traducción aparecida en el Boletín de Información del Laboratorio de Transporte y Mecánica del Suelo, no 40, Dic, 1965).

8. "Detector Technology". Chapter 2. "Emerging technology", Chapter 7. En Traffic Detector Handbook. 2nd Edition. Washington. Institute of Transportation Engineers (ITE), 1994, pp. 7-44 y 159-170.

9. Mimbela, L.E. y Klein, L.A. Summary of Vehicle Detection and Surveillance Technologies used in Intelligent Transportation Systems, The Vehicle Detector Clearinghouse, Sponsored in cooperation with the U.S. Department of Transportation, FHWA, 2000. (obtenido de http://www.nmsu.edu/-traffic/)

10. Management Committee of the COST 323 Action. COST 323 Weigh-in-Motion of Road Vehicles, Final report (1993-1998). Laboratoire Central des Ponts et Chausées, Paris, April, 2002. ISBN 2-7208-1598-5

11. ASTM (2002). ASTM E1318-02 Standard Specification for Highway Weigh-InMotion (WIM) Systems with User Requirements and Test Method. American Society of Testing of Materials (ASTM).

12. COST 323 Weigh-in-motion of Road vehicles (1999). European Specification on Weigh-in-Motion of Road Vehicles, EUCO-COST/323/8/99, LCPC, Paris.

13. OIML (2006). OIML R 134-1 Automatic instruments for weighing road vehicles in-motion and axle-load measuring. Part 1: Metrological and technical requirements - Tests. Edition 2006 (E). OIML (Organisation Internationale de Métrologie Légale). 
14. Stanczyk, D. et Jacob, B. (1998, 14/16 Septembre). Essai Europèen de systèmes de pesage en marche. Essai sur autoroute continentale (CMT), sur l'A-31. En Actes finaux de la 2ème Conference Européenne sur le pesage en marche des véhicules routiers (pp 411-420), Lisboa, ECSC-EEC-EAEC, EUR 18488. ISBN 92828-3678-9.

15. Leal, J. (2012, 4-7 de junio). Evaluation of several piezoelectric WIM Systems, En Proceedings of the International Conference on Weigh-In-Motion ICWIM6 (pp.218-227), Dallas: ISTE and John Wiley.

16. Blab, R., Jacob, B. and Schachhuber, P. (1998). Portable and Multiple-Sensor WIM systems trial (Trappes, June 1996), Final Report. COST (European Cooperation in the Scientific and Technical research) and ISTU (Institut für Starssenbau und Starssenerhaltung), November, 1998.

17. Lavric, I, Znidaric, A. and Kalin, J. (2008, 18-22 de mayo). Improving bridge-WIM results with better road eveness and advanced compensations. En Proceedings of the International Conference on Heavy Vehicles-Weigh-in-Motion (ICWIM 5) (pp. 283-296). París: ISTE and John Wiley.

18. Schmidt, F. and Jacob, B. (2012, 4-7 de junio). Experimentation of a bridge WIM system in France and applications to bridge monitoring and overload screening, En Proceedings of the International Conference on Weigh-In-Motion ICWIM6 (pp. 33-42). Dallas: ISTE and John Wiley.

19. Poulikakos, L. (2012). "Application of Weigh-In-Motion in Pavement Engineering. En Proceedings of the International Conference on Weigh-InMotion ICWIM6 (pp. 485-492), Dallas: ISTE and John Wiley, 2012.

20. Abbas, A. et al. (2014). Effect of Traffic Load Input Level on MechanisticEmpirical Pavement Design. Transportation Research Record, no. 2443: 63-77, TRB, Washington DC (doi: http://dx.doi.org/10.3141/2443-08).

21. Yousif et al. (2012). Evaluating the role of WIM in Mechanistic Pavement Analysis, En Proceedings of the International Conference on Weigh-In-Motion ICWIM6 (pp. 503-513), Dallas, ISTE and John Wiley.

22. Leal Bermejo, J., Pardillo Mayora, J. M. (2016). Aplicación del pesaje de vehículos en movimiento al dimensionamiento de firmes. Influencia de la precisión de los pesajes. Informes de la Construcción, 69(545): e181, eneromarzo 2017 (doi: http://dx.doi.org/10.3989/ic.16.054).

23. Znidaric, A. et al. (2008). Measurement of bridge dynamics with a bridge WIM system, En Proceedings of the International Conference on Heavy VehiclesWeigh-in-Motion (ICWIM 5), (pp. 485-498), Paris: ISTE and John Wiley.

24. Nowak, A. y Pakoczy, P. (2012). WIM-Based Simulation Model of Site Specific Live Load Effect on the Bridges. En Proceedings of the International Conference on Weigh-In-Motion (ICWIM6) (pp. 409-417): Dallas: ISTE and John Wiley.

25. O'Connor, A. and O'Brien, E. (2005). Traffic Load Modelling and factors influencing the accuracy of predicted extremes, Canadian Journal of Civil Engineering, Vol 32, no. 1, pp. 270-278, (DOI 10.1139/LO4-1992).

26. Burnos, P. (2012). Automatic Vehicle Classification for WIM Systems. En Proceedings of the International Conference on Weigh-In-Motion ICWIM6. Dallas: ISTE and John Wiley.

27. Kwigizile, V. (2004). Conectionist Approach to Developing Highway vehicles Classification Table for use in Florida. The Florida State University. Electronic 
Theses, Treatises and dissertations. Paper 3029.

(http://diginole.lib.fsu.edu/etd)

28. Doupal, E. y Calderara, R. (2008). Combined LS (Low Speed) and HS (High Speed) WIM systems for law enforcement and toll road applications. En Proceedings of the International Conference on Heavy Vehicles-Weigh-inMotion (ICWIM 5) (pp. 369-376), Paris: ISTE and John Wiley,

29. E. Doupal et al. (2012). One year WIM Direct Enforcement Experiences in Czech Republic. En Proceedings of the International Conference on Weigh-In-Motion (ICWIM6), (pp. 141-151), Dallas: ISTE and John Wiley.

30. Mactavish, D. y Neumann, D.L. (1982). Vehicle Classification Case Study for the Highway Performance Monitoring Systems. Federal Highway Administration. Washington DC, Estados Unidos, 1982-8.

31. Lyles, R.W. and Wyman, J. (1982). Evaluation of vehicle classification equipment, Federal Highway Administration, U.S. Department of Transportation. Extraído de https://babel.hathitrust.org/cgi/pt?view=image;size=100;id=ien.355560214062 28;page=root;seq=1, Transportation library of Northwestern University.

32. Wyman, J., Braley, G. y Stevens, R., (1985, enero). Field evaluation of FHWA Vehicle Classification Categories, Executive summary, Materials and Research, Technical Paper 84-5.

33. Hernandez, S., Tok, A, y Ritchie, S. (2013, August). Integration of Weigh-inMotion and Inductive Signature Technology for Advanced Truck Monitoring, Institute of Transportation Studies, University of California, Irvine (UCI-ITS_WP13-3).

34. Hernandez, S., Tok, A, y Ritchie, S. (2015). Multiple-Classifier Systems for Truck Body Classification at WIM Sites with Inductive Signature Data, En 94th Anual Meeting of the Transportation Research Board, Washington D.C., January 1115, 2015.

35. Hallenbeck, M. (1995). Quality assurance and automated error detection for WIM and AVC equipment in the long term pavement performance (LTTP) project. En First European Conference on weigh-in-motion of road vehicles (pp. 279-288). COST-ETH (Swiss Federal institute of Technology), Zürich, 8-10, March 1995.

36. Ackermann, G. et al. (2008). Current status of weigh-in-motion in Sub-Sahara Africa, En Proceedings of the International Conference on Heavy VehiclesWeigh-in-Motion (ICWIM 5) (pp. 57-67), Paris: ISTE and John Wiley.

37. Hallenbeck, M. (1995). Seasonal patterns of truck loads and volumes in the United States, En First European Conference on weigh-in-motion of road vehicles (pp. 121-129). COST-ETH (Swiss Federal institute of Technology), Zürich, 8-10, March 1995.

38. Luk, J. et al. (2010), A Method to Correlate Weigh-in-Motion and Classification Data, Austroads, Publication No. AP-T161/10. Sydney , Autralia.

39. Leal, J. (2008). Weigh-in-motion measurements in the national road network of Spain during the 2000-2003 period. Data collection procedure and main results. En Proceedings of the International Conference on Heavy Vehicles-Weigh-inMotion (ICWIM 5) (pp.71-84). París: ISTE and John Wiley. 
40. Schmidt, F., Jacob, J. y Domprobst, F. (2016) Investigation of Truck Weight and Dimensions using WIM Data, En Proceedings of 6th Transport Research Arena. Warsaw, Poland, April 18-21, 2016.

41. Hernandez, S. (2017). Estimation of Average Payloads from Weigh-in-Motion Data, Transportation Research Record: Journal of the Transportation Research Board, No. 2644, 2017, pp. 39-47. (http://dx.doi.org/10.3141/2644-05).

42. Glover, M., Newton, W. (1991). Evaluation of a Multiple-sensor Weigh-InMotion System, TRRL Research Report 307. Transport and Road Research Laboratory, Crowthorne (UK).

43. Ma, S. y Caprez, M. (1995, 8-10 de marzo). The pavement roughness requirement for weigh-in-motion. En First European Conference on Weigh-inMotion of Road Vehicles. Zurich: COST-ETH (Swiss Federal Institute of Technology).

44. Marcos, C. y Rebollo, M. D. (1999, 14-16 de diciembre). Encuesta Permanente del Transporte de Mercancías por carretera", En Jornada sobre Auscultación y Toma de datos para Planificación y Gestión de Carreteras. Asociación Técnica de Carreteras, Cáceres, 2000.

45. Catálogo de vehículos industriales, carrocerías e industria de equipos componentes. Transporte Profesional, Catálogo 2017, BGO Editores S.L., no 369, 2016.

46. Bevington, P. and Robinson, D. Data reduction and error analysis for the physical sciences, Second edition, WCB- McGraw-Hill, 1992.

47. Sanchez del Río, C. Análisis de errores, EUDEMA (Ediciones de la Universidad Complutense), Madrid, 1989.

48. Davies, V. y Hathaway, P.J. (1998, 14-16 de septiembre). Étude de données de pesage en marche en Angleterre. En Actes finaux de la 2ème Conference Européenne sur le pesage en marche des véhicules routiers (pp. 65-72), Lisboa : ECSC-EEC-EAEC, EUR 18488. ISBN 92-828-3678-9.

49. Management Committee of the COST 323 Action (2002). Pavement Applications. En COST 323 Weigh-in-Motion of Road Vehicles, Final report (1993-1998) (pp. 29-52). París: Laboratoire Central des Ponts et Chaussées.

50. AASTHO (2008). Mechanistic-Empirical Pavement Design Guide. Interim Edition: A Manual of Practice. American Association of State Highway and Transportation Officials (AASTHO). Estados Unidos. http://onlinepubs.trb.org/onlinepubs/archive/mepdg/2appendices AA.pdf.

51. Haider, S. W. et al. (2010). Effect of Axle Load Measurement Errors on Pavement Performance and Design Reliability. Transportation Research Record 2160: 107-117. Doi: http://dx.doi.org/103141/2160-12.

52. Tarefder, R., Rodríguez-Ruiz J.I. (2013). WIM data quality and its influence on predicted pavement performance. Transportation Letters -The International Journal of Transportation Research, 5(3): 154-163. doi: http://dx.doi.org/10.1179/1942786713Z.00000000017 


\section{ANEJO 1}

DATOS REGISTRADOS DE LA MUESTRA AMPLIA DE VEHÍCULOS 
1. Datos registrados automáticamente por el sistema de pesaje dinámico

\section{Leyenda}

- No: número de secuencia

- Date: Fecha de paso

- Time : hora-minuto-segundo de paso

- Lne: Carril

- AW: peso del eje (axle weight)

- GVM : Peso total del vehículo (Gross vehicle mass)

- AD: distancia entre ejes (axle distance)

- SPD: Velocidad

- Leng: Longitud

- ESAL: $\mathrm{n}$ - de ejes equivalentes de 8,2 $\mathrm{t}$ 


\begin{tabular}{|c|c|c|c|c|c|c|c|c|c|c|c|c|c|c|c|c|c|}
\hline Date & & Time & Lne & AW1 & AW2 & AW3 & AW4 & AW5 & GVM & AD1 & AD2 & AD3 & AD4 & SPD & LENG & $C L$ & ESAL \\
\hline 519 & 150615 & 165217 & 1 & 6,2 & 7,5 & 3,1 & 3,3 & 3,4 & 23,5 & 3,8 & 6,0 & 1,2 & 1,3 & 91 & 17,4 & 4 & 1.08 \\
\hline 524 & 150615 & 165259 & 1 & 6,6 & 12,5 & 6,2 & 6,1 & 6,4 & 37,8 & 3,9 & 5,9 & 1,3 & 1,2 & 91 & 17,4 & 4 & 5.69 \\
\hline 529 & 150615 & 165412 & 1 & 6,0 & 12,1 & 6,6 & 6,9 & 6,6 & 38,2 & 3,8 & 5,9 & 1,3 & 1,3 & 91 & 16,5 & 4 & 5.26 \\
\hline 533 & 150615 & 165427 & 1 & 5,5 & 6,6 & 2,9 & 3,4 & & 18,4 & 4,2 & 7,3 & 1,3 & & 87 & 17,4 & 4 & 0.65 \\
\hline 540 & 150615 & 165509 & 1 & 6,8 & 11,9 & 8,0 & 7,7 & 8,1 & 42,5 & 3,9 & 5,2 & 1,3 & 1,2 & 91 & 14,8 & 4 & 5.96 \\
\hline 541 & 150615 & 165520 & 1 & 6,0 & 6,7 & 3,1 & 3,3 & 2,1 & 21,2 & 3,9 & 5,7 & 1,3 & 1,3 & 91 & 16,7 & 4 & 0.76 \\
\hline 549 & 150615 & 165606 & 1 & 6,6 & 11,5 & 6,4 & 6,8 & 7,0 & 38,3 & 3,8 & 6,0 & 1,3 & 1,2 & 91 & 17,0 & 4 & 4.75 \\
\hline 558 & 150615 & 165701 & 1 & 7,3 & 14,1 & 4,7 & 4,3 & 4,3 & 34,7 & 3,7 & 6,0 & 1,3 & 1,3 & 90 & 17,5 & 4 & 7.68 \\
\hline 564 & 150615 & 165742 & 1 & 1,2 & 2,6 & & & & 3,8 & 3,6 & & & & 95 & 7,0 & 5 & 0.01 \\
\hline 577 & 150615 & 165924 & 1 & 5,6 & 8,7 & 4,2 & 3,8 & 3,3 & 25,6 & 3,8 & 6,0 & 1,3 & 1,3 & 89 & 17,2 & 4 & 1.56 \\
\hline 590 & 150615 & 170145 & 1 & 6,1 & 11,1 & 6,3 & 6,4 & 7,1 & 37,0 & 4,1 & 5,9 & 1,2 & 1,3 & 86 & 16,1 & 4 & 4.16 \\
\hline 596 & 150615 & 170237 & 1 & 6,1 & 10,8 & 3,0 & 3,0 & 3,0 & 25,9 & 4,1 & 5,9 & 1,2 & 1,3 & 88 & 16,3 & 4 & 3.19 \\
\hline 611 & 150615 & 170351 & 1 & 6,6 & 7,0 & 3,6 & 3,4 & & 20,6 & 3,6 & 6,1 & 1,2 & & 84 & 13,9 & 4 & 1.01 \\
\hline 634 & 150615 & 170647 & 1 & 6,2 & 9,9 & 9,1 & 8,3 & 8,4 & 41,9 & 3,8 & 3,2 & 1,3 & 1,3 & 92 & 12,4 & 4 & 4.46 \\
\hline 635 & 150615 & 170714 & 1 & 6,8 & 12,5 & 7,1 & 7,1 & 7,1 & 40,6 & 3,7 & 4,7 & 1,3 & 1,3 & 87 & 14,7 & 4 & 6.13 \\
\hline 655 & 150615 & 171045 & 1 & 4,6 & 8,9 & & & & 13,5 & 4,0 & & & & 91 & 7,4 & 3 & 1.49 \\
\hline 657 & 150615 & 171052 & 1 & 5,8 & 6,6 & 3,4 & 4,1 & & 19,9 & 4,0 & 7,6 & 1,3 & & 90 & 17,7 & 5 & 0.73 \\
\hline 674 & 150615 & 171334 & 1 & 6,0 & 8,2 & 4,0 & 4,8 & 4,8 & 27,8 & 3,9 & 6,3 & 1,3 & 1,3 & 91 & 17,9 & 4 & 1.45 \\
\hline 677 & 150615 & 171401 & 1 & 6,4 & 11,9 & 8,1 & 8,8 & 8,5 & 43,7 & 3,9 & 3,1 & 1,3 & 1,3 & 92 & 12,6 & 4 & 6.28 \\
\hline 682 & 150615 & 171429 & 1 & 6,7 & 12,4 & 4,8 & 4,5 & & 28,4 & 4,2 & 7,1 & 1,3 & & 91 & 17,3 & 5 & 5.16 \\
\hline 683 & 150615 & 171436 & 1 & 6,7 & 13,5 & 4,1 & 4,0 & 4,2 & 32,5 & 3,7 & 6,1 & 1,3 & 1,3 & 90 & 17,3 & 4 & 6.57 \\
\hline 695 & 150615 & 171611 & 1 & 6,2 & 10,3 & 3,9 & 4,2 & 3,9 & 28,5 & 4,0 & 6,2 & 1,3 & 1,3 & 92 & 17,6 & 4 & 2.82 \\
\hline 696 & 150615 & 171614 & 1 & 6,8 & 8,6 & 3,8 & 3,8 & 3,8 & 26,8 & 3,9 & 5,7 & 1,3 & 1,3 & 93 & 16,5 & 4 & 1.78 \\
\hline 697 & 150615 & 171627 & 1 & 5,8 & 10,7 & 7,7 & 8,4 & 8,5 & 41,1 & 4,0 & 3,6 & 1,3 & 1,4 & 92 & 13,4 & 4 & 4.71 \\
\hline 699 & 150615 & 171638 & 1 & 6,6 & 11,8 & 6,5 & 6,4 & 6,2 & 37,5 & 3,8 & 6,0 & 1,2 & 1,3 & 90 & 16,3 & 4 & 4.92 \\
\hline
\end{tabular}




\begin{tabular}{|c|c|c|c|c|c|c|c|c|}
\hline 700 & 150615 & 171640 & 1 & 6,1 & 10,2 & 5,8 & 5,7 & 5,8 \\
\hline 5184 & 150616 & 100731 & 1 & 3,9 & 6,3 & & & \\
\hline 5187 & 150616 & 100801 & 1 & 6,8 & 12,3 & 7,1 & 6,8 & 7,2 \\
\hline 5193 & 150616 & 100858 & 1 & 7,4 & 11,9 & 3,9 & 3,8 & 4,2 \\
\hline 5208 & 150616 & 101053 & 1 & 5,8 & 9,7 & 5,3 & 5,4 & 5,8 \\
\hline 5215 & 150616 & 101220 & 1 & 6,4 & 9,1 & 3,8 & 3,9 & 3,9 \\
\hline 5217 & 150616 & 101251 & 1 & 6,9 & 8,9 & 8,0 & 7,6 & 7,7 \\
\hline 5218 & 150616 & 101259 & 1 & 6,1 & 10,5 & 7,3 & 7,4 & 7,8 \\
\hline 5219 & 150616 & 101304 & 1 & 6,6 & 11,1 & 5,5 & 5,4 & 5,8 \\
\hline 5220 & 150616 & 101312 & 1 & 6,8 & 9,4 & 7,0 & 7,3 & 7,9 \\
\hline 5221 & 150616 & 101331 & 1 & 5,8 & 13,2 & 5,6 & 5,8 & 5,8 \\
\hline 5229 & 150616 & 101438 & 1 & 6,9 & 11,1 & 7,0 & 7,0 & \\
\hline 5233 & 150616 & 101504 & 1 & 6,6 & 13,0 & 7,0 & 6,8 & 7,0 \\
\hline 5246 & 150616 & 101731 & 1 & 6,0 & 9,7 & 7,3 & 7,2 & 7,1 \\
\hline 5247 & 150616 & 101734 & 1 & 6,5 & 10,3 & 4,4 & 4,1 & 4,4 \\
\hline 5251 & 150616 & 101800 & 1 & 5,5 & 9,1 & & & \\
\hline 5252 & 150616 & 101819 & 1 & 6,5 & 11,2 & 6,6 & 6,4 & 7,0 \\
\hline 5260 & 150616 & 101932 & 1 & 6,5 & 13,2 & 6,1 & 6,9 & 6,4 \\
\hline 5264 & 150616 & 102008 & 1 & 6,4 & 14,7 & 6,6 & 6,2 & 6,2 \\
\hline 5268 & 150616 & 102027 & 1 & 5,8 & 10,0 & 8,1 & 8,2 & 7,9 \\
\hline 5270 & 150616 & 102041 & 1 & 6,3 & 11,8 & 6,0 & 6,9 & 7,4 \\
\hline 5271 & 150616 & 102054 & 1 & 6,5 & 9,2 & 2,8 & 2,8 & 2,6 \\
\hline 5282 & 150616 & 102220 & 1 & 7,1 & 14,7 & 6,0 & 6,0 & 6,6 \\
\hline 5290 & 150616 & 102306 & 1 & 6,2 & 10,6 & 2,6 & 2,6 & 2,7 \\
\hline 5291 & 150616 & 102309 & 1 & 6,3 & 12,5 & 6,2 & 7,1 & 7,0 \\
\hline 5293 & 150616 & 102325 & 1 & 7,1 & 11,2 & 6,5 & & \\
\hline
\end{tabular}

\begin{tabular}{|c|c|c|c|c|}
\hline 33,6 & 3,7 & 5,8 & 1,3 & 1,3 \\
\hline 10,2 & 5,4 & & & \\
\hline 40,2 & 3,7 & 5,9 & 1,3 & 1,3 \\
\hline 31,2 & 3,7 & 6,0 & 1,2 & 1,2 \\
\hline 32,0 & 3,8 & 6,1 & 1,3 & 1,2 \\
\hline 27,1 & 3,7 & 5,9 & 1,2 & 1,2 \\
\hline 39,1 & 3,9 & 6,0 & 1,3 & 1,3 \\
\hline 39,1 & 3,7 & 5,2 & 1,2 & 1,3 \\
\hline 34,4 & 3,8 & 5,9 & 1,2 & 1,3 \\
\hline 38,4 & 4,0 & 5,2 & 1,3 & 1,2 \\
\hline 36,2 & 3,8 & 6,1 & 1,2 & 1,3 \\
\hline 32,0 & 5,6 & 7,8 & 1,5 & \\
\hline 40,4 & 3,6 & 6,1 & 1,3 & 1,3 \\
\hline 37,3 & 3,7 & 4,4 & 1,3 & 1,3 \\
\hline 29,7 & 4,2 & 5,9 & 1,3 & 1,2 \\
\hline 14,6 & 5,5 & & & \\
\hline 37,7 & 3,6 & 6,1 & 1,3 & 1,2 \\
\hline 39,1 & 3,7 & 5,9 & 1,2 & 1,3 \\
\hline 40,1 & 3,7 & 5,4 & 1,2 & 1,3 \\
\hline 40,0 & 3,7 & 3,0 & 1,2 & 1,3 \\
\hline 38,4 & 3,7 & 6,0 & 1,3 & 1,2 \\
\hline 23,9 & 3,7 & 5,8 & 1,3 & 1,3 \\
\hline 40,4 & 3,6 & 5,8 & 1,2 & 1,2 \\
\hline 24,7 & 4,0 & 5,7 & 1,2 & 1,2 \\
\hline 39,1 & 3,5 & 5,9 & 1,2 & 1,2 \\
\hline 24,8 & 5,2 & 1,2 & & \\
\hline
\end{tabular}

CL ESAL 


$\begin{array}{rrrrrrrrr}5302 & 150616 & 102448 & 1 & 6,2 & 10,7 & 6,3 & 7,2 & 7,4 \\ 5303 & 150616 & 102502 & 1 & 6,3 & 11,0 & 5,5 & 5,6 & 5,0 \\ 5311 & 150616 & 102601 & 1 & 6,1 & 7,8 & 4,3 & 4,5 & 4,7 \\ 5312 & 150616 & 102617 & 1 & 6,0 & 12,2 & 7,1 & 6,7 & 7,0 \\ 5313 & 150616 & 102641 & 1 & 7,3 & 9,8 & 5,8 & 5,9 & 7,9 \\ 5320 & 150616 & 102710 & 1 & 6,9 & 11,5 & 6,4 & 6,0 & 6,4 \\ 5321 & 150616 & 102716 & 1 & 6,5 & 10,4 & 2,7 & 2,4 & 3,0 \\ 5324 & 150616 & 102729 & 1 & 6,8 & 14,2 & 5,5 & 6,3 & 6,5 \\ 5325 & 150616 & 102757 & 1 & 5,8 & 7,8 & 4,6 & 4,9 & 4,7 \\ 5331 & 150616 & 102951 & 1 & 6,5 & 12,6 & 6,6 & 6,9 & 6,5 \\ 5337 & 150616 & 103038 & 1 & 5,6 & 8,5 & 3,7 & 3,7 & 3,8 \\ 5341 & 150616 & 103106 & 1 & 8,8 & 9,7 & 5,5 & & \\ 5343 & 150616 & 103132 & 1 & 6,3 & 11,3 & 6,5 & 6,6 & 6,9 \\ 5350 & 150616 & 103224 & 1 & 6,4 & 12,1 & 6,6 & 6,9 & 6,6 \\ 5351 & 150616 & 103256 & 1 & 6,7 & 11,2 & 5,5 & 5,5 & 5,5 \\ 5355 & 150616 & 103317 & 1 & 6,4 & 9,2 & 3,3 & 3,3 & 3,3 \\ 5362 & 150616 & 103424 & 1 & 6,1 & 8,1 & 4,4 & 4,6 & 4,5 \\ 5364 & 150616 & 103438 & 1 & 5,8 & 7,2 & 3,1 & 2,9 & 3,0 \\ 5365 & 150616 & 103451 & 1 & 5,9 & 11,4 & 5,9 & 6,2 & 5,9 \\ 5366 & 150616 & 103515 & 1 & 6,4 & 12,5 & 7,9 & 7,6 & 7,2 \\ 5369 & 150616 & 103544 & 1 & 6,6 & 8,9 & 4,3 & 4,2 & 4,4 \\ 5379 & 150616 & 103703 & 1 & 5,9 & 7,0 & 3,1 & 2,6 & 2,9 \\ 5381 & 150616 & 103713 & 1 & 6,6 & 12,8 & 6,0 & 6,2 & 6,3 \\ 5390 & 150616 & 103815 & 1 & 6,0 & 5,7 & 2,4 & 1,5 & 2,1 \\ 5395 & 150616 & 103843 & 1 & 4,4 & 4,9 & & & \\ 5401 & 150616 & 103922 & 1 & 6,2 & 10,6 & 6,9 & 6,6 & 7,8\end{array}$

\begin{tabular}{|c|c|c|c|c|}
\hline 37,8 & 3,7 & 4,7 & 1,2 & 1,3 \\
\hline 33,4 & 4,1 & 6,0 & 1,3 & 1,2 \\
\hline 27,4 & 3,8 & 5,9 & 1,3 & 1,2 \\
\hline 39,0 & 3,8 & 5,9 & 1,3 & 1,3 \\
\hline 36,7 & 3,7 & 6,2 & 1,3 & 1,2 \\
\hline 37,2 & 3,8 & 5,8 & 1,3 & 1,3 \\
\hline 25,0 & 3,8 & 5,8 & 1,3 & 1,3 \\
\hline 39,3 & 3,8 & 6,3 & 1,3 & 1,2 \\
\hline 27,8 & 3,6 & 6,0 & 1,3 & 1,3 \\
\hline 39,1 & 3,6 & 5,8 & 1,3 & 1,2 \\
\hline 25,3 & 3,8 & 5,8 & 1,2 & 1,3 \\
\hline 24,0 & 4,8 & 1,3 & & \\
\hline 37,6 & 3,8 & 6,0 & 1,2 & 1,2 \\
\hline 38,6 & 4,1 & 5,8 & 1,2 & 1,2 \\
\hline 34,4 & 3,8 & 5,8 & 1,3 & 1,2 \\
\hline 25,5 & 3,8 & 5,8 & 1,2 & 1,2 \\
\hline 27,7 & 3,6 & 5,7 & 1,3 & 1,3 \\
\hline 22,0 & 3,6 & 6,1 & 1,3 & 1,2 \\
\hline 35,3 & 3,8 & 4,4 & 1,2 & 1,3 \\
\hline 41,6 & 3,8 & 5,1 & 1,2 & 1,2 \\
\hline 28,4 & 3,8 & 5,7 & 1,2 & 1,2 \\
\hline 21,5 & 3,7 & 6,2 & 1,3 & 1,2 \\
\hline 37,9 & 3,8 & 6,0 & 1,2 & 1,3 \\
\hline 17,7 & 3,8 & 5,6 & 1,3 & 1,3 \\
\hline 9,3 & 4,0 & & & \\
\hline 38,1 & 3,8 & 4,7 & 1,3 & 1,3 \\
\hline
\end{tabular}

$\begin{array}{rrrr}88 & 15,1 & 4 & 3.98 \\ 90 & 16,5 & 4 & 3.69 \\ 88 & 17,2 & 4 & 1.28 \\ 90 & 17,4 & 4 & 5.49 \\ 89 & 17,8 & 4 & 3.33 \\ 90 & 16,4 & 4 & 4.64 \\ 86 & 17,1 & 4 & 2.92 \\ 90 & 16,5 & 4 & 8.05 \\ 86 & 16,6 & 4 & 1.25 \\ 85 & 16,4 & 4 & 5.96 \\ 88 & 16,4 & 4 & 1.45 \\ 90 & 9,7 & 3 & 2.36 \\ 87 & 16,5 & 4 & 4.43 \\ 86 & 16,2 & 4 & 5.35 \\ 89 & 16,7 & 4 & 4.02 \\ 87 & 16,1 & 4 & 2.00 \\ 88 & 16,3 & 4 & 1.41 \\ 89 & 16,2 & 4 & 0.88 \\ 77 & 14,3 & 4 & 4.20 \\ 86 & 15,2 & 4 & 6.31 \\ 89 & 16,4 & 4 & 1.94 \\ 90 & 17,0 & 4 & 0.83 \\ 91 & 16,8 & 4 & 6.04 \\ 86 & 14,8 & 4 & 0.53 \\ 81 & 7,3 & 3 & 0.19 \\ 85 & 14,1 & 4 & 3.96 \\ & & & \\ 89\end{array}$




\begin{tabular}{|c|c|c|c|c|c|c|c|c|}
\hline 5402 & 150616 & 103935 & 1 & 6,5 & 8,6 & 3,2 & 3,0 & \\
\hline 5412 & 150616 & 104040 & 1 & 1,8 & 3,9 & & & \\
\hline 5415 & 150616 & 104101 & 1 & 6,7 & 14,0 & 5,7 & 5,5 & 5,4 \\
\hline 5423 & 150616 & 104139 & 1 & 6,9 & 12,4 & 6,7 & 6,8 & 6,9 \\
\hline 5425 & 150616 & 104152 & 1 & 6,3 & 8,4 & 4,2 & 3,8 & 4,0 \\
\hline 5429 & 150616 & 104226 & 1 & 6,5 & 11,7 & 7,9 & 8,4 & 8,3 \\
\hline 5433 & 150616 & 104252 & 1 & 5,5 & 5,3 & 3,1 & 3,0 & \\
\hline 5437 & 150616 & 104314 & 1 & 6,0 & 10,3 & 7,3 & 5,4 & 5,5 \\
\hline 5438 & 150616 & 104330 & 1 & 6,7 & 11,1 & 6,0 & 5,5 & 6,4 \\
\hline 5444 & 150616 & 104422 & 1 & 6,1 & 5,5 & 11,9 & 7,5 & \\
\hline 5450 & 150616 & 104510 & 1 & 6,2 & 7,6 & 3,2 & 3,5 & 3,5 \\
\hline 5452 & 150616 & 104520 & 1 & 7,3 & 13,0 & 5,4 & 5,5 & 5,8 \\
\hline 5457 & 150616 & 104613 & 1 & 6,4 & 6,9 & 2,9 & 2,6 & 3,6 \\
\hline 5459 & 150616 & 104630 & 1 & 6,4 & 14,1 & 4,4 & 3,8 & 4,3 \\
\hline 5470 & 150616 & 104755 & 1 & 6,5 & 11,1 & 8,4 & 8,3 & 7,9 \\
\hline 5471 & 150616 & 104810 & 1 & 6,0 & 11,6 & 6,9 & 7,2 & 6,8 \\
\hline 5472 & 150616 & 104817 & 1 & 6,2 & 11,5 & 6,1 & 9,0 & 6,5 \\
\hline 5474 & 150616 & 104850 & 1 & 6,9 & 8,5 & & & \\
\hline 5475 & 150616 & 104901 & 1 & 6,6 & 12,3 & 7,1 & 7,4 & 7,5 \\
\hline 5481 & 150616 & 105009 & 1 & 5,4 & 5,5 & 5,3 & 4,5 & 4,8 \\
\hline 5486 & 150616 & 105029 & 1 & 6,2 & 12,5 & 5,6 & 5,7 & 6,0 \\
\hline 5493 & 150616 & 105121 & 1 & 6,4 & 11,0 & 4,8 & 5,0 & 4,9 \\
\hline 5496 & 150616 & 105136 & 1 & 6,5 & 11,4 & 8,2 & 7,5 & 7,8 \\
\hline 5498 & 150616 & 105143 & 1 & 6,9 & 11,8 & 7,0 & 6,9 & 7,2 \\
\hline 5508 & 150616 & 105252 & 1 & 6,4 & 8,5 & 3,5 & 3,4 & 3,6 \\
\hline 5511 & 150616 & 105318 & 1 & 3,9 & 5,5 & & & \\
\hline
\end{tabular}

$\begin{array}{rrrrr}21,3 & 3,8 & 7,3 & 1,3 & \\ 5,7 & 4,2 & & & \\ 37,3 & 3,8 & 6,1 & 1,2 & 1,2 \\ 39,7 & 3,8 & 5,7 & 1,3 & 1,2 \\ 26,7 & 3,7 & 5,9 & 1,2 & 1,3 \\ 42,8 & 3,8 & 6,0 & 1,2 & 1,3 \\ 16,9 & 4,0 & 6,1 & 1,3 & \\ 34,5 & 4,2 & 5,0 & 1,3 & 1,3 \\ 35,7 & 3,8 & 5,9 & 1,3 & 1,2 \\ 31,0 & 1,9 & 4,0 & 1,3 & \\ 24,0 & 4,1 & 5,9 & 1,3 & 1,2 \\ 37,0 & 3,9 & 5,9 & 1,3 & 1,2 \\ 22,4 & 3,8 & 6,0 & 1,3 & 1,3 \\ 33,0 & 4,2 & 6,0 & 1,3 & 1,3 \\ 42,2 & 3,7 & 3,1 & 1,2 & 1,3 \\ 38,5 & 4,1 & 2,9 & 1,3 & 1,3 \\ 39,3 & 3,8 & 3,6 & 1,3 & 1,2 \\ 15,4 & 6,4 & & & \\ 40,9 & 3,8 & 5,0 & 1,3 & 1,3 \\ 31,0 & 3,3 & 1,3 & 6,6 & 1,3 \\ 36,0 & 3,6 & 6,1 & 1,3 & 1,3 \\ 32,1 & 3,6 & 6,0 & 1,2 & 1,3 \\ 41,4 & 3,8 & 4,7 & 1,3 & 1,3 \\ 39,8 & 3,6 & 5,2 & 1,3 & 1,2 \\ 25,4 & 3,9 & 6,0 & 1,3 & 1,3 \\ 9,4 & 4,8 & & & \\ 5,5 & & & & \\ & & & \\ 34,3 & \end{array}$

\begin{tabular}{|c|c|c|c|c|}
\hline & 89 & 17,4 & 4 & 1.65 \\
\hline & 89 & 7,9 & 5 & 0.05 \\
\hline & 85 & 17,0 & 4 & 7.54 \\
\hline & 93 & 16,9 & 4 & 5.89 \\
\hline & 88 & 16,9 & 4 & 1.55 \\
\hline & 90 & 17,1 & 4 & 5.86 \\
\hline & 88 & 15,1 & 4 & 0.38 \\
\hline & 86 & 15,8 & 4 & 3.19 \\
\hline & 91 & 17,4 & 4 & 4.07 \\
\hline & 88 & 11,5 & 3 & 3.16 \\
\hline & 88 & 16,6 & 4 & 1.13 \\
\hline & 90 & 17,3 & 4 & 6.32 \\
\hline & 90 & 17,0 & 4 & 0.91 \\
\hline & 88 & 16,6 & 4 & 7.38 \\
\hline & 89 & 12,1 & 4 & 5.24 \\
\hline & 88 & 12,0 & 4 & 4.83 \\
\hline & 91 & 12,6 & 4 & 4.89 \\
\hline & 86 & 9,4 & 5 & 1.69 \\
\hline & 87 & 14,6 & 4 & 5.97 \\
\hline 1,3 & 90 & 17,0 & 4 & 0.61 \\
\hline & 87 & 16,1 & 4 & 5.43 \\
\hline & 84 & 16,9 & 4 & 3.61 \\
\hline & 90 & 13,9 & 4 & 5.26 \\
\hline & 88 & 15,2 & 4 & 5.31 \\
\hline & 90 & 17,0 & 4 & 1.60 \\
\hline & 90 & 8,6 & 5 & 0.23 \\
\hline
\end{tabular}




$\begin{array}{rrrrrrrrr}5524 & 150616 & 105534 & 1 & 6,7 & 11,8 & 6,3 & 6,8 & 6,7 \\ 5529 & 150616 & 105617 & 1 & 5,8 & 8,9 & & & \\ 5531 & 150616 & 105626 & 1 & 7,5 & 10,4 & & & \\ 5538 & 150616 & 105710 & 1 & 7,1 & 12,6 & 7,0 & 6,8 & 7,5 \\ 5540 & 150616 & 105804 & 1 & 5,4 & 8,9 & 3,5 & 3,1 & 2,7 \\ 5544 & 150616 & 105820 & 1 & 7,0 & 13,2 & 6,2 & 6,5 & 6,3 \\ 5547 & 150616 & 105845 & 1 & 6,3 & 9,3 & 5,2 & 5,0 & 5,3 \\ 5552 & 150616 & 105956 & 1 & 5,9 & 12,8 & 6,5 & 6,5 & 7,1 \\ 5554 & 150616 & 110024 & 1 & 5,7 & 7,0 & 4,8 & 4,5 & \\ 5556 & 150616 & 110039 & 1 & 5,9 & 10,8 & 6,2 & 6,2 & 6,5 \\ 5562 & 150616 & 110212 & 1 & 5,0 & 6,9 & & & \\ 5570 & 150616 & 110331 & 1 & 6,3 & 10,2 & 2,5 & 2,4 & 2,8 \\ 5577 & 150616 & 110423 & 1 & 5,4 & 7,1 & & & \\ 5581 & 150616 & 110450 & 1 & 6,0 & 9,4 & 4,8 & 4,2 & 4,5 \\ 5583 & 150616 & 110504 & 1 & 6,9 & 12,4 & 7,2 & 7,0 & 6,9 \\ 5591 & 150616 & 110552 & 1 & 5,7 & 7,0 & 4,1 & 4,2 & 3,8 \\ 5601 & 150616 & 110739 & 1 & 6,0 & 6,5 & 3,3 & 3,1 & 3,2 \\ 5614 & 150616 & 110908 & 1 & 6,7 & 13,0 & 6,2 & 5,7 & 6,4 \\ 5624 & 150616 & 111023 & 1 & 6,0 & 8,6 & 4,0 & 4,3 & 4,4 \\ 5629 & 150616 & 111050 & 1 & 5,9 & 11,2 & 7,0 & 7,1 & 6,7 \\ 5631 & 150616 & 111105 & 1 & 6,1 & 8,3 & 3,5 & 3,7 & 3,9 \\ 5636 & 150616 & 111215 & 1 & 5,8 & 8,1 & 2,8 & 2,3 & 3,0 \\ 5640 & 150616 & 111312 & 1 & 4,9 & 7,1 & & & \\ 5641 & 150616 & 111320 & 1 & 6,4 & 12,4 & 7,9 & 8,0 & 7,7 \\ 5649 & 150616 & 111431 & 1 & 6,3 & 8,5 & 4,4 & 4,7 & 5,2 \\ 5653 & 150616 & 111457 & 1 & 6,5 & 10,5 & 4,0 & 3,6 & 3,9\end{array}$

\begin{tabular}{|c|c|c|c|c|}
\hline 38,3 & 3,8 & 6,0 & 1,3 & 1,3 \\
\hline 14,7 & 5,6 & & & \\
\hline 17,9 & 6,3 & & & \\
\hline 41,0 & 3,7 & 6,1 & 1,2 & 1,2 \\
\hline 23,6 & 3,8 & 6,1 & 1,2 & 1,3 \\
\hline 39,2 & 4,2 & 5,7 & 1,2 & 1,3 \\
\hline 31,1 & 3,9 & 5,8 & 1,3 & 1,2 \\
\hline 38,8 & 3,8 & 6,1 & 1,2 & 1,3 \\
\hline 22,0 & 3,7 & 7,2 & 1,3 & \\
\hline 35,6 & 3,9 & 6,0 & 1,3 & 1,3 \\
\hline 11,9 & 5,5 & & & \\
\hline 24,2 & 4,2 & 6,1 & 1,3 & 1,3 \\
\hline 12,5 & 4,3 & & & \\
\hline 28,9 & 4,2 & 5,9 & 1,3 & 1,3 \\
\hline 40,4 & 3,6 & 5,3 & 1,3 & 1,2 \\
\hline 24,8 & 3,7 & 6,0 & 1,3 & 1,3 \\
\hline 22,1 & 3,7 & 6,0 & 1,3 & 1,2 \\
\hline 38,0 & 3,8 & 6,1 & 1,2 & 1,3 \\
\hline 27,3 & 3,8 & 6,2 & 1,3 & 1,3 \\
\hline 37,9 & 4,2 & 4,1 & 1,2 & 1,3 \\
\hline 25,5 & 3,6 & 6,2 & 1,3 & 1,3 \\
\hline 22,0 & 3,8 & 6,0 & 1,3 & 1,2 \\
\hline 12,0 & 5,4 & & & \\
\hline 42,4 & 3,8 & 3,1 & 1,3 & 1,2 \\
\hline 29,1 & 4,1 & 5,9 & 1,3 & 1,2 \\
\hline 28,5 & 3,9 & 5,3 & 1,3 & 1,3 \\
\hline
\end{tabular}

$\begin{array}{rrrr}90 & 16,9 & 4 & 5.04 \\ 90 & 9,8 & 5 & 1.65 \\ 89 & 10,1 & 5 & 3.22 \\ 89 & 16,6 & 4 & 6.35 \\ 83 & 17,1 & 4 & 1.60 \\ 88 & 16,4 & 4 & 6.75 \\ 90 & 17,1 & 4 & 2.25 \\ 90 & 16,8 & 4 & 6.10 \\ 90 & 17,1 & 5 & 0.90 \\ 88 & 17,3 & 4 & 3.71 \\ 87 & 10,3 & 3 & 0.64 \\ 90 & 16,8 & 4 & 2.70 \\ 88 & 7,6 & 3 & 0.75 \\ 92 & 16,4 & 4 & 2.14 \\ 89 & 15,9 & 4 & 6.00 \\ 88 & 16,9 & 4 & 0.86 \\ 90 & 16,7 & 4 & 0.72 \\ 89 & 16,5 & 4 & 6.30 \\ 90 & 16,6 & 4 & 1.62 \\ 81 & 14,3 & 4 & 4.38 \\ 88 & 16,9 & 4 & 1.44 \\ 86 & 16,3 & 4 & 1.24 \\ 90 & 9,2 & 5 & 0.69 \\ 88 & 11,9 & 4 & 6.39 \\ 90 & 16,2 & 4 & 1.70 \\ 85 & 15,5 & 4 & 3.05\end{array}$




\begin{tabular}{|c|c|c|c|c|c|c|c|c|}
\hline 5654 & 150616 & 111507 & 1 & 5,9 & 13,4 & 5,8 & 5,9 & 6,5 \\
\hline 5655 & 150616 & 111514 & 1 & 6,8 & 10,4 & 6,4 & 5,7 & 6,2 \\
\hline 5660 & 150616 & 111602 & 1 & 4,2 & 6,1 & & & \\
\hline 5665 & 150616 & 111643 & 1 & 5,7 & 10,4 & 3,6 & 4,0 & 4,1 \\
\hline 5678 & 150616 & 111846 & 1 & 6,8 & 12,9 & 5,9 & 5,9 & 5,9 \\
\hline 5690 & 150616 & 112050 & 1 & 5,5 & 9,8 & 3,8 & 3,7 & \\
\hline 5695 & 150616 & 112135 & 1 & 6,1 & 11,5 & 7,9 & 8,1 & 8,7 \\
\hline 5705 & 150616 & 112321 & 1 & 5,6 & 8,2 & 4,7 & 5,0 & 4,8 \\
\hline 5712 & 150616 & 112444 & 1 & 6,1 & 6,6 & 2,6 & 3,0 & 2,3 \\
\hline 5716 & 150616 & 112523 & 1 & 6,3 & 8,8 & 5,7 & 5,5 & 5,5 \\
\hline 5724 & 150616 & 112618 & 1 & 4,8 & 4,9 & & & \\
\hline 5731 & 150616 & 112725 & 1 & 5,9 & 8,4 & 6,2 & 6,1 & 5,8 \\
\hline 5737 & 150616 & 112803 & 1 & 6,1 & 12,9 & 6,7 & 6,9 & 6,7 \\
\hline 5738 & 150616 & 112820 & 1 & 5,1 & 7,4 & & & \\
\hline 5742 & 150616 & 112840 & 1 & 6,7 & 6,3 & 3,8 & 3,9 & \\
\hline 5746 & 150616 & 112915 & 1 & 5,7 & 8,3 & 3,5 & 3,5 & 3,9 \\
\hline 5751 & 150616 & 113025 & 1 & 6,6 & 13,0 & 4,2 & 5,9 & 6,2 \\
\hline 5753 & 150616 & 113037 & 1 & 5,3 & 6,4 & 2,8 & 2,8 & 3,1 \\
\hline 5759 & 150616 & 113136 & 1 & 7,0 & 14,2 & 6,0 & 6,3 & 5,5 \\
\hline 5765 & 150616 & 113229 & 1 & 5,9 & 8,4 & 3,5 & 3,6 & 3,8 \\
\hline 5766 & 150616 & 113233 & 1 & 6,7 & 12,2 & 6,5 & 6,9 & 6,5 \\
\hline 5770 & 150616 & 113333 & 1 & 6,7 & 7,6 & 3,6 & 3,2 & 3,4 \\
\hline 5772 & 150616 & 113347 & 1 & 5,8 & 7,5 & 4,1 & 4,5 & 4,5 \\
\hline 5783 & 150616 & 113540 & 1 & 6,8 & 12,5 & 6,4 & 6,5 & 6,4 \\
\hline 5785 & 150616 & 113608 & 1 & 6,2 & 11,1 & 7,7 & 7,5 & \\
\hline 5786 & 150616 & 113618 & 1 & 5,9 & 8,8 & 3,1 & 3,6 & 3,6 \\
\hline
\end{tabular}

$\begin{array}{rrrrr}37,5 & 3,8 & 6,1 & 1,3 & 1,3 \\ 35,5 & 3,7 & 6,0 & 1,2 & 1,3 \\ 10,3 & 3,6 & & & \\ 27,8 & 3,7 & 5,9 & 1,2 & 1,3 \\ 37,4 & 3,6 & 6,0 & 1,2 & 1,3 \\ 22,8 & 6,0 & 8,1 & 1,3 & \\ 42,3 & 3,6 & 3,2 & 1,2 & 1,3 \\ 28,3 & 3,9 & 5,9 & 1,3 & 1,3 \\ 20,6 & 3,7 & 6,1 & 1,2 & 1,3 \\ 31,8 & 3,9 & 5,9 & 1,3 & 1,3 \\ 9,7 & 4,7 & & & \\ 32,4 & 4,2 & 5,0 & 1,3 & 1,2 \\ 39,3 & 3,8 & 5,2 & 1,2 & 1,3 \\ 12,5 & 3,8 & & & \\ 20,7 & 4,1 & 7,1 & 1,3 & \\ 24,9 & 3,7 & 5,8 & 1,2 & 1,2 \\ 35,9 & 3,8 & 4,2 & 1,2 & 1,3 \\ 20,4 & 3,5 & 5,8 & 1,2 & 1,2 \\ 39,0 & 3,5 & 5,8 & 1,2 & 1,2 \\ 25,2 & 3,5 & 5,4 & 1,2 & 1,2 \\ 38,8 & 3,7 & 5,6 & 1,2 & 1,2 \\ 24,5 & 3,8 & 5,6 & 1,2 & 1,2 \\ 26,4 & 4,0 & 5,8 & 1,2 & 1,2 \\ 38,6 & 3,6 & 5,9 & 1,2 & 1,2 \\ 32,5 & 3,7 & 8,4 & 1,3 & \\ 25,0 & 3,7 & 5,9 & 1,3 & 1,2\end{array}$

$\begin{array}{rrrr}90 & 16,7 & 4 & 6.65 \\ 91 & 16,5 & 4 & 3.49 \\ 84 & 6,9 & 5 & 0.37 \\ 90 & 15,9 & 4 & 2.80 \\ 89 & 16,8 & 4 & 6.14 \\ 90 & 19,1 & 5 & 2.25 \\ 87 & 12,1 & 4 & 5.58 \\ 90 & 16,4 & 4 & 1.42 \\ 89 & 15,8 & 4 & 0.75 \\ 90 & 16,6 & 4 & 2.05 \\ 88 & 7,5 & 5 & 0.22 \\ 88 & 15,3 & 4 & 1.88 \\ 89 & 14,7 & 4 & 6.30 \\ 88 & 6,9 & 3 & 0.81 \\ 88 & 15,9 & 4 & 0.86 \\ 86 & 15,5 & 4 & 1.36 \\ 88 & 13,3 & 4 & 6.07 \\ 83 & 15,3 & 4 & 0.56 \\ 86 & 15,8 & 4 & 8.06 \\ 85 & 15,6 & 4 & 1.44 \\ 85 & 15,7 & 4 & 5.51 \\ 86 & 15,9 & 4 & 1.25 \\ 87 & 16,0 & 4 & 1.08 \\ 87 & 16,3 & 4 & 5.82 \\ 82 & 18,0 & 5 & 4.51 \\ 86 & 15,9 & 4 & 1.65\end{array}$


$\begin{array}{lllllllllllllllllllllll}\text { No Date } & \text { Time Lne AW1 AW2 AW3 AW4 AW5 AW6 } & \text { GVM } & \text { AD1 } & \text { AD2 } & \text { AD3 } & \text { AD4 } & \text { AD5 } & \text { SPD } & \text { LENG } & \text { CL } & \text { ESAL }\end{array}$

$\begin{array}{rrrrrrrrr}5789 & 150616 & 113629 & 1 & 6,2 & 8,4 & 3,9 & 4,0 & 3,9 \\ 5791 & 150616 & 113643 & 1 & 3,9 & 6,0 & & & \\ 5797 & 150616 & 113718 & 1 & 6,0 & 10,2 & 3,4 & 3,6 & 3,3 \\ 5800 & 150616 & 113742 & 1 & 5,5 & 5,7 & 2,7 & 2,9 & 2,8 \\ 5803 & 150616 & 113813 & 1 & 6,9 & 10,8 & 7,6 & 8,3 & \\ 5805 & 150616 & 113823 & 1 & 6,1 & 8,2 & 4,7 & 4,7 & 5,4 \\ 5822 & 150616 & 114117 & 1 & 5,7 & 8,9 & 4,4 & 4,4 & 4,6 \\ 5825 & 150616 & 114148 & 1 & 6,5 & 12,7 & 6,7 & 6,1 & 5,9 \\ 5826 & 150616 & 114203 & 1 & 6,0 & 6,8 & 3,2 & 2,6 & 3,1 \\ 5828 & 150616 & 114209 & 1 & 6,5 & 11,2 & 7,6 & 7,5 & 7,2 \\ 5830 & 150616 & 114225 & 1 & 5,0 & 5,8 & 3,4 & 3,1 & \\ 5834 & 150616 & 114256 & 1 & 6,3 & 7,9 & 3,5 & 4,2 & 3,8 \\ 5840 & 150616 & 114330 & 1 & 3,6 & 5,3 & & & \\ 5851 & 150616 & 114658 & 1 & 6,2 & 10,1 & 6,6 & 6,9 & 7,3 \\ 5859 & 150616 & 114736 & 1 & 7,3 & 11,4 & 8,0 & 8,2 & 7,9 \\ 5864 & 150616 & 114805 & 1 & 6,2 & 8,7 & 2,1 & 2,3 & 2,7 \\ 5869 & 150616 & 114844 & 1 & 6,9 & 9,8 & 5,4 & 5,5 & 5,4 \\ 5874 & 150616 & 114913 & 1 & 6,8 & 7,0 & 3,2 & 3,3 & \\ 5880 & 150616 & 114957 & 1 & 7,0 & 12,4 & 7,9 & 7,0 & 7,5 \\ 5883 & 150616 & 115015 & 1 & 6,6 & 9,3 & 4,9 & 4,7 & 5,0 \\ 5895 & 150616 & 115201 & 1 & 6,1 & 9,7 & 6,4 & 6,3 & 6,7 \\ 5899 & 150616 & 115232 & 1 & 5,6 & 7,4 & 4,7 & 4,3 & \\ 5915 & 150616 & 115535 & 1 & 6,8 & 13,7 & 5,8 & 5,8 & 6,0 \\ 5937 & 150616 & 115934 & 1 & 6,1 & 8,7 & 4,8 & 4,5 & 4,6 \\ 5977 & 150616 & 120533 & 1 & 6,0 & 12,8 & 4,2 & 7,7 & 8,1 \\ 5988 & 150616 & 120703 & 1 & 6,2 & 11,1 & 6,9 & 6,7 & 7,1\end{array}$

$\begin{array}{rrrrr}26,4 & 3,7 & 5,5 & 1,2 & 1,3 \\ 9,9 & 5,3 & & & \\ 26,5 & 3,6 & 5,6 & 1,2 & 1,2 \\ 19,6 & 3,5 & 5,8 & 1,2 & 1,2 \\ 33,6 & 3,8 & 8,3 & 1,3 & \\ 29,1 & 3,7 & 5,7 & 1,2 & 1,2 \\ 28,0 & 3,7 & 5,9 & 1,2 & 1,2 \\ 37,9 & 3,8 & 4,6 & 1,2 & 1,2 \\ 21,7 & 3,6 & 5,8 & 1,2 & 1,2 \\ 40,0 & 3,6 & 5,1 & 1,2 & 1,2 \\ 17,3 & 3,8 & 5,5 & 1,3 & \\ 25,7 & 4,1 & 5,8 & 1,2 & 1,3 \\ 8,9 & 4,4 & & & \\ 37,1 & 3,5 & 5,6 & 1,3 & 1,2 \\ 42,8 & 3,8 & 5,9 & 1,2 & 1,3 \\ 22,0 & 3,7 & 6,0 & 1,3 & 1,3 \\ 33,0 & 3,9 & 6,0 & 1,2 & 1,3 \\ 20,3 & 3,9 & 6,7 & 1,3 & \\ 41,8 & 3,7 & 5,2 & 1,3 & 1,2 \\ 30,5 & 4,0 & 5,7 & 1,3 & 1,3 \\ 35,2 & 3,8 & 5,9 & 1,3 & 1,3 \\ 22,0 & 3,6 & 5,7 & 1,3 & \\ 38,1 & 3,9 & 5,9 & 1,3 & 1,3 \\ 28,7 & 3,6 & 6,0 & 1,2 & 1,2 \\ 38,8 & 4,1 & 3,1 & 1,2 & 1,2 \\ 38,0 & 3,9 & 5,0 & 1,3 & 1,3\end{array}$

$\begin{array}{rrrr}86 & 16,3 & 4 & 1.53 \\ 80 & 9,5 & 5 & 0.33 \\ 85 & 15,0 & 4 & 2.66 \\ 86 & 15,7 & 4 & 0.44 \\ 85 & 18,0 & 5 & 4.61 \\ 83 & 15,8 & 4 & 1.52 \\ 87 & 16,1 & 4 & 1.76 \\ 84 & 14,6 & 4 & 5.91 \\ 79 & 15,7 & 4 & 0.79 \\ 86 & 14,7 & 4 & 4.79 \\ 90 & 14,2 & 4 & 0.40 \\ 87 & 15,8 & 4 & 1.30 \\ 85 & 7,5 & 5 & 0.19 \\ 86 & 15,6 & 4 & 3.44 \\ 88 & 16,5 & 4 & 5.65 \\ 85 & 17,1 & 4 & 1.62 \\ 87 & 16,9 & 4 & 2.82 \\ 91 & 15,6 & 4 & 1.05 \\ 87 & 15,8 & 4 & 6.29 \\ 90 & 16,8 & 4 & 2.27 \\ 88 & 17,3 & 4 & 2.90 \\ 88 & 15,2 & 4 & 1.01 \\ 90 & 17,0 & 4 & 7.23 \\ 87 & 16,4 & 4 & 1.74 \\ 87 & 12,0 & 4 & 6.09 \\ 87 & 15,0 & 4 & 4.32 \\ & & & \\ 85 & 15\end{array}$




$\begin{array}{rrrrrrrrr}6000 & 150616 & 120846 & 1 & 7,1 & 13,2 & 8,0 & 7,4 & 8,4 \\ 6003 & 150616 & 120919 & 1 & 7,2 & 9,4 & 5,2 & 6,1 & 5,7 \\ 6006 & 150616 & 120933 & 1 & 6,9 & 12,3 & 7,0 & 7,2 & 7,0 \\ 6007 & 150616 & 121037 & 1 & 6,0 & 8,0 & 4,0 & 3,6 & 3,7 \\ 6011 & 150616 & 121134 & 1 & 6,8 & 11,6 & 7,2 & 7,5 & 7,7 \\ 6013 & 150616 & 121143 & 1 & 5,7 & 6,7 & 2,8 & 2,5 & 2,6 \\ 6015 & 150616 & 121154 & 1 & 6,5 & 8,1 & 4,5 & 4,5 & \\ 6036 & 150616 & 121437 & 1 & 6,6 & 11,8 & 5,9 & 5,9 & 5,7 \\ 6049 & 150616 & 121753 & 1 & 6,8 & 7,8 & 5,8 & 6,7 & 7,2 \\ 6054 & 150616 & 121830 & 1 & 7,1 & 14,1 & 6,2 & 6,8 & 6,8 \\ 6058 & 150616 & 121930 & 1 & 6,5 & 11,7 & 7,9 & 7,6 & 7,7 \\ 6059 & 150616 & 121942 & 1 & 6,2 & 13,2 & 5,6 & 6,0 & 6,3 \\ 6061 & 150616 & 122024 & 1 & 5,8 & 10,9 & 7,1 & 7,6 & 7,7 \\ 6070 & 150616 & 122148 & 1 & 6,8 & 12,6 & 5,3 & 4,9 & 5,2 \\ 6072 & 150616 & 122205 & 1 & 6,6 & 11,3 & 6,9 & 6,8 & 7,2 \\ 6078 & 150616 & 122314 & 1 & 2,0 & 2,6 & & & \\ 6081 & 150616 & 122407 & 1 & 7,0 & 13,2 & 6,5 & 6,7 & 6,2 \\ 6084 & 150616 & 122435 & 1 & 7,2 & 11,7 & 8,7 & 8,9 & 9,2 \\ 6088 & 150616 & 122446 & 1 & 6,7 & 6,5 & 3,9 & 2,9 & \\ 6091 & 150616 & 122459 & 1 & 7,3 & 12,0 & 7,5 & 7,2 & 7,1 \\ 6093 & 150616 & 122522 & 1 & 6,4 & 10,6 & 6,6 & 7,7 & 6,4 \\ 6095 & 150616 & 122533 & 1 & 6,8 & 12,4 & 6,4 & 6,8 & 6,5 \\ 6105 & 150616 & 122648 & 1 & 3,6 & 5,3 & & & \\ 6107 & 150616 & 122708 & 1 & 6,6 & 10,7 & 5,4 & 5,6 & 5,9 \\ 6109 & 150616 & 122719 & 1 & 6,5 & 8,7 & 4,9 & 5,2 & 5,2 \\ 6113 & 150616 & 122741 & 1 & 7,4 & 13,8 & 8,0 & 7,6 & 7,9\end{array}$

$\begin{array}{rllll}44,1 & 3,6 & 4,7 & 1,3 & 1,2 \\ 33,6 & 3,8 & 6,1 & 1,2 & 1,3 \\ 40,4 & 3,6 & 6,1 & 1,3 & 1,2 \\ 25,3 & 3,7 & 6,0 & 1,3 & 1,3 \\ 40,8 & 3,6 & 6,0 & 1,3 & 1,2 \\ 20,3 & 3,6 & 5,6 & 1,3 & 1,3 \\ 23,6 & 3,8 & 7,4 & 1,3 & \\ 35,9 & 4,2 & 5,6 & 1,3 & 1,2 \\ 34,3 & 3,7 & 5,1 & 1,3 & 1,3 \\ 41,0 & 3,8 & 5,7 & 1,2 & 1,3 \\ 41,4 & 3,7 & 5,8 & 1,3 & 1,2 \\ 37,3 & 3,8 & 5,8 & 1,2 & 1,3 \\ 39,1 & 3,8 & 3,1 & 1,2 & 1,3 \\ 34,8 & 3,6 & 6,0 & 1,2 & 1,2 \\ 38,8 & 3,7 & 3,0 & 1,2 & 1,2 \\ 4,6 & 3,6 & & & \\ 39,6 & 3,8 & 6,0 & 1,2 & 1,2 \\ 45,7 & 3,8 & 3,8 & 1,3 & 1,2 \\ 20,0 & 3,6 & 7,0 & 1,3 & \\ 41,1 & 3,7 & 5,9 & 1,2 & 1,2 \\ 37,7 & 3,8 & 6,0 & 1,2 & 1,3 \\ 38,9 & 3,8 & 6,0 & 1,3 & 1,2 \\ 8,9 & 5,4 & & & \\ 34,2 & 3,9 & 5,9 & 1,2 & 1,3 \\ 30,5 & 3,6 & 5,7 & 1,3 & 1,2 \\ 44,7 & 4,1 & 5,5 & 1,2 & 1,3 \\ & & & & \\ 34,3 \\ 34,3\end{array}$

SPD LENG CL ESAL 


$\begin{array}{rrrrrrrrr}6167 & 150616 & 123656 & 1 & 6,6 & 9,3 & 4,7 & 5,0 & 4,6 \\ 6169 & 150616 & 123708 & 1 & 7,1 & 12,4 & 6,4 & 6,8 & 7,1 \\ 6176 & 150616 & 123810 & 1 & 6,6 & 11,9 & 7,1 & 7,7 & 7,5 \\ 6177 & 150616 & 123820 & 1 & 7,2 & 12,2 & 6,8 & 7,3 & 7,0 \\ 6181 & 150616 & 123837 & 1 & 7,2 & 11,5 & 7,3 & 7,2 & 6,9 \\ 6192 & 150616 & 124102 & 1 & 5,9 & 7,6 & 4,2 & 4,2 & 4,3 \\ 6201 & 150616 & 124306 & 1 & 5,4 & 6,4 & 3,3 & 3,2 & 3,4 \\ 6206 & 150616 & 124405 & 1 & 5,4 & 7,3 & 2,1 & 3,4 & 2,4 \\ 6212 & 150616 & 124447 & 1 & 4,9 & 7,5 & 3,8 & 3,5 & 3,4 \\ 6215 & 150616 & 124511 & 1 & 6,7 & 9,8 & 7,8 & 8,3 & 8,2 \\ 6221 & 150616 & 124549 & 1 & 6,4 & 7,9 & 3,4 & 3,4 & 3,4 \\ 6239 & 150616 & 124845 & 1 & 6,1 & 7,5 & 4,1 & 4,0 & 4,0 \\ 6240 & 150616 & 124900 & 1 & 6,1 & 6,7 & 3,0 & 2,9 & 3,1 \\ 6242 & 150616 & 124912 & 1 & 7,0 & 13,3 & 7,8 & 7,7 & 7,7 \\ 6243 & 150616 & 124927 & 1 & 6,1 & 9,4 & 4,7 & 4,8 & 4,4 \\ 6245 & 150616 & 124941 & 1 & 6,6 & 12,2 & 7,2 & 6,1 & 7,0 \\ 6255 & 150616 & 125147 & 1 & 6,8 & 10,2 & 5,5 & 5,4 & 5,7 \\ 6256 & 150616 & 125200 & 1 & 6,6 & 11,1 & 7,8 & 8,2 & 7,8 \\ 6261 & 150616 & 125255 & 1 & 6,4 & 8,2 & 3,9 & 3,5 & 4,0 \\ 6268 & 150616 & 125435 & 1 & 6,4 & 8,1 & 5,6 & 4,6 & 4,9 \\ 6272 & 150616 & 125501 & 1 & 3,7 & 4,7 & & & \\ 6273 & 150616 & 125513 & 1 & 6,1 & 12,0 & & & \\ 6278 & 150616 & 125545 & 1 & 7,3 & 13,0 & 6,8 & 7,5 & 7,4 \\ 6280 & 150616 & 125642 & 1 & 6,7 & 8,9 & 4,4 & 4,0 & 4,9 \\ 6281 & 150616 & 125715 & 1 & 6,2 & 6,6 & 3,7 & 3,2 & 3,0 \\ 6284 & 150616 & 125741 & 1 & 6,5 & 11,6 & 7,6 & 6,8 & 7,8\end{array}$

\begin{tabular}{|c|c|c|c|c|}
\hline 30,2 & 3,9 & 5,6 & 1,2 & 1,2 \\
\hline 39,8 & 3,7 & 5,9 & 1,3 & 1,2 \\
\hline 40,8 & 3,6 & 4,5 & 1,2 & 1,3 \\
\hline 40,5 & 3,9 & 7,0 & 1,3 & 1,3 \\
\hline 40,1 & 3,7 & 6,0 & 1,2 & 1,3 \\
\hline 26,2 & 3,8 & 5,7 & 1,3 & 1,2 \\
\hline 21,7 & 3,8 & 6,9 & 1,2 & 1,2 \\
\hline 20,6 & 3,6 & 6,2 & 1,2 & 1,3 \\
\hline 23,1 & 4,1 & 6,0 & 1,3 & 1,3 \\
\hline 40,8 & 3,7 & 5,9 & 1,3 & 1,2 \\
\hline 24,5 & 3,8 & 5,8 & 1,2 & 1,2 \\
\hline 25,7 & 3,8 & 5,8 & 1,2 & 1,3 \\
\hline 21,8 & 3,7 & 6,2 & 1,3 & 1,2 \\
\hline 43,5 & 3,6 & 6,2 & 1,3 & 1,3 \\
\hline 29,4 & 3,9 & 6,0 & 1,2 & 1,3 \\
\hline 39,1 & 3,7 & 5,9 & 1,3 & 1,2 \\
\hline 33,6 & 3,9 & 5,9 & 1,2 & 1,2 \\
\hline 41,5 & 3,9 & 5,8 & 1,3 & 1,2 \\
\hline 26,0 & 4,1 & 5,9 & 1,3 & 1,2 \\
\hline 29,6 & 3,9 & 5,7 & 1,2 & 1,2 \\
\hline 8,4 & 3,7 & & & \\
\hline 18,1 & 5,9 & & & \\
\hline 42,0 & 3,7 & 5,8 & 1,2 & 1,2 \\
\hline 28,9 & 3,8 & 5,6 & 1,3 & 1,2 \\
\hline 22,7 & 3,6 & 5,9 & 1,2 & 1,2 \\
\hline 40,3 & 4,1 & 5,6 & 1,2 & 1,2 \\
\hline
\end{tabular}

$\begin{array}{llll}85 & 16,5 & 4 & 2.25 \\ 87 & 16,8 & 4 & 5.93 \\ 86 & 14,0 & 4 & 5.56 \\ 75 & 18,0 & 4 & 5.86 \\ 91 & 16,9 & 4 & 5.13 \\ 89 & 16,5 & 4 & 1.13 \\ 87 & 16,1 & 4 & 0.58 \\ 88 & 17,0 & 4 & 0.83 \\ 89 & 16,9 & 4 & 0.88 \\ 88 & 16,7 & 4 & 4.08 \\ 88 & 16,7 & 4 & 1.30 \\ 88 & 16,6 & 4 & 1.11 \\ 93 & 16,7 & 4 & 0.79 \\ 90 & 16,4 & 4 & 7.63 \\ 87 & 16,8 & 4 & 2.18 \\ 88 & 16,8 & 4 & 5.55 \\ 89 & 16,4 & 4 & 3.14 \\ 90 & 16,6 & 4 & 5.06 \\ 91 & 16,4 & 4 & 1.46 \\ 84 & 16,4 & 4 & 1.57 \\ 95 & 6,9 & 3 & 0.13 \\ 87 & 9,9 & 3 & 4.41 \\ 88 & 16,5 & 4 & 7.01 \\ 88 & 16,6 & 4 & 1.98 \\ 90 & 16,0 & 4 & 0.79 \\ 87 & 16,4 & 4 & 5.19 \\ & & & \\ 89 & & \end{array}$




$\begin{array}{rrrrrrrrr}6288 & 150616 & 125756 & 1 & 6,0 & 7,8 & 4,5 & 4,1 & 5,3 \\ 6294 & 150616 & 125851 & 1 & 6,8 & 10,8 & 4,8 & 4,9 & 5,1 \\ 6339 & 150616 & 130650 & 1 & 5,7 & 7,2 & 3,9 & 3,5 & \\ 6343 & 150616 & 130730 & 1 & 6,2 & 8,3 & 3,4 & 3,1 & 3,3 \\ 6349 & 150616 & 130823 & 1 & 5,8 & 11,6 & 5,4 & 5,3 & 5,4 \\ 6367 & 150616 & 131303 & 1 & 7,6 & 7,2 & 2,6 & 2,6 & 2,4 \\ 6370 & 150616 & 131510 & 1 & 6,0 & 9,1 & 4,3 & 3,5 & 3,5 \\ 6387 & 150616 & 131713 & 1 & 6,1 & 8,7 & 3,1 & 3,2 & 3,3 \\ 6388 & 150616 & 131727 & 1 & 2,2 & 3,8 & & & \\ 6401 & 150616 & 131940 & 1 & 6,2 & 7,1 & 4,2 & 4,5 & \\ 6406 & 150616 & 132049 & 1 & 6,0 & 6,7 & 3,5 & 3,0 & 3,0 \\ 6424 & 150616 & 132328 & 1 & 6,2 & 10,0 & 7,6 & 7,4 & 7,7 \\ 6429 & 150616 & 132406 & 1 & 5,1 & 6,2 & 3,3 & 3,4 & \\ 6435 & 150616 & 132434 & 1 & 6,3 & 8,4 & 4,8 & 5,1 & 5,1 \\ 6436 & 150616 & 132436 & 1 & 7,2 & 12,5 & 7,8 & 8,1 & 8,5 \\ 6450 & 150616 & 132638 & 1 & 5,7 & 7,5 & 3,0 & 2,7 & 2,9 \\ 6451 & 150616 & 132702 & 1 & 6,0 & 8,2 & 2,9 & 2,9 & 3,4 \\ 6452 & 150616 & 132722 & 1 & 1,0 & 2,2 & & & \\ 6458 & 150616 & 132824 & 1 & 4,9 & 8,8 & & & \\ 6482 & 150616 & 133418 & 1 & 6,2 & 7,6 & 4,2 & 3,8 & 4,2 \\ 6486 & 150616 & 133451 & 1 & 5,3 & 10,9 & 7,8 & 7,7 & 8,0 \\ 6493 & 150616 & 133613 & 1 & 6,6 & 11,6 & 7,1 & 7,0 & 7,2 \\ 6494 & 150616 & 133623 & 1 & 5,7 & 6,3 & 3,9 & 3,8 & 3,1 \\ 6496 & 150616 & 133657 & 1 & 6,4 & 12,8 & 7,2 & 6,8 & 7,4 \\ 6498 & 150616 & 133712 & 1 & 6,8 & 12,1 & 7,5 & 7,4 & 7,1 \\ 6499 & 150616 & 133722 & 1 & 6,8 & 13,4 & 6,8 & 7,1 & 7,0\end{array}$

\begin{tabular}{|c|c|c|c|c|}
\hline 27,7 & 3,5 & 6,8 & 1,3 & 1,2 \\
\hline 32,4 & 3,8 & 5,6 & 1,3 & 1,2 \\
\hline 20,3 & 5,4 & 6,6 & 1,2 & \\
\hline 24,3 & 3,8 & 6,1 & 1,3 & 1,2 \\
\hline 33,5 & 3,6 & 5,8 & 1,2 & 1,2 \\
\hline 22,4 & 3,8 & 6,4 & 1,2 & 1,2 \\
\hline 26,4 & 3,7 & 5,9 & 1,2 & 1,2 \\
\hline 24,4 & 3,5 & 5,4 & 1,2 & 1,2 \\
\hline 6,0 & 4,0 & & & \\
\hline 22,0 & 3,6 & 7,0 & 1,2 & \\
\hline 22,2 & 3,7 & 5,7 & 1,3 & 1,2 \\
\hline 38,9 & 3,8 & 4,0 & 1,2 & 1,2 \\
\hline 18,0 & 6,1 & 7,0 & 1,3 & \\
\hline 29,7 & 4,1 & 5,6 & 1,3 & 1,2 \\
\hline 44,1 & 3,8 & 5,2 & 1,3 & 1,2 \\
\hline 21,8 & 3,7 & 5,7 & 1,3 & 1,2 \\
\hline 23,4 & 3,8 & 6,0 & 1,2 & 1,3 \\
\hline 3,2 & 3,2 & & & \\
\hline 13,7 & 5,3 & & & \\
\hline 26,0 & 3,7 & 6,1 & 1,4 & 1,3 \\
\hline 39,7 & 3,8 & 3,2 & 1,2 & 1,3 \\
\hline 39,5 & 3,6 & 6,0 & 1,3 & 1,3 \\
\hline 22,8 & 3,9 & 5,6 & 1,3 & 1,2 \\
\hline 40,6 & 3,7 & 5,5 & 1,3 & 1,2 \\
\hline 40,9 & 3,7 & 5,8 & 1,3 & 1,3 \\
\hline 41,1 & 3,8 & 5,8 & 1,2 & 1,2 \\
\hline
\end{tabular}

$\begin{array}{rrrr}86 & 15,0 & 4 & 1.28 \\ 88 & 16,5 & 4 & 3.53 \\ 84 & 16,5 & 5 & 0.89 \\ 88 & 16,3 & 4 & 1.44 \\ 90 & 15,3 & 4 & 4.19 \\ 86 & 16,1 & 4 & 1.38 \\ 86 & 15,5 & 4 & 1.88 \\ 83 & 14,9 & 4 & 1.63 \\ 85 & 7,5 & 3 & 0.04 \\ 88 & 15,3 & 5 & 1.00 \\ 88 & 15,7 & 4 & 0.77 \\ 88 & 13,8 & 4 & 3.73 \\ 89 & 19,1 & 5 & 0.50 \\ 90 & 16,5 & 4 & 1.68 \\ 89 & 15,7 & 4 & 6.95 \\ 89 & 17,1 & 4 & 0.97 \\ 90 & 16,9 & 4 & 1.34 \\ 105 & 6,6 & 2 & 0.00 \\ 89 & 11,0 & 3 & 1.46 \\ 89 & 17,1 & 4 & 1.17 \\ 91 & 12,3 & 4 & 4.52 \\ 91 & 17,0 & 4 & 5.04 \\ 83 & 16,5 & 4 & 0.64 \\ 87 & 15,2 & 4 & 6.42 \\ 89 & 17,1 & 4 & 5.79 \\ 82 & 16,7 & 4 & 7.25\end{array}$




$\begin{array}{rrrrrrrrr}6503 & 150616 & 133808 & 1 & 6,6 & 8,6 & 5,5 & 5,8 & 6,0 \\ 6507 & 150616 & 133905 & 1 & 6,7 & 11,9 & 5,7 & 5,1 & 6,2 \\ 6509 & 150616 & 133937 & 1 & 6,6 & 12,1 & 7,2 & 8,0 & 6,8 \\ 6511 & 150616 & 133952 & 1 & 5,5 & 6,2 & 3,1 & 3,3 & 2,9 \\ 6514 & 150616 & 134049 & 1 & 5,8 & 5,5 & 2,9 & 2,1 & 3,1 \\ 6515 & 150616 & 134101 & 1 & 6,6 & 12,0 & 6,7 & 6,7 & 6,8 \\ 6530 & 150616 & 134245 & 1 & 6,4 & 11,4 & & & \\ 6542 & 150616 & 134358 & 1 & 7,0 & 12,1 & 7,2 & 7,2 & 7,3 \\ 6547 & 150616 & 134456 & 1 & 6,5 & 8,8 & 5,6 & 6,2 & 5,8 \\ 6551 & 150616 & 134523 & 1 & 7,1 & 10,8 & 7,6 & 7,6 & 7,7 \\ 6559 & 150616 & 134618 & 1 & 7,4 & 13,5 & 4,8 & 5,5 & 5,6 \\ 6564 & 150616 & 134658 & 1 & 7,9 & 13,1 & 7,9 & 7,8 & 7,2 \\ 6567 & 150616 & 134730 & 1 & 5,5 & 8,6 & 4,6 & 4,4 & \\ 6574 & 150616 & 134848 & 1 & 4,7 & 10,6 & & & \\ 6576 & 150616 & 134902 & 1 & 5,4 & 4,9 & 2,8 & 2,6 & \\ 6584 & 150616 & 135025 & 1 & 6,6 & 12,1 & 6,5 & 6,7 & 6,6 \\ 12397 & 150617 & 100610 & 1 & 6,7 & 11,2 & 6,2 & 6,0 & 6,9 \\ 12452 & 150617 & 101456 & 1 & 6,5 & 12,5 & 6,1 & 5,7 & 6,6 \\ 12454 & 150617 & 101528 & 1 & 6,8 & 12,7 & 6,2 & 6,7 & 6,8 \\ 12471 & 150617 & 102032 & 1 & 4,0 & 5,9 & & & \\ 12473 & 150617 & 102048 & 1 & 6,5 & 8,7 & 4,6 & 5,2 & 4,4 \\ 12474 & 150617 & 102106 & 1 & 6,8 & 13,6 & 3,9 & 3,4 & 3,9 \\ 12481 & 150617 & 102150 & 1 & 6,0 & 7,0 & 3,2 & 3,0 & 3,4 \\ 12484 & 150617 & 102228 & 1 & 5,7 & 11,2 & 5,9 & 6,2 & 5,7 \\ 12490 & 150617 & 102331 & 1 & 6,1 & 10,5 & 6,9 & 6,9 & 7,1 \\ 12495 & 150617 & 102411 & 1 & 6,2 & 12,0 & 7,8 & 8,0 & 7,9\end{array}$

\begin{tabular}{|c|c|c|c|c|}
\hline 32,5 & 3,6 & 5,8 & 1,3 & 1,3 \\
\hline 35,6 & 3,8 & 5,8 & 1,3 & 1,2 \\
\hline 40,7 & 3,8 & 6,0 & 1,3 & 1,2 \\
\hline 21,0 & 3,8 & 6,5 & 1,3 & 1,3 \\
\hline 19,4 & 3,9 & 5,9 & 1,3 & 1,2 \\
\hline 38,8 & 3,6 & 6,1 & 1,3 & 1,2 \\
\hline 17,8 & 4,8 & & & \\
\hline 40,8 & 3,8 & 5,0 & 1,3 & 1,3 \\
\hline 32,9 & 3,6 & 6,0 & 1,3 & 1,2 \\
\hline 40,8 & 3,8 & 5,8 & 1,3 & 1,3 \\
\hline 36,8 & 3,9 & 6,0 & 1,2 & 1,3 \\
\hline 43,9 & 3,8 & 5,9 & 1,3 & 1,2 \\
\hline 23,1 & 5,7 & 6,7 & 1,5 & \\
\hline 15,3 & 6,1 & & & \\
\hline 15,7 & 3,9 & 5,3 & 1,2 & \\
\hline 38,5 & 3,7 & 6,0 & 1,3 & 1,2 \\
\hline 37,0 & 3,7 & 6,0 & 1,3 & 1,3 \\
\hline 37,4 & 3,8 & 5,9 & 1,2 & 1,2 \\
\hline 39,2 & 3,6 & 6,0 & 1,2 & 1,2 \\
\hline 9,9 & 3,7 & & & \\
\hline 29,4 & 3,8 & 5,7 & 1,3 & 1,3 \\
\hline 31,6 & 3,7 & 6,1 & 1,3 & 1,3 \\
\hline 22,6 & 3,9 & 6,0 & 1,2 & 1,3 \\
\hline 34,7 & 3,8 & 3,9 & 1,3 & 1,3 \\
\hline 37,5 & 3,7 & 5,3 & 1,2 & 1,3 \\
\hline 41,9 & 3,8 & 5,9 & 1,2 & 1,3 \\
\hline
\end{tabular}

$\begin{array}{rrrr}86 & 16,4 & 4 & 2.05 \\ 87 & 16,9 & 4 & 4.81 \\ 88 & 16,8 & 4 & 5.73 \\ 90 & 17,2 & 4 & 0.54 \\ 86 & 16,7 & 4 & 0.47 \\ 87 & 16,2 & 4 & 5.30 \\ 90 & 10,0 & 3 & 3.83 \\ 89 & 15,3 & 4 & 5.79 \\ 89 & 17,0 & 4 & 2.18 \\ 88 & 17,2 & 4 & 4.71 \\ 82 & 17,0 & 4 & 6.98 \\ 89 & 17,2 & 4 & 7.63 \\ 89 & 18,4 & 4 & 1.52 \\ 100 & 11,8 & 5 & 2.77 \\ 92 & 13,4 & 5 & 0.30 \\ 89 & 16,9 & 4 & 5.35 \\ 88 & 17,1 & 4 & 4.30 \\ 87 & 17,1 & 4 & 5.57 \\ 84 & 17,1 & 4 & 6.17 \\ 80 & 6,6 & 5 & 0.32 \\ 90 & 17,3 & 4 & 1.85 \\ 90 & 17,1 & 4 & 6.74 \\ 87 & 17,4 & 4 & 0.85 \\ 83 & 13,2 & 4 & 3.92 \\ 86 & 15,7 & 4 & 3.78 \\ 85 & 17,1 & 4 & 5.82\end{array}$




$\begin{array}{rrrrrrrrr}12504 & 150617 & 102530 & 1 & 6,1 & 9,8 & 5,0 & 4,6 & 5,2 \\ 12507 & 150617 & 102607 & 1 & 5,6 & 8,0 & 3,4 & 3,3 & 3,4 \\ 12515 & 150617 & 102728 & 1 & 6,6 & 10,9 & 7,0 & 7,8 & 7,9 \\ 12517 & 150617 & 102810 & 1 & 6,1 & 12,2 & 7,5 & 7,6 & 7,4 \\ 12525 & 150617 & 102942 & 1 & 6,7 & 12,7 & 4,9 & 5,1 & 5,6 \\ 12527 & 150617 & 103005 & 1 & 6,7 & 13,6 & 5,8 & 6,3 & 6,3 \\ 12532 & 150617 & 103032 & 1 & 7,5 & 12,3 & 6,3 & 6,6 & 6,6 \\ 12533 & 150617 & 103045 & 1 & 6,1 & 10,6 & 7,1 & 8,3 & \\ 12537 & 150617 & 103115 & 1 & 6,1 & 8,1 & 4,2 & 4,2 & 4,3 \\ 12539 & 150617 & 103128 & 1 & 6,1 & 8,0 & 5,8 & 5,8 & 5,6 \\ 12540 & 150617 & 103140 & 1 & 7,4 & 12,9 & 3,0 & 3,6 & 3,6 \\ 12548 & 150617 & 103220 & 1 & 6,3 & 7,1 & 3,4 & 3,2 & 3,1 \\ 12559 & 150617 & 103455 & 1 & 6,6 & 10,1 & 6,2 & 6,8 & \\ 12560 & 150617 & 103509 & 1 & 7,0 & 13,1 & 4,9 & 4,9 & 5,0 \\ 12562 & 150617 & 103520 & 1 & 6,0 & 10,0 & 2,6 & 3,3 & 2,8 \\ 12569 & 150617 & 103619 & 1 & 6,8 & 11,8 & 7,6 & 6,8 & 7,1 \\ 12570 & 150617 & 103627 & 1 & 6,7 & 13,8 & 6,1 & 6,5 & 6,8 \\ 12571 & 150617 & 103634 & 1 & 5,7 & 6,6 & 2,8 & 3,5 & \\ 12579 & 150617 & 103747 & 1 & 6,5 & 4,0 & 3,7 & 3,4 & 3,5 \\ 12582 & 150617 & 103800 & 1 & 6,3 & 7,3 & 4,4 & 3,9 & 4,1 \\ 12594 & 150617 & 103903 & 1 & 6,0 & 7,2 & 3,2 & 3,1 & \\ 12599 & 150617 & 104007 & 1 & 7,1 & 7,9 & 4,2 & 3,7 & 3,7 \\ 12602 & 150617 & 104025 & 1 & 6,8 & 13,4 & 6,2 & 6,4 & 5,8 \\ 12604 & 150617 & 104105 & 1 & 6,3 & 9,5 & 7,6 & 7,7 & 7,9 \\ 12609 & 150617 & 104146 & 1 & 5,7 & 7,9 & 3,2 & 3,1 & 3,3 \\ 12612 & 150617 & 104211 & 1 & 6,7 & 12,5 & 5,9 & 6,1 & 6,3\end{array}$

$\begin{array}{lllll}30,7 & 3,7 & 6,1 & 1,3 & 1,2 \\ 23,7 & 3,9 & 6,0 & 1,3 & 1,2 \\ 40,2 & 3,9 & 5,6 & 1,2 & 1,3 \\ 40,8 & 3,6 & 5,9 & 1,3 & 1,3 \\ 35,0 & 3,9 & 6,0 & 1,3 & 1,3 \\ 38,7 & 3,8 & 6,0 & 1,3 & 1,3 \\ 39,3 & 3,9 & 6,2 & 1,3 & 1,3 \\ 32,1 & 3,9 & 8,7 & 1,3 & \\ 26,9 & 4,1 & 5,9 & 1,2 & 1,2 \\ 31,3 & 3,8 & 5,7 & 1,3 & 1,3 \\ 30,5 & 3,8 & 5,7 & 1,2 & 1,3 \\ 23,1 & 3,8 & 5,9 & 1,3 & 1,3 \\ 29,7 & 5,6 & 7,6 & 1,5 & \\ 34,9 & 3,8 & 6,0 & 1,2 & 1,3 \\ 24,7 & 3,8 & 6,1 & 1,2 & 1,2 \\ 40,1 & 3,7 & 5,7 & 1,2 & 1,2 \\ 39,9 & 3,7 & 5,8 & 1,2 & 1,3 \\ 18,6 & 3,8 & 6,7 & 1,3 & \\ 21,1 & 3,8 & 6,0 & 1,3 & 1,3 \\ 26,0 & 3,6 & 5,9 & 1,3 & 1,2 \\ 19,5 & 3,7 & 7,6 & 1,3 & \\ 26,6 & 4,0 & 5,8 & 1,3 & 1,2 \\ 38,6 & 3,8 & 6,0 & 1,2 & 1,3 \\ 39,0 & 4,0 & 6,1 & 1,3 & 1,2 \\ 23,2 & 3,7 & 6,3 & 1,3 & 1,3 \\ 37,5 & 3,9 & 5,9 & 1,3 & 1,2 \\ & & & & \\ 3,3\end{array}$

$\begin{array}{llll}89 & 17,0 & 4 & 2.49 \\ 85 & 17,2 & 4 & 1.13 \\ 90 & 17,1 & 4 & 4.58 \\ 83 & 15,5 & 4 & 5.77 \\ 85 & 17,6 & 4 & 5.72 \\ 88 & 16,8 & 4 & 7.17 \\ 85 & 16,6 & 4 & 5.77 \\ 89 & 19,5 & 5 & 4.09 \\ 89 & 16,7 & 4 & 1.39 \\ 90 & 16,6 & 4 & 1.63 \\ 91 & 16,6 & 4 & 5.98 \\ 90 & 16,6 & 4 & 0.94 \\ 90 & 19,9 & 5 & 3.17 \\ 89 & 16,6 & 4 & 6.26 \\ 84 & 16,6 & 4 & 2.44 \\ 84 & 14,9 & 4 & 5.30 \\ 88 & 17,8 & 4 & 7.57 \\ 86 & 16,5 & 4 & 0.68 \\ 90 & 17,6 & 4 & 0.50 \\ 88 & 17,0 & 4 & 1.07 \\ 88 & 17,4 & 5 & 0.90 \\ 87 & 16,8 & 4 & 1.48 \\ 87 & 17,5 & 4 & 6.92 \\ 89 & 17,8 & 4 & 3.42 \\ 87 & 17,6 & 4 & 1.10 \\ 83 & 17,1 & 4 & 5.73 \\ & & & \\ 89 & \end{array}$




$\begin{array}{rrrrrrrrr}12619 & 150617 & 104333 & 1 & 6,4 & 13,0 & 5,8 & 5,4 & 5,7 \\ 12622 & 150617 & 104419 & 1 & 6,1 & 11,8 & 6,1 & 8,0 & \\ 12626 & 150617 & 104542 & 1 & 6,5 & 11,6 & 6,2 & 6,9 & 6,9 \\ 12633 & 150617 & 104646 & 1 & 4,9 & 5,8 & & & \\ 12638 & 150617 & 104718 & 1 & 3,5 & 5,6 & 3,5 & 3,7 & 3,5 \\ 12649 & 150617 & 104851 & 1 & 6,5 & 11,4 & 6,6 & 6,2 & 6,5 \\ 12657 & 150617 & 105006 & 1 & 6,2 & 7,6 & 4,3 & 4,3 & 4,1 \\ 12663 & 150617 & 105032 & 1 & 6,8 & 11,8 & 6,8 & 7,3 & 7,4 \\ 12667 & 150617 & 105102 & 1 & 5,9 & 8,2 & 3,6 & 3,5 & 3,8 \\ 12669 & 150617 & 105121 & 1 & 6,2 & 10,9 & & & \\ 12671 & 150617 & 105128 & 1 & 6,9 & 9,2 & & & \\ 12675 & 150617 & 105155 & 1 & 6,6 & 11,6 & 7,2 & 7,3 & 6,7 \\ 12676 & 150617 & 105208 & 1 & 6,5 & 8,6 & 5,1 & 4,9 & 4,6 \\ 12677 & 150617 & 105226 & 1 & 7,1 & 11,1 & 8,0 & 7,5 & 8,0 \\ 12679 & 150617 & 105247 & 1 & 7,5 & 11,3 & 6,0 & 6,1 & 6,6 \\ 12685 & 150617 & 105350 & 1 & 5,7 & 7,1 & 3,2 & 3,5 & \\ 12686 & 150617 & 105353 & 1 & 6,4 & 9,2 & 3,6 & 3,6 & 3,9 \\ 12690 & 150617 & 105408 & 1 & 6,3 & 9,4 & 3,6 & 3,4 & 3,3 \\ 12703 & 150617 & 105533 & 1 & 5,7 & 11,5 & 7,7 & 7,7 & \\ 12717 & 150617 & 105732 & 1 & 6,0 & 10,9 & 5,7 & 6,1 & 5,7 \\ 12725 & 150617 & 105910 & 1 & 6,8 & 12,0 & 6,7 & 5,7 & 6,2 \\ 12735 & 150617 & 110026 & 1 & 5,7 & 8,6 & & & \\ 12800 & 150617 & 110928 & 1 & 6,6 & 13,6 & 6,2 & 6,0 & 6,3 \\ 12803 & 150617 & 111018 & 1 & 6,2 & 8,3 & & & \\ 12804 & 150617 & 111031 & 1 & 6,2 & 9,3 & 6,1 & 6,7 & 7,0 \\ 12811 & 150617 & 111121 & 1 & 5,6 & 7,4 & 3,8 & 3,6 & 3,7\end{array}$

\begin{tabular}{|c|c|c|c|c|}
\hline 36,3 & 3,6 & 5,9 & 1,3 & 1,2 \\
\hline 32,0 & 5,6 & 8,3 & 1,3 & \\
\hline 38,1 & 3,8 & 5,6 & 1,2 & 1,2 \\
\hline 10,7 & 5,2 & & & \\
\hline 19,8 & 3,7 & 3,5 & 1,3 & 1,3 \\
\hline 37,2 & 3,8 & 5,1 & 1,3 & 1,2 \\
\hline 26,5 & 3,8 & 5,9 & 1,3 & 1,2 \\
\hline 40,1 & 3,8 & 5,9 & 1,2 & 1,2 \\
\hline 25,0 & 3,8 & 6,1 & 1,3 & 1,3 \\
\hline 17,1 & 4,8 & & & \\
\hline 16,1 & 4,5 & & & \\
\hline 39,4 & 3,8 & 5,9 & 1,3 & 1,3 \\
\hline 29,7 & 3,7 & 5,9 & 1,3 & 1,3 \\
\hline 41,7 & 3,8 & 5,6 & 1,3 & 1,3 \\
\hline 37,5 & 3,9 & 5,8 & 1,3 & 1,2 \\
\hline 19,5 & 4,1 & 7,3 & 1,3 & \\
\hline 26,7 & 3,8 & 6,0 & 1,3 & 1,3 \\
\hline 26,0 & 3,9 & 6,0 & 1,3 & 1,2 \\
\hline 32,6 & 3,9 & 8,5 & 1,3 & \\
\hline 34,4 & 3,8 & 6,2 & 1,3 & 1,2 \\
\hline 37,4 & 4,2 & 5,7 & 1,3 & 1,3 \\
\hline 14,3 & 6,0 & & & \\
\hline 38,7 & 3,8 & 6,0 & 1,3 & 1,2 \\
\hline 14,5 & 5,1 & & & \\
\hline 35,3 & 3,6 & 6,1 & 1,2 & 1,2 \\
\hline 24,1 & 3,8 & 5,7 & 1,2 & 1,3 \\
\hline
\end{tabular}

$\begin{array}{rrrr}91 & 16,7 & 4 & 6.13 \\ 90 & 20,9 & 5 & 4.94 \\ 88 & 16,8 & 4 & 4.77 \\ 89 & 9,6 & 3 & 0.37 \\ 85 & 12,6 & 4 & 0.29 \\ 84 & 15,9 & 4 & 4.47 \\ 90 & 17,3 & 4 & 1.16 \\ 88 & 16,9 & 4 & 5.30 \\ 81 & 17,1 & 4 & 1.35 \\ 81 & 8,1 & 3 & 3.30 \\ 88 & 8,3 & 3 & 2.08 \\ 89 & 17,0 & 4 & 4.99 \\ 88 & 16,9 & 4 & 1.81 \\ 89 & 17,2 & 4 & 5.10 \\ 90 & 16,6 & 4 & 4.60 \\ 91 & 16,3 & 5 & 0.83 \\ 91 & 17,4 & 4 & 2.01 \\ 89 & 16,9 & 4 & 2.10 \\ 84 & 18,6 & 5 & 4.83 \\ 89 & 17,3 & 4 & 3.67 \\ 86 & 16,7 & 4 & 5.10 \\ 101 & 11,7 & 5 & 1.45 \\ 88 & 16,5 & 4 & 7.16 \\ 87 & 9,4 & 3 & 1.40 \\ 89 & 17,1 & 4 & 2.66 \\ 89 & 16,1 & 4 & 0.92\end{array}$




$\begin{array}{rrrrrrrrr}12818 & 150617 & 111223 & 1 & 5,9 & 6,6 & 2,9 & 3,1 & 3,1 \\ 12823 & 150617 & 111252 & 1 & 5,9 & 6,8 & 3,3 & 3,4 & \\ 12831 & 150617 & 111408 & 1 & 6,7 & 12,4 & 6,7 & 7,5 & 7,1 \\ 12834 & 150617 & 111428 & 1 & 6,4 & 8,1 & 4,9 & 5,1 & \\ 12840 & 150617 & 111510 & 1 & 6,8 & 11,4 & 6,7 & 6,7 & \\ 12846 & 150617 & 111605 & 1 & 1,1 & 2,1 & & & \\ 12849 & 150617 & 111629 & 1 & 6,4 & 12,1 & 6,5 & 6,6 & 6,4 \\ 12877 & 150617 & 112129 & 1 & 5,9 & 9,3 & 4,5 & & \\ 12879 & 150617 & 112152 & 1 & 5,7 & 8,8 & 5,1 & 5,2 & 5,1 \\ 12887 & 150617 & 112241 & 1 & 6,2 & 12,5 & 6,6 & 7,2 & 7,5 \\ 12895 & 150617 & 112335 & 1 & 5,4 & 8,0 & 7,9 & 9,0 & 8,6 \\ 12903 & 150617 & 112542 & 1 & 6,6 & 9,6 & 6,0 & 6,0 & 6,2 \\ 12909 & 150617 & 112636 & 1 & 6,7 & 12,2 & 6,5 & 5,9 & 6,1 \\ 12914 & 150617 & 112700 & 1 & 6,3 & 10,4 & 8,4 & 8,7 & 9,0 \\ 12921 & 150617 & 112740 & 1 & 6,8 & 12,1 & 5,4 & 5,3 & 5,5 \\ 12926 & 150617 & 112806 & 1 & 7,0 & 10,3 & 6,9 & 7,2 & 7,0 \\ 12928 & 150617 & 112821 & 1 & 4,1 & 5,5 & & & \\ 12938 & 150617 & 113053 & 1 & 5,7 & 7,5 & 4,0 & 3,9 & \\ 12947 & 150617 & 113313 & 1 & 5,2 & 5,9 & 3,3 & 3,3 & 3,4 \\ 12951 & 150617 & 113334 & 1 & 6,4 & 6,2 & 2,6 & 2,8 & 2,6 \\ 12955 & 150617 & 113418 & 1 & 6,5 & 10,9 & 6,9 & 7,0 & 7,3 \\ 12960 & 150617 & 113436 & 1 & 6,7 & 11,9 & 6,4 & 6,2 & 6,5 \\ 12965 & 150617 & 113516 & 1 & 6,3 & 7,5 & & & \\ 12974 & 150617 & 113653 & 1 & 6,3 & 8,7 & 4,2 & 5,1 & 4,7 \\ 12978 & 150617 & 113743 & 1 & 6,1 & 10,3 & 5,5 & 5,6 & 5,7 \\ 12985 & 150617 & 113821 & 1 & 6,1 & 8,9 & 3,5 & 3,4 & 3,7\end{array}$

\begin{tabular}{rrrrr}
\multicolumn{1}{l}{ GVM } & \multicolumn{3}{c}{ AD1 } & \multicolumn{3}{c}{ AD2 } & \\
& & & & \\
21,6 & 3,8 & 6,2 & 1,2 & 1,2 \\
19,4 & 3,8 & 7,1 & 1,3 & \\
40,4 & 3,7 & 4,2 & 1,3 & 1,2 \\
24,5 & 3,8 & 7,4 & 1,3 & \\
31,6 & 5,6 & 7,7 & 1,5 & \\
3,2 & 3,8 & & & \\
38,0 & 3,6 & 6,1 & 1,3 & 1,3 \\
19,7 & 7,2 & 1,3 & & \\
29,9 & 3,6 & 5,9 & 1,3 & 1,2 \\
40,0 & 3,9 & 3,0 & 1,2 & 1,2 \\
38,9 & 3,8 & 2,4 & 1,3 & 1,3 \\
34,4 & 3,5 & 5,7 & 1,2 & 1,2 \\
37,4 & 3,8 & 5,9 & 1,2 & 1,2 \\
42,8 & 3,7 & 2,8 & 1,2 & 1,2 \\
35,1 & 3,9 & 6,0 & 1,2 & 1,3 \\
38,4 & 3,9 & 5,5 & 1,3 & 1,3 \\
9,6 & 4,6 & & & 1,3 \\
21,1 & 3,9 & 7,3 & 1,3 & \\
21,1 & 3,8 & 5,6 & 1,3 & 1,3 \\
20,6 & 3,8 & 6,0 & 1,2 & 1,2 \\
38,6 & 3,8 & 5,1 & 1,3 & 1,3 \\
37,7 & 3,8 & 6,3 & 1,2 & 1,2 \\
13,8 & 4,7 & & & \\
29,0 & 4,0 & 5,9 & 1,3 & 1,3 \\
33,2 & 3,6 & 6,1 & 1,3 & 1,3 \\
25,6 & 3,9 & 5,9 & 1,3 & 1,2
\end{tabular}

SPD LENG CL ESAL 


$\begin{array}{rrrrrrrrr}12987 & 150617 & 113828 & 1 & 7,0 & 12,5 & 7,1 & 7,3 & 7,4 \\ 12993 & 150617 & 113905 & 1 & 6,7 & 11,6 & 8,0 & 8,0 & 7,1 \\ 12999 & 150617 & 113947 & 1 & 7,0 & 11,7 & 7,9 & 8,0 & 7,8 \\ 13006 & 150617 & 114041 & 1 & 6,7 & 10,6 & 5,3 & 5,4 & \\ 13033 & 150617 & 114419 & 1 & 7,3 & 10,9 & 7,2 & 7,2 & \\ 13050 & 150617 & 114705 & 1 & 7,0 & 9,7 & 5,2 & 4,8 & 5,0 \\ 13054 & 150617 & 114753 & 1 & 3,1 & 3,8 & & & \\ 13060 & 150617 & 114851 & 1 & 6,6 & 10,7 & 6,9 & 7,0 & 7,1 \\ 13068 & 150617 & 115017 & 1 & 6,2 & 10,7 & 8,2 & 7,5 & 7,5 \\ 13075 & 150617 & 115054 & 1 & 6,8 & 9,2 & 5,6 & 5,5 & \\ 13076 & 150617 & 115108 & 1 & 5,7 & 6,1 & 2,9 & 2,8 & \\ 13078 & 150617 & 115146 & 1 & 5,6 & 5,7 & 2,9 & 3,4 & 2,9 \\ 13085 & 150617 & 115312 & 1 & 2,5 & 2,8 & & & \\ 13089 & 150617 & 115350 & 1 & 6,5 & 13,1 & 6,1 & 6,1 & 6,6 \\ 13171 & 150617 & 120552 & 1 & 6,6 & 11,5 & 7,8 & 7,9 & 7,9 \\ 13182 & 150617 & 120718 & 1 & 6,5 & 10,8 & 5,5 & 5,6 & 6,1 \\ 13190 & 150617 & 120830 & 1 & 6,1 & 11,6 & 6,9 & 6,6 & 6,8 \\ 13193 & 150617 & 120859 & 1 & 5,8 & 9,2 & 5,3 & 5,5 & 5,3 \\ 13201 & 150617 & 121000 & 1 & 7,5 & 14,4 & 6,4 & 6,7 & 6,6 \\ 13205 & 150617 & 121024 & 1 & 5,7 & 11,0 & & & \\ 13212 & 150617 & 121150 & 1 & 6,0 & 5,6 & 2,2 & 2,2 & 2,5 \\ 13217 & 150617 & 121234 & 1 & 5,6 & 7,0 & 3,4 & 3,2 & 3,5 \\ 13221 & 150617 & 121252 & 1 & 6,2 & 11,7 & 5,4 & 6,8 & 7,5 \\ 13222 & 150617 & 121306 & 1 & 6,1 & 8,6 & 3,7 & 2,4 & 2,7 \\ 13225 & 150617 & 121337 & 1 & 6,7 & 12,0 & 4,2 & 3,8 & 4,5 \\ 13237 & 150617 & 121524 & 1 & 5,7 & 8,2 & 4,8 & 4,6 & 4,6\end{array}$

\begin{tabular}{|c|c|c|c|c|}
\hline 41,3 & 3,9 & 5,9 & 1,2 & 1,3 \\
\hline 41,4 & 3,6 & 5,6 & 1,3 & 1,3 \\
\hline 42,4 & 3,6 & 3,1 & 1,2 & 1,3 \\
\hline 28,0 & 5,7 & 7,7 & 1,3 & \\
\hline 32,6 & 5,4 & 7,6 & 1,4 & \\
\hline 31,7 & 3,8 & 5,6 & 1,2 & 1,3 \\
\hline 6,9 & 4,4 & & & \\
\hline 38,3 & 3,9 & 5,7 & 1,3 & 1,3 \\
\hline 40,1 & 3,9 & 3,9 & 1,3 & 1,3 \\
\hline 27,1 & 6,1 & 7,5 & 1,5 & \\
\hline 17,5 & 3,7 & 5,6 & 1,3 & \\
\hline 20,5 & 3,8 & 5,7 & 1,3 & 1,2 \\
\hline 5,3 & 4,3 & & & \\
\hline 38,4 & 3,6 & 5,3 & 1,3 & 1,2 \\
\hline 41,7 & 3,7 & 5,7 & 1,2 & 1,2 \\
\hline 34,5 & 4,0 & 5,8 & 1,3 & 1,2 \\
\hline 38,0 & 3,8 & 5,2 & 1,3 & 1,3 \\
\hline 31,1 & 4,2 & 6,0 & 1,3 & 1,3 \\
\hline 41,6 & 4,0 & 5,9 & 1,2 & 1,3 \\
\hline 16,7 & 6,5 & & & \\
\hline 18,5 & 3,9 & 5,9 & 1,3 & 1,3 \\
\hline 22,7 & 3,5 & 5,8 & 1,2 & 1,2 \\
\hline 37,6 & 3,6 & 4,4 & 1,2 & 1,2 \\
\hline 23,5 & 3,8 & 6,0 & 1,3 & 1,3 \\
\hline 31,2 & 3,8 & 5,9 & 1,3 & 1,2 \\
\hline 27,9 & 3,6 & 5,9 & 1,3 & 1,3 \\
\hline
\end{tabular}

$\begin{array}{rrrr}87 & 17,5 & 4 & 6.20 \\ 88 & 15,5 & 4 & 5.42 \\ 90 & 12,3 & 4 & 5.72 \\ 91 & 19,6 & 5 & 3.38 \\ 87 & 19,4 & 5 & 4.41 \\ 86 & 16,3 & 4 & 2.65 \\ 78 & 8,3 & 5 & 0.06 \\ 89 & 17,1 & 4 & 4.09 \\ 87 & 13,9 & 4 & 4.43 \\ 91 & 20,0 & 5 & 2.32 \\ 90 & 12,4 & 5 & 0.56 \\ 88 & 16,3 & 4 & 0.46 \\ 82 & 7,8 & 5 & 0.02 \\ 89 & 15,1 & 4 & 6.49 \\ 86 & 16,1 & 4 & 5.36 \\ 90 & 17,3 & 4 & 3.65 \\ 90 & 16,3 & 4 & 4.73 \\ 87 & 17,4 & 4 & 2.11 \\ 90 & 16,8 & 4 & 8.76 \\ 86 & 11,3 & 5 & 3.30 \\ 73 & 17,3 & 4 & 0.50 \\ 88 & 16,7 & 4 & 0.77 \\ 87 & 13,8 & 4 & 4.75 \\ 89 & 17,3 & 4 & 1.56 \\ 87 & 16,6 & 4 & 4.63 \\ 90 & 16,7 & 4 & 1.40\end{array}$




$\begin{array}{rrrrrrrrr}13241 & 150617 & 121555 & 1 & 5,9 & 7,7 & 3,9 & 3,7 & 3,7 \\ 13251 & 150617 & 121710 & 1 & 7,1 & 8,7 & & & \\ 13256 & 150617 & 121740 & 1 & 7,1 & 9,0 & & & \\ 13259 & 150617 & 121754 & 1 & 6,6 & 11,5 & 6,6 & 6,5 & 6,9 \\ 13266 & 150617 & 121857 & 1 & 4,9 & 6,1 & & & \\ 13269 & 150617 & 121920 & 1 & 7,3 & 9,6 & 6,3 & 6,1 & 5,9 \\ 13272 & 150617 & 122000 & 1 & 6,2 & 7,7 & 3,2 & 3,3 & 3,8 \\ 13273 & 150617 & 122014 & 1 & 6,4 & 10,3 & 7,4 & 6,8 & \\ 13278 & 150617 & 122104 & 1 & 5,2 & 11,8 & 1,2 & 3,4 & 3,2 \\ 13283 & 150617 & 122202 & 1 & 5,5 & 7,8 & 4,7 & 2,6 & 3,9 \\ 13285 & 150617 & 122225 & 1 & 7,4 & 13,5 & 5,2 & 5,4 & 5,4 \\ 13297 & 150617 & 122506 & 1 & 6,3 & 11,0 & 6,7 & 7,7 & 7,5 \\ 13300 & 150617 & 122538 & 1 & 6,1 & 12,4 & 6,6 & 6,8 & 6,8 \\ 13305 & 150617 & 122601 & 1 & 5,9 & 7,3 & & & \\ 13320 & 150617 & 122833 & 1 & 7,4 & 9,6 & 1,9 & 2,0 & \\ 13322 & 150617 & 122852 & 1 & 6,6 & 12,5 & 3,6 & 4,3 & 3,3 \\ 13323 & 150617 & 122903 & 1 & 6,3 & 13,2 & 3,6 & 3,4 & 4,2 \\ 13328 & 150617 & 122941 & 1 & 6,5 & 12,2 & 6,9 & 7,4 & 7,5 \\ 13335 & 150617 & 123037 & 1 & 5,7 & 8,9 & 4,1 & 4,1 & 3,3 \\ 13375 & 150617 & 123554 & 1 & 6,4 & 8,4 & 3,7 & 4,2 & 4,2 \\ 13376 & 150617 & 123603 & 1 & 6,9 & 12,0 & 6,6 & 6,5 & 7,2 \\ 13386 & 150617 & 123735 & 1 & 6,6 & 11,7 & 7,6 & 7,4 & 7,3 \\ 13411 & 150617 & 124111 & 1 & 6,1 & 8,7 & 4,6 & 4,1 & \\ 13426 & 150617 & 124438 & 1 & 5,8 & 9,4 & 8,5 & 8,3 & 8,3 \\ 13432 & 150617 & 124538 & 1 & 5,7 & 9,2 & 3,7 & 3,6 & 4,1 \\ 13433 & 150617 & 124550 & 1 & 5,6 & 7,2 & 3,7 & 3,4 & \end{array}$

\begin{tabular}{|c|c|c|c|c|}
\hline 24,9 & 3,8 & 5,8 & 1,2 & 1,3 \\
\hline 15,8 & 4,5 & & & \\
\hline 16,1 & 4,2 & & & \\
\hline 38,1 & 3,8 & 5,1 & 1,2 & 1,2 \\
\hline 11,0 & 5,9 & & & \\
\hline 35,2 & 3,9 & 5,6 & 1,3 & 1,3 \\
\hline 24,2 & 3,8 & 6,0 & 1,2 & 1,2 \\
\hline 30,9 & 3,7 & 8,5 & 1,3 & \\
\hline 28,4 & 4,6 & 1,4 & 6,3 & 1,2 \\
\hline 24,5 & 3,9 & 5,9 & 1,3 & 1,3 \\
\hline 36,9 & 3,8 & 5,6 & 1,3 & 1,2 \\
\hline 39,2 & 3,6 & 6,0 & 1,2 & 1,2 \\
\hline 38,7 & 3,7 & 6,1 & 1,2 & 1,2 \\
\hline 13,2 & 6,1 & & & \\
\hline 20,9 & 6,0 & 6,1 & 1,5 & \\
\hline 30,3 & 3,8 & 5,9 & 1,3 & 1,3 \\
\hline 30,7 & 3,8 & 6,1 & 1,3 & 1,3 \\
\hline 40,5 & 3,7 & 5,6 & 1,3 & 1,3 \\
\hline 26,1 & 3,7 & 6,1 & 1,3 & 1,3 \\
\hline 26,9 & 3,9 & 5,7 & 1,2 & 1,3 \\
\hline 39,2 & 3,8 & 5,8 & 1,2 & 1,2 \\
\hline 40,6 & 3,8 & 6,1 & 1,2 & 1,3 \\
\hline 23,5 & 3,8 & 7,4 & 1,3 & \\
\hline 40,3 & 3,9 & 3,1 & 1,3 & 1,3 \\
\hline 26,3 & 4,2 & 6,1 & 1,3 & 1,2 \\
\hline 19,9 & 5,6 & 7,0 & 1,3 & \\
\hline
\end{tabular}

$\begin{array}{lrlr}88 & 16,9 & 4 & 1.10 \\ 89 & 9,8 & 3 & 1.84 \\ 85 & 8,1 & 3 & 2.02 \\ 83 & 15,4 & 4 & 4.70 \\ 85 & 10,6 & 3 & 0.42 \\ 88 & 16,9 & 4 & 2.97 \\ 87 & 17,0 & 4 & 1.14 \\ 89 & 18,6 & 5 & 3.59 \\ 89 & 18,5 & 4 & 0.73 \\ 90 & 16,1 & 4 & 1.06 \\ 88 & 16,3 & 4 & 7.00 \\ 77 & 16,1 & 4 & 4.45 \\ 87 & 16,0 & 4 & 5.60 \\ 79 & 10,0 & 3 & 0.89 \\ 90 & 17,4 & 5 & 2.50 \\ 83 & 17,5 & 4 & 5.14 \\ 81 & 17,0 & 4 & 6.08 \\ 90 & 15,3 & 4 & 5.72 \\ 84 & 17,6 & 4 & 1.70 \\ 89 & 16,7 & 4 & 1.58 \\ 88 & 16,3 & 4 & 5.35 \\ 91 & 17,1 & 4 & 5.29 \\ 93 & 17,3 & 4 & 1.69 \\ 88 & 12,4 & 4 & 3.79 \\ 90 & 17,1 & 4 & 1.88 \\ 93 & 17,9 & 4 & 0.83 \\ & & & \\ 83 & & \\ 83 & & \end{array}$




$\begin{array}{rrrrrrrrr}13451 & 150617 & 124843 & 1 & 6,5 & 11,2 & 7,6 & 7,6 & 7,9 \\ 13456 & 150617 & 124917 & 1 & 6,2 & 8,4 & 4,1 & 4,7 & 4,0 \\ 13457 & 150617 & 124918 & 1 & 4,7 & 5,6 & & & \\ 13458 & 150617 & 124926 & 1 & 5,9 & 7,0 & 4,0 & 3,8 & 3,9 \\ 13459 & 150617 & 124938 & 1 & 7,2 & 9,2 & 5,4 & 5,7 & \\ 13460 & 150617 & 124941 & 1 & 7,6 & 12,7 & 6,4 & 6,6 & 7,4 \\ 13462 & 150617 & 124954 & 1 & 6,3 & 11,7 & 8,0 & 8,0 & 8,0 \\ 13468 & 150617 & 125049 & 1 & 6,6 & 12,3 & 6,2 & 6,5 & 6,9 \\ 13471 & 150617 & 125126 & 1 & 6,6 & 9,9 & 6,1 & 6,6 & 6,7 \\ 13472 & 150617 & 125203 & 1 & 6,9 & 14,2 & 7,1 & 6,9 & 6,9 \\ 13474 & 150617 & 125215 & 1 & 6,8 & 11,1 & 6,8 & 6,8 & 7,0 \\ 13481 & 150617 & 125250 & 1 & 5,7 & 8,2 & 3,5 & 3,7 & \\ 13486 & 150617 & 125331 & 1 & 4,2 & 6,7 & & & \\ 13487 & 150617 & 125339 & 1 & 7,0 & 13,1 & 7,6 & 7,9 & 8,2 \\ 13491 & 150617 & 125436 & 1 & 6,8 & 12,3 & 8,5 & 8,6 & 7,8 \\ 13492 & 150617 & 125437 & 1 & 7,6 & 4,0 & 4,0 & 3,7 & 3,4 \\ 13495 & 150617 & 125501 & 1 & 8,0 & 10,7 & 7,5 & 7,8 & 7,5 \\ 13497 & 150617 & 125528 & 1 & 4,5 & 5,8 & & & \\ 13500 & 150617 & 125545 & 1 & 8,1 & 14,7 & 8,1 & 7,6 & 7,8 \\ 13518 & 150617 & 125805 & 1 & 4,7 & 4,7 & & & \\ 13524 & 150617 & 125856 & 1 & 6,9 & 10,7 & 8,5 & 8,3 & 9,0 \\ 13526 & 150617 & 125930 & 1 & 5,8 & 12,4 & 6,7 & 5,6 & \\ 13532 & 150617 & 130148 & 1 & 6,0 & 9,3 & 5,0 & 4,9 & 4,9 \\ 13542 & 150617 & 130425 & 1 & 6,1 & 10,4 & 6,3 & 6,7 & 7,5 \\ 13558 & 150617 & 130622 & 1 & 7,0 & 12,0 & 3,2 & 2,9 & 3,3 \\ 13561 & 150617 & 130651 & 1 & 6,7 & 10,7 & 8,0 & 7,9 & 8,0\end{array}$

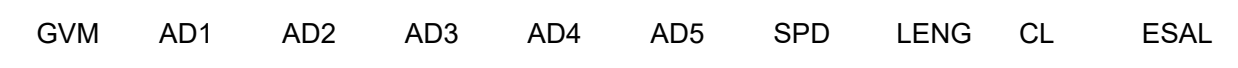

$\begin{array}{rllll}40,8 & 3,6 & 5,0 & 1,3 & 1,3 \\ 27,4 & 4,0 & 6,0 & 1,2 & 1,3 \\ 10,3 & 5,5 & & & \\ 24,6 & 3,9 & 5,8 & 1,2 & 1,3 \\ 27,5 & 3,7 & 7,4 & 1,3 & \\ 40,7 & 3,6 & 5,9 & 1,3 & 1,3 \\ 42,0 & 3,8 & 2,5 & 1,2 & 1,3 \\ 38,5 & 3,6 & 5,7 & 1,2 & 1,2 \\ 35,9 & 3,8 & 5,8 & 1,3 & 1,2 \\ 42,0 & 3,6 & 6,1 & 1,3 & 1,3 \\ 38,5 & 3,7 & 6,2 & 1,2 & 1,3 \\ 21,1 & 3,8 & 7,4 & 1,3 & \\ 10,9 & 5,2 & & & \\ 43,8 & 4,1 & 5,5 & 1,3 & 1,2 \\ 44,0 & 3,6 & 3,9 & 1,3 & 1,3 \\ 22,7 & 3,9 & 5,9 & 1,2 & 1,3 \\ 41,5 & 3,8 & 6,2 & 1,3 & 1,3 \\ 10,3 & 4,2 & & & \\ 46,3 & 3,8 & 6,0 & 1,3 & 1,3 \\ 9,4 & 5,4 & & & \\ 43,4 & 3,9 & 5,8 & 1,4 & 1,3 \\ 30,5 & 5,4 & 8,5 & 1,2 & \\ 30,1 & 3,8 & 5,9 & 1,3 & 1,3 \\ 37,0 & 3,8 & 5,8 & 1,3 & 1,2 \\ 28,4 & 3,8 & 5,8 & 1,3 & 1,2 \\ 41,3 & 4,2 & 5,7 & 1,3 & 1,4\end{array}$

$\begin{array}{rrrl}87 & 14,7 & 4 & 4.92 \\ 85 & 17,3 & 4 & 1.56 \\ 85 & 9,7 & 5 & 0.30 \\ 91 & 17,2 & 4 & 0.87 \\ 80 & 17,5 & 5 & 2.44 \\ 78 & 16,6 & 4 & 6.54 \\ 88 & 12,1 & 4 & 5.61 \\ 82 & 16,5 & 4 & 5.51 \\ 91 & 17,1 & 4 & 3.12 \\ 84 & 17,2 & 4 & 8.44 \\ 88 & 17,6 & 4 & 4.44 \\ 86 & 17,3 & 5 & 1.29 \\ 90 & 9,8 & 3 & 0.51 \\ 89 & 15,7 & 4 & 7.49 \\ 87 & 13,2 & 4 & 6.65 \\ 83 & 17,3 & 4 & 0.84 \\ 90 & 17,2 & 4 & 4.94 \\ 89 & 8,9 & 3 & 0.33 \\ 91 & 17,8 & 4 & 10.22 \\ 87 & 9,1 & 3 & 0.20 \\ 90 & 17,2 & 4 & 5.33 \\ 89 & 20,3 & 5 & 5.21 \\ 87 & 17,3 & 4 & 2.13 \\ 88 & 16,9 & 4 & 3.63 \\ 89 & 17,1 & 4 & 4.64 \\ 82 & 14,5 & 4 & 4.71 \\ & & & \end{array}$




$\begin{array}{rrrrrrrrr}13582 & 150617 & 130942 & 1 & 6,0 & 11,2 & 6,8 & 6,5 & 6,6 \\ 13584 & 150617 & 131005 & 1 & 5,9 & 11,7 & 7,6 & 7,6 & 7,4 \\ 13589 & 150617 & 131048 & 1 & 6,1 & 7,5 & 3,5 & 3,6 & 3,5 \\ 13595 & 150617 & 131154 & 1 & 7,0 & 13,3 & 6,9 & 5,4 & 5,6 \\ 13599 & 150617 & 131251 & 1 & 5,9 & 10,9 & 8,0 & 7,3 & 7,5 \\ 13601 & 150617 & 131328 & 1 & 5,3 & 7,9 & 3,3 & 3,9 & 3,4 \\ 13605 & 150617 & 131413 & 1 & 6,9 & 12,5 & 4,7 & 4,4 & 4,9 \\ 13608 & 150617 & 131434 & 1 & 5,9 & 9,0 & 4,1 & 3,8 & 4,1 \\ 13609 & 150617 & 131502 & 1 & 6,2 & 13,2 & 6,5 & 6,9 & 6,7 \\ 13619 & 150617 & 131644 & 1 & 0,9 & 1,1 & & & \\ 13649 & 150617 & 132217 & 1 & 6,4 & 8,7 & 4,1 & 4,1 & 4,1 \\ 13651 & 150617 & 132239 & 1 & 6,2 & 8,1 & 3,2 & 3,6 & 3,4 \\ 13653 & 150617 & 132333 & 1 & 6,5 & 7,4 & 3,7 & 3,5 & 3,8 \\ 13656 & 150617 & 132403 & 1 & 5,7 & 8,5 & 3,9 & 3,8 & 3,8 \\ 13659 & 150617 & 132424 & 1 & 6,0 & 8,1 & 4,2 & 4,2 & 4,1 \\ 13663 & 150617 & 132438 & 1 & 7,2 & 12,2 & 7,1 & 7,1 & 7,3 \\ 13669 & 150617 & 132512 & 1 & 5,7 & 10,1 & 8,2 & 8,3 & 9,0 \\ 13671 & 150617 & 132529 & 1 & 6,4 & 10,6 & 6,3 & 7,2 & 6,4 \\ 13675 & 150617 & 132554 & 1 & 6,1 & 8,1 & 3,3 & 3,3 & 3,4 \\ 13679 & 150617 & 132633 & 1 & 2,6 & 3,6 & & & \\ 13680 & 150617 & 132649 & 1 & 6,5 & 7,3 & 4,6 & 4,6 & 4,4 \\ 13685 & 150617 & 132751 & 1 & 6,0 & 6,0 & 2,7 & 1,8 & \\ 13689 & 150617 & 132812 & 1 & 6,1 & 6,4 & 3,0 & & \\ 13698 & 150617 & 132957 & 1 & 5,9 & 5,2 & 4,9 & 2,2 & 2,0 \\ 13700 & 150617 & 133018 & 1 & 7,0 & 12,2 & 7,6 & 8,1 & 7,6 \\ 13713 & 150617 & 133236 & 1 & 7,2 & 11,9 & 8,2 & 7,3 & 6,2\end{array}$

\begin{tabular}{|c|c|c|c|c|}
\hline 37,1 & 3,6 & 5,1 & 1,3 & 1,2 \\
\hline 40,2 & 3,8 & 5,4 & 1,2 & 1,2 \\
\hline 24,2 & 3,8 & 6,1 & 1,2 & 1,3 \\
\hline 38,2 & 3,8 & 7,1 & 1,3 & 1,3 \\
\hline 39,6 & 3,6 & 5,6 & 1,3 & 1,2 \\
\hline 23,8 & 3,6 & 6,2 & 1,3 & 1,3 \\
\hline 33,4 & 3,8 & 6,2 & 1,2 & 1,2 \\
\hline 26,9 & 3,9 & 6,0 & 1,3 & 1,3 \\
\hline 39,5 & 3,6 & 5,8 & 1,2 & 1,3 \\
\hline 2,0 & 4,0 & & & \\
\hline 27,4 & 3,8 & 5,8 & 1,3 & 1,3 \\
\hline 24,5 & 3,9 & 6,1 & 1,3 & 1,3 \\
\hline 24,9 & 3,8 & 5,7 & 1,3 & 1,2 \\
\hline 25,7 & 4,1 & 6,0 & 1,3 & 1,2 \\
\hline 26,6 & 3,8 & 5,7 & 1,2 & 1,3 \\
\hline 40,9 & 3,8 & 5,8 & 1,2 & 1,3 \\
\hline 41,3 & 3,7 & 3,1 & 1,3 & 1,3 \\
\hline 36,9 & 4,0 & 3,7 & 1,2 & 1,3 \\
\hline 24,2 & 3,7 & 6,2 & 1,2 & 1,3 \\
\hline 6,2 & 4,1 & & & \\
\hline 27,4 & 3,8 & 5,7 & 1,3 & 1,3 \\
\hline 16,5 & 3,9 & 6,7 & 1,3 & \\
\hline 15,5 & 4,5 & 1,3 & & \\
\hline 20,2 & 3,7 & 6,5 & 1,3 & 1,3 \\
\hline 42,5 & 3,6 & 5,9 & 1,3 & 1,3 \\
\hline 40,8 & 3,9 & 5,8 & 1,3 & 1,3 \\
\hline
\end{tabular}

$\begin{array}{rrrr}87 & 16,0 & 4 & 4.25 \\ 89 & 15,3 & 4 & 5.20 \\ 88 & 17,5 & 4 & 1.05 \\ 88 & 16,9 & 4 & 6.77 \\ 86 & 15,3 & 4 & 4.47 \\ 91 & 17,6 & 4 & 1.06 \\ 88 & 17,5 & 4 & 5.44 \\ 88 & 17,7 & 4 & 1.81 \\ 83 & 16,8 & 4 & 6.73 \\ 96 & 7,2 & 1 & 0.00 \\ 90 & 17,8 & 4 & 1.75 \\ 90 & 18,1 & 4 & 1.35 \\ 89 & 17,5 & 4 & 1.11 \\ 91 & 17,5 & 4 & 1.47 \\ 87 & 17,6 & 4 & 1.37 \\ 89 & 17,2 & 4 & 5.86 \\ 87 & 12,5 & 4 & 4.39 \\ 92 & 13,6 & 4 & 3.78 \\ 90 & 17,4 & 4 & 1.32 \\ 91 & 8,3 & 3 & 0.04 \\ 90 & 17,3 & 4 & 1.16 \\ 91 & 15,7 & 5 & 0.58 \\ 91 & 10,3 & 5 & 0.44 \\ 87 & 16,1 & 4 & 0.44 \\ 90 & 16,4 & 4 & 6.18 \\ 88 & 16,5 & 4 & 5.58 \\ & & & \end{array}$




$\begin{array}{rrrrrrrrr}13718 & 150617 & 133311 & 1 & 6,4 & 12,5 & 7,1 & 8,0 & 7,3 \\ 13720 & 150617 & 133344 & 1 & 6,3 & 12,1 & 7,0 & 7,2 & 7,2 \\ 13727 & 150617 & 133507 & 1 & 3,4 & 3,8 & 4,2 & 3,9 & 3,9 \\ 13740 & 150617 & 133632 & 1 & 7,2 & 8,3 & 5,3 & 4,7 & \\ 13748 & 150617 & 133735 & 1 & 5,0 & 5,7 & 2,3 & 2,1 & \\ 13755 & 150617 & 133831 & 1 & 6,8 & 12,2 & 6,7 & 7,0 & 6,6 \\ 13773 & 150617 & 134129 & 1 & 5,0 & 7,8 & 5,4 & 5,2 & \\ 13774 & 150617 & 134139 & 1 & 4,8 & 9,6 & & & \\ 13778 & 150617 & 134222 & 1 & 6,3 & 7,8 & 3,0 & 2,9 & 3,4 \\ 13781 & 150617 & 134248 & 1 & 7,0 & 12,5 & 8,0 & 7,8 & 8,0 \\ 13785 & 150617 & 134424 & 1 & 5,9 & 9,0 & 3,8 & 3,5 & 3,7 \\ 13811 & 150617 & 134725 & 1 & 7,0 & 9,3 & 5,6 & 5,4 & 5,7 \\ 13826 & 150617 & 135010 & 1 & 7,3 & 11,6 & 8,2 & 7,2 & 8,1 \\ 13828 & 150617 & 135029 & 1 & 6,5 & 11,3 & 5,2 & 5,3 & 5,3 \\ 13829 & 150617 & 135035 & 1 & 6,2 & 7,4 & 3,3 & 4,1 & 4,1 \\ 13831 & 150617 & 135052 & 1 & 6,2 & 8,6 & 5,2 & 5,3 & \\ 13844 & 150617 & 135302 & 1 & 5,8 & 8,1 & 3,4 & 3,4 & 3,5 \\ 20247 & 150618 & 102430 & 1 & 6,3 & 10,9 & 6,8 & 7,3 & 7,1 \\ 20267 & 150618 & 102740 & 1 & 5,9 & 6,5 & 3,2 & & \\ 20270 & 150618 & 102817 & 1 & 5,2 & 10,9 & & & \\ 20273 & 150618 & 102834 & 1 & 6,1 & 9,1 & 3,2 & 3,0 & 3,1 \\ 20280 & 150618 & 103006 & 1 & 5,6 & 5,5 & 2,3 & 2,8 & 3,0 \\ 20281 & 150618 & 103016 & 1 & 5,6 & 9,0 & 5,1 & 5,2 & 5,1 \\ 20282 & 150618 & 103027 & 1 & 6,4 & 12,4 & 7,0 & 7,4 & 7,8 \\ 20287 & 150618 & 103112 & 1 & 6,4 & 9,0 & 7,5 & 7,9 & 8,1 \\ 20289 & 150618 & 103126 & 1 & 6,0 & 12,5 & 6,0 & 6,8 & 7,4\end{array}$

\begin{tabular}{|c|c|c|c|c|}
\hline 41,3 & 3,8 & 4,5 & 1,3 & 1,3 \\
\hline 39,8 & 3,7 & 4,4 & 1,3 & 1,3 \\
\hline 19,2 & 4,0 & 5,9 & 1,3 & 1,3 \\
\hline 25,5 & 3,9 & 7,2 & 1,3 & \\
\hline 15,1 & 4,0 & 6,5 & 1,3 & \\
\hline 39,3 & 3,9 & 5,9 & 1,3 & 1,3 \\
\hline 23,4 & 5,7 & 6,8 & 1,5 & \\
\hline 14,4 & 4,5 & & & \\
\hline 23,4 & 3,9 & 5,9 & 1,3 & 1,3 \\
\hline 43,3 & 3,9 & 6,0 & 1,3 & 1,3 \\
\hline 25,9 & 3,6 & 6,1 & 1,2 & 1,3 \\
\hline 33,0 & 3,9 & 5,7 & 1,3 & 1,2 \\
\hline 42,4 & 3,8 & 5,8 & 1,2 & 1,2 \\
\hline 33,6 & 3,8 & 5,9 & 1,3 & 1,2 \\
\hline 25,1 & 3,9 & 5,6 & 1,2 & 1,3 \\
\hline 25,3 & 3,8 & 7,0 & 1,3 & \\
\hline 24,2 & 3,8 & 6,1 & 1,3 & 1,3 \\
\hline 38,4 & 3,6 & 5,9 & 1,2 & 1,2 \\
\hline 15,6 & 5,3 & 1,3 & & \\
\hline 16,1 & 5,9 & & & \\
\hline 24,5 & 3,6 & 5,8 & 1,2 & 1,3 \\
\hline 19,2 & 3,8 & 5,8 & 1,2 & 1,2 \\
\hline 30,0 & 3,6 & 6,0 & 1,2 & 1,2 \\
\hline 41,0 & 3,6 & 5,3 & 1,3 & 1,2 \\
\hline 38,9 & 3,9 & 5,6 & 1,3 & 1,2 \\
\hline 38,7 & 4,1 & 6,6 & 1,3 & 1,4 \\
\hline
\end{tabular}

$\begin{array}{lrlr}82 & 15,5 & 4 & 6.16 \\ 82 & 15,2 & 4 & 5.49 \\ 93 & 18,2 & 4 & 0.15 \\ 91 & 17,3 & 5 & 1.84 \\ 85 & 15,6 & 5 & 0.35 \\ 90 & 17,3 & 4 & 5.55 \\ 94 & 19,1 & 4 & 1.16 \\ 90 & 9,0 & 3 & 1.95 \\ 88 & 17,5 & 4 & 1.18 \\ 90 & 17,4 & 4 & 6.74 \\ 91 & 17,5 & 4 & 1.78 \\ 88 & 16,7 & 4 & 2.51 \\ 85 & 17,2 & 4 & 5.69 \\ 89 & 17,7 & 4 & 4.01 \\ 88 & 17,4 & 4 & 1.05 \\ 90 & 17,3 & 4 & 1.77 \\ 90 & 17,6 & 4 & 1.28 \\ 73 & 16,5 & 4 & 4.23 \\ 86 & 10,5 & 5 & 0.42 \\ 91 & 11,3 & 5 & 3.12 \\ 84 & 16,0 & 4 & 1.85 \\ 82 & 15,8 & 4 & 0.41 \\ 82 & 16,6 & 4 & 1.89 \\ 87 & 14,0 & 4 & 6.00 \\ 89 & 17,7 & 4 & 3.21 \\ 93 & 18,6 & 4 & 5.82 \\ & & & \\ 91 & & \end{array}$




$\begin{array}{rrrrrrrrr}20292 & 150618 & 103223 & 1 & 6,6 & 12,3 & 5,9 & 7,1 & 6,7 \\ 20299 & 150618 & 103259 & 1 & 5,9 & 6,6 & 3,5 & 3,1 & \\ 20301 & 150618 & 103309 & 1 & 5,7 & 5,7 & 3,2 & 2,8 & \\ 20319 & 150618 & 103437 & 1 & 5,8 & 5,8 & 3,4 & 3,5 & \\ 20320 & 150618 & 103445 & 1 & 3,7 & 9,3 & & & \\ 20327 & 150618 & 103616 & 1 & 6,7 & 11,2 & 6,5 & 6,2 & 6,9 \\ 20337 & 150618 & 103719 & 1 & 6,4 & 11,4 & 7,4 & 6,8 & 7,3 \\ 20338 & 150618 & 103733 & 1 & 6,1 & 8,5 & 3,6 & 3,5 & 2,8 \\ 20339 & 150618 & 103800 & 1 & 6,3 & 10,6 & 6,3 & 8,3 & \\ 20353 & 150618 & 104021 & 1 & 6,1 & 6,5 & 2,8 & 3,3 & 2,9 \\ 20355 & 150618 & 104040 & 1 & 5,9 & 7,8 & 3,6 & 3,8 & 3,7 \\ 20356 & 150618 & 104053 & 1 & 5,9 & 14,0 & 6,0 & 5,7 & 6,0 \\ 20358 & 150618 & 104101 & 1 & 6,2 & 7,9 & 3,6 & 3,7 & \\ 20361 & 150618 & 104135 & 1 & 5,7 & 7,8 & 6,4 & 6,3 & \\ 20363 & 150618 & 104153 & 1 & 6,6 & 13,6 & 5,6 & 5,6 & 5,7 \\ 20366 & 150618 & 104234 & 1 & 6,7 & 11,8 & 8,1 & 9,6 & \\ 20368 & 150618 & 104253 & 1 & 6,8 & 9,3 & & & \\ 20370 & 150618 & 104301 & 1 & 6,1 & 6,1 & 3,2 & 2,9 & 2,9 \\ 20372 & 150618 & 104319 & 1 & 5,5 & 5,9 & 2,7 & 2,6 & 2,4 \\ 20373 & 150618 & 104336 & 1 & 6,4 & 12,3 & 6,4 & 6,7 & 7,2 \\ 20378 & 150618 & 104427 & 1 & 6,7 & 10,4 & 6,9 & 7,0 & 6,9 \\ 20382 & 150618 & 104453 & 1 & 6,0 & 8,2 & 4,1 & 3,9 & 4,4 \\ 20388 & 150618 & 104554 & 1 & 7,0 & 11,9 & 6,1 & 6,5 & 6,3 \\ 20395 & 150618 & 104656 & 1 & 6,1 & 8,3 & 3,3 & 3,4 & 3,3 \\ 20396 & 150618 & 104710 & 1 & 5,6 & 6,6 & 3,2 & 3,5 & \\ 20399 & 150618 & 104735 & 1 & 6,0 & 10,3 & 6,4 & 6,0 & 5,9\end{array}$

\begin{tabular}{|c|c|c|c|c|}
\hline 38,6 & 3,7 & 6,1 & 1,3 & 1,3 \\
\hline 19,1 & 4,0 & 7,7 & 1,3 & \\
\hline 17,4 & 3,7 & 5,7 & 1,3 & \\
\hline 18,5 & 3,8 & 7,4 & 1,3 & \\
\hline 13,0 & 4,9 & & & \\
\hline 37,5 & 3,7 & 5,8 & 1,3 & 1,2 \\
\hline 39,3 & 3,8 & 5,1 & 1,3 & 1,2 \\
\hline 24,5 & 3,8 & 5,6 & 1,2 & 1,3 \\
\hline 31,5 & 3,7 & 8,5 & 1,3 & \\
\hline 21,6 & 3,7 & 5,8 & 1,3 & 1,2 \\
\hline 24,8 & 3,9 & 5,6 & 1,2 & 1,2 \\
\hline 37,6 & 3,8 & 6,0 & 1,3 & 1,3 \\
\hline 21,4 & 3,9 & 7,4 & 1,3 & \\
\hline 26,2 & 3,9 & 7,4 & 1,3 & \\
\hline 37,1 & 3,8 & 6,2 & 1,3 & 1,3 \\
\hline 36,2 & 4,0 & 8,6 & 1,3 & \\
\hline 16,1 & 5,6 & & & \\
\hline 21,2 & 3,8 & 6,1 & 1,3 & 1,3 \\
\hline 19,1 & 3,8 & 6,2 & 1,3 & 1,3 \\
\hline 39,0 & 3,7 & 5,8 & 1,3 & 1,3 \\
\hline 37,9 & 3,7 & 5,9 & 1,3 & 1,3 \\
\hline 26,6 & 4,0 & 6,2 & 1,3 & 1,3 \\
\hline 37,8 & 3,9 & 6,1 & 1,3 & 1,3 \\
\hline 24,4 & 3,8 & 5,5 & 1,2 & 1,3 \\
\hline 18,9 & 3,7 & 7,5 & 1,2 & \\
\hline 34,6 & 3,6 & 5,7 & 1,2 & 1,2 \\
\hline
\end{tabular}

$\begin{array}{rrrr}88 & 17,6 & 4 & 5.52 \\ 93 & 17,6 & 5 & 0.72 \\ 90 & 14,7 & 5 & 0.49 \\ 91 & 17,5 & 5 & 0.54 \\ 91 & 9,7 & 5 & 1.68 \\ 88 & 17,0 & 4 & 4.37 \\ 86 & 15,4 & 4 & 4.79 \\ 86 & 16,7 & 4 & 1.52 \\ 88 & 18,8 & 5 & 3.93 \\ 88 & 16,0 & 4 & 0.72 \\ 87 & 16,4 & 4 & 1.14 \\ 87 & 16,4 & 4 & 7.48 \\ 89 & 17,8 & 5 & 1.23 \\ 91 & 17,8 & 4 & 1.52 \\ 87 & 17,3 & 4 & 6.97 \\ 90 & 20,0 & 5 & 6.19 \\ 95 & 12,1 & 3 & 2.11 \\ 83 & 17,9 & 4 & 0.64 \\ 91 & 17,6 & 4 & 0.47 \\ 92 & 17,3 & 4 & 5.56 \\ 90 & 17,2 & 4 & 3.82 \\ 91 & 17,7 & 4 & 1.41 \\ 91 & 17,1 & 4 & 5.08 \\ 90 & 17,0 & 4 & 1.42 \\ 87 & 16,6 & 5 & 0.65 \\ 84 & 16,0 & 4 & 3.16 \\ & & & \\ 81\end{array}$




$\begin{array}{rrrrrrrrr}20400 & 150618 & 104756 & 1 & 6,1 & 11,7 & 6,2 & 6,3 & 6,1 \\ 20405 & 150618 & 104838 & 1 & 7,5 & 14,0 & 6,3 & 6,1 & 6,4 \\ 20410 & 150618 & 104906 & 1 & 6,1 & 14,2 & 7,1 & 7,4 & 7,5 \\ 20412 & 150618 & 104950 & 1 & 6,1 & 11,8 & 6,8 & 7,2 & 7,8 \\ 20414 & 150618 & 105004 & 1 & 5,6 & 6,0 & 2,3 & 3,1 & \\ 20416 & 150618 & 105029 & 1 & 6,3 & 12,3 & 6,5 & 6,7 & 7,0 \\ 20421 & 150618 & 105119 & 1 & 6,4 & 12,7 & 6,4 & 6,7 & 6,9 \\ 20430 & 150618 & 105246 & 1 & 5,9 & 7,3 & 4,1 & 3,9 & 3,9 \\ 20442 & 150618 & 105417 & 1 & 6,0 & 11,5 & 7,3 & 6,2 & 6,7 \\ 20448 & 150618 & 105449 & 1 & 7,0 & 9,9 & 4,9 & 5,9 & 6,0 \\ 20456 & 150618 & 105601 & 1 & 5,6 & 8,9 & 3,4 & 3,6 & 3,6 \\ 20458 & 150618 & 105617 & 1 & 6,7 & 9,5 & 5,3 & 5,7 & \\ 20459 & 150618 & 105621 & 1 & 2,8 & 5,3 & & & \\ 20463 & 150618 & 105631 & 1 & 5,9 & 9,2 & 5,7 & 5,8 & 5,7 \\ 20468 & 150618 & 105712 & 1 & 6,1 & 10,5 & 6,9 & 6,8 & 6,8 \\ 20472 & 150618 & 105748 & 1 & 6,3 & 11,6 & 6,9 & 7,1 & 7,5 \\ 20474 & 150618 & 105802 & 1 & 6,1 & 11,1 & 7,9 & 7,7 & 7,6 \\ 20476 & 150618 & 105810 & 1 & 5,7 & 6,9 & 3,7 & 3,9 & 3,6 \\ 20478 & 150618 & 105819 & 1 & 7,4 & 10,4 & 7,1 & 7,4 & 7,5 \\ 20480 & 150618 & 105825 & 1 & 6,3 & 9,1 & 4,6 & 4,3 & 4,4 \\ 20489 & 150618 & 105925 & 1 & 7,1 & 9,3 & 5,2 & 5,5 & 5,4 \\ 20494 & 150618 & 110021 & 1 & 5,8 & 13,1 & 6,6 & 7,1 & 7,5 \\ 20508 & 150618 & 110233 & 1 & 7,6 & 11,9 & 7,2 & 6,2 & 7,3 \\ 20521 & 150618 & 110455 & 1 & 5,8 & 9,3 & 4,3 & 4,2 & 4,4 \\ 20522 & 150618 & 110506 & 1 & 7,0 & 12,8 & 5,7 & 6,3 & 6,1 \\ 20523 & 150618 & 110512 & 1 & 3,2 & 3,7 & & & \end{array}$

$\begin{array}{rrrrr}36,4 & 3,7 & 5,9 & 1,2 & 1,3 \\ 40,3 & 3,7 & 5,9 & 1,3 & 1,3 \\ 42,3 & 3,5 & 5,9 & 1,2 & 1,2 \\ 39,7 & 3,6 & 5,1 & 1,2 & 1,2 \\ 17,0 & 3,6 & 5,2 & 1,2 & \\ 38,8 & 3,6 & 6,0 & 1,2 & 1,2 \\ 39,1 & 3,8 & 6,0 & 1,3 & 1,2 \\ 25,1 & 3,8 & 5,6 & 1,2 & 1,2 \\ 37,7 & 3,8 & 6,1 & 1,2 & 1,2 \\ 33,7 & 3,8 & 6,0 & 1,2 & 1,2 \\ 25,1 & 3,5 & 6,0 & 1,2 & 1,2 \\ 27,2 & 3,5 & 6,9 & 1,2 & \\ 8,1 & 3,6 & & & \\ 32,3 & 3,8 & 5,8 & 1,2 & 1,2 \\ 37,1 & 3,8 & 5,0 & 1,3 & 1,3 \\ 39,4 & 3,9 & 6,2 & 1,3 & 1,3 \\ 40,4 & 3,8 & 6,0 & 1,3 & 1,3 \\ 23,8 & 3,8 & 6,5 & 1,3 & 1,3 \\ 39,8 & 3,8 & 6,0 & 1,3 & 1,2 \\ 28,7 & 4,0 & 6,2 & 1,3 & 1,3 \\ 32,5 & 3,9 & 6,0 & 1,3 & 1,3 \\ 40,1 & 3,8 & 6,1 & 1,3 & 1,3 \\ 40,2 & 3,8 & 6,1 & 1,3 & 1,3 \\ 28,0 & 3,9 & 6,2 & 1,3 & 1,3 \\ 37,9 & 3,8 & 6,1 & 1,3 & 1,3 \\ 6,9 & 3,4 & & & \end{array}$

$\begin{array}{rrrr}88 & 16,4 & 4 & 4.61 \\ 87 & 16,6 & 4 & 8.04 \\ 86 & 16,3 & 4 & 8.44 \\ 89 & 14,4 & 4 & 5.19 \\ 88 & 12,6 & 4 & 0.50 \\ 83 & 16,4 & 4 & 5.52 \\ 89 & 16,1 & 4 & 6.12 \\ 87 & 15,6 & 4 & 0.97 \\ 84 & 15,9 & 4 & 4.59 \\ 83 & 16,8 & 4 & 2.94 \\ 86 & 16,2 & 4 & 1.65 \\ 85 & 15,1 & 5 & 2.49 \\ 86 & 7,1 & 5 & 0.17 \\ 87 & 16,5 & 4 & 2.24 \\ 93 & 15,8 & 4 & 3.72 \\ 91 & 17,8 & 4 & 4.97 \\ 89 & 17,3 & 4 & 4.76 \\ 93 & 18,2 & 4 & 0.80 \\ 91 & 18,0 & 4 & 4.24 \\ 93 & 18,1 & 4 & 1.99 \\ 87 & 17,5 & 4 & 2.48 \\ 79 & 17,4 & 4 & 6.69 \\ 88 & 17,3 & 4 & 5.53 \\ 90 & 17,5 & 4 & 2.01 \\ 88 & 17,4 & 4 & 6.16 \\ 87 & 6,9 & 3 & 0.06\end{array}$




$\begin{array}{rrrrrrrrr}20524 & 150618 & 110518 & 1 & 6,4 & 10,3 & 2,4 & 2,5 & 2,5 \\ 20541 & 150618 & 110725 & 1 & 6,4 & 10,4 & 6,6 & 7,4 & 7,3 \\ 20545 & 150618 & 110802 & 1 & 6,4 & 11,2 & 4,9 & 5,1 & 5,1 \\ 20546 & 150618 & 110809 & 1 & 6,0 & 12,2 & 6,7 & 7,0 & 7,2 \\ 20554 & 150618 & 110916 & 1 & 5,9 & 13,4 & 7,3 & 6,8 & 6,6 \\ 20558 & 150618 & 110947 & 1 & 7,1 & 12,1 & 7,5 & 7,4 & 7,2 \\ 20566 & 150618 & 111246 & 1 & 5,8 & 9,6 & 4,8 & 3,9 & 3,6 \\ 20569 & 150618 & 111318 & 1 & 7,3 & 14,1 & 7,3 & 7,4 & 7,6 \\ 20572 & 150618 & 111359 & 1 & 6,5 & 7,5 & 1,4 & 5,9 & 4,6 \\ 20575 & 150618 & 111425 & 1 & 5,9 & 5,7 & 3,2 & 3,6 & 3,1 \\ 20581 & 150618 & 111458 & 1 & 6,5 & 8,0 & & & \\ 20585 & 150618 & 111528 & 1 & 6,9 & 13,7 & 5,9 & 5,9 & \\ 20590 & 150618 & 111611 & 1 & 6,6 & 7,8 & 3,4 & 3,4 & 3,3 \\ 20595 & 150618 & 111637 & 1 & 7,4 & 13,9 & 5,7 & 6,7 & 6,5 \\ 20600 & 150618 & 111727 & 1 & 7,1 & 11,6 & 7,8 & 8,3 & 8,2 \\ 20602 & 150618 & 111744 & 1 & 6,7 & 12,6 & & & \\ 20613 & 150618 & 111911 & 1 & 7,6 & 15,1 & 7,3 & 6,5 & 7,1 \\ 20623 & 150618 & 112122 & 1 & 6,9 & 12,6 & 6,6 & 7,1 & 6,5 \\ 20625 & 150618 & 112130 & 1 & 6,0 & 13,2 & 6,8 & 6,6 & 7,4 \\ 20639 & 150618 & 112405 & 1 & 7,6 & 10,8 & 8,8 & & \\ 20642 & 150618 & 112454 & 1 & 3,9 & 5,1 & & & \\ 20648 & 150618 & 112610 & 1 & 6,9 & 13,0 & 7,5 & 7,0 & 7,0 \\ 20649 & 150618 & 112616 & 1 & 6,9 & 10,7 & 4,7 & 5,2 & 4,9 \\ 20651 & 150618 & 112636 & 1 & 6,3 & 6,4 & 5,1 & 5,1 & \\ 20711 & 150618 & 113543 & 1 & 6,5 & 8,7 & 4,1 & 4,8 & 4,4 \\ 20714 & 150618 & 113600 & 1 & 6,9 & 10,6 & 7,6 & 8,2 & 7,8\end{array}$

\begin{tabular}{|c|c|c|c|c|}
\hline 24,1 & 3,8 & 5,5 & 1,2 & 1,2 \\
\hline 38,1 & 3,9 & 4,5 & 1,2 & 1,2 \\
\hline 32,7 & 3,8 & 5,7 & 1,2 & 1,2 \\
\hline 39,1 & 3,8 & 5,6 & 1,2 & 1,2 \\
\hline 40,0 & 3,5 & 6,0 & 1,2 & 1,2 \\
\hline 41,3 & 3,7 & 6,0 & 1,2 & 1,3 \\
\hline 27,7 & 3,7 & 5,6 & 1,2 & 1,2 \\
\hline 43,7 & 3,6 & 5,8 & 1,2 & 1,2 \\
\hline 25,9 & 3,7 & 5,5 & 1,1 & 1,2 \\
\hline 21,5 & 3,6 & 5,7 & 1,3 & 1,3 \\
\hline 14,5 & 5,7 & & & \\
\hline 32,4 & 3,6 & 7,4 & 1,3 & \\
\hline 24,5 & 3,7 & 5,4 & 1,2 & 1,2 \\
\hline 40,2 & 3,8 & 6,0 & 1,3 & 1,2 \\
\hline 43,0 & 3,6 & 4,6 & 1,2 & 1,2 \\
\hline 19,3 & 6,2 & & & \\
\hline 43,6 & 3,7 & 6,0 & 1,3 & 1,2 \\
\hline 39,7 & 3,9 & 6,2 & 1,3 & 1,3 \\
\hline 40,0 & 4,2 & 4,7 & 1,4 & 1,4 \\
\hline 27,2 & 5,0 & 1,3 & & \\
\hline 9,0 & 4,3 & & & \\
\hline 41,4 & 3,8 & 5,9 & 1,3 & 1,3 \\
\hline 32,4 & 3,7 & 5,7 & 1,3 & 1,3 \\
\hline 22,9 & 4,0 & 7,9 & 1,4 & \\
\hline 28,5 & 3,7 & 5,9 & 1,3 & 1,2 \\
\hline 41,1 & 3,8 & 5,8 & 1,3 & 1,2 \\
\hline
\end{tabular}

$\begin{array}{rrrr}86 & 16,0 & 4 & 2.83 \\ 85 & 14,6 & 4 & 3.83 \\ 86 & 16,7 & 4 & 3.84 \\ 89 & 15,6 & 4 & 5.46 \\ 88 & 16,0 & 4 & 7.03 \\ 88 & 16,5 & 4 & 5.83 \\ 84 & 15,1 & 4 & 2.19 \\ 87 & 16,3 & 4 & 8.66 \\ 86 & 15,7 & 4 & 1.17 \\ 86 & 16,1 & 4 & 0.54 \\ 88 & 10,3 & 5 & 1.33 \\ 84 & 16,6 & 5 & 7.22 \\ 84 & 15,1 & 4 & 1.27 \\ 89 & 16,9 & 4 & 7.86 \\ 84 & 13,9 & 4 & 5.82 \\ 88 & 9,9 & 5 & 5.34 \\ 86 & 16,6 & 4 & 10.27 \\ 93 & 18,3 & 4 & 6.15 \\ 87 & 16,0 & 4 & 6.79 \\ 87 & 10,8 & 5 & 3.51 \\ 87 & 8,5 & 5 & 0.18 \\ 90 & 17,1 & 4 & 6.86 \\ 89 & 17,4 & 4 & 3.49 \\ 91 & 17,3 & 5 & 0.91 \\ 88 & 16,7 & 4 & 1.81 \\ 90 & 16,8 & 4 & 4.61\end{array}$




$\begin{array}{rrrrrrrrr}20726 & 150618 & 113815 & 1 & 6,7 & 11,2 & 4,8 & 5,0 & 4,8 \\ 20732 & 150618 & 113915 & 1 & 6,8 & 9,7 & 3,7 & 3,4 & 3,7 \\ 20740 & 150618 & 114017 & 1 & 7,9 & 13,2 & 6,5 & 7,0 & 6,6 \\ 20744 & 150618 & 114038 & 1 & 7,2 & 10,2 & 8,7 & 8,3 & 8,3 \\ 20760 & 150618 & 114243 & 1 & 6,6 & 13,2 & 6,9 & 7,1 & 6,8 \\ 20766 & 150618 & 114338 & 1 & 6,2 & 12,0 & 4,8 & 4,7 & 4,7 \\ 20790 & 150618 & 114747 & 1 & 6,6 & 8,5 & 4,0 & 4,0 & 4,6 \\ 20791 & 150618 & 114802 & 1 & 6,0 & 7,4 & & & \\ 20793 & 150618 & 114807 & 1 & 6,9 & 7,9 & & & \\ 20794 & 150618 & 114811 & 1 & 7,4 & 9,6 & 5,7 & & \\ 20796 & 150618 & 114820 & 1 & 7,0 & 14,3 & 7,3 & 7,4 & 7,7 \\ 20803 & 150618 & 114926 & 1 & 6,0 & 11,5 & 5,7 & 5,8 & 6,0 \\ 20827 & 150618 & 115308 & 1 & 6,8 & 12,5 & 7,8 & 7,9 & 7,7 \\ 20829 & 150618 & 115314 & 1 & 6,2 & 10,6 & & & \\ 20848 & 150618 & 115627 & 1 & 5,7 & 8,6 & 4,6 & 4,2 & 4,4 \\ 20856 & 150618 & 115749 & 1 & 5,8 & 11,2 & 5,5 & 5,3 & 5,7 \\ 20866 & 150618 & 115927 & 1 & 6,4 & 11,5 & 6,5 & 6,8 & 6,5 \\ 20867 & 150618 & 115933 & 1 & 6,2 & 10,6 & 6,0 & 6,3 & 6,2 \\ 20872 & 150618 & 120014 & 1 & 6,5 & 10,7 & 4,7 & 5,0 & 5,1 \\ 20880 & 150618 & 120131 & 1 & 5,5 & 5,6 & 3,3 & 2,9 & 3,0 \\ 20887 & 150618 & 120234 & 1 & 7,0 & 12,1 & 4,9 & 5,1 & 5,7 \\ 20896 & 150618 & 120336 & 1 & 7,0 & 11,6 & 7,9 & 7,7 & 7,8 \\ 20898 & 150618 & 120347 & 1 & 6,7 & 11,5 & 7,3 & 8,6 & \\ 20908 & 150618 & 120521 & 1 & 6,3 & 11,5 & 7,3 & 7,0 & 7,3 \\ 20912 & 150618 & 120541 & 1 & 6,3 & 11,8 & 7,7 & 7,8 & 7,8 \\ 20922 & 150618 & 120645 & 1 & 6,3 & 9,7 & 5,0 & 4,6 & 4,3\end{array}$

$\begin{array}{lllll}32,5 & 3,7 & 5,9 & 1,2 & 1,2 \\ 27,3 & 3,5 & 5,9 & 1,2 & 1,2 \\ 41,2 & 3,8 & 5,8 & 1,2 & 1,2 \\ 42,7 & 3,9 & 3,1 & 1,3 & 1,3 \\ 40,6 & 4,0 & 6,0 & 1,3 & 1,3 \\ 32,4 & 3,7 & 6,3 & 1,3 & 1,2 \\ 27,7 & 3,8 & 6,3 & 1,3 & 1,3 \\ 13,4 & 5,3 & & & \\ 14,8 & 6,1 & & & \\ 22,7 & 4,7 & 1,3 & & \\ 43,7 & 3,6 & 6,0 & 1,2 & 1,3 \\ 35,0 & 3,7 & 5,9 & 1,2 & 1,2 \\ 42,7 & 3,8 & 4,0 & 1,2 & 1,2 \\ 16,8 & 3,6 & & & \\ 27,5 & 3,8 & 6,1 & 1,3 & 1,3 \\ 33,5 & 3,7 & 6,1 & 1,2 & 1,3 \\ 37,7 & 3,9 & 6,0 & 1,3 & 1,3 \\ 35,3 & 3,6 & 6,0 & 1,3 & 1,3 \\ 32,0 & 3,8 & 5,9 & 1,2 & 1,2 \\ 20,3 & 4,0 & 6,0 & 1,3 & 1,2 \\ 34,8 & 3,8 & 6,0 & 1,2 & 1,2 \\ 42,0 & 3,7 & 5,9 & 1,2 & 1,3 \\ 34,1 & 3,9 & 8,4 & 1,3 & \\ 39,4 & 3,7 & 5,6 & 1,2 & 1,2 \\ 41,4 & 3,6 & 5,9 & 1,2 & 1,2 \\ 29,9 & 3,8 & 6,0 & 1,3 & 1,3\end{array}$

$\begin{array}{rrrr}89 & 16,5 & 4 & 3.89 \\ 87 & 16,2 & 4 & 2.44 \\ 86 & 16,4 & 4 & 7.25 \\ 86 & 13,0 & 4 & 4.77 \\ 86 & 17,8 & 4 & 6.93 \\ 91 & 17,9 & 4 & 4.58 \\ 86 & 17,3 & 4 & 1.70 \\ 89 & 9,0 & 3 & 0.95 \\ 86 & 9,7 & 3 & 1.35 \\ 87 & 8,9 & 3 & 1.69 \\ 82 & 16,6 & 4 & 8.89 \\ 82 & 16,5 & 4 & 4.25 \\ 88 & 13,8 & 4 & 6.59 \\ 81 & 6,6 & 3 & 3.03 \\ 88 & 16,8 & 4 & 1.59 \\ 87 & 17,0 & 4 & 3.82 \\ 87 & 16,9 & 4 & 4.62 \\ 83 & 17,5 & 4 & 3.56 \\ 82 & 17,4 & 4 & 3.38 \\ 90 & 16,4 & 4 & 0.42 \\ 87 & 17,0 & 4 & 4.99 \\ 87 & 16,8 & 4 & 5.53 \\ 87 & 18,1 & 5 & 5.23 \\ 86 & 16,0 & 4 & 4.88 \\ 87 & 16,6 & 4 & 5.53 \\ 88 & 16,2 & 4 & 2.41 \\ & & & \\ 89 & \end{array}$




$\begin{array}{rrrrrrrrr}20934 & 150618 & 120728 & 1 & 6,5 & 12,3 & 7,4 & 7,5 & 7,1 \\ 20937 & 150618 & 120751 & 1 & 6,7 & 8,1 & 3,6 & 3,2 & 3,6 \\ 20940 & 150618 & 120815 & 1 & 6,6 & 7,8 & 4,6 & 5,0 & 3,4 \\ 20948 & 150618 & 120906 & 1 & 7,3 & 13,5 & 7,5 & 6,8 & 7,3 \\ 20955 & 150618 & 121031 & 1 & 6,4 & 10,9 & 7,4 & 7,1 & 7,0 \\ 20969 & 150618 & 121238 & 1 & 4,1 & 9,5 & & & \\ 20977 & 150618 & 121329 & 1 & 6,3 & 8,8 & 3,1 & 3,2 & 3,0 \\ 20980 & 150618 & 121358 & 1 & 7,0 & 8,8 & 4,5 & 4,5 & 4,4 \\ 20981 & 150618 & 121413 & 1 & 7,3 & 11,7 & 4,5 & 4,2 & 4,6 \\ 20985 & 150618 & 121442 & 1 & 6,6 & 12,2 & 7,2 & 8,2 & 6,9 \\ 20993 & 150618 & 121540 & 1 & 7,7 & 11,2 & 7,7 & 7,1 & \\ 21017 & 150618 & 121903 & 1 & 6,1 & 11,9 & 8,0 & 7,9 & 8,0 \\ 21030 & 150618 & 122218 & 1 & 5,7 & 7,7 & & & \\ 21031 & 150618 & 122228 & 1 & 6,2 & 9,1 & 4,8 & 4,3 & 4,6 \\ 21035 & 150618 & 122330 & 1 & 8,2 & 7,4 & 5,5 & & \\ 21040 & 150618 & 122415 & 1 & 6,7 & 11,4 & 6,6 & 7,2 & 6,8 \\ 21043 & 150618 & 122443 & 1 & 4,9 & 6,6 & & & \\ 21048 & 150618 & 122508 & 1 & 6,9 & 14,4 & 7,6 & & \\ 21051 & 150618 & 122538 & 1 & 7,4 & 13,7 & 6,7 & 6,7 & 6,8 \\ 21053 & 150618 & 122557 & 1 & 6,2 & 8,6 & & & \\ 21056 & 150618 & 122609 & 1 & 7,2 & 12,2 & 7,4 & 7,5 & 7,7 \\ 21060 & 150618 & 122623 & 1 & 6,4 & 12,0 & 7,2 & 7,0 & 6,9 \\ 21063 & 150618 & 122701 & 1 & 5,4 & 5,9 & 2,4 & 2,6 & \\ 21066 & 150618 & 122718 & 1 & 6,4 & 9,5 & 7,0 & 7,7 & 7,8 \\ 21070 & 150618 & 122747 & 1 & 6,8 & 11,8 & 7,8 & 7,9 & 8,0 \\ 21071 & 150618 & 122825 & 1 & 5,3 & 6,0 & & & \end{array}$

$\begin{array}{lllll}40,8 & 3,7 & 4,5 & 1,2 & 1,3 \\ 25,2 & 3,8 & 5,6 & 1,2 & 1,2 \\ 27,4 & 3,5 & 5,7 & 1,2 & 1,3 \\ 42,4 & 3,5 & 5,9 & 1,2 & 1,2 \\ 38,8 & 3,6 & 3,8 & 1,3 & 1,3 \\ 13,6 & 6,0 & & & \\ 24,4 & 3,7 & 5,9 & 1,3 & 1,3 \\ 29,2 & 3,7 & 5,6 & 1,2 & 1,2 \\ 32,3 & 3,7 & 5,9 & 1,2 & 1,2 \\ 41,1 & 3,6 & 5,6 & 1,2 & 1,3 \\ 33,7 & 5,4 & 7,5 & 1,0 & \\ 41,9 & 3,9 & 3,0 & 1,3 & 1,2 \\ 13,4 & 4,3 & & & \\ 29,0 & 3,8 & 7,6 & 1,3 & 1,2 \\ 21,1 & 4,8 & 1,3 & & \\ 38,7 & 3,8 & 5,9 & 1,2 & 1,3 \\ 11,5 & 4,9 & & & \\ 28,9 & 4,7 & 1,4 & & 1,3 \\ 41,3 & 3,6 & 6,0 & 1,2 & 1,2 \\ 14,8 & 6,3 & & & \\ 42,0 & 3,6 & 5,9 & 1,2 & 1,2 \\ 39,5 & 3,9 & 5,9 & 1,3 & 1,3 \\ 16,3 & 3,8 & 7,0 & 1,2 & \\ 38,4 & 3,8 & 5,5 & 1,3 & 1,4 \\ 42,3 & 3,7 & 5,7 & 1,3 & 1,3 \\ 11,3 & 4,6 & & & \end{array}$

$\begin{array}{rrrr}85 & 15,0 & 4 & 5.87 \\ 86 & 16,8 & 4 & 1.47 \\ 87 & 16,5 & 4 & 1.34 \\ 85 & 16,3 & 4 & 7.67 \\ 90 & 13,3 & 4 & 4.30 \\ 95 & 11,2 & 5 & 1.83 \\ 87 & 16,9 & 4 & 1.71 \\ 89 & 16,8 & 4 & 2.00 \\ 85 & 16,3 & 4 & 4.52 \\ 88 & 15,5 & 4 & 5.86 \\ 88 & 18,2 & 5 & 4.93 \\ 80 & 12,4 & 4 & 5.76 \\ 89 & 7,9 & 5 & 0.99 \\ 85 & 17,1 & 4 & 1.99 \\ 88 & 10,8 & 3 & 1.54 \\ 89 & 17,0 & 4 & 4.71 \\ 88 & 9,7 & 3 & 0.54 \\ 88 & 9,3 & 5 & 4.65 \\ 88 & 16,7 & 4 & 7.76 \\ 90 & 11,6 & 3 & 1.56 \\ 86 & 16,8 & 4 & 6.07 \\ 89 & 16,7 & 4 & 5.35 \\ 91 & 15,6 & 5 & 0.45 \\ 89 & 14,1 & 4 & 3.29 \\ 89 & 16,7 & 4 & 5.77 \\ 84 & 7,4 & 3 & 0.45\end{array}$




$\begin{array}{rrrrrrrrr}21076 & 150618 & 122858 & 1 & 6,6 & 7,0 & 3,3 & 3,5 & 3,3 \\ 21089 & 150618 & 123108 & 1 & 6,6 & 11,6 & 5,1 & 5,0 & 5,8 \\ 21090 & 150618 & 123123 & 1 & 6,8 & 11,7 & 8,7 & 9,0 & 9,0 \\ 21096 & 150618 & 123216 & 1 & 5,7 & 5,5 & 2,7 & 2,5 & \\ 21100 & 150618 & 123311 & 1 & 5,4 & 6,3 & 2,8 & 2,4 & \\ 21104 & 150618 & 123344 & 1 & 3,8 & 4,8 & & & \\ 21119 & 150618 & 123512 & 1 & 7,9 & 15,2 & 6,7 & 7,2 & 6,5 \\ 21124 & 150618 & 123551 & 1 & 6,6 & 9,3 & 5,9 & 5,7 & \\ 21125 & 150618 & 123607 & 1 & 6,3 & 8,9 & & & \\ 21128 & 150618 & 123620 & 1 & 7,0 & 12,5 & & & \\ 21135 & 150618 & 123731 & 1 & 6,6 & 8,3 & 3,7 & 4,0 & 3,9 \\ 21139 & 150618 & 123801 & 1 & 6,7 & 8,2 & 5,6 & 5,7 & 5,7 \\ 21143 & 150618 & 123836 & 1 & 7,5 & 12,0 & 9,0 & 8,5 & 8,9 \\ 21154 & 150618 & 123940 & 1 & 8,0 & 8,9 & 5,7 & 5,7 & \\ 21161 & 150618 & 124054 & 1 & 6,2 & 9,8 & 4,1 & 3,6 & 3,9 \\ 21165 & 150618 & 124118 & 1 & 7,0 & 12,2 & 8,1 & 8,1 & 8,0 \\ 21171 & 150618 & 124158 & 1 & 7,1 & 13,3 & 6,4 & 6,6 & 6,9 \\ 21191 & 150618 & 124437 & 1 & 6,7 & 3,4 & 12,3 & 5,7 & 4,3 \\ 21193 & 150618 & 124505 & 1 & 5,9 & 8,1 & 3,1 & 3,4 & 3,4 \\ 21209 & 150618 & 124809 & 1 & 6,4 & 7,4 & 4,0 & 4,2 & 4,0 \\ 21215 & 150618 & 124849 & 1 & 6,2 & 8,2 & 3,7 & 2,9 & 3,5 \\ 21230 & 150618 & 125056 & 1 & 6,8 & 11,6 & 8,1 & 8,1 & 8,5 \\ 21234 & 150618 & 125113 & 1 & 5,2 & 8,8 & & & \\ 21243 & 150618 & 125308 & 1 & 5,9 & 7,7 & 4,2 & 3,5 & \\ 21251 & 150618 & 125413 & 1 & 6,3 & 6,2 & 5,6 & 5,4 & 5,5 \\ 21262 & 150618 & 125536 & 1 & 6,1 & 5,1 & 3,0 & 2,3 & 2,9\end{array}$

\begin{tabular}{|c|c|c|c|c|}
\hline 23,7 & 3,7 & 6,1 & 1,3 & 1,3 \\
\hline 34,1 & 3,8 & 6,0 & 1,3 & 1,2 \\
\hline 45,2 & 3,7 & 5,7 & 1,3 & 1,3 \\
\hline 16,4 & 3,7 & 6,0 & 1,2 & \\
\hline 16,9 & 3,5 & 6,1 & 1,2 & \\
\hline 8,6 & 5,3 & & & \\
\hline 43,5 & 3,7 & 5,7 & 1,2 & 1,2 \\
\hline 27,5 & 5,9 & 7,3 & 1,4 & \\
\hline 15,2 & 5,4 & & & \\
\hline 19,5 & 6,2 & & & \\
\hline 26,5 & 3,8 & 5,7 & 1,2 & 1,2 \\
\hline 31,9 & 3,7 & 5,5 & 1,2 & 1,2 \\
\hline 45,9 & 3,8 & 3,7 & 1,3 & 1,3 \\
\hline 28,3 & 3,8 & 7,4 & 1,2 & \\
\hline 27,6 & 4,9 & 7,0 & 1,2 & 1,3 \\
\hline 43,4 & 3,8 & 5,7 & 1,3 & 1,3 \\
\hline 40,3 & 3,6 & 6,1 & 1,2 & 1,2 \\
\hline 36,6 & 4,2 & 1,2 & 7,9 & 1,1 \\
\hline 23,9 & 3,9 & 6,0 & 1,3 & 1,3 \\
\hline 26,0 & 3,7 & 6,0 & 1,3 & 1,2 \\
\hline 24,5 & 3,7 & 5,9 & 1,3 & 1,2 \\
\hline 43,1 & 3,7 & 3,1 & 1,2 & 1,2 \\
\hline 14,0 & 5,7 & & & \\
\hline 21,3 & 5,5 & 6,7 & 1,3 & \\
\hline 29,0 & 3,8 & 7,6 & 1,1 & 1,1 \\
\hline 19,4 & 3,9 & 5,6 & 1,2 & 1,2 \\
\hline
\end{tabular}

$\begin{array}{lrll}92 & 16,3 & 4 & 0.99 \\ 88 & 16,6 & 4 & 4.35 \\ 86 & 13,5 & 4 & 6.55 \\ 86 & 14,2 & 4 & 0.42 \\ 84 & 14,2 & 4 & 0.53 \\ 86 & 9,1 & 3 & 0.15 \\ 84 & 16,1 & 4 & 10.48 \\ 86 & 19,2 & 5 & 2.39 \\ 84 & 10,3 & 3 & 1.74 \\ 84 & 10,9 & 5 & 5.31 \\ 87 & 16,6 & 4 & 1.57 \\ 85 & 15,9 & 4 & 1.82 \\ 89 & 13,7 & 4 & 7.00 \\ 86 & 17,3 & 4 & 2.61 \\ 88 & 19,4 & 4 & 2.38 \\ 88 & 17,0 & 4 & 6.44 \\ 86 & 16,4 & 4 & 7.07 \\ 92 & 19,1 & 4 & 1.79 \\ 78 & 16,8 & 4 & 1.29 \\ 88 & 17,0 & 4 & 1.12 \\ 87 & 16,7 & 4 & 1.40 \\ 84 & 12,1 & 4 & 5.86 \\ 91 & 11,0 & 5 & 1.49 \\ 86 & 17,1 & 4 & 1.10 \\ 89 & 16,1 & 4 & 0.99 \\ 86 & 15,7 & 4 & 0.46 \\ & & & \end{array}$




$\begin{array}{rrrrrrrrr}21264 & 150618 & 125603 & 1 & 6,1 & 8,2 & 3,6 & 3,9 & 4,2 \\ 21272 & 150618 & 125711 & 1 & 6,2 & 8,2 & 3,4 & 2,9 & 3,3 \\ 21300 & 150618 & 130153 & 1 & 8,0 & 13,4 & 8,6 & 8,8 & 8,5 \\ 21391 & 150618 & 131758 & 1 & 6,0 & 9,0 & 3,5 & 3,7 & 3,7\end{array}$

$\begin{array}{lllll}26,0 & 3,7 & 5,8 & 1,2 & 1,2 \\ 24,0 & 3,9 & 6,2 & 1,3 & 1,3 \\ 47,3 & 4,0 & 4,8 & 1,3 & 1,3 \\ 25,9 & 3,8 & 6,2 & 1,3 & 1,3\end{array}$

$\begin{array}{llll}83 & 16,7 & 4 & 1.41 \\ 92 & 18,0 & 4 & 1.39 \\ 89 & 15,3 & 4 & 8.89 \\ 90 & 17,1 & 4 & 1.80\end{array}$




\section{Datos tomados visualmente por operarios o recibidos de la Dirección General de Tráfico}

\section{Leyenda}

- No: número de secuencia

- Date: Fecha de paso

- Time : hora-minuto-segundo de paso

- Lne: Carril

- CATEG VEH: Categoría de vehículo (P: Camión pesado; B: Autobús)

- CLASE VEH: Clase de vehículo (1: Vehículo rígido; 2: Vehículo articulado; 3 Tren de carretera)

- TIPO VEH: Tipo de vehículo (12: Camión rígido de 2 ejes; 14: Camión rígido de 3 ejes, con los dos últimos formando tándem de ruedas gemelas; 17 : camión rígido de 3 ejes con los dos últimos formando tándem asimétrico; 124: articulado de 4 ejes con cabeza tractora de 2 ejes y los 2 últimos formando un tándem en la parte trasera del semirremolque; 125: articulado de 5 ejes con cabeza tractora de 2 ejes y los 3 últimos formando un eje trídem en la parte trasera del semirremolque)

- EJES ELEVADOS: no de orden que ocupa en el vehículo el eje que va elevado (si hay alguno que vaya elevado). Por ejemplo, un 3 significa que es el tercer eje el que va elevado.

- TARA TRACTOR, TARA REMOLQUE: Peso en vacío (tara) del camión o cabeza tractora, $y$ del remolque o semirremolque

- PMA TRACTOR, PMA REMOLQUE: Peso máximo admitido del camión o de la cabeza tractora, y del conjunto del (tractor+ semirremolque o remolque) 


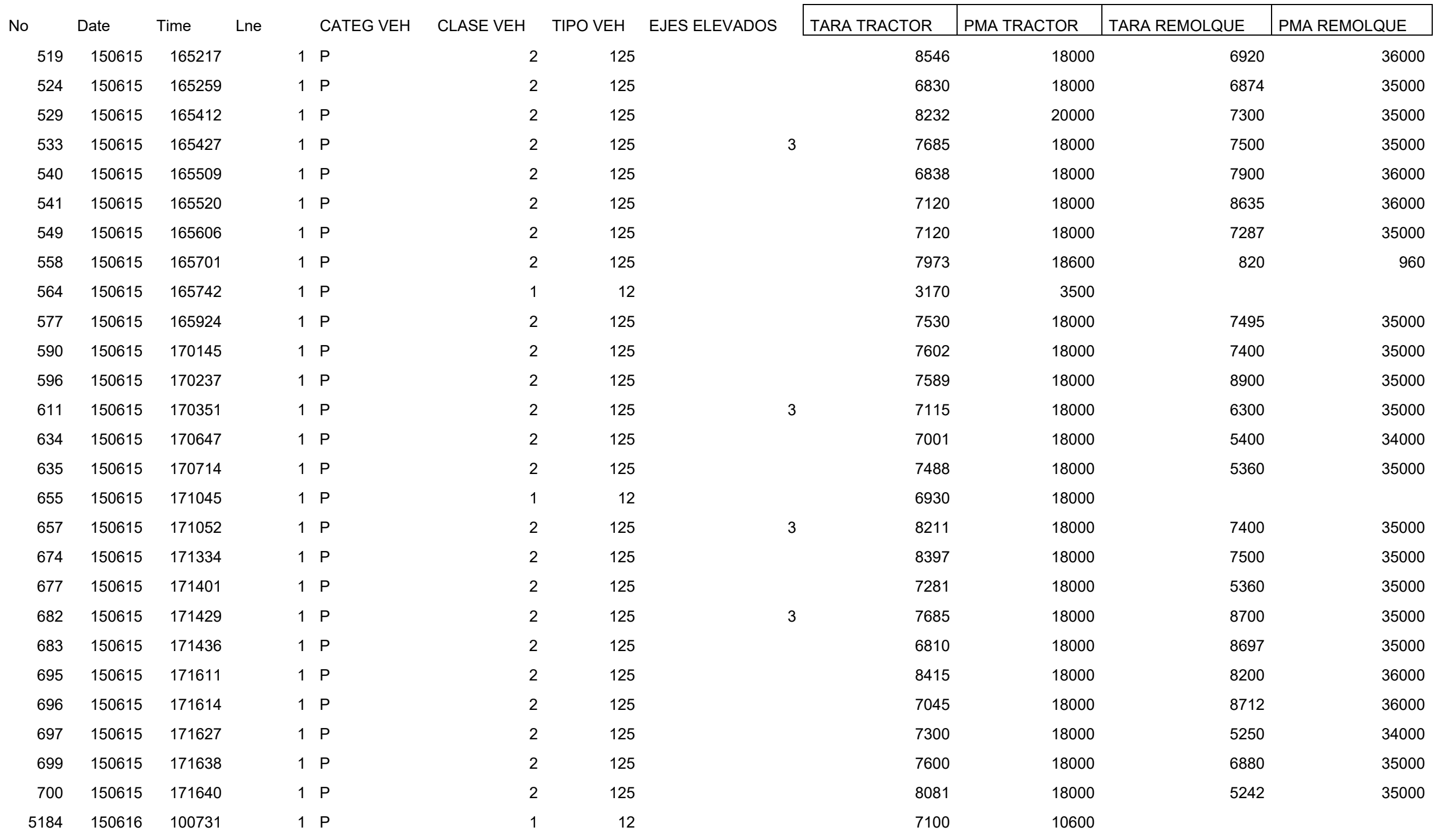




\begin{tabular}{|c|c|c|c|c|c|c|c|c|c|c|c|}
\hline No & Date & Time & Lne & & CATEG VEH & CLASE VEH & EJES ELEVADOS & TARA TRACTOR & PMA TRACTOR & TARA REMOLQUE & PMA REMOLQUE \\
\hline 5187 & 150616 & 100801 & & 1 & $\mathrm{P}$ & 2 & 125 & 8458 & 18000 & 8820 & 36000 \\
\hline 5193 & 150616 & 100858 & & 1 & $\mathrm{P}$ & 2 & 125 & 8593 & 18000 & 8633 & 35000 \\
\hline 5208 & 150616 & 101053 & & 1 & $\mathrm{P}$ & 2 & 125 & 8000 & 18000 & 7200 & 35000 \\
\hline 5215 & 150616 & 101220 & & 1 & $\mathrm{P}$ & 2 & 125 & 8230 & 18000 & 8900 & 35000 \\
\hline 5217 & 150616 & 101251 & & 1 & $\mathrm{P}$ & 2 & 125 & 7120 & 18000 & 9100 & 36000 \\
\hline 5218 & 150616 & 101259 & & 1 & $\mathrm{P}$ & 2 & 125 & 6800 & 18000 & 7100 & 34000 \\
\hline 5219 & 150616 & 101304 & & 1 & $\mathrm{P}$ & 2 & 125 & 7730 & 18000 & 6430 & 35000 \\
\hline 5220 & 150616 & 101312 & & 1 & $\mathrm{P}$ & 2 & 125 & 8546 & 18000 & 7000 & 35000 \\
\hline 5221 & 150616 & 101331 & & 1 & $\mathrm{P}$ & 2 & 125 & 7235 & 18000 & 7280 & 35000 \\
\hline 5229 & 150616 & 101438 & & 1 & $\mathrm{P}$ & 3 & 124 & 1290 & 1840 & 7200 & 16480 \\
\hline 5233 & 150616 & 101504 & & 1 & $\mathrm{P}$ & 2 & 125 & 6810 & 18000 & 8500 & 36000 \\
\hline 5246 & 150616 & 101731 & & 1 & $\mathrm{P}$ & 2 & 125 & 7289 & 18000 & 6405 & 34000 \\
\hline 5247 & 150616 & 101734 & & 1 & $\mathrm{P}$ & 2 & 125 & 7420 & 18000 & 7390 & 35000 \\
\hline 5251 & 150616 & 101800 & & 1 & $P$ & 1 & 12 & 1312 & 1840 & & \\
\hline 5252 & 150616 & 101819 & & 1 & $P$ & 2 & 125 & 8297 & 18000 & 6220 & 35000 \\
\hline 5260 & 150616 & 101932 & & 1 & $P$ & 2 & 125 & 7482 & 18000 & 7955 & 35000 \\
\hline 5264 & 150616 & 102008 & & 1 & $\mathrm{P}$ & 2 & 125 & 6120 & 18000 & 8000 & 35000 \\
\hline 5268 & 150616 & 102027 & & 1 & $\mathrm{P}$ & 2 & 125 & 7134 & 20000 & 5110 & 34000 \\
\hline 5270 & 150616 & 102041 & & 1 & $P$ & 2 & 125 & 8000 & 18000 & 8000 & 35000 \\
\hline 5271 & 150616 & 102054 & & 1 & $P$ & 2 & 125 & 6965 & 18000 & 6883 & 35000 \\
\hline 5282 & 150616 & 102220 & & 1 & $\mathrm{P}$ & 2 & 125 & 7900 & 18000 & 6000 & 34000 \\
\hline 5290 & 150616 & 102306 & & 1 & $\mathrm{P}$ & 2 & 125 & 7450 & 18000 & 8900 & 35000 \\
\hline 5291 & 150616 & 102309 & & 1 & $\mathrm{P}$ & 2 & 125 & 8700 & 18000 & 10150 & 36000 \\
\hline 5293 & 150616 & 102325 & & 1 & $P$ & 1 & 17 & 11645 & 26000 & & \\
\hline 5302 & 150616 & 102448 & & 1 & $\mathrm{P}$ & 2 & 125 & 7720 & 18000 & 7500 & 35000 \\
\hline 5303 & 150616 & 102502 & & 1 & $P$ & 2 & 125 & 7454 & 18000 & 6820 & 35000 \\
\hline 5311 & 150616 & 102601 & & 1 & $P$ & 2 & 125 & 8263 & 18000 & 6980 & 39000 \\
\hline
\end{tabular}




\begin{tabular}{|c|c|c|c|c|c|c|c|c|c|c|c|}
\hline No & Date & Time & Lne & CATEG VEH & CLASE VEH & TIPO VEH & EJES ELEVADOS & TARA TRACTOR & PMA TRACTOR & TARA REMOLQUE & PMA REMOLQUE \\
\hline 5312 & 150616 & 102617 & 1 & $\mathrm{P}$ & 2 & 125 & & 8000 & 18000 & 8500 & 36000 \\
\hline 5313 & 150616 & 102641 & 1 & $P$ & 2 & 125 & & 7480 & 18000 & 8050 & 35000 \\
\hline 5320 & 150616 & 102710 & 1 & $\mathrm{P}$ & 2 & 125 & & 8550 & 18000 & 0 & 0 \\
\hline 5321 & 150616 & 102716 & 1 & $\mathrm{P}$ & 2 & 125 & & 8700 & 18000 & 8640 & 35000 \\
\hline 5324 & 150616 & 102729 & 1 & $P$ & 2 & 125 & & 6545 & 18000 & 8350 & 34000 \\
\hline 5325 & 150616 & 102757 & 1 & $P$ & 2 & 125 & & 8087 & 18000 & 7400 & 35000 \\
\hline 5331 & 150616 & 102951 & 1 & $\mathrm{P}$ & 2 & 125 & & 6620 & 18000 & 6320 & 34000 \\
\hline 5337 & 150616 & 103038 & 1 & $\mathrm{P}$ & 2 & 125 & & 7612 & 18000 & 7257 & 35000 \\
\hline 5341 & 150616 & 103106 & 1 & $\mathrm{P}$ & 1 & 17 & & 11585 & 26000 & & \\
\hline 5343 & 150616 & 103132 & 1 & $\mathrm{P}$ & 2 & 125 & & 8121 & 18000 & 7000 & 35000 \\
\hline 5350 & 150616 & 103224 & 1 & $P$ & 2 & 125 & & 7794 & 18000 & 7000 & 34000 \\
\hline 5351 & 150616 & 103256 & 1 & $\mathrm{P}$ & 2 & 125 & & 8591 & 18000 & 8400 & 36000 \\
\hline 5355 & 150616 & 103317 & 1 & $\mathrm{P}$ & 2 & 125 & & 7120 & 18000 & 10130 & 39000 \\
\hline 5362 & 150616 & 103424 & 1 & $\mathrm{P}$ & 2 & 125 & & 7913 & 18000 & 8945 & 36000 \\
\hline 5364 & 150616 & 103438 & 1 & $\mathrm{P}$ & 2 & 125 & & 8068 & 18000 & 6070 & 35000 \\
\hline 5365 & 150616 & 103451 & 1 & $\mathrm{P}$ & 2 & 125 & & 8025 & 18000 & 6150 & 34000 \\
\hline 5366 & 150616 & 103515 & 1 & $\mathrm{P}$ & 2 & 125 & & 8371 & 18000 & 7500 & 35000 \\
\hline 5369 & 150616 & 103544 & 1 & $\mathrm{P}$ & 2 & 125 & & 8650 & 18000 & 8900 & 36000 \\
\hline 5379 & 150616 & 103703 & 1 & $\mathrm{P}$ & 2 & 125 & & 8000 & 18000 & 9000 & 36000 \\
\hline 5381 & 150616 & 103713 & 1 & $\mathrm{P}$ & 2 & 125 & & 7310 & 18000 & 7200 & 35000 \\
\hline 5390 & 150616 & 103815 & 1 & $\mathrm{P}$ & 2 & 125 & & 7120 & 18000 & 6080 & 34000 \\
\hline 5395 & 150616 & 103843 & 1 & $\mathrm{P}$ & 1 & 12 & & 7260 & 14500 & & \\
\hline 5401 & 150616 & 103922 & 1 & $\mathrm{P}$ & 2 & 125 & & 8000 & 18000 & 5900 & 36000 \\
\hline 5402 & 150616 & 103935 & 1 & $\mathrm{P}$ & 2 & 125 & 3 & 8392 & 18000 & 7500 & 35000 \\
\hline 5412 & 150616 & 104040 & 1 & $\mathrm{P}$ & 1 & 12 & & 3440 & 6940 & & \\
\hline 5415 & 150616 & 104101 & 1 & $\mathrm{P}$ & 2 & 125 & & 8395 & 18000 & 6900 & 35000 \\
\hline 5423 & 150616 & 104139 & 1 & $\mathrm{P}$ & 2 & 125 & & 8040 & 18000 & 8785 & 35000 \\
\hline
\end{tabular}




\begin{tabular}{|c|c|c|c|c|c|c|c|c|c|c|c|c|}
\hline No & Date & Time & Lne & & CATEG VEH & CLASE VEH & TIPO VEH & EJES ELEVADOS & TARA TRACTOR & PMA TRACTOR & TARA REMOLQUE & PMA REMOLQUE \\
\hline 5425 & 150616 & 104152 & & 1 & $P$ & 2 & 125 & & 8682 & 18000 & 7280 & 35000 \\
\hline 5429 & 150616 & 104226 & & 1 & P & 2 & 125 & & 6120 & 18000 & 7600 & 35000 \\
\hline 5433 & 150616 & 104252 & & 1 & $P$ & 2 & 125 & 3 & 6810 & 18000 & 6350 & 35000 \\
\hline 5437 & 150616 & 104314 & & 1 & $P$ & 2 & 125 & & 8009 & 18000 & 7600 & 34000 \\
\hline 5438 & 150616 & 104330 & & 1 & $P$ & 2 & 125 & & 6830 & 18000 & 7780 & 35000 \\
\hline 5444 & 150616 & 104422 & & 1 & P & 1 & 37 & & 12805 & 32000 & & \\
\hline 5450 & 150616 & 104510 & & 1 & $P$ & 2 & 125 & & 7685 & 18000 & 8900 & 35000 \\
\hline 5452 & 150616 & 104520 & & 1 & $P$ & 2 & 125 & & 8180 & 18000 & 6500 & 36000 \\
\hline 5457 & 150616 & 104613 & & 1 & $P$ & 2 & 125 & & 8268 & 18000 & 6860 & 42000 \\
\hline 5459 & 150616 & 104630 & & 1 & $\mathrm{P}$ & 2 & 125 & & 8469 & 18000 & 8900 & 36000 \\
\hline 5470 & 150616 & 104755 & & 1 & $P$ & 2 & 125 & & 7600 & 18000 & 5360 & 35000 \\
\hline 5471 & 150616 & 104810 & & 1 & $P$ & 2 & 125 & & 7598 & 18000 & 5110 & 34000 \\
\hline 5472 & 150616 & 104817 & & 1 & $P$ & 2 & 125 & & 7120 & 18000 & 5560 & 35000 \\
\hline 5474 & 150616 & 104850 & & 1 & $P$ & 1 & 12 & & 8000 & 18000 & & \\
\hline 5475 & 150616 & 104901 & & 1 & $P$ & 2 & 125 & & 7630 & 18000 & 5780 & 34000 \\
\hline 5481 & 150616 & 105009 & & 1 & $P$ & 2 & 146 & & 8980 & 26000 & 10340 & 36000 \\
\hline 5486 & 150616 & 105029 & & 1 & $P$ & 2 & 125 & & 8117 & 18000 & 7280 & 35000 \\
\hline 5493 & 150616 & 105121 & & 1 & $P$ & 2 & 125 & & 6810 & 18000 & 6677 & 35000 \\
\hline 5496 & 150616 & 105136 & & 1 & $P$ & 2 & 125 & & 7600 & 18000 & 5933 & 35000 \\
\hline 5498 & 150616 & 105143 & & 1 & $P$ & 2 & 125 & & 8050 & 18000 & 7000 & 35000 \\
\hline 5508 & 150616 & 105252 & & 1 & $P$ & 2 & 125 & & 8700 & 18000 & 7120 & 36000 \\
\hline 5511 & 150616 & 105318 & & 1 & $P$ & 1 & 12 & & 7130 & 10600 & & \\
\hline 5524 & 150616 & 105534 & & 1 & $P$ & 2 & 125 & & 6545 & 18000 & 8200 & 36000 \\
\hline 5529 & 150616 & 105617 & & 1 & $P$ & 1 & 12 & & 10270 & 13750 & & \\
\hline 5531 & 150616 & 105626 & & 1 & $P$ & 1 & 12 & & 8260 & 18000 & & \\
\hline 5538 & 150616 & 105710 & & 1 & $P$ & 2 & 125 & & 8505 & 18000 & 7020 & 35000 \\
\hline 5540 & 150616 & 105804 & & 1 & $P$ & 2 & 125 & & 7320 & 18000 & 0 & 35000 \\
\hline
\end{tabular}




\begin{tabular}{|c|c|c|c|c|c|c|c|c|c|c|c|c|}
\hline No & Date & Time & Lne & & CATEG VEH & CLASE VEH & TIPO VEH & EJES ELEVADOS & TARA TRACTOR & PMA TRACTOR & TARA REMOLQUE & PMA REMOLQUE \\
\hline 5544 & 150616 & 105820 & & 1 & $P$ & 2 & 125 & & 7859 & 18000 & 6165 & 34000 \\
\hline 5547 & 150616 & 105845 & & 1 & $P$ & 2 & 125 & & 8557 & 18000 & 8695 & 42000 \\
\hline 5552 & 150616 & 105956 & & 1 & $P$ & 2 & 125 & & 6830 & 18000 & 7200 & 35000 \\
\hline 5554 & 150616 & 110024 & & 1 & $\mathrm{P}$ & 2 & 125 & 3 & 7724 & 18000 & 7600 & 35000 \\
\hline 5556 & 150616 & 110039 & & 1 & $\mathrm{P}$ & 2 & 125 & & 6545 & 18000 & 6826 & 35000 \\
\hline 5562 & 150616 & 110212 & & 1 & $P$ & 1 & 12 & & 8280 & 18000 & & \\
\hline 5570 & 150616 & 110331 & & 1 & $\mathrm{P}$ & 2 & 125 & & 7685 & 18000 & 7080 & 35000 \\
\hline 5577 & 150616 & 110423 & & 1 & $\mathrm{P}$ & 1 & 12 & & 10070 & 19000 & & \\
\hline 5581 & 150616 & 110450 & & 1 & $P$ & 2 & 125 & & 8690 & 18000 & 7000 & 35000 \\
\hline 5583 & 150616 & 110504 & & 1 & $\mathrm{P}$ & 2 & 125 & & 6965 & 18000 & 6610 & 35000 \\
\hline 5591 & 150616 & 110552 & & 1 & $P$ & 2 & 125 & & 8044 & 18000 & 7310 & 36000 \\
\hline 5601 & 150616 & 110739 & & 1 & $P$ & 2 & 125 & & 7750 & 18000 & 7120 & 35000 \\
\hline 5614 & 150616 & 110908 & & 1 & $P$ & 2 & 125 & & 6545 & 18000 & 7750 & 39000 \\
\hline 5624 & 150616 & 111023 & & 1 & $\mathrm{P}$ & 2 & 125 & & 6810 & 18000 & 8100 & 35000 \\
\hline 5629 & 150616 & 111050 & & 1 & $P$ & 2 & 125 & & 7839 & 18000 & 7200 & 35000 \\
\hline 5631 & 150616 & 111105 & & 1 & $P$ & 2 & 125 & & 6995 & 18000 & 7200 & 36000 \\
\hline 5636 & 150616 & 111215 & & 1 & $P$ & 2 & 125 & & 8371 & 18000 & 7080 & 35000 \\
\hline 5640 & 150616 & 111312 & & 1 & $\mathrm{P}$ & 1 & 12 & & 7315 & 18000 & & \\
\hline 5641 & 150616 & 111320 & & 1 & $P$ & 2 & 125 & & 6830 & 18000 & 5340 & 35000 \\
\hline 5649 & 150616 & 111431 & & 1 & $P$ & 2 & 125 & & 7685 & 18000 & 6880 & 35000 \\
\hline 5653 & 150616 & 111457 & & 1 & $P$ & 2 & 125 & & 6810 & 18000 & 7900 & 36000 \\
\hline 5654 & 150616 & 111507 & & 1 & $P$ & 2 & 125 & & 6830 & 18000 & 7500 & 35000 \\
\hline 5655 & 150616 & 111514 & & 1 & $P$ & 2 & 125 & & 8227 & 18000 & 6883 & 35000 \\
\hline 5660 & 150616 & 111602 & & 1 & $P$ & 1 & 12 & & 6840 & 10500 & & \\
\hline 5665 & 150616 & 111643 & & 1 & $P$ & 2 & 125 & & 7040 & 18000 & 6830 & 35000 \\
\hline 5678 & 150616 & 111846 & & 1 & $P$ & 2 & 125 & & 7300 & 18000 & 7110 & 36000 \\
\hline 5690 & 150616 & 112050 & & 1 & $P$ & 3 & 174 & 3 & 12920 & 26000 & 5000 & 18000 \\
\hline
\end{tabular}




\begin{tabular}{|c|c|c|c|c|c|c|c|c|c|c|c|}
\hline No & Date & Time & Lne & & CATEG VEH & CLASE VEH & EJES ELEVADOS & TARA TRACTOR & PMA TRACTOR & TARA REMOLQUE & PMA REMOLQUE \\
\hline 5695 & 150616 & 112135 & & 1 & $\mathrm{P}$ & 2 & 125 & 6965 & 18000 & 6000 & 35000 \\
\hline 5705 & 150616 & 112321 & & 1 & $\mathrm{P}$ & 2 & 125 & 8196 & 18000 & 7480 & 36000 \\
\hline 5712 & 150616 & 112444 & & 1 & $\mathrm{P}$ & 2 & 125 & 8100 & 18000 & 8200 & 36000 \\
\hline 5716 & 150616 & 112523 & & 1 & $\mathrm{P}$ & 2 & 125 & 8550 & 18000 & 8500 & 36500 \\
\hline 5724 & 150616 & 112618 & & 1 & $P$ & 1 & 12 & 7500 & 14000 & & \\
\hline 5731 & 150616 & 112725 & & 1 & $\mathrm{P}$ & 2 & 125 & 8496 & 9429 & 8390 & 35000 \\
\hline 5737 & 150616 & 112803 & & 1 & $\mathrm{P}$ & 2 & 125 & 8224 & 18000 & 6400 & 35000 \\
\hline 5738 & 150616 & 112820 & & 1 & $\mathrm{P}$ & 1 & 12 & 7043 & 18000 & & \\
\hline 5742 & 150616 & 112840 & & 1 & $\mathrm{P}$ & 2 & 124 & 8362 & 25200 & 5700 & 29000 \\
\hline 5746 & 150616 & 112915 & & 1 & $\mathrm{P}$ & 2 & 125 & 8000 & 18000 & 7500 & 35000 \\
\hline 5751 & 150616 & 113025 & & 1 & $P$ & 2 & 125 & 7600 & 18000 & 5480 & 35000 \\
\hline 5753 & 150616 & 113037 & & 1 & $\mathrm{P}$ & 2 & 125 & 7075 & 18000 & 7200 & 35000 \\
\hline 5759 & 150616 & 113136 & & 1 & $\mathrm{P}$ & 2 & 125 & 7968 & 18000 & 8300 & 36000 \\
\hline 5765 & 150616 & 113229 & & 1 & $\mathrm{P}$ & 2 & 125 & 8000 & 18000 & 9725 & 35000 \\
\hline 5766 & 150616 & 113233 & & 1 & $P$ & 2 & 125 & 8000 & 18000 & 8400 & 36000 \\
\hline 5770 & 150616 & 113333 & & 1 & $\mathrm{P}$ & 2 & 125 & 8506 & 18000 & 8670 & 42000 \\
\hline 5772 & 150616 & 113347 & & 1 & $\mathrm{P}$ & 2 & 125 & 7685 & 18000 & 7280 & 35000 \\
\hline 5783 & 150616 & 113540 & & 1 & $\mathrm{P}$ & 2 & 125 & 7510 & 18000 & 7400 & 36000 \\
\hline 5785 & 150616 & 113608 & & 1 & $P$ & 3 & 124 & 11840 & 18000 & 7600 & 17000 \\
\hline 5786 & 150616 & 113618 & & 1 & $P$ & 2 & 125 & 6830 & 20500 & 6980 & 35000 \\
\hline 5789 & 150616 & 113629 & & 1 & $\mathrm{P}$ & 2 & 125 & 7820 & 18000 & 8500 & 36000 \\
\hline 5791 & 150616 & 113643 & & 1 & $\mathrm{P}$ & 1 & 12 & 8520 & 11990 & & \\
\hline 5797 & 150616 & 113718 & & 1 & $\mathrm{P}$ & 2 & 125 & 8000 & 18000 & 9000 & 34000 \\
\hline 5800 & 150616 & 113742 & & 1 & $P$ & 2 & 125 & 7918 & 18000 & 6820 & 35000 \\
\hline 5803 & 150616 & 113813 & & 1 & $\mathrm{P}$ & 3 & 124 & 10805 & 18000 & 7600 & 18000 \\
\hline 5805 & 150616 & 113823 & & 1 & $P$ & 2 & 125 & 8081 & 18000 & 7200 & 35000 \\
\hline 5822 & 150616 & 114117 & & 1 & $P$ & 2 & 125 & 6830 & 18000 & 8600 & 36000 \\
\hline
\end{tabular}




\begin{tabular}{|c|c|c|c|c|c|c|c|c|c|c|c|}
\hline No & Date & Time & Lne & CATEG VEH & CLASE VEH & TIPO VEH & EJES ELEVADOS & TARA TRACTOR & PMA TRACTOR & TARA REMOLQUE & PMA REMOLQUE \\
\hline 5825 & 150616 & 114148 & 1 & $\mathrm{P}$ & 2 & 125 & & 8279 & 18000 & 7200 & 35000 \\
\hline 5826 & 150616 & 114203 & 1 & $\mathrm{P}$ & 2 & 125 & & 8014 & 18000 & 6950 & 35000 \\
\hline 5828 & 150616 & 114209 & 1 & $\mathrm{P}$ & 2 & 125 & & 7400 & 40000 & 7200 & 34000 \\
\hline 5830 & 150616 & 114225 & 1 & $\mathrm{P}$ & 2 & 125 & 3 & 6622 & 18000 & 6150 & 34000 \\
\hline 5834 & 150616 & 114256 & 1 & $\mathrm{P}$ & 2 & 125 & & 7685 & 18000 & 16000 & 35000 \\
\hline 5840 & 150616 & 114330 & 1 & $\mathrm{P}$ & 1 & 12 & & 5960 & 11990 & & \\
\hline 5851 & 150616 & 114658 & 1 & $\mathrm{P}$ & 2 & 125 & & 10755 & 18000 & 6390 & 36000 \\
\hline 5859 & 150616 & 114736 & 1 & $\mathrm{P}$ & 2 & 125 & & 6830 & 18000 & 6520 & 35000 \\
\hline 5864 & 150616 & 114805 & 1 & $\mathrm{P}$ & 2 & 125 & & 8010 & 18000 & 6825 & 36000 \\
\hline 5869 & 150616 & 114844 & 1 & $\mathrm{P}$ & 2 & 125 & & 7275 & 18000 & 8700 & 36000 \\
\hline 5874 & 150616 & 114913 & 1 & $\mathrm{P}$ & 2 & 125 & 3 & 8982 & 18000 & 6600 & 34000 \\
\hline 5880 & 150616 & 114957 & 1 & $\mathrm{P}$ & 2 & 125 & & 8095 & 18000 & 7400 & 35000 \\
\hline 5883 & 150616 & 115015 & 1 & $\mathrm{P}$ & 2 & 125 & & 6800 & 18000 & 8800 & 36000 \\
\hline 5895 & 150616 & 115201 & 1 & $\mathrm{P}$ & 2 & 125 & & 8135 & 18000 & 5800 & 36000 \\
\hline 5899 & 150616 & 115232 & 1 & $P$ & 2 & 125 & 3 & 7800 & 18000 & 11080 & 32600 \\
\hline 5915 & 150616 & 115535 & 1 & $\mathrm{P}$ & 2 & 125 & & 7036 & 18000 & 7700 & 37000 \\
\hline 5937 & 150616 & 115934 & 1 & $\mathrm{P}$ & 2 & 125 & & 7970 & 18000 & 8900 & 35000 \\
\hline 5977 & 150616 & 120533 & 1 & $\mathrm{P}$ & 2 & 125 & & 7598 & 18000 & 6150 & 35000 \\
\hline 5988 & 150616 & 120703 & 1 & $\mathrm{P}$ & 2 & 125 & & 6810 & 18000 & 6200 & 34000 \\
\hline 6000 & 150616 & 120846 & 1 & $\mathrm{P}$ & 2 & 125 & & 7300 & 18000 & 4800 & 34000 \\
\hline 6003 & 150616 & 120919 & 1 & $\mathrm{P}$ & 2 & 125 & & 7300 & 19000 & 8100 & 35000 \\
\hline 6006 & 150616 & 120933 & 1 & $\mathrm{P}$ & 2 & 125 & & 6810 & 18000 & 6500 & 36000 \\
\hline 6007 & 150616 & 121037 & 1 & $\mathrm{P}$ & 2 & 125 & & 8400 & 18000 & 8900 & 35000 \\
\hline 6011 & 150616 & 121134 & 1 & $P$ & 2 & 125 & & 8135 & 18000 & 7200 & 35000 \\
\hline 6013 & 150616 & 121143 & 1 & $\mathrm{P}$ & 2 & 125 & & 6810 & 18000 & 7400 & 36000 \\
\hline 6015 & 150616 & 121154 & 1 & $\mathrm{P}$ & 2 & 125 & 3 & 8000 & 18000 & 9200 & 36000 \\
\hline 6036 & 150616 & 121437 & 1 & $\mathrm{P}$ & 2 & 125 & & 7685 & 18000 & 10270 & 39000 \\
\hline
\end{tabular}




\begin{tabular}{|c|c|c|c|c|c|c|c|c|c|c|c|}
\hline No & Date & Time & Lne & CATEG VEH & CLASE VEH & TIPO VEH & EJES ELEVADOS & TARA TRACTOR & PMA TRACTOR & TARA REMOLQUE & PMA REMOLQUE \\
\hline 6049 & 150616 & 121753 & 1 & $\mathrm{P}$ & 2 & 125 & & 7800 & 18000 & 8400 & 34000 \\
\hline 6054 & 150616 & 121830 & 1 & $P$ & 2 & 125 & & 7800 & 18000 & 8500 & 36000 \\
\hline 6058 & 150616 & 121930 & 1 & $\mathrm{P}$ & 2 & 125 & & 6300 & 18000 & 6220 & 39000 \\
\hline 6059 & 150616 & 121942 & 1 & $\mathrm{P}$ & 2 & 125 & & 6622 & 18000 & 3120 & 22000 \\
\hline 6061 & 150616 & 122024 & 1 & $\mathrm{P}$ & 2 & 125 & & 6830 & 18000 & 5110 & 34000 \\
\hline 6070 & 150616 & 122148 & 1 & $\mathrm{P}$ & 2 & 125 & & 8050 & 18000 & 8800 & 35000 \\
\hline 6072 & 150616 & 122205 & 1 & $\mathrm{P}$ & 2 & 125 & & 7120 & 19000 & 5600 & 35000 \\
\hline 6078 & 150616 & 122314 & 1 & $P$ & 1 & 12 & & 3425 & 5600 & & \\
\hline 6081 & 150616 & 122407 & 1 & $P$ & 2 & 125 & & 8000 & 18000 & 6500 & 41000 \\
\hline 6084 & 150616 & 122435 & 1 & $\mathrm{P}$ & 2 & 125 & & 7120 & 18000 & 5500 & 34000 \\
\hline 6088 & 150616 & 122446 & 1 & $P$ & 2 & 125 & 3 & 6810 & 18000 & 5490 & 36000 \\
\hline 6091 & 150616 & 122459 & 1 & $\mathrm{P}$ & 2 & 125 & & 8230 & 18000 & 10000 & 34000 \\
\hline 6093 & 150616 & 122522 & 1 & $\mathrm{P}$ & 2 & 125 & & 8000 & 18000 & 8500 & 34000 \\
\hline 6095 & 150616 & 122533 & 1 & $\mathrm{P}$ & 2 & 125 & & 8000 & 18000 & 8200 & 36000 \\
\hline 6105 & 150616 & 122648 & 1 & $\mathrm{P}$ & 1 & 12 & & 7160 & 13500 & & \\
\hline 6107 & 150616 & 122708 & 1 & $\mathrm{P}$ & 2 & 125 & & 8344 & 18000 & 8200 & 36000 \\
\hline 6109 & 150616 & 122719 & 1 & $\mathrm{P}$ & 2 & 125 & & 6830 & 18000 & 6350 & 35000 \\
\hline 6113 & 150616 & 122741 & 1 & $\mathrm{P}$ & 2 & 125 & & 7839 & 18000 & 8811 & 36000 \\
\hline 6167 & 150616 & 123656 & 1 & $P$ & 2 & 125 & & 8575 & 18000 & 9286 & 35000 \\
\hline 6169 & 150616 & 123708 & 1 & $\mathrm{P}$ & 2 & 125 & & 7490 & 18000 & 7400 & 35000 \\
\hline 6176 & 150616 & 123810 & 1 & $P$ & 2 & 125 & & 6700 & 18000 & 5760 & 34000 \\
\hline 6177 & 150616 & 123820 & 1 & $\mathrm{P}$ & 2 & 125 & & 8418 & 18000 & 7812 & 35000 \\
\hline 6181 & 150616 & 123837 & 1 & $P$ & 2 & 125 & & 7872 & 18000 & 5290 & 35000 \\
\hline 6192 & 150616 & 124102 & 1 & $P$ & 2 & 125 & & 7120 & 18000 & 8488 & 42000 \\
\hline 6201 & 150616 & 124306 & 1 & $\mathrm{P}$ & 2 & 126 & & 8081 & 18000 & 10300 & 35000 \\
\hline 6206 & 150616 & 124405 & 1 & $\mathrm{P}$ & 2 & 125 & & 7878 & 18000 & 7990 & 35000 \\
\hline 6212 & 150616 & 124447 & 1 & $P$ & 2 & 125 & & 7685 & 18000 & 7500 & 36000 \\
\hline
\end{tabular}




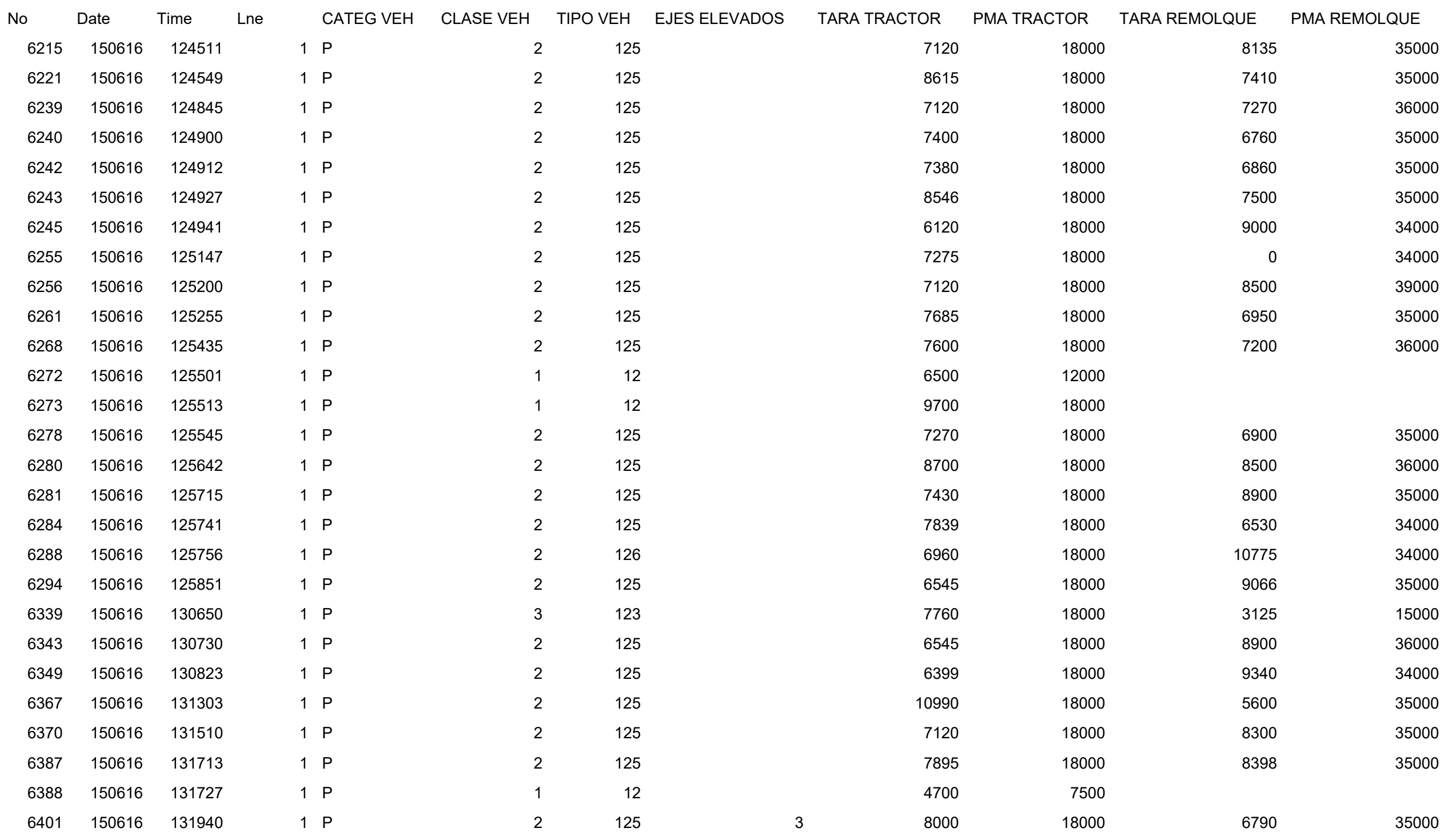




\begin{tabular}{|c|c|c|c|c|c|c|c|c|c|c|c|}
\hline No & Date & Time & Lne & CATEG VEH & CLASE VEH & TIPO VEH & EJES ELEVADOS & TARA TRACTOR & PMA TRACTOR & TARA REMOLQUE & PMA REMOLQUE \\
\hline 6406 & 150616 & 132049 & 1 & $\mathrm{P}$ & 2 & 125 & & 6924 & 18000 & 5400 & 34000 \\
\hline 6424 & 150616 & 132328 & 1 & $\mathrm{P}$ & 2 & 125 & & 6830 & 18000 & 6060 & 34000 \\
\hline 6429 & 150616 & 132406 & 1 & $\mathrm{P}$ & 3 & 124 & & 9030 & 18000 & 4830 & 18000 \\
\hline 6435 & 150616 & 132434 & 1 & $\mathrm{P}$ & 2 & 125 & & 7685 & 18000 & 8500 & 36000 \\
\hline 6436 & 150616 & 132436 & 1 & $P$ & 2 & 125 & & 8000 & 18000 & 6770 & 35000 \\
\hline 6450 & 150616 & 132638 & 1 & $\mathrm{P}$ & 2 & 125 & & 7240 & 18000 & 7360 & 35000 \\
\hline 6451 & 150616 & 132702 & 1 & $\mathrm{P}$ & 2 & 125 & & 8494 & 18000 & 7260 & 35000 \\
\hline 6452 & 150616 & 132722 & 1 & $\mathrm{P}$ & 1 & 12 & & 2860 & 3500 & & \\
\hline 6458 & 150616 & 132824 & 1 & $\mathrm{P}$ & 1 & 17 & 3 & 12070 & 26000 & & \\
\hline 6482 & 150616 & 133418 & 1 & $\mathrm{P}$ & 2 & 125 & & 7898 & 18000 & 7550 & 36000 \\
\hline 6486 & 150616 & 133451 & 1 & $P$ & 2 & 125 & & 6100 & 18000 & 5490 & 35000 \\
\hline 6493 & 150616 & 133613 & 1 & $P$ & 2 & 125 & & 6810 & 18000 & 8200 & 35000 \\
\hline 6494 & 150616 & 133623 & 1 & $\mathrm{P}$ & 2 & 125 & & 7430 & 18000 & 5900 & 36000 \\
\hline 6496 & 150616 & 133657 & 1 & $\mathrm{P}$ & 2 & 125 & & 7120 & 18000 & 6500 & 35000 \\
\hline 6498 & 150616 & 133712 & 1 & $P$ & 2 & 125 & & 8288 & 18000 & 8304 & 35000 \\
\hline 6499 & 150616 & 133722 & 1 & $\mathrm{P}$ & 2 & 125 & & 7036 & 18000 & 6790 & 36000 \\
\hline 6503 & 150616 & 133808 & 1 & $\mathrm{P}$ & 2 & 125 & & 7560 & 18000 & 8682 & 35000 \\
\hline 6507 & 150616 & 133905 & 1 & $\mathrm{P}$ & 2 & 125 & & 7500 & 18000 & 6890 & 35000 \\
\hline 6509 & 150616 & 133937 & 1 & $P$ & 2 & 125 & & 7120 & 18000 & 7660 & 35000 \\
\hline 6511 & 150616 & 133952 & 1 & $\mathrm{P}$ & 2 & 126 & & 7831 & 18000 & 5950 & 34000 \\
\hline 6514 & 150616 & 134049 & 1 & $\mathrm{P}$ & 2 & 125 & & 6800 & 18000 & 8200 & 36000 \\
\hline 6515 & 150616 & 134101 & 1 & $\mathrm{P}$ & 2 & 125 & & 8135 & 18000 & 7280 & 35000 \\
\hline 6530 & 150616 & 134245 & 1 & $\mathrm{P}$ & 1 & 14 & 3 & 14055 & 26000 & & \\
\hline 6542 & 150616 & 134358 & 1 & $\mathrm{P}$ & 2 & 125 & & 6830 & 18000 & 6325 & 39000 \\
\hline 6547 & 150616 & 134456 & 1 & $\mathrm{P}$ & 2 & 125 & & 6810 & 18000 & 6700 & 35000 \\
\hline 6551 & 150616 & 134523 & 1 & $\mathrm{P}$ & 2 & 125 & & 8358 & 18000 & 9000 & 36000 \\
\hline 6559 & 150616 & 134618 & 1 & $\mathrm{P}$ & 2 & 125 & & 8071 & 18000 & 7200 & 35000 \\
\hline
\end{tabular}




\begin{tabular}{|c|c|c|c|c|c|c|c|c|c|c|c|c|}
\hline No & Date & Time & Lne & & CATEG VEH & CLASE VEH & TIPO VEH & EJES ELEVADOS & TARA TRACTOR & PMA TRACTOR & TARA REMOLQUE & PMA REMOLQUE \\
\hline 6564 & 150616 & 134658 & & 1 & $P$ & 2 & 125 & & 6885 & 18000 & 6500 & 38000 \\
\hline 6567 & 150616 & 134730 & & 1 & P & 3 & 123 & & 7760 & 18000 & 3020 & 18000 \\
\hline 6574 & 150616 & 134848 & & 1 & B & 1 & 12 & & 13768 & 18000 & & \\
\hline 6576 & 150616 & 134902 & & 1 & $P$ & 2 & 125 & 3 & 7120 & 18000 & 4800 & 34000 \\
\hline 6584 & 150616 & 135025 & & 1 & $P$ & 2 & 125 & & 7300 & 18000 & 7900 & 35000 \\
\hline 12397 & 150617 & 100610 & & 1 & P & 2 & 125 & & 740 & 18000 & 8500 & 36000 \\
\hline 12452 & 150617 & 101456 & & 1 & $P$ & 2 & 125 & & 8000 & 18000 & 7042 & 35000 \\
\hline 12454 & 150617 & 101528 & & 1 & $P$ & 2 & 125 & & 8205 & 18000 & 7600 & 34000 \\
\hline 12471 & 150617 & 102032 & & 1 & $P$ & 1 & 12 & & 5400 & 8600 & & \\
\hline 12473 & 150617 & 102048 & & 1 & $P$ & 2 & 125 & & 8484 & 18000 & 8500 & 36000 \\
\hline 12474 & 150617 & 102106 & & 1 & $P$ & 2 & 125 & & 6120 & 18000 & 7200 & 36000 \\
\hline 12481 & 150617 & 102150 & & 1 & $P$ & 2 & 125 & & 6810 & 18000 & 7320 & 36000 \\
\hline 12484 & 150617 & 102228 & & 1 & $P$ & 2 & 125 & & 6100 & 18000 & 5000 & 35000 \\
\hline 12490 & 150617 & 102331 & & 1 & $P$ & 2 & 125 & & 6840 & 18000 & 5300 & 36000 \\
\hline 12495 & 150617 & 102411 & & 1 & $P$ & 2 & 125 & & 8286 & 18000 & 8452 & 35000 \\
\hline 12504 & 150617 & 102530 & & 1 & $P$ & 2 & 125 & & 0 & 0 & 0 & 0 \\
\hline 12507 & 150617 & 102607 & & 1 & $P$ & 2 & 125 & & 8344 & 18000 & 8200 & 32000 \\
\hline 12515 & 150617 & 102728 & & 1 & $P$ & 2 & 125 & & 8090 & 18000 & 8918 & 36000 \\
\hline 12517 & 150617 & 102810 & & 1 & $P$ & 2 & 125 & & 7454 & 18000 & 6820 & 35000 \\
\hline 12525 & 150617 & 102942 & & 1 & $P$ & 2 & 125 & & 7300 & 18000 & 8800 & 35000 \\
\hline 12527 & 150617 & 103005 & & 1 & $P$ & 2 & 125 & & 8459 & 18000 & 5150 & 35000 \\
\hline 12532 & 150617 & 103032 & & 1 & $P$ & 2 & 125 & & 8546 & 18000 & 7650 & 35000 \\
\hline 12533 & 150617 & 103045 & & 1 & $P$ & 3 & 124 & & 12025 & 18000 & 8920 & 18000 \\
\hline 12537 & 150617 & 103115 & & 1 & $P$ & 2 & 125 & & 7685 & 18000 & 7000 & 35000 \\
\hline 12539 & 150617 & 103128 & & 1 & $P$ & 2 & 125 & & 7120 & 18000 & 6240 & 36000 \\
\hline 12540 & 150617 & 103140 & & 1 & $\mathrm{P}$ & 2 & 125 & & 7800 & 18000 & 8800 & 36000 \\
\hline 12548 & 150617 & 103220 & & 1 & $P$ & 2 & 125 & & 8459 & 18000 & 6810 & 39000 \\
\hline
\end{tabular}




\begin{tabular}{|c|c|c|c|c|c|c|c|c|c|c|c|c|}
\hline No & Date & Time & Lne & & CATEG VEH & CLASE VEH & TIPO VEH & EJES ELEVADOS & TARA TRACTOR & PMA TRACTOR & TARA REMOLQUE & PMA REMOLQUE \\
\hline 12559 & 150617 & 103455 & & 1 & $P$ & 3 & 124 & & 11380 & 18000 & 6680 & 16480 \\
\hline 12560 & 150617 & 103509 & & 1 & P & 2 & 125 & & 8088 & 18000 & 8400 & 40000 \\
\hline 12562 & 150617 & 103520 & & 1 & $P$ & 2 & 125 & & 6810 & 18000 & 8900 & 36000 \\
\hline 12569 & 150617 & 103619 & & 1 & $P$ & 2 & 125 & & 7583 & 18000 & 6280 & 39000 \\
\hline 12570 & 150617 & 103627 & & 1 & $P$ & 2 & 125 & & 8409 & 18000 & 6740 & 35000 \\
\hline 12571 & 150617 & 103634 & & 1 & $P$ & 2 & 125 & 3 & 7800 & 18000 & 8000 & 35000 \\
\hline 12579 & 150617 & 103747 & & 1 & $P$ & 2 & 125 & & 7750 & 18000 & 7680 & 35000 \\
\hline 12582 & 150617 & 103800 & & 1 & $P$ & 2 & 125 & & 7370 & 18000 & 6030 & 34000 \\
\hline 12594 & 150617 & 103903 & & 1 & $P$ & 2 & 125 & 3 & 7385 & 18000 & 8900 & 35000 \\
\hline 12599 & 150617 & 104007 & & 1 & $P$ & 2 & 125 & & 6810 & 18000 & 5475 & 35000 \\
\hline 12602 & 150617 & 104025 & & 1 & $P$ & 2 & 125 & & 8315 & 18000 & 7500 & 35000 \\
\hline 12604 & 150617 & 104105 & & 1 & $P$ & 2 & 125 & & 6810 & 18000 & 6950 & 35000 \\
\hline 12609 & 150617 & 104146 & & 1 & $P$ & 2 & 125 & & 6995 & 18000 & 7200 & 36000 \\
\hline 12612 & 150617 & 104211 & & 1 & $P$ & 2 & 125 & & 8296 & 18000 & 7925 & 35000 \\
\hline 12619 & 150617 & 104333 & & 1 & $P$ & 2 & 125 & & 7120 & 18000 & 7500 & 36000 \\
\hline 12622 & 150617 & 104419 & & 1 & $P$ & 3 & 124 & & 12120 & 18000 & 7500 & 17480 \\
\hline 12626 & 150617 & 104542 & & 1 & $P$ & 2 & 125 & & 6830 & 18000 & 9100 & 36000 \\
\hline 12633 & 150617 & 104646 & & 1 & $P$ & 1 & 12 & & 9520 & 13000 & & \\
\hline 12638 & 150617 & 104718 & & 1 & $P$ & 2 & 125 & & 6800 & 18000 & 8750 & 36000 \\
\hline 12649 & 150617 & 104851 & & 1 & $P$ & 2 & 125 & & 8225 & 18000 & 6730 & 35000 \\
\hline 12657 & 150617 & 105006 & & 1 & $P$ & 2 & 125 & & 8000 & 18000 & 6883 & 35000 \\
\hline 12663 & 150617 & 105032 & & 1 & $P$ & 2 & 125 & & 6622 & 18000 & 7540 & 35000 \\
\hline 12667 & 150617 & 105102 & & 1 & $P$ & 2 & 125 & & 6120 & 18200 & 8500 & 36000 \\
\hline 12669 & 150617 & 105121 & & 1 & $P$ & 1 & 12 & & 9460 & 18000 & & \\
\hline 12671 & 150617 & 105128 & & 1 & $P$ & 1 & 12 & & 7950 & 18000 & & \\
\hline 12675 & 150617 & 105155 & & 1 & $\mathrm{P}$ & 2 & 125 & & 6830 & 18000 & 3750 & 35000 \\
\hline 12676 & 150617 & 105208 & & 1 & $P$ & 2 & 125 & & 7317 & 18000 & 8400 & 37000 \\
\hline
\end{tabular}




\begin{tabular}{|c|c|c|c|c|c|c|c|c|c|c|c|c|}
\hline No & Date & Time & Lne & & CATEG VEH & CLASE VEH & TIPO VEH & EJES ELEVADOS & TARA TRACTOR & PMA TRACTOR & TARA REMOLQUE & PMA REMOLQUE \\
\hline 12677 & 150617 & 105226 & & 1 & $P$ & 2 & 125 & & 8080 & 18000 & 7200 & 35000 \\
\hline 12679 & 150617 & 105247 & & 1 & $\mathrm{P}$ & 2 & 125 & & 6810 & 18000 & 7000 & 35000 \\
\hline 12685 & 150617 & 105350 & & 1 & $P$ & 2 & 125 & 3 & 7839 & 18000 & 7300 & 35000 \\
\hline 12686 & 150617 & 105353 & & 1 & $\mathrm{P}$ & 2 & 125 & & 8327 & 18000 & 7040 & 36000 \\
\hline 12690 & 150617 & 105408 & & 1 & $P$ & 2 & 125 & & 8408 & 18000 & 8200 & 36000 \\
\hline 12703 & 150617 & 105533 & & 1 & $P$ & 3 & 124 & & 11925 & 18000 & 7600 & 18000 \\
\hline 12717 & 150617 & 105732 & & 1 & $\mathrm{P}$ & 2 & 125 & & 8371 & 18000 & 8900 & 35000 \\
\hline 12725 & 150617 & 105910 & & 1 & $P$ & 2 & 125 & & 7685 & 18000 & 8700 & 36000 \\
\hline 12735 & 150617 & 110026 & & 1 & B & 1 & 12 & & 13109 & 18000 & & \\
\hline 12800 & 150617 & 110928 & & 1 & $\mathrm{P}$ & 2 & 125 & & 7120 & 18000 & 6425 & 38000 \\
\hline 12803 & 150617 & 111018 & & 1 & $P$ & 1 & 12 & & 11265 & 18000 & & \\
\hline 12804 & 150617 & 111031 & & 1 & $P$ & 2 & 125 & & 8297 & 18000 & 7200 & 35000 \\
\hline 12811 & 150617 & 111121 & & 1 & $P$ & 2 & 125 & & 6408 & 18000 & 6890 & 36000 \\
\hline 12818 & 150617 & 111223 & & 1 & $\mathrm{P}$ & 2 & 125 & & 8284 & 20000 & 7000 & 35000 \\
\hline 12823 & 150617 & 111252 & & 1 & $P$ & 2 & 125 & 3 & 8000 & 18000 & 8600 & 36000 \\
\hline 12831 & 150617 & 111408 & & 1 & $P$ & 2 & 125 & & 8371 & 18000 & 8100 & 35000 \\
\hline 12834 & 150617 & 111428 & & 1 & $P$ & 2 & 126 & 3 & 6830 & 18000 & 11300 & 36000 \\
\hline 12840 & 150617 & 111510 & & 1 & $\mathrm{P}$ & 3 & 124 & & 11905 & 18000 & 7020 & 16480 \\
\hline 12846 & 150617 & 111605 & & 1 & $\mathrm{~F}$ & 1 & 11 & & 1891 & 3500 & & \\
\hline 12849 & 150617 & 111629 & & 1 & $P$ & 2 & 125 & & 6890 & 18000 & 0 & 0 \\
\hline 12877 & 150617 & 112129 & & 1 & B & 1 & 17 & & 16000 & 24000 & & \\
\hline 12879 & 150617 & 112152 & & 1 & $P$ & 2 & 125 & & 7040 & 18000 & 9520 & 36000 \\
\hline 12887 & 150617 & 112241 & & 1 & $P$ & 2 & 125 & & 7000 & 17000 & 5280 & 35000 \\
\hline 12895 & 150617 & 112335 & & 1 & $P$ & 2 & 125 & & 7060 & 18000 & 5520 & 35000 \\
\hline 12903 & 150617 & 112542 & & 1 & $P$ & 2 & 125 & & 7575 & 18000 & 8682 & 35000 \\
\hline 12909 & 150617 & 112636 & & 1 & $P$ & 2 & 125 & & 7600 & 18000 & 5950 & 35000 \\
\hline 12914 & 150617 & 112700 & & 1 & $P$ & 2 & 125 & & 7050 & 18000 & 6000 & 35000 \\
\hline
\end{tabular}




\begin{tabular}{|c|c|c|c|c|c|c|c|c|c|c|c|c|}
\hline No & Date & Time & Lne & & CATEG VEH & CLASE VEH & TIPO VEH & EJES ELEVADOS & TARA TRACTOR & PMA TRACTOR & TARA REMOLQUE & PMA REMOLQUE \\
\hline 12921 & 150617 & 112740 & & 1 & $P$ & 2 & 125 & & 8200 & 18000 & 6710 & 35000 \\
\hline 12926 & 150617 & 112806 & & 1 & P & 2 & 125 & & 8074 & 18000 & 8500 & 36000 \\
\hline 12928 & 150617 & 112821 & & 1 & $P$ & 1 & 12 & & 5960 & 11990 & & \\
\hline 12938 & 150617 & 113053 & & 1 & $P$ & 2 & 125 & 3 & 6545 & 18000 & 6770 & 36000 \\
\hline 12947 & 150617 & 113313 & & 1 & $P$ & 2 & 125 & & 8000 & 18000 & 6890 & 35000 \\
\hline 12951 & 150617 & 113334 & & 1 & P & 2 & 125 & & 7630 & 18000 & 7570 & 35000 \\
\hline 12955 & 150617 & 113418 & & 1 & $P$ & 2 & 125 & & 8000 & 18000 & 6660 & 35000 \\
\hline 12960 & 150617 & 113436 & & 1 & $P$ & 2 & 125 & & 8286 & 18000 & 8900 & 35000 \\
\hline 12965 & 150617 & 113516 & & 1 & $P$ & 1 & 12 & & 9835 & 13000 & & \\
\hline 12974 & 150617 & 113653 & & 1 & $P$ & 2 & 125 & & 6800 & 18000 & 7433 & 35000 \\
\hline 12978 & 150617 & 113743 & & 1 & $P$ & 2 & 125 & & 8052 & 18000 & 8200 & 36000 \\
\hline 12985 & 150617 & 113821 & & 1 & $P$ & 2 & 125 & & 8088 & 18000 & 8825 & 35000 \\
\hline 12987 & 150617 & 113828 & & 1 & $p$ & 2 & 125 & & 7905 & 18000 & 8900 & 35000 \\
\hline 12993 & 150617 & 113905 & & 1 & $P$ & 2 & 125 & & 7202 & 18000 & 5620 & 34000 \\
\hline 12999 & 150617 & 113947 & & 1 & $P$ & 2 & 125 & & 6810 & 18000 & 5110 & 34000 \\
\hline 13006 & 150617 & 114041 & & 1 & $P$ & 3 & 123 & & 11620 & 18000 & 6000 & 12400 \\
\hline 13033 & 150617 & 114419 & & 1 & $P$ & 3 & 124 & & 12920 & 18000 & 9305 & 16480 \\
\hline 13050 & 150617 & 114705 & & 1 & $P$ & 2 & 125 & & 8459 & 18000 & 8932 & 36000 \\
\hline 13054 & 150617 & 114753 & & 1 & $P$ & 1 & 12 & & 6430 & 12000 & & \\
\hline 13060 & 150617 & 114851 & & 1 & $P$ & 2 & 125 & & 7960 & 18000 & 6700 & 35000 \\
\hline 13068 & 150617 & 115017 & & 1 & $P$ & 2 & 125 & & 6830 & 18000 & 5980 & 35000 \\
\hline 13075 & 150617 & 115054 & & 1 & $P$ & 3 & 124 & & 10706 & 18000 & 4350 & 16480 \\
\hline 13076 & 150617 & 115108 & & 1 & $P$ & 2 & 125 & 3 & 6850 & 18000 & 5050 & 34000 \\
\hline 13078 & 150617 & 115146 & & 1 & $P$ & 2 & 125 & & 8561 & 18000 & 8300 & 35000 \\
\hline 13085 & 150617 & 115312 & & 1 & $P$ & 1 & 12 & & 4330 & 8600 & & \\
\hline 13089 & 150617 & 115350 & & 1 & $\mathrm{P}$ & 2 & 125 & & 7480 & 18000 & 8100 & 35000 \\
\hline 13171 & 150617 & 120552 & & 1 & $P$ & 2 & 125 & & 8700 & 18000 & 8500 & 34000 \\
\hline
\end{tabular}




\begin{tabular}{|c|c|c|c|c|c|c|c|c|c|c|c|c|}
\hline No & Date & Time & Lne & & CATEG VEH & CLASE VEH & TIPO VEH & EJES ELEVADOS & TARA TRACTOR & PMA TRACTOR & TARA REMOLQUE & PMA REMOLQUE \\
\hline 13182 & 150617 & 120718 & & 1 & $P$ & 2 & 125 & & 8031 & 18000 & 8942 & 35000 \\
\hline 13190 & 150617 & 120830 & & 1 & $P$ & 2 & 125 & & 8375 & 18000 & 7690 & 39000 \\
\hline 13193 & 150617 & 120859 & & 1 & $P$ & 2 & 125 & & 7535 & 19000 & 8025 & 35000 \\
\hline 13201 & 150617 & 121000 & & 1 & $P$ & 2 & 125 & & 6800 & 18000 & 6550 & 34000 \\
\hline 13205 & 150617 & 121024 & & 1 & $P$ & 1 & 12 & & 10570 & 14000 & & \\
\hline 13212 & 150617 & 121150 & & 1 & $\mathrm{P}$ & 2 & 125 & & 7050 & 18000 & 6980 & 35000 \\
\hline 13217 & 150617 & 121234 & & 1 & $\mathrm{P}$ & 2 & 125 & & 7050 & 18000 & 6820 & 35000 \\
\hline 13221 & 150617 & 121252 & & 1 & $\mathrm{P}$ & 2 & 125 & & 6700 & 18000 & 6000 & 34000 \\
\hline 13222 & 150617 & 121306 & & 1 & $P$ & 2 & 125 & & 8303 & 18000 & 8900 & 35000 \\
\hline 13225 & 150617 & 121337 & & 1 & $\mathrm{P}$ & 2 & 125 & & 8224 & 18000 & 6420 & 36000 \\
\hline 13237 & 150617 & 121524 & & 1 & $P$ & 2 & 125 & & 8067 & 18000 & 8500 & 36000 \\
\hline 13241 & 150617 & 121555 & & 1 & $P$ & 2 & 125 & & 8594 & 18000 & 8565 & 36000 \\
\hline 13251 & 150617 & 121710 & & 1 & $P$ & 1 & 17 & 3 & 13595 & 26000 & & \\
\hline 13256 & 150617 & 121740 & & 1 & $\mathrm{P}$ & 1 & 12 & & 10640 & 18000 & & \\
\hline 13259 & 150617 & 121754 & & 1 & $P$ & 2 & 125 & & 7120 & 18000 & 8500 & 35000 \\
\hline 13266 & 150617 & 121857 & & 1 & $P$ & 1 & 12 & & 10000 & 13500 & & \\
\hline 13269 & 150617 & 121920 & & 1 & $P$ & 2 & 125 & & 7350 & 18000 & 8492 & 35000 \\
\hline 13272 & 150617 & 122000 & & 1 & $\mathrm{P}$ & 2 & 125 & & 6830 & 18000 & 4600 & 35000 \\
\hline 13273 & 150617 & 122014 & & 1 & $P$ & 3 & 123 & & 7469 & 18000 & 7800 & 34000 \\
\hline 13278 & 150617 & 122104 & & 1 & $P$ & 3 & 176 & & 11654 & 26000 & 6650 & 24000 \\
\hline 13283 & 150617 & 122202 & & 1 & $P$ & 2 & 125 & & 6800 & 18000 & 7390 & 35000 \\
\hline 13285 & 150617 & 122225 & & 1 & $P$ & 2 & 125 & & 8434 & 18000 & 8745 & 36000 \\
\hline 13297 & 150617 & 122506 & & 1 & $P$ & 2 & 125 & & 8175 & 18000 & 7040 & 35000 \\
\hline 13300 & 150617 & 122538 & & 1 & $P$ & 2 & 125 & & 8473 & 18000 & 7555 & 42000 \\
\hline 13305 & 150617 & 122601 & & 1 & $P$ & 1 & 12 & & 9500 & 12950 & & \\
\hline 13320 & 150617 & 122833 & & 1 & $P$ & 3 & 124 & & 15460 & 18000 & 3745 & 13200 \\
\hline 13322 & 150617 & 122852 & & 1 & $P$ & 2 & 125 & & 8225 & 18000 & 7366 & 35000 \\
\hline
\end{tabular}




\begin{tabular}{|c|c|c|c|c|c|c|c|c|c|c|c|}
\hline No & Date & Time & Lne & CATEG VEH & CLASE VEH & TIPO VEH & EJES ELEVADOS & TARA TRACTOR & PMA TRACTOR & TARA REMOLQUE & PMA REMOLQUE \\
\hline 13323 & 150617 & 122903 & 1 & $\mathrm{P}$ & 2 & 125 & & 6408 & 18000 & 7500 & 34000 \\
\hline 13328 & 150617 & 122941 & 1 & $\mathrm{P}$ & 2 & 125 & & 7345 & 18000 & 6550 & 34000 \\
\hline 13335 & 150617 & 123037 & 1 & $\mathrm{P}$ & 2 & 125 & & 8227 & 18000 & 6883 & 35000 \\
\hline 13375 & 150617 & 123554 & 1 & $\mathrm{P}$ & 2 & 125 & & 8341 & 18000 & 8400 & 36000 \\
\hline 13376 & 150617 & 123603 & 1 & $\mathrm{P}$ & 2 & 125 & & 8588 & 18000 & 7417 & 35000 \\
\hline 13386 & 150617 & 123735 & 1 & $\mathrm{P}$ & 2 & 125 & & 8280 & 18000 & 7200 & 34000 \\
\hline 13411 & 150617 & 124111 & 1 & $\mathrm{P}$ & 2 & 125 & 3 & 6830 & 18000 & 8900 & 36000 \\
\hline 13426 & 150617 & 124438 & 1 & $\mathrm{P}$ & 2 & 125 & & 7074 & 18000 & 5500 & 35000 \\
\hline 13432 & 150617 & 124538 & 1 & $\mathrm{P}$ & 2 & 125 & & 7705 & 18000 & 8925 & 35000 \\
\hline 13433 & 150617 & 124550 & 1 & $\mathrm{P}$ & 3 & 123 & & 7760 & 18000 & 3125 & 15000 \\
\hline 13451 & 150617 & 124843 & 1 & $P$ & 2 & 125 & & 7090 & 18000 & 6050 & 35000 \\
\hline 13456 & 150617 & 124917 & 1 & $\mathrm{P}$ & 2 & 125 & & 6800 & 18000 & 7200 & 35000 \\
\hline 13457 & 150617 & 124918 & 1 & $\mathrm{P}$ & 1 & 12 & & 6750 & 15000 & & \\
\hline 13458 & 150617 & 124926 & 1 & $\mathrm{P}$ & 2 & 125 & & 6800 & 18000 & 6711 & 35000 \\
\hline 13459 & 150617 & 124938 & 1 & $P$ & 2 & 125 & 3 & 9097 & 18000 & 8400 & 37000 \\
\hline 13460 & 150617 & 124941 & 1 & $\mathrm{P}$ & 2 & 125 & & 7360 & 18000 & 6690 & 35000 \\
\hline 13462 & 150617 & 124954 & 1 & $\mathrm{P}$ & 2 & 125 & & 7281 & 18000 & 5980 & 35000 \\
\hline 13468 & 150617 & 125049 & 1 & $\mathrm{P}$ & 2 & 125 & & 8135 & 18000 & 6400 & 36000 \\
\hline 13471 & 150617 & 125126 & 1 & $P$ & 2 & 125 & & 8000 & 18000 & 7370 & 36000 \\
\hline 13472 & 150617 & 125203 & 1 & $\mathrm{P}$ & 2 & 125 & & 8210 & 18000 & 5242 & 35000 \\
\hline 13474 & 150617 & 125215 & 1 & $\mathrm{P}$ & 2 & 125 & & 8344 & 18000 & 7030 & 35000 \\
\hline 13481 & 150617 & 125250 & 1 & $\mathrm{P}$ & 2 & 125 & 3 & 8324 & 18000 & 8400 & 38000 \\
\hline 13486 & 150617 & 125331 & 1 & $\mathrm{P}$ & 1 & 12 & & 8535 & 12000 & & \\
\hline 13487 & 150617 & 125339 & 1 & $P$ & 2 & 125 & & 7685 & 18000 & 7500 & 35000 \\
\hline 13491 & 150617 & 125436 & 1 & $P$ & 2 & 125 & & 7568 & 18000 & 7650 & 35000 \\
\hline 13492 & 150617 & 125437 & 1 & $\mathrm{P}$ & 2 & 125 & & 6545 & 18000 & 6780 & 36000 \\
\hline 13495 & 150617 & 125501 & 1 & $\mathrm{P}$ & 2 & 125 & & 8001 & 18000 & 8500 & 15000 \\
\hline
\end{tabular}




\begin{tabular}{|c|c|c|c|c|c|c|c|c|c|c|c|}
\hline No & Date & Time & Lne & & CATEG VEH & CLASE VEH & EJES ELEVADOS & TARA TRACTOR & PMA TRACTOR & TARA REMOLQUE & PMA REMOLQUE \\
\hline 13497 & 150617 & 125528 & & 1 & $P$ & 1 & 12 & 7505 & 11990 & & \\
\hline 13500 & 150617 & 125545 & & 1 & $P$ & 2 & 125 & 8000 & 18000 & 8200 & 36000 \\
\hline 13518 & 150617 & 125805 & & 1 & $P$ & 1 & 12 & 7830 & 18000 & & \\
\hline 13524 & 150617 & 125856 & & 1 & $P$ & 2 & 125 & 7120 & 18000 & 8220 & 35000 \\
\hline 13526 & 150617 & 125930 & & 1 & $\mathrm{P}$ & 3 & 124 & 11755 & 18000 & 8400 & 18000 \\
\hline 13532 & 150617 & 130148 & & 1 & $P$ & 2 & 125 & 7120 & 18000 & 7620 & 35000 \\
\hline 13542 & 150617 & 130425 & & 1 & $\mathrm{P}$ & 2 & 125 & 8056 & 18000 & 9000 & 36000 \\
\hline 13558 & 150617 & 130622 & & 1 & $\mathrm{P}$ & 2 & 125 & 8286 & 18000 & 6470 & 39000 \\
\hline 13561 & 150617 & 130651 & & 1 & $P$ & 2 & 125 & 7589 & 18000 & 8000 & 34000 \\
\hline 13582 & 150617 & 130942 & & 1 & $\mathrm{P}$ & 2 & 125 & 7608 & 18000 & 0 & 36000 \\
\hline 13584 & 150617 & 131005 & & 1 & $\mathrm{P}$ & 2 & 125 & 6870 & 18000 & 5700 & 36000 \\
\hline 13589 & 150617 & 131048 & & 1 & $P$ & 2 & 125 & 6830 & 18000 & 7490 & 35000 \\
\hline 13595 & 150617 & 131154 & & 1 & $P$ & 2 & 126 & 7850 & 18000 & 10700 & 36000 \\
\hline 13599 & 150617 & 131251 & & 1 & $\mathrm{P}$ & 2 & 125 & 7490 & 18000 & 5850 & 34000 \\
\hline 13601 & 150617 & 131328 & & 1 & $P$ & 2 & 125 & 6875 & 18000 & 8900 & 35000 \\
\hline 13605 & 150617 & 131413 & & 1 & $P$ & 2 & 125 & 8371 & 18000 & 8900 & 35000 \\
\hline 13608 & 150617 & 131434 & & 1 & $P$ & 2 & 125 & 8300 & 18000 & 6883 & 35000 \\
\hline 13609 & 150617 & 131502 & & 1 & $\mathrm{P}$ & 2 & 125 & 7540 & 18000 & 8918 & 36000 \\
\hline 13619 & 150617 & 131644 & & 1 & C & 1 & 11 & 1762 & 3500 & & \\
\hline 13649 & 150617 & 132217 & & 1 & $P$ & 2 & 125 & 8700 & 18000 & 8161 & 35000 \\
\hline 13651 & 150617 & 132239 & & 1 & $P$ & 2 & 125 & 6830 & 18000 & 8200 & 36000 \\
\hline 13653 & 150617 & 132333 & & 1 & $P$ & 2 & 125 & 8297 & 18000 & 8500 & 36000 \\
\hline 13656 & 150617 & 132403 & & 1 & $P$ & 2 & 125 & 7685 & 18000 & 0 & 37000 \\
\hline 13659 & 150617 & 132424 & & 1 & $P$ & 2 & 125 & 8250 & 18000 & 8900 & 35000 \\
\hline 13663 & 150617 & 132438 & & 1 & $P$ & 2 & 125 & 8546 & 18000 & 8500 & 36000 \\
\hline 13669 & 150617 & 132512 & & 1 & $P$ & 2 & 125 & 6399 & 18000 & 5350 & 35000 \\
\hline 13671 & 150617 & 132529 & & 1 & $\mathrm{P}$ & 2 & 125 & 7683 & 18000 & 5850 & 34000 \\
\hline
\end{tabular}




\begin{tabular}{|c|c|c|c|c|c|c|c|c|c|c|c|}
\hline No & Date & Time & Lne & CATEG VEH & CLASE VEH & TIPO VEH & EJES ELEVADOS & TARA TRACTOR & PMA TRACTOR & TARA REMOLQUE & PMA REMOLQUE \\
\hline 13675 & 150617 & 132554 & 1 & $\mathrm{P}$ & 2 & 125 & & 8546 & 18000 & 8048 & 35000 \\
\hline 13679 & 150617 & 132633 & 1 & $\mathrm{P}$ & 1 & 12 & & 5074 & 10000 & & \\
\hline 13680 & 150617 & 132649 & 1 & $\mathrm{P}$ & 2 & 125 & & 7990 & 18000 & 8770 & 42000 \\
\hline 13685 & 150617 & 132751 & 1 & $\mathrm{P}$ & 2 & 125 & 3 & 8371 & 18000 & 6030 & 34000 \\
\hline 13689 & 150617 & 132812 & 1 & $\mathrm{P}$ & 1 & 17 & & 11875 & 26000 & & \\
\hline 13698 & 150617 & 132957 & 1 & $\mathrm{P}$ & 2 & 126 & & 7844 & 18000 & 7380 & 32000 \\
\hline 13700 & 150617 & 133018 & 1 & $\mathrm{P}$ & 2 & 125 & & 6810 & 18000 & 6450 & 35000 \\
\hline 13713 & 150617 & 133236 & 1 & $\mathrm{P}$ & 2 & 125 & & 7000 & 40000 & 8580 & 34800 \\
\hline 13718 & 150617 & 133311 & 1 & $\mathrm{P}$ & 2 & 125 & & 6100 & 18000 & 5150 & 34000 \\
\hline 13720 & 150617 & 133344 & 1 & $\mathrm{P}$ & 2 & 125 & & 7000 & 18000 & 6150 & 34000 \\
\hline 13727 & 150617 & 133507 & 1 & $P$ & 2 & 125 & & 7685 & 18000 & 7955 & 35000 \\
\hline 13740 & 150617 & 133632 & 1 & $P$ & 2 & 125 & 3 & 7120 & 18000 & 6770 & 39000 \\
\hline 13748 & 150617 & 133735 & 1 & $\mathrm{P}$ & 2 & 125 & 3 & 7275 & 18000 & 4950 & 36000 \\
\hline 13755 & 150617 & 133831 & 1 & $P$ & 2 & 125 & & 8270 & 18000 & 7310 & 35000 \\
\hline 13773 & 150617 & 134129 & 1 & $P$ & 3 & 123 & & 7760 & 18000 & 3020 & 18000 \\
\hline 13774 & 150617 & 134139 & 1 & $P$ & 1 & 14 & 3 & 11300 & 26000 & & \\
\hline 13778 & 150617 & 134222 & 1 & $\mathrm{P}$ & 2 & 125 & & 8615 & 18000 & 7410 & 35000 \\
\hline 13781 & 150617 & 134248 & 1 & $\mathrm{P}$ & 2 & 125 & & 7000 & 17000 & 7200 & 35000 \\
\hline 13785 & 150617 & 134424 & 1 & $P$ & 2 & 125 & & 7878 & 18000 & 8100 & 35000 \\
\hline 13811 & 150617 & 134725 & 1 & $P$ & 2 & 125 & & 8430 & 18000 & 8918 & 36000 \\
\hline 13826 & 150617 & 135010 & 1 & $\mathrm{P}$ & 2 & 125 & & 6830 & 18000 & 6750 & 35000 \\
\hline 13828 & 150617 & 135029 & 1 & $\mathrm{P}$ & 2 & 125 & & 6810 & 18000 & 8600 & 36000 \\
\hline 13829 & 150617 & 135035 & 1 & $P$ & 2 & 125 & & 14355 & 26000 & 9260 & 35000 \\
\hline 13831 & 150617 & 135052 & 1 & $P$ & 2 & 125 & 3 & 6545 & 18000 & 6950 & 36000 \\
\hline 13844 & 150617 & 135302 & 1 & $P$ & 2 & 125 & & 7520 & 18000 & 8900 & 36000 \\
\hline 20247 & 150618 & 102430 & 1 & $\mathrm{P}$ & 2 & 125 & & 8000 & 18000 & 8900 & 36000 \\
\hline 20267 & 150618 & 102740 & 1 & $P$ & 1 & 17 & & 12010 & 26000 & & \\
\hline
\end{tabular}




\begin{tabular}{|c|c|c|c|c|c|c|c|c|c|c|c|c|}
\hline No & Date & Time & Lne & & CATEG VEH & CLASE VEH & TIPO VEH & EJES ELEVADOS & TARA TRACTOR & PMA TRACTOR & TARA REMOLQUE & PMA REMOLQUE \\
\hline 20270 & 150618 & 102817 & & 1 & B & 1 & 12 & & 13624 & 18000 & & \\
\hline 20273 & 150618 & 102834 & & 1 & $P$ & 2 & 125 & & 8085 & 18000 & 8412 & 35000 \\
\hline 20280 & 150618 & 103006 & & 1 & $P$ & 2 & 125 & & 7670 & 19500 & 8600 & 36000 \\
\hline 20281 & 150618 & 103016 & & 1 & $P$ & 2 & 125 & & 7495 & 18000 & 8900 & 35000 \\
\hline 20282 & 150618 & 103027 & & 1 & $P$ & 2 & 125 & & 8062 & 18000 & 5800 & 36000 \\
\hline 20287 & 150618 & 103112 & & 1 & $P$ & 2 & 125 & & 8550 & 18000 & 7080 & 35000 \\
\hline 20289 & 150618 & 103126 & & 1 & $\mathrm{P}$ & 2 & 125 & & 6120 & 18000 & 9000 & 35000 \\
\hline 20292 & 150618 & 103223 & & 1 & $P$ & 2 & 125 & & 7050 & 18000 & 6480 & 35000 \\
\hline 20299 & 150618 & 103259 & & 1 & $\mathrm{P}$ & 2 & 125 & 3 & 8310 & 18000 & 7370 & 35000 \\
\hline 20301 & 150618 & 103309 & & 1 & $\mathrm{P}$ & 2 & 125 & 3 & 7580 & 18000 & 7100 & 34000 \\
\hline 20319 & 150618 & 103437 & & 1 & $P$ & 2 & 125 & 3 & 7300 & 18000 & 5338 & 34000 \\
\hline 20320 & 150618 & 103445 & & 1 & $P$ & 1 & 12 & & 6455 & 9500 & & \\
\hline 20327 & 150618 & 103616 & & 1 & $P$ & 2 & 125 & & 8494 & 18000 & 6200 & 34000 \\
\hline 20337 & 150618 & 103719 & & 1 & $\mathrm{P}$ & 2 & 125 & & 6830 & 18000 & 6430 & 35000 \\
\hline 20338 & 150618 & 103733 & & 1 & $P$ & 2 & 125 & & 8546 & 18000 & 8720 & 35000 \\
\hline 20339 & 150618 & 103800 & & 1 & $P$ & 3 & 124 & & 10940 & 18000 & 7800 & 17000 \\
\hline 20353 & 150618 & 104021 & & 1 & $P$ & 2 & 125 & & 8546 & 18000 & 6500 & 36000 \\
\hline 20355 & 150618 & 104040 & & 1 & $\mathrm{P}$ & 2 & 125 & & 6800 & 18000 & 8048 & 35000 \\
\hline 20356 & 150618 & 104053 & & 1 & $P$ & 2 & 125 & & 7281 & 18000 & 7765 & 35000 \\
\hline 20358 & 150618 & 104101 & & 1 & $P$ & 2 & 125 & 3 & 8700 & 18000 & 7479 & 35000 \\
\hline 20361 & 150618 & 104135 & & 1 & $P$ & 2 & 125 & 3 & 7120 & 18000 & 7510 & 35000 \\
\hline 20363 & 150618 & 104153 & & 1 & $P$ & 2 & 125 & & 6120 & 18000 & 6670 & 36000 \\
\hline 20366 & 150618 & 104234 & & 1 & $P$ & 3 & 124 & & 12300 & 18000 & 7600 & 18000 \\
\hline 20368 & 150618 & 104253 & & 1 & $P$ & 1 & 14 & 3 & 14030 & 26000 & & \\
\hline 20370 & 150618 & 104301 & & 1 & $P$ & 2 & 125 & & 7750 & 18000 & 7200 & 35000 \\
\hline 20372 & 150618 & 104319 & & 1 & $P$ & 2 & 125 & & 7475 & 18000 & 8200 & 36000 \\
\hline 20373 & 150618 & 104336 & & 1 & $\mathrm{P}$ & 2 & 125 & & 4150 & 18000 & 8500 & 36000 \\
\hline
\end{tabular}




\begin{tabular}{|c|c|c|c|c|c|c|c|c|c|c|c|}
\hline No & Date & Time & Lne & CATEG VEH & CLASE VEH & TIPO VEH & EJES ELEVADOS & TARA TRACTOR & PMA TRACTOR & TARA REMOLQUE & PMA REMOLQUE \\
\hline 20378 & 150618 & 104427 & 1 & $\mathrm{P}$ & 2 & 125 & & 8415 & 18000 & 10000 & 36000 \\
\hline 20382 & 150618 & 104453 & 1 & $\mathrm{P}$ & 2 & 125 & & 8211 & 18000 & 7000 & 35000 \\
\hline 20388 & 150618 & 104554 & 1 & $\mathrm{P}$ & 2 & 125 & & 8301 & 21000 & 7200 & 35000 \\
\hline 20395 & 150618 & 104656 & 1 & $\mathrm{P}$ & 2 & 125 & & 8442 & 18000 & 9725 & 35000 \\
\hline 20396 & 150618 & 104710 & 1 & $P$ & 2 & 125 & 3 & 8000 & 18000 & 8900 & 39000 \\
\hline 20399 & 150618 & 104735 & 1 & $\mathrm{P}$ & 2 & 125 & & 7435 & 18000 & 8500 & 36000 \\
\hline 20400 & 150618 & 104756 & 1 & $\mathrm{P}$ & 2 & 125 & & 6830 & 18000 & 7240 & 35000 \\
\hline 20405 & 150618 & 104838 & 1 & $\mathrm{P}$ & 2 & 125 & & 7937 & 18000 & 9000 & 36000 \\
\hline 20410 & 150618 & 104906 & 1 & $\mathrm{P}$ & 2 & 125 & & 6399 & 18000 & 8100 & 35000 \\
\hline 20412 & 150618 & 104950 & 1 & $\mathrm{P}$ & 2 & 125 & & 7460 & 18000 & 6150 & 35000 \\
\hline 20414 & 150618 & 105004 & 1 & $P$ & 2 & 125 & 3 & 6850 & 18000 & 5500 & 34000 \\
\hline 20416 & 150618 & 105029 & 1 & $\mathrm{P}$ & 2 & 125 & & 6810 & 18000 & 6930 & 35000 \\
\hline 20421 & 150618 & 105119 & 1 & $\mathrm{P}$ & 2 & 125 & & 8810 & 18000 & 7150 & 35000 \\
\hline 20430 & 150618 & 105246 & 1 & $\mathrm{P}$ & 2 & 125 & & 6800 & 18000 & 6560 & 36000 \\
\hline 20442 & 150618 & 105417 & 1 & $P$ & 2 & 125 & & 7000 & 18000 & 8610 & 35000 \\
\hline 20448 & 150618 & 105449 & 1 & $\mathrm{P}$ & 2 & 125 & & 7719 & 18000 & 6520 & 35000 \\
\hline 20456 & 150618 & 105601 & 1 & $\mathrm{P}$ & 2 & 125 & & 7105 & 18000 & 7400 & 34000 \\
\hline 20458 & 150618 & 105617 & 1 & $\mathrm{P}$ & 2 & 125 & 3 & 8000 & 18000 & 8490 & 36000 \\
\hline 20459 & 150618 & 105621 & 1 & $P$ & 1 & 12 & & 4720 & 9000 & & \\
\hline 20463 & 150618 & 105631 & 1 & $\mathrm{P}$ & 2 & 125 & & 8700 & 18000 & 6800 & 36000 \\
\hline 20468 & 150618 & 105712 & 1 & $\mathrm{P}$ & 2 & 125 & & 7580 & 18000 & 6350 & 38000 \\
\hline 20472 & 150618 & 105748 & 1 & $\mathrm{P}$ & 2 & 125 & & 8453 & 18000 & 7400 & 36000 \\
\hline 20474 & 150618 & 105802 & 1 & $\mathrm{P}$ & 2 & 125 & & 6870 & 18000 & 0 & 35000 \\
\hline 20476 & 150618 & 105810 & 1 & $P$ & 2 & 125 & & 7105 & 18000 & 6980 & 39000 \\
\hline 20478 & 150618 & 105819 & 1 & $\mathrm{P}$ & 2 & 125 & & 8010 & 18000 & 7090 & 35000 \\
\hline 20480 & 150618 & 105825 & 1 & $\mathrm{P}$ & 2 & 125 & & 8016 & 18000 & 6600 & 35000 \\
\hline 20489 & 150618 & 105925 & 1 & $\mathrm{P}$ & 2 & 125 & & 8550 & 18000 & 6500 & 36000 \\
\hline
\end{tabular}




\begin{tabular}{|c|c|c|c|c|c|c|c|c|c|c|c|c|}
\hline No & Date & Time & Lne & & CATEG VEH & CLASE VEH & TIPO VEH & EJES ELEVADOS & TARA TRACTOR & PMA TRACTOR & TARA REMOLQUE & PMA REMOLQUE \\
\hline 20494 & 150618 & 110021 & & 1 & $P$ & 2 & 125 & & 6399 & 18000 & 8100 & 35000 \\
\hline 20508 & 150618 & 110233 & & 1 & P & 2 & 125 & & 9097 & 18000 & 8900 & 35000 \\
\hline 20521 & 150618 & 110455 & & 1 & $P$ & 2 & 125 & & 6830 & 18000 & 7260 & 35000 \\
\hline 20522 & 150618 & 110506 & & 1 & $P$ & 2 & 125 & & 8546 & 18000 & 7200 & 35000 \\
\hline 20523 & 150618 & 110512 & & 1 & $P$ & 1 & 12 & & 5530 & 12000 & & \\
\hline 20524 & 150618 & 110518 & & 1 & P & 2 & 125 & & 8058 & 18000 & 6600 & 39000 \\
\hline 20541 & 150618 & 110725 & & 1 & $P$ & 2 & 125 & & 6810 & 18000 & 6125 & 35000 \\
\hline 20545 & 150618 & 110802 & & 1 & $P$ & 2 & 125 & & 7905 & 18000 & 8350 & 36000 \\
\hline 20546 & 150618 & 110809 & & 1 & $P$ & 2 & 125 & & 6545 & 40000 & 6750 & 34000 \\
\hline 20554 & 150618 & 110916 & & 1 & $P$ & 2 & 125 & & 8120 & 18000 & 6711 & 35000 \\
\hline 20558 & 150618 & 110947 & & 1 & $P$ & 2 & 125 & & 8000 & 18000 & 7400 & 36000 \\
\hline 20566 & 150618 & 111246 & & 1 & $P$ & 2 & 125 & & 7736 & 18000 & 7380 & 35000 \\
\hline 20569 & 150618 & 111318 & & 1 & $P$ & 2 & 125 & & 8593 & 18000 & 8577 & 35000 \\
\hline 20572 & 150618 & 111359 & & 1 & $P$ & 2 & 125 & & 7790 & 18000 & 8552 & 35000 \\
\hline 20575 & 150618 & 111425 & & 1 & $P$ & 2 & 125 & & 7285 & 18000 & 6900 & 35000 \\
\hline 20581 & 150618 & 111458 & & 1 & $P$ & 1 & 12 & & 8500 & 18000 & & \\
\hline 20585 & 150618 & 111528 & & 1 & $P$ & 2 & 125 & 3 & 8042 & 18000 & 9000 & 37000 \\
\hline 20590 & 150618 & 111611 & & 1 & $P$ & 2 & 125 & & 8510 & 18000 & 8500 & 36000 \\
\hline 20595 & 150618 & 111637 & & 1 & $P$ & 2 & 125 & & 6545 & 18000 & 8200 & 36000 \\
\hline 20600 & 150618 & 111727 & & 1 & $P$ & 2 & 125 & & 6910 & 18000 & 5900 & 34000 \\
\hline 20602 & 150618 & 111744 & & 1 & $P$ & 1 & 12 & & 8260 & 18000 & & \\
\hline 20613 & 150618 & 111911 & & 1 & $P$ & 2 & 125 & & 8378 & 20500 & 6890 & 35000 \\
\hline 20623 & 150618 & 112122 & & 1 & $P$ & 2 & 125 & & 7120 & 18000 & 8200 & 36000 \\
\hline 20625 & 150618 & 112130 & & 1 & $P$ & 2 & 125 & & 6800 & 18000 & 6720 & 35000 \\
\hline 20639 & 150618 & 112405 & & 1 & $P$ & 1 & 14 & & 10660 & 26000 & & \\
\hline 20642 & 150618 & 112454 & & 1 & $P$ & 1 & 12 & & 6385 & 10000 & & \\
\hline 20648 & 150618 & 112610 & & 1 & $P$ & 2 & 125 & & 6830 & 18000 & 6780 & 35000 \\
\hline
\end{tabular}




\begin{tabular}{|c|c|c|c|c|c|c|c|c|c|c|c|c|}
\hline No & Date & Time & Lne & & CATEG VEH & CLASE VEH & TIPO VEH & EJES ELEVADOS & TARA TRACTOR & PMA TRACTOR & TARA REMOLQUE & PMA REMOLQUE \\
\hline 20649 & 150618 & 112616 & & 1 & $P$ & 2 & 125 & & 8233 & 18000 & 8740 & 35000 \\
\hline 20651 & 150618 & 112636 & & 1 & $P$ & 2 & 126 & 3 & 6955 & 18000 & 10360 & 36000 \\
\hline 20711 & 150618 & 113543 & & 1 & $P$ & 2 & 125 & & 7920 & 18000 & 7200 & 35000 \\
\hline 20714 & 150618 & 113600 & & 1 & $P$ & 2 & 125 & & 7120 & 18000 & 8500 & 39000 \\
\hline 20726 & 150618 & 113815 & & 1 & P & 2 & 125 & & 6830 & 18000 & 7150 & 36000 \\
\hline 20732 & 150618 & 113915 & & 1 & $P$ & 2 & 125 & & 7300 & 18000 & 10790 & 36000 \\
\hline 20740 & 150618 & 114017 & & 1 & $P$ & 2 & 125 & & 8550 & 18000 & 8400 & 37000 \\
\hline 20744 & 150618 & 114038 & & 1 & $P$ & 2 & 125 & & 7600 & 18000 & 5360 & 35000 \\
\hline 20760 & 150618 & 114243 & & 1 & $\mathrm{P}$ & 2 & 125 & & 6800 & 18000 & 7200 & 35000 \\
\hline 20766 & 150618 & 114338 & & 1 & $P$ & 2 & 125 & & 7350 & 18000 & 8900 & 35000 \\
\hline 20790 & 150618 & 114747 & & 1 & $P$ & 2 & 125 & & 8135 & 18000 & 800 & 900 \\
\hline 20791 & 150618 & 114802 & & 1 & $P$ & 1 & 12 & & 10400 & 18000 & & \\
\hline 20793 & 150618 & 114807 & & 1 & $P$ & 1 & 12 & & 9000 & 18000 & & \\
\hline 20794 & 150618 & 114811 & & 1 & $P$ & 1 & 17 & & 10245 & 26000 & & \\
\hline 20796 & 150618 & 114820 & & 1 & $P$ & 2 & 125 & & 8227 & 18000 & 6570 & 35000 \\
\hline 20803 & 150618 & 114926 & & 1 & $P$ & 2 & 125 & & 8088 & 18000 & 8300 & 34000 \\
\hline 20827 & 150618 & 115308 & & 1 & $P$ & 2 & 125 & & 8546 & 18000 & 5300 & 36000 \\
\hline 20829 & 150618 & 115314 & & 1 & $P$ & 1 & 12 & & 8450 & 18000 & & \\
\hline 20848 & 150618 & 115627 & & 1 & $P$ & 2 & 125 & & 8074 & 18000 & 7835 & 35000 \\
\hline 20856 & 150618 & 115749 & & 1 & $P$ & 2 & 125 & & 8000 & 18000 & 8760 & 35000 \\
\hline 20866 & 150618 & 115927 & & 1 & $P$ & 2 & 125 & & 8224 & 18000 & 6840 & 35000 \\
\hline 20867 & 150618 & 115933 & & 1 & $P$ & 2 & 125 & & 7040 & 18000 & 8725 & 35000 \\
\hline 20872 & 150618 & 120014 & & 1 & $P$ & 2 & 125 & & 8473 & 18000 & 8900 & 35000 \\
\hline 20880 & 150618 & 120131 & & 1 & $P$ & 2 & 125 & & 6838 & 18000 & 6880 & 39000 \\
\hline 20887 & 150618 & 120234 & & 1 & $P$ & 2 & 125 & & 8356 & 18000 & 7205 & 36000 \\
\hline 20896 & 150618 & 120336 & & 1 & $P$ & 2 & 125 & & 0 & 0 & 7180 & 35000 \\
\hline 20898 & 150618 & 120347 & & 1 & $P$ & 3 & 124 & & 6800 & 18000 & 7600 & 18000 \\
\hline
\end{tabular}




\begin{tabular}{|c|c|c|c|c|c|c|c|c|c|c|c|c|}
\hline No & Date & Time & Lne & & CATEG VEH & CLASE VEH & TIPO VEH & EJES ELEVADOS & TARA TRACTOR & PMA TRACTOR & TARA REMOLQUE & PMA REMOLQUE \\
\hline 20908 & 150618 & 120521 & & 1 & $P$ & 2 & 125 & & 7036 & 18000 & 7700 & 37000 \\
\hline 20912 & 150618 & 120541 & & 1 & $P$ & 2 & 125 & & 7540 & 18000 & 7000 & 35000 \\
\hline 20922 & 150618 & 120645 & & 1 & $P$ & 2 & 125 & & 7120 & 18000 & 8700 & 36000 \\
\hline 20934 & 150618 & 120728 & & 1 & $\mathrm{P}$ & 2 & 125 & & 7600 & 18000 & 6300 & 35000 \\
\hline 20937 & 150618 & 120751 & & 1 & $\mathrm{P}$ & 2 & 125 & & 8088 & 18000 & 8500 & 36000 \\
\hline 20940 & 150618 & 120815 & & 1 & $\mathrm{P}$ & 2 & 125 & & 7435 & 18000 & 9725 & 35000 \\
\hline 20948 & 150618 & 120906 & & 1 & $\mathrm{P}$ & 2 & 125 & & 7050 & 18000 & 6920 & 36000 \\
\hline 20955 & 150618 & 121031 & & 1 & $P$ & 2 & 125 & & 6965 & 18000 & 5600 & 34000 \\
\hline 20969 & 150618 & 121238 & & 1 & $\mathrm{~B}$ & 1 & 12 & & 13520 & 18000 & & \\
\hline 20977 & 150618 & 121329 & & 1 & $\mathrm{P}$ & 2 & 125 & & 6830 & 18000 & 7650 & 35000 \\
\hline 20980 & 150618 & 121358 & & 1 & $P$ & 2 & 125 & & 8672 & 18000 & 8900 & 35000 \\
\hline 20981 & 150618 & 121413 & & 1 & $P$ & 2 & 125 & & 8518 & 18000 & 8400 & 38000 \\
\hline 20985 & 150618 & 121442 & & 1 & $P$ & 2 & 125 & & 7400 & 18000 & 6400 & 34000 \\
\hline 20993 & 150618 & 121540 & & 1 & $\mathrm{P}$ & 3 & 124 & & 11665 & 18000 & 7250 & 35000 \\
\hline 21017 & 150618 & 121903 & & 1 & $P$ & 2 & 125 & & 7000 & 17000 & 5410 & 35000 \\
\hline 21030 & 150618 & 122218 & & 1 & $P$ & 1 & 12 & & 5420 & 18000 & & \\
\hline 21031 & 150618 & 122228 & & 1 & $P$ & 2 & 126 & & 8000 & 40000 & 8000 & 35000 \\
\hline 21035 & 150618 & 122330 & & 1 & $\mathrm{P}$ & 1 & 14 & & 18240 & 26000 & & \\
\hline 21040 & 150618 & 122415 & & 1 & $P$ & 2 & 125 & & 6545 & 18000 & 8200 & 36000 \\
\hline 21043 & 150618 & 122443 & & 1 & $P$ & 1 & 17 & 3 & 9660 & 26000 & & \\
\hline 21048 & 150618 & 122508 & & 1 & $P$ & 1 & 14 & & 10990 & 26000 & & \\
\hline 21051 & 150618 & 122538 & & 1 & $p$ & 2 & 125 & & 7600 & 18000 & 8698 & 35000 \\
\hline 21053 & 150618 & 122557 & & 1 & $P$ & 1 & 12 & & 11235 & 18000 & & \\
\hline 21056 & 150618 & 122609 & & 1 & $P$ & 2 & 125 & & 3525 & 18000 & 8633 & 35000 \\
\hline 21060 & 150618 & 122623 & & 1 & $P$ & 2 & 125 & & 8264 & 18000 & 6400 & 36000 \\
\hline 21063 & 150618 & 122701 & & 1 & $P$ & 2 & 125 & 3 & 7612 & 18000 & 5300 & 40000 \\
\hline 21066 & 150618 & 122718 & & 1 & $\mathrm{P}$ & 2 & 125 & & 6830 & 18000 & 8160 & 39000 \\
\hline
\end{tabular}




\begin{tabular}{|c|c|c|c|c|c|c|c|c|c|c|c|}
\hline No & Date & Time & Lne & CATEG VEH & CLASE VEH & TIPO VEH & EJES ELEVADOS & TARA TRACTOR & PMA TRACTOR & TARA REMOLQUE & PMA REMOLQUE \\
\hline 21070 & 150618 & 122747 & 1 & $\mathrm{P}$ & 2 & 125 & & 7938 & 18000 & 8910 & 39000 \\
\hline 21071 & 150618 & 122825 & 1 & $\mathrm{P}$ & 1 & 12 & & 9040 & 20000 & & \\
\hline 21076 & 150618 & 122858 & 1 & $\mathrm{P}$ & 2 & 125 & & 8180 & 18000 & 8930 & 36000 \\
\hline 21089 & 150618 & 123108 & 1 & $\mathrm{P}$ & 2 & 125 & & 8187 & 20500 & 6600 & 39000 \\
\hline 21090 & 150618 & 123123 & 1 & $P$ & 2 & 125 & & 8187 & 18000 & 6440 & 39000 \\
\hline 21096 & 150618 & 123216 & 1 & $\mathrm{P}$ & 2 & 125 & 3 & 7478 & 18000 & 5710 & 35000 \\
\hline 21100 & 150618 & 123311 & 1 & $\mathrm{P}$ & 2 & 125 & 3 & 7000 & 18000 & 6900 & 36000 \\
\hline 21104 & 150618 & 123344 & 1 & $\mathrm{P}$ & 1 & 12 & & 7040 & 15000 & & \\
\hline 21119 & 150618 & 123512 & 1 & $\mathrm{P}$ & 2 & 125 & & 8664 & 18000 & 8900 & 35000 \\
\hline 21124 & 150618 & 123551 & 1 & $\mathrm{P}$ & 3 & 124 & & 10100 & 18000 & 4000 & 16480 \\
\hline 21125 & 150618 & 123607 & 1 & $P$ & 1 & 17 & 3 & 12580 & 26000 & & \\
\hline 21128 & 150618 & 123620 & 1 & $P$ & 1 & 12 & & 12000 & 18000 & & \\
\hline 21135 & 150618 & 123731 & 1 & $\mathrm{P}$ & 2 & 125 & & 6120 & 18000 & 7230 & 36000 \\
\hline 21139 & 150618 & 123801 & 1 & $\mathrm{P}$ & 2 & 125 & & 7120 & 18000 & 7270 & 36000 \\
\hline 21143 & 150618 & 123836 & 1 & $P$ & 2 & 125 & & 7510 & 18000 & 5700 & 34000 \\
\hline 21154 & 150618 & 123940 & 1 & $\mathrm{P}$ & 2 & 125 & 3 & 8360 & 20500 & 7200 & 35000 \\
\hline 21161 & 150618 & 124054 & 1 & $\mathrm{P}$ & 3 & 125 & & 10670 & 18000 & 5900 & 24000 \\
\hline 21165 & 150618 & 124118 & 1 & $\mathrm{P}$ & 2 & 125 & & 7120 & 18000 & 6137 & 36000 \\
\hline 21171 & 150618 & 124158 & 1 & $P$ & 2 & 125 & & 8130 & 18000 & 7200 & 35000 \\
\hline 21191 & 150618 & 124437 & 1 & $\mathrm{P}$ & 3 & 176 & & 11460 & 23100 & 8950 & 24000 \\
\hline 21193 & 150618 & 124505 & 1 & $\mathrm{P}$ & 2 & 125 & & 6835 & 18000 & 7200 & 35000 \\
\hline 21209 & 150618 & 124809 & 1 & $\mathrm{P}$ & 2 & 125 & & 7990 & 18000 & 8600 & 36000 \\
\hline 21215 & 150618 & 124849 & 1 & $\mathrm{P}$ & 2 & 125 & & 8116 & 18000 & 8750 & 35000 \\
\hline 21230 & 150618 & 125056 & 1 & $P$ & 2 & 125 & & 7844 & 18000 & 5110 & 34000 \\
\hline 21234 & 150618 & 125113 & 1 & $\mathrm{P}$ & 1 & 14 & 3 & 10560 & 26000 & & \\
\hline 21243 & 150618 & 125308 & 1 & $\mathrm{P}$ & 3 & 123 & & 7760 & 18000 & 3125 & 15000 \\
\hline 21251 & 150618 & 125413 & 1 & $\mathrm{P}$ & 3 & 126 & & 8056 & 18000 & 11400 & 35000 \\
\hline
\end{tabular}




\begin{tabular}{|c|c|c|c|c|c|c|c|c|c|c|c|}
\hline No & Date & Time & Lne & & CATEG VEH & CLASE VEH & EJES ELEVADOS & TARA TRACTOR & PMA TRACTOR & TARA REMOLQUE & PMA REMOLQUE \\
\hline 21262 & 150618 & 125536 & & 1 & $P$ & 2 & 125 & 6810 & 18000 & 6750 & 35000 \\
\hline 21264 & 150618 & 125603 & & 1 & $P$ & 2 & 125 & 6830 & 18000 & 8200 & 36000 \\
\hline 21272 & 150618 & 125711 & & 1 & $P$ & 2 & 125 & 8451 & 18000 & 8900 & 35000 \\
\hline 21300 & 150618 & 130153 & & 1 & $P$ & 2 & 125 & 6800 & 18000 & 6900 & 35000 \\
\hline 21391 & 150618 & 131758 & & 1 & P & 2 & 125 & 6800 & 18000 & 6890 & 35000 \\
\hline
\end{tabular}


